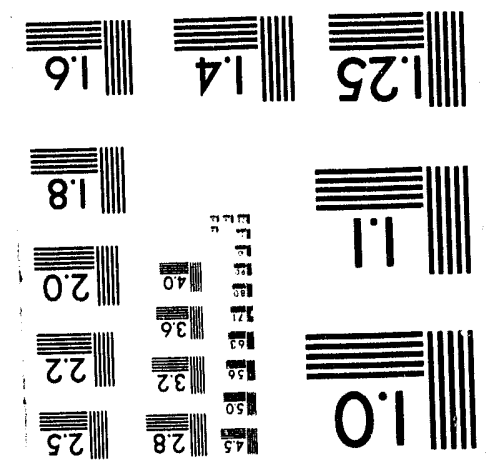



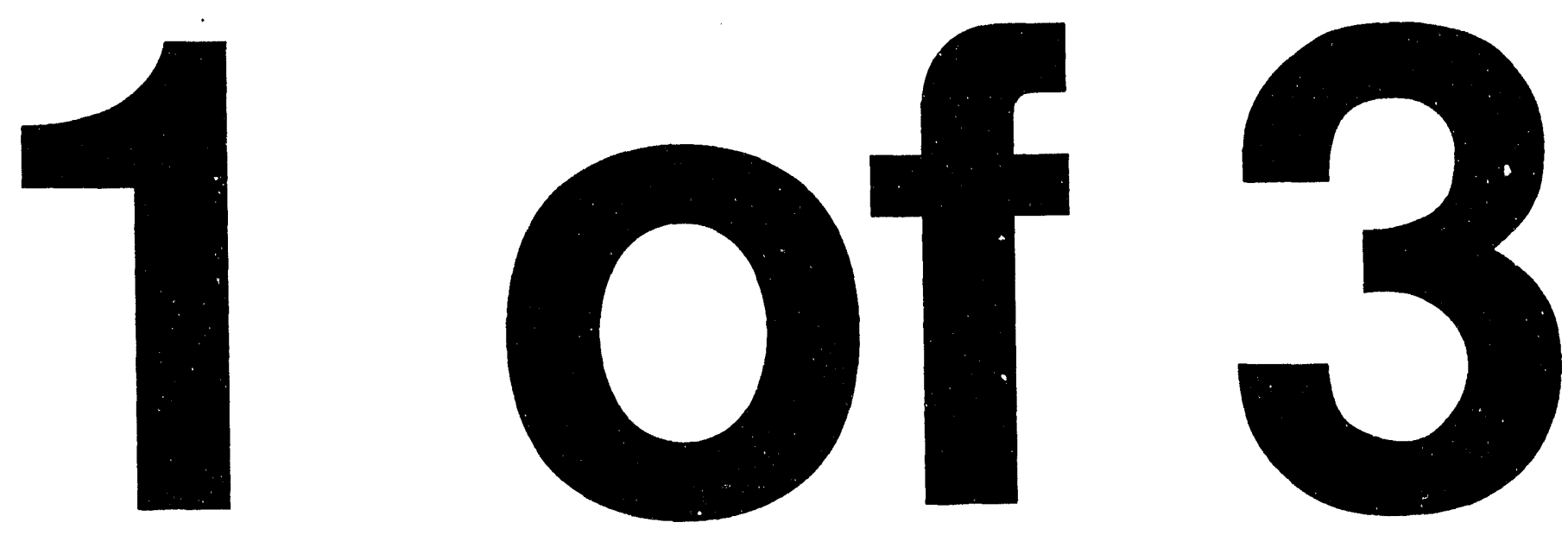
NUREG-1489

\section{A Review of NRC Staff Uses of Probabilistic Risk Assessment}

Manuscript Completed: March 1994

Date Published: March 1994

PRA Working Group

U.S. Nuclear Regulatory Commission

Washington, DC 20555-0001

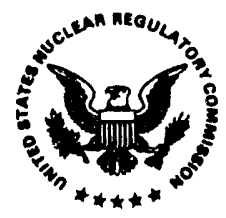




\begin{abstract}
The NRC staff uses probabilistic risk assessment (PRA) and risk management as important elements of its licensing and regulatory processes. In October 1991, the NRC's Executive Director for Operations established the PRA Working Group to address concerns identified by the Advisory Committee on Reactor Safeguards with respect to unevenness and inconsistency in the staff's current uses of PRA. After surveying current staff uses of PRA and identifying needed improvements, the Working Group defined a set of basic principles for staff PRA use and identified three areas for improvements: guidance development, training enhancements, and PRA methods development. For each area of improvement, the Working Group took certain actions and recommended additional work. The Working Group recommended integrating its work with other recent PRA-related activities the staff completed and improving staff interactions with PRA users in the nuclear industry. The Working Group took two key actions by developing general guidance for two uses of PRA within the NRC (that is, screening or prioritizing reactor safety issues and analyzing such issues in detail) and developing guidance on basic terms and methods important to the staff's uses of PRA.
\end{abstract}




\section{CONTENTS}

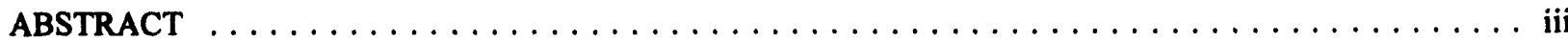

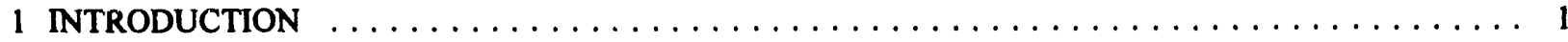

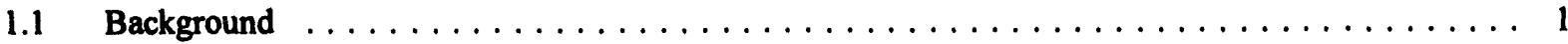

1.2 Objectives and Scope $\ldots \ldots \ldots \ldots \ldots \ldots \ldots \ldots \ldots \ldots \ldots \ldots \ldots \ldots \ldots \ldots$

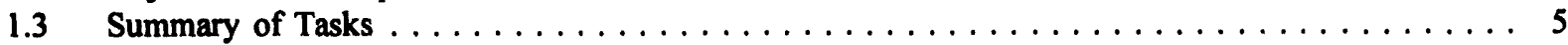

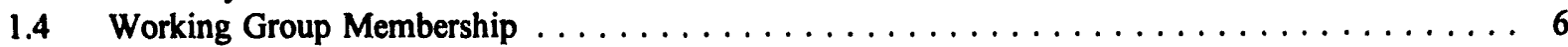

1.5 Reviews of Working Group Activities $\ldots \ldots \ldots \ldots \ldots \ldots \ldots \ldots \ldots \ldots \ldots \ldots$

1.6 General Recommendations $\ldots \ldots \ldots \ldots \ldots \ldots \ldots \ldots \ldots \ldots \ldots \ldots \ldots \ldots$

Exhibit ACRS Letter that Resulted in the Formation of the PRA Working Group $\ldots \ldots \ldots \ldots \ldots$

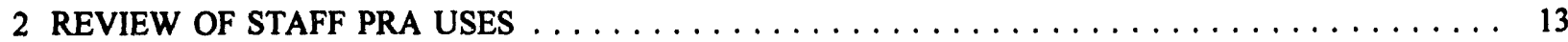

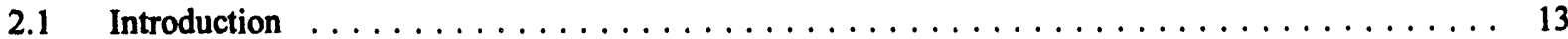

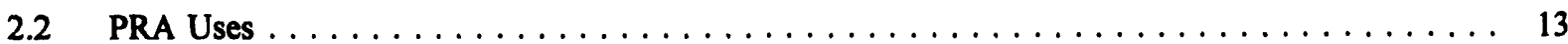

2.3 Characteristics of Present Staff PRA Uses $\ldots \ldots \ldots \ldots \ldots \ldots \ldots \ldots \ldots \ldots \ldots \ldots$

2.4 Needed Improvements in Present Staff Uses $\ldots \ldots \ldots \ldots \ldots \ldots \ldots \ldots \ldots \ldots \ldots$

3 GUIDANCE ON STAFF USES OF PRA $\ldots \ldots \ldots \ldots \ldots \ldots \ldots \ldots \ldots \ldots \ldots \ldots \ldots \ldots$

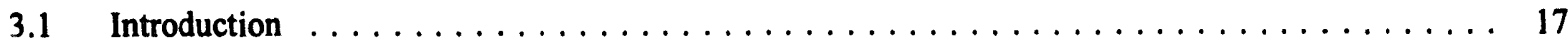

3.2 Basic Principles for Staff PRA Work $\ldots \ldots \ldots \ldots \ldots \ldots \ldots \ldots \ldots \ldots \ldots \ldots \ldots \ldots$

3.3 Guidance on PRA Use in Issue Screening and Analysis $\ldots \ldots \ldots \ldots \ldots \ldots \ldots \ldots \ldots \ldots$

3.4 Recommendations on Developing Additional Guidance $\ldots \ldots \ldots \ldots \ldots \ldots \ldots \ldots \ldots \ldots$

3.5 Suggested Timetable for Implementing Recommendations $\ldots \ldots \ldots \ldots \ldots \ldots \ldots \ldots \ldots$

4 SKILLS, TRAINING, AND METHODS FOR PRA $\ldots \ldots \ldots \ldots \ldots \ldots \ldots \ldots \ldots \ldots \ldots \ldots$

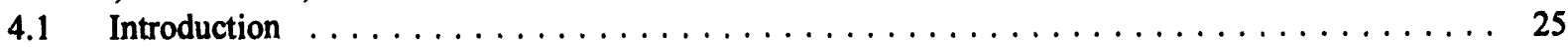

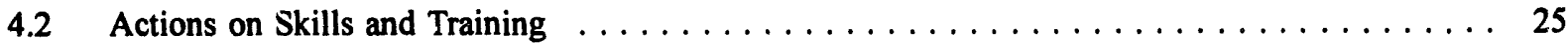

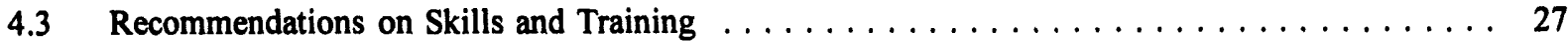

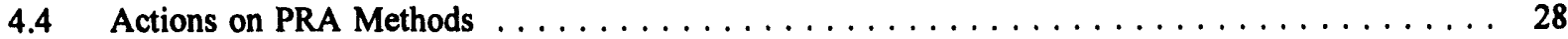

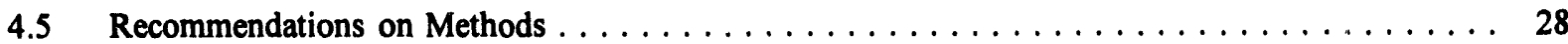

4.6 Suggested Timetable for Implementing Recommendations $\ldots \ldots \ldots \ldots \ldots \ldots \ldots \ldots \ldots$

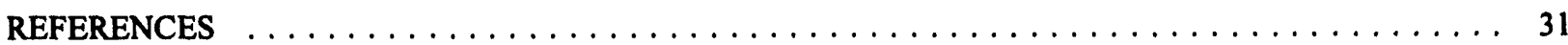

\section{APPENDICES}

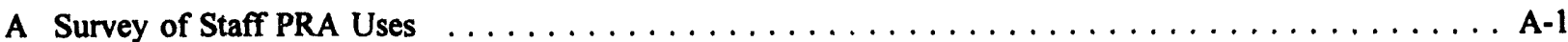

B Review of and Recommendations on Agency PRA Uses $\ldots \ldots \ldots \ldots \ldots \ldots \ldots \ldots \ldots \ldots$ B-1

C Guidance on PRA Terms and Methods $\ldots \ldots \ldots \ldots \ldots \ldots \ldots \ldots \ldots \ldots \ldots \ldots \ldots \ldots \ldots$

\section{TABLES}

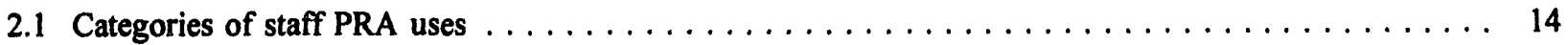

3.1 Working Group actions and recommendations on staff uses of PRA $\ldots \ldots \ldots \ldots \ldots \ldots \ldots \ldots$

3.2 Suggested timetable for implementing Working Group recommendations on use guidance $\ldots \ldots \ldots 23$

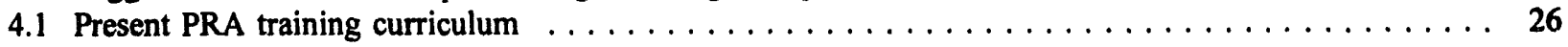

4.2 Suggested timetable for implementing Working Group recommendations on skills and methods . . . 30 


\section{INTRODUCTION}

\subsection{Background}

Probabilistic risk assessment (PRA) and risk management ${ }^{1}$ are used by the NRC staff as important elements of its licensing and regulatory processes. The NRC's first PRA, the Reactor Safety Study (Ref. 1), was completed soon after the creation of the NRC in 1975. Since that time, the NRC has made use of risk assessment to address complex safety issues. A particular strength of risk assessment, which has made it valuable to the NRC, is the structure it brings to the analysis of an issue. That is, PRA provides a logical and structured approach for issue analysis with the capacity to provide estimates of the relative and absolute safety significance of issues, as well as the benefits and detriments of plant design or operational changes under consideration to deal with an issue. Another important strength of risk assessment is its capacity to quantitatively estimate the uncertainties associated with a safety issue and with possible changes to plant design or operation to address the issue. This is particularly germane to many of the safety issues facing the staff, which often are related to rare combinations of facility system failures, poorly understood accident processes, and other uncertain factors.

The strengths of risk assessment have led to its use in a spectrum of NRC licensing and regulatory functions, including:

- The licensing of advanced reactor designs, in which the design is reviewed with respect to the balance of prevention versus mitigation capabilities for core damage accidents;

- The licensing of high-level waste repositories, for which probabilistic acceptance criteria have been established in terms of public health risk;

- The monitoring of licensed reactor facilities, when operational events are routinely evaluated for their risk significance;

- The analysis of benefits, in terms of risk reduction, of possible improvements in licensed reactors for which a probabilistic criterion has been established in terms of public health risk; and

- The allocation of staff resources in such areas as inspections and safety issue analyses.

Related to these uses of risk assessment are certain fundamental risk management policies and rules. These include:

- A policy statement characterizing the acceptable risks from accidents in licensed reactors ("safety goals") (Ref. 4);

- A rule establishing the process and decision criteria ${ }^{2}$ for value/impact analyses for certain potential changes in licensed reactor design and operations (the "backfit" rule) (Ref. 5); and

- An EPA rule establishing the acceptance criteria for high-level waste repositories (40 CFR Part 190).

\footnotetext{
' Other parts of the Federal government describe the process of using risk infurmation as having two general components: (1) risk assessment, the application of credible scientific principles and statistical methods to develop estimates of the likely effects of natural phenomena and human activities (Ref. 2) and the characterization of these estimates in a form appropriate for the intended audience (agency decisionmakers, public, etc), and (2) risk management, the process of weighing policy alternatives and selecting the most appropriate regulatory action, integrating the results of risk assessment with engineering data and with social, economic, and policial concerns to reach a decision (Ref. 3). In this report, the Working Group describes the staff's work in the same svay and recommends more general use of this two-component description by NRC.

The term "risk" should be restricted to either the risk triplet definition widely used in PRA work or the more simplified "aggregate risk," defined as the sum of the products of the scenario frequencies and the scenario consequences. While the use of aggregate risk estimates provides a simple message, it can also provide a misleading message. The use of aggregate risk can mask information conveyed by the specific numerical values of the frequency and consequence. (See Appendix C, Section C.4.4.4, for a more complete discussion.)

${ }^{2}$ Decision criteria are defined here as standards on which a decision or judgment is based. In the regulatory process, these decision criteria may or may not be risk-based. An example of the former is the safety goal decision criteria in the draft Regulatory Analysis Guidelines (Ref. 6); an example of the latter is the Standard Review Plan (Ref. 7).
} 
In a July 1991 letter, the NRC's Advisory Committee on Reactor Safeguards (ACRS) identified a number of problems with the staff's risk assessment work. The letter identified concerns related to unevenness and inconsistency in the staff's uses of PRA, provided a number of examples illustrating their concerns, and included some recommendations as to how to address the identified concerns. The full text of the ACRS letter may be found at the end of this chapter as an exhibit.

In response to the ACRS letter, the NRC's Executive Director for Operations formed a working group of staff management (the "PRA Working Group") to:

Consider what improvements in methods and data analysis are possible and needed, the role of uncertainty analysis in different staff uses of PRA, if improvements are needed in the allocation of existing PRA staff, and the need for recruitment of more staff (or for identifying other means for supplementing staff resources).

(Ref. 8)

This report describes the activities and results of the PRA Working Group in addressing the issues raised by the ACRS. From its genesis in the ACRS' comments on the staff's present uses of risk assessment, the Working Group has focused on the review and development of guidance for these current uses. ${ }^{3}$

In parallel with the Working Group's activities, there are other current or recently completed efforts related to the staff's uses of PRA. Key among these are two other staff groups:

- The Regulatory Analysis Steering Group-This group of agency senior management has focused on certain risk management issues related to the backfitting of licensed reactors (Ref. 9). They have now completed a revised draft version of the agency's "Regulatory Analysis Guidelines" (Ref. 6) and the associated "Regulatory Analysis Technical Evaluation Handbook" (Ref. 10), which have been released for public comment. Two key risk management issues are included in this work, making use of safety goal policy in the backfitting process and changes that are needed with respect to the monetary value of public health effects used in value impact studies. While this group is focused on risk management policy and guidance, the PRA Working Group is focused on risk assessment practices of the NRC staff.

- The Regulatory Review $G$ up-This group of NRC senior management and staff has been responsible for reviewing reactor regulations and related staff practices, including a detailed review to identify "those regulations or implementation practices which appear to go beyond that which is required for 'adequate protection'" (Ref. 11). With respect to risk assessment, the group has examined how PRA can be used to provide more flexibility in the regulations and their implementation (Ref. 12). This aspect of the group's work is thus related to additional ways PRA could be used in reactor regulation. In contrast, the PRA Working Group is focused on current uses of PRA by the staff.

In parallel with the Working Group's activities are two efforts by the reactor industry:

- Individual Plant Examinations (IPEs)-In response to an NRC generic letter (Ref. 13), essentially all reactor licensees are performing PRAs on their facilities. Given its charter, the Working Group has focused its consideration of IPEs and the follow-on Individual Plant Examinations for External Events (IPEEEs) on how these PRAs could be used in present staff activities. As discussed in Chapter 3, the Working Group believes that IPEs and IPEEEs are of principal benefit in the staff's consideration of plant-specific licensing actions (e.g., technical specification modifications) and development of plant-specific inspection guidance.

\footnotetext{
"NRC staff "use" PRA in the sense that risk assessment methods and results are used to help make regulatory decisions, allocate staff resources, etc. Some risk assessments are performed by the staff, such as screening of operational events and generic issues. Most risk assessments are, however, performed by contractors to the staff or by applicants and licensees. Given this, the Working Group's efforts are focused on providing basic guidance on the attributes of risk assessments needed for particular purposes and basic information on PRA terms and methods like:y to be encountered by a staff member reviewing a contractor or applicant/licensee risk assessment.
} 
- Risk-Based Regulation Initiatives-In the past several years, the reactor industry has advocated the use of PRA to reduce unnecessary regulatory burdens. The consideration of such uses is included in the charter of the Regulatory Review Group (described above), and thus has not been addressed by the Working Group.

In summary, the Working Group initiated efforts in three areas to address limitations in the present staff's capabilities in PRA:

- Guidance development relates to technical matters such as the need for and performance of uncertainty analyses, procedural matters such as documentation and quality assurance requirements, and decision criteria.

- Training enhancements relates to expansion of the agency's PRA training program, including additional consideration of how PRA currently is used by the staff and additional training in both PRA techniques and the design and operation of licensed facilities.

- PRA methods development relates to developing additional PRA methods and related data bases for the staff's uses of PRA, including an agency-wide reactor classification structure, with representative PRA models available for each class of reactor that are compatible with the staff's PRA computer codes, IRRAS and SARA, and with guidance on adapting these PRAs for staff use, for example, in issue analyses.

The July 1991 ACRS letter (shown in the exhibit at the end of this chapter) that led to the formation of the Working Group provided four recommendations for addressing their concerns. The Working Group's efforts in these areas address the ACRS recommendations in the following ways:

1. The ACRS recommended that a mechanism be found for the staff to work toward a consistent position on the use of PRA at NRC. The Working Group believes that such a position is achievable by providing guidance on appropriate PRA use in specific staff functions, on PRA terms and methods, and on common PRA methods and data bases available to all staff.

2. The ACRS recommended that the Commission give credence and force to consistent staff positions on the use of PRA. The Working Group's recommendations are being made to the NRC's Executive Director for Operations (EDO). The Commission will be informed of the Working Group's recommendations and the EDO's plans for implementation.

3. The ACRS recommended the recruitment of more staff with expertise in PRA and statistics. The Working Group makes a similar recommendation, emphasizing the need for people with extensive expertise in systems reliability analysis (PRA Level 1) or statistics.

4. The ACRS recommended that any agency documents that contain or depend on PRA or statistics be reviewed by experts in these areas. The Working Group's guidance recommends such a quality assurance review.

The remaining sections of this chapter summarize the objectives, scope, and membership of the Working Group, including staff and supporting contractors; the five tasks undertaken by the Working Group; interactions of the Working Group with external reviewers and the ACRS; and the Group's general recommendations.

Chapter 2 summarizes some characteristics of present staff uses of PRA, based on a survey conducted by the Working Group.

Chapter 3 describes the Working Group's efforts with respect to guidance development. The chapter summarizes the guidance developed by the Working Group, provides recommendations for additional guidance development, and concludes with the Working Group's suggested timetable for implementing these recommendations.

Chapter 4 describes the Group's efforts with respect to enhanced training and methods development. That is, the chapter describes the actions taken and recommendations made by the Working Group with respect to inprovements 
1 Introduction

in skills, training, and PRA methods needed by the staff to properly use PRA, as well as a suggested timetable for implementing these recommendations.

Three appendices provide additional detail in the following areas:

- Appendix A discusses the results of a survey of present staff uses and practices in PRA.

- Appendix B describes present PRA uses at the NRC and guidance to the staff on the scope, products, decision criteria, and quality assurance for PRA uses in the screening and analysis of reactor safety issues.

- Appendix $\mathrm{C}$ discusses methods and terms important to the use of PRA by the staff.

\subsection{Objectives and Scope}

The objectives of the PRA Working Group are:

- To develop guidance on consistent and appropriate uses of PRA within the NRC;

- To identify knowledge and skills necessary for each category of staff use; and

- To identify improvements in PRA methods and associated data necessary for each category of staff use.

The activities of the Working Group potentially overlap a variety of normal functions of the NRC staff and management. To avoid duplication of efforts, the Working Group has defined the scope of its work as follows:

- The principal focus of the Working Group is the NRC staff's present uses of PRA. Future PRA uses that are not now well defined (e.g., possible transition to risk-based reactor regulation) are not included in the Working Group's scope of work. (As noted above, the Regulatory Review Group has considered the issue of risk-based reactor regulation.)

- The Group's second objective is to assess the knowledge and skills needed by the NRC staff to appropriately apply PRA, including staff organizational considerations, if appropriate. While the assessment of knowledge and skills is within the scope of the Working Group, the development and implementation of plans to change staffing levels, staff training, or organizational arrangements are, in general, the responsibility of the Office of Personnel and the affected NRC offices as part of the overall development and implementation of the agency's human resources strategic planning. The Working Grdup has, however, initiated some work as part of its review of staff training needs. This work is described in Section 4.2.

- The Working Group's third objective is to determine improvements needed in PRA techniques and data to support appropriate staff use of risk assessment. This determination focuses on improvements needed for pa:ticular usis, rather than a broad assessment of improvements needed in risk assessment methods, and uses state-of-the-art risk studies such as NUREG-1150 (Ref. 14) as reference and resource material. Any such improvements are, in general, the responsibility of the appropriate staff organization, not the Working Group, and should be incorporated by that organization into the agency's long-term planning efforts. Here also the Working Group has initiated some work, which is described in Section 4.4 .

- A number of procedures guides for performing detailed risk assessments (e.g., NUREG/CR-2300, Ref. 15) are available. It is not within the Working Group's scope to update or replace such guides, although the Working Group may recommend updating them. 
- A number of documents are available (e.g., NUREG-0933, Ref. 16) or in development to assist the staff in certain uses of risk assessment. The Working Group's work includes reviewing such documents and guides and developing recommendations for improvement. Such improvements are the responsibility of the user organization, with oversight by the Working Group.

\subsection{Summary of Tasks}

A set of tasks was defined by the Working Group to fulfill the objectives identified in Section 1.2. These tasks are:

\section{TASK 1 IDENTIFY HOW THE STAFF IS USING PRA.}

Task 1.1 Itemize the present staff uses of PRA.

Working Group members compiled the set of present staff uses of PRA for their respective offices.

Task 1.2 Survey the characteristics of PRA use.

A set of survey questions was developed to determine the important characteristics of each PRA use identified in Task 1.1, including both process characteristics (such as availability of formal procedures and decision criteria) and technical characteristics (such as type of risk assessment method used and extent of sensitivity and uncertainty analysis conducted). The survey questions were transmitted to PRA users (see Appendix A to this report), and roughly 80 responses representing the spectrum of agency PRA work wcre received and reviewed by the Working Group.

Task 1.3 Categorize the present uses.

Based on the results of Tasks 1.1 and 1.2, a set of PRA uses was defined by the Working Group for use in the remaining tasks.

The results of Task 1 are summarized in Chapter' 2, with additional detail on survey contents and results provided in Appendix A.

\section{TASK 2 IDENTIFY LIMITATIONS THAT EXIST IN THE PRESENT STAFF USES OF PRA.}

Task 1 categorized and assessed the present characteristics of PRA practices within NRC. Using this information combined with the Working Group's experience with PRA and the regulatory process, Task 2 focused on identifying limitations in the present staff practices.

The results of Task 2 are summarized in Chapter 2.

\section{TASK 3 DEVELOP GUIDANCE FOR PRA USES.}

Task 3.1 Develop guidance for specific PRA uses.

General guidance has been developed for two uses of PRA within the NRC: screening or prioritizing reactor safety issues and analyzing such issues in detail. More specific guidance has also been developed on one particular screening process (for generic safety issues) and one issue analysis process (again, for generic safety issues). All this guidance is summarized in Section 3.2 and discussed in more detail in Appendix B. Recommendations for additional guidance for other agency PRA uses are provided in Section 3.3. 
Task 3.2 Develop case studies of specific uses.

The Commission indicated in a January 1992 staff requirements memorandum (Ref. 17) that the Working Group should develop case studies of specific PRA uses and discuss these with the ACRS. As noted above, the Working Group has developed guidance for two specific PRA uses: generic issue prioritization and generic issue resolution. This guidance has been discussed with the ACRS and subsequently modified by the Working Group. Sections B.3.2 and B.4.2 in Appendix B provide this guidance.

The results of Task 3 are summarized in Chapter 3, with guidance provided in Appendix B.

\section{TASK 4 IDENTIFY NEEDED SKILLS, TRAINING, AND METHODS.}

Based on the results of Task 3, the Working Group initiated certain tasks and developed recommendations on skill and training needed by the staff in such areas as reliability analysis and statistics. Recommendations were also made for the development of PRA methods and associated data.

As noted in Section 1.2, developing specific staffing and training plans along with improved PRA methods, tools, and related data bases was not, in general, within the scope of the Working Group. Rather, such work is the responsibility of the appropriate staff organization.

The activities of the Working Group with respect to Task 4, and the subsequent results, are described in Chapter 4.

\section{TASK 5 DEVELOP A FINAL REPORT.}

The individual task reports described above were compiled into a draft report for comment by a set of external reviewers and the ACRS. Following receipt of comments, this final report has been prepared.

\subsection{Working Group Membership}

In December 1991, the Director of the Office of Nuclear Regulatory Research requested that other NRC offices designate representatives to the PRA Working Group (Ref. 18). The designated representatives were:

- Mark Cunningham, Chief, Probabilistic Risk Analysis Branch, Office of Nuclear Regulatory Research (Chair)

- Patrick Baranowsky, Chief, Trends and Patterns Analysis Branch, Office for Analysis and Evaluation of Operational Data

- William Beckner, Chief, Probabilistic Safety Analysis Branch, Office of Nuclear Reactor Regulation

- Patricia Rathbun, Senior Risk Analyst, Office of Nuclear Material Safety and Safeguards

Other NRC staff supporting the Working Group included:

- Lee Abramson, Senior Statistician, Probabilistic Risk Analysis Branch, Office of Nuclear Regulatory Research

- Kazimieras Campe, Section Leader, Probabilistic Safety Analysis Branch, Office of Nuclear Reactor Regulation

- Seth Coplan, Section Leader, Geosciences and Systems Performance Branch, Office of Nuclear Material Safety and Safeguards

- Christopher Fisher, Intern, Office of Nuclear Reactor Regulation

· J.S. Hyslop, Intern, Office of Nuclear Regulatory Research 
- Mohammed Modarres, Visiting Professor, University of Maryland

- Ann Ramey-Smith, Senior Reliability and Risk Analyst, Probabilistic Risk Analysis Branch, Office of Nuclear Regulatory Research

- Dale Rasmuson, Senior Plant Systems Engineer, Trends and Patterns Analysis Branch, Office for Analysis and Evaluation of Operational Data

- Christopher Ryder, Risk Analyst, Probabilistic Risk Analysis Branch, Office of Nuclear Regulatory Research

- Harold VanderMolen, Section Leader, Probabilistic Risk Analysis Branch, Office of Nuclear Regulatory Research

- Lillian VanSanten, PRA Technology Transfer Program Project Manager, Office of Personnel

Contractors supporting the Working Group included:

- George Apostolakis, Professor and Vice Chairman, Mechanical, Aerospace, and Nuclear Engineering Department, University of California at Los Angeles

- Thomas Brown, Reactor Modeling and Regulatory Applications Department, Sandia National Laboratories

- Allen Camp, Risk Assessment and Systems Modeling Department, Sandia National Laboratories

- Heidi Hahn, Cognitive Systems Engineering Group, Los Alamos National Laboratory

- Stephen Hora, College of Business Administration, University of Hawaii

- Harry Martz, Analysis Group, Los Alamos National Laboratory

\subsection{Reviews of Working Group Activities}

\subsubsection{External Review}

The activities of the Working Group have been reviewed by a set of individuals with expertise in risk assessment, statistics, decision analysis, safety analysis, and NRC's regulatory process. The charter for the external review was defined as, "to review the technical adequacy of the guidance and recommendations of the PRA Working Group with respect to the associated intended uses and, as appropriate, to the state of technology of risk assessment and related technical disciplines."

The Working Group contracted with Brookhaven National Laboratory (BNL) to manage this external review, with Dr. John Weeks of BNL assigned as project manager. Individuals performing this review include:

- Dr. B. John Garrick, President, PLG Inc.

- Dr. Bernard Harris, Professor, Department of Statistics, University of Wisconsin

- Dr. Ralph L. Keeney, Professor, Department of Systems Management, University of Southern Califormia

- Dr. Herbert J. C. Kouts, Defense Nuclear Facilities Safety Board

The Working Group met on four occasions (on October 20, 1992, February 17-18, 1993, June 29, 1993, and July $9-10,1993$ ) with these external reviewers. Comments provided by the reviewers (Refs. 19 to 25 ) were factored in to this report. 


\subsubsection{Review by the Advisory Committee on Reactor Safeguards}

The Working Group met on four occasions with the ACRS. The Working Group's program plan was transmitted to the ACRS in March 1992 (Ref. 26), and an introductory meeting to discuss the plan was held on April 3, 1992. Reference 27 is the ACRS' response to that briefing. A status report on the Group's work was provided on October 9, 1992. A third briefing was held on May 11 and 13,1993, to discuss a version of the Working Group report transmitted to the Committee in April 1993 (Ref. 28). Reference 29 provides the ACRS' comments on that version of the report; Reference 30 provides the staff's response. A fourth briefing was held on November 4, 1993; Reference 31 provides the ACRS' comments from that meeting.

\subsection{General Recommendations}

The Working Group has developed a number of recommendations for improving the quality of staff uses of PRA. Most of these deal with the three areas of improvements considered by the Working Group. However, two recommendations are of a more general nature. These recommendations are:

- Develop a Single Document on Staff Risk Assessment and Risk Management Practices. The Working Group's objectives and scope have been directed toward the resolution of the specific issues raised by the ACRS in their July 1991 letter. There are additional issues related to the staff's uses of PRA, some of which are being or recently have been addressed by the Regulatory Analysis Steering Group and the Regulatory Review Group. The Working Group recommends that all staff activities related to PRA uses be described in a single document that delineates the present structure of the agency's risk assessment and risk management practices, summarizes the key elements of the staff's work, and lays out plans for improving present risk assessment and risk management practices and for expanding PRA uses within the NRC. When completed, it may be appropriate to summarize the basic principles in the document in a Commission policy statement. (It should be noted that the Regulatory Review Group has made a similar recommendation in its report (Ref. 12).)

In other disciplines, formal decision analysis methods have been applied which use mathematical formalisms to improve the consistency, quality, and transparency of decisionmaking. Formal decision analysis structures a problem to result in the following elements: identification of the range of strategies or alternatives; evaluation of the consequences of the strategies; and identification of an optimum strategy. The Working Group recommends that the use of such "decision analysis" methods be investigated as part of the improvement of agency risk management practices.

- Improve Interactions with Industry PRA Users. The nuclear industry has developed considerable capabilities in risk assessment and risk management. The Working Group recommends that mechanisms be found to improve interactions between industry PRA users and in the NRC staff. The recently formed NUMARC "Regulatory Threshold" Working Group (Ref. 32), EPRI-proposed meetings on PRA methods, and interactions with specific reactor licensees with active risk assessment and risk management programs are possible mechanisms. 
1 Introduction

Exhibit ACRS Letter that Resulted in the Formation of the PRA Working Group

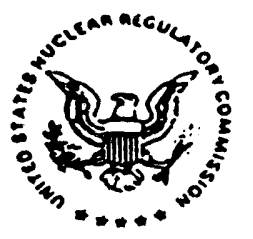

\author{
UNITED STATES \\ NUCLEAR REGULATORY.COMMISSION \\ AOVISORY COMMITTEE ON REACTOR SAFEGUAROS \\ TASHINGTON. D. C. 20555
}

July 19,1991

The Honorable Ivan selin

Chairman

- U.S. Nuclear Regulatory Commission

Washington, D.C. 20555

Dear Chairman selin:

SUBJECT: THE CONSISTENT USE OF PROBABILISTIC RISK ASSESSINNT

During the 375th meeting of the Advisory Committee on Reactor Safeguards, July 11-13, 1991, and in earlier meetings, we discussed the unevenness and inconsistency in the use of probabilistic risk assessment (PRA) in NRC. PRA can be a valuable tool for judging the guality of regulation, and for helping to ensure the optimal use of regulatory and industry resources, so we would have liked to see a deeper and more deliberate integration of the methodology into the NRC activities. Our recommendations to this end are directed at problems that took time to develop, and are likely to take a long time to solve.

PRA is not a simple subject, so there are wide variations in the sophistication with which it is used by the various elements of NRC. There are only a few staff members expert in some of the unfamiliar disciplines -- especially statistics -- that go into a PRA, so it is not surprising that there are inconsistencies in the application of the methodology to regulatory problems.

To illustrate the problems, let us just list a few of the fundamental aspects of the use of PRA, in which different elements of the staff seem to go their own ways. These are just illustrations, but each can lead to an erroneous regulatory decision.

1. The proper use of significant figures is in principle a trivial matter, but it does provide a measure of a person's understanding of the limitations of an analysis. Yet we often hear from members of the staff who quote core-damage probabilities to three significant figures, and who appear to believe that the numbers are meaningful. It is a rare PRA in which even the first significant figure should be regarded as sufficiently accurate to play an important role in a regulatory decision, but there is something mesmerizing about numbers, which imbues them with misleading verisimilitude. 
1 Introduction

Exhibit (continued)

The Honorable Ivan Selin

July 19, 1991

They deserve respect, but not too much, and it is wrong to err in either direction.

2. closely related is uncertainty. There is no way to know how seriousiy to take the results of a PRA without some estimate of the uncertainty, yet we often hear thoroughly unsatisfactory answers (some perhaps invented on the spot) when we ask about uncertainty. One of the advantages of PRA is that it provides a mechanism for estimating uncertainty, uncertainty which is equally present, but not guantified, in deterministic analyses.

3. Conservatism. A PRA should be done realistically. The proper time to add an appropriate measure of conservatism is when its results are used in the regulatory process. If the PRA Itself is done with conservative assumptions (more the rule than the exception at NRC), and is then used in a conservative regulatory decision-making process, self-deception can result, or resources can be squandered.

The inconsistent use of conservatism was illustrated by a pair of briefings at our April 1991 meeting, which included updates on proposed rules on license renewal and on maintenance. In the former case, we were told that a licensee could use PRA to add an item for later review, but never to remove one -a one-way sieve. In the latter case we were told that PRA could be used to justify either enhancement or relaxation of maintenance requirements. Foolish consistency may be a hobgoblin, as Emerson said, but there is nothing foolish in seeking consistency in regulation.

4. The bottom line. It has been widely recognized since WASH1400 that the bottom-line probabilities (of either core melt or immediate or delayed fatalities) are among the weakest results of a PRA, subject to the greatest uncertainties. (That doesn't mean they are useless, only that they should be used with caution and sophistication.) Yet we find staff members unaware of these subtleties, often dealing with small problems, justifying their actions in terms of the bottomline probabilities: This is only in part due to the Backfit Rule, which almost requires such behavior; it is also inexperience and lack of sensitivity to the limitations of the methodology.

A number of staff actions and proposals use bottom-line results of a PRA as thresholds for decision making, often with the standard litany about the uncertainty in the reliability of these results. In fact, the quantified uncertainty in the bottom-line results of a PRA is just as important a number as the probability itself. It would be straightforward to employ a decision-making algorithm that prescribes a confidence level 
1 Introduction

\section{Exhibit (continued)}

for the decision, and uses both the bottom-line probability and the uncertainty to achieve this. A further improvement would be to incorporate the consequences of erroneous decisions, what statisticians would call the loss function, into the decision-making process. The commission has come close to this approach in its recent instructions to the staff on the diesel generator reliability question.

These are just a few examples of problems with the use of PRA in - NRC, all common enough to be disturbing, and increasing in frequency as the use of PRA increases. It has been more than fifteen years since the publication of WASH-1400, a pioneering study which, despite known shortcomings, established the NRC at the forefront of quantitative risk assessment. One could have hoped that by now a coherent policy on the appropriate use of PRA within the agency, on both large and small problems, could have evalved.

We recommend that:

A. A mechanism be found (perhaps a retreat) through which the few PRA and statistical experts now scattered throughout the agency (and generally ignored) can be brought together with the appropriate senior managers and outside experts, to work toward a consistent position on the use of PRA at NRC. It could be worth the time expended. (Among other long-ters benefits, such an interaction would add an element of horizontal structure to the NRC's predominantly vertical organization.)

B. The commission then find a way to give credence and force to that position.

c. The commission emphasize recruitment of larger numbers of professionals expert in PRA and statistics.

D. The Commission consider some kind of mandate that any letter, order, issue resolution, etc.. that contains or depends on a statistical analysis or PRA, be reviewed by one of the expert PRA or statistical: groups.

We do not pretend that this is an easy problem. The solution involves not only a cultural shift, so that those few experts already at NRC have some impact, but also substantial enhancement of the staff capabilities. That will require incentives that only the commission can supply. It is interesting that the commission's Severe Accident Policy Statement, dated August 1985, stated that "within 18 months of the publication of this severe accident statement, the staff will issue guidance on the form, purpose and role thac PRAs are to play in severe accident analysis and decision making for both existing and future plant designs...." 
1 Introduction

\section{Exhibit (continued)}

The Honorable Ivan Selin

Additional comments by ACRS Members Harold $w$. Lewis and J. Ernest wilkins are presented below.

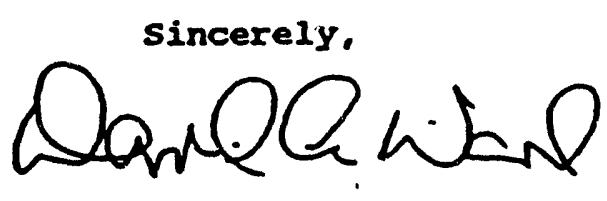

David A. Ward

Chairman

Additional comments by ACRs Yembers farold $W$. Iexts and I. Fanest ilikins

We thoroughly endorse this letter, and regret only that the Committee chose to ignore the paraliels between the PRA problems and those in a number of other newer technologies significant to nuclear safety. Recommendation $C$ should have included mention of some of these -- electronics and computers, for example -- which are of increasing importance. Weaknesses in those areas also need correction. Computerized protection and control systems, in particular, require the kind of sophisticated review that NRC is in no position to provide. 


\section{REVIEW OF STAFF PRA USES}

\subsection{Introduction}

The PRA Working Group's first task consisted of a review of existing PRA uses by the NRC staff in its regulatory activities. Surveys were distributed to staff in the Offices for Analysis and Evaluation of Operational Data, Nuclear Materials Safety and Safeguards, Nuclear Reactor Regulation, Nuclear Regulatory Research, and regional offices (e.g., Ref. 33). The survey was used to identify characteristics of staff PRA uses, including:

- The set of present uses by the staff;

- The general (nontechnical) attributes of these uses; and

- The technical attributes of the uses.

With the survey's focus on the present uses of PRA, the surveys were directed to staff members directly involved in using PRA at that time, not at management. The surveys, in general, were only sent to groups known to be using PRA. In a number of cases, certain individuals within a group were given the survey; their responses were treated as representative of all staff within their group using PRA in a particular staff activity.

Roughly 80 responses representing the spectrum of agency PRA uses were obtained and reviewed by the Working Group to help determine current uses and the important characteristics of these uses. From the survey results, the uses were categorized according to the licensing or regulatory function and by reactors or fuel cycle and materials. These uses are described in Section 2.2. The present PRA practices of the NRC staff are discussed in Section 2.3; improvements needed in these uses are discussed in Section 2.4. The survey's contents and results are presented in more detail in Appendix A.

\subsection{PRA Uses}

The Working Group defined sets of PRA uses by the staff, shown in Table 2.1, according to licensing and regulatory function as well as by reactors or fuel cycle and materials. Some of the important characteristics of each are:

- Licensing of reactors - PRA uses in this category include the review of analyses submitted as part of advanced reactor design certification applications, as well as plant-specific licensing actions such as technical specification modifications or justifications for continued operations. The principal responsibility for this work is in NRR, with support provided in some instances by RES.

- Regulation of reactors - PRA is used in many aspects of reactor regulation, including monitoring operations (with risk-based inspections); screening events for significance (including operational event screenings, generic safety issue screenings, and facility screening risk assessment); analyses of events and issues (including operational events analyses, component and system failure data analyses and trends, reliability monitoring that is now developing as a result of the maintenance rule, generic safety issue analyses, and severe accident research studies); facility analyses (both those performed by the staff such as NUREG-1150 (Ref. 14) and by licensees in the IPE process (Ref. 13)); and in regulatory analyses supporting regulatory actions such as backfits. These uses of PRA are performed by NRR, AEOD, and RES.

- Licensing of fuel cycle and materials - Risk assessment methods, known as performance assessment methods, are being used as part of the licensing of the proposed high-level waste repository (Ref. 34). Staff work in this area is concentrated in NMSS.

- Regulation of fuel cycle and materials - Risk assessment methods are being applied to certain medical devices using radioactive material - "gamma knife" and remote afterloader facilities (Ref. 35). Staff work in this area is concentrated in NMSS. 
Table 2.1 Categories of staff PRA uses

Licensing of Reactors

- Reviews

- Advanced reactors

- Plant-specific licensing actions

\section{Regulation of Reactors}

- Monitoring Operations

- Inspections

- Issue Screening

- Operational events

- Generic safety issues

- Issue Analyses

- Operational events

- Operational data analyses

- Operational trending

- Generic safety issues

- Severe accident issues

- Facility Analyses

- Staff studies

- Individual plant examinations
Licensing of Fuel Cycle and Materials

- Reviews

- High-level waste facilities

\section{Regulation of Fuel Cycle and Materials}

- Facility analyses

- Staff studies of medical devices

- Regulatory analyses

The Working Group identified several areas of staff work that could involve PRA in the near future or in which PRA is just beginning to be used, but these areas were not sufficiently well defined to permit consideration by the Working Group. These areas include the broad area usually referred to as "risk-based reactor regulation," reactor license renewal, and the use of risk-based performance indicators.

The Working Group also noted that risk assessment is used by the staff in a more qualitative manner to support decisions such as the need for research in specific areas. The Group has not reviewed or commented on such qualitative uses of risk assessment.

\subsection{Characteristics of Present Staff PRA Uses}

The responses to the Working Group survey were reviewed to gain perspectives on present staff uses of PRA. Some key perspectives are presented here.

Experience and Training

- Most of the staff surveyed had taken one or more of the NRC training courses; however,

- Roughly one-half of the staff surveyed had limited (less than 1 year) experience with PRA methods such as event and fault tree development and accident sequence quantification; and

- Roughly two-thirds of the staff surveyed indicated limited experience with PRA-related technical skills such as statistics. 


\section{Staff PRA Uses}

- Most staff surveyed cited substantial experience with topics important to the proper use of PRA, such as reactor systems, instrumentation and control, and reactor operations.

- A small percentage of the staff surveyed had a formal education in PRA-related topics (e.g., university courses in statistics or reliability).

\section{Guidance}

- In many cases, there was limited or no formal guidance on how to perform or use PRA methods and results in a particular regulatory activity.

- Almost all the staff surveyed used best-estimate (meaning, in this context, not purposely conservative) calculations in the PRA. However, conservatisms in PRA models and assumptions were cited, mostly in the prioritization use category.

- No staff member surveyed identified a use of formal decision analysis methods in their work.

\section{Methods and Scope}

- The majority of PRA applications and studies were Level 1 PRAs (i.e., with the product being a core damage frequency or change in core damage frequency). Since some agency decision criteria are risk-based (i.e., Level 3), some method for converting Level 1 results was used.

- The majority of PRA applications by the staff relied on adaptation of existing PRAs.

- No preference for any specific PRA method or PRA was reported. Past PRAs such as the Reactor Safety Study (Ref. 1), NUREG-1150 (Ref. 14), and industry-sponsored PRAs were equally cited.

\subsection{Needed Improvements in Present Staff Uses}

These survey perspectives led the Working Group to define a set of improvements needed for staff uses of PRA. The most significant improvements needed include:

- Guidance and training on how to use PRA in various staff functions, including:

- The fundamental technical concepts of PRA, including how to structure issues in a PRA context,

- The terms and methods underlying the use of PRA and likely to be encountered in staff PRA uses,

- The scope and other characteristics of a PRA needed to accomplish the function,

- The decision criteria, documentation, and quality assurance for particular staff PRA uses,

- PRA models and associated data which represent a spectrum of modern plant design and operational practices,

- Guidance on how to choose appropriate plant models, and how to adapt these models, for use in a specific analysis.

The Working Group's contributions to addressing these improvements are described in Chapters 3 and 4 . However, a number of improvements could not be completed under the scope and resources of the Working Group. In such cases, the Working Group has made specific recommendations on needed work and the appropriate organization to perform it. These recommendations are also provided in Chapters 3 and 4. 


\section{GUIDANCE ON STAFF USES OF PRA}

\subsection{Introduction}

The Working Group's first objective was to develop guidance for staff uses of PRA. The Working Group's assessment of needed guidance was based on its survey of the present staff uses of PRA, described in Chapter 2. The survey indicated that there was little guidance available to the staff on either the characteristics of the risk assessment to be performed in a particular staff job or on the associated risk management processes and decision c: iteria.

The Working Group has developed some basic principles for PRA work to help ensure consistent staff use of PRA. These principles are described in Section 3.2. In addition, the Working Group has reviewed current uses of PRA in the NRC and has either developed general guidance for that use or has made recommendations on the need for and type of guidance appropriate for that use. The actions taken by the Working Group are summarized in Table 3.1. This table shows that a number of current staff uses of PRA involve applying risk assessment methods to screen or prioritize issues or events or applying these methods as part of more detailed studies of the higher priority issues or events. Because of the broad use (throughout the NRC) of PRA in these two ways and because of the general lack of guidance for these uses, the Working Group has focused its development of guidance on these uses. This guidance is described in Section 3.3. Table 3.1 also shows a number of staff PRA uses not related to screening or analyzing issues or events. For each of these, the table provides a summary of the Working Group's recommendations for action. Section 3.4 discusses these recommendations in more detail. A timetable for implementing these recommendations is suggested in Section 3.5.

\subsection{Basic Principles for Staff PRA Work}

The Working Group identified a number of basic principles for PRA work to help ensure consistent staff use. These principles include:

- Staff who apply PRA methods should have training and experience commensurate with the particular use of PRA being undertaken.

- Methods should be used that:

- Reflect the current PRA state of technology, plant design and operational features, and data, and

- Reflect the intended use in both the appropriate level of detail and the associated decision criteria.

- Guidance to the staff should explicitly identify decision criteria for the particular use.

- Documentation of analyses should use proper PRA terminology, identify key uncertainties and sensitivities and their significance, and be sufficiently complete and scrutable to permit a quality assurance review.

- Quality assurance by knowledgeable staff should be performed, with the extent of review commensurate with the intended use.

These principles have been used by the Working Group in the development of guidance on two staff uses of PRA. This guidance is discussed in the following section. 
Table 3.1 Working Group actions and recommendations on staff uses of PRA

\begin{tabular}{|c|c|c|c|}
\hline PRA use & $\begin{array}{l}\text { Screening } \\
\text { analysis* }\end{array}$ & $\begin{array}{c}\text { Issue } \\
\text { analysis * }\end{array}$ & $\begin{array}{l}\text { Other comment } \\
\text { or recommendation }\end{array}$ \\
\hline \multicolumn{4}{|l|}{ Licensing of Reactors } \\
\hline \multicolumn{4}{|l|}{ - Reviews } \\
\hline Advanced reactors & & & Review SRP revisions when available. \\
\hline $\begin{array}{l}\text { Plant-specific licensing actions } \\
\text { (e.g., technical specification changes) }\end{array}$ & & & $\begin{array}{l}\text { NRR develop guidance for PRA/IPE/IPEEE } \\
\text { use in various licensing actions. }\end{array}$ \\
\hline \multicolumn{4}{|l|}{ Regulation of Reactors } \\
\hline \multicolumn{4}{|l|}{ - Monitoring operations } \\
\hline Inspections & & & NRR develop guidance for using IPEs/IPEEEs. \\
\hline \multicolumn{4}{|l|}{ - Issue screening } \\
\hline Operational events & $\mathbf{x}$ & & \\
\hline Generic safety issues & $\mathbf{x}$ & & \\
\hline \multicolumn{4}{|l|}{ - Issue analyses } \\
\hline Operational events & & $\mathbf{X}$ & \\
\hline Operational data analyses & & $\mathbf{X}$ & \\
\hline Operational data trending & & $\mathbf{x}$ & \\
\hline Generic safety issues & & $\mathbf{x}$ & \\
\hline Severe accident research issues & & $\mathrm{x}$ & \\
\hline \multicolumn{4}{|l|}{ - Facility analyses } \\
\hline Staff studies & $\mathbf{X}$ & $\mathbf{x}$ & $\begin{array}{l}\text { PRA needed (screening vs. detailed) dependent } \\
\text { on analysis use. }\end{array}$ \\
\hline Individual plant examinations & & & $\begin{array}{l}\text { Define how best to use IPE and IPEEE results } \\
\text { in regulation. }\end{array}$ \\
\hline - Regulatory analyses & & $\mathbf{X}$ & \\
\hline \multicolumn{4}{|l|}{ Licensing of Fuel Cycle and Materials } \\
\hline \multicolumn{4}{|l|}{ - Reviews } \\
\hline High-level waste repositories & & & Continue coordination with reactor studies. \\
\hline \multicolumn{4}{|l|}{ Regulation of Fuel Cycle and Materials } \\
\hline \multicolumn{4}{|l|}{ - Facility analyses } \\
\hline Staff studies of medical devices & & & Continue coordination with reactor studies. \\
\hline
\end{tabular}

* An $\mathrm{X}$ in this column indicates that this use of PRA involves screening or prioritizing issues or events. General guidance for such uses, as well as more detailed guidance for generic issue prioritization, has been developed by the Working Group and is provided in Section B.3 of Appendix B.

** An X in this column indicates that this use of PRA involves more detailed analysis of issues or events. General guidance for such uses, as well as more detailed guidance for generic issue analyses, has been developed by the Working Group and is provided in Section B.4 of Appendix B. 


\subsection{Guidance on PRA Use in Issue Screening and Analysis}

Guidance has been developed by the Working Group on the scope, products, decision criteria, and quality assurance for two general types of staff uses of PRA:

- Screening and prioritizing issues or events and

- Performing more detailed analyses of specific issues or events.

In each case, the guidance has elements related to risk assessment (including determining the scope of PRA to perform, quality assurance requirements, and results characterization) and risk management (describing present decision criteria). This guidance is summarized below, with detailed information provided in Appendix B.

While the various staff uses of PRA to screen and analyze issues and events have many important similarities, the Working Group found that they also have sufficient differences to prevent developing one set of detailed guidance for all uses. Therefore, the guidance described below has been intentionally developed at a general level. Appendix B contains examples of more detailed guidance, used for generic issue prioritization and generic issue analysis. These are intended to act as models for the development of more detailed guidance for other screening and analysis uses of PRA (e.g., AEOD studies of operational events). This guidance will also be tested in actual prioritizations and analyses of generic issues and revised accordingly. Chapter 4 describes a study initiated by the Working Group to systematically review the generic issue prioritization and analysis process with respect to skill, training, and procedural needs. This guidance will also be revised, as necessary, to reflect the results of this study.

\subsubsection{Guidance on Issue Screening}

The Working Group identified several activities within the NRC in which PRA is used to screen or prioritize events and issues, including:

- The screening of operational events in licensed reactors, as identified in daily reviews, licensee event reports, etc. (in NRR and AEOD);

- The prioritization of generic safety issues (in RES) (Ref. 16); and

- Some risk assessments that are used to focus more detailed studies on the most significant issues (e.g., the RES screening analysis of all reactor low power and shutdown modes) (Ref. 36).

The general guidance on using PRA for screening and prioritizing issues and events includes the following:

- The analysis should make use of up-to-date PRA information. This includes logic diagrams (such as event sequence diagrams, fault trees, and event trees) and other risk performance displays such as dependency matrices, current design and operational information, and data (such as component failure rates). Valuable references in this regard are the NUREG-1150 studies (Ref. 14) and the reviewed industry PRAs.

- The analysis should define the class of affected plants as specifically as possible and should make use of PRAs most closely resembling the class of affected plants.

- Uncertainty analyses and mean values should be calculated whenever this is practical. Even when formal uncertainty analyses are not possible, sensitivity studies should be performed to determine the impact of key assumptions, uncertainties in the inputs, and other factors. When no data are readily available and the analyst must use engineering judgment, the documentation of the analysis should always explicitly so state and give the rationale for substituting for unavailable information. ${ }^{4}$

\footnotetext{
4 Judgment, of course, is used throughout the analysis process. Here it is important to explicitly identify key judgments and discuss their impact.
} 
- The analysis should be as realistic as is practical. However, some conservatism may appropriately be used in screening calculations, for example, when bounding calculations can demonstrate that an issue should be dropped from consideration.

- The decision criteria for the screening of issues and events should be similar to the guidance provided in NUREG-0933 (Ref. 16) (for generic issue prioritizations).

- The analysis should explicitly ensure that the thuncation level of the base PRA is sufficiently low for calculations of differences (e.g., change in core damage frequency) to be meaningful. The issue being evaluated may well call the dropped sequences into consideration. That is, these sequences may no longer be negligible when the effect of the issue being evaluated is included.

There is no a priori definition of a sufficiently low truncation limit. However, the analyst must recognize that as accident sequences with very low frequencies are considered, concerns as to the completeness and adequacy of the models become much more serious.

- The analysis should receive an independent review by staff knowledgeable in PRA and in the design of the affected systems or components, plus reviews by the individual or group that identified the issue and the group that would be responsible for implementing the resolution, in a manner similar to that done for generic issue prioritizations. (If it is anticipated that considerable resources will be needed for this review, the review should be started early in the process, to allow incorporation of the reviewers' comments as the analysis progresses.)

- The documentation should not present calculational results with more significant figures than are appropriate. More than one significant figure in the mantissa is not appropriate in most cases. (It should be noted, however, that if intermediate results are presented, a reader attempting to use these intermediate results in duplicating the calculation may not get exactly the same final results because of the round-off error.)

For some screening and prioritizatipn processes (e.g., generic safety issues), the decision criteria and products are put in a qualitative form ("High," "Medium," "Low," or "Drop") to appropriately reflect the precision of the analysis.

- The analysis should be documented with sufficient detail to enable the analysis to be repeated. In addition, sufficient explanatory material should be provided to enable the reader to understand the significance of the calculations and to reconcile the various calculations with engineering judgment (a "sanity check"). Thus, the event or issue, its relationship to safety, the calculational approach, and all assumptions should be listed and justified, including the choice of the base PRA, choice of parameters, source of basic data, and any mathematical approximations used. Also, the accident sequences affected should be described and explanations of why they are affected should be provided.

A sample set of guidance for generic issue prioritization has been developed by the Working Group and is provided in Appendix B. This guidance will be revised, as necessary, after testing in actual prioritizations. As discussed in Section 3.4, the Working Group has also recommended that detailed guidance be developed for other issue prioritization and screening work performed by the staff.

\subsubsection{Guidance on Issue Analyses}

The Working Group identified a number of activities within the NRC in which PRA is used to analyze events and issues. These include:

- Detailed analyses of operational events (in NRR and AEOD);

- Detailed analyses and trending of operational data information and trends in this data (in AEOD);

- Detailed analyses supporting the resolution of generic safety issues (in RES); 
- Detailed analyses supporting the resolution of severe accident issues (e.g., BWR Mark I shell failure (Ref. 37)) (in RES);

- Detailed facility risk assessments (in RES); and

- Regulatory analyses to support backfits and rulemakings (in NRR, AEOD, and RES).

The general guidance on using PRA for issue analyses includes the following:

- The analysis should explicitly define the class of affected plants and justify the use of specific PRAs to represent that class.

- The PRA should reflect the current state of PRA technology and include the analysis of uncertainties.

- The product of the analyses should be mean values and uncertainty estimates for use in value/impact analyses, except in cases where there would be no effect on the conclusion (e.g., if "no action" could be justified by a bounding analysis).

- The decision criteria cor issue analyses should be based on the guidance provided in the draft Regulatory Analysis Guidelines (Ref. 6), which are themselves based on the Safety Goal Policy Statement (Ref. 4) and the Backfit Rule, 10 CFR 50.109.

- The analysis should receive an independent review by NRC staff who are knowledgeable and experienced in PRA, plus reviews by the individual or group who identified the issue and the group who would be responsible for implementing the resolution. (If it is anticipated that considerable resources will be needed for this review, the review should be started early in the process, to allow incorporation of the reviewers' comments as the analysis progresses.)

- The analysis should be documented with sufficient detail to enable the analysis to be repeated. In addition, sufficient explanatory material should be provided to enable the reader to understand the significance of the calculations and to reconcile the various calculations with engineering judgment (a "sanity check"). Thus, the event or issue, its relationship to safety, the calculational approach, and all assumptions should be listed and justified, including the choice of base PRA, choice of parameters, source of basic data, any mathematical approximations used. Also, the accident sequences affected should be described and explanations of why they are affected should be provided.

:- The documentation should not present calculational results with more significant figures than are appropriate. More than one significant figure in the mantissa is not appropriate in most cases. (It should be noted, however, that if intermediate results are presented, a reader attempting to use these intermediate results in duplicating the calculation may not calculate exactly the same final results because of the round-off error.)

A set of sample guidance for generic issue analysis has been developed by the Working Group and is provided in Appendix B. This guidance will be revised, as necessary, after testing in actual issue analyses. As discussed in Section 3.4, the Working Group has also recommended that detailed guidance be developed for other issue analysis work performed by the staff.

\subsection{Recommendations on Developing Additional Guidance}

The guidance summarized in the previous section does not cover all uses of PRA within the NRC. For those uses not covered, the Working Group has made recommendations for future staff actions; these are described in more detail in Appendix B. In summary, these recommendations are:

- Other issue prioritizations and analyses - As discussed in the previous two sections, guidance specific to the use of PRA to prioritize and analyze generic issues has been developed by the Working Group. The Working Group 


\section{Guidance}

recommends that specific guidance also be developed by AEOD and NRR for other issue prioritizations and analyses.

- Plant-specific licensing actions - Plant-specific licensing issues can involve a spectrum of PRA uses, from detailed reviews of licensee submittals to rough studies supporting assessment of a licensee's justification for continued operation. The Working Group recommends that NRR complete guidance on how PRA (including individual plant examinations (IPE) (Ref. 13) and individual plant examination for external events (IPEEE) information (Ref. 38)) should be used to support resolution of these licensing actions, and that the Working Group review the guidance when completed. (Development of such guidance has been started as part of NRR's revisions to the Standard Review Plan (Ref. 7).)

- Inspections - PRA results are used by NRR and regional offices to focus inspection activities on risk-significant components and systems (see, for example, Reference 39). The Group recommends that NRR develop guidance on the use of IPEs and IPEEEs to support this focusing of inspection activities.

- Advanced reactor PRA reviews - NRR is responsible for revising the Standard Review Plan to reflect the policies and practices developed during its advanced reactor reviews. As part of this revision, guidance is being developed on the review process for advanced reactor PRA submittals. When completed, the Working Group should review this revision.

- High-level waste repositories - The performance assessment methods being used in the licensing of high-level waste repositories (Ref. 34) have a number of similarities to detailed reactor risk assessments. Close coordination should be maintained between the staff groups involved in these areas.

- Risk studies on medical devices - Studies of the risks of certain medical devices using radioactive material, the "gamma knife" and remote afterloader facilities, are now under way in NMSS (Ref. 35). These risk studies are expected to show that human actions and errors have much greater influence on the estimated risk. Close coordination should be maintained between the staff groups involved in these studies in NMSS and those developing human reliability analysis methods in RES. As the use of risk assessment in the regulation of such facilities becomes more clear, the Working Group recommends that guidance for performing risk studies be developed.

\subsection{Suggested Timetable for Implementing Recommendations}

The Working Group has developed a suggested timetable for implementing the recommendations described in Section 3.4. This timetable, shown in Table 3.2, shows the year when the work should be completed and reflects the Working Group's assessment of both the importance of the recommendation and the amount of resources required to complete each effort. 
Table 3.2 Suggested timetable for implementing Working Group recommendations on use guidance

\begin{tabular}{|l|c|c|}
\hline \multicolumn{1}{|c|}{ Recommendation } & $\begin{array}{c}\text { Responsible } \\
\text { Office }\end{array}$ & Timing \\
\hline $\begin{array}{l}\text { Develop detailed guidance (including } \\
\text { decision criteria) for issue screenings } \\
\text { and analyses (beyond that in } \\
\text { Appendix B). }\end{array}$ & $\begin{array}{c}\text { AEOD, NRR, } \\
\text { RES }\end{array}$ & 1994 \\
\hline $\begin{array}{l}\text { Complete development of guidance } \\
\text { for PRA uses (including IPEs and } \\
\text { IPEEEs) in plant-specific reactor } \\
\text { licensing issues. }\end{array}$ & NRR & 1994 \\
\hline $\begin{array}{l}\text { Develop guidance on tow to use } \\
\text { IPEs and IPEEEs in risk-based } \\
\text { inspection process. }\end{array}$ & NRR & 1994 \\
\hline $\begin{array}{l}\text { Update standard review plan to } \\
\text { reflect advanced reactor PRA review } \\
\text { process. }\end{array}$ & NRR & 1995 \\
\hline $\begin{array}{l}\text { Maintain ciose coordination between } \\
\text { high-level waste performance } \\
\text { assessment process and reactor risk } \\
\text { assessment process. }\end{array}$ & NMSS & (Ongoing) \\
\hline $\begin{array}{l}\text { Maintain close coordination between } \\
\text { medical device PRA and reactor risk } \\
\text { assessment process. }\end{array}$ & NMSS & (Ongoing) \\
\hline
\end{tabular}




\section{SKILLS, TRAINING, AND METHODS FOR PRA}

\subsection{Introduction}

The Working Group's second and third objectives involve improvements needed in knowledge, skills, training requirements, PRA methods, and data to achieve consistent and appropriate uses of PRA by the staff.

The Working Group's assessment of these areas was based on its survey of the staff and a review of the present PRA training program (Ref. 40). As discussed in Chapter 2, the survey indicated that most of the staff had limited experience and familiarity with PRA and related methods.

The present PRA training program at NRC consists of nine courses, outlined in Table 4.1. In addition, NRC offers two courses on statistics, and several courses included in the agency's Technical Training Center curriculum discuss PRA methods and results. This curriculum appears to provide adequate training for certain current PRA uses in the : NRC (e.g., for PRA use in inspection). However, the Working Group has concluded that the present PRA training program, and the other courses noted above, provide an incomplete curriculum relative to the staff knowledge and skills needed for other important agency PRA uses.

Based on these findings, the Working Group has taken certain actions and has developed a set of recommendations with respect to improvements in skills, training, and methods. These actions and recommendations are discussed in the following sections.

As noted in Section 1.2, developing specific staffing and training plans, as well as improvements in PRA methods, tools, and data bases, are not generally within the scope of the Working Group. Rather, such work is principally the responsibility of the appropriate staff organization as part of the overall development and implementation of the agency's budget and human resources planning. However, as described below, the Working Group did initiate certain specific actions in these areas during the conduct of its study and did develop a set of recommendations.

\subsection{Actions on Skills and Training}

The Working Group has taken two actions to initiate an improvement in the NRC staff's knowledge, skills, and training in PRA. First, the Working Group has developed, as an interim measure, guidance on basic terms and methods important to appropriate PRA use by the staff. This guidance is provided in Appendix $C$ and is summarized below. Second, and as an illustration of a recommended longer term approach to PRA training, the Working Group has initiated a systematic review of tasks associated with certain PRA-related staff functions. This review uses the job and task analysis aspect of the Systems Approach to Training methods, also known as Instructional System Design and performance-based training. This review is also summarized below.

\subsubsection{Summary of Guidance on Terms and Methods}

The Working Group has developed guidance on basic terms and methods important to the staff's uses of PRA. This guidance defines terms used in PRA and related skills, with the goal of agency-wide adoption of these definitions; describes methods commonly applied in the NRC's business, including descriptions of the strengths and limitations of each; and lists references for obtaining more detailed information. This guidance, provided in Appendix C, includes discussions on:

- Statistics and probability

- Reliability and accident sequence (Level 1) analysis

- Accident progression (Level 2) analysis

- Source term analysis (also part of Level 2 analysis)

- Consequence (Level 3) analysis 
Table 4.1 Present PRA training curriculum*

\begin{tabular}{|c|c|}
\hline Course & Purpose \\
\hline PRA Overview & $\begin{array}{l}\text { Provide a general overview of risk concepts, PRA objectives } \\
\text { and methods, and how PRA is used by NRC. }\end{array}$ \\
\hline PRA Fundamentals & $\begin{array}{l}\text { Develop introductory practitioner-level skills, including PRA } \\
\text { methods, strengths, limitations, and results. }\end{array}$ \\
\hline $\begin{array}{l}\text { PRA Basics for } \\
\text { Inspection Applications }\end{array}$ & $\begin{array}{l}\text { Provide regional and resident inspectors with specialized } \\
\text { information on PRA issues and insights. }\end{array}$ \\
\hline $\begin{array}{l}\text { PRA Basics for } \\
\text { Licensing } \\
\text { Project Managers }\end{array}$ & $\begin{array}{l}\text { Provide NRR project managers, project engineers, and } \\
\text { project directors with specialized information on PRA issues } \\
\text { and insights. }\end{array}$ \\
\hline IRRAS Basics & $\begin{array}{l}\text { Provide hands-on training to use the IRRAS computer code } \\
\text { to build and evaluate PRA models. }\end{array}$ \\
\hline SARA Basics & $\begin{array}{l}\text { Provide hands-on training to use the SARA computer code to } \\
\text { perform sensitivity studies with existing PRA models. }\end{array}$ \\
\hline $\begin{array}{l}\text { Human Reliability } \\
\text { Assessment (HRA) }\end{array}$ & $\begin{array}{l}\text { Provide introduction to HRA methods for modeling human } \\
\text { errors and estimating their probabilities. }\end{array}$ \\
\hline $\begin{array}{c}\text { Overview of } \\
\text { Performance Assessment } \\
\text { Techniques for High-Level Waste }\end{array}$ & $\begin{array}{l}\text { Provide general overview of regulatory bases, analytical } \\
\text { methods, and programmatic objectives of performance } \\
\text { assessment of high-level waste repositories. }\end{array}$ \\
\hline $\begin{array}{l}\text { Probability and Statistics } \\
\text { for PRA }\end{array}$ & $\begin{array}{l}\text { Exposes participant to selected concepts from the fields of } \\
\text { probabilistic modeling, statistics, and reliability theory that } \\
\text { frequently arise in modern risk assessments. }\end{array}$ \\
\hline
\end{tabular}

* In addition to these courses, NRC also offers courses on introductory and advanced statistics. Further, a number of the courses offered by NRC's Technical Training Center on reactor systems contain summary information on PRA methods and results.

- Risk integration (the combination of Levels 1,2 , and 3)

- Sensitivity and uncertainty analysis methods

The Working Group has arranged to have these subjects addressed in a staff workshop to be conducted by agency and contractor staff. The first workshop is expected to be in early 1994 . Following some initial offerings of the course, Appendix $C$ will be revised, as necessary.

\subsubsection{Review of Staff's Screening and Analyses of Issues}

The Working Group has initiated a review of the staff's screening and analysis of issues. This review uses the job and task analysis technique of the Systems Approach to Training (SAT) method. The SAT methods of 
training system development have been widely adopted in industrial organizations and in government organizations such as the Department of Energy (see, for example, Reference 41), the Department of Defense, and the NRC. Fundamentally, this method links training objectives and content, as well as associated task procedures and guidance, to the individual tasks making up particular jobs.

The first step in the job and task analysis involves identifying the jobs of interest. After considering the various staff uses of PRA, the Working Group selected the generic issue screening and analysis process for an initial study. For the job of interest, the job and task analysis identified the specific tasks performed. The job tasks that are critical to the successful conduct of generic issue screening and analysis at the NRC were identified. For each of these critical tasks, knowledge and skill requirements will be established. From the identified knowledge and skill requirements, "terminal learning objectives" (i.e., behavior that trainees are expected to demonstrate to fulfill on-the-job tasks) and "enabling learning objectives" (i.e., behaviors that must be learned first) will be developed.

In summary, the results of the job and task analysis of the staff's generic issue screening and analysis work will be used to identify tasks for which training or procedures are needed. A training program for this staff use of PRA can then be developed that is tailored to task-specific learning objectives. As other uses of PRA are reviewed by using job and task analysis techniques (as recommended by the Working Group in Section 3.3), the PRA training program can be modified as needed. In addition to the requirements for training, the procedures and guidance needed for generic issue screening and analysis will be identified. This information will then be used to refine the initial guidance for generic issues provided in Appendix B and the guidance on PRA methods provided in Appendix $\mathrm{C}$.

The review of the generic issue screening and analysis process is scheduled to be completed in January 1994. Following that, the Working Group has arranged for job and task analysis techniques to be used in the review of other issue screening and analysis processes performed by agency staff (e.g., the review of operational events by AEOD staff). This review is expected to be completed in FY 1994.

\subsection{Recommendations on Skills and Training}

In addition to the actions taken, the Working Group has developed recommendations to improve PRA skills and training at the NRC. These include:

- Developing a Complete PRA Curriculum - The Systems Approach to Training method should be applied to other major uses of PRA within the NRC to tailor a complete program for PRA training (see Table 2.1 for the Working Group's list of such PRA uses).

The PRA curriculum should reflect the different goals of the NRC with respect to the level of PRA exper ise required. Based on the identified uses of PRA within the NRC, there are several broad categories that would need different levels of PRA training.

- Staff who use PRA results, and thus require some basic information on how PRAs are performed and the results obtained;

- Staff who work with PRA models or manage contractor efforts to work with PRA models require more extensive training, and

- Staff who perform quality assurance and expert advisory functions as well as develop new PRA methods require very extensive training.

As the PRA training curriculum is being developed, consideration should be given to including a formal curriculum that would enable a small number of NRC employees to attain the level of proficiency necessary to perform the the third level of, expertise identified above. Existing university-level courses should be considered for their suitability for inclusion in the PRA curriculum. 


\section{Training and Methods}

The training curriculum should include rotational assignments to NRC branches with particular PRA expertise or to national laboratories in order to acquire hands-on experience in the activities being performed.

The PRA curriculum should prescribe a minimum set of courses, practical experience, etc., needed to adequately use PRA in specific staff activities. The set would vary according to the type of PRA tasks being performed, as the tasks vary with the job being performed.

- Incorporating Technical Training - A key element of the successful use of PRA methods is a knowledge of the design and operations of the facility or device under study. Agency training in this area is, in general, provided by the Technical Training Center (TTC). The SAT reviews recommended above should also explicitly identify needs for training in the design and operation of the facility or device and should be in consonance with the present TTC curriculum. Appropriate changes to that curriculum should be made.

- Recruiting Staff with Critical PRA Skills - PRA is a technical discipline that requires skills in many areas, including facility design and operations, probability, statistics, reliability and risk methods, human factors, accident analysis methods, atmospheric sciences, health physics, and decision analysis. A "critical mass" of all these skills must be available within the staff. Considering the education and experience of the present NRC staff, personnel with specific knowledge and skills are both needed and in particularly short supply. People with extensive experience in systems reliability (PRA Level 1) analysis or skills in statistics should be recruited by the NRC.

\subsection{Actions on PRA Methods}

The Working Group's third objective is to identify PRA methods needed for the consistent and appropriate uses of PRA by the staff.

As noted in Section 1.2, the development of improved PRA methods, tools, and data bases is not generally within the scope of the Working Group. Rather, such work is principally the responsibility of the appropriate staff organization, as part of the development and implementation of the agency's long-term planning process.

The Working Group has initiated one effort to improve PRA methods used by the staff related to the transformation of PRA Level 1 results to Level 3 results. The Working Group's survey found that most event and issue analyses performed by the staff relate to Level 1 PRA information (e.g., failures of components or systems that prevent core damage). However, the agency's risk management decision criteria are often related to Level 3 products (e.g., regulatory analyses use risk information in terms of averted population dose).

In one case (generic issue prioritization), a simple transformation now exists for converting Level 1 to Level 3 results (Ref. 16). However, this transformation is based on results of the Reactor Safety Study (Ref. 1), completed in 1975. The Working Group concluded that this present core damage frequency-to-risk transformation should be replaced with information based on NUREG-1150 (Ref. 14). The Working Group has initiated an effort to provide NUREG-1150 results in forms appropriate for such transformations. This work is expected to be completed in early FY 1994.

\subsection{Recommendations on Methods}

Based on its review of present uses of PRA and the recommended guidance for these uses, the Working Group has identified a number of areas of needed methods development. As noted above, the responsibility for this development is not within the purview of the Working Group, but is the responsibility of the appropriate staff organization. Recommendations of the Working Group with respect to methods development include:

- The Working Group's survey results indicated that most uses of PRA by the NRC staff were adaptations of existing PRAs, rather than new studies. To support such adaptations, the Group recommends:

- Continuing to develop PC-based codes (i.e., IRRAS and SARA, Refs. 42 and 43) with a focus on using such codes to adapt PRA models; 
- Continuing efforts to put a set of modern PRA models in a form that is usable with the PC-based codes;

- Developing guidance on how to adapt PRAs for use in staff studies such as regulatory analyses; and

- Developing sensitivity and uncertainty analysis tools suitable for the types of PRA calculations performed by the staff.

- Both the issue screening and issue analysis uses of PRA could benefit from a structured classification of licensed reactors (e.g., structured by design type and containment design), with modern PRAs identified to represent each class. The feasibility of developing such a classification structure for use throughout the NRC should be investigated. This feasibility study should consider the present categorization scheme used for accident sequence precursor analyses for broader use throughout the agency.

As part of identifying modern PRAs for use in this classification structure, it may be necessary to replace sitespecific data in these PRAs with generic data and eliminate the site-specific portions of the model. The Working Group recommends that the need for and feasibility of such replacement of plant-specific data be studied.

- It would be beneficial to have detailed PRA models for use in issue analyses that can also be "rolled-up" to more simple models for use in screening analyses. The feasibility of such models is now under study in RES (at the request of AEOD). If feasible, such models should be developed for a representative set of plants in accordance with the classification structure described above.

- The use of PRA in operational events analyses would benefit from accident sequence analysis models that can be more readily updated to account for changes in plant design and operations, data on new components or system failures, etc. The Working Group recommends that existing methods be adapted to more readily permit such dynamic (or "living") PRA analyses.

\subsection{Suggested Timetable for Implementing Recommendations}

The Working Group has developed a suggested timetable for implementing the recommendations described in Section 3.3. This timetable, shown in Table 4.2, shows the year the work would be completed and reflects the Group's assessment of both the importance of the recommendation and the amount of resources required to complete each effort. 
Table 4.2 Suggested timetable for implementing Working Group recommendations on skills and methods

\begin{tabular}{|c|c|c|}
\hline Recommendation & $\begin{array}{l}\text { Responsible } \\
\text { Office }\end{array}$ & $\begin{array}{l}\text { Completion } \\
\text { Date }\end{array}$ \\
\hline $\begin{array}{l}\text { Complete job and task analysis of issue screening } \\
\text { and analysis process using SAT methods. }\end{array}$ & RES, AEOD, NRR, OP & 1994 \\
\hline $\begin{array}{l}\text { Hold workshops on Working Group guidance on } \\
\text { PRA terms and methods. }\end{array}$ & RES, AEOD, NRR, NMSS & 1994 \\
\hline $\begin{array}{l}\text { Revise PRA training based on completion of job } \\
\text { and task analysis. }\end{array}$ & OP & 1994 \\
\hline $\begin{array}{l}\text { Develop a comprehensive PRA training program } \\
\text { that is based on job and task analyses of major } \\
\text { PRA uses. }\end{array}$ & OP & 1995 \\
\hline $\begin{array}{l}\text { Develop a minimum set of courses for specific } \\
\text { PRA uses. }\end{array}$ & OP & 1995 \\
\hline $\begin{array}{l}\text { Coordinate PRA training and TTC systems } \\
\text { training. }\end{array}$ & OP, AEOD & 1994 \\
\hline $\begin{array}{l}\text { Complete initial guidance for adapting PRA } \\
\text { methods and results. }\end{array}$ & RES & 1994 \\
\hline $\begin{array}{l}\text { Complete Level } 1 \text { to Level } 3 \text { transformation } \\
\text { capability. }\end{array}$ & RES & 1994 \\
\hline $\begin{array}{l}\text { Continue development of PC-based PRA tools } \\
\text { and plant data base. }\end{array}$ & RES & (Ongoing) \\
\hline $\begin{array}{l}\text { Assess the feasibility of an agency-wide reactor } \\
\text { classification system. }\end{array}$ & RES & 1994 \\
\hline $\begin{array}{l}\text { Complete feasibility study of "roll-up" reactor } \\
\text { PRA models. }\end{array}$ & RES & 1994 \\
\hline $\begin{array}{l}\text { Develop "living" PRA models and data bases for } \\
\text { staff use. }\end{array}$ & RES, AEOD & 1995 \\
\hline $\begin{array}{l}\text { Develop sensitivity and uncertainty analysis tools } \\
\text { for staff use. }\end{array}$ & RES & 1995 \\
\hline
\end{tabular}




\section{REFERENCES}

1. NRC, "Reactor Safety Study--An Assessment of Accident Risks in U.S. Commercial Nuclear Power Plants," WASH-1400 (NUREG-75/014), October 1975.

2. "Current Regulatory Issues in Risk Assessment and Risk Management," Regulatory Program of the United States Government, Office of Management and Budget, April 1, 1990 - March 31, 1991."

3. National Research Council, "Risk Assessment in the Federal Government: Managing the Process," National Academy Press, Washington, D.C., 1983.

4. NRC, "Safety Goals for the Operation of Nuclear Power Plants" (Corrections and Republication of Policy Statement), Federal Register, Vol. 51, pp. 30028-30033, August 21, 1986.

5. NRC, "Revision of Backfitting Process for Power Reactors, " Federal Register, Vol. 53, p. 20603, June 6, 1988.

6. NRC, "Regulatory Analysis Guidelines of the U. S. Nuclear Regulatory Commission, "NUREG/BR-0058, Rev. 2, Draft Report for Comment, August 1993."

7. NRC, "Standard Review Plan," NUREG-0800 (updated periodically).

8. Letter from James M. Taylor, Executive Director for Operations, NRC, to David A. Ward, Chairman, ACRS, October 1, 1991."

9. Commission paper from James M. Taylor, EDO, to the Commissioners, "Regulatory Analysis Guidelines of the U.S. Nuclear Regulatory Commission," SECY-93-043; February 22, 1993."

10. NRC, "Regulatory Analysis Technical Evaluation Handbook," NUREG/BR-0184, Draft Report, August 1993.

11. Memorandum from James M. Taylor, EDO, to Chairman Ivan Selin et al., "COMIS-92-025 - Regulatory Review, "January 4, 1993:

12. NRC, "Regulatory Review Group," August 1993."

13. NRC, "Individual Plant Examination for Severe Accident Vulnerabilities," Generic Letter No. 88-20, November 23, 1988."

14. NRC, "Severe Accident Risks: An Assessment for Five U.S. Nuclear Power Plants," NUREG-1150, Volumes 1 and 2, December 1990.

15. J. W. Hickman, "PRA Procedures Guide. A Guide to the Performance of Probabilistic Risk Assessments for Nuclear Power Plants, "NUREG/CR-2300, Vols. 1 and 2 (American Nuclear Society), January 1983.

16. R. Emrit et al., "A Prioritization of Generic Safety Issues, Main Report and Supplements 1-16," NUREG-0933, NRC, September 1993.

17. Memorandum from Samuel J. Chilk, Secretary, NRC, to James M. Taylor, Executive Director for Operations, NRC, "Staff Requirements - Briefing on Regulatory Applications of PRA, 10:00 A.M., Monday, December 16, 1991, Commissioners' Conference Room, One White Flint North, Rockville, Maryland (Open to Public Attendance)," January 24, 1992."

\footnotetext{
- Copies are available for inspection or copying for a fee from the NRC Public Document Room.
} 
18. Memorandum from Eric S. Beckjord, Director, NRC/RES, to Thomas E. Murley, Director, NRC/NRR, et al., "Review of Staff PRA Activities, "December 11, 1991."

19. Letter from B. John Garrick, PLG, to John R. Weeks, Brookhaven National Laboratory, "Early Reactions to NRC PRA Working Group Activities, "November 13,1992."

20. Letter from John R. Weeks, Brookhaven National Laboratory, to Mark Cunningham, USNRC, "PRAERG First Report," March 10, 1993.

21. Letter from B. John Garrick, PLG, to John R. Weeks, Brookhaven National Laboratory, "PRA-ERG First Report," May 27, 1993."

22. Comments on the April 1993, NRC report, "A Review of NRC Staff Uses of PRA, "by Ralph L. Keeney, May 1993."

23. Comments on PRA Working Group Report, Draft of April 16, 1993, by Bernard Harris, May 1993.

24. Letter from H. Kouts, Defense Nuclear Facilities Safety Board, to Mark A. Cunningham, NRC, June 24, 1993."

25. Letter from John R. Weeks, Brookhaven National Laboratory, to Mark Cunningham, USNRC, "PRA ERG Final Report," November 10, 1993."

26. Memorandum from Eric S. Beckjord, Director, Office of Nuclear Regulatory Research, to Raymond F. Fraley, Executive Director, Advisory Committee on Reactor Safeguards, "PRA Working Group Program Plan," March 24, 1992."

27. Letter from David A. Ward, Chairman, Advisory Committee on Reactor Safeguards, to James M. Taylor, Executive Director for Operations, "NRC Staff Probabilistic Risk Assessment Working Group Program Plan," April 9, 1992."

28. Memorandum from Eric S. Beckjord, Director, Office of Nuclear Regulatory Research, to James M. Taylor, Executive Director for Operations, "Draft Report of the PRA Working Group," April 22, 1993."

29. Letter from Paul Shewmon, Chairman, Advisory Committee on Reactor Safeguards, to James M. Taylor, Executive Director for Operations, "Draft Report of the PRA Working Group," May 20, 1993.

30. Letter from James M. Taylor, Executive Director for Operations, to J. Ernest Wilkins, Jr., Chairman, Advisory Committee on Reactor Safeguards, July 6, 1993."

31. Letter from J. Ernest Wilkins, Jr., Chairman, Advisory Committee on Reactor Safeguards, to James M. Taylor, Executive Director for Operations, "Draft Final Report of the PRA Working Group, " November 10, 1993.

32. Letter from Joe F. Colvin, NUMARC, to James H. Sniezek, USNRC, July 13, 1993.

33. Memorandum from Eric S. Beckjord, Director, Office of Nuclear Regulatory Research, to Lawrence C. Shao, Director, Division of Engineering, Office of Nuclear Regulatory Research, et al., "Survey of PRA Uses in RES," March 20, 1992."

34. R. Codell et al., "Initial Demonstration of the U.S. NRC's Capability To Conduct a Performance Assessment for a High-Level Waste Repository," NUREG-1327, NRC, May 1992.

\footnotetext{
- Copies are available for inspection or copying for a fee from the NRC Public Document Room.
} 
35. "Risk Analysis in Regulating the Use of Nuclear Medical Devices," Lawrence Livermore National Laboratory (Draft of February 1994).

36. T-L Chu et al., "PWR Low Power and Shutdown Accident Frequencies Program: Phase 1 - Coarse Screening Analysis, "Brookhaven National Laboratory, November 1991."

37. T. Theofanous et al., "The Probability of Liner Failure in a Mark I Containment," NUREG/CR-5423 (University of California - Santa Barbara), NRC, August 1991.

38. NRC, "Individual Plant Examination of External Events (IPEEE) for Severe Accident Vulnerabilities 10 CFR 50.54F," Generic Letter No. 88-20, Supplement 4, June 28, 1991.

39. R. Pugh, B.F. Gore, and T.V. Vo., "Auxiliary Feedwater System Risk-Based Inspection Guide for the St. Lucie Unit 1 Nuclear Power Generation 'Station," NUREG/CR-5896 (Pacific Northwest Laboratory, PNL-8102), August 1992.

40. NRC, "Probabilistic Risk Assessment (PRA) Technology Transfer Program," NUREG/BR-0154, Rev. 3, September 1992."

41. J. Fries et al., "An Analysis of LANL Nuclear Materials Control and Accountability Jobs: Final Report," Los Alamos National Laboratory, Report Number A6:U-91-97, September 1991."

42. K.D. Russell et al., "Integrated Reliability and Risk Analysis System (IRRAS) Version 4.0 Reference Manual, "NUREG/CR-5813, Vol. 1, NRC, January 1992.

43. K.D. Russell et al., "System Analysis and Risk Assessment (SARA) System, Version 4.0, Reference Manual, NUREG/CR-5303, Vol. 1, NRC, February 1992.

- Copies are available for inspection or copying for a fee from the NRC Public Document Room. 
Appendix A

Survey of Staff PRA Uses 


\section{CONTENTS}

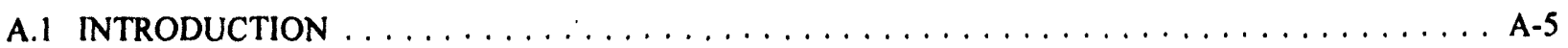

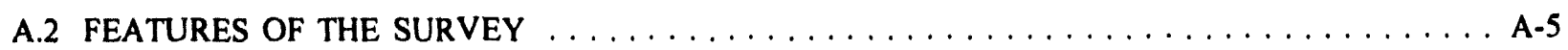

A.3 CATEGORIES OF STAFF PRA USES $\ldots \ldots \ldots \ldots \ldots \ldots \ldots \ldots \ldots \ldots \ldots \ldots \ldots \ldots$

A.4 GENERAL CHARACTERISTICS OF PRA USES $\ldots \ldots \ldots \ldots \ldots \ldots \ldots \ldots \ldots \ldots \ldots \ldots$

A.5 TECHNICAL CHARACTERISTICS OF PRA USES $\ldots \ldots \ldots \ldots \ldots \ldots \ldots \ldots$

\section{TABLES}

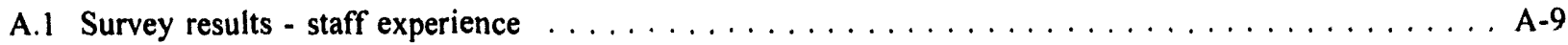

A.2 Survey results - technical issues $\ldots \ldots \ldots \ldots \ldots \ldots \ldots \ldots \ldots \ldots \ldots \ldots \ldots \ldots \ldots \ldots$

\section{EXHIBIT}

Working Group Survey .

A-12 


\section{A.1 INTRODUCTION}

The first task of the PRA Working Group was to review the uses of PRA by the NRC staff. This review was based on information obtained in a survey of the staff from April through June of 1992.

The survey was used to identify characteristics of PRA uses, including:

- The set of present uses by the staff;

- The general (nontechnical) attributes of these uses; and

- The technical attributes of the uses.

The survey was distributed to staff members in the Offices for Analysis and Evaluation of Operational Data (AEOD), Nuclear Materials Safety and Safeguards (NMSS), Nuclear Reactor Regulation (NRR), and Nuclear Regulatory Research (RES) and in NRC regional offices. Since the survey focused on the present uses of PRA, the surveys were targeted toward staff members who were using PRA at that time, and not at staff management. The surveys were, in general, only sent to groups known to be using PRA. In a number of cases, individuals within a group were provided the survey; their responses were treated as representative of all staff within their group.

Eighty responses to the survey were received, representing essentially all surveys distributed. Individual offices contributed responses as follows:

- NRR (and regions): 50 responses

- RES: 20 responses

- AEOD: 7 responses

- NMSS: 3 responses

This appendix discusses the survey and its results in detail, including the features of the survey (Section A.2), categories of PRA uses identified (Section A.3), general (nontechnical) characteristics of PRA uses (Section A.4), and technical characteristics of uses of PRA (Section A.5).

\section{A.2 FEATURES OF THE SURVEY}

The Working Group's survey was intended to identify general and technical characteristics of PRA uses by the NRC staff. The survey's first part focused on the general characteristics and included questions on:

- The objectives of the study;

- The level of effort involved;

- The availability of formal guidance on how to perform the PRA aspects of the study;

- The principal form of output from the PRA application or study (e.g., core damage frequency estimate, importance rankings, qualitative perspectives);

- How the PRA application or study results were used to reach a regulatory conclusion;

- The availability of formal guidance on how to use the results of the PRA in the agency's decisionmaking process; 


\section{Appendix A}

- The availability of formal decision criteria for the PRA use;

- The level and type of review performed for the study (including the extent of review and the groups performing the review);

- The PRA experience and training of the staff and contractors, including:

- Experience in PRA

Event tree/fault tree development

Data analysis

Quantification of sequences or fault trees

Human performance

Containment failure analysis

Offsite consequence analysis

External events

- Experience in Other Technical Disciplines

Reactor systems

Auxiliary systems

Instrumentation and control

Electrical systems

Thermal-hydraulics

Containment analysis

Source term analysis

Reactor operation

Inspection

Chemistry

Materials science

Consequence analysis

Statistics

External events

- Type of PRA Education

NRC courses

Formal PRA education

Experience

Other

- Other technical skills occasionally or routinely made use of (within the responder's division, other parts of NRC, or via contractors), including:

- Accident frequency (Level 1) analysis

- Statistics

- Human reliability analysis

- Fire analysis

- Seismic (or other external event) analysis

- Accident progression (Level 2) analysis

- Offsite consequence (Level 3) analysis. 
The second part of the survey focused on the technical characteristics of the PRAs the staff use, with questions on:

- Plant-specific vs. generic nature of the study;

- Extent to which the study generated its own unique PRA results or adapted results of previously performed PRAs;

- The PRA level and method used;

- The degree of conservatism employed in this application;

- The performance of uncertainty or sensitivity analyses;

- Consideration of the effects of common cause failures;

- Consideration of the effects of human failures, including:

- Pre-accident human errors

- Post-accident human errors

- Types of errors considered

- Consideration of accidents initiated by external events;

- The quantification process:

- Average time-independent unavailabilities calculated for input events

- Point-wise time-dependent unavailabilities developed for input events

- Codes used in the quantification process

- The method of accident progression and containment loading analysis;

- The method of fission product release and transport (source term) analysis;

- The method of offsite consequence analysis.

An example survey, one used in the Office of Nuclear Regulatory Research, is provided in the exhibit at the end of this appendix.

\section{A.3 CATEGORIES OF STAFF PRA USES}

The results of the survey were combined with the Working Group's familiarity with the staff's risk assessment work to define a set of PRA use categories. The categories and major staff PRA efforts included in each are:

- Licensing of reactors

- Reviews of advanced reactors

- Reviews of plant-specific licensing actions

- Regulation of reactors

- Monitoring operations

- Inspections

- Screening of issues

- Operational events

- Generic safety issues 
- Analyses of issues

- Operational events

- Operational data analyses

- Operational trending

- Generic safety issues

- Severe accident issues

- Facility Analyses

- Staff studies

- Individual plant examinations

- Regulatory analyses

- Licensing of Fuel Cycle and Materials Facilities

- Reviews

- High-level waste facilities

- Regulation of Fuel Cycle and Materials Facilities

- Facility analyses

- Staff studies of medical devices

The survey responses were divided into these use categories and subsequently analyzed. (In some cases a response was assigned to more than one category when the associated activities included more than one type of PRA use.) The results of the analyses are provided in the following sections.

\section{A.4 GENERAL CHARACTERISTICS OF PRA USES}

The survey results were reviewed by the Working Group to define some of the general characteristics of the staff's uses of PRA and how these characteristics varied with the category of use. As noted in Section A.2, the general characteristics included such items as the level of effort for each use, the availability of guidance for performing the study and using it in regulatory decisionmaking, and the experience of the staff and supporting contractors in risk assessment and related disciplines. Table A.1 summarizes the results of the Working Group's review with respect to the more general characteristics of the staff's PRA uses.

Some important perspectives on the general characteristics of staff PRA uses were indicated by respondents' replies.

\section{- Staff PRA Experience}

- The staff's PRA experience and familiarity with PRA techniques was generally low (with the exception of a few respondents with medium to high experience).

- The staff involved with prioritization had the least amount of experience.

- No noticeable variability was observed among offices with respect to the extent of experience.

- Other PRA-Related Technical Skills

- Most respondents cited substantial experience with topics not directly related to PRAs, but useful to understanding and performing them, such as reactor systems, instrumentation and control, and reactor operations.

- Staff experience with PRA-related technical skills such as statistical analysis and decision analysis was generally low. 
Table A.1 Survey results - staff experience

\begin{tabular}{|c|c|c|c|c|c|c|c|c|c|c|c|c|c|c|c|}
\hline Category & \multicolumn{3}{|c|}{ All Offices } & \multicolumn{3}{|c|}{ NRR } & \multicolumn{3}{|c|}{ RES } & \multicolumn{3}{|c|}{ NMSS } & \multicolumn{3}{|c|}{ AEOD } \\
\hline $\begin{array}{l}\text { PRA } \\
\text { Experience of } \\
\text { Staff Project } \\
\text { Manager }(1,2)\end{array}$ & $\begin{array}{l}\text { L } \\
\text { M } \\
\text { H } \\
\text { NA }\end{array}$ & $\begin{array}{c}33 \\
30 \\
9 \\
28\end{array}$ & $\begin{array}{l}46 \\
42 \\
12 \\
--\end{array}$ & $\begin{array}{l}\text { L } \\
\text { M } \\
\text { H } \\
\text { NA }\end{array}$ & $\begin{array}{c}38 \\
26 \\
8 \\
28\end{array}$ & $\begin{array}{l}56 \\
33 \\
11 \\
--\end{array}$ & $\begin{array}{l}\mathrm{L} \\
\mathrm{M} \\
\mathrm{H} \\
\mathrm{NA}\end{array}$ & $\begin{array}{c}35 \\
5 \\
15 \\
45\end{array}$ & $\begin{array}{c}64 \\
9 \\
27 \\
--\end{array}$ & $\begin{array}{l}\text { L } \\
M \\
H \\
\text { NA }\end{array}$ & $\begin{array}{c}0 \\
80 \\
20 \\
0\end{array}$ & $\begin{array}{l}0 \\
80 \\
20 \\
--\end{array}$ & $\begin{array}{l} \\
M \\
H \\
\text { NA }\end{array}$ & $\begin{array}{c}0 \\
100 \\
0 \\
0\end{array}$ & $\begin{array}{c}0 \\
100 \\
0 \\
--\end{array}$ \\
\hline $\begin{array}{l}\text { PRA } \\
\text { Experience } \\
\text { of Contractors }\end{array}$ & $\begin{array}{l}\text { L } \\
M \\
H \\
\text { NA }\end{array}$ & $\begin{array}{c}1 \\
6 \\
30 \\
63\end{array}$ & $\begin{array}{c}3 \\
17 \\
80 \\
--\end{array}$ & $\begin{array}{l}\text { L } \\
M \\
H \\
\text { NA }\end{array}$ & $\begin{array}{c}0 \\
2 \\
14 \\
84\end{array}$ & $\begin{array}{c}0 \\
12 \\
88 \\
--\end{array}$ & $\begin{array}{l}\text { L } \\
M \\
\text { H } \\
\text { NA }\end{array}$ & $\begin{array}{c}5 \\
20 \\
35 \\
40\end{array}$ & $\begin{array}{c}9 \\
33 \\
58 \\
--\end{array}$ & $\begin{array}{l}\mathrm{L} \\
\mathrm{M} \\
\mathrm{H} \\
\mathrm{NA}\end{array}$ & $\begin{array}{c}0 \\
0 \\
100 \\
0\end{array}$ & $\begin{array}{c}0 \\
0 \\
100 \\
--\end{array}$ & $\begin{array}{l}\text { L } \\
M \\
\text { H } \\
\text { NA }\end{array}$ & $\begin{array}{c}0 \\
0 \\
100 \\
0\end{array}$ & $\begin{array}{c}0 \\
0 \\
100 \\
--\end{array}$ \\
\hline $\begin{array}{l}\text { Other PRA- } \\
\text { Related Staff } \\
\text { Technical Skills } \\
\text { (c.g., Statistics) }\end{array}$ & $\begin{array}{l}\mathrm{L} \\
\mathrm{M} \\
\mathrm{H} \\
\mathrm{NA}\end{array}$ & $\begin{array}{c}44 \\
20 \\
8 \\
28\end{array}$ & $\begin{array}{l}61 \\
28 \\
11 \\
--\end{array}$ & $\begin{array}{l}\text { L } \\
M \\
\text { H } \\
\text { NA }\end{array}$ & $\begin{array}{c}60 \\
8 \\
4 \\
28\end{array}$ & $\begin{array}{c}83 \\
11 \\
6 \\
--\end{array}$ & $\begin{array}{l}\text { L } \\
M \\
\text { H } \\
\text { NA }\end{array}$ & $\begin{array}{l}25 \\
10 \\
20 \\
45\end{array}$ & $\begin{array}{l}46 \\
18 \\
36 \\
--\end{array}$ & $\begin{array}{l}\text { L } \\
\text { M } \\
\text { H } \\
\text { NA }\end{array}$ & $\begin{array}{c}0 \\
100 \\
0 \\
0\end{array}$ & $\begin{array}{c}0 \\
100 \\
0 \\
--\end{array}$ & $\begin{array}{l}\text { L } \\
M \\
H \\
\text { NA }\end{array}$ & $\begin{array}{c}0 \\
100 \\
0 \\
0\end{array}$ & $\begin{array}{c}0 \\
100 \\
0 \\
--\end{array}$ \\
\hline $\begin{array}{l}\text { Type of PRA } \\
\text { Education - } \\
\text { Staff (3) }\end{array}$ & $\begin{array}{l}\text { NRC } \\
\text { Form } \\
\text { Exp } \\
\text { None } \\
\text { NA }\end{array}$ & $\begin{array}{c}39 \\
6 \\
20 \\
4 \\
31\end{array}$ & $\begin{array}{c}56 \\
9 \\
29 \\
6 \\
--\end{array}$ & $\begin{array}{l}\text { NRC } \\
\text { Form } \\
\text { Exp } \\
\text { None } \\
\text { NA }\end{array}$ & $\begin{array}{c}33 \\
8 \\
12 \\
5 \\
43\end{array}$ & $\begin{array}{c}57 \\
14 \\
20 \\
9 \\
--\end{array}$ & $\begin{array}{l}\text { NRC } \\
\text { Form } \\
\text { Exp } \\
\text { None } \\
\text { NA }\end{array}$ & $\begin{array}{c}40 \\
4 \\
24 \\
4 \\
28\end{array}$ & $\begin{array}{c}56 \\
5 \\
33 \\
5 \\
--\end{array}$ & $\begin{array}{l}\text { NRC } \\
\text { Form } \\
\text { Exp } \\
\text { None } \\
\text { NA }\end{array}$ & $\begin{array}{c}100 \\
0 \\
0 \\
0 \\
0\end{array}$ & $\begin{array}{c}100 \\
0 \\
0 \\
0 \\
--\end{array}$ & $\begin{array}{l}\text { NRC } \\
\text { Form } \\
\text { Exp } \\
\text { None } \\
\text { NA }\end{array}$ & $\begin{array}{c}50 \\
0 \\
50 \\
0 \\
0\end{array}$ & $\begin{array}{c}50 \\
0 \\
50 \\
0 \\
-\end{array}$ \\
\hline $\begin{array}{l}\text { Type of PRA } \\
\text { Education - } \\
\text { Contractors }\end{array}$ & $\begin{array}{l}\text { NRC } \\
\text { Form } \\
\text { Exp } \\
\text { NA }\end{array}$ & $\begin{array}{c}11 \\
2 \\
30 \\
57\end{array}$ & $\begin{array}{c}24 \\
5 \\
71 \\
--\end{array}$ & $\begin{array}{l}\text { NRC } \\
\text { Form } \\
\text { 'Exp } \\
\text { NA }\end{array}$ & $\begin{array}{c}8 \\
0 \\
14 \\
76\end{array}$ & $\begin{array}{c}29 \\
0 \\
58 \\
--\end{array}$ & $\begin{array}{l}\text { NRC } \\
\text { Form } \\
\text { Exp } \\
\text { NA }\end{array}$ & $\begin{array}{c}20 \\
8 \\
32 \\
40\end{array}$ & $\begin{array}{l}33 \\
14 \\
53 \\
-\end{array}$ & $\begin{array}{l}\text { NRC } \\
\text { Form } \\
\text { Exp } \\
\text { NA }\end{array}$ & $\begin{array}{c}0 \\
0 \\
100 \\
0\end{array}$ & $\begin{array}{c}0 \\
0 \\
100 \\
--\end{array}$ & $\begin{array}{l}\text { NRC } \\
\text { Form } \\
\text { Exp } \\
\text { NA }\end{array}$ & $\begin{array}{c}0 \\
0 \\
100 \\
0\end{array}$ & $\begin{array}{c}0 \\
0 \\
100 \\
--\end{array}$ \\
\hline
\end{tabular}

Notes:

(1) The first column in each box indicates percentages based on all responses received; the second column indicates percentages normalized to remove nonanswers.

(2) L: Low (less than 1 year)

M: Medium (between 1 and 5 years)

H: High (greater than 5 years)

NA: Question not answered

(3) NRC: NRC training course(s)

Form: Formal education

Exp: Experience

None: No education or training

NA: Question not answered

\section{- Contractors' PRA Experience}

- Only a small percentage of respondents answered the survey question on the extent of contractor experience, apparently because of a lack of readily available information. However, for those responses provided, the PRA experience of the contractors was generally high. 
Appendix A

- Form of PRA Training

- Most of the respondents received their PRA education from the NRC training courses.

- A small percentage of the respondents had formal education in a PRA-related topic.

- A small percentage of respondents had received no formal education or training in PRA-related subjects.

- Many of the contractors developed their PRA skills through experience. As with the staff, the percentage of the contractors with formal education in PRA-related subjects was low.

- Level of Effort for PRA Applications/Studies

- A majority of the studies and applications reported by the respondents involved less than one staff-year of effort for the PRA portion.

- Generally, the level of effort spent on PRA applications in RES projects was higher than those in NRR, $A E O D$, and NMSS, reflecting the more extensive facility risk assessments and generic issue analyses performed in RES.

- Availability of Guidance

- A large proportion of respondents indicated that they have no formal guidance on how to perform or use a PRA in their studies or applications.

- No application of a formal decision analysis was cited.

\section{A.5 TECHNICAL CHARACTERISTICS OF PRA USES}

Table A.2 summarizes the results of the Working Group's review with respect to the technical characteristics of PRA uses. Some important perspectives with respect to these technical characteristics include:

- Scope of Analysis

- The majority of PRA applications and studies were Level I PRA (i.e., the product is a core damage frequency or change in core damage frequency).

- More Level 2 applications were performed in RES than in the other offices surveyed.

- Extent of Conservatism

- Essentially all the respondents indicated that they used best estimate (meaning, in this case, not purposely conservative) values in their PRAs.

- Adaptation of Existing PRAs

- The majority of the staff's PRA applications relied on adaptation of results from existing PRAs.

- No variability among offices was observed regarding the extent of adaptation of the PRA results.

- No preference for any specific PRA or PRA method was reported. Past PRAs such as the Reactor Safety Study, NUREG-1150, and industry-sponsored PRAs were equally favored. 
Table A.2 Survey results - technical issues

\begin{tabular}{|c|c|c|c|c|c|c|c|c|c|c|c|c|c|c|c|}
\hline \multirow{2}{*}{$\begin{array}{l}\text { Category } \\
\text { Level of Effort } \\
\text { Spent on the } \\
\text { PRA Portion } \\
(1,2)\end{array}$} & \multicolumn{3}{|c|}{ Total } & \multicolumn{3}{|c|}{ NRR } & \multicolumn{3}{|c|}{ RES } & \multicolumn{3}{|c|}{ NMSS } & \multicolumn{3}{|c|}{ AEOD } \\
\hline & $\begin{array}{l}\mathbf{L} \\
\mathrm{M} \\
\mathrm{H} \\
\mathrm{NA}\end{array}$ & $\begin{array}{l}13 \\
25 \\
25 \\
37\end{array}$ & $\begin{array}{l}20 \\
40 \\
40 \\
--\end{array}$ & $\begin{array}{l}\text { L } \\
M \\
\text { H } \\
\text { NA }\end{array}$ & $\begin{array}{l}12 \\
22 \\
18 \\
48\end{array}$ & $\begin{array}{l}23 \\
42 \\
35 \\
-- \\
\end{array}$ & $\begin{array}{l}\mathrm{L} \\
\mathrm{M} \\
\mathrm{H} \\
\mathrm{NA}\end{array}$ & $\begin{array}{c}5 \\
15 \\
50 \\
30\end{array}$ & $\begin{array}{c}7 \\
22 \\
71 \\
--\end{array}$ & $\begin{array}{l}L \\
M \\
H \\
N A\end{array}$ & $\begin{array}{c}0 \\
100 \\
0 \\
0\end{array}$ & $\begin{array}{c}0 \\
100 \\
0 \\
-\end{array}$ & $\begin{array}{l}\text { L } \\
\text { M } \\
\text { H } \\
\text { NA }\end{array}$ & $\begin{array}{c}43 \\
43 \\
14 \\
0\end{array}$ & $\begin{array}{l}43 \\
43 \\
14 \\
-.\end{array}$ \\
\hline $\begin{array}{l}\text { Availability of } \\
\text { Guidance }\end{array}$ & $\begin{array}{l}\text { No } \\
\text { Yes } \\
\text { NA }\end{array}$ & $\begin{array}{c}78 \\
5 \\
17\end{array}$ & $\begin{array}{r}94 \\
6 \\
-\end{array}$ & $\begin{array}{l}\text { No } \\
\text { Yes } \\
\text { NA }\end{array}$ & $\begin{array}{c}80 \\
2 \\
18\end{array}$ & $\begin{array}{c}98 \\
2 \\
--\end{array}$ & $\begin{array}{l}\text { No } \\
\text { Yes } \\
\text { NA }\end{array}$ & $\begin{array}{l}60 \\
15 \\
25\end{array}$ & $\begin{array}{l}80 \\
20 \\
--\end{array}$ & $\begin{array}{l}\text { No } \\
\text { Yes } \\
\text { NA }\end{array}$ & $\begin{array}{c}100 \\
0 \\
0\end{array}$ & $\begin{array}{c}100 \\
0 \\
-\end{array}$ & $\begin{array}{l}\text { No } \\
\text { Yes } \\
\text { NA }\end{array}$ & $\begin{array}{c}100 \\
0 \\
0\end{array}$ & $\begin{array}{c}100 \\
0 \\
+\end{array}$ \\
\hline $\begin{array}{l}\text { Scope of Risk } \\
\text { Assessment (3) }\end{array}$ & $\begin{array}{l}\text { L-1 } \\
\text { L-2 } \\
\text { L-3 } \\
\text { NA }\end{array}$ & $\begin{array}{c}31 \\
9 \\
10 \\
50\end{array}$ & $\begin{array}{l}62 \\
18 \\
20 \\
--\end{array}$ & $\begin{array}{l}L-1 \\
L-2 \\
L-3 \\
\text { NA }\end{array}$ & $\begin{array}{c}20 \\
8 \\
14 \\
58\end{array}$ & $\begin{array}{l}48 \\
19 \\
33 \\
--\end{array}$ & $\begin{array}{l}\text { L-1 } \\
\text { L-2 } \\
\text { L-3 } \\
\text { NA }\end{array}$ & $\begin{array}{c}45 \\
15 \\
5 \\
35\end{array}$ & $\begin{array}{c}74 \\
22 \\
7 \\
\cdots\end{array}$ & $\begin{array}{l}L-1 \\
L-2 \\
L-3 \\
\text { NA }\end{array}$ & (4) & & $\begin{array}{l}\text { L-1 } \\
\text { L-2 } \\
\text { L-3 } \\
\text { NA }\end{array}$ & $\begin{array}{c}71 \\
0 \\
0 \\
29\end{array}$ & $\begin{array}{c}100 \\
0 \\
0 \\
-\end{array}$ \\
\hline $\begin{array}{l}\text { Extent of } \\
\text { Conservatism }\end{array}$ & $\begin{array}{l}\text { None } \\
\text { Some } \\
\text { NA }\end{array}$ & $\begin{array}{c}53 \\
0 \\
47\end{array}$ & $\begin{array}{c}100 \\
0 \\
--\end{array}$ & $\begin{array}{l}\text { None } \\
\text { Some } \\
\text { NA }\end{array}$ & $\begin{array}{l}42 \\
0 \\
58\end{array}$ & $\begin{array}{c}100 \\
0 \\
--\end{array}$ & $\begin{array}{l}\text { None } \\
\text { Some } \\
\text { NA }\end{array}$ & $\begin{array}{c}65 \\
0 \\
35\end{array}$ & $\begin{array}{c}100 \\
0 \\
\cdots\end{array}$ & $\begin{array}{l}\text { None } \\
\text { Some } \\
\text { NA }\end{array}$ & $\begin{array}{c}100 \\
0 \\
0\end{array}$ & $\begin{array}{c}100 \\
0 \\
\cdots\end{array}$ & $\begin{array}{l}\text { None } \\
\text { Some } \\
\text { NA }\end{array}$ & $\begin{array}{c}71 \\
0 \\
23\end{array}$ & $\begin{array}{c}100 \\
0 \\
-\end{array}$ \\
\hline $\begin{array}{l}\text { Adapt or } \\
\text { Perform New } \\
\text { PRA }\end{array}$ & $\begin{array}{l}\text { Adapt } \\
\text { Perform } \\
\text { NA }\end{array}$ & $\begin{array}{c}51 \\
5 \\
44\end{array}$ & $\begin{array}{c}91 \\
9 \\
--\end{array}$ & $\begin{array}{l}\text { Adapt } \\
\text { Perform } \\
\text { NA }\end{array}$ & $\begin{array}{c}40 \\
4 \\
56\end{array}$ & $\begin{array}{c}91 \\
9 \\
--\end{array}$ & $\begin{array}{l}\text { Adapt } \\
\text { Perform } \\
\text { NA }\end{array}$ & $\begin{array}{c}75 \\
5 \\
20\end{array}$ & $\begin{array}{c}94 \\
6 \\
--\end{array}$ & $\begin{array}{l}\text { Adapt } \\
\text { Perform } \\
\text { NA }\end{array}$ & $\begin{array}{c}100 \\
0 \\
0\end{array}$ & $\begin{array}{c}100 \\
0 \\
-\end{array}$ & $\begin{array}{l}\text { Adapt } \\
\text { Perform } \\
\text { NA }\end{array}$ & $\begin{array}{l}43 \\
14 \\
43\end{array}$ & $\begin{array}{l}75 \\
25 \\
--\end{array}$ \\
\hline
\end{tabular}

Notes

(1) The first column in each box indicates percentages based on all responses; the second column indicates percentages normalized to remove non-answers.

(2) L: Low (less than 1 staff-week)

M: Medium (between 1 and 12 staff-weeks)

H: High (greater than 12 staff-weeks)

NA: Question not answered

(3) L-1: Level 1 PRA

L-2: Level 2 PRA

L-3: Level 3 PRA

NA: Question not answered

(4) Staff use was performance assessment of high-level waste facility. 


\section{Exhibit Working Group Survey}

\section{A Survey Of NRC PRA Uses}

In late 1991, the Executive Director for Operations established an interoffice group (the "PRA Working Group") to review present staff uses of PRA and to consider what additional guidance to the staff would assure the consistent development, content, and use of PRA within the NRC. This review was initiated by the EDO in response to ACRS comments on the staff's uses of PRA.

The Working Group has developed this survey to help in the characterization of present staff uses of PRA. This survey has two sections. The first section relates to the process of PRA use in the agency. The second section relates to the technical attributes of the PRA applications. After evaluating the results of this survey, some of the respondents may be asked to provide additional information: in this case, a more detailed survey will be sent to the respondent.

This survey covers both PRA applications and studies, as well as non-PRA applications and studies which use PRA as a support tool. It also covers those applications that adapt results of PRA studies.

If you have any questions please call:

Mark Cunningham

Chief, DSIR/PRAB

X23965

Name of The Respondent:

Affiliation:

Mail Stop and Telephone Number:

INSTRUCTIONS

1) If, for a particular type of application, (e.g., generic issue analysis), the PRA methods used vary considerably, please fill out individual surveys for a representative sample of applications (e.g., normal case, very complex study, simple study)

2) Check the appropriate answer whenever possible; if desired, provide further information or clarifications in a brief form.

3) Only include applications or studies in which PRA was used and which were initiated or completed in the past 2 years. 


\section{Exhibit (continued)}

\section{The Process of PRA Use}

\section{I.1 Description of the Application or Study}

a) Name of the application or study.

b) Applicable references.

\section{I.2 Objectives of the Application or Study}

a) Briefly describe the objectives of the overall project for which the PRA application or study was performed.

b) Briefly describe the specific objectives of the PRA application/study portion of the project.

c) Indicate the approximate level of effort involved:

- Total staff-weeks spent on the PRA portion of the project.

- Fraction of project's overall effort spent on the PRA portion.

\section{I.3 Uses of the PRA Results}

a) How were the PRA application/study results used to reach a regulatory conclusion?

- PRA results directly used to reach a regulatory decision.

- PRA results indirectly used to reach a regulatory decision.

- PRA results not used to reach a regulatory decision.

- Other

b) What was the principal form of output from the PRA application/study?

- Core damage frequency or risk.

- Change in core damage frequency or risk.

- Importance or other relative ranking.

- Review and comment on PRA performed by others.

- Qualitative insights.

- Other

c) Does formal guidance exist on how to perform the PRA application?

- Guidance does not exist.

- Guidance exists (briefly describe and reference). 


\section{Appendix A}

\section{Exhibit (continued)}

d) Does formal guidance exist on how to use the results of the PRA in the agency's decisionmaking process?

- Guidance does not exist.

- Guidance exists (briefly describe and reference).

e) Do formal decision criteria exist for this use of PRA?

- Formal decision criteria exist (briefly describe and reference).

- Decision criteria do not exist.

\section{I.4 Staff and Contractor PRA Experience}

a) Identify the level of PRA knowledge of the people who performed this application or study. Please answer the questions with respect to the NRC project manager here and. if a contractor was used. with respect to the principal investigator in question I.4.b.

Name of NRC Project Manager

- PRA Related Experience

Event Tree/Fault Tree Development

* Fault Tree Construction

* Event Tree Construction

* Review of ET/FTS

* Project Management

* Other (please specify)

Data Analysis

* Screening/Rev. / Categorizing

* Bayesian Analysis

* Statistical Analysis

* Common Cause Data

* Human Performance Data

* Other (please specify)
Yrs. No. of

Studies
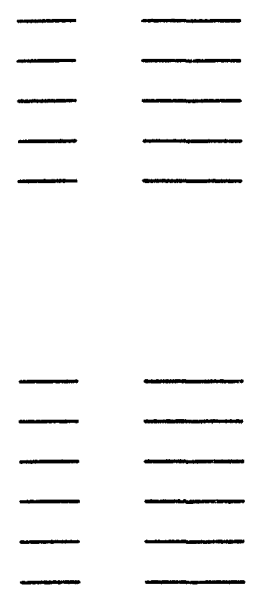

Quantification of Sequences (or fault trees)

* Quantified Fault Trees

* Quant. Accident Sequences

* Performed Uncertainty Anal.

* Performed Sensitivity Anal.

Human Performance

Containment Failure Analysis

In-Vessel Phenomena/Source Term 


\section{Exhibit (continued)}

Offsite Consequence Analysis

External Events

* Qualitative Analysis

* Probabilistic

* Other (please specify)

- Non-PRA Background/Experience

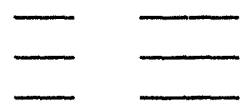

Reactor Systems

Auxiliary Systems

Instrumentation and Control

Electrical Systems

Thermal-Hydraulics

Containment Analysis

Source Term Analysis

Reactor Operation

Inspection

Chemistry

Materials Science

Consequence Analysis

Statistics

External Events

Other (Please Specify)

$\underline{\text { Yrs }}$

- Type of PRA Education

* NRC courses

* Formal PRA education

* Experience

* Other (please specify)

b) If a contractor was used, describe the experience of the principal investigator.

Name and Affiliation of Principal Investigator

- PRA Related Experience

Yrs. No. of

Event Tree/Fault Tree Development

Studies

* Fault Tree Construction

* Event Tree Construction

* Review of ET/FTs

* Project Management

* Other (please specify)

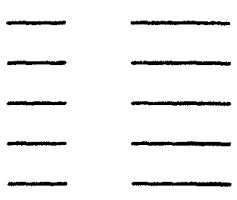




\section{Appendix A}

\section{Exhibit (continued)}

Data Analysis

* Screening/Rev. / Categorizing

* Bayesian Analysis

* Statistical Analysis

* Common Cause Data

* Human Performance Data

* Other (please specify)

Quantification of Sequences (or fault trees)

* Quantified Fault Trees

* Quant. Accident Sequences

* Performed Uncertainty Anal.

* Performed Sensitivity Anal.

Human Performance

Containment Failure Analysis

In-Vessel Phenomena/Source Term

Offsite Consequence Analysis

External Events

* Qualitative Analysis

* Probabilistic

* Other (please specify)

- Non-PRA Background/Experience

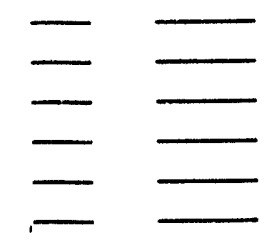

Reactor Systems

Auxiliary Systems

Instrumentation and Control

Electrical Systems

Therma 1-Hydraulics

Containment Analysis

Source Term Analysis

Reactor Operation

Inspection

Chemistry

Materials Science

Consequence Analysis

Statistics

External Events

Other (Please Specify)

- Type of PRA Education

* NRC courses

* Formal PRA education

* Experience

* Other (please specify) 


\section{Exhibit (continued)}

c) In performing this PRA application/study, what other technical skills did you occasionally or routinely make use of (check all that apply):

- In the staff of your division:

Occasionally Routinely

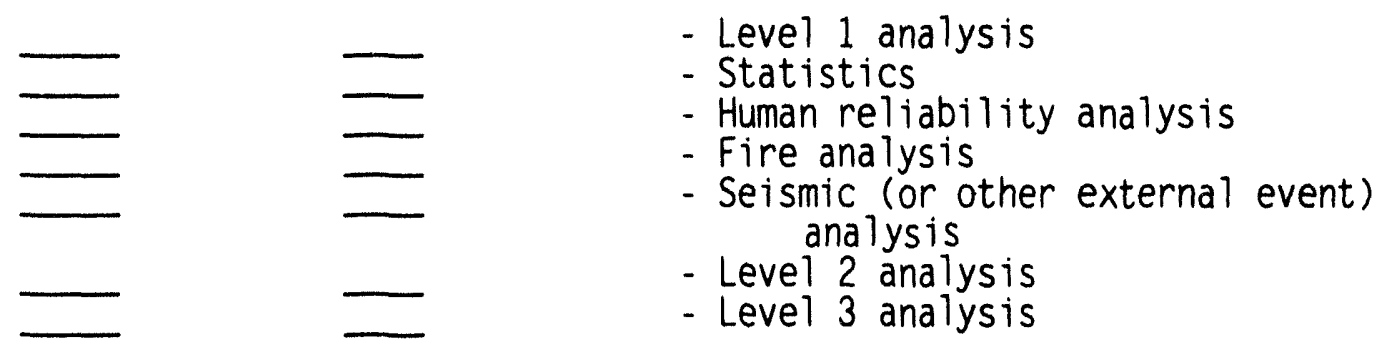

- In other parts of NRC:

Occasionally Routinely

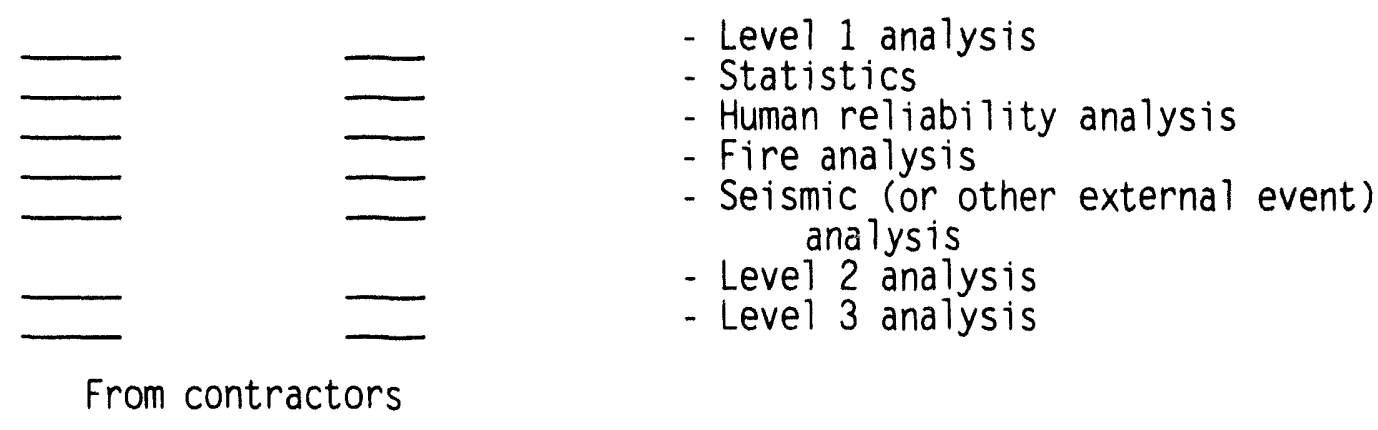

Occasionally Routinely

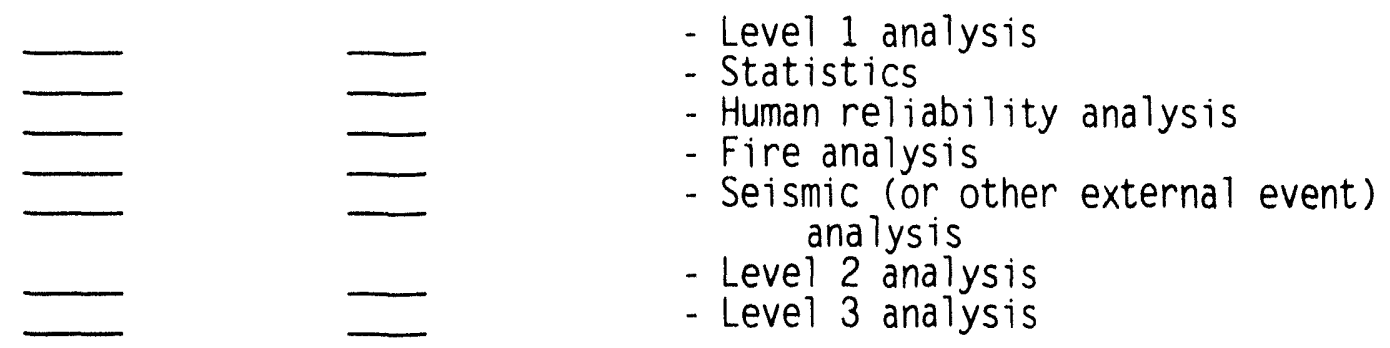

\section{I.5 Review of application or study}

a) Describe the level and type of review performed for this application or study.

- Extent of review

* Spot checks

* Detailed review

* Independent verification

* Other

* None 
Appendix A

\section{Exhibit (continued)}

- Reviewers

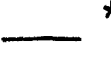

* NRC staff (include their names)

* ACRS

* Contractors (include their names)

* Universities (include their names)

- Major areas included in the review (check all that apply).

* Fault trees

- Event trees

* Initiating events

* Data

- * Common cause failures

* Quantification

* Plant damage states

* Source term

* Uncertainty analysis

- * Human reliability

- * Containment analysis

- *xternal events

* Others

\section{I.6 Documentation}

a) What form of documentation was developed for the application?

$\begin{array}{ll} & \text { - None } \\ & \text { - Informal note } \\ & \text { - Memorandum } \\ & \text { - Letter report } \\ \text { - NUREG or NUREG/CR } & \text { - Other }\end{array}$

\section{Technical Attributes of the PRA Application/Study}

a) Was this application or study a generic application?

- It was a generic study.

What makes it generic?

_ Multiple plants studied: how many?

— * Hypothetical plant studied

- * other

_ - It was a plant specific study

_ - Other 
Appendix A

\section{Exhibit (continued)}

b) Did the application or study generate its own unique PRA calculations, adapt results of previously performed PRAs, or was it a mixture?

- Unique PRA calculations were generated.

- It adapted PRA results from other PRAs, or was a mixture. Which of the following are unique or adapted (check as many as apply):

Unique Adapted

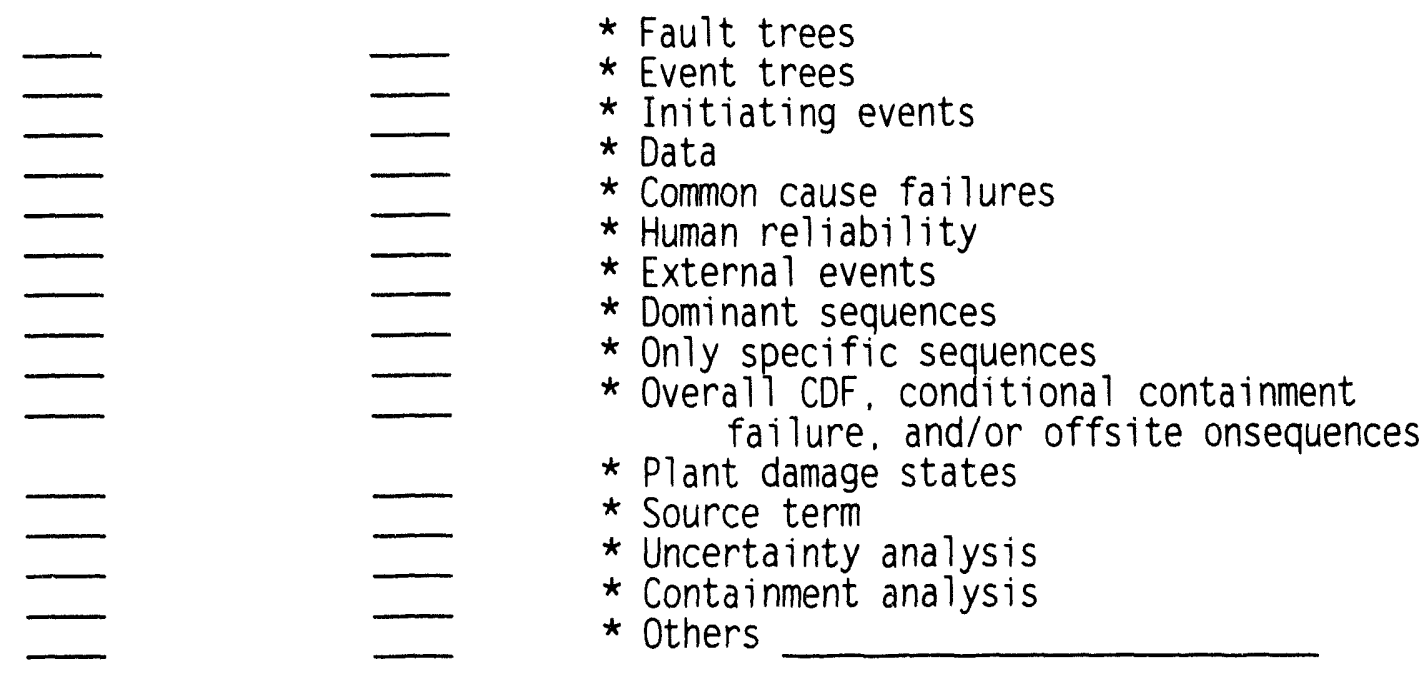

- If the results were mainly adapted, identify the PRA sources.

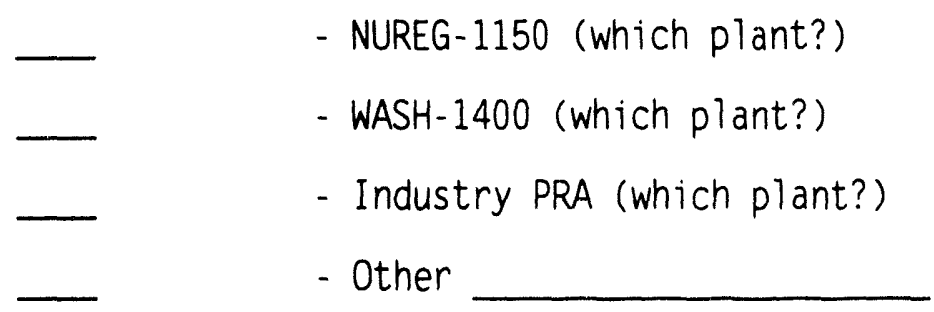

c) Identify the relevant PRA level and methodology used.

- Check the appropriate level:

$\begin{array}{ll}- & \text { - Level-I } \\ - & \text { - Level-II } \\ - & \text { - Level-III }\end{array}$ 


\section{Exhibit (continued)}

- Methodology: check applicable methods (check as many as apply)

- Large fault tree-small event tree

- Small fault tree-large event tree

- Support systems are included

- Sequences are modified and adapted

- Sequences are adapted without modification

- Cut sets of systems or sequences are adapted without modification

- Cut sets of systems or sequences are adapted with modifications

- Fault trees are adapted without modifications

- Fault trees are adapted with modifications

- Plant damage states are created

- Initiating events. Check all applicable initiators:

- LOCAs (what sizes?)

- Transients (which ones?)

- Support system initiators (which ones?)

- Internal fire and flood

- External events

- Other initiating events (which ones?)

- What sources of data were used? Check all applicable items:

- Only generic data (identify the source)

- Only plant specific data

- Combination of generic and plant specific

- Used that in existing PRA (which one?)

- Plant conditions evaluated:

$\begin{array}{ll} & \text { - Full power } \\ \text { - Low power } \\ \text { - Shutdown } \\ \text { - Refueling } \\ \text { - Other }\end{array}$

d) Identify the degree of conservatism employed in this application:

- Strictly best estimate inputs used for models, data base, assumptions, etc.

- Conservative values were employed in the following areas:

e) Did this application or study perform uncertainty or sensitivity analysis?

- No uncertainty analysis was performed: only point estimates were used as inputs.

- A full scope uncertainty analysis was performed.

- A limited scope uncertainty analysis was performed. What was the scope?

- No sensitivity study was performed.

- A sensitivity analysis was performed. (For which elements of the application or study?) 


\section{Exhibit (continued)}

- If an uncertainty analysis was performed, identify the following:

* Types of distributions used

- Log-Normal

- Maximum Entropy

- Empirical

- Others

* Method of propagating distributions

- Monte-Cario

- LHS

- Moments Method

- Others

* Model uncertainty

- Qualitatively considered

- Quantitatively considered

- Not considered

* How is uncertainty information used?

- Only displayed the range

- Factored into the conclusion of the

application/study (explain how)

- To calculate mean value

- Other

* Were experts used to estimate uncertainty distribution or were they derived from data?

- Experts estimated uncertainty

- Uncertainty derived from data

- Both

- Uncertainty taken from existing PRA (which one?)

f) Did this application or study incorporate the effects common cause failures (CCF), and how did it do so?

- Did the application or study consider CCF?

$$
\text { —_ } \quad \text { * Yes }
$$

- How were CCFs treated?

* Implicitly

* System level

* Train level

* Component groups within a system

* Other 


\section{Exhibit (continued)}

- Method of CCF treatment

* Generic beta factor

* Plant specific beta factor

* Alpha factor method

* Multiple Greek letter

* Basic parameter

* Shock model

* Stress-strength model

* Other

- CCF data sources

* Generic (source?)

- * Existing PRA

- $\quad$ * Plant-specific

— $\quad$ Other

g) Did this application or study consider probability of human failures?

$\begin{array}{ll}- \text { Yes } \\ - & - \text { No }\end{array}$

- Pre-accident human errors were considered

- Yes
- No

- Post-accident human errors were considered

- Yes
$-\quad$ - No

- Types of errors considered

- Procedural

- - Control room errors

- - Ex-control room errors

- Errors of omission only

- - Errors of omission and commission

— - Equipment restoration errors

- Others

- Analysis methods used

- Expert judgment
- - THERP
- SLIM-MAUD
- HCR
- TRC
- Other 


\section{Exhibit (continued)}

- Human reliability data source

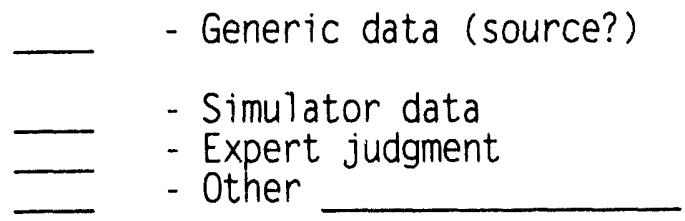

- Identify the following aspects of the recovery actions considered:

- Only recoveries from a control room were considered.

- Ex-control room recoveries were included.

- Data used

$$
\begin{array}{ll}
\text { - } & \text { * Plant specific } \\
\text { — } & * \text { Generic } \\
& * \text { Other }
\end{array}
$$

- Recovery actions were added after the initial quantification.

- - Recovery actions were an explicit part of the model.

h) Were external events considered?

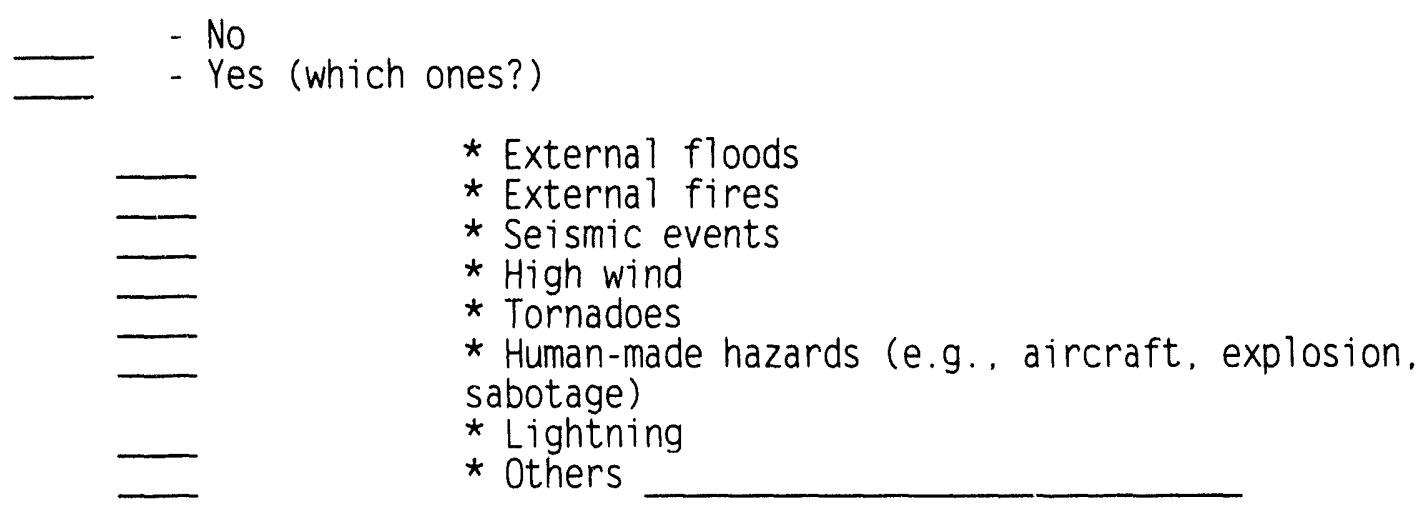

- For those external events consider, what method was used?

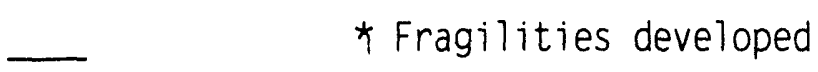

o generic

o plant specific

\begin{tabular}{ll}
$\square$ & * Event trees adapted \\
$\square$ & * Event trees developed \\
& * Initiating event frequency \\
& - Genericaliy considered \\
& - Plant specifically considered \\
$\square$ & * Other \\
\hline & * Fault Erees developed \\
$\square$ & * Fault trees adapted \\
&
\end{tabular}




\section{Appendix A}

\section{Exhibit (continued)}

i) Describe the applicable aspects of the application or study's quantification process:

- Cut sets of sequences generated and quantified.

- Cut sets of fault trees developed and quantified.

- Average, time independent unavailabilities calculated for input events.

- Point-wise time dependent unavailabilities developed for input events.

- What codes were used in the quantification?

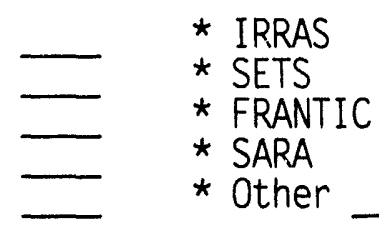

- Calculations were made by hand.

- What form of truncation was used?

* Probability or frequency based truncation (describe the level).

* Cut set size truncation (describe the level).

* Other

j) Identify the method of accident progression and containment loading analysis used in this application or study.

- Not modeled

- Explicitly modeled

- What computer models were used for the loading analysis?

MELIOR

- STCP

MAAP

Other

- Adapted from other study (what study?)

- Other 


\section{Exhibit (continued)}

k) Identify the method of fission product release and transport (source term) analysis used in this application or study.

- Not modeled

- Explicitly modeled

- What computer models were used for the analysis?

MELCOR

STCP

- MAAP

- Other

- Adapted from other study (what study?)

- Other

1) If offsite consequences were analyzed, indicate the nature of such calculations and the form of the results.

- Codes used

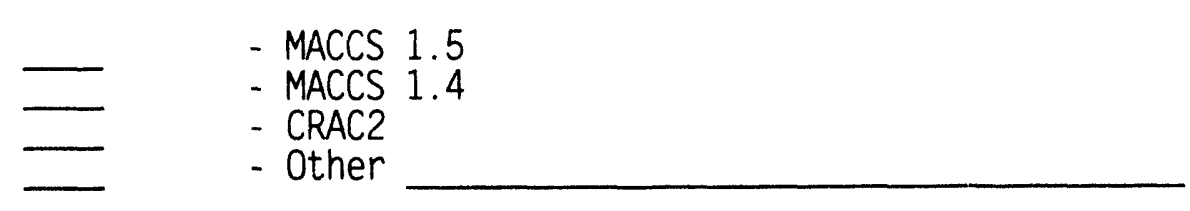

- Consequence measures estimated:

- Early fatalities

- - Latent cancer fatalities

- Population dose (50 mile)

- - Safety goal measures

- - Others

- Site parameters

- Site specific

- - Generic (how developed?) 
Appendix B

\section{Review of and Recommendations on}

Agency PRA Uses 


\section{CONTENTS}

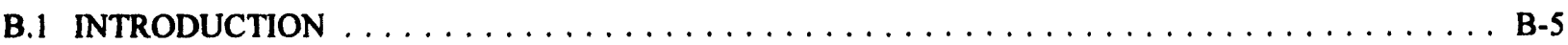

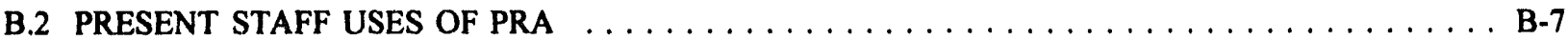

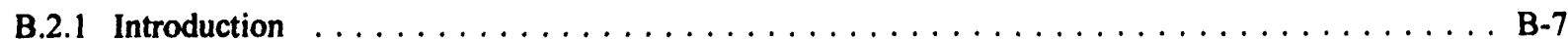

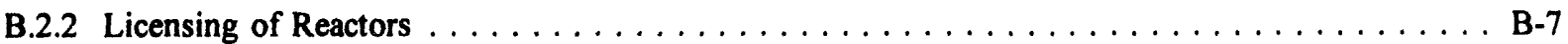

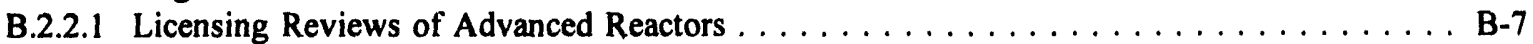

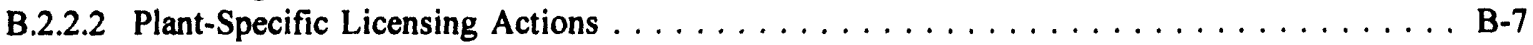

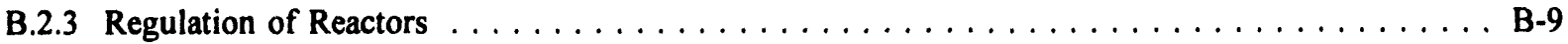

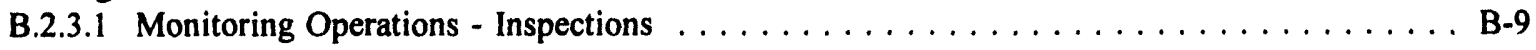

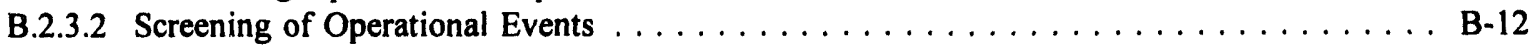

B.2.3.3 Screening for Generic Safety Issues $\ldots \ldots \ldots \ldots \ldots \ldots \ldots \ldots \ldots \ldots \ldots \ldots \ldots \ldots \ldots \ldots \ldots, 12$

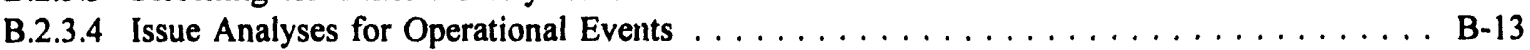

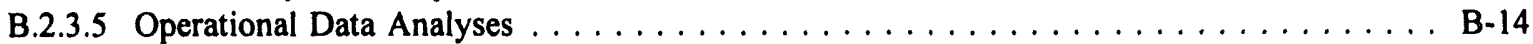

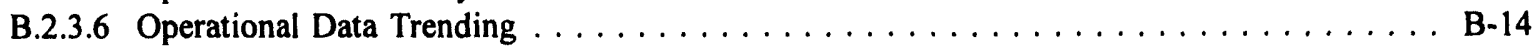

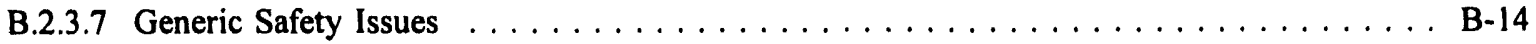

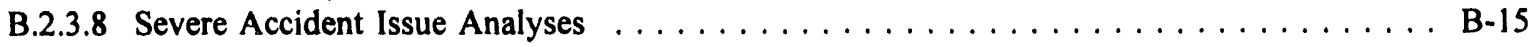

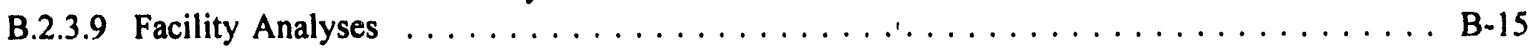

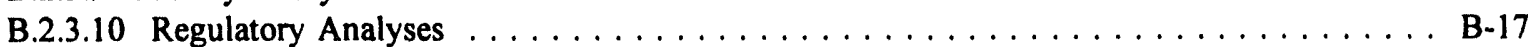

B.2.4 Licensing of Fuel Cycle Facilities and Materials Uses $\ldots \ldots \ldots \ldots \ldots \ldots \ldots \ldots \ldots$ B-17

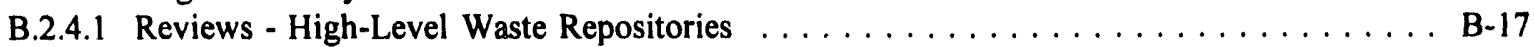

B.2.5 Regulation of Fuel Cycle Facilities and Materials Uses $\ldots \ldots \ldots \ldots \ldots \ldots \ldots \ldots \ldots$ B-18

B.2.5.1 Facility Analyses - Medical Devices $\ldots \ldots \ldots \ldots \ldots \ldots \ldots \ldots \ldots \ldots \ldots \ldots \ldots$

B.3 GUIDANCE FOR USING PRA TO SCREEN AND PRIORITIZE ISSUES $\ldots \ldots \ldots \ldots \ldots \ldots$ B-20

B.3.1 Introduction and General Guidance $\ldots \ldots \ldots \ldots \ldots \ldots \ldots \ldots \ldots \ldots \ldots \ldots \ldots \ldots$

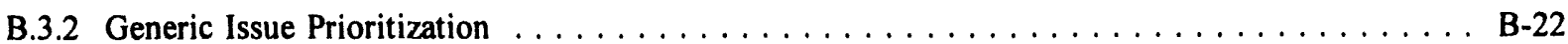

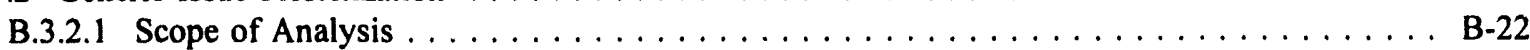

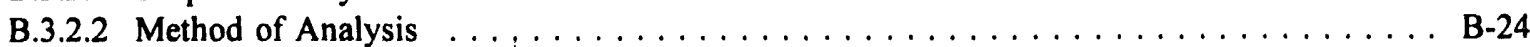

B.3.2.3 Product and Documentation of Analysis $\ldots \ldots \ldots \ldots \ldots \ldots \ldots \ldots \ldots \ldots \ldots \ldots \ldots$

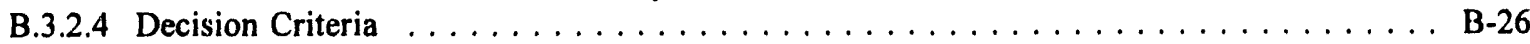

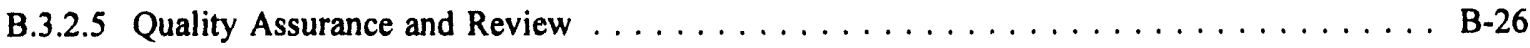

B.4 GUIDANCE FOR PRA USE IN RESOLVING ISSUES $\ldots \ldots \ldots \ldots \ldots \ldots \ldots \ldots \ldots \ldots$ B-28

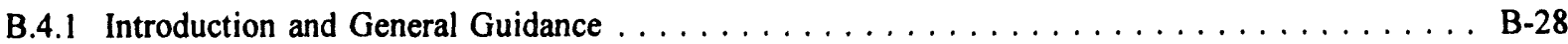

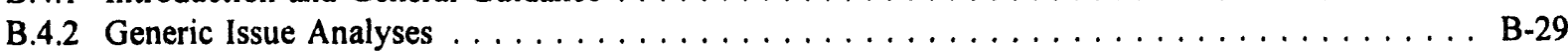

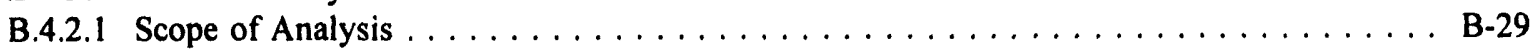

B.4.2.2 Product and Documentation of Issue Analysis $\ldots \ldots \ldots \ldots \ldots \ldots \ldots \ldots \ldots \ldots \ldots$

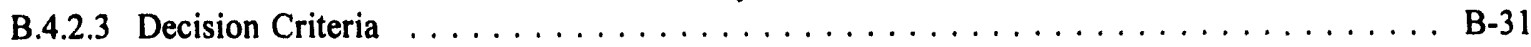

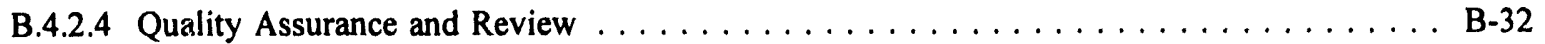

\section{FIGURES}

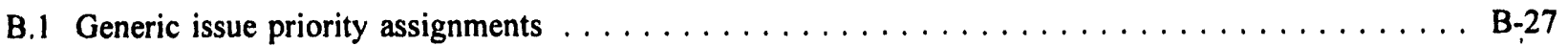

B.2 Safety goal implementation guidance $\ldots \ldots \ldots \ldots \ldots \ldots \ldots \ldots \ldots \ldots \ldots \ldots \ldots \ldots \ldots \ldots$

\section{TABLES}

B.1 Working Group actions and recommendations on staff uses of PRA $\ldots \ldots \ldots \ldots \ldots \ldots$

B.2 Standard Review Plan elements involving PRA $\ldots \ldots \ldots \ldots \ldots \ldots \ldots \ldots \ldots \ldots \ldots \ldots$

B.3 Currently available risk-based inspection guidelines $\ldots \ldots \ldots \ldots \ldots \ldots \ldots \ldots \ldots \ldots \ldots$ 


\section{B.1 INTRODUCTION}

The PRA Working Group's survey identified a large number of PRA uses within NRC that support many of the agency's basic functions. The survey also determined that formal guidance does not exist as to how a PRA should be performed or what products and associated decision criteria are needed. Section B.2 contains a description of each staff use of PRAs, including information on the purpose of each program, the specific objective of the PRA portion of that program, the key elements for that use of PRAs, the existing guidance, and the Group's actions and recommendations. Table B.1 itemizes the staff PRA uses identified by the Working Group and states the action taken or recommendation made by the Group for each use.

The Working Group identified a number of different staff uses of PRA that it judged to have the same general attributes and thus could share general guidance. The PRA uses were in two groups, reflecting two different levels of PRA sophistication needed: (1) for screening the many events and issues before the staff and (2) for analyzing in detail the more important events and issues in a manner consistent with the agency's decisionmaking process (e.g., the backfitting process). The Group developed general guidance for these two groups of uses of PRA, including guidance on the scope, form of the product, decision criteria, and quality assurance. This general guidance is provided in Sections B.3 and B.4. Recognizing that differences do exist in specific PRA uses, the Working Group recommends that more detailed guidance be developed by the appropriate office for each specific use. As examples of such more detailed guidance, Sections B.3 and B.4 provide more detailed guidance on the prioritization and resolution processes for generic issues.

The Working Group also identified several areas of staff work that could involve PRA in the near future or in which PRA is just beginning to be used, but these areas were not sufficiently well defined to permit consideration by the group. These areas include broad areas usually referred to as "risk-based reactor regulation," reactor license renewal, and the use of risk-based performance indicators.

The Working Group also notes that risk assessment is used by the staff in a more qualitative manner to support decisions such as the need for research in specific areas. The group has not reviewed or commented on such qualitative uses of risk assessment.

The guidance in Appendix B is supported by fundamental information on methods and terms important to an understanding of PRA. Information on the following topics is provided in Appendix C.

o Statistics and probability

- Reliability and accident sequence (Level 1) analysis

- Accident progression (Level 2) analysis

o Source term analysis (also part of Level 2 analysis)

- Consequence (Level 3) analysis

o Risk integration (the combination of Levels 1,2 , and 3)

o Sensitivity and uncertainty analysis methods

- Decision analysis

For each area, basic terms are defined and methods are described, including information on the strengths and limitations of each, and references are provided for the reader seeking additional information.

Training is a key element to the success of this guidance. The Working Group has taken actions and made recommendations to identify needed changes in the present agency PRA curriculum (Ref. B.1). These actions and recommendations are discussed in Chapter 4 of the main report. 
Table B.1 Working Group actions and recommendations on staff uses of PRA

\begin{tabular}{|c|c|c|c|}
\hline PRA use & $\begin{array}{c}\text { Sereening } \\
\text { analysis" }\end{array}$ & $\begin{array}{c}\text { Issue } \\
\text { analysis* }\end{array}$ & $\begin{array}{l}\text { Other comment } \\
\text { or recommendation }\end{array}$ \\
\hline \multicolumn{4}{|l|}{ Licensing of Reactor } \\
\hline \multicolumn{4}{|l|}{ - Reviews } \\
\hline Advanced reactors & & & Review SRP revisions when available. \\
\hline $\begin{array}{l}\text { Plant-specific licensing actions } \\
\text { (e.g., technical specification changes) }\end{array}$ & & & $\begin{array}{l}\text { Develop guidance for PRA/IPE/IPEEE } \\
\text { use in various licensing actions. }\end{array}$ \\
\hline \multicolumn{4}{|l|}{ Regulation of Reactors } \\
\hline \multicolumn{4}{|l|}{ o Monitoring Operations } \\
\hline Inspections & & & Develop guidance for using IPEs/lPEEEs. \\
\hline \multicolumn{4}{|l|}{ o Issue Screening } \\
\hline Operational events & $\mathbf{x}$ & & \\
\hline Generic safety issues & $\mathbf{x}$ & & \\
\hline \multicolumn{4}{|l|}{ - Issue Analyses } \\
\hline Operational events & & $\mathbf{x}$ & \\
\hline Operational data analyses & & $\mathbf{x}$ & \\
\hline Operational data trending & & $\mathbf{x}$ & \\
\hline Generic safety issues & & $\mathbf{x}$ & \\
\hline Severe accident research issues & & $\mathbf{x}$ & \\
\hline \multicolumn{4}{|l|}{ - Facility analyses } \\
\hline Staff studies & $\mathbf{x}$ & $\mathbf{x}$ & $\begin{array}{l}\text { PRA needed (screening vs. detailed) dependent } \\
\text { on analysis use. }\end{array}$ \\
\hline Individual Plant Examinations & & & $\begin{array}{l}\text { Define how best to use IPE and IPEEE results } \\
\text { in regulation. }\end{array}$ \\
\hline o Regulatory analyses & & $\mathbf{x}$ & \\
\hline \multicolumn{4}{|l|}{ Licensing of Fuel Cycle and Materials } \\
\hline \multicolumn{4}{|l|}{0 Reviews } \\
\hline High-level waste repositories & & & Continue coordination with reactor studies. \\
\hline \multicolumn{4}{|l|}{ Regulation of Fuel Cycle and Materials } \\
\hline \multicolumn{4}{|l|}{ - Facility Analyses } \\
\hline Staff studies of medical devices & & & Continue coordination with reactor studies. \\
\hline
\end{tabular}

- An $\mathbf{X}$ in this column indicates that this use of PRA involves screening or prioritizing issues or events. General guidance for such uses, as well as more detailed guidance for generic issue prioritization, has been developed by the Working Group and is provided in Section B.3 of Appendix B.

** An X in this column indicates that this use of PRA involves more detailed analysis of issues or events. General guidance for such uses, as well as more detailed guidance for generic issue analyses, has been developed by the Working Group and is provided in Section B.4 of Appendix B. 


\section{B.2 PRESENT STAFF USES OF PRA}

\section{B.2.1 Introduction}

This section summarizes the overall purpose of each staff program in which PRA is being used, the specific objective of the PRA use within that program, the existing guidance for the PRA use, and the key elements of the PRA methods for that use, either as they are or as the Working Group believes they should be. For each use of PRA, the Working Group's actions and recommendations are provided.

\section{B.2.2 Licensing of Reactors}

\section{B.2.2.1 Licensing Reviews of Advanced Reactors}

PURPOSE OF PROGRAM: Under the provisions of 10 CFR Part 52, "Early Site Permits; Standard Design Certifications; and Combined Licenses for Nuclear Power Plants," the NRC staff is currently reviewing submittals from several reactor vendors on advanced reactor designs, as part of a certification process for these designs.

OBJECTIVE OF PRA USE: Part 52 requires that a PRA be submitted as part of the application for design certification. However, it does not include specific guidance as to how the PRA should be used. The staff uses of the PRA now include characterizing the design risk profile for the reactors under review, including identification of design strengths and weaknesses, the degree of tolerance to human errors, and the capability to withstand severe accidents. The PRA could be used as an adjunct to the reliability assurance program (postcertification) through the identification of safety-significant components that should be monitored by the applicant.

EXISTING GUIDANCE: The Office of Nuclear Reactor Regulation (NRR) staff will be updating the Standard Review Plan (SRP) (Ref. B.2) to reflect the PRA reviews that have been performed for advanced reactors. A regulatory guide on the form and content of an advanced reactor design PRA is being developed by the Office of Nuclear Regulatory Research (RES) in support of this SRP revision. The purpose of the guide is to provide guidance on what the PRA should contain in order to support its use by the staff. The Advanced Boiling Water Reactor (ABWR) is the lead plant with respect to the development of risk-related policy and guidance.

ESSENTIAL PRA ELEMENTS: PRAs that are submitted as part of applications for design certification for standard reactor designs should include a PRA for full-power operation that considers a complete set of internally initiated events. The PRA should be of Level 3 and should include a spectrum of possible sites of varying meteorology and population distribution. Evaluation of external hazards should also be submitted, but may make use of PRA-based margins methods (e.g., for seismic risk) or bounding evaluations to show that a hazard poses negligible risk for the design. Probabilistic evaluations of conditions at other than full-power operation (e.g., cold shutdown with reduced coolant inventory for maintenance purposes), in sufficient detail to determine the strengths and weaknesses of the design under these modes of operation, are also required.

The Working Group has no recommendations at this time but will review the revised SRP section and associated regulatory guide when they become available.

\section{B.2.3.2 Plant-Specific Licensing Actions}

PURPOSE OF PROGRAM: Licensing actions, including license issuance, amendments, waivers, justifications for continued operation, extensions, and revocations, involve technical and regulatory reviews and a determination of adequate safety. The purposes of the program are to ensure that licensing actions keep the plant's design and operation within acceptable risk leveis and that compliance with regulations is maintained so that the health and safety of the public are assured.

OBJECTIVE OF PRA USE: The objectives of using PRA in plant-specific licensing actions include providing support for licensing decisions that are based upon or justified by risk assessments. This use of PRA includes riskbased reviews and assessments with respect to license amendments, waivers, technical specifications, modifications, and backfits. 
EXISTING GUIDANCE: The Standard Review Plan (SRP) (Ref. B.2) provides limited PRA guidance for a few isolated review areas, as shown in Table B.2. Currently, NRR is addressing the need for incorporating more comprehensive guidance on PRA use throughout the SRP.

\section{Table B.2 Standard Review Plan elements involving PRA}

SRP 2.2.3, "Evaluation of Potential Accidents," provides review guidance and acceptance criteria with respect to the evaluation of potential accidents in the vicinity of a nuclear power plant. This section applies primarily to various forms of man-made hazards and transportation hazards as well as military and industrial facilities.

SRP 3.5.1.6, "Aircraft Hazards," provides some review guidance on assessing the likelihood of plant damage from aircraft impacts. It includes a set of screening criteria for evaluating hazards associated with nearby airports.

SRP 3.5.1.3, "Turbine Missiles," provides extensive guidance for the evaluation of turbine missile strike and damage probabilities, including guidance on turbine failure probabilities as well as the probability of barrier penetration and target strike probability.

SRP 3.5.1.4, "Missiles Generated by Natural Phenomena," primarily addresses tornado-generated missiles. The review guidance is in terms of design basis wind speeds and missiles, which were established on the basis of probabilistic considerations sucil as maximum wind speed return frequencies and missile generation and strike probabilities.

ESSENTIAL PRA ELEMENTS: Licensing actions span a relatively wide range of technical areas. Currently, there is no established guidance for a specific PRA form or content in relation to specific licensing actions. Further, essential elements vary with each licensing action, and it is impractical to identify specific PRA elements used in each type of application. However, an overall perspective may be obtained by looking at a few representative samples of past licensing actions. The following is a list of some past licensing actions that involved the use of PRA. To some extent, the essential elements can be identified from these examples.

- A Level 1 risk assessment for San Onofre Unit 1 was used to demonstrate that proposed modifications to upgrade against tornado impacts would not be justified. The licensee's analysis included the calculation of importance measures; the NRC staff performed a sensitivity study.

- Connecticut Yankee Atomic Power Co. performed a PRA for Haddam Neck in support of a justification for deviation from General Design Criteria 54 through 57 in Appendix A, "General Design Criteria for Nuclear Power Plants," of 10 CFR Part 50, "Domestic Licensing of Production and Utilization Facilities," with respect to a number of containment penetrations. The analysis involved a Level I PRA and the calculation of importance measures.

o Commonwealth Edison Co. submitted a PRA to justify technical specification changes for the emergency diesel generators at Zion, Units 1 and 2. The licensee performed a Level 1 PRA and a sensitivity study.

- Carolina Power and Light Co. submitted an aircraft hazards study intended to show that Shearon Harris Unit 1 met the acceptance criteria in Section 3.5.1.6 of the SRP providing that the 10-year projection for the operational level of the proposed airport is not significantly exceeded. No core damage frequency was calculated; instead, probability calculations involving a limited number of plant systems were performed. 
- The Northern States Power Company (the licensee for Prairie Island Nuclear Station, Units 1 and 2) had requested amendments to their technical specifications regarding the surveillance test frequency of turbine valves. The report, reviewed and approved by the staff, was used to show that an increase in the mean time between tests of turbine valves yielded an acceptably low increase in missile ejection probability. Common causes, human errors, and maintenance outages played a role in modeling.

Recommendations: As can be seen from the above examples, the risk assessments for licensing actions vary with each specific case. Establishing a systematic list of essential elements that would cover all these types of reactor licensing actions is beyond the scope of this document. The Working Group recommends that guidance, including how individual plant examination (IPE) and individual plant examination for external events (IPEEE) results should be used, be developed by NRR.

\section{B.2.3 Regulation of Reactors}

\section{B.2.3.1 Monitoring Operations - Inspections}

PURPOSE OF THE PROGRAM: NRC inspections help to ensure that the operation of licensed facilities does not introduce undue risk to the health and safety of the public. This is achieved through the inspection of all safetyrelated aspects, including the construction, operation, and decommissioning of licensed facilities. The principal measure of inspection findings is in terms of compliance with technical specifications or other applicable regulatory requirements.

OBJECTIVE OF PRA USE: The objective of PRA use in inspections is to provide risk-based insights as guides for efficient use of limited staff inspection resources. PRAs can provide a relative ranking of safety-related plant systems, components, and operations so that the inspection can be directed at the most risk-significant items.

EXISTING GUIDANCE: The NRC Inspection Manual contains management guidance for the development and maintenance of the NRC inspection program. Portions of the manual identify the need for and applicability of riskbased information in the inspection process. The principal section addressing PRA use is in Appendix C of Chapter 2515, "Light Water Reactor Inspection Program - Operations Phase - Inspection Applications." This appendix provides guidance on the use of the risk-based inspection guides (RIGs) in inspection activities. Other portions of the Inspection Manual with information on the use of PRA include Part 9900 as well as Inspection Procedures 71707, 71710 , and 93804. In addition, some guidance on the use of PRA is included in Temporary Instructions 2515/97 and $2515 / 107$, as well as chapters on specialized team inspections.

For PWRs and BWRs, more detailed risk-based inspection guidance is provided in NUREG/CR-5637 and NUREG/CR-5692 (Refs. B.3 and B.4), respectively. Although the information in these documents is generic, guidance for making plant-specific adjustments is included. The previously mentioned RIGs are another source of inspection guidance. These are primarily plant-specific risk-based system and component descriptions intended to help the planning and conduct of plant walkdowns by resident inspectors. A complete listing of all RIGs that have been issued to date is provided in Table B.3. As some additional RIGs will be issued in the future, NRR/SPSB should be contacted for the latest listing.

ESSENTIAL PRA ELEMENTS: Inspection applications are primarily based on ranking plant systems, components, and operations according to significance to core damage frequency. The objective is to identify most of the significant items for inspection. For this reason, precise ranking of systems is not necessary and uncertainty analyses and bottom line numbers are seldom used.

The process calls for the identification of dominant accident sequences and the use of importance measures. The specific types of importance measures used for ranking are risk reduction, risk achievement, Fussell-Vesely, and relative (normalized Fussell-Vesely) importance measures. 
Appendix B

Table B.3 Currently avallable risk-based Inspection guidelines

\begin{tabular}{|c|c|c|}
\hline Pecillity & Number & Repont Thes \\
\hline ANO 1 & MURBCUCR-s0s: & PRA Applications Proeram for Inapection at Astenese Nuclaer One Unil I (Ref. B.S) \\
\hline Brunowict 2 & $\begin{array}{l}\text { BNL Tech Repont } \\
\text { A.3872-T4 Rov. }\end{array}$ & Bnunuwick Stoem Electric Plant Unit 2 Riak-Bened Inspection Oulde (Ref. B.6) \\
\hline Calven Cirs 1 & NUREOCR-SI87 & PRA Applications Prownen be bepaction at Catwen Clim Unit I Nuclear Power Ptant (Re. B.7) \\
\hline Cryotel River 3 & NURECKCR-5467 & Risk-Bened Inepection Guide for Cryatel River Unit 3 Nucloer Power Pient (Ref. B.I) \\
\hline Cread Culf I & $\begin{array}{l}\text { BNL Tech Repon } \\
\text { A.3453-47.5 }\end{array}$ & 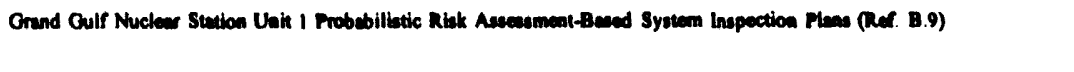 \\
\hline Haddem Nect & EOOREQ-7601 & PRA Applications Progenem for lnspection at the Hadden Neck Nucleur Power Stution (Ref. B. 10) \\
\hline Indian Point 2 & $\begin{array}{l}\text { BOGEA.7136, } \\
\text { Rov. } 2\end{array}$ & Pilot PRA Applications Proquen for Inspection a Indien Point 2 (Ref. B.11) \\
\hline Indian Point 3 & $\begin{array}{l}\text { BNL Tech Repont } \\
\text { A.3453-3-37(-1). } \\
\text { Rov. } 0\end{array}$ & Indien Point Unit 3 Probabiliatic Sefay Sudy-Beed Syarem Inapection Plens (Rer. B.12) \\
\hline Limerick 1 & $\begin{array}{l}\text { BN. Tech Repon } \\
\text { A-3453-3-37(-2), } \\
\text { Rev. } 0\end{array}$ & 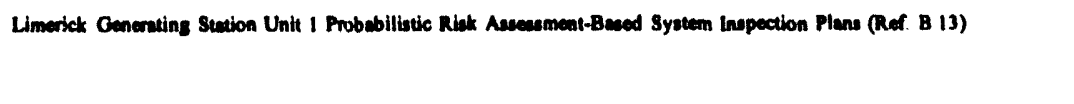 \\
\hline Millewone 1 & $\begin{array}{l}\text { BNL. Tech Repon } \\
\text { A.3453.2.97 }\end{array}$ & 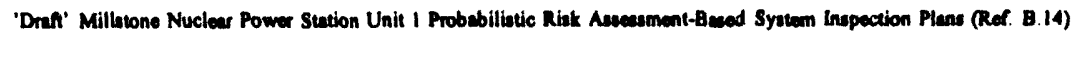 \\
\hline Mallesone 3 & BCO-SSRE-S016 & PRA Applications Program for Inspection a Millbtone, Unit 3, Drant Report (Ref. B.15) \\
\hline Oocenen 3 & NUREOKR-S006 & PRA Applications Progrem for Inspection a Oconee Unit 3 (Rer. B.16) \\
\hline $\begin{array}{l}\text { Peach Botion } \\
2 \leqslant 3\end{array}$ & $\begin{array}{l}\text { BNL. Tech Report } \\
\text { A.3E64-2. } \\
\text { Rev. } 0\end{array}$ & Peach Botrom Alomic Pown Station Unit 2 Probebilistic Risk Asecament-Besed System Imspection Plen (Ref. B.17) \\
\hline Secobrook & BOO-EA.7194 & PRA Applications Progrun for Inspection at Seabrook Stution. Draft Repon (Ref B.18) \\
\hline Sequoych & BCa-SSRE- 720 & Rink-Beed inepection Guide for the Sequoyeh Nuclear Power Sention Final Report (Ref. B. 19) \\
\hline surny 1 & ECG-RBQ-7746 & PRA Applications Program for Inapection at the Surry Nuclear Power Station, Unin I (Ref. B.20) \\
\hline ma 1 & NURBCKCR-5488 & Risk-Beed Inspection Guide for Throe Mile bland Nuctear Semion Unit I (Ref. B.21) \\
\hline Trojes & $\begin{array}{l}\text { BNL Tech Repon } \\
\text { A-3875-T2B, Rov.1 }\end{array}$ & $\begin{array}{l}\text { Riak-Bened Inspection Cuide (RIG) for the Trojen Nuclear Plent } \\
\text { (Beed on Ceneric PRA-Based Information for Preseurized Water Reacton) (Ref. B.22) }\end{array}$ \\
\hline Voutile & $\begin{array}{l}\text { BNL Tech Report } \\
\text { A-3875-T2D, Rov. } 1\end{array}$ & 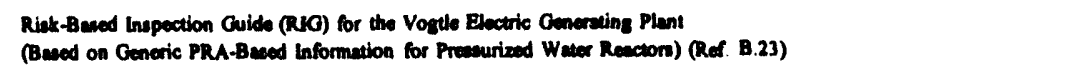 \\
\hline Wolf Creat & $\begin{array}{l}\text { BNL. Toch Repont } \\
\text { A-387S-T2C, Rev.1 }\end{array}$ & 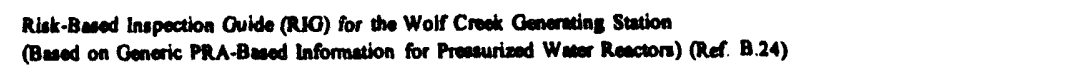 \\
\hline Yeakes Row & ECG-SSREA257 & Risk-Beed Inspection Ouide for the Yankee Rowo Nuclear Power Station (Ref. B.2S) \\
\hline Zion & ECGEA-73O4 & PRA Applications Program for Inspection at the Zion Nuclear Power Station (Rer. B.26) \\
\hline
\end{tabular}


Table B.3 Currently available risk-based inspection guidelines (cont.)

\begin{tabular}{|c|c|c|}
\hline Pecilliny & Number & Repon Thts \\
\hline \multicolumn{3}{|l|}{ 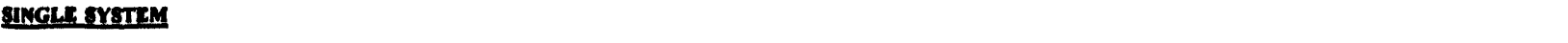 } \\
\hline \multicolumn{3}{|c|}{ 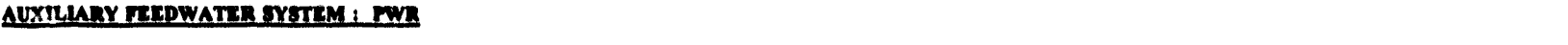 } \\
\hline ANO 2 & NURBCKCR-5828 & 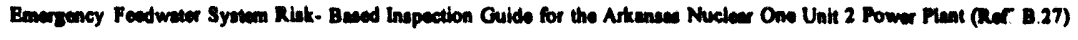 \\
\hline Bridwood/Byron & NURBOCR-427 & 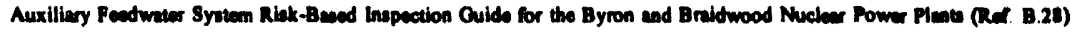 \\
\hline Calloway & NURECKR-5763 & Auxiliary Foadwater Syatem Riak-Besed Inspection Guide for the Callawny Nuclewr Power Plent (Rer. B.29) \\
\hline Catowba & NURBCKR-5127 & 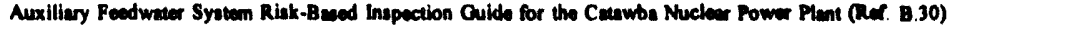 \\
\hline Comanche Peak & NURECKCR-5831 & Auxiliery Peodwater Syatem Risk-Bend Inapection Cuide for the Comenche Peal Nuclear Powe Plent (Ref B.31) \\
\hline Cook & NURECYCR-5832 & Auxiliary Feodwater System Risk-Besed Inspection Guide for the D.C. Cook Nuclear Power Plant (Rer. B.32) \\
\hline Disblo Canyon 1 & NUREGCR-5616 & Auxiliary Peedwater Syotem Rist-Bened Inapection Guide for the Disblo Canyon Unit I Nucleax Power Ptant (her. B.33) \\
\hline Farloy & NURRG/CR-5617 & Auxiliery Feedwater System Risk-Based Inspection Ouide fot the J M. Farley Nuclear Power Pient (Ref. B.34) \\
\hline Ginne & NURBOCR-\$764 & Auxiliary Foedwater Syatem Riak-Based Inapection Guide for the Ginna Nuclear Power Plant (Ref. B.35) \\
\hline Kenmunee & NUREOCR-5821 & Auxiliery Feadwater Syotem Risk-Besed Inapection Guide for the Kewmunce Nuclear Power Plent (Ref. B.36) \\
\hline Maise Yeakee & NURBGCR-5826 & Auxiliery Feadwater Syatem Risk-Bued Inspection Guide for the Maine Yankee Nuclear Power Plant (Ref. B.37) \\
\hline North Anna 1 Q 2 & NURBGCR-5837 & Auxiliary Foedwater Syotem Riat-Besed Inspection Guide for the North Anne Nuclase Plante (Ref. B.38) \\
\hline Pruirite blead & NUREOCR-5839 & Auxiliery Feedwater System Riak-Based Inspection Guide for the Prairie blend Units 1 2 2 Nuclew Power Plantu (Ref. B.39) \\
\hline Sulem & NURBCKCR-\$761 & Auxiliary Feedwater System Riak-Based Inapection Guide for the Salen Nuclear Power Plant (Ref. B.40) \\
\hline Si Lucie & NURECKR-5896 & Auxillary Feadwater System Risk-Beed Inapection Guide for the St Lucie Unit I Nuclear Power Genention Stution (Ref. B.41) \\
\hline Summer & NURECKCR-se38 & Auxiliary Feodwater Syatem Risk-Bned Inspection Guide for the Virzil C Summer Nuclear Power PInat (Ref. B.42) \\
\hline Turtoy Point & NUREOCR.5633 & Auxiliery Feodwater System Risk-Bmed Inspection Guide for the Turkey Point Nuclear Power Plant (Ref. B.43) \\
\hline \multicolumn{3}{|c|}{ HUGA FRESURT COOLANT INJECTION SYSTEM: BWR } \\
\hline Pilgrim & NURBCKCR-5924 & High Prousure Coolent Injection (HPCn Syatem Risk-Bued Inspection Guide, Pilgrim Nuclear Power Stuion (Ref. B.44) \\
\hline \multicolumn{3}{|c|}{ SERVICE WATER SYSTEM } \\
\hline Coneric & NUREOCR-s865 & Generic Service Weter Syatem Riak-Baned Inspection Guide (Ref. B.45) \\
\hline
\end{tabular}




\section{Appendix B}

Recommendations: The IPEs being done in response to Reference B.46 and now becoming available could provide valuable risk perspectives to the inspection program in the form of plant-specific importance measures. Guidance on the use of IPE and IPEEE results in the inspection process is not presently available, although some initial efforts are under way in NRR. The Working Group recomsiends that such guidance be developed and that a process be defined to check IPE results to be used in inspection for reasonableness (e.g., by comparison of results among similar plants). This checking process would be in addition to the IPE process reviews, focusing on the specific information to be used in inspections.

\section{B.2.3.2 Screening of Operational Events}

PURPOSE OF PROGRAM: Certain types of operational events that occur at licensed reactor facilities must be reported to NRC under the provisions of 10 CFR 50.72 or 50.73 . The overall purpose of this program is to provide an initial screening of these events for safety significance by considering a number of factors, including significance to core damage frequency. The Accident Sequence Precursor (ASP) Project is part of this program performed by the Office for Analysis and Evaluation of Operational Data (AEOD). More specifically, the purpose of this program is to determine (1) which events merit further review and (2) what aspects of the event are of most significance and should be addressed in additional reviews.

OBJECTIVE OF PRA USE: In this screening process, the ASP program or simple PRA models are used to obtain an estimate of conditional core damage probability, given that the event has occurred. This estimate is used as a rioritization measure.

EXISTING GUIDANCE: Basic guidance and modeling guidelines for analyses of this type are presented in Reference B.47. Deterministic criteria for screening events reportable under 10 CFR 50.73 now exist and are included in Reference B.47. (Please note that the events that require immediate notification under $10 \mathrm{CFR} 50.72$ are now being screened by using the criteria in 10 CFR 50.73.)

ESSENTIAL PRA ELEMENTS: Point estimates (defined in Appendix C, Section C.2.2.2.1) are satisfactory for screening and prioritization uses. Class-specific event trees and fault trees, with generic recovery actions, are used to provide point estimates of conditipnal core damage probability. For screening with PRA, it is important that uncertainties and assumptions relative to the specific operational event being studied be explicitly delineated and discussed as to how they are incorporated into the screening analysis. Sensitivity studies are important to illuminate the importance of key assumptions, uncertainties, and other factors. However, formal uncertainty analyses are not necessary.

Recommendations: Screening analyses for events should follow the general guidance provided in Section B.3 for screening and prioritization. AEOD should develop more specific guidance following the example for generic issue prioritization that is provided in Section B.3. When completed, this guidance should be reviewed by the Working Group. In parallel with the development of this guidance, the event tree and fault tree models used in event screening should be improved to be comparable to those used in other screening analyses such as generic safety issues.

The results of these screening analyses should not be used for other purposes without more detailed analysis (see the discussion of the analysis of operational events on page B-13). Conditional core damage probability estimates must not be confused with core damage frequency results.

\section{B.2.3.3 Screening for Generic Safety Issues}

PURPOSE OF PROGRAM: Since there are far more generic safety issues than can be investigated in detail and resolved with the available staff resources, they must be prioritized so that the maximum benefit will be gained from the resources available for working on these issues.

OBJECTIVES OF PRA USE: For generic issue prioritizations, there are three objectives of the risk assessment.

1. To provide a systematic and disciplined framework that forces the analyst to explicitly define the issue and its relationship to risk. 
2. To screen out the issues that do not merit further attention because they have no or very little risk significance.

3. To provide a quantitative measure for placing the remaining issues in order of priority, thus permitting the most cost-effective use of the agency's resources.

EXISTING GUIDANCE: General guidance on the prioritization of generic issues is provided in NUREG-0933 (Ref. B.48). However, NUREG-0933 does not provide guidance on the essential elements of a PRA to be used in the resolution process.

ESSENTIAL PRA ELEMENTS: The essential PRA elements used in this program are the calculation of consequences and risk to the public (in terms of person-rem averted) in addition to core damage frequency and the calculation of point estimates (defined in Appendix C, Section C.2.2.2.1) with sensitivity studies on key variables. These sensitivity studies are intended to ensure that the overall ranking given to an issue is not sensitive to key uncertainties and assurnptions made in the analysis. A formal uncertainty analysis is currently not considered necessary for these studies.

Recommendations: The Working Group has developed guidance on the scope, product, decision criteria, and quality assurance for generic issue prioritization, supplementing the broad guidance provided in NUREG-0933 (Ref. B.48). The Working Group recommends the use of this guidance, which is provided in Section B.3.

\section{B.2.3.4 Issue Analyses for Operational Events}

PURPOSE OF PROGRAM: If an operational event passes the initial screening above, additional analyses may be performed, possibly a more detailed risk assessment. This program includes more detailed analyses of accident sequence precursor events and important events that are reported under the provisions of 10 CFR 50.72 and 50.73 .

OBJECTIVE OF PRA USE: The objective of the analysis of operational events is a more detailed understanding of the event and its quantitative "risk" impact as part of an evaluation of possible regulatory action. Such analyses are also used to obtain a "risk index" for the nuclear industry (i.e., a measure of the risk posed by the set of licensed reactors as a function of time).

EXISTING GUIDANCE: No formal guidance currently exists for this use of PRA.

ESSENTIAL PRA ELEMENTS: The essential elements for this use of PRA include event trees and fault trees specific to a class of plants, generic recovery actions, and estimates of conditional core damage probabilities for the event. The plant-specific nature of the event should be incorporated into the analysis as much as possible, including any assumptions of equipment operability. The analyses should include uncertainty analyses in order to illuminate important contributing factors.

Recommendations: Guidance on PRAs on operational events should be developed that follows the general guidance and example on generic issue resolution in Section B.4. When this guidance is completed, it should be reviewed by the PRA Working Group. In parallel, the event tree and fault tree models used should be improved to be comparable to those used in other issue analyses (e.g., generic issue analyses).

This use of PRA requires a more rigorous and detailed analysis than does a screening analysis. An uncertainty analysis should be performed, and mean values should be calculated. These analyses should also undergo a thorough review process. Under these conditions, the results of these analyses can be used for a wide variety of applications.

Care should be taken when using conditional core damage probability to make certain that this conditional probability will not be confused with core damage frequency results. For this particular use of PRA, it is also important that assumptions relative to the operational event be explicitly delineated, including how these assumptions are incorporated into the screening analysis. 


\section{B.2.3.5 Operational Data Analyses}

PURPOSE OF PROGRAM: In this program, engineering evaluations are made of groups of operational events from Licensee Event Reports (LERs) and from the Nuclear Plant Reliability Data System (NPRDS) data on specific components or systems in order to determine failure mechanisms, safety implications, and core damage frequency impacts.

OBJECTIVE OF PRA USE: In this program, the objective is to use PRA to evaluate the effect of the set of events and data on estimates of core damage frequency.

EXISTING GUIDANCE: No formal guidance is presently available to the staff for this use of PRA.

ESSENTIAL PRA ELEMENTS: The essential elements of this use of PRA include all those of a Level 1 PRA, since usually only a change in core damage frequency is calculated. Existing PRA models are used.

Recommendations: The Working Group recommends that formal PRA guidance be developed for this PRA use that parallels the guidance in Section B.4 for issue resolution. For this use, core damage frequency should be calculated, not conditional core damage probability. The guidance should permit the incorporation of consequence considerations. When the guidance has been developed, it should be reviewed by the Working Group.

\section{B.2.3.6 Operational Data Trending}

PURPOSE OF PROGRAM: Licensed reactor facilities report equipment failures to NRC through two data systems, the Nuclear Plant Reliability Data System (NPRDS) and Licensee Event Reports (LERs). The staff uses the NPRDS and LER event databases to determine trends in component and system availability or reliability and to identify safety and risk concerns.

OBJECTIVE OF PRA USE: In this program, PRA is used to evaluate the impact on estimated core damage frequency of a change in a failure rate or failure probability of a component or system.

EXISTING GUIDANCE: No formal guidance is presently available to the staff for this use of PRA.

ESSENTIAL PRA ELEMENTS: These trending analyses make use of existing Level 1 risk models (with the IRRAS computer code (Ref. B.49)). In general, the analyses are performed using the dominant accident sequence cut sets contained in the models.

Recommendations: Formal guidance should be developed for this PRA use. The models used in trending the NPRDS and LER data should be the same as or be very similar to those used in other issue analyses (e.g., operational event and generic safety issue analyses), for which general guidance is given in Section B.4.

\section{B.2.3.7 Generic Safety Issues}

PURPOSE OF PROGRAM: A generic safety issue is defined as a possible deficiency in the design, construction, or operation of a class of NRC-licensed installations or activities. The purposes of the generic issue resolution process are to decide whether the issue does indeed represent a significant deficiency, to identify a cost-effective solution, and to implement this solution or set of solutions, if appropriate. Issues studied in this process will have first been screened in an issue prioritization process that is described in Section B.2.3.3.

OBJECTIVE OF PRA USE: The objective of a risk assessment is to evaluate the potential change in risk associated with resolution of the issue. This analysis must be capable of supporting a decision on whether the potential change in risk is sufficient to justify regulatory action. The analysis also provides the benefit portion of the cost-benefit analysis sometimes needed to support regulatory action (a cost-benefit analysis is discussed in more detail below). In addition to its quantitative uses, the probabilistic analysis of a generic safety issue provides an important secondary use, in that it serves as a disciplined, uniform and comprehensive framework that generally forces the staff to carefully define the issue and to consider all aspects, both positive and negative, of its resolution. 
EXISTING GUIDANCE: General guidance on the generic issue resolution process is provided in the Regulatory Analysis Guidelines (Ref. B.50) and the supporting handbook (Ref. B.51). However, these documents do not provide explicit guidance on the essential elements of a PRA to be used in the resolution process.

ESSENTIAL PRA ELEMENTS: The essential elements of this use of PRA include:

- An assessment of the core damage frequency impact associated with the issue,

- Calculation of the consequences and risk to the public (in terms of person-rem averted) in addition to core damage frequency,

- An uncertainty analysis that permits the calculation of mean values for comparisons with decision criteria (which are in terms of mean values), so as not to overlook or dismiss potentially risk-significant issues prematurely,

- Applicability to the set of affected plants (meaning that more than one PRA may be needed to cover the entire spectrum of plants under consideration), and

- Integration of related issues under study to avoid piecemeal evaluation of issues.

Recommendations: The Working Group has developed guidance on the scope, product, decision criteria, and quality assurance for this PRA use, supplementing the broad guidance provided in the Regulatory Analysis Guidelines and supporting handbook (Refs. B.5O and B.51). The Working Group recommends the use of this guidance, which is provided in Section B.4.

\section{B.2.3.8 Severe Accident Issue Analyses}

PURPOSE OF PROGRAM: The NRC is responsible for planning and executing an extensive research program on the physical processes expected to occur during a severe accident in LWRs (Ref. B.52).

OBJECTIVE OF PRA USE: In some cases, PRA is used in the analysis and resolution of the impact of a physical process or set of physical processes (e.g., in the resolution of BWR Mark I shell failure by direct contact with molten core material (Ref. B.53)).

EXISTING GUIDANCE: There is no formal guidance on the use of PRA in severe accident research issue analysis.

ESSENTIAL PRA ELEMENTS: By their nature, severe accident issue analyses relate to the Level 2 portion of a risk assessment, so PRAs performed in such analyses should, at a minimum, be Level 2 studies. Because of the poorly understood nature of severe accident physical processes, uncertainty analyses are also very important.

Recommendations: Risk analyses performed to support resolution of severe accident research issues should follow the general guidelines developed by the Working Group for issue analyses as provided in Section B.4.

\section{B.2.3.9 Facility Analyses}

\section{B.2.3.9.1 Staff Studies}

PURPOSE OF PROGRAM: The purpose of a facility analysis is to realistically assess the risk to the public from the operation of an entire nuclear power plant, i.e., the risk from the entire set of initiating events, component failures, human errors, etc., as opposed to the risk from one issue. This analysis may provide a general measure of present plant risks (e.g., such as in NUREG-1150 (Ref. B.54)), or it may be done in response to specific regulatory concerns (e.g., to provide an integrated perspective on a new design).

OBJECTIVE OF PRA USE: Facility analysis was the original use of probabilistic risk assessment, at least at NRC, beginning with the Reactor Safety Study (Ref. B.55) in 1975. By using probabilistic techniques to estimate the frequencies of various accident scenarios, along with realistic calculations of the consequences of these scenarios, 


\section{Appendix B}

the safety profile of the installation can be analyzed in a systematic, realistic, and integrated manner. In addition, facility PRAs may improve or extend the capabilities of PRA by introducing new methods or updated data.

EXISTING GUIDANCE: A number of procedures guides exist on how to perform a reactor PRA, for example, the PRA Procedures Guide (Ref. B.56). However, the objectives of staff-sponsored facility analyses may vary, and no formal guidance exists to define the essential elements of this use of PRA.

ESSENTIAL PRA ELEMENTS: As noted above, the essential elements of a PRA to be used in a facility analysis are defined by the specific purpose of the study. Thus, facility analyses such as those in NUREG-1150 (Ref. B.54) include Level 3 studies for accidents initiated by both internal and external events as well as detailed uncertainty analyses. Other facility studies may be less extensive and be more for screening analysis, such as those performed in the first phase of the agency's analysis of low power and shutdown accident risks (Ref. B.57).

Recommendations: Recognizing that the objectives of a facility analysis vary, and thus the essential elements of the PRA vary, the Working Group makes no specific recommendations on guidance for this PRA use. However, if the analysis is to be for screening, the general guidance provided in Section B.3 would be appropriate. If the analysis is intended to support the identification, analysis, and resolution of issues facing the staff, the general guidance provided in Section B.4 would be appropriate.

\section{B.2.3.9.2 Individual Plant Examinations (IPEs)}

PURPOSE OF PROGRAM: The purposes of the IPE/IPEEE program (Ref. B.46) are to have each licensee (1) develop an overall appreciation of severe accident behavior, (2) understand the most likely severe accident sequences that could occur at the plant, (3) gain a more quantitative understanding of the overall frequencies of core damage and radioactive releases, and if necessary, (4) reduce the overall frequencies of core damage and radioactive material releases, by modifying hardware and procedures to help prevent or mitigate severe accidents. This program principally focuses on licensee use of IPE/PRA information. However, the information contained in the IPEs is also of potential benefit to the NRC staff in its uses of PRA.

OBJECTIVE OF PRA USE: The objectives of this use of PRA are the same as the purposes of the IPE program, as stated above. A PRA is not required of a licensee to meet the specifications of the IPE program. However, almost all licensees have elected to perform a Level 2 PRA.

When such a submittal is received, the staff review concentrates on the licensee's process. The review is not sufficiently deep or thorough to validate the correctness of the results of the licensee's PRA. Thus, the review of the IPE does not imply that the licensee's PRA is acceptable as a basis for licensing actions (such as modifications to technical specifications). The review only concludes that the process is sufficient for the licensee to have met the first three purposes of the IPE.

EXISTING GUIDANCE: Guidance on the content of IPE submittals is provided in Generic Letter 88-20 (Ref. B.46) and NUREG-1335 (Ref. B.58). Guidance on staff reviews of the IPE submittals is now under development; guidance on how IPE information should be used by the staff is not available now.

ESSENTIAL PRA ELEMENTS: The principal focus of the IPE program is identifying and, where appropriate, reducing the frequency of potential core damage accidents; an IPE program is principally a Level 1 analysis. However, the staff's generic letter (Ref. B.46) also identified the need for assessing potential containment vulnerabilities, so some Level 2 analysis is also needed. The IPE submittals to the staff also do not necessarily include Level 3 information, uncertainty analyses, or Level 1 importance measures.

Recommendations: Guidance should be developed by NRR on the use of IPE and IPEEE information, particularly plant-specific inspection guidance and plant-specific licensing actions (e.g., technical specification modifications). This guidance should include the additional staff review that is needed to support these uses of IPE information. 


\section{B.2.3.10 Regulatory Analyses}

PURPOSE OF PROGRAM: In essence, $a$ backfit can be thought of as a situation in which the NRC changes the rules after some licensing process has already started. (An extensive legal definition of a "backfit" is given in 10 CFR 50.109, "Backfitting.") Whenever there is such a change in regulations or in staff positions supporting these regulations, a decision must be made as to whether facilities already licensed under the old rules should be made to conform to the new rules.

OBJECTIVE OF PRA USE: Backfitting is permitted under the provisions of 10 CFR 50.109 (the "backfit rule"). This regulation permits the NRC to require backfit only under certain circumstances. One such circumstance is when it is determined that "there is a substantial increase in the overall protection of the public health and safety ... and that the direct and indirect costs of implementation for that facility are justified in view of this increased protection." Another such circumstance is when "regulatory action is necessary to ensure that the facility provides adequate protection to the health and safety of the public." There are still other circumstances that would require backfitting, e.g., having to do with the common defense and security, but the two circumstances listed above would use PRA.

The first circumstance implies a backfit that is for the purpose of increasing the level of safety above that which was formerly considered to be adequate. The backfit rule requires a "systematic and documented analysis" in this circumstance and requires a finding that the analysis justifies the proposed backfit in terms of both the magnitude of the increase in safety and in cost effectiveness. The objective of the risk assessment is to provide a basis for this analysis.

The latter circumstance implies a backfit for the purpose of correcting an oversight or otherwise raising the level of safety from some lower level up to the original standards. The backfit rule does not require a "backfit analysis" in this circumstance, but still requires an "appropriately documented evaluation" that justifies the action in terms of adequate protection of the public health and safety. The objective of a risk assessment (if one is used) is to provide quantitative measures of the "inadequacy" of the situation before imposition of the backfit and the quantitative change in safety the backfit would cause.

EXISTING GUIDANCE: General guidance on the backfit process is provided in the Regulatory Analysis Guidelines (Ref. B.50) and the supporting handbook (Ref. B.51). However, these documents do not provide explicit guidance on the essential elements of a PRA to be used in the resolution process.

ESSENTIAL PRA ELEMENTS: The essential elements of this use of PRA should include calculation of consequences and risk to the public (in terms of person-rem averted) in addition to calculation of core damage frequency and an uncertainty analysis, permitting the calculation of mean values for comparisons with decision criteria (which are in terms of mean values).

Recommendations: The Working Group has developed general guidance on the scope, product, decision criteria, and quality assurance for PRAs to be used in regulatory analyses, supplementing the broad guidance provided in the Regulatory Analysis Guidelines (Ref. B.50) and supporting handbook (Ref. B.51). This general guidance is provided in Section B.4.

\section{B.2.4 Licensing of Fuel Cycle Facilities and Materials Uses}

\section{B.2.4.1 Reviews - High-Level Waste Repositories}

PURPOSE OF PROGRAM: Performance assessment plays a major role in the NRC's licensing program for the disposal of high-level radioactive waste (HLW), Planned and recent performance assessment activities include reactive work, such as the review of the Site Characterization Plan prepared by the U.S. Department of Energy for a repository at Yucca Mountain, Nevada, and proactive work such as development and deployment of an NRC staff performance assessment capability, development of regulatory guidance in the form of technical positions and rulemakings, conduct of a research program, and participation in a variety of international activities. 
OBJECTIVE OF PRA USE: Because the performance assessment of a repository for HLW involves comparing quantitative estimates for repository performance to quantitative performance standards, performance assessment is often the discipline or phase of repository development in which information and knowledge from a variety of technical and scientific disciplines are integrated into a few quantitative measures of performance.

EXISTING GUIDANCE: The staff is currently developing a license application review plan (LARP) to provide guidance on the review of the DOE license application. In addition, draft Regulatory Guide DG-3003, "Format and Content for the License Application for the High-Level Waste Repository," was issued in November 1990. This draft guide is being developed to provide guidance to DOE on the performance assessments to be included in the license application.

ESSENTIAL PRA ELEMENTS: The steps in performance assessment are:

- System Description. In this step the various important components of the waste disposal system, the waste form, the engineered barrier (the canister, the repository, backfill, if any), and the site, are described in terms useful to modeling radionuclide migration to the environment.

- Scenario Analysis. In this step a range of potential future conditions in which the repository must operate, called scenarios, are postulated and screened. Also, the frequencies of individual scenarios are estimated.

- Consequence Analysis. The consequence analysis step estimates the performance of the repository for a given scenario. For the performance measure of most interest, cumulative release of radionuclides to the accessible environment, consequence models need to treat the release of radionuclides from the repository to the host rock and the migration of radionuclides (as liquid or gas) through the geosphere. Modeling these processes may require detailed consideration of phenomena affecting these processes, such as ground-water flow and waste package degradation.

- Performance Calculation. The performance calculation step combines the estimate of consequences with the corresponding probability of occurrence. The resulting distribution is displayed as a complementary cumulative distribution function (CCDF).

- Sensitivity and Uncertainty Analyses. In order to compare the characterization of the system obtained in the previous step to the regulatory performance standards, the uncertainties inherent in the estimates of performance must be estimated and evaluated.

- Comparison to Regulatory Standards. In this step, judgment is used to evaluate whether the estimated performance, with its associated uncertainties, satisfies or fails to satisfy regulatory standards.

Recommendations: Performance assessment studies have many key issues similar to those for detailed reactor facility and issue analyses (e.g., the role of uncertainty analyses). Close coordination should be maintained between the staff involved in the two types of studies to ensure consistency.

\section{B.2.5 Regulation of Fuel Cycle Facilities and Materials Uses}

\section{B.2.5.1 Facility Analyses - Medical Devices}

\section{B.2.5.1.1 Medical Devices}

PURPOSE OF PROGRAM: The purpose of this program is to evaluate the use of PRA in developing risk-based regulation of devices with radioisotope sources used in medicine.

OBJECTIVE OF PRA USE: Traditional methods used in assessing risk in nuclear reactors may be inappropriate to use in assessing medical radiation risks. Reactor PRAs are machine-oriented with a human failure component associated with critical machine failure events. In assessing the risk of administering an incorrect radiation dose to a patient, the primary source of failures seems to stem from the actions of people and only secondarily from machine 
failures. This basic difference has led to the development of a person-centered approach to risk assessment that yields relative risk profiles.

EXISTING GUIDANCE: There is no existing guidance on this use of risk assessment.

ESSENTIAL PRA ELEMENTS: This person-centered approach to risk assessment includes a hierarchy of steps: (1) identify the critical human and machine processes and sequences, (2) evaluate hazards to medical personnel and patients, (3) perform a modified task analysis, and (4) develop relative risk profiles for each task sequence.

Recommendations: Medical risk assessments have key issues similar to those for detailed reactor facility and issue analyses. Close coordination should be maintained between the staff groups involved in these studies in NMSS and those developing human reliability analysis methods in RES. As the potential use of risk assessment in the regulation of such devices becomes more clear, the Working Group recommends that guidance for performing these risk studies be developed. 


\section{B.3 GUIDANCE FOR USING PRA TO SCREEN AND PRIORITIZE ISSUES}

\section{B.3.1 Introduction and General Guidance}

This section provides general guidance on the use of PRA for screening and prioritization. The specific guidance of the Working Group is presented here in bold-face italic type. It is assumed that the user is already proficient in the techniques of performing PRA or will make use of staff or contractors already proficient in these techniques. As noted in Section B.1, the guidance is focused on determining what type of PRA to perform (e.g., the PRA scope), not how to perform the calculation. The Working Group has recommended that more detailed guidance on how to perform the calculations be developed.

The PRA uses to which this guidance applies include event screening, generic safety issue prioritization, and screening risk analyses of entire facilities.

The motivation for using PRA for prioritization is to maximize the effect of limited staff and financial resources on risk, i.e., get the maximum safety benefit for the public's dollar. As used by the NRC staff, the term "prioritization" may include both "ordering" (i.e., placing tasks in an ordered list) and "screening" (i.e., making a decision that some tasks will not be done at all), depending on the particular application. In applications that need only an ordered list or relative ranking, consistency in assumptions and methods is of prime impertance, and the absolute values of the results are secondary. In applications that involve screening, i.e., applications that will dismiss some issues or will propose actions based on some absolute criterion, the absolute value takes on primary importance.

The nature of the application also dictates the necessity for modifying existing models. If the items under study (components, procedures, phenomena, etc.) are already modeled in an existing PRA, the existing PRA's importance measures (risk reduction and risk achievement ratios) may be sufficient to set priorities. For example, if a facility already has a PRA, inspection activities for the facility can be guided by the PRA's importance measures calculated for the various systems and components.

In contrast, other applications (such as operational event evaluations and generic safety issues) may involve new phenomena or dependencies that are not modeled in an existing PRA, and more extensive calculations would be necessary. However, these calculations must be kept relatively simple for the prioritization process to be cost effective. The particular application will dictate which simplifications and approximations are appropriate.

Lastly, the nature of the application governs the particular calculational product that is used to make a prioritization decision. Some applications calculate conditional core damage probabilities, while other applications may have decisions based on core damage frequency, change in core damage frequency, or change in public risk. Some caution is required when comparing the calculational results of the various applications, since some of these parameters may' have units or absolute values similar to other parameters but in reality be very different in what is being estimated. Total core damage frequency and change in core damage frequency will both have units of "per reactor-year," but are very different.

The prioritization process for generic issues will be described as an example. This particular application is primarily a screening process, i.e., the effect of the process is to drop low priority issues from further consideration. Moreover, many generic issues involve situations or phenomena that were not known when the base PRA was performed, and thus these issues must be prioritized by modifying an existing model. This may be as simple as changing a component failure probability, or it may be a significant modification involving the addition of new fault trees and event trees to the model. For example, older PRAs did not model PWR reactor coolant pump seal failure on loss of seal cooling. Thus, the evaluation of issues involving seal failure would require some modification of these PRA models. 
For screening and prioritizing events and issues, the Working Group has developed the following general guidance:

- The analysis should make use of up-to-date PRA information. This includes logic diagrams (such as event sequence diagrams, fault trees, and event trees) and other risk performance displays such as dependency matrices, current design and operational information, and data (such as component fallure rates). Valuable references in this regard are the NUREG-1150 studies (Ref. B.54) and the reviewed industry PRAs.

- The analysis should define the class of affected plants as specifically as possible and should make use of PRAs most closely resembling the class of affected plants. (The Working Group recommends that a plant classification structure that would be usable in the spectrum of staff issue analyses be investigated by RES.)

- Uncertainty analyses and mean values should be calculated whenever this is practical. Even when formal uncertainty analyses are not possible, sensitivity studies should be performed to determine the impact of key assumptions, uncertainties in the inputs, and other factors. When no data are readily avallable and the analyst must use engineering judgment, the documentation of the analysis should always explicitly so state and give the rationale for substituting for unavailable information.'

- The analysis should be as realistic as is practical. However, some conservatism may appropriately be used in screening calculations, when, for example, bounding calculations can demonstrate that an issue should be dropped from consideration. (See the discussion of conservatism for the specific example of generic safety issue prioritization in Section B.3.2.2 on page B-24.)

- The decision criteria for screening issues and events should be similar to the guidance provided in NUREG-0933 (Ref. B.48) (for generic issue prioritizations). The Working Group recommends that the present core damage frequency-to-risk transformations in NUREG-093.3 (Ref. B.48) (which are based on the Reactor Safety Study) be replaced with information based on NUREG-1150 (Ref. B.54).

- The analysis should explicitly ensure that the truncation level of the base PRA is sufficiently low for calculations of differences (e.g., change in core damage frequency) to be meaningful. The issue being evaluated may well call the dropped sequences into consideration. That is, these sequences may no longer be negligible when the effect of the issue being evaluated is included. There is no a priori definition of a sufficiently low truncation limit. However, the analyst must recognize that as accident sequences with very low frequencies are considered, concerns as to the completeness and adequacy of the models become much more serious.

- The analysis should receive an independent review by staff knowledgeable in PRA and in the design of the affected systems or components, plus reviews by the individual or group that identifled the issue and the group that would be responsible for implementing the resolution, in a manner similar to that for generic issue prioritizations. (If it is anticipated that considerable resources will be needed for this review, the review should be started early in the process to allow incorporation of the reviewers' comments as the analysis progresses.)

- The documentation should not present calculational results with more significant flgures than are appropriate. More than one significant figure in the mantissa is not appropriate in most cases.

It should be noted, however, that if intermediate results are presented, a reader attempting to use these intermediate results in duplicating the calculation may not get exactly the same final results because of the roundoff error.

For some screening and prioritization processes (e.g., generic safety issues), the decision criteria and products are put in a qualitative form ("High," "Medium," "Low," or "Drop") to appropriately reflect the precision of the analysis.

\footnotetext{
1 Judgment is, of course, used throughout the analysis process. It is important here to explicitly identify key judgments and discuss their impact.
} 
Appendix B

- The analysis should be documented with sufficient detall to enable the analysis to be repeated. In addition, sufficient explanatory material should be provided to enable the reader to understand the significance of the calculations and to reconclle the various calculations with engineering Judgment (a "sanity check"). Thus, the event or issue, its relationship to safety, the calculational approach, and all assumptions should be listed and justified, including the choice of the base PRA, choice of parameters, source of basic data, and any mathematical approximations used. Also, the accident sequences affected should be described and explanations of why they are affected should be provided.

\section{B.3.2 Generic Issue Prioritization}

In the generic issue prioritization process, issues are reviewed to determine their safety significance. Some issues primarily involve the licensing process and others involve nonradiological environmental protection and thus do not involve significant radiological safety improvement elements. These issues are not considered here. The guidance here is concerned with issues that are safety issues (i.e., possible deficiencies in the design, construction, or operation of an NRC-licensed facility that can affect the health and safety of the public by virtue of radiological effects) and that are generic (i.e., potentially apply to all, several, or a class of facilities).

The risk estimates developed for prioritization purposes are useful as rough approximations for comparative purposes but are not necessarily useful for assessing absolute levels of risk attributable to particular issues. Similarly, the value/impact scores provide, for the limited purpose of prioritization, tentative assessments of relative potential for cost-effective resolution. They are not intended to be applied as value/impact determinations for any regulatory proposal that may ultimately result from efforts to resolve an issue. In addition, the assumed resolutions are not intended to pre-judge the final resolutions but are only assumptions that are necessary in prioritizations.

Recommendations for this use of risk assessment are provided in the following sections on the:

1. Scope of analysis,

2. Method of analysis,

3. Product and documentation of analysis,

4. Decision criteria, and

5. Quality assurance and review.

\section{B.3.2.1 Scope of Analysis}

\section{B.3.2.1.1 Nature of the Issue}

Regulatory activities and potential safety issues that can be prioritized using PRA techniques are not restricted to commercial nuclear generating plants. Even within the context of a nuclear power generating plant, such activities and issues can involve parts of the plant other than the reactor, for example, normal effluent releases or the spent fuel pool. In principle, all safety-related activities and issues can be evaluated using risk assessment techniques. The guidance given here will apply primarily to activities and issues involving core damage accidents and associated risks. However, other activities and issues can also be evaluated. In some cases, the incident with the potential to release radioactivity may be something other than a severe core damage event (e.g., a departure from nucleate boiling event, an effluent spill, or a transportation accident). These cases are still "event-oriented" and can be evaluated in the same manner as a core damage issue - the frequency of the radioactivity-releasing event is calculated, the consequences of the event are calculated, and the two figures (frequency and consequences) are multiplied together to obtain an estimate of the aggregate risk of the event (see Appendix C, Section C.4.4.4, for a definition of aggregate risk). In other cases, there may be a continuous release and the "frequency" parameter becomes a release rate. Issues governing normal effluent release would come under this category. These cases are not event-oriented, but it is still possible to estimate risk. 


\section{B.3.2.1.2 Tractability}

Although it is possible in principle to evaluate any activity or issue affecting safety using risk assessment techniques, such an evaluation can prove quite challenging in actual practice, because:

- In potential generic safety issues, the issue is often not well defined. In some cases, the analyst is given only a title of the issue. Considerable investigation may be necessary to determine the exact nature and context of the issue.

- The safety significance is not always clear. For example, steam generator tube rupture events release primary coolant activity and possibly gap activity from any failed fuel to the environment, and they also can lead to a core damage event. The classic "Chapter 15" deterministic analyses will only include the former effect. In contrast, although both effects can be included in a probabilistic model, existing whole-plant PRA analyses normally consider only the latter effect. A specific issue, depending on its origin and definition, may address either or both of the two effects.

- The significance of the activity or issue in terms of PRA parameters is not always straightforward. For example, an issue involving emergency core cooling system modeling has safety significance in that, should a design basis LOCA occur, a certain number of fuel rods could exceed the $2200^{\circ} \mathrm{F}$ limit. PRAs do not currently allow for the possibility of partial core damage in this fashion (although it is possible to do so). Such issues have, in fact, arisen and have had to be addressed.

- Because of the great diversity of regulatory activities and issues, it is difficult to give general guidance. Moreover, considerable latitude is necessary if the analyst is to be able to address the entire spectrum of issues. It is often necessary for the analyst to develop an entirely new model in order to prioritize the more unusual cases. Thus, the guidance given here includes recommendations for expanding the set of analytical tools, as well as directing how these tools should be used.

\section{B.3.2.1.3 Affected Facilities}

Some activities and issues are specific to one site or one reactor, but most are "generic" to a specific set of plants or facilities. The set of affected plants consists of all plants for which the activity or issue has the potential to affect risk. The prioritization analysis should attempt to define the class of affected plants as specifically as possible in terms of an objectively observable characteristic, such as the presence or absence of a particular design characteristic.

In some cases, it may not be possible at the prioritization stage to ascertain which plants have the particular characteristic. In such cases, the analysts should assume that at least one plant has the necessary characteristic. The estimate of the cost of resolution should include the cost of determining which plants are affected.

\section{B.3.2.1.4 Use of Existing PRA}

Most activities and issues that involve core damage accidents can be evaluated by changing numerical parameters in an existing PRA and observing the consequent change in the risk profile. Some cases may require more extensive modification of an existing PRA (e.g., adding a new safety system to the model). Some are sufficiently novel as to require the analyst to develop a completely new model.

In the inierest of the efficient use of resources, prioritization analyses should make use of existing work to the maximum possible extent. In most cases, this will mean using an existing PRA, or more than one existing PRA if more than one is needed to cover the spectrum of affected plants.

The analyst or team of analysts should be famillar with the base PRA before undertaking the analysis. This includes familiarity with the system and component nomenclature used in the PRA, the modeling assumptions and consequent limitations, the calculational tools used, and the truncation level. The objective here is to avoid using an existing PRA as a "black box" with little or no understanding of what changes in which parameters will be appropriate for the issue being investigated. 
Currently, many potential generic issue prioritizations that are based on existing PRAs use either the Reactor Safety Study (Ref. B.55) or the Oconee or Grand Gulf RSSMAP studies (Refs. B.59 and B.60). The use of PRA techniques for prioritizing generic issues began in the early 1980s (Ref. B.61), and these PRAs had the advantages of familiarity and availability. However, these PRAs make use of obsolete calculational techniques. Moreover, the four plants modeled (Surry, Peach Bottom, Grand Gulf, and Oconee) are not representative of the spectrum of currently operating plant designs. Finally, these old PRAs do not include phenomena and system dependencies that have been discovered in the intervening years (e.g., reactor coolant pump seal failures), nor do they include external events. Therefore, modern PRAs, particularly the NUREG-1150 PRAs when appropriate, should be used as bases for generic issue prioritization. The existing population of plants should be divided into classes consistent with avallable representative PRAs, with these classes used consistently throughout the agency. It will be necessary to modify the existing plant-specific PRAs somewhat for prioritization work, as discussed below.

\section{B.3.2.1.5 Level}

If the activity or issue involves the possibility of a core damage accident, the change in core damage frequency resulting from correcting the issue should always be given, to hulp place the activity or issue in perspective as well as provide a decision parameter. As such, the principal focus of the screening analyses should be toward a change in core damage frequency. However, a risk (Level 3) context is also important and is required for generic safety issues. For these analyses, it is recommended that simple core damage frequency to risk transformations (such as those in NUREG-0933 (Ref. B.48), which are based on a generic site) be used.

Current practice in generic safety issue prioritization is to use the Reactor Safety Study (Ref. B.48) source terms and calculate person-rem (to a radius of 50 miles) assuming a uniform population density of 340 persons per square mile and the Braidwood site meteorology. The estimated average population for domestic sites as of the year 2000 is 340 persons per square mile. The Braidwood meteorology was selected as being typical of a central Midwest plain

In the future, the NUREG-1150 (Ref. B.54) risk assessment results, generalized as appropriate for site characteristics, should be used in future prioritizations. [Note: NUREG-1150 results are not now in a form for making such core damage frequency to risk transformations. The Working Group has initiated (via the Office of Nuclear Regulatory Research) the development of such transformations in a form compatible with the computer codes often used in prioritization studies (IRRAS and SARA, Refs. B.49 and B.62).]

The analysis should explicitly ensure that the truncation level of the base PRA is sufficiently low for calculations of differences (e.g., changes in core damage frequency) to be meaningful. Most PRAs employ a truncation level or "cutoff" when quantifying sequences. Sequences with frequencies below the "cutoff" are dropped from further consideration and, because of their negligible contribution, these sequences are not included in the calculation of core damage frequency and risk. This is an appropriate approximation when the desired result is the "bottom line" core damage frequency or risk. However, it may not be appropriate when using the PRA to evaluate changes in the bottom line results. The generic issue under consideration may well call the dropped sequences into consideration. Had the issue been known when the PRA was performed, some of these sequences may well not have been dropped. (Sequences that are not affected by the issue under consideration should cancel out when calculating the change in core damage frequency or risk. Thus, unaffected sequences may be ignored.)

\section{B.3.2.2 Method of Analysis}

\section{B.3.2.2.1 Conservatism in Prioritization}

The objective of a conventional PRA is, ideally, to provide an estimate of risk with no intentional bias, i.e., not a "conservative" or "bounding" estimate. This is not always possible at the prioritization stage.

If a prioritization analysis were to err in the direction of a higher than necessary priority, the error would presumably be corrected at the issue resolution stage. The consequence of the error would at most be the expenditure of funds for further investigation and, because of the diversion of resources, a delay in addressing a more deserving problem. However, if a prioritization analysis were to err in the direction of a lower than appropriate priority, there might be no further investigation and the consequence would be ignoring an issue with safety significance. Although the 
consequences of an error in the high direction are not desirable, the consequences of an error in the low direction are worse. Thus, at the prioritization stage, the analysis should be as reallstic as is practical. However, If reallsm is not possible (eg., because no data are readily avallable), it is preferable for the analysis to "aim high" (he., introduce some conservatlsm) rather than "aim low." If possible, this should be accompanied by sensitivity studies to explore the effect of this conservatism on the analysis.

\section{B.3.2.2.2 Use of Judgmental "Data"}

At the prioritization stage, it is often necessary for the analyst to use judgmental estimates if actual data do not exist or are not readily available. The documentation of the analysis should always expllcitly so state when such estimates are used, as well as provide the rationale for this judgment. ${ }^{2}$

In addition, this is one area where it may be appropriate to introduce some conservatism, as discussed above. The purpose is to avoid screening out an issue prematurely, i.e., to provide justification for further study of the issue. It is expected that such conservatisms will be removed when the resolution continues to the "resolution" stage. When using engineering judgment to estimate a parameter, some conservatism may be used provided this is explicitly stated in the analysis. For key parameters, a sensitivity study should also be performed to explore the effect of this conservatism, except in cases where there would be no effect on the conclusion (e.g., if an issue were to receive a "drop" priority even with the estimated parameter at the top of its range, a sensitivity study would not be necessary). When conservatism is used, $i t$ would also be beneficial to include a qualitative discussion of the analyst's rationale for the choice of parameter value and how conservative this value is believed to be.

\section{B.3.2.3 Product and Documentation of Analysis}

The parameters used for potential generic safety issue prioritization (person-rem per million dollars, person-rem per reactor, total person-rem for all affected reactors, core damage events per reactor-year, and core damage events per year) are given and justified in NUREG-0933 (Ref. B.48). It should be noted that these parameters require, in addition to the core damage frequency and risk from a PRA, knowledge of the number of reactors affected, the aggregate remaining lifetime of these reactors (reactor-years), and an estimate of the cost of resolving the issue and implementing this resolution.

The decision parameters should be "net" values. Although the net effect of a proposed change in procedures or hardware will presumably be in the direction of increased safety, it will often be found in practice that some accident sequences will decrease in frequency but some others will increase. If the analysis is done by modifying an existing PRA, it is relatively straightforward to include both positive and negative effects and thus produce a "net" value. However, when it is necessary to customize a model, the analyst should explicitly and consciously look for the existence of negative effects.

The "value" or "benefit" should be summed over the remaining life of the affected installations, and the prioritization parameters specified in NUREG-0933 assume this summation. The PRA-based calculations generally result in averted person-rem per reactor-year. The summed value would be calculated by multiplying this figure by the remaining reactor-years of the affected plant class, as of the expected date of implementation (assuming the perreactor-year figure does not vary with time).

A narrative description of the principal accident sequences should be included in the write-up of any eventoriented prioritization analysis. This greatly aids the decision-maker's understanding of the issue and provides some additional quality assurance. If there are any "trade-off" sequences, i.e., potential accident sequences that are made worse by the proposed action, they should also be described explicitly.

\footnotetext{
${ }^{2} J u d g m e n t$ is, of course, used throughout the analysis process. It is important here to explicitly identify key judgments and discuss their impact.
} 


\section{B.3.2.4 Decision Criteria}

The final product of a PRA-based prioritization analysis is the assignment of a qualitative priority ("high," "medium," "low," or "drop") to the issue. The decision criteria for these assignments are specified in NUREG-0933 (Ref. B.48). Currently, issues with a prioritization parameter above a certain value (e.g., a core damage frequency above $10^{-4}$ per reactor-year) are automatically given a "high" priority assignment (see Figure B.1). Issues with all prioritization parameters below a certain level (e.g., a core damage frequency less than $10^{-7}$ per reactor-year and a total risk of 10 person-rem integrated over the remaining lifetime of the plant) are automatically given a "drop" priority assignment. For values between these limits, the value/impact ratio (person-rem per $\$ 1$ million) is used in conjunction with the prioritization parameters to assign a priority level as shown in Figure B.1. It should be noted, however, that some issues may be raised in priority based on other considerations. For example, a decision may be made to investigate a new phenomenon with the intent of reducing uncertainty, even though it is expected that there will be little or no change in plant safety. More discussion of these "other considerations" can be found in NUREG-0933 (Ref. B.48); they are beyond the scope of this document.

\section{B.3.2.5 Quality Assurance and Review}

The screening of issues should, as a minimum, include an independent review by a group knowledgeable and experienced in PRA practice and a group knowledgeable in the design of the systems and components affected by the issue (or other appropriate technical area). If applicable, there should be reviews by the individual or group responsible for discovering or identifying the issue and by the organizational unit that would be responsible for implementing the resolution of the issue or carrying out the activity. The reviews would normally be done by routing copies of the documentation to the appropriate persons or organizational units. The review should, at minimum, cover the following areas:

- The definition of the issue. This definition should be clear, and the individual or group who identified the issue should agree that this definition completely encompasses the issue.

- The selection of the systems, components, or proct cted by the issue.

- The selection and justification of the base PRA, if . $R A$ is used.

- The manner in which the issue is incorporated into the base PRA, specifically, which parameters are affected by the issue.

- The limitations of the PRA models in addressing the issue.

- Any new PRA models. That is, if it was necessary to construct new fault or event trees to address the issue, these models should be reviewed.

- The selection and justification of failure data.

- The dominant affected accident sequences. These should be described in sufficient detail to permit a qualitative understanding of the analysis and its result ("sanity check").

- The cost analysis, including both the cost to the industry and the cost to the NRC.

- The context of the issue in the total safety profile of the plant. Specifically, the review should ensure that all potential mitigative actions have been credited. In addition, the review should ensure that negative effects (eg., accident scenarios that might increase in frequency or consequences because of fixing the issue) have not been ignored. 
Figure B.1 Generic issue priority assignments

(from NUREG-0933)

\section{Impact/Value}

(\$/Person-Rem)

\begin{tabular}{|c|c|c|c|c|c|c|}
\hline $\begin{array}{r}>1,000 \\
1,000\end{array}$ & DROP & DROP & LOW & MEDIUM & \multicolumn{2}{|l|}{ HIGH } \\
\hline \multirow[t]{5}{*}{$<1,000$} & DROP & LOW & MEDIUM & HIGH & HIGH & \\
\hline & & \multicolumn{2}{|c|}{$10^{-6}$} & \multicolumn{2}{|c|}{$10^{-4}$} & CDF/Year \\
\hline & \multicolumn{2}{|c|}{$3 \times 10^{-6}$} & \multicolumn{2}{|c|}{$3 \times 10^{-4}$} & & $\begin{array}{l}\text { CDF/Year } \\
\text { Total, All Affected } \\
\text { eeactors) }\end{array}$ \\
\hline & \multicolumn{2}{|c|}{$10^{1}$} & \multicolumn{2}{|c|}{$10^{3}$} & \multicolumn{2}{|r|}{$\begin{array}{l}\Delta \text { Person-Rem/Reactor } \\
\text { (Offsite) }\end{array}$} \\
\hline & \multicolumn{2}{|c|}{$3 \times 10^{2}$} & $3 \times 10^{4}$ & & \multicolumn{2}{|r|}{$\begin{array}{l}\Delta \text { Person-Rem (Total } \\
\text { Offsite, All Affected } \\
\text { Reactors) }\end{array}$} \\
\hline
\end{tabular}


Appendix B

\section{B.4 GUIDANCE FOR PRA USE IN RESOLVING ISSUES}

\section{B.4.1 Introduction and General Guidance'}

This section provides general guidance on the use of PRA in issue resolution analyses. It is assumed that the user either is already proficient in the techniques of performing probabilistic risk assessment and in plant design and operation or will make use of staff or contractors already proficient in these techniques.

Staff work for which this general guidance applies includes:

- Operational event analyses;

- Operational data and trending analyses;

- Generic safety issue resolution;

- Severe accident research analyses;

- Detailed facility risk analyses; and

- Regulatory analyses.

For issue analyses, the Working Group has developed the following general guidance:

- The analysis should explicitly define the class of affected plants and justify the use of specific PRAs to represent that class.

- The PRA should reflect the current state of PRA technology and include the analysis of uncertainties.

- The product of the analyses should be mean values and uncertainty estimates for use in ulue/impact analyses, except in cases where there would be no effect on the conclusion (e.g., if "no action" could be justified by a bounding analysis).

- 'The decision criteria for issue analyses should be based on the guidance provided in the (draft] Regulatory Analysis Guidelines (Ref. B.50), which are themselves based on the Safety Goal Policy Statement (Ref. B.63) and the Backfit Rule, 10 CFR 50.109.

- The analysis should receive an independent review by NRC staff who are knowledgeable and experienced in PRA, plus reviews by the individual or group who identified the issue and the group who would be responsible for implementing the resolution. (If it is anticipated that considerable resources will be needed for this review, the review should be started early in the process, to allow incorporation of the reviewers' comments as the analysis progresses.)

- The analysis should be documented with sufficient detail to enable the analysis to be repeated. In addition, sufficient explanatory material should be provided to enable the reader to understand the significance of the calculations and to reconcile the various calculations with engineering judgment (a "sanity check"). Thus, the event or issue, its relationship to safety, the calculational approach, and all assumptions should be listed and justified, including the choice of base PRA, choice of parameters, source of basic data, and any mathematical approximations used. Also, the accident sequences affected should be described and explanations of why they are affected should be provided.

- The documentation should not present calculational results with more significant figures than are appropriate. More than one significant figure in the mantissa is not appropriate in most cases. (It should be noted, however, that if intermediate results are presented, a reader attempting to use these intermediate results in duplicating the calculation may not calculate exactly the same finai results because of the round-off error.) 


\section{B.4.2 Generic Issue Analyses}

Guidance is provided in this section on the basic elements of a PRA used in this resolution process. Before issues are addressed using this guidance, they should have been screened for potential risk significance using the procedures described in Section B.3.

The generic issue analysis process includes an assessment of the risk reduction benefit of the resolution of a specific issue. Recommendations for this use of risk assessment are provided in the following sections on:

- The scope of analysis,

- The type and form of the risk assessment product,

- The decision criteria for this use, and

- Quality assurance and review.

\section{B.4.2.1 Scope of Analysis}

\section{B.4.2.1.1 Nature of Generic Issues}

A generic issue can be defined as any concern that has the potential to require regulatory action for all, several, or a class of reactors. The guidance given here applies only to safety issues. Generic safety issues are defined as those issues that involve a safety concern that may affect the design, construction, operation, or decommissioning of all, several, or a class of reactors and may have the potential to require safety improvements or promulgate new or revised requirements. Other issues, such as administrative, legal, and environmental issues, are not addressable with PRA, and thus are not discussed further here.

Safety issues can involve any type of NRC-regulated activity; they are not restricted to commercial nuclear generating plants. Even within the context of a nuclear power generating plant, safety issues can involve parts of the plant other than the reactor, such as normal effluent releases or the spent fuel pool. In principle, all safety issues can be evaluated using risk assessment techniques. The guidance given here will apply primarily to issues involving core damage accidents and associated risks. However, other issues can also be evaluated. In some cases, the incident that has the potential to release radioactivity may be something other than a core danage event (e.g., a departure from nucleate boiling [DNB] event, an effluent spill, or a transportation accident). These issues are still event-oriented and can be evaluated in the same manner as a core damage issue - the frequency of the radioactivity-releasing event is calculated, the consequences of the event are calculated, and the two figures (frequency and consequences) are multiplied together to get consequences per year. In other cases, there may be a continuous release and the "frequency" parameter becomes unity. Issues governing normal effluent release would come under this category. These issues are not event-oriented, but it is still possible to obtain an estimate of risk.

\section{B.4.2.1.2 Affected Plants}

Some issues are specific to one site or one reactor, but most are "generic" to a specific set of plants. The set of affected plants consists of all plants for which the issue has the potential to affect risk. The analysis of any issue should explicitly define the class of affected plants in terms of an objectively observable characteristic, such as the presence or absence of a particular design characteristic. For example, an issue could apply to all BWRs equipped with an isolation condenser, or all plants equipped with a posttensioned concrete containment. [Note: The Working Group recommends that the feasibility of a plant classification structure usable in the spectrum of staff issue analyses be investigated by RES.]

\section{B.4.2.1.3 Use of Existing PRAs}

Most issues that involve core damage accidents can be evaluated by changing numerical parameters in an existing PRA and observing the consequent change in the risk profile. Some issues may require more extensive modification 
of an existing PRA (e.g., adding a new safety system to the model). Some are sufficiently novel as to require the analyst to develop a completely new model.

In the interest of the efficient use of resources, issue resolution analyses should make use of existing work to the maximum possible extent. In most cases, this will mean using an existing PRA, or more than one existing PRA if more than one is needed to cover the spectrum of affected plants. The analysis should always state which PRA is being used and the reasons for choosing that PRA.

The analyst or team of analysts should be famillar with the base PRA and famillar with the plant involved before undertaking the analysis. This includes familiarity with the system and component nomenclature used in the PRA, the modeling assumptions, the calculational tools used, the uncertainty analysis, and the truncation level. The objective here is to avoid using an existing PRA as a "black box" with little or no understanding of what changes in which parameters will be appropriate for the issue being investigated.

The base PRA (or PRAs) should reflect the current state of PRA technology. That is, the base PRA should be at the component rather than the system level, include common cause failures, include an uncertainty analysis, include human reliability analyses, and include credit for recovery actions. The base PRA should incorporate newly discovered effects (such as the failure of reactor coolant pump shaft seals when seal cooling is lost). The base PRA should model the issue and be well understood and defendable by the NRC staff. The documentation of the analysis should state why the particular PRA was chosen.

The base PRA (or PRAs) should be representative of the affected plants. Since almost all existing PRAs were performed to evaluate the risk profile of a specific plant, these PRAs make use of site-specific features and often site-specific failure data as well. It may be necessary to replace site-specific data with generic data and eliminate the site-specific portions of the model. [Note: The Working Group recommends that the need for and feasibility of such replacements of plant-specific data be studied by the staff.]

The base PRA should include both internal and external events, unless it can be shown that some initiators can be excluded.

If the issue involves low power or shutdown conditions, a PRA covering this condition should be used or constructed.

In order to properly include the effect of multiple generic issues, it would be highly desirable to use models that have been updated periodically to reflect major changes in plant design and operation. [Note: The Working Group recommends that the feasibility of developing such models, and updating them periodically, should be investigated by RES.]

If a second suitable PRA is avallable, even if only in printed rather than computer-readable form, the second PRA should be used as a qualitative check on the first base PRA, if practical. $A$ "second opinion" such as this is not strictly necessary, but, if avallable, will greatly strengthen conclusions.

\section{B.4.2.1.4 Level of Analysis}

If the issue involves the possibility of a core damage accident, the change in core damage frequency from resolution of the issue should always be given to help place the issue in perspective as well as to provide a decision parameter. This "Level 1" calculation is usually the main focus of the analysis. However, imposition of an issue resolution requires Level 3 information since the cost/benefit ratios are cast in terms of person-rem. Thus, the analysis must be carried out to Level 3 .

If the issue does not involve core damage at a reactor, but is still event-oriented, the frequency of the event should always be glven to aid the decisionmaker in understanding the nature of the calculation.

For generic (not plant-specific) issues that affect risk primarlly by affecting core damage frequency, the analysis should assume and justify a containment type and plant site appropriate to the affected plant class. [Note: The 
Working Group recommends that methods be developed to adapt existing Level 2 and 3 information to support issue analyses.]

\section{B.4.2.1.5 Uncertainty Analysis}

An uncertainty analysis (as described in Appendix C) should be performed, including the effects of key parameters (as defined by using sensitivity studies, judgment, and other considerations).

\section{B.4.2.1.6 Truncation Level}

The analysis should explicitly ensure that the truncation level of the base PRA is sufficiently low for the appropriate differential calculations to be meaningful. Most PRAs employ a truncation level or "cutoff" when quantifying sequences. Sequences with frequencies below the "cutoff" are dropped from further consideration and, because of their negligible contribution, these sequences are not included in the calculation of core damage frequency and risk. This is appropriate when the desired result is the "bottom line" core damage frequency or risk. However, it may not be appropriate when using the PRA to evaluate changes in the bottom line results. The generic issue under consideration may well call the dropped sequences into consideration. Had the issue been known when the PRA was performed, these sequences may well have not been dropped.

Thus, if the base PRA has a truncation level such that most or all of the sequences affected by the issue under consideration have already been dropped from consideration, the effect or the issue on core damage frequency and risk will be significantly underestimated. There is no a priori definition of a sufficiently low truncation limit. The analyst must consciously check to be sure that, the affected sequences are not all below the truncation level.

\section{B.4.2.2 Product and Documentation of Issue Analysis}

A narrative description of the principal accident sequences (at the system level) should be included in the documentation of any issue analysis. This greatly aids in the decisionmaker's understanding of the issue and provides some additional quality assurance. If there are any "trade-off" sequences, i.e., potential accident sequences that are made worse by resolving the issue, these should also be explicitly described.

Frequency/probability calculations for issue resolution result in value/impact ratios. Mean values for these ratios should be calculated, using uncertainty analyses, unless the nature of the issue makes such calculations impractical.

The decision parameters should be "net" values. Although the net effect of a proposed change in procedures or hardware will presumably be in the direction of increased safety, it will often be found in practice that some accident sequences will decrease in frequency but some others will increase. If the analysis is done by modifying an existing PRA, it is relatively straightforward to include both positive and negative effects. However, when it is necessary . to build a "custom" model, the analyst should explicitly and consciously look for the existence of negative effects.

The "net value" or "net benefit" should be integrated over the remaining life of the affected installations. The differential calculations generally result in averted person-rem per reactor-year. The integrated value would be calculated by multiplying this figure by the remaining reactor-years of the affected plant class, as of the expected date of implementation.

\section{B.4.2.3 Decision Criteria}

The resolution of generic issues must make use of decision criteria, since the end result is a choice of one of a spectrum of potential fixes, including the option of no action.

Currently, the decision criteria are applied in two phases. The first phase consists of a decision on whether the potential net improvement in the health and safety of the public is sufficient to justify regulatory action. The Safety Goal Objectives discussed in the Regulatory Analysis Guidelines (Ref. B.50) provide guidance in this area, as shown in Figure B.2. 
Figure B.2 Safety goal implementation guidance

(From draft NUREG/BR-0958 [Ref. B.64])

\begin{tabular}{|c|c|c|c|}
\hline & $1 \mathrm{E}-03$ & & \\
\hline & $1 \mathrm{E}-04$ & $\begin{array}{l}\text { PROCEED TO V/I PORTION } \\
\text { OF REGULATORY } \\
\text { ANALYSIS }\end{array}$ & $\begin{array}{l}\text { PROCEED TO V/I PORTION OF } \\
\text { REGULATORY ANALYSIS* } \\
\text { (PRIORITY) }\end{array}$ \\
\hline$\uparrow$ & $1 E-05$ & $\begin{array}{l}\text { MANAGEMENT DECISION } \\
\text { WHETHER TO PROCEED } \\
\text { WITH V/I PORTION OF } \\
\text { REGULATORY ANALYSIS }\end{array}$ & $\begin{array}{l}\text { PROCEED TO V/I PORTION OF } \\
\text { REGULATORY ANALYSIS }\end{array}$ \\
\hline $\begin{array}{l}\text { CHANGE IN } \\
\text { CORE } \\
\text { DAMAGE } \\
\text { FREQUENCY } \\
(\triangle \mathrm{CDF}) / \mathrm{RY}\end{array}$ & $1 \mathrm{E}-06$ & NO ACTION & $\begin{array}{l}\text { MANAGEMENT DECISION } \\
\text { WHETHER TO PROCEED WITH } \\
\text { V/I PORTION OF REGULATORY } \\
\text { ANALYSIS }\end{array}$ \\
\hline & & & 1 \\
\hline
\end{tabular}

* A determination is needed regarding adequate protection or compliance; a value impact analysis may . not be appropriate.

** Conditional upon core damage accident that releases radionuclides into the containment.

If either the change in core damage frequency or the change in conditional containment failure probability are above the thresholds given above, the potential net improvement in the health and safety of the public is considered to be sufficient to justify a value/impact analysis and the analysis proceeds to the second phase.

The second phase consists of evaluating the cost effectiveness of the proposed action against a standard (currently $\$ 1000 /$ person-rem). ${ }^{3}$ If there are several alternatives that meet the cost-effectiveness criterion, the analysis usually indicates the most cost-beneficial alternative.

\section{B.4.2.4 Quality Assurance and Review}

It is recommended that, for each issue, a review be performed on the technical findings and proposed issue resolution. This review should be performed by a person knowledgeable in PRA practice, a person knowledgeable in plant systems, a person hnowledgeable in the specific technical area appropriate to the issue (If a specific discipline other than plant systems is involved), the individual who first identified the issue (or a representative of the organizational unit who identifled the issue), and a representative of the organizational unit that would be responsible for implementing the resolution of the issue. This review should then be attached to the

\footnotetext{
3 This standard is currently under reevaluation by the staff.
} 
documentation of the issue and accompany this documentation through all concurrences and any additional reviews the indlvidual NRC offlces may require.

The review should, at minimum, cover the following areas:

- The definition of the issue. This definition should be clear, and the individual or group who identlfied the issue should agree that this definition completely encompasses the issue.

- The selection of the systems, components, or procedures affected by the issue.

- The selection and Justification of the base PRA, if a base PRA is used.

- The manner in which the issue is incorporated into the base PRA. Specifically, the review should examine which parameters are affected by the issue and how these parameters are modified.

- The limitations of the base PRA models in addressing the issue.

- Any new PRA models. That is, if new fault or event trees were constructed to address the issue, they should be revlewed.

- The selection and justiflcation of fallure data, other than that already included in the base PRA, if used. This revlew should include uncertainty distributions and parameters and any common cause fallure data, including source, applicability, and model.

- The dominant affected accident sequences. These should be described in sufficlent detail to permit a qualitative understanding of the anaiysis and its result (sanity check).

- The cost analysis, including both the cost to the industry and the cost to the NRC.

- The context of the issue in the total safety profile of the plant. Speciflcally, the review should ensure that all potentlal mitigative actions have been credited. In addition, the review should ensure that negative effects (e.g., accident scenarios that increase in frequency or consequences because of fixing the issue) have not been ignored. 
Appendix B

\section{REFERENCES FOR APPENDIX B}

B.1 NRC, "Probabilistic Risk Assessment (PRA) Technology Transfer Program," September 1992.

B.2 NRC, "Standard Review Plan," NUREG-0800 (updated periodically).

B.3 R. Travis et al., "Generic Risk Insights for Westinghouse and Combustion Engineering Pressurized Water Reactors," NUREG/CR-5637 (Brookhaven National Laboratory, BNL-NUREG-52260), NRC, November 1990.

B.4 R. Travis, J. Taylor, and J. Chung, "Generic Risk Insights for General Electric Boiling Water Reactors," NUREG/CR-5692 (Brookhaven National Laboratory, BNL-NUREG-52282), NRC, May 1991.

B.5 T.V. Vo et al., "PRA Applications Program for Inspection at Arkansas Nuclear One Unit 1," NUREG/CR-5058 (Pacific Northwest Laboratory, PNL-6394), March 1988.

B.6 A. Fresco et al., "Brunswick Steam Electric Plant Unit 2 Risk-Based Inspection Guide," Brookhaven National Laboratory, A-3872-T4, Rev. 1, November 1989.

B.7 T.V. Vo et al., "PRA Applications Program for Inspection at Calvert Cliffs Unit 1 Nuclear Power Plant," NUREG/CR-5187 (Pacific Northwest Laboratory, PNL-6574), June 1989.

B.8 B.W. Smith et al., "Risk-Based Inspection Guide for Crystal River Unit 3 Nuclear Power Plant," NUREG/CR5467 (Pacific Northwest Laboratory, PNL-7108), June 1991.

B.9 J. Usher and A. Fresco, "Grand Gulf Nuclear Station Unit 1 Probabilistic Risk Assessm nt-Based System Inspection Plans," Brookhaven National Laboratory, A-3453-87-5, Rev. 0, September 1987.

B.10 R.E. Gregg et al., "PRA Applications Program for Inspection at the Haddam Neck Nuclear Power Station, Draft Report," EG\&G Idaho, Inc., EGG-REQ-7601, March 1987.

B.11 M.F. Hinton and R.E. Wright, "Pilot PRA Applications Program for Inspection at Indian Point 2," EG\&G Idaho, Inc., EGG-EA-7136, Rev. 2, February 1987.

B.12 A. Fresco et al., "Indian Point Unit 3 Probabilistic Safety Study-Based System Inspection Plans," Brookhaven National Laboratory, A-3453-3-87 (-1), Rev. 0, March 1987.

B.13 A. Fresco et al., "Limerick Generating Station Unit 1 Probabilistic Risk Assessment-Based System Inspection Plans," Brookhaven National Laboratory, A-3453-3-87 (-2), Rev. 0, March 1987.

B.14 J. Higgins et al., "'Draft' Millstone Nuclear Power Station Unit 1 Probabilistic Risk Assessment-Based System Inspection Plans," Brookhaven National Laboratory, A-3453-2-87, March 1987.

B.15 R.E. Gregg and R.E. Wright, "PRA Applications Program for Inspection at Millstone, Unit 3, Draft Report," EG\&G Idaho, Inc., EGG-SSRE-8016, March 1988.

B.16 B.F. Gore et al., "PRA Application Program for Inspection at Oconee Unit 3," NUREG/CR-5006 (Pacific Northwest Laboratories, PNL-6291), October 1987.

B.17 J. Usher and E. MacDougall, "Peach Bottom Atomic Power Station Unit 2 Probabilistic Risk Assessment-Based System Inspection Plan," Brookhaven National Laboratory, A-3864-2, Rev. 0, April 1988.

- Copies are available for inspection or copying for a fee from the NRC Public Document Room. 
B.18 M.F. Hinton and R.E. Wright, "PRA Applications Program for Inspection at Seabrook Station, Draft Report," EG\&G Idaho, Inc., EGG-EA-7194, Rev. 1, February 1987.

B.19 R.E. Gregg, "Risk-Based Inspection Guide for the Sequoyah Nuclear Power Station," EGG-SSRE-8720, EG\&G Idaho, Inc., November 1989.

B.20 R.E. Gregg et al., "PRA Applications Program for Inspection at the Surry Nuclear Power Station, Unit 1, Draft Report," EG\&G Idaho, Inc., EGG-REQ-7746, July 1987.

B.21 D.G. Harrison et al., "Risk-Based Inspection Guide for Three Mile Island Nuclear Station Unit 1," NUREG/CR-5488 (Pacific Northwest Laboratory, PNL-7187), February 1993.

B.22 A. Fresco, "Risk-Based Inspection Guide (RIG) for the Trojan Nuclear Plant," Brookhaven National Laboratory, A-3875-T2B, Rev. 1, December 1990.

B.23 W. Shier, "Risk-Based Inspection Guide (RIG) for the Vogtle Electric Generating Plant," Brookhaven National Laboratory, A-3875-T2D, Rev. 1, December 1990.

B.24 A. Fresco and W. Shier, "Risk-Based Inspection Guide (RIG) for the Wolf Creek Generating Station," Brookhaven National Laboratory, A-3875-T2C, Rev. 1, December 1990.

B.25 R.E. Gregg, "Risk-Based Inspection Guide for the Yankee Rowe Nuclear Power Station, Final Report," EG\&G Idaho, Inc., EGG-SSRE-8257, May 1990.

B.26 C.L. Atwood et al., "PRA Applications Program for Inspection at the Zion Nuclear Power Station, Draft Report," EG\&G Idaho, Inc., EGG-EA-7304, June 1986.

B.27 R. Pugh et al., "Emergency Feedwater System Risk-Based Inspection Guide for the Arkansas Nuclear One Unit 2 Power Plant," NUREG/CR-5828 (Pacific Northwest Laboratory, PNL-7727), September 1992.

B.28 N.E. Moffitt, B.F. Gore, and T.V. Vo, "Auxiliary Feedwater System Risk-Based Inspection Guide for the Byron and Braidwood Nuclear Power Plants," NUREG/CR-4427 (Pacific Northwest Laboratory, PNL-7492), July 1991.

B.29 N.E. Moffitt, B.F. Gore, and T.V. Vo, "Auxiliary Feedwater System Risk-Based Inspection Guide for the Callaway Nuclear Power Plant," NUREG/CR-5763 (Pacific Northwest Laboratory, PNL-7725), August 1991.

B.30 N.E. Moffitt et al., "Auxiliary Feedwater System Risk-Based Inspection Guide for the Catawba Nuclear Power Plant," NUREG/CR-5827 (Pacific Northwest Laboratory, PNL-7726), September 1992.

B.31 R.C. Lloyd et al., "Auxiliary Feedwater System Risk-Based Inspection Guide for the Comanche Peak Nuclear Power Plant," NUREG/CR-5831 (Pacific Northwest Laboratory, PNL-7783), October 1992.

B.32 R.C. Lloyd et al., "Auxiliary Feedwater System Risk-Based Inspection Guide for the D. C. Cook Nuclear Power Plant," NUREG/CR-5832 (Pacific Northwest Laboratory, PNL-7782), October 1992.

B.33 B.F. Gore, T.V. Vo, and D.G. Harrison, "Auxiliary Feedwater System Risk-Based Inspection Guide for the Diablo Canyon Unit 1 Nuclear Power Plant," NUREG/CR-5616 (Pacific Northwest Laboratory, PNL-7351), August 1990.

B.34 T.V. Vo et al., "Auxiliary Feedwater System Risk-Based Inspection Guide for the J.M. Farley Nuclear Power Plant," "JREG/CR-5617 (Pacific Northwest Laboratory, PNL-7349), October 1990.

B.35 R. Pugh et al., "Auxiliary Feedwater System Risk-Based Inspection Guide for the Ginna Nuclear Power Plant," NUREG/Cit-5764 (Pacific Northwest Laboratory, PNL-7594), September 1991. 
Appendix B

B.36 R.C. Lloyd et al., "Auxiliary Feedwater System Risk-Based Inspection Guide for the Kewaunee Nuclear Power Plant," NUREG/CR-5821 (Pacific Northwest Laboratory, PNL-7724), April 1992.

B.37 B.F. Gore et al., "Auxiliary Feedwater System Risk-Based inspection Guide for the Maine Yankee Nuclear Power Plant," NUREG/CR-5826 (Pacific Northwest Laboratory, PNL-7654), October 1992.

B.38 J.R. Nickolaus et al., "Auxiliary Feedwater System Risk-Based Inspection Guide fur the North Anna Nuclear Power Plants," NUREG/CR-5837 (Pacific Northwest Laboratory, PNL-7923), October 1992.

B.39 N.E. Moffitt, B. F. Gore, T.V. Vo, "Auxiliary Feedwater System Risk-Based Inspection Guide for the Prairie Island Units 1 and 2 Nuclear Power Plants," NUREG/CR-5839 (Pacific Northwest Laboratory, PNL-7605), October 1992.

B.40 R. Pugh, B.F. Gore, T.V. Vo, "Auxiliary Feedwater System Risk-Based Inspection Guide for the Salem Nuclear Power Plant," NUREG/CR-5761 (Pacific Northwest Laboratory, PNL-7518), August 1991.

B.41 R. Pugh, B.F. Gore, T.V. Vo, "Auxiliary Feedwater System Risk-Based Inspection Guide for the St. Lucie Unit 1 Nuclear Power Generationi Station," NUREG/CR-5896 (Pacific Northwest Laboratory, PNL-8102), August 1992.

B.42 R.C. Lloyd et al., "Auxiliary Feedwater System Risk-Based Inspection Guide for the Virgil C. Summer Nuclear Power Plant," NUREG/CR-5838 (Pacific Northwest Laboratory, PNL-7924), September 1992.

B.43 N.E. Moffitt, B.F. Gore, T.V. Vo, "Auxiliary Feedwater System Risk-Based Inspection Guide for the Turkey Point Nuclear Power Plant," NUREG/CR-5633 (Pacific Northwest Laboratory, PNL 7454), April 1992.

B.44 W. Shier and W. Gunther, "High Pressure Coolant Injection (HPCI) System Risk-Based Inspection Guide, Pilgrim Nuclear Power Station," NUREG/CR-5924 (Brookhaven National Laboratory, BNL-NUREG-52339), October 1992.

B.45 M.A. Stewart and C.L. Smith, "Generic Service Water System Risk-Based Inspection Guide," NUREG/CR5865 (EG\&G Idaho, Inc., EGG-2674), May 1992.

B.46 NRC, "Individual Plant Examination for Severe Accident Vulnerabilities," Generic Letter No. 88-20, November 23, 1988."

B.47 J. W. Minarick et al., "Precursors to Potential Severe Core Damage Accidents: 1991, A Status Report," NUREG/CR-4674, Volume 16, NRC, September 1992.

B.48 R. Emrit et al., "A Prioritization of Generic Safety Issues," NUREG-0933, Main Report and Supplements 1-12, NRC, July 1991.

B.49 K.D. Russell et al., "Integrated Reliability and Risk Analysis System (IRRAS) Version 4.0. Reference Manual," NUREG/CR-5813, Vol. 1 (EGG-2664), NRC, January 1992.

B.50 Commission paper from James M. Taylor, EDO, to the Commissioners, "Regulatory Analysis Guidelines of the U.S. Nuclear Regulatory Commission," SECY-93-043, February 22, 1993."

B.51 NRC, "Regulatory Analysis Technical Evaluation Handbook," NUREG/BR-0184, Draft Report, August 1993.

B.52 NRC, "Severe Accident Research Program Plan Update," NUREG-1365, Rev. 1, December 1992.

- Copies are available for inspection or copying for a fee from the NRC Public Document Room. 
B.53 T. Theofanous et al., "The Probability of Liner Failure in a Mark I Containment," NUREG/CR-5423 (University of California - Santa Barbara), NRC, August 1991.

B.54 NRC, "Severe Accident Risks: An Assessment for Five U.S. Nuclear Power Plants," NUREG-1150, Volumes 1 and 2, December 1990.

B.55 NRC, "Reactor Safety Study--An Assessment of Accident Risks in U.S. Commercial Nuclear Power Plants," WASH-1400 (NUREG-75/014), October 1975.

B.56 J. W. Hickman, "PRA Procedures Guide. A Guide to the Performance of Probabilistic Risk Assessments for Nuclear Power Plants," NUREG/CR-2300, Volumes 1 and 2, January 1983.

B.57 T-L Chu et al., "PWR Low Power and Shutdown Accident Frequencies Program: Phase 1 - Coarse Screening Analysis," Brookhaven National Laboratory, November 1991."

B.58 NRC, "Individual Plant Examination: Submittal Guidance," NUREG-1335, August 1989.

B.59 G.J. Kolb et al., "Reactor Safety Study Methodology Applications Program: Oconee No. 3 PWR Power Plant," NUREG/CR-1659, Vol. 2, Revision 1, May 1981.

B.60 S. Hatch et al., "Reactor Safety Study Methodology Applications Program: Grand Gulf No. 1 BWR Power Plant," NUREG/CR-1659, Vol. 4, November 1981.

B.61 Commission Paper, "Plan for Early Resolution of Safety Issues," SECY-81-513, August 25, 1981."

B.62 K. D. Russell et al., "System Analysis and Risk Assessment (SARA) System, Version 4.0, Reference Manual," NUREG/CR-5303, Vol. 1 (EGG-2628), NRC, February 1992.

B.63 NRC, "Safety Goals for the Operation of Nuclear Power Plants" (Corrections and Republication of Policy Statement), Federal Register, Vol. 51, pp. 30028-30033, August 21, 1986.

B.64 NRC, "Regulatory Analysis Guidelines of the U. S. Nuclear Regulatory Commission," NUREG/BR-0058, Rev. 2, Draft Report for Comment, August 1993.

- Copies are available for inspection or copying for a fee from the NRC Public Document Room. 


\section{Appendix C}

Guidance on PRA Terms and Methods 


\section{CONTENTS}

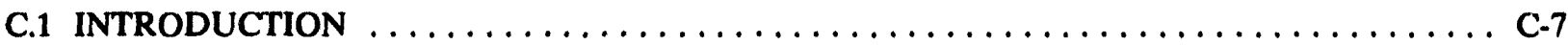

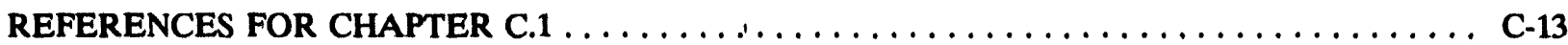

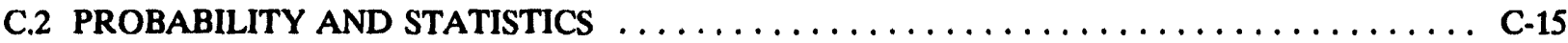

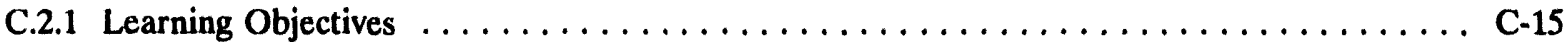

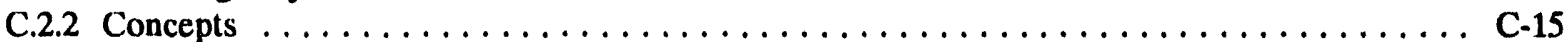

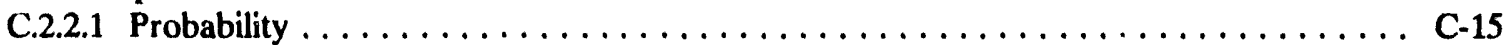

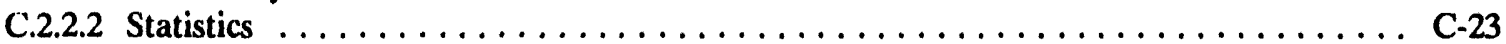

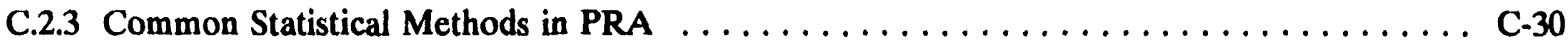

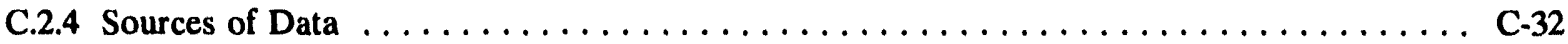

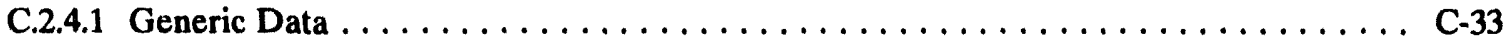

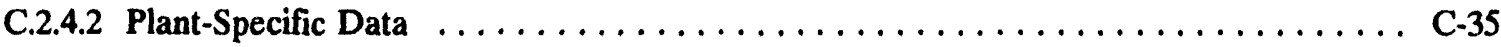

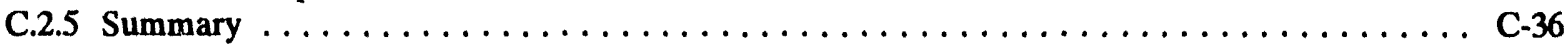

REFERENCES FOR CHAPTER $C .2 \ldots \ldots \ldots \ldots \ldots \ldots \ldots \ldots \ldots \ldots \ldots \ldots \ldots$

C.3 ACCIDENT SEQUENCE AND RELIABILITY ANALYSES $\ldots \ldots \ldots \ldots \ldots \ldots \ldots \ldots$ C-41

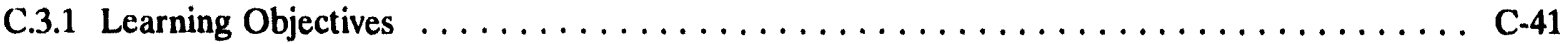

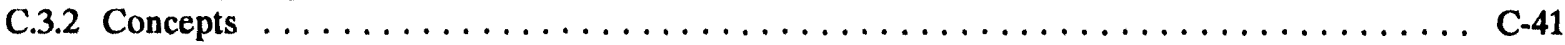

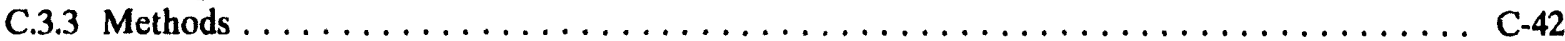

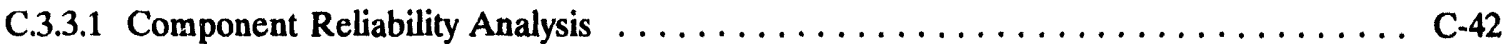

C.3.3.2 System Reliability Analysis $\ldots \ldots \ldots \ldots \ldots \ldots \ldots \ldots \ldots \ldots \ldots \ldots \ldots \ldots \ldots \ldots$ C-44

C.3.3.3 Accident Sequence Analysis . . . . . . . . . . . . . . . . . . . . . . C-49

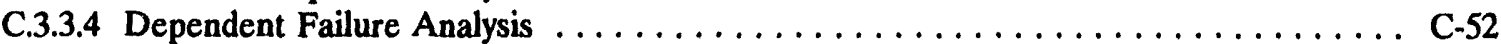

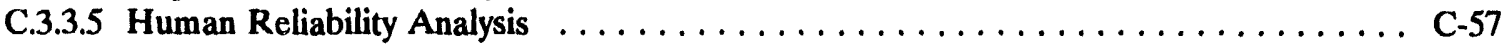

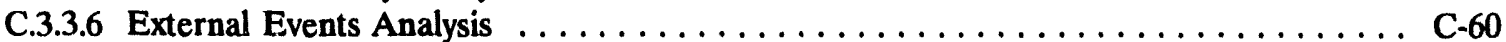

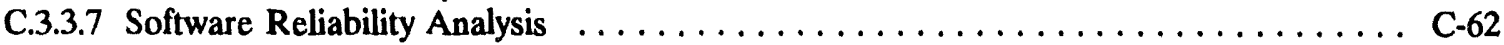

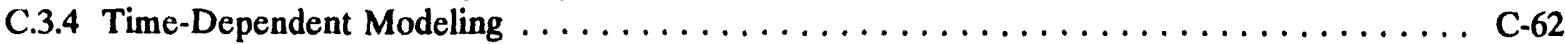

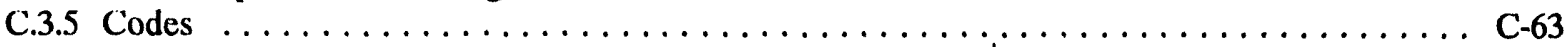

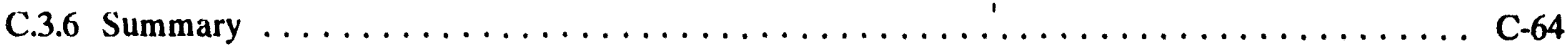

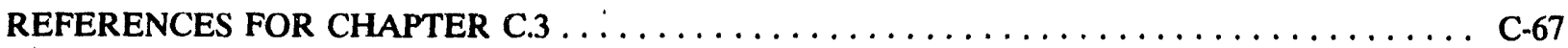

C.4 ACCIDENT PROGRESSION AND RISK ANALYSES $\ldots \ldots \ldots \ldots \ldots \ldots \ldots \ldots \ldots \ldots$ C-73

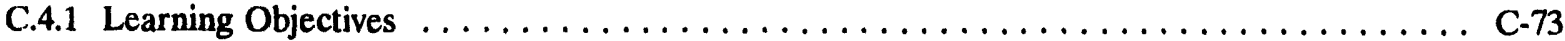

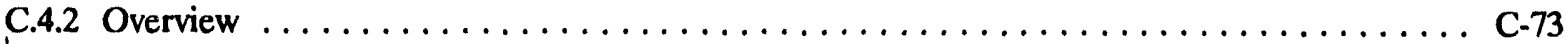

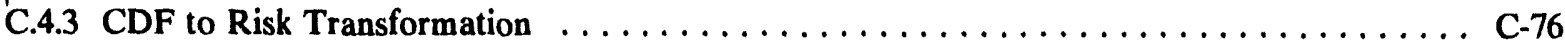

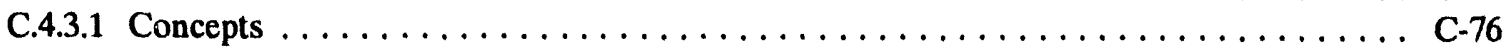

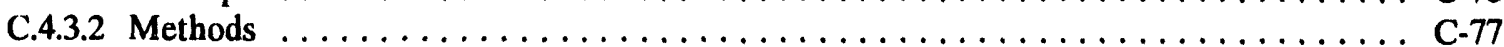

C.4.3.3 Application to Future Plant Designs $\ldots \ldots \ldots \ldots \ldots \ldots \ldots \ldots \ldots \ldots \ldots$ C -83

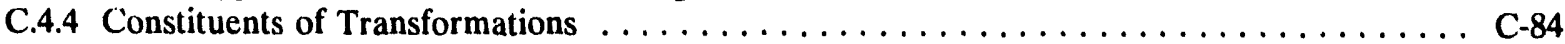

C.4.4.1 Accident Progression Analysis $\ldots \ldots \ldots \ldots \ldots \ldots \ldots \ldots \ldots \ldots \ldots \ldots \ldots \ldots$ C-84

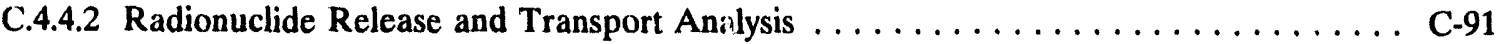

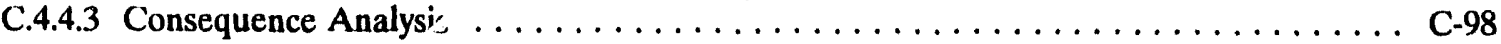

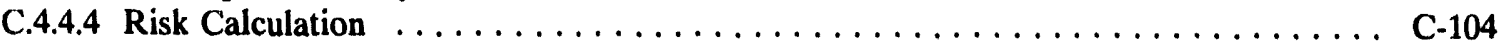

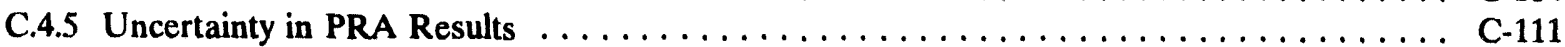

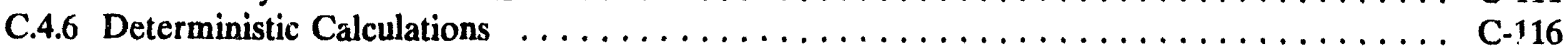




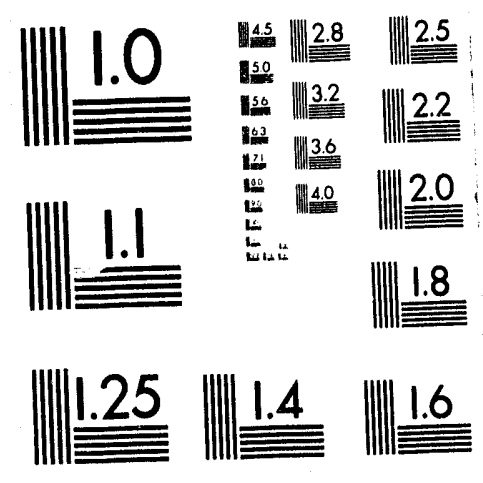



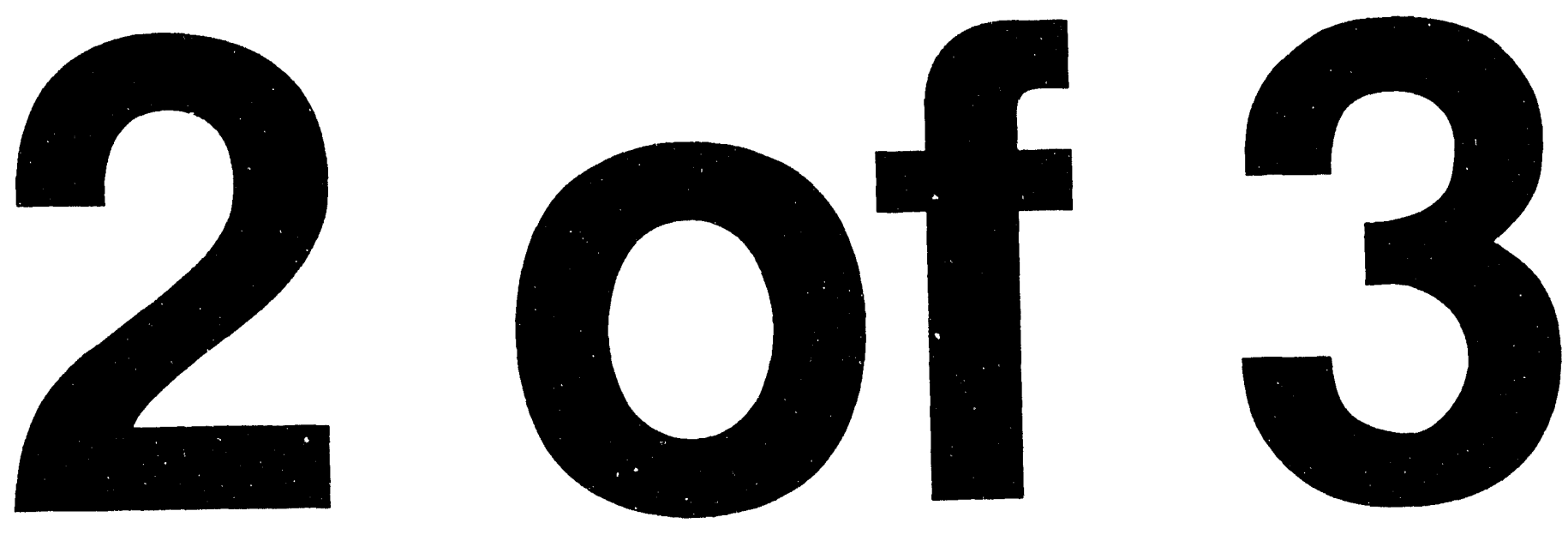


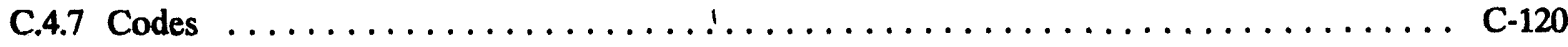

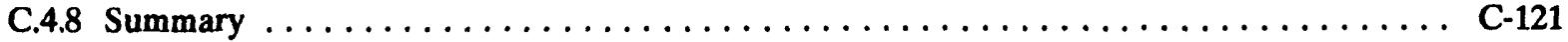

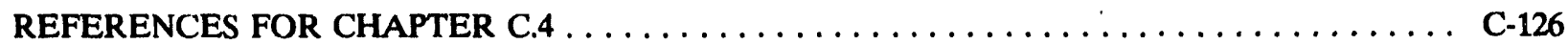

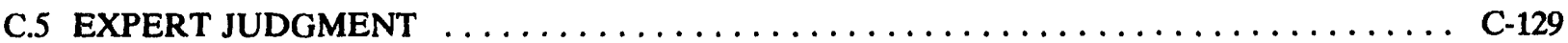

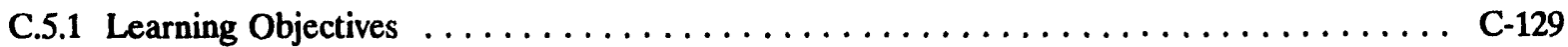

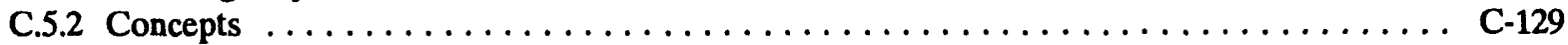

C.5.3 Formal Use of Expert Judgment $\ldots \ldots \ldots \ldots \ldots \ldots \ldots \ldots \ldots \ldots \ldots \ldots \ldots \ldots$ C-130

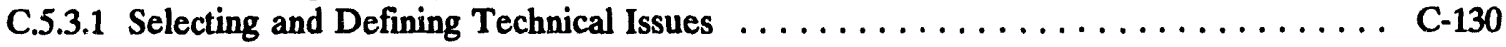

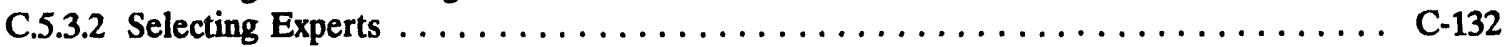

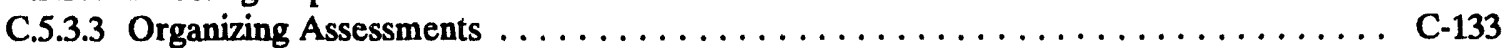

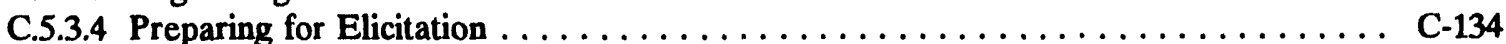

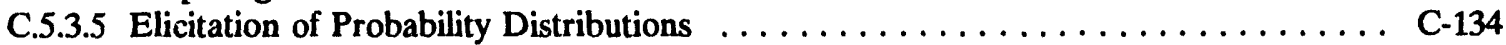

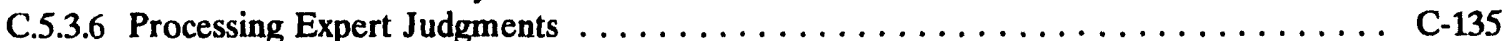

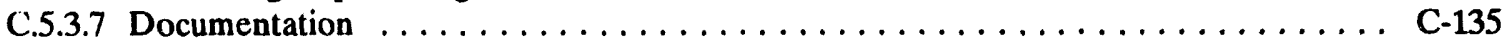

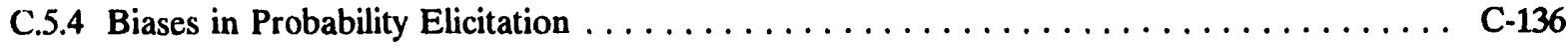

C.5.5 Evaluating the Quality of Judgments $\ldots \ldots \ldots \ldots \ldots \ldots \ldots \ldots \ldots \ldots \ldots \ldots \ldots \ldots \ldots \ldots \ldots$

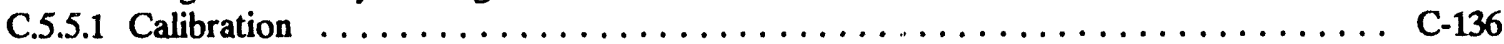

C.5.5.2 Refinement . . . . . . . . . . . . . . . . . . . . . . . . . . C-139

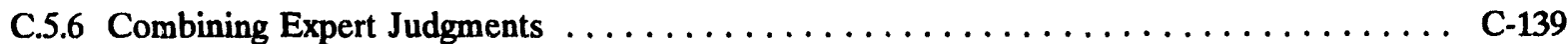

C.5.7 Advantages, Disadvantages, and Cautions $\ldots \ldots \ldots \ldots \ldots \ldots \ldots \ldots \ldots \ldots$ C-142

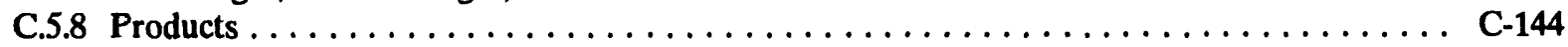

C.5.9 Summary $\ldots \ldots \ldots \ldots \ldots \ldots \ldots \ldots \ldots \ldots \ldots \ldots \ldots \ldots \ldots \ldots \ldots \ldots \ldots \ldots \ldots \ldots \ldots \ldots, 144$

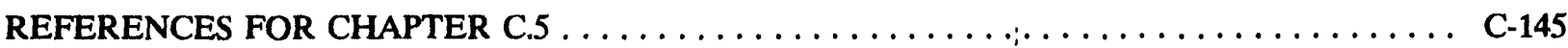

C.6 UNCERTAINTY AND SENSITIVITY ANALYSES $\ldots \ldots \ldots \ldots \ldots \ldots \ldots \ldots \ldots \ldots$ C-149

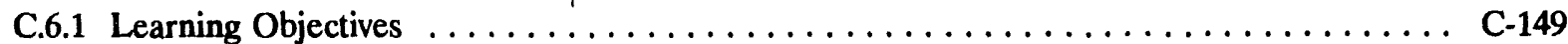

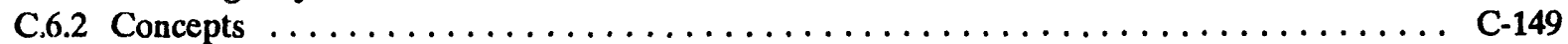

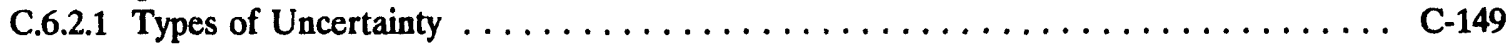

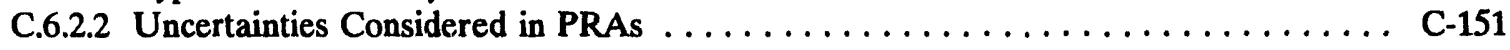

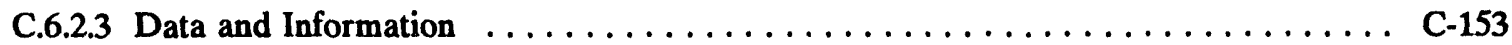

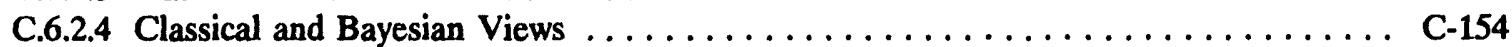

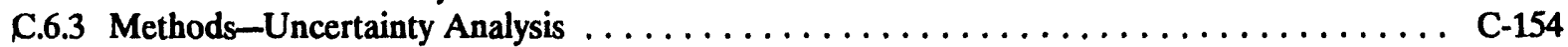

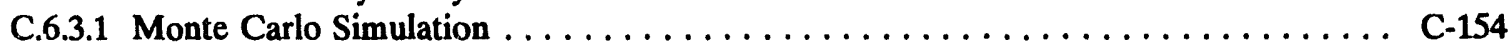

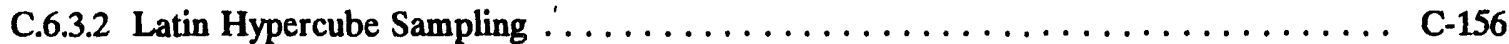

C.6.3.3 Other Uncertainty Analysis Methods $\ldots \ldots \ldots \ldots \ldots \ldots \ldots \ldots \ldots \ldots \ldots \ldots \ldots$

C.6.4 Display and Interpretation of Uncertainties $\ldots \ldots \ldots \ldots \ldots \ldots \ldots \ldots \ldots \ldots \ldots \ldots \ldots$ C-159

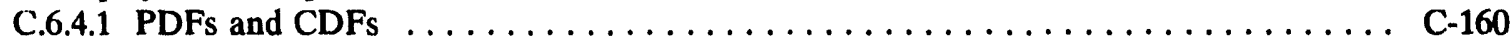

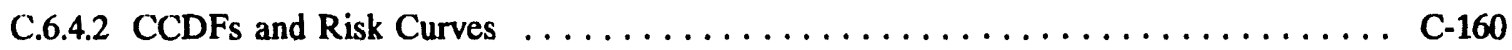

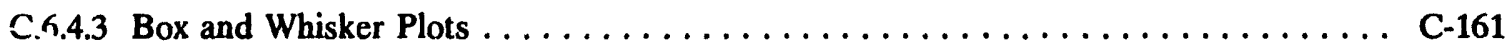

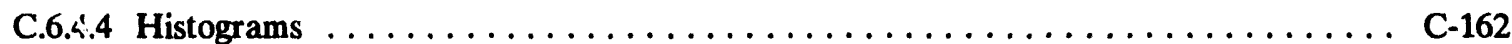

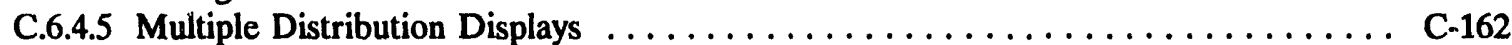

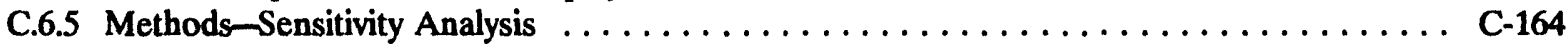

C.6.5.1 Risk Reduction Importance Measure $\ldots \ldots \ldots \ldots \ldots \ldots \ldots \ldots \ldots \ldots \ldots \ldots \ldots \ldots$

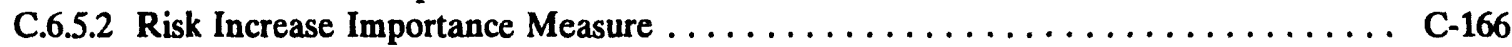

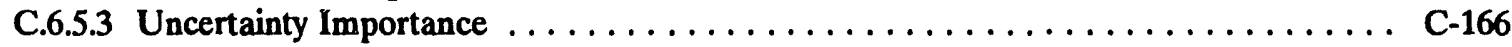

C.6.5.4 Birnbaum's Structural Importance Measure $\ldots \ldots \ldots \ldots \ldots \ldots \ldots \ldots \ldots$ C-166

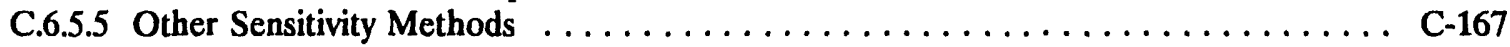

C.6.6 Selecting Variables for an Uncertainty Analysis $\ldots \ldots \ldots \ldots \ldots \ldots \ldots \ldots \ldots \ldots$ C-167

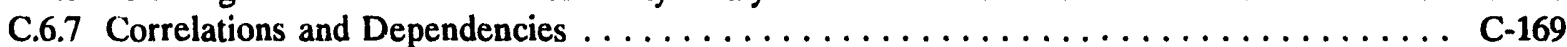


C.6.8 Completeness . . . . . . . . . . . . . . . . . . . . . . . . . . . . . . C-169

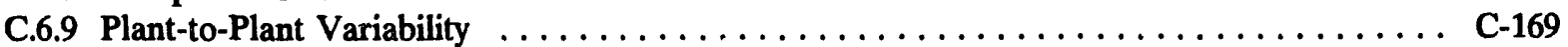

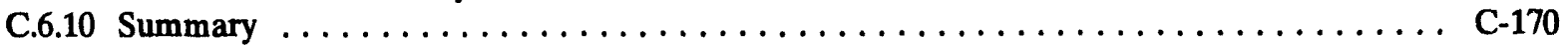

REFERENCES FOR CHAPTER C.6 $\ldots \ldots \ldots \ldots \ldots \ldots \ldots \ldots \ldots \ldots \ldots \ldots \ldots \ldots \ldots \ldots \ldots \ldots \ldots$

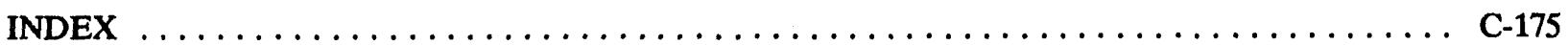

\section{FIGURES}

C.1.1 Effect of differing assumptions on PRA results $\ldots \ldots \ldots \ldots \ldots \ldots \ldots \ldots \ldots \ldots \ldots$

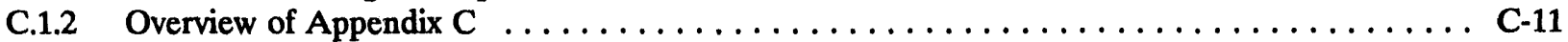

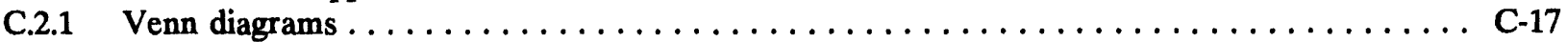

C.2.2 Probability distribution and density function and corresponding cumulative distribution

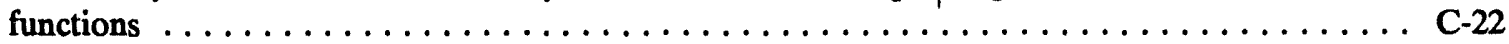

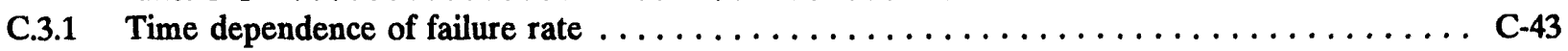

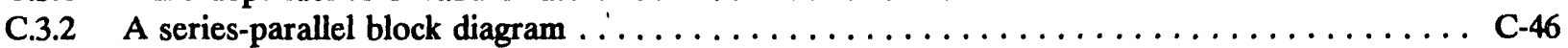

C.3.3 Fault tree for a simple warning system $\ldots \ldots \ldots \ldots \ldots \ldots \ldots \ldots \ldots \ldots \ldots \ldots \ldots$ C-47

C.3.4 Example of event tree analysis with fault trees $\ldots \ldots \ldots \ldots \ldots \ldots \ldots \ldots \ldots \ldots$ C-50

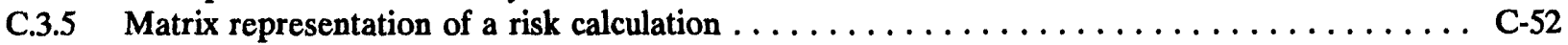

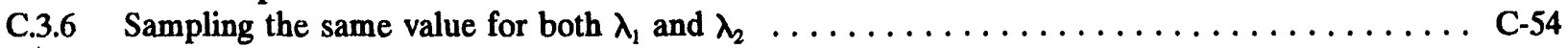

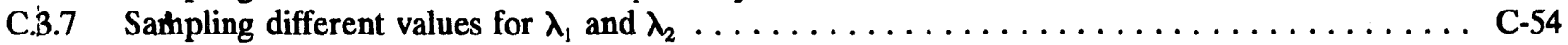

C.3.8 Time reliability correlation (TRC) curve $\ldots \ldots \ldots \ldots \ldots \ldots \ldots \ldots \ldots \ldots \ldots \ldots \ldots$ C-58

C.3.9 Seismic hazard curves for a hypothetical site $\ldots \ldots \ldots \ldots \ldots \ldots \ldots \ldots \ldots \ldots \ldots \ldots$ C-61

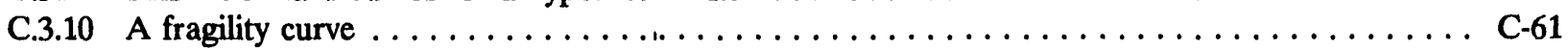

C.4.1 Overview of the discussions on CDF to risk transformations $\ldots \ldots \ldots \ldots \ldots \ldots \ldots \ldots$ C-75

C.4.2 Exceedance frequency curves $\ldots \ldots \ldots \ldots \ldots \ldots \ldots \ldots \ldots \ldots \ldots \ldots \ldots$

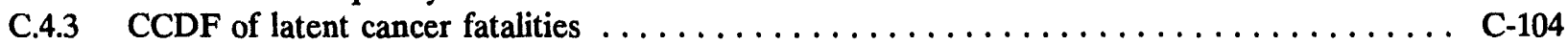

C.4.4 Illustration of aggregate risk and the expected value of aggregate risk $\ldots \ldots \ldots \ldots \ldots \ldots$ C-108

C.4.5 Overview of risk calculations as done in the NUREG-1150 study $\ldots \ldots \ldots \ldots \ldots \ldots \ldots$ C-110

C.4.6 Distribution of risk estimates, $R_{m}$, made with differing sets of inputs selected by

Monte Carlo sampling . .............................. C-111

C.4.7 Comparing a PRA risk estimate to a safety goal $\ldots \ldots \ldots \ldots \ldots \ldots \ldots \ldots \ldots \ldots$ C-114

C.4.8 Comparison of risk distributions from the NUREG-1150 study $\ldots \ldots \ldots \ldots \ldots \ldots \ldots$ C-115

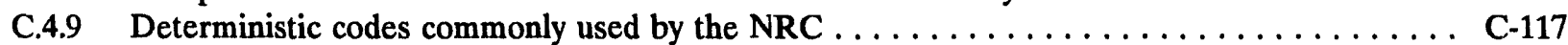

C.5.1 Expert-supplied probabilities of containment failure pressure $\ldots \ldots \ldots \ldots \ldots \ldots \ldots \ldots$ C-132

C.5.2 Probability of precipitation forecasts versus observed relative frequency of precipitation . . . C C-137

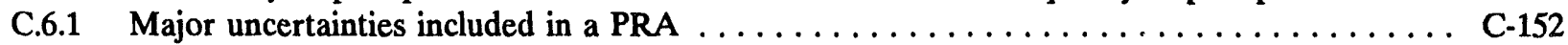

C.6.2 Output distribution from a Monte Carlo sampie $\ldots \ldots \ldots \ldots \ldots \ldots \ldots \ldots \ldots \ldots$ C-155

C.6.3 Selection of intervals for Latin Hypercube sampling $\ldots \ldots \ldots \ldots \ldots \ldots \ldots \ldots \ldots \ldots$ C-157

C.6.4 Risk curve from a Monte Carlo sample $\ldots \ldots \ldots \ldots \ldots \ldots \ldots \ldots \ldots \ldots \ldots \ldots \ldots$ C-161

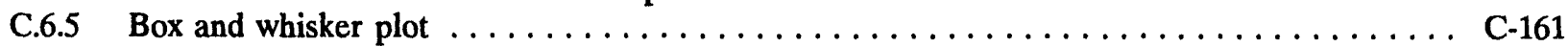

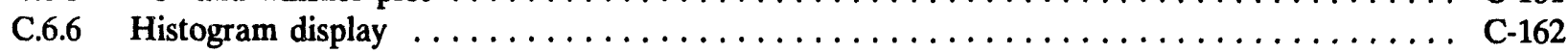

C.6.7 Uncertainty in time-dependent recovery $\ldots \ldots \ldots \ldots \ldots \ldots \ldots \ldots \ldots \ldots \ldots \ldots \ldots$ C-163

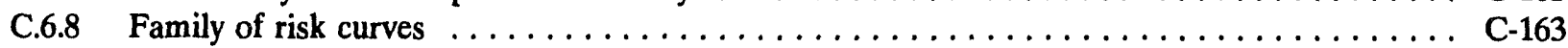

C.6.9 Quantiles about a risk curve $\ldots \ldots \ldots \ldots \ldots \ldots \ldots \ldots \ldots \ldots \ldots \ldots \ldots \ldots \ldots \ldots \ldots$ 


\section{TABLES}

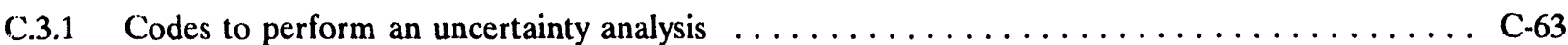

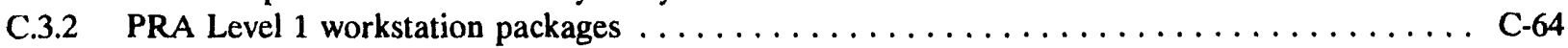

C.3.3 Codes to perform a fault tree analysis $\ldots \ldots \ldots \ldots \ldots \ldots \ldots \ldots \ldots \ldots \ldots \ldots \ldots \ldots$ C-65

C.4.1 Population doses within 50 miles of the Surry reactor $\ldots \ldots \ldots \ldots \ldots \ldots \ldots \ldots \ldots$ C-80

C.4.2 Isotopes in the release classes from the NUREG-1150 study $\ldots \ldots \ldots \ldots \ldots \ldots \ldots \ldots$ C-93

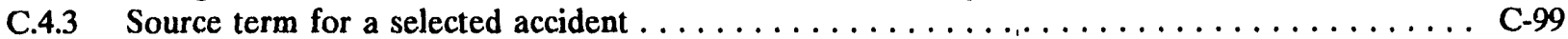

C.4.4 Consequence measures reported in the NUREG-1150 study $\ldots \ldots \ldots \ldots \ldots \ldots \ldots \ldots$ C-103

C.4.5 Hypothetical risk triplets collapsed into aggregate risk $\ldots \ldots \ldots \ldots \ldots \ldots \ldots \ldots \ldots$ C-106

C.4.6 Comparison of aggregate risk and mean aggregate risk $\ldots \ldots \ldots \ldots \ldots \ldots \ldots \ldots \ldots$ C-107

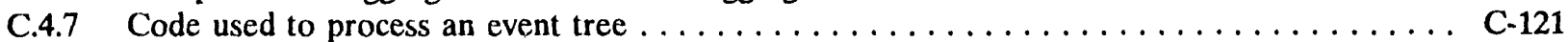

C.4.8 Major deterministic codes used at the NRC in support of an accident progression analysis . . C-122

C.4.9 Domestic codes used in consequence assessments $\ldots \ldots \ldots \ldots \ldots \ldots \ldots \ldots \ldots \ldots$ C-123

C.4.10 Consequence codes used by the European Community .................. C-124

C.5.1 Comparison of data and expert opinion on the distribution of component maintenance time . C-138 


\section{C.1 Introduction}

\section{C.1 INTRODUCTION}

Probabilistic risk assessment (PRA) is used by the NRC staff as an important element of its licensing and regulatory processes. PRA has been found by the staff to be a systematic method for incorporating realistic information on the design and operation of a facility into a logical and integrated model. Using this model, both the overall reliability and risk of the facility, as well as the relative importance of components, human actions and errors, and potential accident initiators, can be estimated.

The performance and use of risk assessments requires skills in many disciplines, including knowledge of the facility, risk assessment methods (including statistics and probability, component reliability analysis, human factors and reliability analysis, accident analysis, atmospheric dispersion sciences, and health physics), and risk management (decision making) policies. Hence, Appendix $\mathrm{C}$ was written by several authors from outside of the NRC with substantial support from the NRC staff. As the sections were developed, text was exchanged and critiqued among all of the authors with relevant expertise.

Principal authors

- Chapter C.2, Probability and Statistics. Dr. Harry Martz, Statistics Group, Los Alamos National Laboratory

- Chapter C.3, Accident Sequence and Reliability Analysis. Prof. George Apostolakis, Department of Mechanical, Aerospace, and Nuclear Engineering, University of California, Los Angeles

- Chapter C.4, Accident Progression and Risk Analysis. Thomas Brown, Department of Accident Analysis and Consequence Assessment, Sandia National Laboratories, and Christopher Ryder, Probabilistic Risk Analysis Branch, U. S. Nuclear Regulatory Commission.

- Chapter C.5, Expert Judgment. Dr. Stephen Hora, Department of Business and Economics, University of Hawaii, Hilo, and Prof. George Apostolakis, Department of Mechanical, Aerospace, and Nuclear Engineering, University of California, Los Angeles

- Chapter C.6, Uncertainty and Sensitivity Analysis. Dr. Allen Camp, Department of Reactor Systems Safety Analysis, Sandia National Laboratories

\section{NRC Staff}

- Dr. Lee Abramson, Probabilistic Risk Analysis Branch

- Dr. Dale Rasmuson, Trends and Patterns Analysis Branch

The development of the sections benefited much from the critiques of individual reviewers who met with the authors after drafts were completed:

- Dr. B. John Garrick, President, PLG, Inc.

- Dr. Bernard Harris, Professor, Department of Statistics, University of Wisconsin 
- Dr. Ralph L. Keeney, Professor, Department of Systems Management, University of Southern California

- Dr. Herbert J. C. Kouts, Defense Nuclear Facilities Safety Board.

Additional review of the discussion on expected value on page C-106 was given by Dr. Jon Helton, Arizona State University.

Since the NRC staff members using PRA will have differing combinations of skills and knowledge, a common understanding of certain fundamental concepts, terms, and methods is essential to the consistent and adequate use of risk assessment in the agency's business. The purpose of Appendix $C$ is to define terms and concepts that are essential to the correct and consistent practice of PRA. Discussions are necessarily brief to keep the appendix to a reasonable size. Other material will be needed to learn unfamiliar concepts, hence, there are frequent references throughout the text. Appendix $C$ is not a procedures guide on how to perform a PRA; it is not to be used as a replacement for the PRA procedures guide (Ref. C.1.1). With the material in Appendix $C$, the NRC staff will be able to apply many of the methods to less complex problems that occur in PRA. For more complex problems, the staff should consult with experts in the respective fields.

The aspects of PRA that are discussed in Appendix C stem from the experience of the NRC staff and its contractors in reviewing and performing risk assessments of commercial power plants. Much of this orientation stems from the NRC's first large-scale application of PRA, the Reactor Safety Study (Ref. C.1.2), the NUREG1150 study (Ref. C.1.3), the LaSalle PRA (Ref C.1.4), and a review of a PRA of an advanced plant (Ref. C.1.5). Such PRAs are much more developed than risk assessments in other important fields, such as waste disposal, fuel reprocessing, and materials safety. Although many of the concepts are relevant to the other areas of NRC, discussions in this appendix are oriented towards commercial nuclear power plants.

Appendix $\mathrm{C}$ is not oriented toward issues beyond the performance or review of a PRA, such as using PRA results in the regulatory decisionmaking process. This can be a large undertaking as a discussion on risk results suggests, given the results from a PRA. The situation the NRC staff encounters can be complicated when regulatory decisions involve several differing PRAs, such as from a vendor and an NRC contractor. Figure C.1.1 shows a case of significantly different perspectives on risk arising from differences in assumptions (Ref. C.1.5). Obviously, these views siould not be combined, but instead should be kept separate for decisionmaking. However, there are times when differing views should be combined within a PRA. The use of PRA results in the regulatory decisionmaking process and reconciliation of differing PRA results can be addressed by the techniques of formal decision analysis. However, such techniques are not being used in a formal way at the NRC, hence, guidance at this time is beyond the current work scope. For related discussions, see Section C.4.4.4 (page C-105) on aggregating risk triplets to form aggregate risk estimates and Section C.5.6 (page C-139) on combining expert judgments.

The structure of Appendix $\mathrm{C}$ is intended to facilitate its use as a reference, and it follows the general structure of the NRC staff's most recent set of large-scale PRAs found in Reference C.1.3.

- Chapter C.2 (page C-15) introduces fundamental concepts about probability and statistics that are particularly relevant to risk assessment.

- Chapter C.3 (page C-41) discusses system reliability, accident initiators, and analyses of the sequences of events that can lead to core damage.

- Chapter C.4 (page C-73) discusses the analysis of events after the onset of core damage, the release of radionuclides into the plant, the transport of radionuclides into the environment, health and economic impacts, and the calculation of risk.

NUREG-1489 

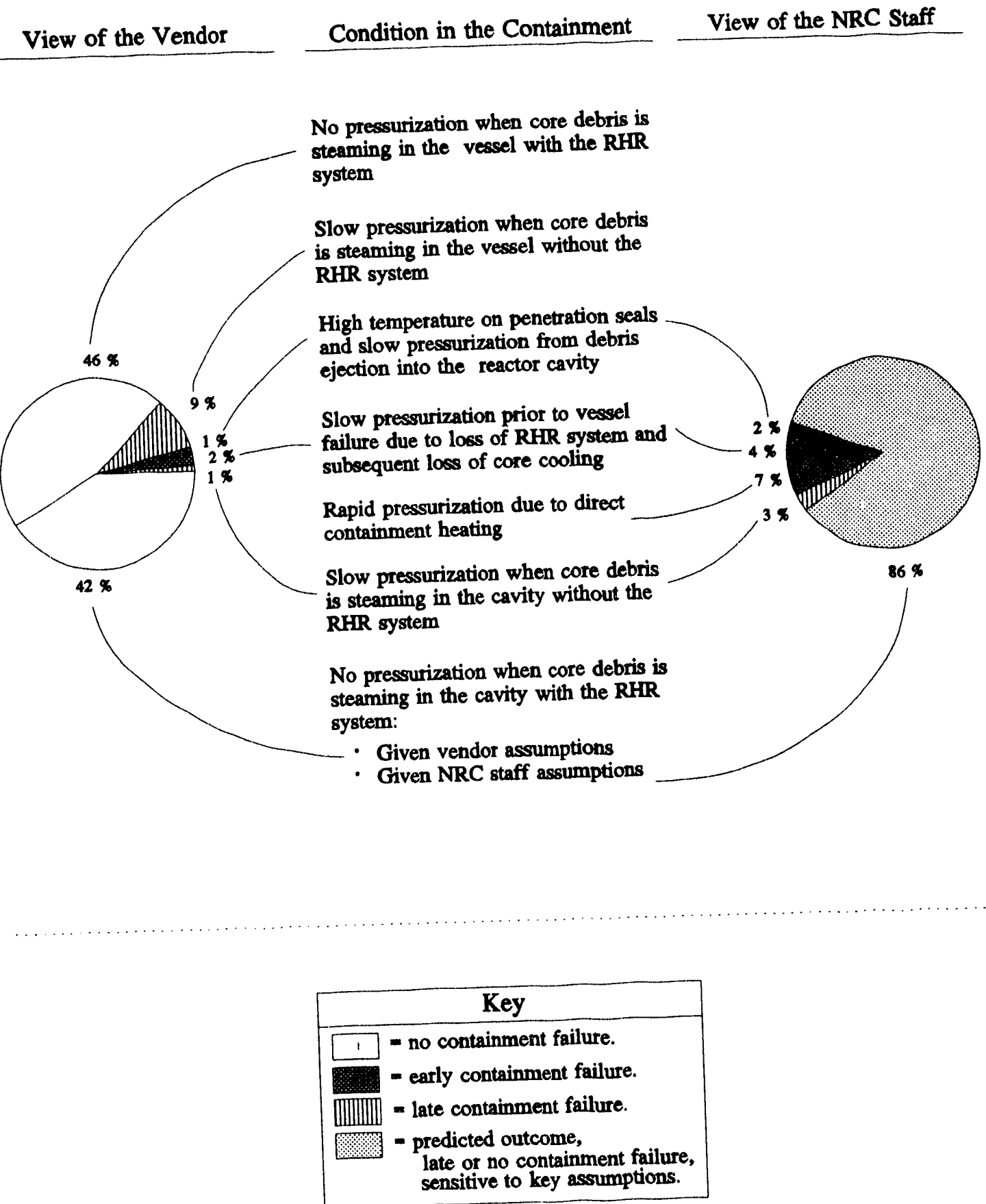

Figure C.1.1 Effect of differing assumptions on PRA results 


\section{C.1 Introduction}

- Chapter C.5 (page C-129) discusses the use of expert judgment in determining the inputs to a PRA.

- Chapter C.6 (page C-149) discusses modeling of uncertainty in PRA results and the analysis of the sensitivity of results to changes in the inputs and other aspects of a PRA.

The structure of Appendix $C$ and the relationship of the sections is shown in Figure C.1.2. ${ }^{1}$ The chapters on statistics (C.2), expert judgment (C.5), and uncertainty/sensitivity (C.6) support the main discussions of the PRA analyses, which are, for the study of commercial power reactors, the accident frequency analysis (C.3), the ' accident progression analysis (C.4.4.1), the source terms analysis (C.4.4.2), the consequence analysis (C.4.4.3), and risk calculation. The structure of Appendix $\mathrm{C}$ also parallels a definition of risk known as the risk triplet, defined as the set, $\left\langle\mathrm{s}_{\mathrm{i}}, \mathrm{f}_{\mathrm{i}}, \mathrm{x}_{\mathrm{i}}\right\rangle$, in which $s$ represents scenarios, $f$ is the frequency of that scenario, and $x$ is the consequence (Ref. C.1.6).

The format of Appendix $\mathrm{C}$ differentiates among various types of information.

- Each section begins with learning objectives, which delineate the thoughts to be discussed, and ends with a summary that complements the learning objectives.

- Key terms that are defined in the text are indicated in bold type and are indexed both where they are discussed and where they are important parts of other discussions. The index also lists some other significant terms and concepts that are not in bold type.

- Important concepts are indexed.

- Guidance is set off as indented statements in italic type.

- Examples are set off between horizontal lines and are in small type.

- References at the end of each section supplement or explain the presented material.

To the extent possible, the sections have the same structure to assist NRC staff in organizing information. Basic concepts are discussed then followed by commonly applied methods; the discussions point out advantages and disadvantages. Computer programs that are commonly seen by the NRC staff are listed.

Figure C.1.2 uses three terms that will be seen throughout Appendix C. The accident frequency analysis is also known as the Level 1 or front-end portion of a PRA. The Level 2 portion encompasses two analyses, accident progression and source terms. The Level 3 analysis is the consequence analysis; sometimes the term includes the risk calculation as well. The term back-end analysis refers to at least accident progression and source term analyses, but it can also include the consequence analysis and risk calculation.

The use of consistent terms and concepts will enhance the NRC staff's capability to review is PRA, perform various kinds of risk analyses, interpret results, and make regulatory decisions supported by PRA results. The need for the information in this appendix is evidenced by the survey in Appendix B and by other indications, such. as the following:

\footnotetext{
'This structure is based on the PRAs done by the NRC staff in NUREG-1150 (Ref. C.1.3). Other schemes, using other structures, are available as well.
}

NUREG-1489

C-10 
C.1 Introduction

Supporting Discussions
Discussions of PRA Analyses
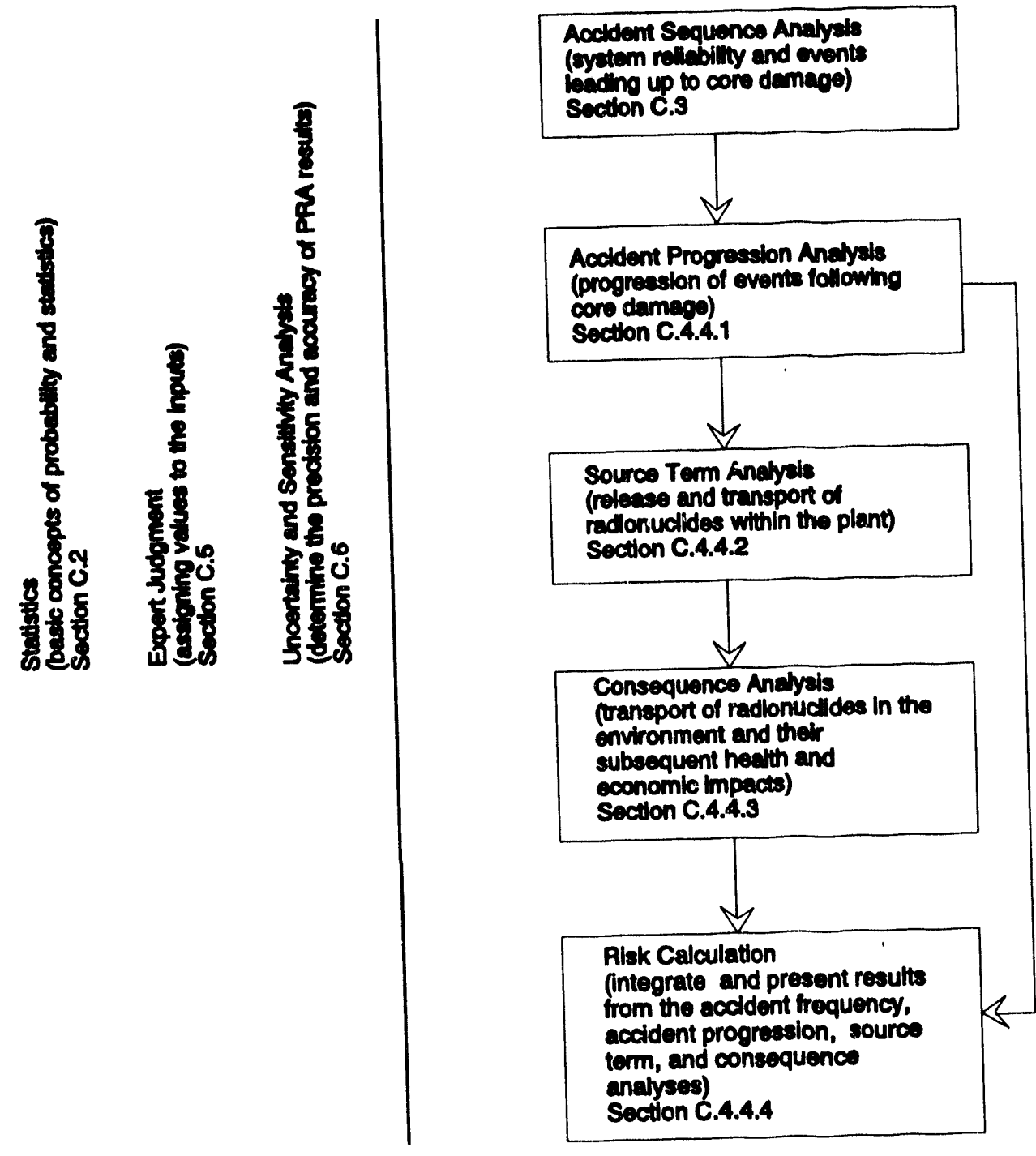

5
3
3

$\mathbf{N}$
$\mathbf{3}$
3

Accidant Prog of events following

coro damage)

source Term Anabyais

(rolease and transport o

radionuclides within the plant)

Section C.4.4.2

Risk Calculation

integrate and present results

term, and consequence

nelyses)

Section C.4.4.4

Figure C.1.2 Overview of Appendix C 
C.1 Introduction

- The NRC staff has used the term best estimate when discussing PRA results, even though the term has no precise definition. Guidance on the use of this term can be found in Chapter C.2 (see page C-24).

- The NRC staff has used the terms uncertainty and sensitivity, sometimes referring to methods of the latter when discussing the former. Terms and methods regarding the respective analyses are discussed in Chapter C.6 (see page C-149).

Although this appendix will not provide definitive answers to all the NRC staff's questions regarding PRA, it sets in place fundamental concepts needed to develop additional guidance. 
C.1 Introduction

\section{REFERENCES FOR CHAPTER C.1}

C.1.1 J. W. Hickman, "PRA Procedures Guide," NUREG/CR-2300, Volumes 1 and 2, NRC, January 1983.

C.1.2 NRC, "Reactor Safety Study - An Assessment of Accident Risks in U.S. Commercial Nuclear Power Plants," WASH-1400 (NUREG-75/014), October 1975.

C.1.3 NRC, "Severe Accident Risks: An Assessment for Five U.S. Nuclear Power Plants," NUREG-1150, December 1990.

C.1.4 T. D. Brown et al., "Integrated Risk Assessment for LaSalle Unit 2 Nuclear Power Plant: Phenomenology and Risk Uncertainty Evaluation Program," NUREG/CR-5305, Volume 1 (Sandia National Laboratories, SAND90-2765), NRC, August 1992.

C.1.5 Policy Issue, from James M. Taylor, Executive Director for Operations, to The Commissioners, "Draft Safety Evaluation Report on the General Electric Boiling Water Reactor Design Covering Chapter 19 of the Standard Review Plan, 'Response to Severe Accident Policy Statement.," SECY-91-309, NRC, September 1, 1991."

C.1.6 S. Kaplan and B. J. Garrick, "On the Quantitative Definition of Risk," Risk Analysis, Volume 1, pp. 11-27, 1981.

- Copies are available for inspection or copying for a fee in the NRC Public Document room. 


\section{C.2 PROBABILITY AND STATISTICS}

\section{C.2.1 Learning Objectives}

The purpose of this section is to introduce and summarize the basic elements of probability and statistics that are commonly used in PRA. For example, the frequency of occurrence of various accident sequences that are defined in a PRA is estimated using both probability and statistics techniques.

The reader will gain an understanding of the following:

- The subject matter of a study of probability theory

- Subjective versus frequentist probability

- Basic rules for calculating probabilities

- Point and interval estimates

- Proper use and interpretation of best estimate

- Bayesian versus classical statistics

- Confidence versus probability intervals

- Sources of data

The basic elements of probability and statistics that are routinely encountered and used in PRA are presented.

\section{C.2.2 Concepts}

\section{C.2.2.1 Probability}

\section{C.2.2.1.1 Probability Theory}

Probability theory is a basic tool used throughout PRA because many events are conveniently modeled with probabilistic rather than deterministic laws. Thus, probability theory is the appropriate framework for use in quantifying the frequency of accidents, as reflected in the term probabilistic risk assessment. Basic notions of applied probability can be found in Reference C.2.1.

The study of probability is concerned with probability experiments, which are governed by probabilistic, as opposed to deterministic, laws. For example, a simple experiment might'consist of a single test of a motor driven pump to see if it will start. In the simplest nontrivial case, an experiment has only two outcomes. The sample space $S$ of an experiment is the set that contains all the possible outcomes of the experiment. Thus, in the example, the sample space $S$ consists of only the two outcomes (pump starts operating, pump fails to start operating\}.

In order to mathematically consider probability experiments further, the notion of a random variable is defined and considered. A random variable is a quantity whose value is determined by the outcome of a probability experiment. This notion of a random variable may be generalized to include vector-valued outcomes of probability experiments (random vectors) and experiments whose outcomes are random functions (stochastic processes). In the simplest case, which is the only case considered in this report, a random variable is a function whose domain is the outcomes in the sample space of the experiment and whose range is the real numbers. Thus, for this case, a random variable must be real-valued and single-valued. Sometimes the range of the 
function (the assigned numbers) is referred to as the random variable. For example, in testing the motor driven pump to see if it will start, the random variable can be defined as $X=1$ if the pump starts operating and $X=0$ if it fails to operate. Alternatively, other numbers could have been chosen, such as $X=18$ if it starts and $X=133$ if it fails to start. The issue is not the numbers themselves but that values were chosen. Typically, values such as 0 and 1 are assigned as in the example.

An event is defined to be any subset of a sample space. For example, consider a random variable $T$ that is the failure time (in hours) of a certain pump while operating (assuming that it has successfully started operation). The corresponding sample space is thus the set of all positive real numbers; that is, $S \equiv\{0<t<\infty\}$. Suppose that event $A$ is that the pump survives at least 24 operating hours. The event $A$ is thus the subset $A \equiv\{24 \leq$ $t<\infty\}$ of $S$.

If $A_{1}$ and $A_{2}$ denote any two events in the sample space $S$, then their union $A_{1} \cup A_{2}$ is the event that contains all the outcomes in $S$ that are either in $A_{1}$, in $A_{2}$, or in both; the intersection $A_{1} \cap A_{2}$ is the event that contains all outcomes that are in both $A_{1}$ and $A_{2}$; and the complement of $A$ is the event that contains all the outcomes in $S$ that are not in $A$. The union of two events can be indicated as the event " $A_{1}$ or $A_{2}$ "; and the intersection as " $A_{1}$ and $A_{2}$ " or, even more simply, as " $A_{1}, A_{2}$ " or " $A_{1} A_{2}$ ".

Sample spaces and events, particularly relationships among events, are often illustrated by means of Venn diagrams. Figure C.2.1 illustrates the above events using Venn diagrams. In each case, the sample space is represented by a rectangle, while events are represented by regions within the rectangle, usually by means of circles or portions of circles. The cross-hatched areas represent the events of interest. The probabilities (see below) of the events are also indicated.

In PRA theory and applications, there are two basic interpretations of probability: frequentist and subjectivist. Let $A$ denote some event of interest; for example, the failure of a pump to start on demand. The probability of $A$, denoted by $P(A)$, is a nonnegative real-yalued function satisfying certain axioms that permit algebraic manipulation of probabilities (such as in PRA). Both notions of probability satisfy the three axioms of probability: (1) $0 \leq \mathrm{P}(\mathrm{A}) \leq 1 ;(2) \mathrm{P}(\mathrm{S})=1$; and (3) If $\mathrm{A}_{1}, \mathrm{~A}_{2}, \ldots$ are a set of mutually exclusive events, then $P\left(A_{1} \cup A_{2} \cup \cdots\right)=P\left(A_{1}\right)+P\left(A_{2}\right)+\ldots$.

Events that are mutually exclusive or disjoint are a set of events such that the occurrence of any one precludes the simultaneous occurrence of any of the remaining events in the set. That is, no two events can happen together. The bottom panel for Figure C.2.1 gives a Venn diagram of two mutually exclusive events. If two events are mutually exclusive, then their intersection is the null set (a set containing no outcomes); thus, $P\left(A_{1} \cap A_{2}\right)=0$.

The frequentist view of probability ${ }^{2}$ considers $\mathrm{P}(\mathrm{A})$ as a fixed quantity, which may be either known or unknown. This view leads to the so-called Neyman-Pearson (or classical) system of statistical inference, the core of which are the procedures of confidence interval and hypothesis testing (see Section C.2.2.2, page C-24).

In the frequentist view, a mathematical theory of probability is developed by deriving theorems based on the axioms of probability. In applying the theory to the real world, the probability of an event is considered a property of the physical object involved and can be estimated from data. For example, if the event is $A=\{$ failure of a pump to start on demand $\}$, then the probability $P(A)$ is a property of the pump analogous to its mass, $m$. Just as $m$ can be measured by weighing the pump, $P(A)$ can be estimated by repeated attempts to

\footnotetext{
${ }^{2}$ Frequentist probabilities are sometimes known as empirical or objective probabilities. This view was first formulated by Venn in 1886 and further developed by von Mises in the late 1920 s.
}

NURE( $;-1489$ 
C.2 Probability and Statistics C.2.2 Concepts C.2.2.1 Probability

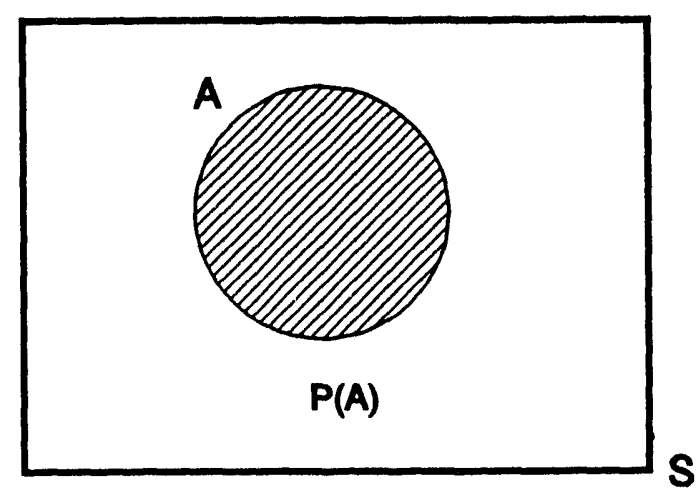

Event A

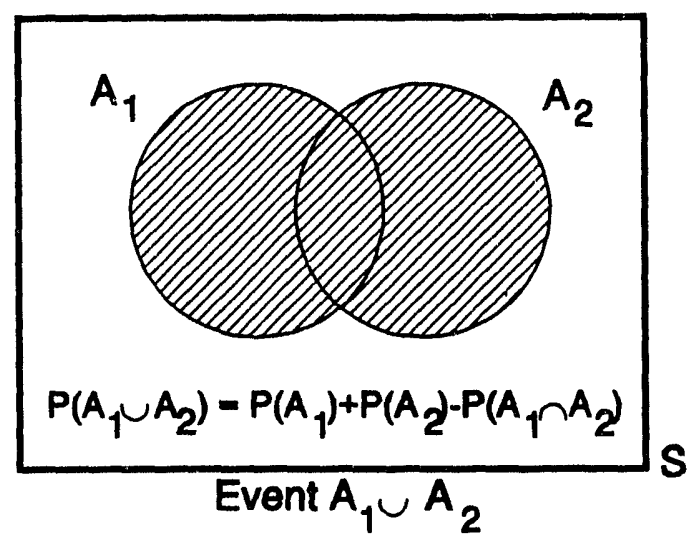

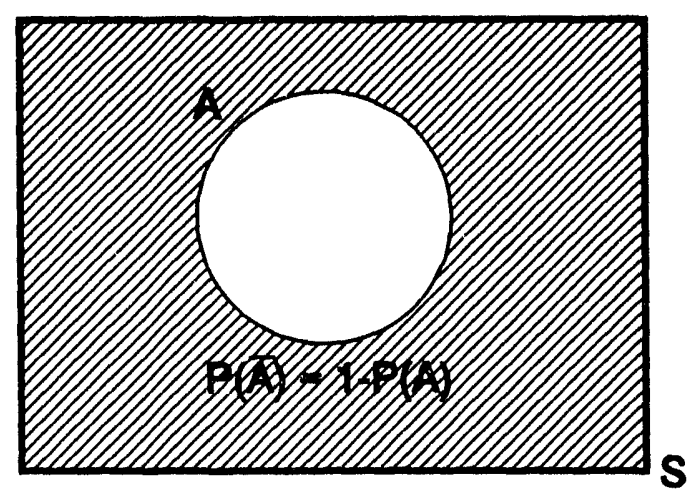

Event $\bar{A}$

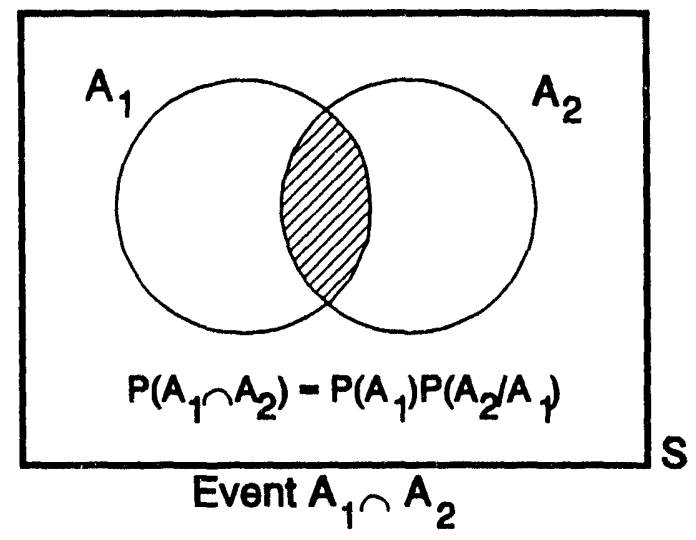

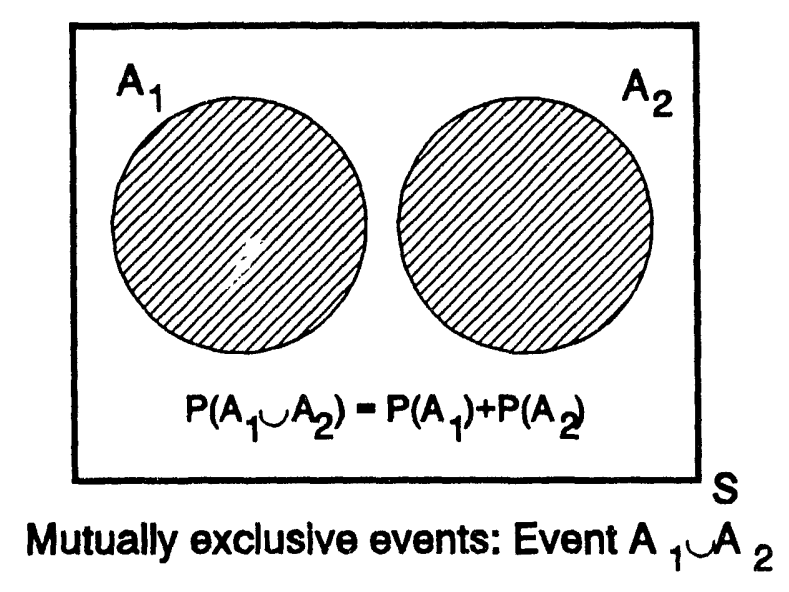

Figure C.2.1 Venn diagrams

C-17

NUREG-1489 


\section{C.2 Probability and Statistics \\ C.2.2 Concepts \\ C.2.2.1 Probability}

start the pump. For a real pump, $\mathrm{m}$ can never be determined exactly (no matter how many times the pump is weighed), just as $P(A)$ can never be determined exactly (no matter how many repeated attempts there are to start the pump). Recognizing that any estimate of $P(A)$ for a real pump (whether based on data, theory, or subjective judgment) can never be exact, the frequentist view emphasizes the necessity of evaluating the uncertainty in any estimated probability (Ref. C.2.2). It should be noted that it is a theorem (that is, a consequence of the axioms) that, if an experiment is repeated $n$ times under identical conditions with the outcome $A$ occurring $n_{A}$ times, the observed relative frequency of occurrence $n_{A} / n$ of the event $A$ approaches $P(A)$ in the limit.

The subjectivist view also considers $\mathrm{P}(\mathrm{A})$ as an unknown quantity to be estimated and a theory of probability is likewise developed by proving theorems based on the axioms of probability. However, the subjectivist view considers probability as a subjective statement of an analyst's personal state-of-knowledge or degree-of-belief regarding the occurrence of the event $A$ based on the available evidence. It has been shown that degree-of-belief possesses real-world meaning and obeys the axioms of probability stated above (Ref. C.2.3). In the pump example, $P(A)$ is thus a subjective statement of the analyst's degree-of-belief regarding the failure of the pump to start on demand. This belief is based on the analyst's totality of knowledge of such pumps, and it is noted here that this knowledge may in fact include any relative-frequency-based data on such pumps. Reference C.2.4 is an introductory discussion of the subjectivist notion of probability.

Because PRA often involves the frequencies of rare events, there is ongoing controversy regarding which notion of probability is the appropriate one for use in PRA (Ref. C.2.5). Even though PRA models attempt to decompose rare events into more frequent events, the problem persists. In such cases, engineering judgment is often used as an aid in estimating probabilities and frequencies of rare events. Because of this formal use of degree-of-belief, the subjectivist view of probability is widely used in PRA. References C.2.6 through C.2.9 and many others argue that the subjectivist notion of probability is philosophically and practically appropriate for use in PRA. This view of probability is the foundation for the so-called Bayesian method of statistical inference, which is discussed in Section C.2.2.2.3 (page C-26).

Guidance: There is general agreement that both the frequentist and subjectivist interpretations of probability are appropriate for use in PRA. However, one view or the other may be preferable for particular analyses.

The concept of probability of frequency, which is an integration of both notions of probability, was introduced in Reference C.2.10. The authors of Reference C.2.10 refer to frequency as "the outcome of any experiment or observation that can be repeated. As such, it is, in principle, a quantity that can be measured." On the other hand, they use the term probability to denote a state of knowledge regarding the uncertainty of such observable quantities. In other words, they refer to subjective probabilities as "probabilities," and refer to all ratios of repeatable (or measurable) events of interest as "frequencies" (e.g., the number of failures to start divided by the number of attempts to start a pump). However, the denotation of all such ratios as frequencies is inconsistent with one common statistical definition of frequency, namely, a simple count of events or observations. At the same time, it is a broadening of another common statistical definition of frequency, namely, the rate of occurrence of an event per unit of time. Thus, one traditional use of the term frequency does not involve a ratio, while the authors of Reference C.2.10 always use and interpret this term as a ratio in which the denominator is time, starts, application of shocks, or events. The concept of probability of frequency is applied when the interpretation of the evidence leads to the statement that there is a $95 \%$ probability that a frequency of interest is less than a certain calculated value. The probability (state of knowledge) regarding the unknown frequency is expressed in the form of a subjective distribution, which is discussed below (also see Section 4.2 of Reference C.2.8). 


\section{C2.2.1.2 Basic Rules and Principles of Probability}

There is an important rule for calculating the probability of the union of two or more events. For any two events $A_{1}$ and $A_{2}, P\left(A_{1} \cup A_{2}\right)=P\left(A_{1}\right)+P\left(A_{2}\right)-P\left(A_{1} \cap A_{2}\right)$. The corresponding Venn diagram in Fig. C.2.1 can be used to illustrate this important rule. By adding $P\left(A_{1}\right)$ and $P\left(A_{2}\right)$, the probability of the intersection, $P\left(A_{1}\right.$ $\left.\cap A_{2}\right)$, has been double counted; thus $P\left(A_{1} \cap A_{2}\right)$ must be subtracted. Of course, if $A_{1}$ and $A_{2}$ are mutually exclusive events, then $P\left(A_{1} \cap A_{2}\right)=0$, and the rule reduces to the third axiom of probability. For three events, $P\left(A_{1} \cup A_{2} \cup A_{3}\right)=P\left(A_{1}\right)+P\left(A_{2}\right)+P\left(A_{3}\right)-P\left(A_{1} \cap A_{2}\right)-P\left(A_{1} \cap A_{3}\right)-P\left(A_{2} \cap A_{3}\right)+P\left(A_{1} \cap A_{2} \cap A_{3}\right)$, which again can be proven by use of a Venn diagram. This rule is known as the inclusion-exclusion principle and may be generalized to $n$ events. It is widely used in PRA because there is often interest in computing the probability of an "or" gate (a union of events) in a fault tree (Ref. C.2.11).

Guidance: The inclusion-exclusion rule is used to calculate the probability of the union of a set of events; that is, the probability that any (one or more) of the events occur.

The inclusion-exclusion principle also provides numerous useful upper and lower bounds on the probability of a union of $n$ events that are not mutually exclusive. One particularly useful upper bound is commonly known as the rare event approximation. It can be shown with the aid of a Venn diagram that the upper bound (the rare event approximation) is $\mathbf{P}\left(\mathbf{A}_{1} \cup \mathbf{A}_{2} \cup \ldots \cup \mathbf{A}_{n}\right) \leq \mathbf{P}\left(\mathbf{A}_{1}\right)+\mathbf{P}\left(\mathbf{A}_{2}\right)+\ldots+\mathbf{P}\left(\mathbf{A}_{n}\right)$. The rare event approximation should be used only when the probabilities of the $n$ events are very small. The error is zero if the $n$ events are mutually exclusive. An approximation of the error is $n^{2} \max P\left(A_{i}\right)$, which is valid regardless of the independence of events. The error in the approximation is the contribution from the remaining terms in the full inclusion-exclusion expansion of the left-hand side of the inequality. The approximation is widely used in accident sequence quantification (see Section C.3.3.3, page C-49).

Guidance: When using the rare event approximation, the error should be examined to ensure that the approximation is sufficiently accurate for its intended purpose.

The conditional probability of an event $A_{1}$, given that an event $A_{2}$ has already occurred, is widely used in PRA and is defined as $P\left(A_{1} \mid A_{2}\right)=P\left(A_{1} \cap A_{2}\right) / P\left(A_{2}\right)$. Here $P\left(A_{2}\right)$ is referred to as the marginal probability of event $A_{2}$ (that is, unconditioned on the occurrence of any other event).

If the conditional probability of an event $A_{1}$ is the same, whether or not an event $A_{2}$ has occurred, then $A_{1}$ is statistically independent of $A_{2}$. In other words, $P\left(A_{1} \mid A_{2}\right)=P\left(A_{1}\right)$, and this implies that $P\left(A_{1} \cap A_{2}\right)=P\left(A_{1}\right) P\left(A_{2}\right)$. If $P\left(A_{1}\right)$ varies depending upon whether or not event $A_{2}$ has occurred, then the events $A_{1}$ and $A_{2}$ are said to be dependent. Dependent events often occur in PRA because of common initiating events, common environmental conditions, repeated human errors, etc. Thus, the consideration and analysis of dependent events is an important PRA activity (see Section C.3.3.4, page C-52).

The notions of mutually exclusive and statistically independent events are often confused. Suppose that the two events are mutually exclusive. By definition, this implies that their intersection is the null set. It follows directly from the rule of conditional probability that, in this case, $P\left(A_{1} \mid A_{2}\right)=0$, which is not $P\left(A_{1}\right)$, and thus the two events cannot be independent.

Guidance: If neither event has a probability of 0 or 1 , then events that are mutually exclusive cannot be statistically independent and vice versa. 
C.2 Probability and Statistics

C.2.2 Concepts

C.2.2.1 Probability

From this definition, the chain rule for two events says that the simultaneous occurrence of events $A_{1}$ and $A_{2}$ is equivalent to the occurrence of event $A_{1}$ and the occurrence of event $A_{2}$ given that event $A_{1}$ has already occurred. In general, for $\mathbf{n}$ events, the chain rule can be expressed as

$$
P\left(A_{1} \cap A_{2} \cap \ldots \cap A_{n}\right)=P\left(A_{1}\right) P\left(A_{2} \mid A_{1}\right) P\left(A_{3} \mid A_{2} \cap A_{1}\right) \ldots P\left(A_{n} \mid A_{n-1} \cap \ldots \cap A_{1}\right) \text {. }
$$

This rule is used to calculate the probability that a given accident sequence occurs where $A_{1}$ denotes the initiating event and the remaining events correspond to the failure or success (see Section C.3.3.3, page C-51) of the systems that must function in order to mitigate such an accident.

Guidance: The chain rule is used to calculate the probability of the intersection of a set of events, that is, the probability that all the events occur simultaneously.

If $A_{1}, A_{2}, \ldots A_{n}$ are mutually independent events, the probability that at least one of the $n$ events occurs is

$$
P\left(A_{1} \cup A_{2} \cup \ldots \cup A_{n}\right)=1-\left[1-P\left(A_{1}\right)\right]\left[1-P\left(A_{2}\right)\right] \ldots\left[1-P\left(A_{n}\right)\right],
$$

which is equivalent (upon expansion) to using the inclusion-exclusion rule. If the $\mathbf{n}$ events are not mutually independent, then the right-hand side of this expression may be greater than or less than the left-hand side. However, in one important situation, which arises often in PRA applications, the right-hand side of this expression is an upper bound for the left-hand side. If the $n$ events are cut sets which are positively associated (see Refs. C.2.12 and C.2.13), then the right-hand side is an upper bound for $P\left(A_{1} \cup A_{2} \cup \ldots \cup A_{n}\right)$ and is known as the min cut upper bound. This name derives from common PRA applications in which $A_{i}$ is the $i^{\text {ih }}$ minimal cut set (see Section C.3.3.2, page C-47) of some system or accident sequence of interest. In this case, the min cut upper bound is superior to the rare event approximation and can never exceed unity (as can the rare event approximation). If the $\mathrm{n}$ events satisfy conditions similar to those of the rare event approximation, the min cut set upper bound is a useful approximation to the left-hand side. The min cut upper bound is not applicable to mutually exclusive events. The same guidance applies to this bound as to the rare event approximation.

In the pump example, the random variable $X$ has two outcomes $\{0,1\}$, and for each outcome, there is an associated probability. These two sets of numbers, the values of the random variable and the corresponding probabilities that the random variable takes or assumes these values, constitute a probability distribution. Here, the random variable takes on only two values. Probability distributions are universally classified according to whether or not the sample space has a finite or countable number of outcomes or whether the sample space is a continuum. Countable means that the number of possible outcomes in the sample space can be put into a oneto-one correspondence with the positive integers (the counting numbers). For example, the number of earthquakes of magnitude greater than 2.0 on the Richter scale at a given site can be any positive integer and is thus countable.

If the sample space is finite or countable, then the random variable is discrete and its probability distribution is referred to as a discrete probability distribution (or, equivalently, a discrete distribution or probability mass function). If $x$ denotes a value that the discrete random variable $X$ can assume, then the mass function is often denoted by $\mathrm{P}(\mathrm{x})$. It follows that the sum of the probabilities over all the values of $\mathrm{x}$ (that is, over all the values that the random variable can assume) must be 1 . Because of their widespread application, certain discrete random variables have been defined and given particular names. The two most commonly used discrete random variables in PRA are the binomial and Poisson random variables (see Section C.2.3, page C-31).

If the sample space contains an uncountably infinite number of outcomes (such as are contained in any interval), then the random variable is continuous. For example, consider the operating time $T$ (in hours) between successive failures of a certain pump. Theoretically, the random variable $T$ can assume any one of a continuum of values over the range 0 to $\infty$; thus, $T$ is a continuous random variable.

NURE( $;-1489$

C-20 
For a continuous nonsingular ${ }^{3}$ random variable, the probability distribution is a non-negative integrable function and the area between the graph of the function and the abscissa is equal to 1. It is referred to as a probability density function (PDF), or sometimes more simply as a density function. If $x$ denotes a value that the continuous random variable $X$ can assume, then the density function is denoted by $f(x)$. The most common random variables in PRA are the normal, lognormal, exponential, gamma, and beta random variables (see Section C.2.3, page C-32). The definitions of these commonly used continuous random variables are given in many textbooks on probability and statistics, such as References C.2.1 and C.2.14. Sections 5.5.1 and 5.5.2 of Reference C.2.15 also discusses several of these random variables.

A useful and widely used probability function in PRA is the cumulative distribution function (CDF) or, simpiy; the distribution function. This function gives the probability that the random variable does not exceed a given value $x$. For example, one may want to know the probability that the flow from an emergency cooling system is less than $x$ gallons per minute. For a discrete random variable $X$, if the outcomes are denoted by $x_{i}$ and the corresponding probabilities by $P\left(x_{i}\right)$, then, for $x_{i} \leq x$,

$$
F(x)=P(X \leq x)=\Sigma P\left(x_{i}\right) \text {. }
$$

In the case of a continuous random variable $X, F(x)$ is the area under the probability density function $f(x)$ up to $\mathrm{x}$; that is,

$$
F(x)=P(X \leq x)=\int_{-\infty}^{x} f(y) d y
$$

It $X$ takes on only positive values, then the limits of integration are 0 to $x$. Note that $0 \leq F(x) \leq 1$ and that $F(x)$ is a nondecreasing function of $x$.

Figure C.2.2 illustrates a probability distribution $P(x)$ for a discrete random variable $X=\{1,2,3\}$ and corresponding CDF. A typical PDF $f(x)$ and corresponding CDF $F(x)$ are also shown. Because of the relationship between a PDF and CDF discussed above, the shaded area under the PDF to the left of $x=a$ is $P(X \leq a)=\int f(x) d x=F(a)$, where the limits of integration are $-\infty$ to a.

Not all random variables are purely discrete or purely continuous, and mixed cases do exist. The corresponding PDFs and CDFs are mixed combinations as well. However, because mixed combinations are relatively rare in modern PRA applications, such combinations are not considered further; for additional information on mixed combinations of random variables, see Reference C.2.16.

The mean, $\mu$, of a random variable $\mathrm{X}$ is the weighted average of the outcomes, where the weights are the probabilities of the outcomes. For a discrete random variable, $\mu=\sum x_{i} P\left(x_{i}\right)$ for all $x_{i}$. For a continuous random variable, $\mu=\int \mathrm{xf}(\mathrm{x}) \mathrm{dx}$, where the integral is from $-\infty$ to $\infty$. This can be visualized as a plot in which the values of the pump-testing random variable are placed on a horizontal axis and the corresponding probabilities as vertical lines to form a bar-graph. If the horizontal axis is placed on a fulcrum, the position of the fulcrum where the plot would balance would be the mean of the distribution, often denoted by $\mu$. In the pump example, the mean is 0.5 if $P(x=0)=P(x=1)=0.5$.

In general, the expectation (expected value or mathematical expectation) of any function $g(X)$, denoted by $\mathrm{E}[\mathrm{g}(\mathrm{X})]$, of the random variable $\mathrm{X}$ equals $\sum g\left(\mathrm{x}_{\mathrm{i}}\right) \mathrm{P}\left(\mathrm{x}_{\mathrm{i}}\right)$, summed over all $\mathrm{x}_{\mathrm{i}}$, when $\mathrm{X}$ is discrete. Similarly, $E[g(X)]=\int g(x) f(x) d x$, evaluated from $-\infty$ to $\infty$, when $X$ is continuous. In the special case in which $g(X)=$

\footnotetext{
${ }^{3}$ Without theoretically possible properties that do not occur in practice.
} 


\section{C.2 Probability and Statistics}

\section{C.2.2 Concepts}

C.2.2.1 Probability

$\mathrm{X}$, the expectation $\mathrm{E}(\mathrm{X})$ becomes the mean $\mathrm{m}$ of $\mathrm{X}$, and for this reason the mean is also commonly known as the expected value (or expectation) of the random variable $X$.

There is an important rule involving expectations that is widely used in PRA. The rule is that the expected value of a product of independent random variables is the product of their respective expected values. That is, $E\left(X_{1} X_{2} \ldots X_{n}\right)=E\left(X_{1}\right) E\left(X_{2}\right) \ldots E\left(X_{n}\right)$ when all $X_{1}$ are independent. This rule can be generalized to conditionally independent random variables. If the random variables $X_{2}, X_{3}, \ldots, X_{n}$ are all conditionally independent given $\mathbf{X}_{1}=\mathbf{x}_{1}$,

then $f\left(x_{2}, x_{3}, \ldots, x_{n} \mid x_{1}\right)=f\left(x_{2} \mid x_{1}\right) f\left(x_{3} \mid x_{1}\right) \ldots f\left(x_{n} \mid x_{1}\right)$.

It follows that $E\left(X_{2} X_{3} \ldots X_{n} \mid x_{1}\right)=E\left(X_{2} \mid x_{1}\right) E\left(X_{3}\left|x_{1}\right| \ldots E\left(X_{n} \mid x_{1}\right)\right.$.

Thus, in this case, $E\left(X_{1} X_{2} \ldots X_{n}\right)=E\left[X_{1} E\left(X_{2} \mid x_{1}\right) E\left(X_{3} \mid x_{1}\right) \ldots E\left(X_{n} \mid x_{1}\right)\right]$.
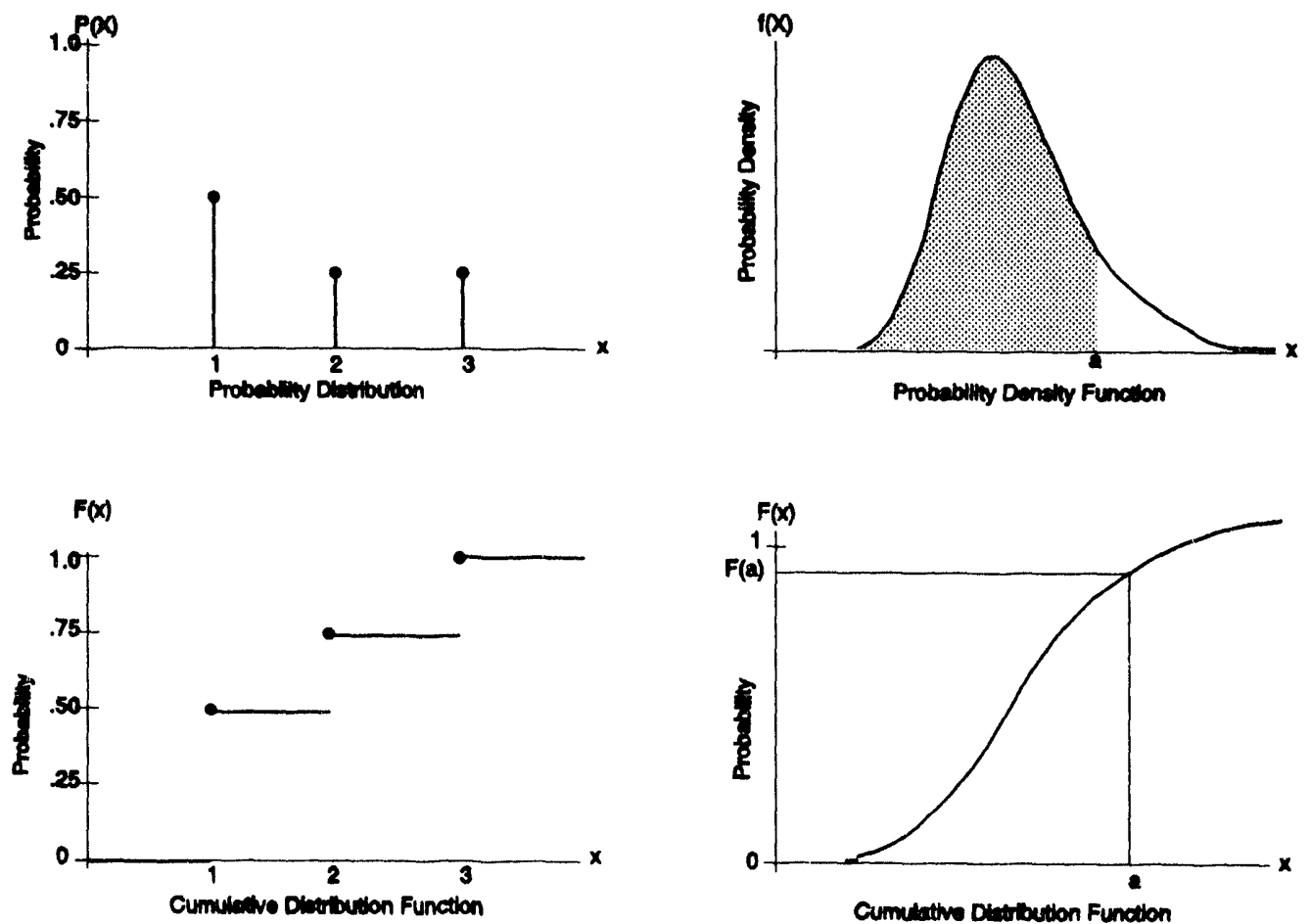

Figure C.2.2 Probability distribution and density function (above) and corresponding cumulative distribution functions (below) 
The median of a continuous distribution is that value $\mathbf{M}$ for which there is a probability of 0.5 that the random variable $\mathrm{X}$ is less than $\mathrm{M}$ (and thus a probability of 0.5 that $\mathrm{X}$ is also greater than $\mathrm{M}$ ). Both the mean and median are used to measure the center or location of a distribution. Because the median is less affected by the tail-area probabilities of the distribution, the median is sometimes a more appropriate measure of location than the mean if the distribution is highly skewed. Both the mean and median are widely used in PRA. The mode is another parameter used to measure the center of a distribution, and it is defined as the maximum value of the probability density or probability mass function.

Another important characteristic of a distribution is its variance, denoted by $\sigma^{2}$. The variance is the average of the squared deviations from the mean, $\mu$. The standard deviation, $\sigma$, of the distribution is the square root of the variance, and is one measure of how much spread or dispersion there is in a distribution. For a discrete random variable, the variance is $\Sigma\left(x_{1}-\mu\right)^{2} P\left(x_{2}\right)$. For a continuous random variable, the variance is $\int(x-\mu)^{2} f(x) d x$.

Given two random variables $X$ and $Y$ with means $\mu_{x}$ and $\mu_{y}$, the expected value of the product $\left(X-\mu_{x}\right)\left(Y-\mu_{y}\right)$ is called the covariance of $X$ and $Y$. The (linear) correlation coefincient [or, simply, the (linear) correlation] between $X$ and $Y$ is the covariance divided by the product of the respective standard deviations of $X$ and $Y$. It measures the strength of a linear association between $X$ and $Y$. For example, consider the two random variables $X=$ Human Error Rate (while performing some task) and $Y=$ Amount of Training (for performing this same task). If $\mathrm{Y}$ increases as $\mathrm{X}$ decreases, then $\mathrm{X}$ and $\mathrm{Y}$ are negatively correlated. If $\mathrm{X}$ and $\mathrm{Y}$ are independent, the covariance (and thus the correlation) is zero, and the two variables are uncorrelated. That the correlation is zero does not imply that there is no relationship between $\mathrm{X}$ and $\mathrm{Y}$; it implies that there is no linear relationship: This should be kept in mind when considering the relationship between random variables.

The p-th quantile, or $100 \mathrm{p}$-th percentile of a continuous distribution, is a solution, $\mu$, of $F(\mu)=p$. If $\mu$ is the 95th percentile, $95 \%$ of the area under the PDF is to the left of $\mu$. The 25th, 50th, and 75th percentiles are referred to as quartiles of the distribution. The median is the 50 th percentile, 0.5 quantile, or second quartile.

\section{C.2.2.2 Statistics}

\section{C.2.2.2.1 Terminology}

A parametric family of distributions is a collection of distributions that is indexed by one or more quantities called parameters. For example, suppose that $f(t ; \lambda)=\lambda e^{-\lambda t}$, where $t, \lambda>0$. For each value of $\lambda>0, f(t, \lambda)$ is a PDF. Here, $\lambda$ is the parameter, and as $\lambda$ ranges over all the positive numbers, the collection $\{f(t, \lambda), \lambda>0\}$ denotes the parametric family of exponential density functions. Other parametric families have two or more parameters. For example, the normal family has two parameters, the mean and the variance.

The distribution of a random variable is seldom completely known in the sense that the values of the parameters in the underlying probability distribution (or model) are precisely known. However, with some assumptions and information from an assumed random sample of data from the distribution, the values of the unknown parameters can often be estimated sufficiently well that probabilities may then be computed from the respective distribution.

Parametric statistical inference is concerned with determining values for unknown parameters (and their associated properties) from sample data for a given or assumed family of distributions. Functions of sample data (known as estimators) are used to calculate values for unknown parameters. Much effort in the field of statistics is directed toward deriving and studying the performance properties of various estimators. The value of a parameter produced by an estimator is the corresponding estimate of the parameter. An unbiased estimator 
is one whose mean value is equal to the parameter being estimated. Reference C.2.14 discusses basic elements of engineering statistics and Reference C.2.16 discusses the basic elements of mathematical statistics.

Not all statistical inference is based on the notion of a parametric family. In many cases, not only are the values of the parameters unknown, but the form of the basic parametric family is unknown as well. In such cases, the analyst needs statistical techniques that are applicable regardless of the form of the distribution. These techniques are call nonparametric or distribution-free methods (Ref. C.2.17). Goodness-of-nit tests are an important class of nonparametric methods that are used to determine whether or not a given set of data follows a hypothesized distribution.

An estimate of a parameter in the form of a single number is called a point estimate of the parameter. For example, the sample mean is a point estimate of the mean of a distribution, and the sample standard deviation is a point estimate of the standard deviation of the distribution. The difference between the largest and smallest values of a sample is called the range of the sample. The range can also be used to describe the spread of a distribution.

Although it is commonly used in PRA, best estimate is not a precisely defined statistical term. In current PRA practice, best estimate is usually vague and seldom defined. In recent PRA applications, best estimate usually refers to a function of point estimates, in which the point estimates are estimates of a mean or median. However, unless the best estimate is a linear function of mean estimates, the best estimate is generally not an unbiased estimate of the mean median of the distribution of the desired function. For example, consider two asymmetric random variables $X$ and $Y$ with means $m_{x}$ and $m_{y}$, respectively, and corresponding medians $M_{x}$ and $M_{y}$. Now suppose that there is interest in the product $W=X Y$ of these two random variables. Let $m_{w}$ and $M_{W}$ be the mean and median of $W$. Unless $X$ and $Y$ are independent or uncorrelated, then $m_{w} \neq m_{x} m_{Y}$. Furthermore, it is generally the case that $M_{w} \neq M_{X} M_{Y}$, even if $X$ and $Y$ are independent. Thus, if $X$ and $Y$ are dependent random variables, neither the product of the mean estimates nor the product of the median estimates is an unbiased estimate of the mean or median, respectively, of W. Despite these facts, the product of the mean estimate is sometimes used as an estimate of $\mathrm{m}_{\mathrm{w}}$ and the product of the median estimate is sometimes used as an estimate of $\mathbf{M}_{\mathrm{w}}$; each of these products is sometimes termed a "best estimate."

\footnotetext{
Guidance: Because it is not a precisely defined statistical term, the term "best estimate" should be avoided in PRA applications. However, if it is necessary to use this term, the analyst should carefully describe what the best estimate represents. In other contexts, such as thermal hydraulic analyses, the use of the term best estimate may be appropriate.
}

Another way to estimate a parameter is by stating, with a specified degree of certainty, that it lies in some interval $(\mathrm{L}, \mathrm{U})$. The interval $(\mathrm{L}, \mathrm{U})$ is then called an interval estimate of the parameter. If one were to take a large number of independent samples from a given distribution and use the same procedure on each sample to get an interval estimate of the mean, then a large number of interval estimates would result. If $95 \%$ of these intervals contained the true mean (and 5\% of them did not), the procedure would be described as one that yields a $95 \%$ confidence interval. The level 'of confidence desired, such as $95 \%$, is called the confidence coefficient, or simply, the desired confidence. In practice, the use of such a procedure on a single sample and the interval obtained is called a 95\% confidence interval. The interval either contains the true parameter or it doesn't; the confidence is in the fraction of such intervals that are expected to contain the parameter, not in the particular interval.

Guidance: Confidence intervals cannot be interpreted as a probability statement regarding the parameter estimated because, in this context, the parameter is not a random variable. 


\section{EXAMPLE}

The Reactor Safety Study (Ref.C.2.18) reported that in 1972 there were 50 failures out of a total of 5613 such instruments (of a certain class) in operation in US commercial nuclear power plants. Using Page 122 of Reference C.2.19, a 95\% two-sided confidence interval on the unknown Poisson instrument failure rate was calculated (see Section C.2.3) as $\left(7.5 \times 10^{-7}, 1.3 \times 10^{-6}\right)$. This means that, with $95 \%$ confidence, the instrument failure rate can be assumed to be between $7.5 \times 10^{-7}$ and $1.3 \times 10^{-6}$ failures per hour.

A confidence interval is an interval estimate of the parameters of a distribution. There are other types of interval estimates for other characteristics of interest in a population or distribution. An interval estimate that contains a specific percentage of the sample values drawn from a certain distribution with a high degree of confidence is called a tolerance interval. A third type of interval estimate is one that will contain the next sample value with a high degree of confidence; such an interval is called a prediction interval. Tolerance intervals and prediction intervals have the same interpretation as confidence intervals; given a large number of them, a certain percentage of them would contain the quantity of interest (Ref. C.2.16).

The testing of statistical hypotheses is another major statistical topic. A hypothesis is a statement about one or more of the parameters of a distribution. One could hypothesize that the operating failure rate of a certain pump, in which failures are assumed to follow Poisson distribution, is no larger than $10^{-4}$ per hour. The basic problem is to decide, upon the basis of a sample, whether the hypothesis is true. The hypothesis to be tested is called the null hypothesis and is denoted by $\mathrm{H}_{0}$. Its negation is the alternative hypothesis, denoted by $\mathrm{H}_{1}$ or by $\mathrm{H}_{\mathrm{a}}$. A test of a hypothesis is a rule or procedure for deciding whether to reject the null hypothesis. Rejection is a decision that the sample values are not favorable to the hypothesis. If $\mathrm{H}_{0}$ is not rejected, it is accepted by default, that is, by lack of evidence to the contrary. When testing a hypothesis, the experimenter may make one of two errors: (1) reject the null hypothesis when it is true, which is known as a Type I error, or (2) accept the null hypothesis when it is false, which is said to be a Type II error.

The probability of making a Type I error is the significance level or the alpha-level of the test and is denoted by $\alpha$; the probability of making a Type II error is called the beta-level and is denoted by $\beta$. It is a function of the parameter and is called the operating characteristic of the test. The function $1-\beta$ is called the power of the test.

If a null hypothesis, $\mathrm{H}_{\mathrm{o}}$, is rejected at the significance level of $\alpha$, then the result is said to be statistically significant at the level $\alpha$. If the test is based on a large amount of data, then the result will tend to be statistically significant unless the data fit $H_{o}$ very closely. Hence, a result that is statistically significant may not be of practical significance, i.e., $H_{o}$ may be rejected even though it describes the data quite well.

Goodress-of-nit tests are special hypothesis tests in which, given a set of observed sample data from some distribution, a test is made of the hypothesis that the data are distributed according to a specified distribution. For example, one could test the hypothesis that a given set of failure times of a pump which must operate continuously follows an exponential distribution.

\section{C.2.2.2.2 Classical Estimation Methods}

Confidence intervals exemplify methods known as classical estimation. Classical estimation limits inferences about parameters to the information contained in the sample data and to assumptions regarding a model for the sample data. There is no attempt to formally incorporate degree-of-belief regarding the value of the parameter within the estimation process. The parameter of interest is simply treated as an unknown constant. Past 
C.2 Probability and Statistics

C.2.2 Concepts

C.2.2.2 Statistics

experience and knowledge previously gained about a parameter play a less crucial role. Classical methods make minimum use of information that is outside the information contained in the sample data.

There are several advantages and disadvantages of classical estimation methods in PRA.

\section{Advantages}

$\triangle \quad$ The results depend only on the data.

$\Delta \quad$ When the quantity of data is large, classical methods produce good estimates.

$\checkmark \quad$ Classical methods are well known and widely used in all areas of science and thus have historical precedence. Classical estimation is tried and proven, and less education and effort is required for its understanding and use.

\section{Disadvantages}

D A confidence interval cannot be directly interpreted as a probability that the corresponding parameter lies in the interval.

$\Delta \quad$ Relevant information regarding the parameter may exist outside the sample data. While it is possible to model such external information about a parameter using classical estimation, the techniques for doing this are complicated. It is not a straightforward procedure to formally include engineering judgment in the estimation process, and because PRA usually deals with rare events, engineering judgment is often the only source of information available about an unknown parameter.

D It is a complicated process to propagate classical confidence intervals through fault and event tree models common in PRA to produce corresponding interval estimates on output quantities of interest (such as accident sequence frequencies of occurrence).

$D \quad$ In most applications of PRA to nuclear power plants, the available data are often a conglomeration of various data sources and types. That is, a host of applicable related data are available. This related data may consist of observed operating experience from similar plants but for different environmental or operating conditions. Usually the precise differences in conditions are unknown. The result is that the quality of more-or-less relevant data available for use in PRA is almost never of the precise form and format required for using classical methods of estimation.

D Classical methods are sensitive to the way in which sample data were obtained; that is, to the data generating and collection process. In PRA practice, the precise details of this process are either unknown or unavailable, and classical methods become either difficult or impossible to use.

\section{C.2.2.2.3 Bayesian Estimation Methods}

Bayesian estimation represents another mi.jor class of methods of statistical inference. Bayesian methods are similar to classical methods in that both point and interval estimates are usually obtained. They differ in both practical and philosophical aspects, though. The practical distinction is in the incorporation of belief and information beyond that contained in the sample data; the philosophical distinction lies in the subjective interpretation of probability. The analyst's prior belief about the value of a parameter is embedded in the socalled prior distribution. That is, the prior distribution expresses the analyst's state of knowledge (or subjective 
probability) about the parameter prior to obtaining the sample data. Thus, Bayesian estimation is defined as those methods that involve parameter estimation in which one or more of the parameters is considered to be a random variable with a prior distribution that expresses the analyst's prior degree-of-belief about the parameters.

Bayesian estimation encompasses two basic situations, both of which require and use the notion of subjective probability. The first occurs when available data are used to fit a subjective (or prior) distribution to a parameter of interest, such as a failure rate. This distribution expresses the analyst's degree-of-belief regarding uncertainty about the parameter in the form of a prior distribution. In this case, Bayes' theorem is not used at all (Ref. C.2.19). The second occurs when additional (or new) sample data are used to update an existing prior distribution, commonly known as Bayesian updating. Bayesian updating involves the formal use of Bayes' theorem as follows.

Before the sample data are used, the parameter value is uncertain, which is expressed by the prior distribution. The new information contained in the sample tells us something about the value of the parameter in the form of the sampling distribution. However, even after this sample information is known, there is still uncertainty about the value of the parameter, but the uncertainty has been reduced. Bayes' theorem is used to combine the prior and sampling distributions to form the so-called posterior distribution. The posterior distribution expresses the new updated state of knowledge (again in the form of subjective probability) about the parameter after the sample data have been obtained and combined with the prior distribution.

The prior distribution or posterior distribution is the distribution used in Bayesian analysis to obtain desired point and interval estimates. Bayesian interval estimates obtained from the prior or posterior are subjective probability intervals or credibility intervals. For example, a $95 \%$ Bayesian posterior probability interval $(A, B)$ may be interpreted as follows: there is a subjective probability of $95 \%$ that the parameter is contained in the interval (A,B) given the prior information and the sample data. Reference C.2.4 discusses the basic theory of Bayesian estimation, and Reference C.2.19 discusses the use with Bayesian estimation in reliability analysis.

Guidance: Probability intervals can be interpreted as a subjective probability statement regarding a parameter of interest.

EXAMPLE

The probability $\mathrm{p}$ with which diesel generators fail to start per demand was assumed in the Reactor Safety Study (Ref. C.2.18) to have a Jognormal distribution (see Section C.2.3) with 5th and 95 th percentiles of $10^{-2}$ and $10^{-1}$, respectively. If the prior distribution is updated using Bayes' theorem in conjunction with binomial (see Section C.2.3) sample data from a certain plant consisting of 5 failures in 227 test demands, then the $90 \%$ probability interval estimate on p given by $(0.013,0.045)$ is obtained. Thus, for the plant under consideration, $\mathrm{P}(0.013<\mathrm{p}<0.045)=0.90$.

The Bayesian method must be based on a credible analytical work. The method cannot be used to put forth a prior distribution. The prior distribution represents the interpretation of available evidence, but this interpretation also provides a challenge to communicate the reasonableness of the evidence. In this way, the Bayesian method can add value to a decision analysis process and therefore avoid misunderstandings.

As in the case of classical methods, there are advantages and disadvantages of Bayesian estimation. 
C.2 Probability and Statistics

C.2.2 Concepts

C.2.2.2 Statistics

\section{Advantages}

D Bayesian estimation provides a logical and unified approach to estimation in that it can mcasure uncertainty about parameters using probabilities. To the extent that the information embodied in the prior distribution accurately reflects the uncertainty about a parameter, Bayesian methods produce better parameter estimates than classical estimates.

$\triangle \quad$ Bayesian computations are often straightforward.

D Bayesian methods provide a formal method of explicitly introducing prior information and knowledge into the analysis. This is particularly useful when sample data are scarce, as in the case of rare events. This knowledge often exists in the nuclear industry in the form of industry-wide generic data (see Section C.2.4.1, page C-33). That is, Bayesian estimation permits the use of various types of relevant generic data in a PRA.

While a confidence interval cannot be interpreted as a probability statement about a parameter, probability intervals do have this desired interpretation. They are interpreted as a subjective probability that the parameter is contained in the interval. As a direct consequence of this, probability intervals can be easily combined with other sources of uncertainty in a PRA using the usual and well known laws of probability in a straightforward manner. These probability intervals can then be propagated through PRA fault and event trees to produce corresponding probability intervals on output parameters of interest (see Section C.6.3.1, page C-154).

- Bayesian estimation provides a natural and convenient method for use in updating the state of knowledge about a parameter as future additional sample data become available; Bayes' theorem is the vehicle used in this updating process.

$\triangle \quad$ The reasoning process used in Bayesian estimation is straightforward deductive as opposed to the indirect inductive process used in classical inference. Thus it is easy to follow, explain, and appreciate.

D There are interval estimation problems for which no classical solution exists, although there are Bayesian procedures. That is, Bayesian estimation is applicable to a larger class of situations likely to be encountered in practice without resorting to ad hoc procedures.

D Bayesian methods are more applicable and easier to use than classical procedures when only generic data exist (such as for a proposed or new facility).

\section{$\underline{\text { Disadvantages }}$}

$\Delta \quad$ A suitable prior distribution must be identified and justified, which is often a difficult task in practice.

B Bayesian inference may be sensitive to the choice of a prior distribution.

$\triangle \quad$ A PRA practioner may find difficulty in convincing the technical community at large to adopt their subjective prior distribution.

D In this same regard, a PRA practioner using Bayesian estimation is open to the criticism that a selfserving prior distribution has been selected that reflects a point of view (or bias) that may be inappropriate or incorrect. 
Bayesian inference is less well known and has less modern precedents than corresponding classical methods.

Because they are less widely used and available, Bayesian estimation methods sometimes require more concerted effort to appreciate, obtain, implement, and interpret in practice.

\section{C.2.2.2.4 Choosing an Estimation Method}

Although there are no universal rules to follow when deciding whether an analyst should use classical or Bayesian estimation methods, there are certain situations in which each has been found to be particularly appropriate. Bayesian estimation methods should be used to determine subjective distributions of input parameters whose uncertainties are required to be propagated through system models using Monte Carlo simulation (see Section C.6.3.1, page C-154). Bayesian methods should also be used when generic data are to be combined with plantspecific data to produce a plant-specific distribution of a parameter of interest. On the other hand, classical methods should be used for diagnostic testing of modeling assumptions, such as goodness-of-fit tests of an assumed distribution model.

\section{Guidance: Although there are situations in which classical methods are appropriate (such as goodness-of-fit testing), it is generally believed by most PRA analysts that, for most nuclear power plant PRA applications, the disadvantages of classical methods outweigh the advantages; thus, classical estimation has found only rather limited and restricted use in PRA.}

It is generally believed by most PRA analysts that, for PRA applications to complex systems such as nuclear power plants, the advantages of Bayesian methods outweigh the disadvantages; thus, Bayesian estimation methods are widely used in PRA.

There are no universal or clear-cut rules to follow for deciding when classical or Bayesian estimation methods should be used.

When using Bayesian methods, the sensitivity to the choice of the prior distribution should be investigated.

When there is strong direct evidence (i.e., when there is a large quantity of observable sample data) both approaches produce similar results.

Empirical Bayes represents another major class of methods of statistical inference that differ markedly in philosophy from Bayesian methods. Empirical Bayes is characterized by the fact that the prior distribution (sometimes referred to as the prior) has a relative frequency interpretation in contrast to the degree-of-belief interpretation of Bayesian statistics. For example, if a component belongs to a population of similar components in similar applications, such as a set of similar plants, then the prior distribution of the component failure rate represents the plant-to-plant differences in the failure rate. The empirical Bayes prior is sometimes referred to as the population variability curve. The prior is empirically determined using observed plant-specific data for a given set of plants, after which Bayes' theorem may then be applied. Reference C.2.20 illustrates the empirical Bayes approach for estimating the failure rate of nuclear power plant emergency diesel generators to start and load on demand. Reference C.2.21 present the basic theoretical foundation of empirical Bayes estimation, while Reference C.2.19 contains a chapter on empirical Bayes. 


\section{C.2.3 Common Statistical Methods in PRA}

Statistics play a central role in PRA. Among other things, PRA is concerned with estimating the frequency of accidents that can have undesirable consequences to penple, property, or the environment. For example, severe core damage accidents are of common interest in Level 1 nuclear reactor PRAs, and the frequency of such accidents may be quantified using probability and statistics.

Statistics is used to estimate the frequencies of occurrence of accident-initiating events and the probabilities of occurrence of the basic events identified in the system fault tree models. Thus, statistics is commonly used at the component level of PRA. The data used to estimate the desired parameters are in two forms: (1) industrywide generic reliability data (non-plant or non-application specific) on similar components in similar applications and (2) site or plant-specific operating experience on the specific component of interest.

The procedure for estimating unknown parameters, such as a failure rate, has two phases. First, a prior distribution for each unknown parameter using the generic data is determined. Second, this distribution is specified to the subject plant using Bayesian statistics in conjunction with plant-specific operating data. Thus, the plant-specific operating data constitute an assumed random sample of data according to an assumed sampling distribution. Of course, in many applications, such as a planned facility, there are no readily available plantspecific data and thus only generic data are used. In such cases Bayes' theorem is not used and the required estimates are completely based on the prior distribution. For these cases, it is important to investigate the sensitivity of the results to the particular choice of a prior distribution. When there are site-specific or plantspecific data, these data are then combined with the prior distribution using Bayes' theorem to produce the desired posterior distribution (the so-called site-specific or plant-specific distribution) on the parameter of interest. Point and probability interval estimates of the unknown parameter are ultimately obtained from this posterior.

There are numerous techniques for fitting (determining) an appropriate prior distribution. References C.2.22 and C.2.23 describe methods used to determine prior distributions based on generic (industry-wide) data (see Section C.2.4.1, page C-33). They also discuss how these prior distributions can be updated to form site-specific (or plant-specific) distributions. Bayesian updating is successively employed using additional data in conjunction with Bayes' theorem to obtain better, more appropriate plant-specific distributions.

The two-stage Bayesian procedure described in Reference C.2.24 is also used to determine suitable prior and posterior distributions. For example, methods based on the information-theoretic notion of maximum entropy can also be used to determine appropriate prior distributions that maximize the lack of information or entropy (uncertainty) inferred in the prior distribution conditional on what is known about the parameter of interest (Refs. C.2.25 and C.2.26). Other methods can be used to determine noninformative prior distributions (Ref. C.2.19).

Standard statistical techniques can and should be used in conjunction with the data to check departures from modeling assumptions. In statistical parlance this is known as diagnostic checking.

There are two basic types of failure measures of interest at the component level in a PRA: demand-dependent failure probabilities and time-dependent failure rates. Each corresponds to a different probability model, the binomial and Poisson models, respectively. However, it has been common practice in PRA to call the demanddependent probability a demand-dependent failure rate, where "rate" is the probability of failure per demand. Because the term rate usually refers to time, this usage may be confusing. It is better to use either of the terms demand-dependent failure probability or probability of failure on demand. 
The binomial distribution describes the number of failures $\mathrm{x}$ in $\mathrm{n}$ independent trials. The number of trials must be known in advance; the outcomes, success or failure on each trial, are statistically independent for each trial; and the probability of failure $p$ per trial is constant across the trials. For example, the binomial is the appropriate model to use when the probability of failure to start on demand of an emergency diesel generator must be estimated. In this case, the sample data (if any) consist of the number of observed failures $\mathbf{x}$ in $\mathbf{n}$ total operational or test demands. ${ }^{4}$ Either a lognormal or beta prior distribution (see below) is often fitted using appropriate generic data for use in Bayes' theorem (Ref. C.2.15). The resulting posterior distribution is used to obtain desired point and interval estimates of the unknown demand failure probability. The posterior mean is the Bayes estimator for $p$ under a squared-error loss function, while the posterior median is the Bayes estimator for an absolute-error loss function (Ref. C.2.19). Thus, both the posterior mean and median are often reported as point estimates of $p$.

The Poisson distribution describes the number of failures $\mathrm{x}$ in total time $\mathrm{T}$ when the times between successive failures are independently and identically distributed according to an exponential distribution. The quantity $T$ is known and failures occur independently and at a constant time-dependent failure rate $\lambda$ per unit time across different items. For example, the Poisson is the appropriate model to use when the failure rate is to be estimated for motor driven pumps while in operation. In this case, the sample data (if any) consist of the observed number of failures $x$ in a given total number of hours of operation $T$. Either a gamma or lognormal prior distribution (see below) is often fitted to appropriate generic data for use in Bayes' theorem. As for the binomial, the posterior distribution is used to calculate point estimates; both the posterior mean and median are commonly reported. Probability interval estimates are likewise often computed from the posterior distribution.

A closely related concept is that of frequency. In general, frequency is defined as the expected number of failures per unit time. In PRA applications, it is usually modeled by the Poisson distribution. from the Poisson distribution, the probability of $n$ failures occurring in time $t$ is given by the following expression:

$$
\frac{(\lambda t)^{n}}{n !} e^{-\lambda t} \text { for } \mathrm{n}=1,2,3 \ldots, \text { where } \lambda=\text { constant failure rate per unit time. }
$$

The expected number of failures per unit time is $\lambda t$ and the frequency is $\lambda$

It is important to understand that there are two possible sources of uncertainty when estimating both demand and time-dependent failure rates. The usual point estimator of a failure rate is the observed number of failures divided by the corresponding total population exposure time (the total exposure time for which the population is at risk of failure). Although only the numerator is traditionally considered to be the value of a random variable (and thus is the first and oftentimes the only source of uncertainty), in practice there is often uncertainty associated with the denominator as well. This additional source of uncertainty in the denominator introduces further uncertainty into calculated point and interval failure rate estimates, which is commonly ignored in PRA. In practice, there is uncertainty associated with population exposure times, which is customarily ignored when estimating failure rates in nuclear power plant PRAs.

The lognormal distribution is often used as a prior distribution for the unknown failure rate for many different kinds of basic failure events in PRA fault tree models when using Bayesian estimation methods in PRA (Section 5.5.2.2 of Reference C.2.15). A random variable $X$ is said to have a lognormal distribution if $Y=\ln X$ has a normal distribution or (iaussian distribution. The lognormal distribution has two parameters, often represented as the median and corresponding error factor for the failure rate, which must be estimated from the available

\footnotetext{
- In many PRA applications, because $n$ is not precisely known, an estimate of $n$ is used. However, the uncertainty in $n$ is usually not taken into account and is thus ignored.
} 
failure rate data. The error factor is a particularly useful parameter because the product of the median and the error factor produces an upper probability bound for the failure rate. Similarly, the median divided by the error factor yields a corresponding lower probability bound for the failure rate. Reference C.2.15 discusses several methods for obtaining the required estimates of these parameters.

The beta family of distributions is often used as a suitable family of prior distributions in Bayesian estimation of the binomial parameter $\mathrm{p}$, the demand failure rate. Reference C.2.15 describes the use of beta prior distributions and the estimation of the corresponding two prior parameters from available data. Beta distributions are also used in Bayesian common-cause failure analysis for quantifying the uncertainties in Multiple Greek Letter (MGL) parameter estimates (see Section C.3.3.4, page C-55). A thorough description of the beta family of distributions and methods for fitting beta prior distributions is given in Reference C.2.19.

The gamma family of distributions is a commonly used family of priors for Bayesian estimation of the Poisson time-dependent failure rate. A gamma distribution has a shape and a scale parameter. Each of these parameters must be estimated from available failure data in order to use it as a prior distribution for Bayesian failure rate estimation. Both Reference C.2.19 and Section 5.5.2.2 of Reference C.2.15 discuss methods for use in fitting gamma prior distributions.

The statistical estimates of these parameters are then used in conjunction with simple models to compute the required basic event probabilities of occurrence. Basic events, such as unavailability because of failure while on standby, unavailability from annunciated failure in time, and unavailability from an unannunciated failure while on standby, each require a different model for computing the desired unavailability. The statistical estimates just described are basic inputs to these model calculations.

The point estimates of the basic event probabilities of occurrence are then combined using standard methods of probability, such as the inclusion-exclusion rule or the rare-event approximation (Ref. C.2.11), to calculate point estimates of the desired fault tree top event probabilities of interest. The chain rule is then used to compute the desired accident sequence frequencies of occurrence.

The posterior distributions of basic fault tree event parameters are also useful for propagating uncertainties. These distributions can be directly propagated upward through the trees to produce corresponding distributions on the top event probabilities of occurrence. These distributions on the top event occurrence probabilities may then be similarly combined using the event tree models to produce distributions on such quantities of interest as the accident sequence frequencies of occurrence. Section C.6.3 (page C-154) discusses methods for propagating these distributions through fault and event tree models.

\section{C.2.4 Sources of Data}

In order to apply the reliability and unavailability models to be discussed in Chapter C.3 (page C-41), the analyst must first estimate the parameters of such models using appropriate statistical estimation methods, such as those discussed above, in conjunction with available data.

Three categories of data or information about a parameter of interest (such as a demand failure rate) are often available: (1) engineering knowledge about the design, construction, and performance of the component, (2) past performance of similar components in similar environments, and (3) past performance of the specific component in question. The first two types constitute generic data or information and may include varying degrees of subjective judgment. The third type, consisting of observed sample data, is the plant-specific or applicationspecific data. A fourth type of information, expert judgment, is sometimes used for rare events when little or no generic or plant-specific data exist (such as for the frequency of occurrence of a severe earthquake in a region 
for which there has never been an earthquake of the magnitude under consideration). The elicitation and use of expert opinion is discussed in Chapter C.5 (page C-129).

Some of the more common sources of generic and plant-specific data are described below. Regardless of the source, the quality of the data should match the quality of the models. The analyst should ensure that the data conform to the statistical model and accurately represent the situation for which statistical inference (such as parameter estimates) are desired. The sources of data described below vary tremendously in both quality and applicability. Care and caution must be exercised in both collecting and using data from these sources. For example, many generic data sources utilize the same basic failure event data and thus cannot be assumed to be independent sources. Also, industry participation in a given data base effort may be voluntary. Consequently, parameter estimates calculated from these data sources may be nonrepresentative (that is, biased). Section 5.9 ' of Reference C.2.15 discusses data quality.

\section{C.2.4.1 Generic Data}

Useful sources of generic data (such as failure and maintenance data) are found in the reliability data bases supporting current (modern) PRAs. These PRAs are often performed for recent or current NRC-sponsored PRA programs, such as NUREG-1150 (Ref. C.2.27). During the NUREG-1150 study, a generic component data base was developed and used in PRAs of five commercial nuclear power plants. The reliability data base was developed for Reference C.2.28.

An older publication from the NRC is the Reactor Safety Study (Ref C.2.18), which contained much information on methods of data collection, failure rate data, and model development for risk analysis. The Reactor Safety Study summarizes generic (and some specific) component failure rate data for nuclear plant PRAs. This data source was largely compiled using expert judgment based, nonnuclear operating experience. In spite of this and the fact that this data source is nearly 20 years old, it continues to be used as a source of generic failure rate data and is the basis of a number of other generic sources of data. However, it has now been superseded by Reference C.2.27.

The Institute of Electrical and Electronics Engineers (IEEE) publishes ANSI/IEEE Std 500-1984 (Ref. C.2.29), a manual that contains useful data on failure modes, failure rate ranges, and environmental factors on generic components actually or potentially used in nuclear power plants. It contains information on over 1000 electrical, electronic, sensing, and mechanical components and is arranged for easy data access. Some comments on the resulting aggregated failure rate distributions are given in Chapter C.5.6 (page C-139). The Industrial and Commercial Power Systems Committee of the IEEE conducts a survey of 68 industrial plants in 9 industries and reports on equipment failures, cost of outages, loss causes, and types of failures.

Another source of reliability data is the Nuclear Computerized Library for Assessing Reactor Reliability (NUCLARR) (Ref. C.2.30). The primary goal of NUCLARR is to establish and operate computerized data base management tools for use in estimating human error probabilities and hardware component failure rates in the nuclear power industry. It is implemented as a user-friendly, menu-driven system for retrieving and manipulating data obtained from other sources.

The International Atomic Energy Agency (IAEA) developed a component reliability data base that is a good source of generic data (Ref. C.2.31). It consists of approximately 1000 records compiled from 21 different data sources around the world. It includes data for all components usually modeled in nuclear power plant PRAs. It was compiled using DBASE III commercial software. 
C.2 Probability and Statistics

C.2.4 Sources of Data

In addition to NUREG-1150 (Ref. C.2.27), generic data for maintenance can be derived from the NERC/GADS reports. The National Electric Reliability Council (NERC) operates the Generating Availability Data System (GADS), formerly called the Edison Electric Institute Equipment Availability Data System. Its major concern is with summary performance data on all types of electric power generating equipment. It is the primary means of collecting, processing, analyzing, and reporting data on outage, availability, and maintenance of systems and components.

Maintenance data for component outage frequencies and durations compiled from nuclear plant experience is also of use in PRA. PLG, Inc. and other private consulting firms, such as Science Applications International Corporation (SAIC) and Westinghouse Corporation, have compiled and maintain proprietary generic reliability data bases for use in their own PRAs and for other commercial uses (for example, the Pickard, Lowe, and Garrick, Inc. proprietary report, "Database for Probabilistic Risk Assessment of Light Water Nuclear Power Plants," PLG-0500, November 1991). In addition to component data, these contain common cause failure data and initiating event data, generally in a format that is compatible with the reliability and unavailability models defined for a PRA. The Electric Power Research Institute has been regularly funding projects for compilation of common cause events. NUREG/CR-4780 (Ref. C.2.32) documents these data and provides detailed methodologies for common cause failure models. The EPRI report has been recently updated (Ref. C.2.33). The NRC Office for the Analysis of Event and Operating Data (AEOD) also has two projects under way to compile a common cause failure event data base and update initiating event frequencies.

There are many other less widely used sources of generic reliability data, some of which are described here. The Government-Industry Data Exchange Program (GIDEP) seeks to reduce the costs, in time and money, of gathering data by providing for an exchange of data that is essential in the research, design, development, production, and operational life-cycle phases of systems and equipment. There are four major areas for exchange of common data: (1) engineering, (2) metrology, (3) reliability-maintainability, and (4) failure experience. A major program sponsored by GIDEP is the Failure Rate Data Program (FARADA), which involves the joint collection, analysis, compilation, and distribution of failure rate data and failure mode data by the Army, Navy, Air Force, and NASA.

The United Kingdom Atomic Energy Authority Data Program (UKAEA) is a comprehensive source of reliability data on nuclear power reactors. The data classification and coding format are similar to that used by the FARADA and GIDEP programs. The data come from a long-standing incident-reporting system on some 900 components. There is also a reliability data bank called the National Center of Systems Reliability (SYREL). It has information on performance availability and generic reliability data, some of it from industries other than nuclear power plants.

Reference C.2.34 provides data from military and space applications in four sections: (1) generic level failure rate data, (2) detailed part failure-rate data, (3) data from commercial applications on parts, and (4) failure modes and mechanisms.

The Energy Systems Group of Rockwell International operates the Energy Technology Engineering Center (ETEC), formerly called the Liquid Metal Engineering Center (LMEC). This program was concerned with equipment and parts used in tests of liquid metal systems and experimental reactors. Information on general reactor components used to be included in the program, but that practice was discontinued. However, information from it can still be obtained. 


\section{C.2.4.2 Plant-Specific Data}

The best sources of plant-specific failure and maintenance data are the plant records themselves. However, different plants have different means of keeping logs on component failure and maintenance events. In general, no single source provides all the data necessary for estimation of the statistical parameters required in the PRA. Various sources must be consulted, and similar sources may be called by different names in different plants. The NRC does not have direct access to these sources of data on a routine basis. Collecting this information is usually very labor-intensive and often requires clarification from plant personnel.

Control room logs generally track all systems that are necessary for continued plant operation and all safetyrelated equipment. The amount of information entered, however, is generally quite brief. Data for an event may be spread over several days, making this source quite cumbersome. The control room logs, however, are possibly the best source of data for system switchovers. Every time the trains of an operating system are switched from operating to standby mode, the information is reported. A survey of a few months of such logs can provide a good estimate on the number of actuations of such components.

Every plant maintains a system for reports on component failures. These reports are created when failures or degraded states are noticed during plant walk-through or during surveillance tests. For example, these may be called action reports, failure reports, discrepancy reports, or trouble reports.

All maintenance work performed in a nuclear plant is cleared by the operations utility staff and is logged as, for example, maintenance requests, clearance requests, work requests, or tag-out orders. The advantage of using this source is that all the information for a given event appears on a single record, unlike the control room logs.

Other sources that may be available at some plants are component history logs that contain all information about a specific component, such as failures, maintenance events, operating time, and actuation demands. Data from run meters and cycle counters may also be available at some plants, and these simplify the task of estimating failure rates considerably.

Licensees report off-normal events to the NRC as Licensee Event Reports (LERs) in accordance with 10 CFR 50.73. It states that an event involving a system required to (1) shut down the reactor, (2) remove residual heat, (3) control the release of radioactivity, or (4) mitigate the consequences of an accident must be reported to the NRC. For this reason, LERS are more useful for obtaining system information than component information. An LER consists of the facility name, the operating conditions at the plant, a description of the event, the significance of the event, a root cause analysis, and the corrective actions taken. A total of 2128 LERs were reported in 1990, 1858 in 1991, and 1767 in 1992.

The Sequence Coding and Search System (SCSS), a data base maintained for the NRC by the Nuclear Operations Analysis Center at the Oak Ridge National Laboratory, is designed to facilitate the storage and retrieval of LER data. On average, SCSS contains 150 pieces of related information for each LER. SCSS is also a good source for common cause failure event data. SCSS can be used to obtain system failure information and component failure information for components involved in LER-reportable events. Because many component failures are not reportable under the LER reporting requirements, component failure information obtained from SCSS is incomplete and should be used with caution to estimate failure rates. This limitation reduces the usefulness of LER data as a plant-specific data source.

The NRC also issues the Gray Book (Ref. C.2.35), a report that is a source of data on all operating commercial U. S. nuclear power plants. It is a compilation of operating status information submitted in licensee monthly operating reports, such as operating status, average daily power levels, unit shutdowns, and power reductions. 
It also contains information about the status of NRC inspections at the various units. Another source of potential information is the immediate notification reports required under 10 CFR 50.72, some of which become LERs.

The Nuclear Plant Reliability Data System (NPRDS), maintained and managed by the Institute of Nuclear Power Operations (INPO) is a source of plant-specific component failure data. NPRDS accumulates, stores, and reports failure statistics on components in nuclear power plants. This data base does not currently contain information on component demands or actual operating time. The data base currently contains approximately 140,000 component failure records and approximately 565,000 component engineering records. These records are related to 32 major component types in 112 nuclear units. However, because plant participation in this effort is voluntary, a question of completeness of the plant-specific information arises. The data are also proprietary.

\section{C.2.5 Summary}

- Both subjective and frequentist interpretations of probability are important for and used in PRA. There are no universal a priori rules for deciding whether a classical or Bayesian estimation method is the preferred method in each and every situation.

- Basic rules used to calculate probabilities are the inclusion-exclusion rule and the chain rule. The inclusion-exclusion rule is used to calculate the probability of the union of a set of events; that is, the probability that any one or more of the events occurs. The chain rule is used to calculate the probability of the intersection of a set of events; that is, the probability that all the events occur simultaneously.

- Two basic types of parameter estimates are the point estimate and interval estimate. Stating a parameter with a single number is called a point estimate. Stating with a specified degree of certainty, that a parameter lies in some interval $(L, U)$ is an interval estimate.

- Because of its ambiguity, the use of the term "best estimate" should be avoided in statistical estimation.

- Because the advantages of Bayesian statistics often outweigh the disadvantages in PRA applications, Bayesian statistics play a major role in PRA relative to classical statistics.

- A confidence interval differs from a probability interval. Confidence intervals are interval estimates of the parameters of a distribution. Bayesian interval estimates obtained from the prior or posterior are subjective probability intervals or credibility intervals. While a classical confidence interval cannot be interpreted as a probability statement regarding a PRA parameter to be estimated, a Bayesian probability interval has such an interpretation.

- Four categories of reliability data or information about a parameter of interest are (1) engineering knowledge about the design, construction, and performance of the component, (2) past performance of similar components in similar environments, (3) past performance of the specific component in question, and (4) expert opinion regarding the parameter. Both generic and plant-specific data sources are available. In performing PRA, the quality of the reliability data is of tantamount importance and cannot be overemphasized. 


\section{REFERENCES FOR CHAPTER C.2}

C.2.1 A. H-S Ang and W. H. Tang, Probability Concepts in Engineering Planning and Design, Volume I - Basic Principles, John Wiley, New York, 1975.

C.2.2 L. R. Abramson, "The Philosophical Basis for the Use of Probabilities in Safety Assessments," in Reliability Engineering and System Safety, Volume 23, No. 4, pp. 253-257, 1988.

C.2.3 L. J. Savage, The Foundations of Statistics, John Wiley, New York, 1954.

C.2.4 S. J. Press, Bayesian Statistics: Principles, Models, and Applications, John Wiley, New York, 1989.

C.2.5 Reliability Engineering and System Safety, Volume 23, No. 4, 1988.

C.2.6 G. W. Parry, "A Discussion on the Use of Judgment in Representing Uncertainty in PRAs," Nuclear Engineering and Design, Volume 93, pp. 135-144, 1986.

C.2:7 G. Apostolakis, "The Concept of Probability in Safety Assessments of Technological Systems," Science, Volume 250, pp. 1359-1364, 1990.

C.2.8 S. Kaplan, "Will the Real Probability Please Stand Up?" Reliability Engineering and System Safety, Volume 23, No. 4, pp. 285-292, 1988.

C.2.9 H. F. Martz and R. A. Waller, "On the Meaning of Probability," Reliability Engineering and System Safety, Volume 23, No. 4, pp. 299-304, 1988.

C.2.10 S. Kaplan and B. J. Garrick, "On the Quantitative Definition of Risk," Risk Analysis, Volume 1, No. 1, pp. 11-27, 1981.

C.2.11 E. J. Henley and H. Kumamoto, Probabilistic Risk Assessment: Reliability Engineering, Design, and Analysis, IEEE Press, Piscataway, New Jersey, 1992.

C.2.12 J.D. Esary and F. Proschan, "A Reliability Bound for Systems of Maintained, Interdependent Components," Joumal of the America Statistical Association, Volume 65, pp. 329-338, 1970.

C.2.13 J.D. Esary and F. Proschan, "Coherent Structures of Non-Identical Components," Technometrics, Volume 6, pp. 191-209, 1963.

C.2.14 R. E. Walpole and R. H. Myers, Probability and Statistics for Engineers and Scientists (Third Edition), Macmillan, New York, 1985.

C.2.15 J. W. Hickman, "PRA Procedures Guide, A Guide to the Performance of Probabilistic Risk Assessments for Nuclear Power Plants," NUREG/CR-2300, Volume 1, NRC, January 1983.

C.2.16 A. M. Mood et al., Introduction to the Theory of Statistics, Third Edition, McGraw-Hill, New York, 1974. 
C.2 Probability and Statistics

C.2.17 W. J. Conover, Practical Nonparametric Statistics, John Wiley, New York, 1971.

C.2.18 NRC, "Reactor Safety Study - An Assessment of Accident Risks in U.S. Commercial Nuclear Power Plants," Appendix 3-"Failure Data," WASH-1400 (NUREG-75/014), October 1975.

C.2.19 H. F. Martz and R. A. Waller, Bayesian Reliability Analysis, Krieger, Malabar, Florida, 1991.

C.2.20 H. F. Martz, "On Broadening Failure Rate Distributions in PRA Uncertainty Analyses," Risk Analysis, Volume 4, No. 1, pp. 15-23, 1984.

4.2.21 J. S. Maritz and T. Lwin, Empirical Bayes Methods, Second Edition, Chapman and Hall, London, 1989.

C.2.22 G. Apostolakis, "Data Analysis in Risk Assessments," Nuclear Engineering and Design, Volume 71', pp. 375-381, 1982.

C.2.23 G. Apostolakis et al., "Data Specialization for Plant-Specific Risk Studies," Nuclear Engineering and Design, Volume 56, pp. 321-329, 1980.

C.2.24 S. Kaplan, "On a 'Two-Stage' Bayesian Procedure for Determining Failure Rates from Experimental Data," IEEE Transactions on Power Apparatus and Systems, Volume PAS-102, No. 1, pp. 195-202, 1983.

C.2.25 R. A. Bari and C. K. Park, "Uncertainty Characterization of Data for Probabilistic Risk Assessment," Reliability Engineering and System Safety, Volume 26, pp. 163-172, 1989.

C.2.26 S. D. Unwin et al., "An Information-Theoretic Basis for Uncertainty Analysis: Application to the QUASAR Severe Accident Study," Reliability Engineering and System Safety, Volume 26, pp. 143-162, 1989.

C.2.27 NRC, "Severe Accident Risks: An Assessment for Five U.S. Nuclear Power Plants," NUREG-1150, Volumes 1 and 2, December 1990.

C.2.28 D. M. Ericson et al., "Analysis of Core Damage Frequency: Internal Events Methodology," NUREG/CR-4550, Volume 1, Rev. 1 (Sandia National Laboratories Report, SAND86-2084), NRC, January 1990.

C.2.29 Institute of Electrical and Electronic Engineers (IEEE), "IEEE Guide to the Collection and Presentation of Electrical, Electronic, Sensing Component, and Mechanical Equipment Reliability Data for Nuclear Power Generating Stations," ANSI/IEEE Std 500-1984, Wiley-Interscience, New York, 1983.

C.2.30 D. 1. Gertman et al., "Nuclear Computerized Library for Assessing Reactor Reliability (NUCLARR)," NUREG/CR-4639, Volume 1, Rev. 1, (EG\&G Idaho, Inc. EGG-2458), May 1990.

C.2.31 "Component Reliability Data for Use in Probabilistic Safety Assessment," IAEA-TECDOC-478, International Atomic Eneroy Agency, Vienna, Austria, October 1988. 
C.2.32 A. Mosleh et al., "Procedures for Treating Common Cause Failures in Safety and Reliability Studies - Procedural Framework and Examples," NUREG/CR-4780, Volume 1 (EPRI, NP-5613) NRC, January 1988.

C.2.33 K.N. Fleming et al., "A Database of Common-Cause Events for Risk and Reliability Evaluations," EPRI-100382, Electric Power Research Institute (Pickard, Lowe, and Garrick, Inc., PLG-0866), June 1992.

C.2.34 W. Denseon et al., "Nonelectronic Parts Reliability Data," Reliability Analysis Center, P.O. Box 4700, Rome, NY 13440-8200, 1991.

C.2.35 NRC, "Licensed Operating Reactors; Status Summary Report," NUREG-0020, published annually. 


\section{C.3 ACCIDENT SEQUENCE AND RELIABILITY ANALYSES}

\section{C.3.1 Learning Objectives}

Chapter C.3 presents basic probabilistic methods and tools useful in performing a Level 1 PRA, i.e., identifying accident sequences leading to core damage and quantifying their frequencies. The emphasis is on models most commonly used. The ultimate use of these models is enabling the analysts to identify the accident sequences that dominate the core damage frequency so that risk management can be accomplished on a rational basis. The results are also used as input to Level 2 and 3 PRAs. The concepts and techniques involved are presented in References C.3.1 through C.3.6, which are also the primary sources for the material presented in Sections C.3.2 and C.3.3.1. The reader will gain an understanding of the following:

- Failure rates of components

- Probability distribution functions as failure distributions

- Component unavailabilities

- Redundancy

- Common cause failures

- Fault tree analysis

- Component reliability analysis

- System reliability analysis

- Accident sequence analysis

- Dependent failure analysis

- Human reliability analysis

- External events analysis

- Software reliability analysis

- Time-dependent models of components and accident sequences

- Commonly used computer programs' for reliability analysis

\section{C.3.2 Concepts}

The quantification of the reliability of or risk from an industrial facility requires the construction of models for the various ways that the facility can succeed or fail in its mission. Conceptually, success and failure are similar; we may develop a set of events whose occurrence guarantees the successful operation of the system or we may search for sequences of events whose occurrence guarantees the failure of the system. The latter are called accident sequences when we deal with the whole facility, or minimal cut sets when we deal with a specific system. It is common practice to work with failures and, consequently, most of the established terminology refers to failures. This chapter follows this practice of emphasizing the analysis of failures; still, it is important to bear in mind that the definitions and methods that are introduced have a counterpart in the domain of success.

Failures of technological systems that lead to severe consequences are infrequent. Therefore, a significant statistical data base does not exist and the application of statistical methods at the system level is not practical. This is the reason the probability of system failure is synthesized using models that relate system failures to component failures and human errors. The probability of failure of the system is, then, calculated from these more elementary and better understood failures. These models contain parameters, such as the rates of occurrence of various events, that are not known prècisely. In addition, the assumptions on which the models themselves are based may not be universally accepted or valid. These two kinds of uncertainty, parameter and model uncertainty, must also be quantified for the analysis to be complete. This chapter deals primarily with the models that identify the accident sequences and calculate the system failure probability from the probabilities 


\section{C.3 Accident Sequence \& Reliability Analyses \\ C.3.3 Methods \\ C.3.3.1 Component Reliability Analysis}

of elementary events. Some discussion on parameter uncertainty is offered, where appropriate. More detailed discussions on parameter and model uncertainties are given in Chapter C.6.

The concepts and methods presented in this chapter are applicable to any facility in which an undesirable event (for which adequate statistical data do not exist) is to be analyzed. The presence of safety systems that may prevent this event from occurring is typical of such analyses. The historical reason for this is that most of these models have evolved from Level 1 PRA studies, where the undesirable event is, of course, core damage. For facilities in which the occurrence of the undesirable event includes the modeling of physical phenomena, e.g., waste repositories, some of our discussion on modeling the failures of redundant systems may be of lesser importance, while the models of Level 2 PRAs, presented in Chapter C.4, may be more relevant.

\section{C.3.3 Methods}

\section{C.3.3.1 Component Reliability Analysis}

This section presents the basic methods commonly used to estimate the reliability of a single device or component. A component is the smallest part of a system that must be considered as part of a system analysis. There are two basic types of components to be considered, those that operate continuously and those that operate on demand. For a component in continuous operation, the failure characteristics are described by a conditional failure rate sometimes called the hazard rate, denoted by $\lambda(t)$. This failure rate is defined as follows: $\lambda(t) \Delta t$ is the conditional probability that the component will fail in the interval $(t, t+\Delta t)$, given that it has survived up to $t$.

A component that operates on demand is called upon intermittently, and it either operates on the nth demand or it doesn't. It is common practice to assume that demand events are identical and independent. Therefore, failures are assumed to occur randomly at a constant rate resulting in a single probability of failure per demand. Often, however, such a component may also have a failure rate associated with latent faults that occur during non-operation. Such a failure rate is called a standby failure rate, $\lambda_{,}(t)$, which is a conditional failure rate similar to the hazard rate. The component's probability of failure on demand thus includes its unavailability from latent faults.

After the component starts successfully, it may have another failure rate, $\lambda(t)$, which would be associated with failures that may occur while running. For a standby component that may be needed for a period of time $t$, the calculation of its reliability would have to include the probability of a successful start and the probability of running successfully. Sometimes this compound probability is called the operational reliability of the component.

Most commonly, the time-dependent failure rate, $\lambda(t)$, is characterized by the bathtub curve. The bathtub curve is made up of three distinct regions as shown in Figure C.3.1 (from Reference C.3.1). The first of these is called the early failure period, during which the failure rate starts from a maximum and decreases rapidly. The high failure rate early in the component's life cycle is caused by poor quality control practices and a natural wear-in or debugging period. The next region of the bathtub curve is the constant failure rate period, during which random failures occur at an approximately uniform rate. This period corresponds to the component's useful life. Last is the wear-out or aging failure period. Here the failure rate again increases rapidly. Failures occur with increasing frequency because of irreversible processes such as corrosion.

The failure rate, $\lambda(t)$, contains all the information necessary to find the time-dependent reliability, $R(t)$, of the component. The reliability function, $R(t)$, is defined as the probability that the component has not failed for a given period of time, $t$, under specific operating conditions. In other words, it is the probability that a component performs its specified function under given conditions for a prescribed time. 


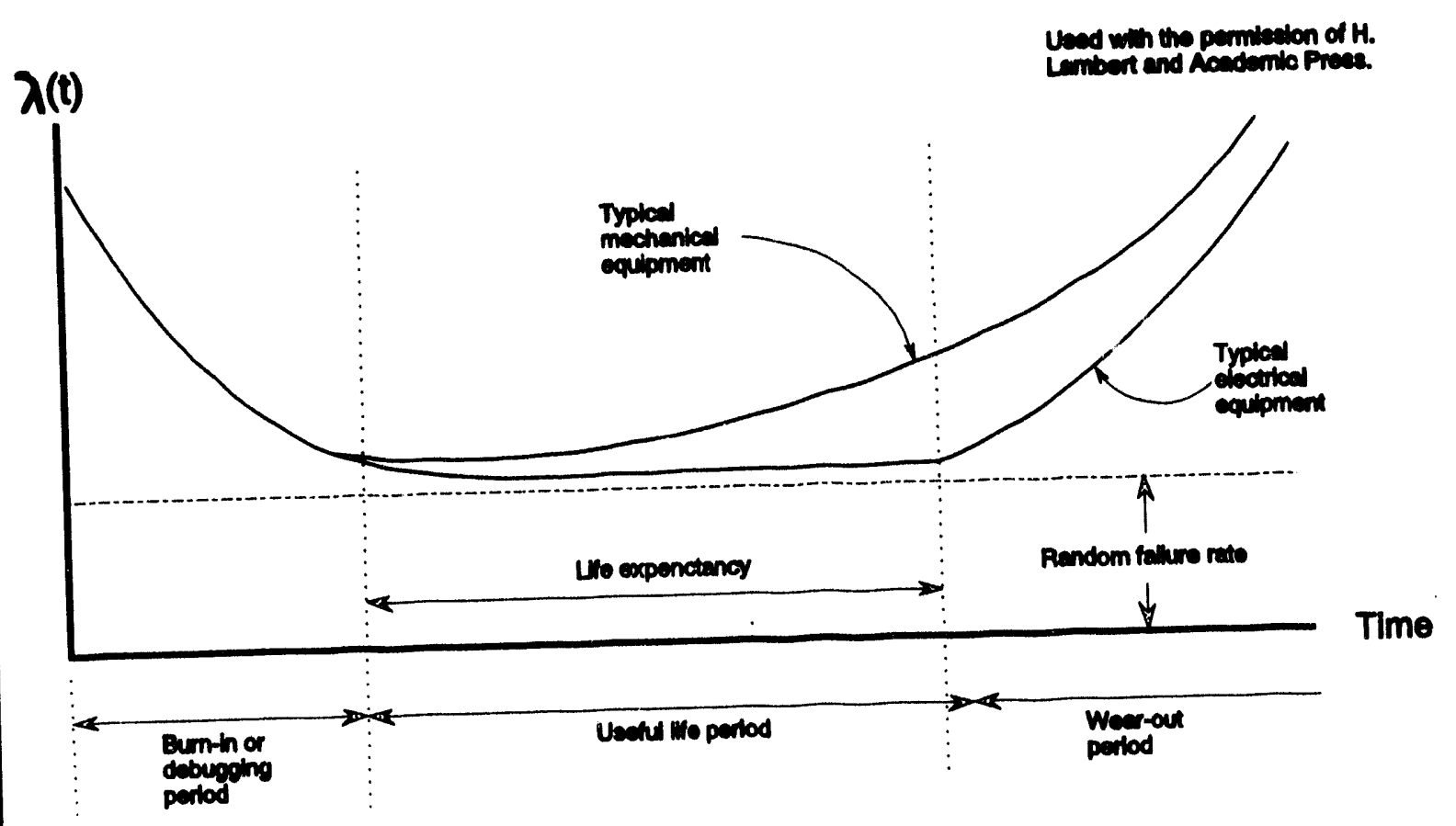

Figure C.3.1 Time dependence of failure rate (from Reference C.3.1)

Guidance: If $\lambda(t)$ is not known precisely, and since the flat region of the bathtub curve corresponds to the component's useful life, the failure rate is frequently approximated by a constant, $\lambda$ For components that have a constant failure rate, the failure time is govemed by an exponential distribution.

Probability models for single components frequently used in PRA include unattended components, repairable components, and periodically renewed components. These models are discussed in turn.

\section{C.33.1.1 Unattended Components}

The most common model used for the failure of components is the exponential distribution:

$$
F(t)=1-e^{-\lambda t} \quad \begin{aligned}
\lambda & =\text { failure rate } \\
t & =\text { time }
\end{aligned}
$$

This is the probability of failure in the interval $(0, t)$. The failure rate is constant, i.e., the component is assumed to be in the useful life period of Figure C.3.1. For small values of $\lambda t$, as usually happens in practice, the failure probability is $F(t) \approx \lambda t$. Some pitfalls of this approximation are discussed in Reference C.3.7.

The reliability of the component is $R(t)=1-F(t)=e^{-\lambda t}$.

The mean time to failure is $1 / \lambda$. 


\section{C.3 Accident Sequence \& Reliability Ànalyses \\ C.3.3 Methods \\ C.3.3.2 System Reliability Analysis}

\section{C3.3.1.2 Repairable Components}

In a typical case, a component has both an exponential failure and repair distribution. Similar to the mean time to failure, the mean time to repair (MTTR) is $\tau$.

The repair dist:ibution is as follows:

$$
G(t)=1-e^{-t / t} \quad \text { where } \tau=\text { average time to repair }
$$

This distribution yields the probability that the repair process is completed in the time interval $(0, t)$. An assumption made is that the repair process begins immediately when the failure occurs, i.e., the component is continually monitored and its failure is detected when the failure occurs. In this case, the unavailability, $q(t)$, or its complement, the availability, $p(t)$, is of interest. Unavailability is expressed as

$$
q(t)=\frac{\lambda \tau}{1+\lambda \tau}\left\{1-e^{-[\lambda+(1 / \tau)]} \cdot\right\}
$$

The asymptotic unavailability is the limit of this expression for large values of $t$, such as those typically greater than $3 \tau$, and is given by the equation $Q=\lambda \tau$ under the assumption that $\lambda \tau \ll 1$. This assumption is usually satisfied.

\section{C.3.3.1.3 Periodically Renewed Components}

Standby components are usually tested and repaired periodically to ensure their availability. Assuming that the test occurs every $\mathrm{T}$ hours and that the renewal is instantaneous, Reference C.3.8 shows that the average unavailability is $q=(\lambda \tau) / 2$.

When a constant failure rate is not assumed, a commonly used distribution for modeling the failure time is the Weibull distribution. The failure rate using the Weibull model is given by $\lambda(t)=(\alpha / \beta)(t / \beta)^{\alpha-1}$, where $\alpha$ and $\beta$ are the parameters of the distribution. Depending, on the value chosen for $\alpha, \lambda(t)$ can be either an increasing, decreasing, or constant function of time. If $\alpha<1, \lambda(t)$ decreases in time, as in the wear-in portion of the bathtub curve; and if $\alpha>1, \lambda(t)$ increases in time, as in the wear-out portion of the bathtub curve. Notice that for the special case of $\alpha=1, \lambda(t)$ is constant and the Weibull distribution reduces to the exponential distribution.

\section{C.3.3.2 System Reliability Analysis}

A system is defined as a set of components that interact in concert to perform a given function. As such, a system can fail in many different ways (Ref. C.3.4). Each of these ways is called a system failure mode and involves the failure of one or more components. System reliability is, in general, a complex function of the individual component reliabilities. Moreover, when a component fails; the logic of the system changes and the reliability function changes along with it.

The reason for the complexity of the system reliability function is the variety of redundancy and maintenance schemes into which the individual components can be organized. Redundancy is defined as the existence of more than one component or system (usually identical) for performing a function. Adding more than one component for accomplishing a given task or replicating entire systems or subsystems, so that more than one component must fail before there is an overall failure of the system, makes it possible to reduce the consequences of one or several failures. However, failures that affect redundant components simultaneously (such as power failure or inadequate design) can render redundancy ineffective. Note that redundancy is different from diversity. 
Diverse components or systems are not "identical," as redundant elements are usually assumed to be. For example, a motor-driven pump and a turbine-driven pump would constitute a diverse system of pumps.

There are two main types of redundancy, parallel redundancy and standby redundancy. In parallel redundancy, two or more elements (components or systems) operate simultaneously to perform the required function, but they are still capable of performing their function even in the presence of one or more individual failures. The most general form of parallel redundancy is the k-out-of-n system, which is a system of $\mathbf{n}$ identical elements of which $k$ are needed at any time for the system to operate. For the system to be redundant, $k$ must be less than $\mathrm{n}$; when it is equal to $\mathrm{n}$, the logic is that of a series system. A standby redundant component does not begin operation until the primary component has already failed. Standby redundancy can be classified into the following two types based on component failure characteristics: Hot standby is when the standby component failure rate is non-zero but is smaller than the operating component failure rate (this use of the term differs from the hot standby mode of reactor operation); cold standby is when components do not fail while they are in standby. Sometimes there are different interpretations of these terms; for instance, the failure rate of the standby component may not be smaller than that of the on-line component. In both types of standby, the failure characteristics of the standby components are affected by the failure of the primary components, thus component failures are not statistically independent. Also, components may not be maintained, or they may be repaired after failure. If they are repaired, their availability depends on the method of failure detection. Components that operate continuously may be continuously monitored and repaired immediately upon detection of a failure. Components that must operate on demand may be tested periodically. The system availability also depends on the amount of time that a component is unavailable while down for repairs or testing.

Components can be arranged in series, which requires that all components be operating to accomplish their function, or in parallel, which allows for the function to be accomplished even if one or perhaps more of the individual components have failed. One or more in a group of parallel redundant components may also be standby. The overall system availability depends on the individual component availabilities, the frequency and order in which the components are tested and repaired, and the downtime required for each component during maintenance.

Analytical solutions exist for the reliabilities of simple systems (such as one-out-of-two, one-out-of-three, and twoout-of-three parallel systems) undergoing periodic testing and maintenance (Refs. C.3.8 and C.3.9). However, as such systems are combined into more complicated, real-life systems, an analytical approach could become unwieldy. A common approach in many safety studies is the use of numerical computer codes (Ref. C.3.1(ij that plot the individual reliabilities of the components and then numerically integrate the overall system reliability. This approach allows the incorporation of several different component failure modes as well as different maintenance schemes and their effects on downtime, repair time, test-caused failures, etc.

Evaluation of system reliability is often facilitated by developing a logic diagram of the system that models the relationships between system components graphically. The first such type of diagram to be used was the block diagram (Ref. C.3.3). In a block diagram model, components, subsystems, or other functions are represented by blocks. The modeling consists of finding links between the blocks. Blocks representing components whose failure causes a failure of the system are joined in series. Blocks representing components whose failure can only cause a system failure if coupled with other blocks are placed in parallel with the latter. The failure of a block interrupts the signal through that block. System failure occurs when an input signal fails to reach the output as shown in Figure C.3.2 (from Reference C.3.3). A similar type of model is the directed graph or digraph (Ref. C.3.4). Instead of blocks, a digraph has 'nodes' that represent process variables or parameters connected by 'directed edges' or arcs that represent relations of influence or cause-and-effect between the nodes (another term for this type of diagram is a network). These models are better suited than block diagrams for representing process causality and provide a compact representation of physical processes. 


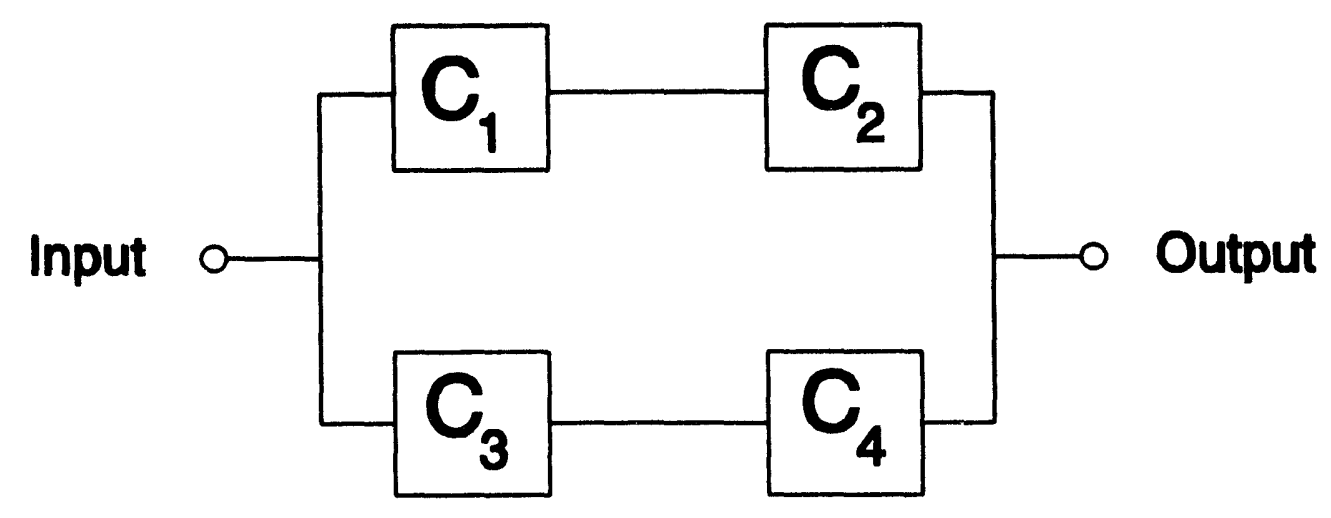

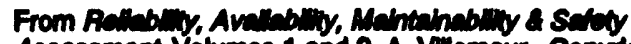
Aeprinted by permiation of John Wiey end Sons, Lipht 1901.

Figure C.3.2 A series-parallel block diagram (from Reference C.3.3)

Failure modes and effects analysis (FMEA) is a tool frequently used to understand system failure modes (Refs. C.3.1 - C.3.5). The objective is to identify all the individual component failure modes and analyze the effects they have on the system. Several slightly different formats are used, but all require that all the significant failure modes of each component are considered and that their effects are traced through the system in order to assess their ultimate effect on system performance. The failure mode effect and criticality analysis (FMECA) is related to the FMEA, but the occurrence probability of each failure mode and the criticality of its effects are analyzed in more detail (Refs. C.3.2 and C.3.3). The purpose of FMECA is to ensure that failure modes with severe effects have sufficiently low occurrence probabilities.

Fault trees are the primary tools for system level PRAs. A fault tree is a graphical tool that is very common in system analysis when an undesired state of the system (called a top event) is specified, and then the system is analyzed in detail, within the context of its environment and operation, to determine all the possible ways in which that event could occur (Refs. C.3.1 - C.3.5). It addresses the question of how a system can fail to perform its intended function. The fault tree itself is a graphic model that represents the combinations of individual component failures that lead to the occurrence of the undesired state. In FMEA a component failure is postulated and then the effects are studied; fault tree analysis proceeds in the opposite way. It identifies the various causes, whether they be component failures, human errors, or any other pertinent events, of a single predefined event by utilizing engineering knowledge of the system. Therefore, a fault tree will only contain those failures that contribute to the particular system top event to which it is tailored.

Consider the following simple example from Reference C.3.1. A warning system consists of three sensors that are used to provide a warning of whether or not a system is functioning properly. Each sensor is connected to an indicator light. If it is working properiy, each sensor activates its indicator light when the system is up, and extinguishes the light when the system is down. The operator judges the system to be up if at least two out of the three indicator lights are lit. Suppose that the lights are perfect, but it is possible for the operator to misinterpret them and it is also possible for each of the sensors to fail "on," i.e., its output lights the indicator light regardless of whether the system is up or down. Figure C.3.3 (from Reference C.3.1) shows a fault tree for the top event "Operator incorrectly judges the system to be up ( 2 or 3 lights are on when they should be off)." The top event can occur either as the result of an operator error or as the result of two or more sensors failing oh. The event "operator error" is assumed to be a primary event and is not developed further. However, the

NUREG-1489 


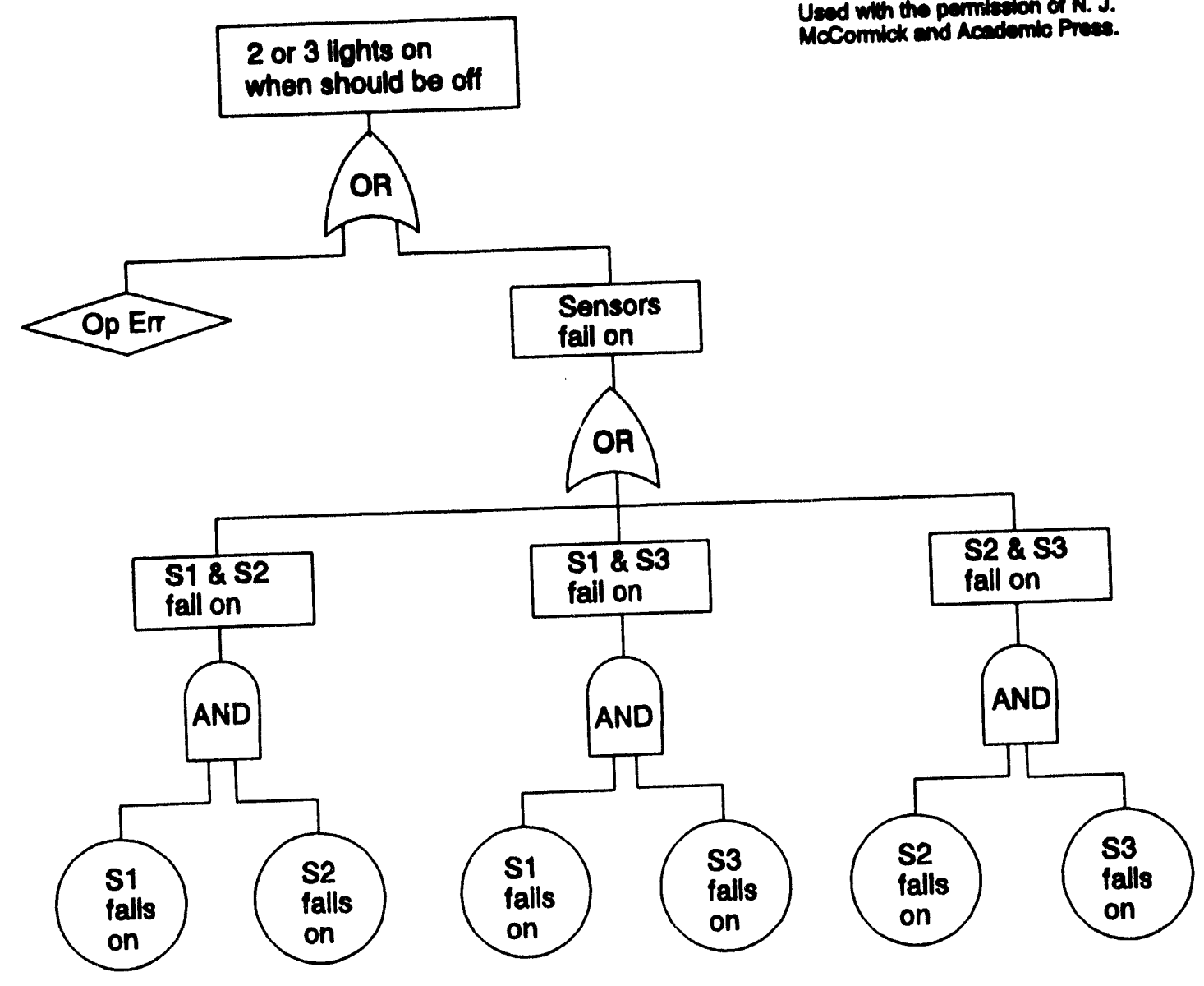

Figure C.3.3 Fault tree for a simple warning system (from Reference C.3.1)

event "sensors fail on" can be further resolved into the three events "S1 \& S2 fail on," "S1 \& S3 fail on" or "S2 \& S3 fail on." If one or more of these three events occurs, the top event will occur. Likewise, each of these three events can be developed into the constituent primary events. For instance, occurrence of the event "S1 \& S2 fail on" requires that the events "S1 fails on" and "S2 fails on" both occur, and so on.

A cut set of a system is defined as a set of system events that, if they all occur, will lead to system failure (Ref. C.3.2). A minimal cut set of a system is a cut set that does not have any other cut set as a subset. The removal of any event from a minimal cut set would cause it to no longer be a cut set. For instance, in the example above, the set $\{$ "S1 fails on," "S2 fails on"\} is a minimal cut set. The set \{"operator error"\} is also a minimal cut set. The set $\{$ "S1 fails on," "S2 fails on," "S3 fails on" $\}$ is a cut set but it is not a minimal cut set since the occurrence of all three of those events is not required for the top event to occur. 


\section{C.3 Accident Sequence \& Reliability Analyses \\ C.3.3 Methocis \\ C.3.3.2 System Reliability Analysis}

Once the fault tree for a system has been developed, it can be represented in mathematical form by what is called its structure function. To develop the structure function, each of the basic events, $E_{1}$, represented in the tree is assigned a binary indicator variable, $X_{1}$. The indicator variable $X_{i}$ takes the value of 1 if event $E_{1}$ occurs and the value of 0 if $E_{i}$ does not occur. Each minimal cut set can also be assigned an indicator variable, MCS $_{\mathrm{j}}$, which takes the value of 1 if all of the events in the $j$-th minimal cut set occur, and takes the value of 0 if at least one of the events does not occur. Therefore, $\mathrm{MCS}_{j}=\Pi \mathrm{X}_{1}{ }^{\left({ }^{0}\right)} \ldots \mathrm{X}_{\mathrm{m}}{ }^{\left({ }^{)}\right)}$, where $\mathrm{n}$ is the number of basic events in the $j$-th minimal cut set. The indicator variable for the top event, $X_{\text {opp }}$, is equal to 1 if at least one of the MCS $_{j}$ is equal to 1 , and it is equal to 0 if all of the MCS $_{\mathrm{j}}$ s are equal to 0 . Thus $\mathrm{X}_{\text {lop }}=1-\Pi\left(1-\mathrm{MCS}_{\mathrm{f}}\right)$. This function of the $\mathrm{X}_{i} \mathrm{~s}$ is the fault tree's structure function. As a simple example, consider, as a top event, the failure of a two-out-of-three redundant system. In such a case, the

structure function is $X_{\text {top }}=1-\left(1-X_{1} X_{2}\right)\left(1-X_{1} X_{3}\right)\left(1-X_{2} X_{3}\right)$.

After expansion, this becomes $X_{\text {top }}=X_{1} X_{2}+X_{1} X_{3}+X_{2} X_{3}-X_{1}^{2} X_{2} X_{3}-X_{1} X_{2}^{2} X_{3}-X_{1} X_{2} X_{3}^{2}+X_{1}^{2} X_{2}^{2} X_{3}^{2}$.

However, each indicator variable can only have the values 0 or 1 , so $X_{i}^{2}=X_{i}$.

Therefore, $X_{\text {top }}=X_{1} X_{2}+X_{2} X_{3}+X_{1} X_{3}-2 X_{1} X_{2} X_{3}$.

The fault tree quantification relies on the structure function. The expression for $X_{\text {top }}$ in terms of minimal cut sets given above is expanded as follows:

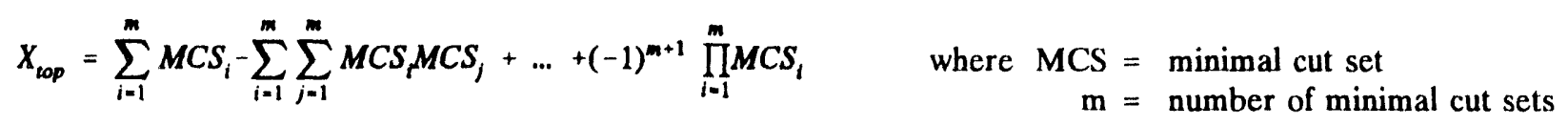

Although the probability of the top-event being true $\left(P\left(X_{\text {top }}\right)=1\right)$ can be calculated from this expression, the expression is too complicated for practical use. Analysts usually resort to the rare-event approximation, which is derived from the inclusion-exclusion principle discussed in Section C.2.2.1.2 (page C-19), namely,

$$
P\left(X_{\text {top }}\right)=P\left(M C S_{1}\right)+\ldots+P\left(M C S_{m}\right)
$$

A more accurate notation is $\mathrm{P}\left(\mathrm{X}_{\text {wop }}=1\right)$ in lieu of $\mathrm{P}\left(\mathrm{X}_{\text {wop }}\right)$; the simpler notation used above is commonly employed to create simple expressions.

In screening analyses, the rare-event approximation may lead to unrealistic results, such as probabilities greater than unity, when high values for the minimal cut set probabilities are used. In such cases, the minimal cut set upper bound is the recommended approach:

$$
P\left(X_{\text {top }}\right) \leq 1-\prod_{i=1}^{m}\left\{1-P\left(M C S_{i}\right)\right\}
$$

Reference C.3.11 shows that the above inequality is exact when none of the cut sets have a basic event in common. Furthermore, the fault tree must not contain NOT gates, otherwise the upper bound may be too conservative. In such cases, other calculational techniques should be used, such as the SIGPI algorithm (Ref. C.3.12).

Calculating the probability of each minimal cut set requires the calculation of the probability of compound events. For this discussion, a minimal cut set containing two events is considered, i.e., $M C S=X_{1} X_{2}$. To calculate this 
probability, knowledge of the details of the events that these indicator variables represent is needed. Common situations are independent events and dependent events.

\section{C.3.3.2.1 Independent Events}

When two events are independent, the probability of the minimal cut set is the product of the probabilities of the individual events, i.e., $\mathbf{P}(\mathbf{M C S})=\mathbf{P}\left(\mathrm{X}_{1}\right) \mathbf{P}\left(\mathrm{X}_{2}\right)$. The failure of unattended components is discussed in Section C.3.3.1.1 (page C-43); the unavailability of a component that is subject to repair which begins immediately after the failure occurs is discussed in Section C.3.3.1.2 (page C-44); these expressions can be used directly in the above equation.

\section{C.33.2.2 Dependent Events}

When the two events are dependent, the characteristics of the dependence must be known for the probability to be calculated correctly. For example, when common-cause failures are analyzed, one may choose the expressions given in Section C.3.3.4 (page C-52). A different type of dependence arises when the two components are on standby and under periodic testing. Then it can be shown (Ref. C.3.8) that, for identical components, the expression for the unavailability of the minimal cut set includes terms such as the following:

$$
\begin{aligned}
& \text { - } \frac{(\lambda T)^{2}}{3} \text {, which is the approximate contribution from random failures. } \\
& \text { - } \lambda \tau_{i} \text {, which is the approximate contribution from the event of one } \\
& \text { component being down for testing and the other randomly failing. }
\end{aligned}
$$

Here, $\lambda$ is the common failure rate of the components, $T$ is the time interval, $\tau_{i}$ is the test duration. Other contribution terms may be added depending on the failure modes that we wish to include. Furthermore, the type of test (i.e., whether simultaneous or staggered and whether or not the component is disabled during a test) affects these expressions. Additional details can be found in References C.3.2 and C.3.8.

Guidance: For fault trees containing only a few basic events the top event probability may be calculated by hand, but for most trees, this calculation generally requires the use of a computer. Computer codes are available for this purpose, such as IRRAS (Refs. C.3.11 and C.3.12).

\section{C.3.3.3 Accident Sequence Analysis}

Accident sequence analysis is the process of identification of the combinations of initiating events and system failures that may lead to core damage. An initiating event, or initiator, is the first in a sequence of events that may lead to undesirable consequences. Initiators challenge an otherwise normally operating system (or plant) and cause an off-normal reaction that must be dealt with. For example, a potentially serious accident may result from a pipe break in the primary cooling system of a reactor, and such a break may adversely affect core cooling. The first event in this sequence, the event "break of a primary system pipe," is therefore called an initiating event. The initiating events are usually taken from standard tables that have been developed by past PRAs (Ref. C.3.13 or any recent PRA). A master logic diagram may also be employed to systematically define plant-specific initiating events.

Accident sequence analysis requires intimate knowledge of the plant and its operation. The accident sequences are identified by utilizing a combination of event trees and fault trees (see Figure C.3.4). An event tree is 
C.3 Accident Sequence \& Reliability Analyses

C.3.3 Methods

C.3.3.3 Accident Sequence Analysis

Initiating Protective Protective

ovent

system S1

system S2

Outcome

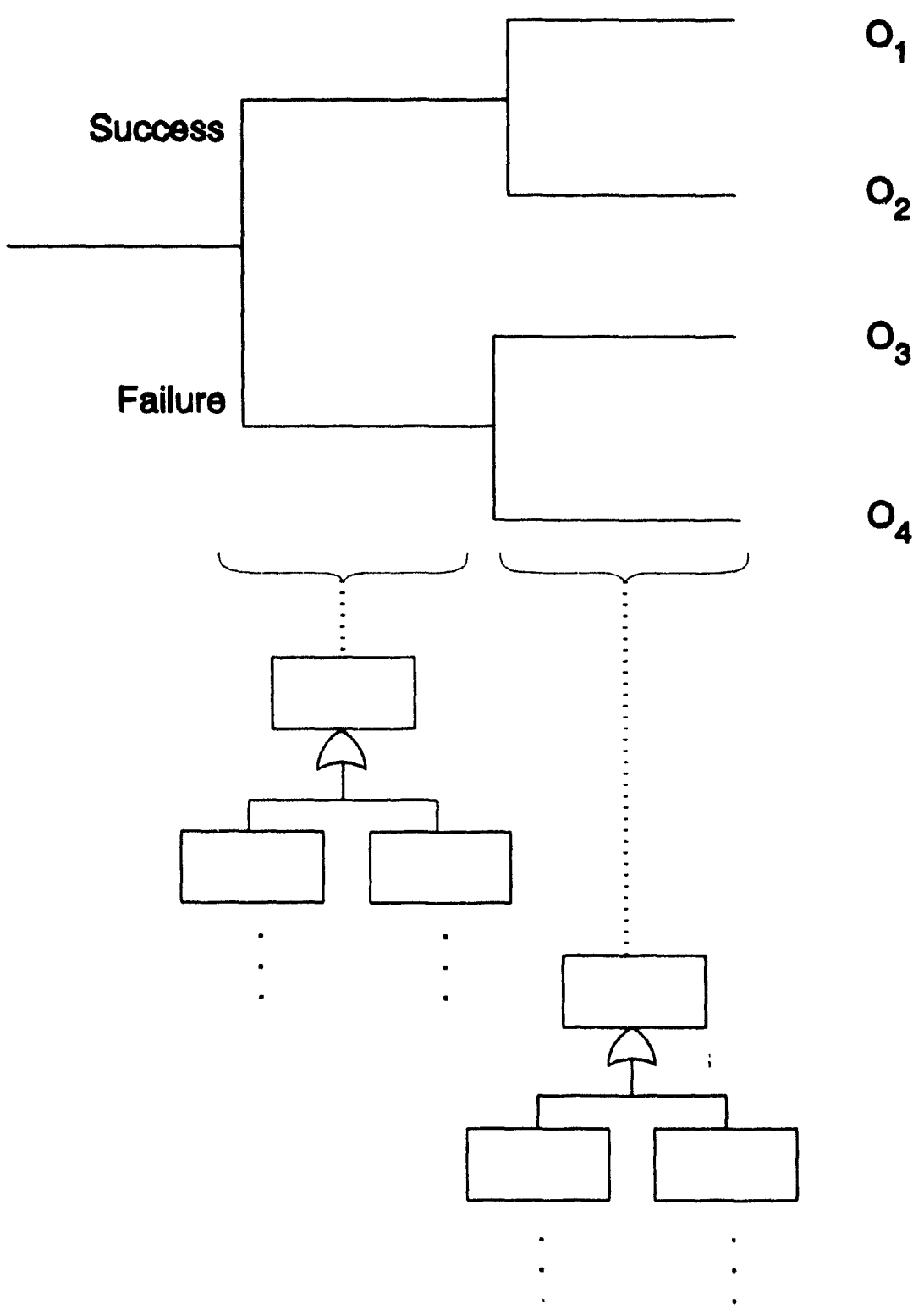

Figure C.3.4 Example of event tree analysis with fault trees

NUREG-1489

C-50 


\section{C.3 Accident Sequence \& Reliability Analyses \\ C.3.3 Methods \\ C.3.3.3 Accident Sequence Analysis}

another graphical tool frequently used to characterize and quantify accident sequences by postulating an initiating event and propagating its consequences through a series of safety-related system failures or operations. The event trees start with the initiating event and proceed to systematically identify the failures of safety functions (and the systems that implement them) that may lead to core damage. Event trees thus address the question of what happens as a result of some (specified) accident initiator. Two key difficulties in accident sequence analyses are defining system success criteria and including system interactions in the event trees.

The events that appear in the event tree are analyzed using fault trees to find the component failures and human errors that lead to the failures. A separate fault tree is built for each system failure branch point in the event tree. Each of these fault trees is conditioned by the system state at its branch. A set of minimal cut sets is thus generated for each branch of the tree that leads to an accident. Accident sequences are generated by going back to the event tree and replacing each system failure with the corresponding group of minimal cut sets (fault-tree linking).

The frequencies of the accident sequences are usually determined by multiplying the conditional frequencies of the events appearing in the sequence using the probability chain rule (see Section C.2.2.1.2, page C-20). The calculation is facilitated by using matrices (Refs. C.3.14 and C.3.15). In the matrix formulation, the plant event trees are represented as matrices whose rows correspond to the different initiating events and whose columns correspond to the different plant damage states (the states correspond to the endpoints of the branches of the tree). Each individual entry in the matrix $\left[m_{i j}\right]$ is the conditional probability of occurrence of plant damage state $j$, given the occurrence of initiating event $i$. Thus the vector of frequencies of occurrence of each plant damage state is calculated simply by pre-multiplying this matrix by the vector of occurrence frequencies of the initiating events. Furthermore, by representing the containment event trees and site-model as matrices, propagating the initiating event frequencies into consequence frequencies can be accomplished by straightforward matrix multiplication as in Figure C.3.5 (Reference C.3.14). Although the details of these calculations may vary, such as between Reference C.3.14 and the NUREG-1150 study (Ref. C.3.15), the basic process is the same. See Section C.4.4.4, page C-109, for details of the process used in the NUREG-1150 study (Ref. C.3.15).

Each accident sequence is then ranked according to its contribution to the aggregate risk (Section C.4.4.4.1, page C-105) to determine which events constitute the major contributors to risk. In this regard, a broader definition of risk, the set of triplets definition, is often employed that contrasts with the customary definition of risk as the expected value of the consequences per unit time (usually expressed in units such as fatalities/yr or $\$ / \mathrm{yr}$ ). In the set of triplets $\left\{\left\langle s_{i}, f_{i}, x_{i}\right\rangle\right\}, s_{i}$ identifies one of several possible scenarios, $f_{i}$ is the frequency of that scenario, and $x_{i}$ is the consequence of that scenario. The risk is the set of all possible scenarios, their frequencies, and their consequences. This definition distinguishes between low-frequency high-consequence scenarios and highfrequency low-consequence scenarios, while the total risk does not (Ref. C.3.16). Additional discussion is in Section C.4.4.4 on page C-104.

An issue that has been debated in the past is the amount of detail that should go into the event trees versus that in the fault trees. In the "small" event tree approach, the event tree includes only front-line safety systems that are analyzed separately using fault trees. The fault trees contain most of the dependencies. In the large event tree approach, the process is essentially reversed in that most of the information about the support system and other known dependencies is placed in the event tree, thus leading to small fault trees. Hypothetically, both the large event tree and small event tree approaches should produce the same cut sets and numerical results. Furthermore, they are comparable in the amount of effort required (Ref. C.3.17). For additional discussion, see Section C.4.4.1.2.2 (page C-89). 


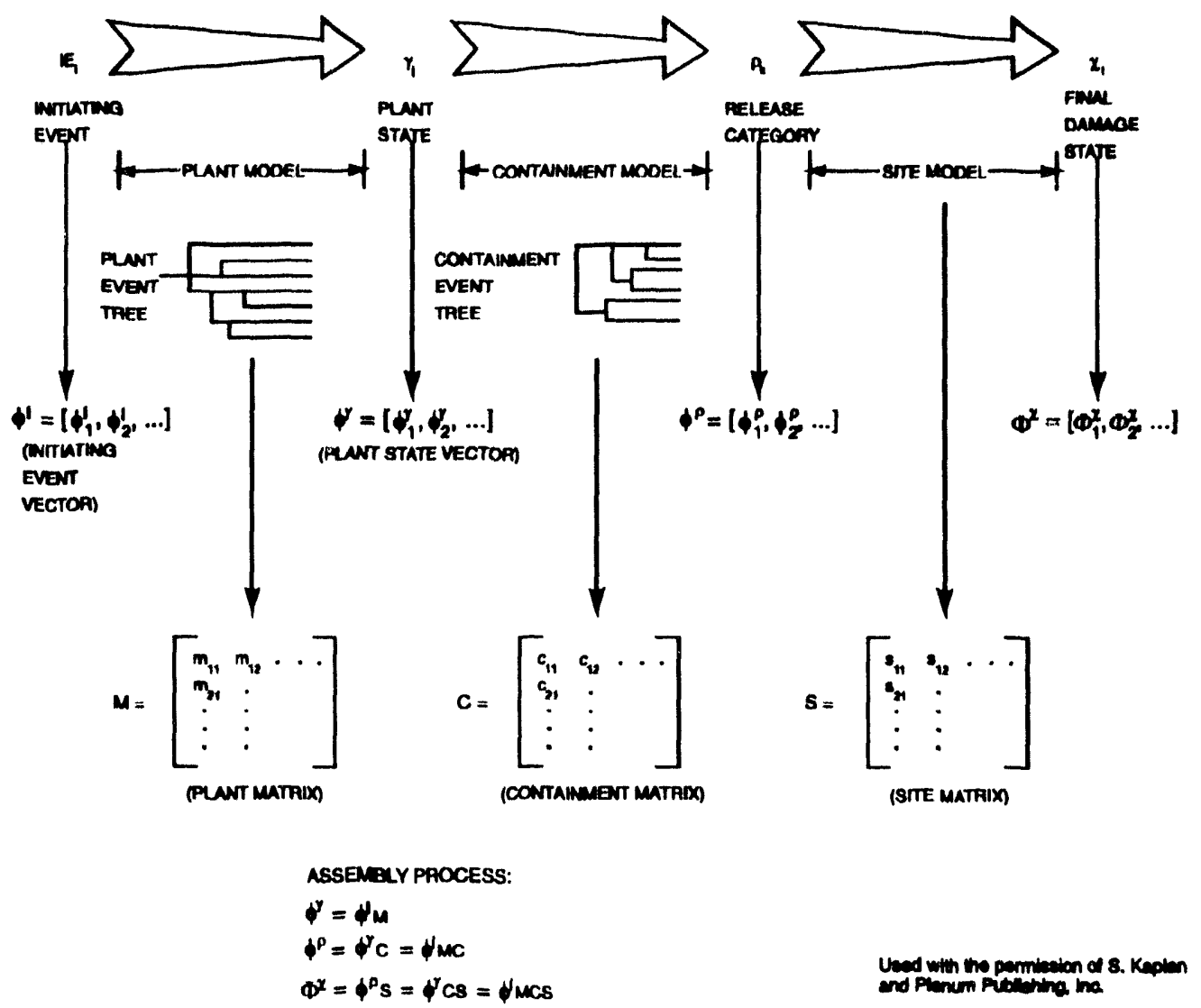

Figure C.3.5 Matrix representation of a risk calculation (Reference C.3.14)

\section{C.3.3.4 Dependent Failure Analysis}

The concept of dependence arises when simultaneous or concomitant failures of multiple components are considered. If the conditional probability of the occurrence of an event, given the occurrence of another event, is not equal to the unconditional probability of the first event, then those two events are said to be dependent (see also Section C.2.2.1.2, page C-19). For instance, in a loss-of-coolant accident, the probability of failure of the emergency core cooling pumps and sprays is affected by whether there has been a loss of electric power to the pumps. Therefore, these two events are dependent. Some examples of different types of dependencies are (1) standby redundancies, since the probability of failure of the standby component is conditioned by the failure of the operational component, (2) common causes, e.g., a fire can result in the simultaneous failure of several components in its vicinity, (3) components supporting loads, since the failure of a component that supports loads such as stresses or currents can increase the load supported by the other components and thereby increase their chances of failure, and (4) mutually exclusive events, e.g., valve fails open and valve fails closed, in which the occurrence of one event precludes the occurrence of the other. 
There are two fundamental types of dependencies involved in a PRA: causal dependencies and state-ofknowledge dependencies (Refs. C.3.18 and C.3.19). Causal dependencles refer to the dependencies between multiple component failures. There are several types:

- Explicit functional dependency: a dependency among the functions of components that results from the design of the system, for example, the function of electric pumps depends on the availability of electric power.

- Shared-equipment dependency: a dependency that results from sharing equipment among more than one function, for example, two different systems pumping water from the same tank.

- Human-interaction dependency: a dependency that may result from human action at any stage in the life of a system, e.g., design, manufacture, or operation.

Dependencies can also result from subtle system interactions that are difficult to identify and model explicitly.

A common situation in which state-of-knowledge dependencles are introduced into the model occurs when two components have the same failure rate and this common failure rate is assessed from a single data source. In a Bayesian analysis, the uncertainty in the failure probability of both components is represented by the same random variable. The following example illustrates this dependency. Consider the simple case of a system failing if two motor-operated valves (MOVs) operating in parallel fail to open on demand. If $q$ is the probability of failure on demand of each MOV, the system unavailability is $Q=q^{2}$. If the uncertainty distribution of $q$ for each MOV is based on the same data source, the mean value of the uncertainty distribution of $Q$ is given by $\alpha_{Q}=\alpha_{q}{ }^{2}+\beta_{q}{ }^{2}$, where $\alpha_{q}$ and $\beta_{q}{ }^{2}$ represent the mean and variance, respectively, of $q$. On the other hand, if it is assumed the MOV failure probabilities are assessed from independent data sources, then the system unavailability is given by $Q^{*}=q_{1} q_{2}$. The mean of $Q^{*}$ is $\alpha_{\mathrm{Q}^{*}}=\alpha_{q} \alpha_{q}=\alpha_{q}{ }^{2}$. If the distribution of $q$ is broad enough, the contribution of the variance to the mean of $Q$ can be significant. Thus, it is important to be very specific about the assumptions being made regarding the state of knowledge of component failure probabilities.

Guidance: In a system consisting of two or more components, the uncertainty distribution of the system unavailability depends on the dependency structure of the uncertainty distributions of the component failure rates.

In typical PRAs one often has to deal with functions of the form $Q=f\left(\lambda_{1}, \lambda_{2}, \ldots \lambda_{n}\right)$ where $Q$ may be the unavailability of a system and the $\lambda_{i} \mathrm{~s}$ may be the component failure rate. The function $f$ (the stochastic model) is determined by the structure of the system, usually through the use of a fault tree. However, the numerical values of the $\lambda_{i} s$ are generally not known and the analyst must express his state of knowledge concerning their possible values using probability density functions, $\pi_{i}\left(\lambda_{i}\right)$. These probability distributions must then be propagated through the function $f$ to yield a distribution for $Q$. Often this is done through Monte Carlo sampling over the distributions of $\lambda_{i}$. However, this is where the state-of-knowledge dependencies come in.

Guidance: If failure rates $\lambda_{1}$ and $\lambda_{2}$ refer to the failure rates of nominally identical components and since the state of knowledge concerning each failure rate is the same, then the analyst must sample the same value for both failure rates (see Figure C.3.6). If the analyst samples different values for $\lambda_{1}$ and $\lambda_{2}$ as shown in Figure C.3.7, the result will be incorrect.

Several different techniques exist for modeling stochastic dependencies (Refs. C.3.20 and C.3.21). Many dependencies arise from functional or physical relationships among components of the system and are reflected 


\section{C.3 Accident Sequence \& Reliability Analyses}

\section{C.3.3 Methods}

C.3.3.4 Dependent Failure Analysis

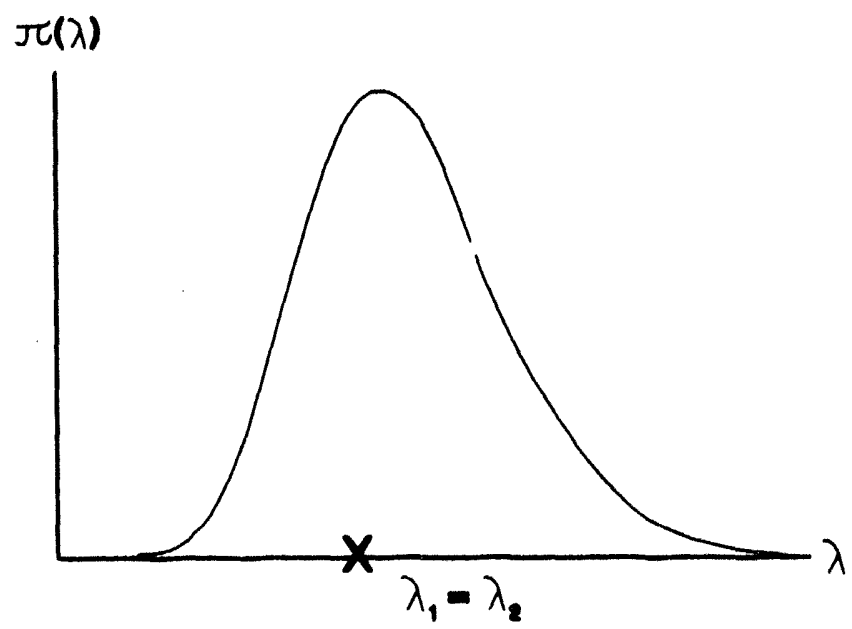

Figure C.3.6 Sampling the same value for both $\lambda_{1}$ and $\lambda_{2}$

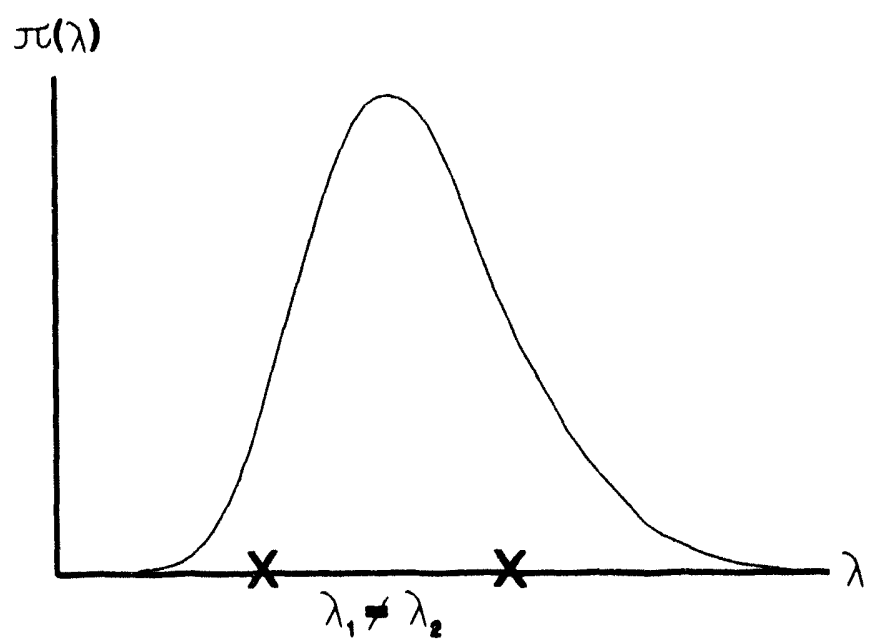

Figure C.3.7 Sampling different values for $\lambda_{1}$ and $\lambda_{2}$

directly and explicitly in the logic model of the system. Common modeling techniques such as fault trees provide a convenient mechanism for representing such dependencies explicitly. After the explicit models have been developed, however, many sources of dependencies remain, caused by unanticipated or unmodeled causes involving the failure of two or more components. Such failures are called common cause fallures. In PRA, common cause failures are the subset of dependent failures not explicitly modeled in the fault trees or event trees. The most common approach taken by analysts to handle such dependencies has been through the use of parametric models. Several models have been proposed and debated over the past 17 years.

The first such model to estimate the frequency of common cause failures was the beta factor model (Ref. C.3.22). Despite its limitations, the beta factor model appeals to many analysts because of its simplicity. Simply 


\section{C.3 Accident Sequence \& Reliability Analyses C.3.3 Methods \\ C.3.3.4 Dependent Failure Analysis}

put, the beta factor model uses a parameter $\beta$ which is interpreted as the fraction, caused by common cause failures, of the component's total failure rate:

$$
\begin{aligned}
& \beta=\frac{Q_{c c}}{Q_{1}} \text { where } Q_{1}=\text { total failure rate of a component } \\
& Q_{1}=Q_{1}+Q_{\infty}=\text { independent failure rate of the component } \\
& Q_{\infty}=\text { failure rate from common causes of the } \\
& \text { component }
\end{aligned}
$$

Notice that $Q_{1}=(1-\beta) Q_{1}$ and $Q_{\infty}=\beta Q_{1}$. So, for example, for a system composed of two identical and independent components in parallel with total hazard rate $\lambda$, the probability of system failure, $Q_{0}$, in time $t$ is given by

$$
Q_{s}=\beta \lambda t+(1-\beta)^{2} \lambda^{2} t^{2}
$$

for small $\lambda t$ (see Section C.3.3.1, page C-43). With estimates of $\beta$ typically ranging from 0.1 to 0.2 for components such as diesel generators or pumps (Ref. C.3.1), it can be seen that the contribution to system unavailability from common cause failures can easily dominate that from multiple independent failures.

A more elaborate model, the binomial failure rate (BFR) model, which was developed later, addresses how common cause failures occur and propagate (Ref. C.3.24). Efforts to bring more physical characteristics of common cause failures into the probabilistic models have continued with both new models, such as the common load model (Ref. C.3.25), and modifications to existing models (Refs. C.3.22, C.3.26 - C.3.30).

Currently, the most widely used technique for quantifying common cause failures are parametric common cause failure methods that are extensions of the beta factor method discussed above. Three equivalent methods exist, depending upon the way the data are collected. The three methods are (1) the Multiple Greek Letter (MGL) Method (Ref. C.3.31), (2) the Alpha Factor Method (Ref. C.3.23), and (3) the "Scaled" Basic Parameter Method.

To illustrate these models consider a common cause component group of three. Also define $\mathbf{Q}_{1}, \mathbf{Q}_{2}$, and $\mathbf{Q}_{3}$ as the probability of exactly one, two, or three components failing at the same time. The probability of the group failing is given by:

$$
Q_{\text {group }}=Q_{1}^{s}+3 Q_{2} Q_{1}+Q_{3}
$$

Since all three components can fail independently, two components can fail from a common cause and one can fail independently, or all three can fail from a common cause. This formulation is called the basic parameter model.

The $Q_{k}, k=1,2,3$, can be estimated directly from failure data, or they can be estimated using relationships that relate the number of failures of exactly $k$ components to the total failure probability of a component, $Q_{t}$. To accomplish this, the number of failures involving one, two, and three components is needed. Thus, let $n_{1}, n_{2}$, and $\mathrm{n}_{3}$ denote the number of observed failures involving one, two, and three components, respectively. 


\section{C.3 Accident Sequence \& Reliability Analyses}

\section{C.3.3 Methods}

C.3.3.4 Dependent Failure Analysis

The MGL factors are estimated by:

$$
\begin{aligned}
& \beta=\frac{2 n_{2}+3 n_{3}}{n_{1}+2 n_{2}+3 n_{3}} \\
& \gamma=\frac{3 n_{3}}{2 n_{2}+3 n_{3}}
\end{aligned}
$$

In this formulation, $\beta$ and $\gamma$ are estimates of the conditional probabilities of failure.

In the alpha factor formulation, $\alpha_{\mathbf{k}}$ is the fraction of failures in the data involving exactly $k$ components. Thus, the $\alpha_{k}$ are defined by:

$$
\alpha_{k}=\frac{n_{k}}{n_{1}+n_{2}+n_{3}}, \quad k=1,2,3
$$

The $\alpha_{k}$ sum to one.

For the scaled basic parameter formulation, the factor for exactly $\mathrm{k}$ components failing is given by:

$$
S_{k}=\frac{3}{\left(\begin{array}{l}
3 \\
k
\end{array}\right)} \frac{n_{k}}{n_{1}+2 n_{2}+3 n_{3}}, \quad k=1,2,3
$$

For the MGL method, the $Q_{k}$ are given by:

$$
\begin{aligned}
& Q_{1}=(1-\beta) Q_{t} \\
& Q_{2}=\frac{1}{2} \beta(1-\gamma) Q_{t} \\
& Q_{3}=\beta \gamma Q_{t}
\end{aligned}
$$

For the Alpha factor method, the $\mathrm{Q}_{k}$ are given by:

$$
Q_{k}=\frac{3 \alpha_{k}}{\left(\begin{array}{l}
3 \\
k
\end{array}\right) \alpha_{t}} \quad \text { where } \alpha \mathrm{t}=\alpha 1+2 \alpha 2+3 \alpha 3
$$

For the basic parameter model, the $Q_{k}$ are given by $Q_{k}=S_{k} Q_{1}, k=1,2,3$.

Common cause failure events are rare for an individual nuclear power plant. Thus, data from the industry must be used to develop a pseudo plant-specific common cause event data base for use in a plant-specific study. Guidelines for doing this are contained in NUREG/CR-4780 (Ref C.3.20).

Guidance: Common cause failures are important contributors to system unavailability and core damage frequency. Care must be taken in the quantification of common cause failures by using appropriate common cause failure quantification models and data. The analysis should include the rationale for the selection of the model and the choice of the data and estimates of the parameters. 


\section{C.3.3.5 Human Reliability Analysis}

There are two general classes of human errors that are considered in a PRA, namely, errors committed during normal operations (pre-initiator or routine errors) and errors committed during accidents (post-initiator or dynamic errors). While the methods for the analysis of pre-accident errors are fairly well established (Ref. C.3.28, commonly referred to as the NRC Handbook or, simply, the Handbook), those for dynamic errors are still evolving.

The pre-initiator error analysis includes routine control room tasks, preventive and corrective maintenance tasks, calibration tasks, as well as recovery tasks (inspections). Two categories of errors are distinguished, namely, errors of omission (i.e., a task or part of a task is omitted) and errors of commission (e.g., selecting the wrong control, mispositioning a valve, acting too early, and so forth). For each specific error, the Handbook provides a best estimate and an error factor (EF) for the corresponding human error rate or human error probability (HER or HEP). For example, Table 20-7 of the Handbook (Ref. C.3.28) gives a best estimate of $10^{-3}$ and an error factor of 3 for an error of omission per item of instruction in a short list (containing less than 10 items). Thus, this HER is assumed to be lognormally distributed with the median equal to the best estimate and the 95th percentile equal to $3 \times 10^{-3}$.

These basic HERs can be modified to reflect the stress level on the crew, as well as their experience. For example, Table 20-16 of the Handbook states that the given HER must be multiplied by a factor of two when novices (people with less than six months experience) are involved and the stress level is moderately high.

When two or more tasks are performed, the question of dependence between human errors must be addressed. The Handbook defines five levels of dependence: zero, low, moderate, high, and complete dependence. An expression is given for each level of dependence for the conditional probability of repeating the error, assuming that it has been committed once. For example, the conditional probability for the case of high dependence is $(1+$ HER $) / 2$. Regarding the errot of omission discussed above, this conditional probability would be $\left(1+10^{-3}\right) / 2=0.5$.

\section{Guidance: Even though the information contained in the Handbook (Ref. C.3.28) is widely used, it should be borme in mind that the basis for these numbers is the professional judgment of the Handbook's authors as shaped by analyses, field experience, and laboratory experience.}

There is much less agreement regarding the methods and results to be used for post-initiator human actions. In this context, it is useful to bear in mind the three levels of control of human actions that have been widely debated in the literature (Ref. C.3.24). These levels are defined as follows in Reference C.3.24.

Skill-based behavior represents sensorimotor performance during acts or activities that, after a statement of an intention, take place without conscious control as smooth, automated, and highly integrated patterns of behavior.

At the next level of rule-based behavior, the composition of a sequence of subroutines in a familiar work situation is typically consciously controlled by a stored rule or precedure that may have been obtained empirically during previous occasions....

During unfamiliar situations, faced with an environment for which no know-how or rules for control are available from previous encounters, the control of performance must move to a higher conceptual level, in which performance is goal-controlled and knowledge-based .... 


\section{C.3 Accident Sequence \& Rcliability Analyses}

\section{C.3.3 iviethods}

\section{C.3.3.5 Human Reliability Analysis}

Because operators may have to act in a knowledge-based mode under accident conditions, the analysis of such actions is unique and difficult. Various models proposed in the literature tend to emphasize different aspects of the problem. Two classes of models can be distinguished, models that treat the time available to the operators for action as the central quantity of interest (time-oriented models) and models that rate human actions according to various characteristics (e.g., difficulty in diagnosis); error rates can be developed from these ratings (rating-oriented models) (Ref. C.3.25). Several models are discussed below.

\section{C.3.3.5.1 Time-Oriented Models}

These models are based on the simple observation that operator success is governed by the time available for . action and the time required for diagnosis and action. There is evidence indicating that, beyond a certain critical time, the operator nonresponse probabilities depend only very weakly on the amount of available time (Ref. C.3.26). Nevertheless, in PRA practice, the time available for recovery is considered critical in evaluating human performance (Ref. C.3.27). Time-oriented models generally provide HERs as functions of the available time for diagnosis and action. A curve, called a time reliability correlation (TRC), is the most common form. See Figure C.3.8 (from Reference C.3.28) for an illustration of TRCs.

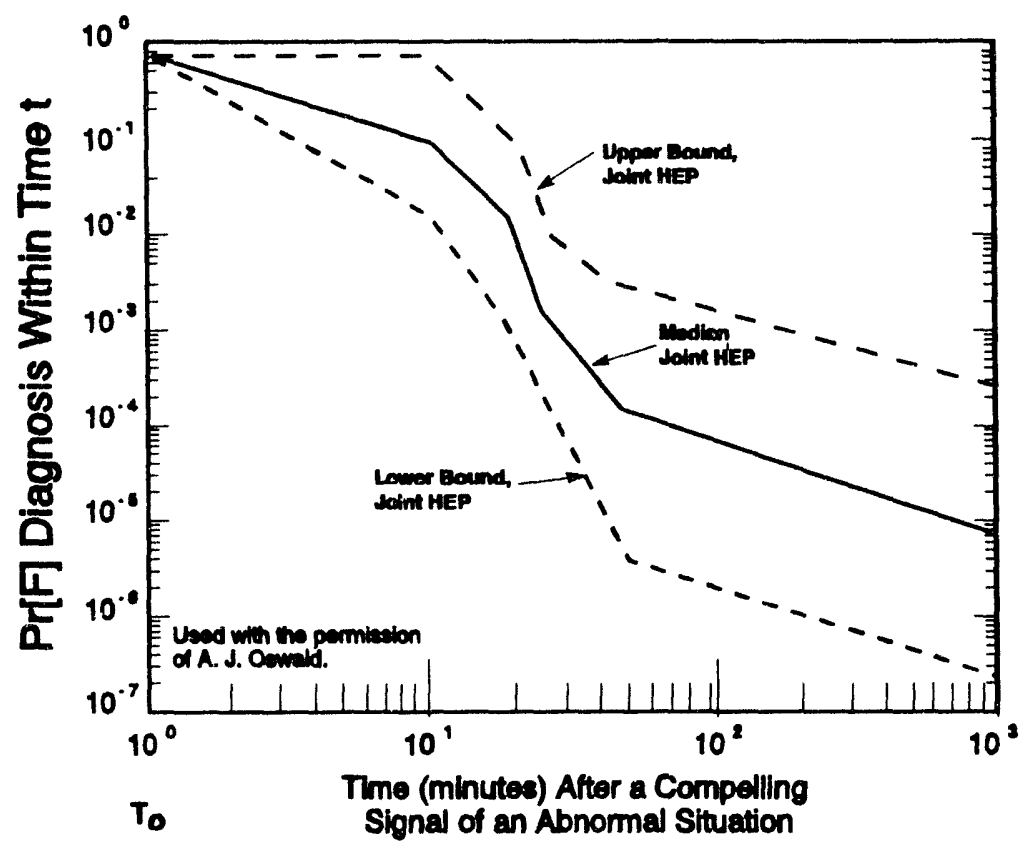

Figure C.3.8 Time reliability correlation (TRC) curve (from Reference C.3.28) 


\section{C.3 Accident Sequence \& Reliability Analyses \\ C.3.3 Methods \\ C.3.3.5 Human Reliability Analysis}

\section{Advantages}

D The available time is central to the approach. This time is determined by the physics of the problem.

$\Delta \quad$ They are easier to use, because most of the information is tabulated.

\section{$\underline{\text { Disadvantage }}$}

D The error rates are given in a generic sense and they may fail to capture the special circumstances of a particular accident.

Two well known models are THERP and HCR/ORE:

THERP: The Technique for Human Error Rate Prediction (THERP) is the model most widely used by practitioners (Ref. C.3.29). A task is analyzed using event trees in which subtasks and various performance-shaping factors, i.e., factors such as stress level and work environment, that affect human performance in nuclear power plants are identified. These subtasks and PSFs are utilized in determining the error rates. Recovery actions in response to alarms are also modeled. The uncertainties in the error rates are given as a function of the available time.

HCR/ORE: The Human Cognitive Reliability (HCR) model provides time reliability correlations for each of the three modes of cognitive processing discussed above (Ref. C.3.30). The Operator Reliability Experiments (ORE) have been sponsored by EPRI in an effort to test the HCR model (Refs. C.3.30 and C.3.31). Simulator exercises have been carried out at six nuclear power plants and the reaction of crews to simulated accidents has been recorded. A conclusion of these experiments is that the assumptions behind HCR are only partially supported; in particular, the dispersion of crew response times does not appear to follow the skill-based, rule-based, and knowledge-based grouping. A modified HCR/ORE model is being developed (Ref. C.3.31).

\section{C.33.5.2 Rating-Oriented Models}

The basic idea behind these models is that the human error rates for a set of specified actions can be derived by investigating how a small set of performance-shaping factors (PSFs) influence the success or failure of the operators. No time correlation curves are utilized. However, time may be one of the PSFs. It is evident that the analyst must exercise considerable judgment to determine the HERs. The use of expert judgment for this purpose is investigated in References C.3.32 and C.3.33.

\section{Advantages}

$\triangle \quad$ No generic time-correlation curves are employed. Each situation is analyzed by taking into account the specific circumstances that define it.

$\checkmark \quad$ Many experts may be utilized, thus allowing the formation of multidisciplinary teams of analysts.

\section{Disadvantages}

D The available time for action, as determined by physical processes, may not get the attention it deserves and may be treated as just another performance-shaping factor. 
The analysts must quantify their judgments in terms of probabilities and they may not have been trained to do so to avoid well known biases.

The most widely used model is SLIM-MAUD. The Success Likelihood Index Methodology (SLIM) requires the analyst to first calculate the Success Likelihood Index (SLI), which is the sum of the ratings of the PSFs under the given circumstances weighted by their relative importance. For example, one PSF may range on a scale from 1 to 9 where (1) is "requires diagnosis" and (9) is "mandated by procedures." The rating on this scale will be multiplied by the relative contribution (importance) of this PSF to the successful performance of the task in question. This product is, then, the contribution to the SLI of this PSF. The final step involves the conversion of the SLI to a probability using anchor points. MAUD is an interactive computer program that implements SLIM (Ref. C.3.34).

It is evident from the above discussion that expert judgment is prevalent in the assessment of dynamic HERs. This judgment is explicit in SLIM, while in time-oriented models it is behind the time correlation curves (even when simulator experiments are utilized, their results must be interpreted and extrapolated for the derivation of HERs). Reference C.3.35 reports on the results of a benchmark exercise on HERs. Fifteen teams of analysts used several methods to assess the HER for a given task. The results varied significantly, even when the same team used different methods. A conclusion offered was that human behavior is extremely context dependent and cannot be deterministically modeled. Reference C.3.36 uses a different setting (simulation of discrete part manufacturing scenarios) to compare empirical error rates with predictions; the author concludes that THERP performs better than SLIM in these experiments. The user of these models should be aware that there is a school of thought among cognitive scientists that argues that the operator cannot be treated as a component and human performance cannot be investigated independently of the task context (Ref. C.3.37). Dougherty's editorial (Ref. C.3.38) and the accompanying responses indicate that perhaps a new, more widely accepted, approach to human reliability is needed.

\section{C.3.3.6 External Events Analysis}

External events are events that are "external" to the plant, e.g., earthquakes and fires, although it is recommended that, in practice, such events be treated as "internal." The general approach to risk quantification from these events involves the quantification of the hazard intensity, e.g., the intensity of an earthquake, the heat release rate from a fire, the velocities of a tornado, and the probability that plant components will be damaged given various levels of the intensity. Once this damage is assessed, the plant model (event and fault trees) can be modified to include these new accident sequences (Ref. C.3.13).

The hazard analysis for earthquakes involves the development of curves that give the frequency of various peak ground accelerations (pga), i.e., the pga is used as the measure of intensity (see Figure C.3.9). It is also recognized that the pga may not capture all the significant features of the earthquake and other measures are used as well, e.g., the spectral acceleration. Major numerical uncertainties exist regarding the seismic hazard curves for the Eastern United States. The results of two major studies by the Electric Power Research Institute (Ref. C.3.39) and Lawrence Livermore National Laboratory (Ref. C.3.40) differ by factors of ten. These differences are a direct consequence of the fact that these curves are produced by polling experts; the problems associated with the use of expert opinions in risk assessments have been well documented in the literature (Refs. C.3.41 - C.3.43).

The fragility curves give the probability of component and structure failures as a function of the pga (or the spectral acceleration, as the case may be) (see Figure C.3.10). These curves are based on test data as well as expert opinions (Refs. C.3.44 and C.3.45). 


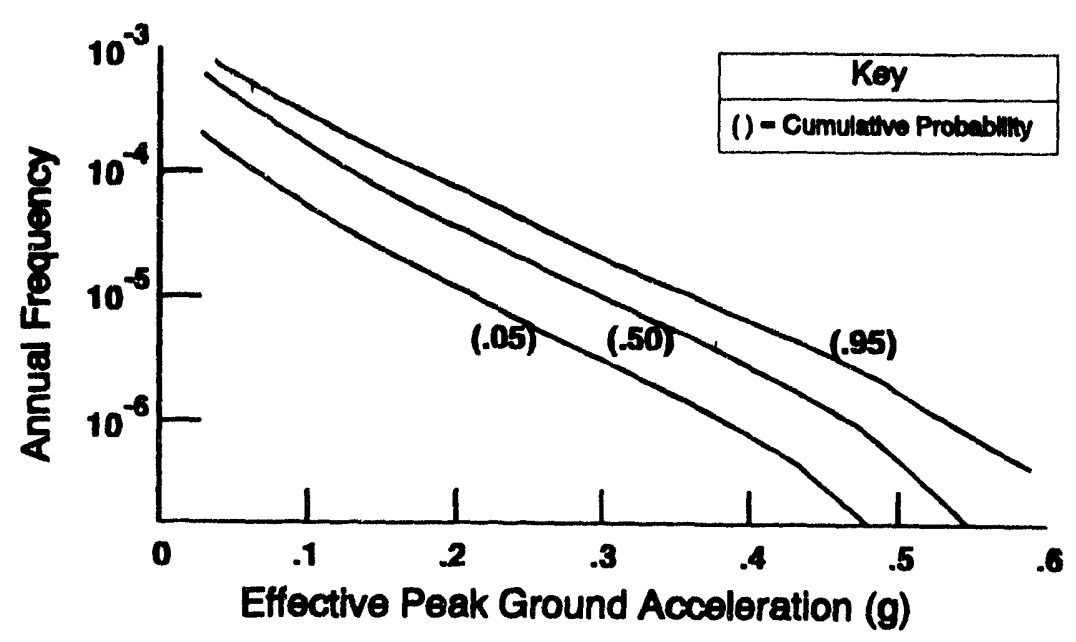

Figure C.3.9 Seismic hazard curves for a hypothetical site

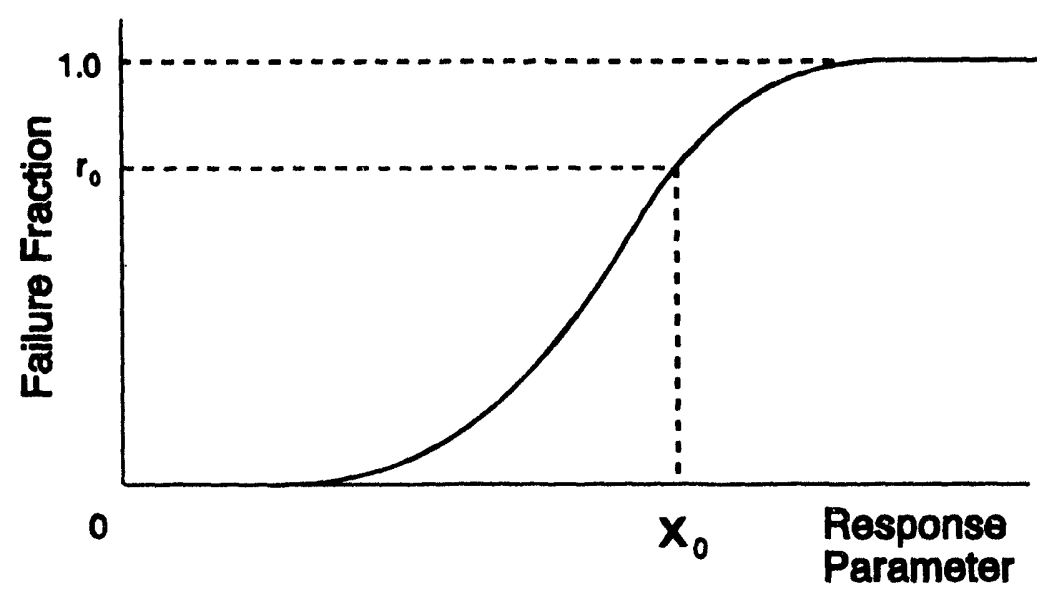

Figure C.3.10 A fragility curve

A simpler approach to seismic risk has been developed by the NRC (Ref. C.3.46) and EPRI (Ref. C.3.47). These "seismic margin" methods are designed to identify vulnerabilities below a "review level" earthquake, which is greater than the design basis earthquake.

The fire risk assessment methodology proceeds in a similar fashion. The plant is screened to identify areas where a fire may disable redundant components (usually cable trays), and fires of sufficient magnitude are postulated to occur at these "critical" locations (Ref. C.3.48). The time to damage for redundant components is calculated using the computer code COMPBRN IIIe, which characterizes the thermal environment in a compartment (Ref. C.3.49). The Fire-Induced Vulnerability Evaluation (FIVE) methodology has been developed to make the screening of locations more systematic, so that fewer locations would need to be analyzed with the code (Ref. C.3.50). 
C.3 Accident Sequence \& Reliability Analyses

C.3.3 Methods

C.3.4 Time-Dependent Modeling

Models for other external events have also been developed, e.g., for floods (Ref. C.3.13), tornadoes (Ref. C.3.51), and winds (Ref. C.3.52).

\section{C.3.3.7 Software Reliability Analysis}

Software, unlike hardware, is unique in that its only failure modes are the result of design flaws, as opposed to any kind of physical mechanisms such as aging (Ref. C.3.53). As a result, traditional reliability techniques, which have tended to focus on physical component failures rather than system design faults, have been unable to close the widening gap between the powerful capabilities of modern software systems and the levels of reliability that can be computed from them. The real problem of software reliability is one of managing complexity. There is a natural limitation on the complexity of hardware systems. With the introduction of digital computer systems, however, designers have been able to implement arbitrarily complex designs in software. The result is that the central assumption implicit in traditional reliability theory, that the design is correct and failures are the result of fallible components, is no longer valid.

The most common approach to software reliability analysis is testing. Testing is often performed by feeding random inputs into the software and observing the produced output to discover incorrect behavior. Because of the extremely complex nature of today's modern computer systems, however, these techniques often result in the generation of an enormous number of test cases. For example, Ontario Hydro's validation testing of its Darlington Nuclear Generating Station's new computerized emergency reactor shutdown systems required a minimum of 7000 separate tests to demonstrate $99.99 \%$ reliability at $50 \%$ confidence (Ref. C.3.54).

Software reliability growth models, which attempt to estimate the reliability of software based on a statistical analysis of its failure history, have been proposed to aid the testing strategies (Ref. C.3.55). 'The applicability to software of reliability models extrapolated from the hardware reliability realm is seriously questioned, even from within the software reliability research community itself (Ref. C.3.56). This is because there are many fundamental differences between software failures and hardware failures, e.g., software does not wear out, its failure modes are frequently unpredictable, etc.

Software reliability growth models have not had a great impact so far in reducing the quantity and cost of software testing necessary to achieve a reasonable level of reliability.

Recognizing that the traditional practice of estimating failure rates and reliabilities may be inappropriate for software analysis, some researchers have applied fault tree analysis to software, focusing on identifying and eliminating software failures with the most serious consequences (Refs. C.3.57 - C.3.60). Fault tree analysis for software systems is very similar to that for conventional hardware systems. A catastrophic failure of the system is identified as a top event and is traced backwards through the logic of the software to identify cut sets of basic events (in this case, values of the software input variables) that lead to the top event.

\section{C.3.4 Time-Dependent Modeling}

The PRA models are, by and large, static. They depict logical relationships among events and phenomena. There are situations, however, in which time must be included explicitly. Such a situation arises when recovery actions are modeled (Ref. C.3.27). The time available to the operators for action is usually calculated using simple thermal hydraulic models (as well as neutronic models, if necessary). Similarly, in fire risk analysis, the competition between fire growth and detection and suppression is modeled explicitly (Ref. C.3.61).

Several models have been proposed in the last few years that go beyond the isolated inclusion of time dependence in PRA. These models investigate the evolution in time of accident sequences, and they include the 
physics of the relevant processes and equipment failures, as well as operator actions (Refs. C.3.62 - C.3.64). Given the enormity of the research effort required to develop satisfactory approaches, these models are still evolving.

A different kind of time dependence occurs when considering the impact of aging on plant components, systems, and structures. The NRC's Nuclear Plant Aging Research Program (NPAR) is investigating the impact of aging on risk. A model that allows the failure rate to increase linearly with time has been developed under this program (Refs. C.3.65 - C.3.66). A more general time-dependent failure rate is proposed in Reference C.3.67.

Finally, in recognition of the fact that a nuclear plant and its operating procedures are continually being modified, the concept of a living PRA has evolved, i.e., a PRA that is periodically updated, so that it reflects the current plant status.

\section{C.3.5 Codes}

This subsection provides an overview of the PC-based computer codes for Level I PRA analysis. Tables C.3.1, C.3.2, and C.3.3 list commonly used codes, listing for each the function, the source, the hardware requirements, and a brief description. For more codes developed for risk analysis, see References C.3.68 - C.3.69.

Table C.3.1 Codes to perform an uncertainty analysis

\begin{tabular}{|l|l||}
\hline Program: & TEMAC (Top Event Matrix Analysis Code) \\
Source: & Sandia National Laboratories \\
System: & $\begin{array}{l}\text { VAX } 8650 \\
\text { TEMAC performs matrix-based analyses on top events, including the calculation of uncertainty } \\
\text { bounds, and has the capability to output the information in easily digested line printer plots. For } \\
\text { uncertainty analysis it uses Latin Hypercube Sampling (Ref. C.3.77). } \\
\text { C.3.76 }\end{array}$ \\
References: & $\begin{array}{l}\text { LHS } \\
\text { Program: }\end{array}$ \\
Source: & $\begin{array}{l}\text { Sandia National Laboratories } \\
\text { IBM PC } \\
\text { System: }\end{array}$ \\
Description: & $\begin{array}{l}\text { LHS (Latin Hypercube Sampling) is a method for efficiently sampling a large number of input } \\
\text { variables. }\end{array}$ \\
References: &
\end{tabular}




\section{C.3 Accident Sequence and Reliability Analyses}

\section{C.3.6 Summary}

Table C.3.2 PRA Level 1 workstation packages

\begin{tabular}{|c|c|}
\hline Program: & IRRAS 4.0 \\
\hline Source: & Idaho National Engineering Laboratory, EG\&G Idaho, Inc. \\
\hline System: & IBM PC \\
\hline Description: & $\begin{array}{l}\text { IRRAS } 4.0 \text { (Integrated Reliability and Risk Analysis System) is an integrated PRA software tool } \\
\text { that creates and analyzes fault irees and accident sequences using an IBM-compatible } \\
\text { microcomputer. The program provides functions that range from graphical fault tree and event } \\
\text { tree construction and cut set generation and quantification to uncertainty calculation (Monte } \\
\text { Carlo or Latin Hypercube sampling) }\end{array}$ \\
\hline References: & C.3.11, C.3.12, C.3.78 \\
\hline Program: & NUPRA \\
\hline Source: & NUS Corporation \\
\hline System: & $\begin{array}{l}\text { IBM PC, } 640 \mathrm{~KB} \text { RAM, hard drive, } 1 \text { high density diskette drive, math coprocessor; CGA } \\
\text { monitor, pen plotter supporting HPGL ( } 7475 \mathrm{~A} \text { up) or laser printer, DOS } 3.0 \text { or higher }\end{array}$ \\
\hline Description: & $\begin{array}{l}\text { NUPRA is a workstation for Level } 1 \text { and } 2 \text { PRA. It is an interactive menu-driven system } \\
\text { comprising event tree and fault tree construction, event tree and fault tree evaluation and } \\
\text { quantification, and uncertainty analysis. }\end{array}$ \\
\hline References: & C.3.78 \\
\hline Program: & RISKMAN \\
\hline Source: & PLG Inc. \\
\hline System: & $\begin{array}{l}\text { IBM 386PC, } 3 \text { MB RAM, hard drive, math coprocessor, EGA/VGA monitor; MS-DOS } 3.3 \text { or } \\
\text { higher }\end{array}$ \\
\hline Description: & $\begin{array}{l}\text { RISKMAN is a completely integrated menu- and window-driven software system for performing } \\
\text { quantitative risk analysis. RISKMAN can be used to analyze the frequency of event sequences } \\
\text { for scenarios in any industrial system or plant. }\end{array}$ \\
\hline References: & C.3.69 \\
\hline
\end{tabular}

\section{C.3.6 Summary}

- The failure of complex technological systems is analyzed by decomposition into elementary events that are better understood.

- Accident sequences are initiated by an initiating event and include the unavailabilities of safety systems. The initiating events are tabulated (for nuclear power plants), while the unavailabilities are calculated using models. 
Table C.3.3 Codes to perform a fault tree analysis

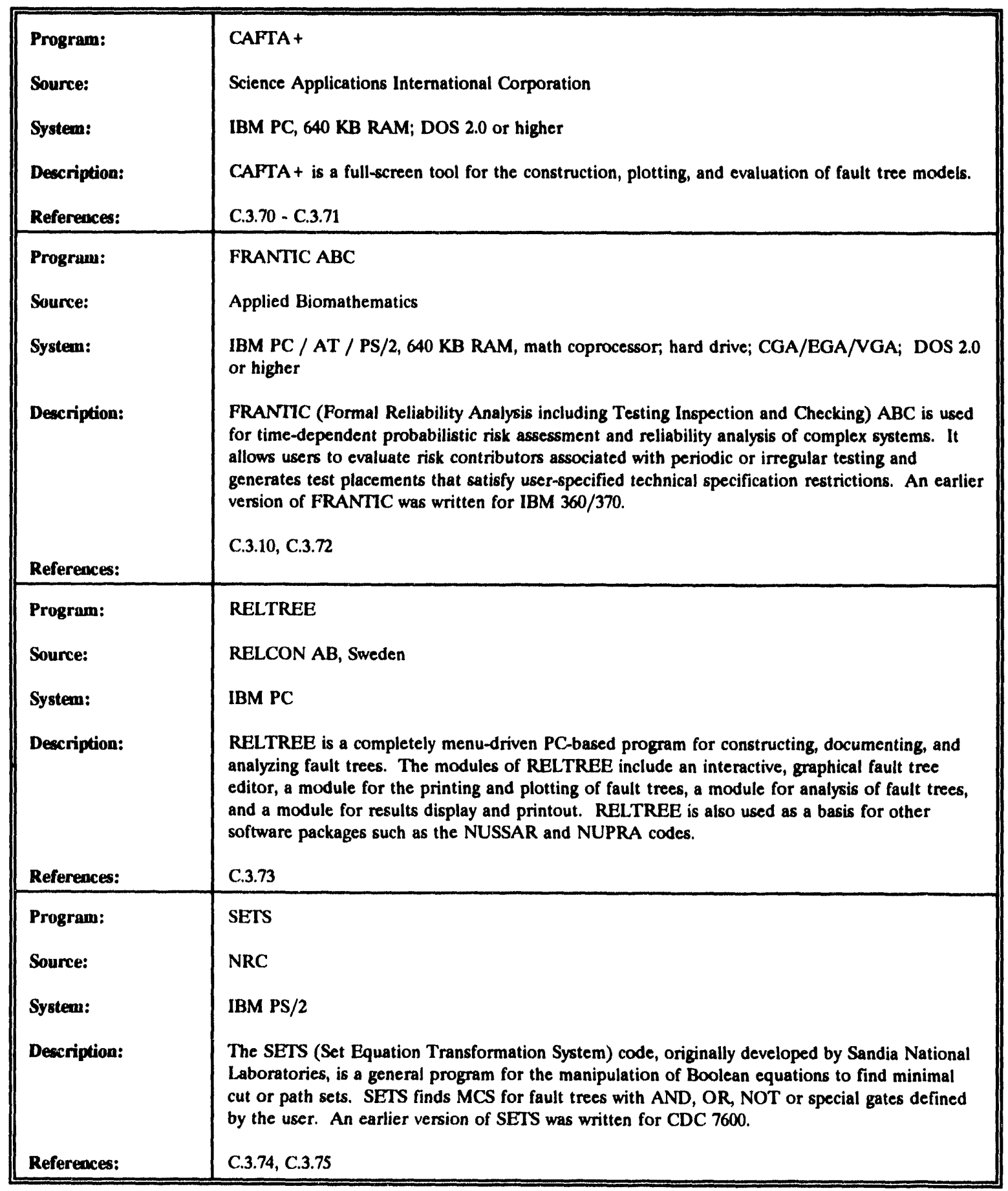


C.3 Accident Sequence and Reliability Analyses

C.3.6 Summary

- The development of a structured list of accident sequences is achieved using event tree and fault tree analyses. The analyst may choose to place more detail in the event trees (large-event-tree approach) or in the fault trees (small-event-tree approach). Either approach should lead to the same results for the undesirable event.

- Typical events that are included in the calculation of system unavailabilities are independent component failures, common-cause failures, human errors, and unavailabilities because of test and maintenance.

- Events such as earthquakes and fires are historically called "external" events and are treated separately. They are usually considered to be accident initiators, as well as contributors to system unavailability.

- There are several PC-based computer codes that facilitate the quantification of accident sequences. 


\section{REFERENCES FOR CHAPTER C.3}

C.3.1 N.J. McCormick, Reliability and Risk Analysis, Academic Press, Inc., San Diego, 1981.

C.3.2 D. F. Haasl et al., "Fault Tree Handbook," NUREG-0492, NRC, January 1981.

C.3.3 A. Villeneur, Reliability, Availability, Maintainability \& Safety Assessment, Volumes 1 and 2, John Wiley and Sons, Chichester, 1920, reprinted 1991.

C.3.4 E.J. Henley and H. Kumamoto, Probabilistic Risk Assessment: Reliability Engineering, Design, and Analysis, IEEE Press, Piscataway, NJ, 1992.

C.3.5 R.R. Fullwood and R.E. Hall, Probabilistic Risk Assessment in the Nuclear Power Industry - Fundamentals \& Applications, Pergamon Press, Oxford, 1988.

C.3.6 A.H. Ang and W.H. Tang, Probability Concepts in Engineering and Design, Volumes 1 and 2, John Wiley and Sons, Inc., New' York, 1984.

C.3.7 G.E. Apostolakis and S. Kaplan, "Pitfalls in Risk Calculations," Reliability Engineering, Volume 2, pp. $135-145,1980$.

C.3.8 G.E. Apostolakis and T.L. Chu, "The Unavailability of Systems under Periodic Test and Maintenance," Nuclear Technology, Volume 50, pp. 5-15, 1980.

C.3.9 NRC, "Reactor Safety Study-An Assessment of Accident Risks in U.S. Commercial Nuclear Power Plants," WASH-1400 (NUREG-75/014), Appendix 2, October 1975.

C.3.10 W.E. Vesely and F.F. Goldberg, "FRANTIC - A Computer Code For Time-Dependent Unavailability Analysis," NUREG-0193, NRC, October 1977.

C.3.11 K.D. Russell et al., "Integrated Reliability and Risk Analysis System (IRRAS) User's Guide - Version 1.0," NUREG/CR-4844 (Draft), NRC, June 1987."

C.3.12 K.D. Russell and D.M. Rasmuson, "Fault Tree Reduction and Quantification - An Overview of IRRAS Algorithms," Reliability Engineering and System Safety, Volume 40, pp. 149-164, 1993.

C.3.13 J. W. Hickman, "PRA Procedures Guide," NUREG/CR-2300, NRC, January 1983.

C.3.14 S. Kaplan, "Matrix Theory Formalism for Event Tree Analysis," Risk Analysis, Volume 2, pp. 9-18, 1982.

C.3.15 R.J. Breeding et al., "Summary Description of the Methods Used in the Probabilistic Risk Assessments for NUREG-1150," Nuclear Engineering and Design, Volume 135, pp. 1-27, 1992.

\footnotetext{
- Copies are available for inspection or copying for a fee in the NRC Public Document room.
} 
C.3 Accident Sequence and Reliability Analyses

C.3.16 S. Kaplan and B.J. Garrick, "On the Quantitative Definition of Risk," Risk Analysis, Volume 1, pp. 1127, 1981.

C.3.17 D.M. Rasmuson, "A Comparison of the Small and Large Event Tree Approaches Used in PRAs," Reliability Engineering and System Safety, Volume 37, pp. 79,90, 1992.

C.3.18 G.E. Apostolakis and P. Moieni, "The Foundations of Models of Dependence in Probabilistic Safety Assessment," Reliability Engineering and System Safety, Volume 18, pp. 177-195, 1987.

C.3.19 G. Apostolakis, "The Concept of Probability in Safety Assessments of Technological Systems," Science, Volume 250, pp. 1359-1364, 1990.

C.3.20 A. Mosleh et al., "Procedures for Treating Common Cause Failures in Safety and Reliability Studies," NUREG/CR-4780 (EPRI NP-5613), NRC, Volume 1, January 1988; Volume 2, January 1989.

C.3.21 A. Mosleh, "Common Cause Failures: An Analysis Methodology and Examples," Reliability Engineering and System Safety, Volume 34, pp. 249-292, 1991.

C.3.22 K.N. Fleming, "A Reliability Model for Common Mode Failure in Redundant Safety Systems," Proceedings of the Sixth Annual Pittsbungh Conference on Modeling and Simulation, General Atomic Report GA-A13284, 1975.

C.3.23 K.N. Fleming et al., "On the Analysis of Dependent Failures in Risk Assessment and Reliability Evaluation," Nuclear Safety, 24, 1983.

C.3.24 J. Rasmussen, Information Processing and Human-Machine Interaction: An Approach to Cognitive Engineering, North-Holland, New York, 1986.

C.3.25 G.E. Apostolakis, V.M. Bier, and A. Mosleh, "A Critique of Recent Models for Human Error Rate Assessment," Reliability Engineering and System Safety, Volume 22, pp. 201-217, 1988.

C.3.26 D.D. Woods, J.A. Rumancile, and M.J. Hitchler, "Issues in Cognitive Reliability," P.L. Lassahn et al., Eds., Anticipated and Abnormal Plant Transients in Light Water Reactors, Plenum Publishing Corp., New York, 1984.

C.3.27 D.C. Bley et al., "Light Water Reactor Sequence Timing: Its Significance to PSA Modeling," Reliability Engineering and System Safety, Volume 22, pp. 27-60, 1988.

C.3.28 A.D. Swain and H.E. Guttmann, "Handbook of Human Reliability Analysis with Emphasis on Nuclear Power Plant Applications," NUREG/CR-1278 (Sandia National Laboratories, SAND80-0200), NRC, October 1983.

C.3.29 A.D. Swain, "Accident Sequence Evaluation Program Human Reliability Analysis Procedure," NUREG/CR-4772 (Sandia National Laboratories, SAND86-196), NRC, February 1987.

C.3.30 A.J. Spurgin and P. Moieni, "Interpretation of Simulator Data in the Context of Human Reliability Modeling," Procecdings of ,the Intemational Conference on Probabilistic Safety Assessment and Management, G. Apostolakis, Editor, Elsevier, New York, 1991. 
C.3.31 P. Moieni et al., "The Use of Simulator Data in Human Reliability Analysis: Results from the EPRI Operator Reliability Experiments Program," Proceedings of the International Conference on Probabilistic Safety Assessment and Management, G. Apostolakis, Editor, Elsevier, New York, 1991.

C.3.32 M.K. Comer et al., "Generating Human Reliability Estimates Using Expert Judgment," NUREG/CR3688, Volumes 1 and 2, November 1984.

C.3.33 O. Svenson, "On Expert Judgments in Safety Analyses in the Process Industries," Reliability Engineering and System Safety, Volume 25, pp: 219-256, 1989.

C.3.34 D.E. Embrey et al., "SLIM-MAUD: An Approach to Assessing Human Error Probabilities Using Structured Expert Judgment," NUREG/CR-3518, Volume 1, July 1984; Volume 2, December 1984.

C.3.35 A. Poucet, "The European Benchmark Exercise on Human Reliability Analysis," Proceedings of PSA '89, Pittsburgh, Pennsylvania, American Nuclear Society, 1989.

C.3.36 B. Zimolong, "Empirical Evaluation of THERP, SLIM and Ranking to Estimate HEPs," Reliability Engineering and System Safety, Volume 35, pp. 1-11, 1992.

C.3.37 E. Hollnagel, "What Is a Man that He Can Be Expressed by a Number?" Proceedings of the Intemational Conference on Probabilistic Safety Assessment and Management, G. Apostolakis, Editor, Elsevier, New York, 1991.

C.3.38 E. Dougherty, "Human Reliability Analysis - Where Shouldst Thou Turn?" Reliability Engineering and " System Safety, Volume 29, No. 3, 1990.

C.3.39 EPRI, Seismic Hazard Methodology for the Central and Eastem United States, EPRI NP-4726, Volume 1-10, 1986.

C.3.40 D.L. Bernreuter et al., "Seismic Hazard Characterization of 69 Plant Sites East of the Rocky Mountains," NUREG/CR-5250, Volume 1-8 (Lawrence Livermore National Laboratory, UCID 215-7), NRC, January 1989.

C.3.41 R.M. Cooke, Experts in Uncertainty: Expert Opinion and Subjective Probability in Science, Oxford University Press, New York, 1991.

C.3.42 M.A. Meyer and J.M. Booker, Sources of Correlation Between Experts, NUREG/CR-4814, NRC, April 1987.

C.3.43 A. Mosleh, V.M. Bier, and G. Apostolakis, "Methods for the Estimation and Use of Expert Opinion in Risk Assessment," Reliability Engineering and System Safety, Volume 20, pp. 63-8, 1988.

C.3.44 K.K. Bandyopadhyay and C.H. Hofmayer, "Seismic Fragility of Nuclear Power Plant Components (Phase 1)," NUREG/CR-4659, Volume 1, NRC, June 1986.

C.3.45 K.K. Bandyopadhyay and C.H. Hofmayer, "Seismic Fragility of Nuclear Power Plant Components (Phase II)," NUREG/CR-4659, Volume 2, NRC, January 1988. 
C.3 Accident Sequence and Reliability Analyses

C.3.46 R.J. Budnitz et al., "An Approach to the Quantification of Seismic Margins in Nuclear Power Plants," NUREG/CR-4334, NRC, August ' 1985.

C.3.47 EPRI, "A Methodology for Assessment of Nuclear Power Plant Seismic Margin," EPRI NP-6041, Palo Alto, CA, October 1988.

C.3.48 M. Kazarians, N. Siu, and G. Apostolakis, "Fire Risk Analysis for Nuclear Power Plants," Risk Analysis, Volume 5. pp. 33-51, 1985.

C.3.49 V. Ho, S. Chien, and G. Apostolakis, "COMPBRN IIIe: An Interactive Computer Code for Fire Risk Analysis," EPRI, NP-7282, Palo Alto, CA, 1991.

C.3.50 EPRI, "Fire-Induced Vulnerability Evaluation (FIVE)," EPRI TR-100370, Palo Alto, CA, 1992.

C.3.51 R. Sues et al., "Integrating Internal Events in an External Event Probabilistic Risk Assessment: Tornado PRA Case Study," Reliability Engineering and System Safety, Volume 40, pp. 173-186, 1993.,

C.3.52 L.A. Twisdale, and W.L. Dunn, "Probability of Facility Damage from Extreme Wind Effects," ASCE Joumal of the Structural Division, Volume 114, No.10, 1988.

C.3.53 J.A. McDermid, "Issues in Developing Software for Safety Critical Systems," Reliability Engineering and System Safety, Volume 32, pp. 1-24, 1991.

C.3.54 S. Petrella et al., "Random Testing of Reactor Shutdown System Software," Proceedings of the International Conference on Probabilistic Safety Assessment and Management, G. Apostolakis, Editor, Elsevier, New York, 1991.

C.3.55 A.L. Goel, "Software Reliability Models: Assumptions, Limitations, and Applicability," IEEE Transactions on Software Engineering, SE-11, IEEE, 1985.

C.3.56 B. Littlewood and D. Miller, "Preface: Special Issue on Software Reliability and Safety," Reliability Engineering and System Safety, Volume 36, 1991.

C.3.57 C.T. Muthukumar, S.B. Guarro, and G.E. Apostolakis, "Logic Flowgraph Methodology: A Tool for Modeling Embedded Systems," Proceedings of the IEEE/ALAA $10^{\text {th }}$ Digital Avionics Systems Conference, IEEE, 1991.

C.3.58 N.G. Leveson and P.R. Harvey, "Analyzing Software Safety," IEEE Transactions on Software Engineering, SE-9, IEEE, 1983.

C.3.59 S.S. Cha et al., "Safety Verification in Murphy Using Fault Tree Analysis," Proceedings of the International Conference on Software Engineering, IEEE Press, 1988.

C.3.60 M.S. Jaffe et al., "Software Requirements Analysis for Real-Time Process-Control Systems," Proceedings of the 1lth Intermational Conference on Software Engineering, IEEE Press, 1989.

C.3.61 N. Siu and G. Apostolakis, "A Methodology for Analyzing the Detection and Suppression of Fires in Nuclear Power Plants," Nuclear Science and Engineering, Volume 94, pp. 213-226, 1986. 
C.3.62 A. Amendola, "Accident Sequence Dynamic Simulation versus Event Trees," Reliability Engineering and System Safety, Volume 22, pp. 3-25, 1988.

C.3.63 N. Siu and C. Acosta, "Dynamic Event Tree Analysis - An Application to SGTR," Proceedings of the Intermational Conference on Probabilistic Safety Assessment and Management, G. Apostolakis, Editor, Elsevier, New York, 1991.

C.3.64 J. Devooght and C. Smidts, "Probabilistic Reactor Dynamics-1: The Theory of Continuous Event Trees," Nuclear Science and Engineering, Volume 111, pp. 229-240, 1992.

C.3.65 W.E. Vesely et al., Evaluations of Core Melt Frequency Effects Due to Component Aging and Maintenance, NUREG/CR-5510, NRC, June 1990.

C.3.66 W.E. Vesely, "Incorporating Aging Effects into Probabilistic Risk Analysis Using a Taylor Expansion Approach," Reliability Engineering and System Safety, Volume 32, pp. 315-337, 1991.

C.3.67 V. Bier, D. Bley, and D. Johnson, "Methods for Bayesian Aging Analysis," Proceedings of the Intemational Conference on Probabilistic Safety Assessment and Management, G. Apostolakis, Editor, Elsevier, New York, 1991.

C.3.68 P. Kafka and P. Kunitz, "Computerized Systems for High-Level Information Processing and DecisionMaking in PSA," Reliability Engineering and System Safety, Volume 30, pp. 3-20, 1990.

C.3.69 R.J. Marnicio et al., "Risk Analysis Software and Databases: Review of Riskware '90 Conference and Exhibition," Risk Analysis, Volume 11, pp. 545-560, 1991.

C:3.70 J. Koren and J. Gaertner, "CAFTA: A Fault Tree Analysis Tool Designed for PSA," Proceedings from Probabilistic Safety Assessment and Risk Management, PSA '87, Volume 11, European Nuclear Society and Swiss Nuclear Society, Zürich, 1987.

C.3.71 J. Koren et al., "CAFTA +: A Comprehensive Fault Tree Development Workstation," Proceedings of the Annual Reliability and Maintainability Symposium, Institute of Electrical and Electronics Engineering Inc., New York, 1987.

C.3.72 R.E. Hall et al., "FRANTIC II -A Computer Code for Time-Dependent Unavailability Analysis," NUREG/CR-1924, NRC, April 1981.

C.3.73 U. Berg, "RELTREE and Risk Spectrum: Experience from and Development of PSA Software for PC's," Reliability Engineering and System Safety, Volume 30, pp. 323-338, 1990.

C.3.74 D.W. Stack, "A SETS User's Manual for Accident Sequence Analysis," NUREG/CR-3547, NRC, January 1984.

C.3.75 R.B. Worrell, "SETS Reference Manual," NUREG/CR-4213, NRC, July 1985.

C.3.76 R.L. Iman, "A Matrix Based Approach to Uncertainty and Sensitivity Analyses for Fault Trees," Risk Analysis, Volume 7, pp. 21-33, 1987. 
C.3 Accident Sequence and Reliability Analyses

C.3.77 R.L.Iman and M.J. Shortencarier, "A FORTRAN 77 Program and User's Guide for the Generation of Latin Hypercube and Random Samples for Use with Computer Models," NUREG/CR-3624 (Sandia National Laboratories, SAND83-2365), NRC, June 1984.

C.3.78 B.O.Y. Lydell and P.J. Fulford, "Retrospective Review of Experience with Using the NUPRA Software," Reliability Engineering and System Safety, Volume 30, pp. 339-353, 1990. 


\section{C.4 ACCIDENT PROGRESSION AND RISK ANALYSES}

\section{C.4.1 Learning Objectives}

- Delineate three types of transformations that are commonly used at the NRC to convert a core damage frequency to a risk estimate.

- Understand the role of an accident progression event tree in a PRA and realize that its construction will impact the extent to which the stated purposes of an analysis can be achieved.

- Understand the concept of a source term, how source terms are used in a PRA, and how source terms are calculated.

- Understand the content and organization of consequence assessments that are performed in PRAs, the types of measures that are used to describe the consequences, the products and display formats of a consequence analysis, and the methods that are used for estimating consequences.

- Understand the concept of risk integration, the two definitions of risk commonly used at the NRC, and the use of risk estimates.

- Understand how deterministic calculations are used to support a PRA.

\section{C.4.2 Overview}

The objectives of the accident progression and risk analyses are to determine the spectrum of accident progressions after core damage, ${ }^{5}$ to determine their likelihood, and to determine their severity in terms of health effects and other impacts. In the Level 1 analysis, accident sequences were developed up to the point of core damage. Aspects of accidents after core damage, such as fission product release from fuel and core debris, containment loads, containment response, and mitigative actions, are taken into account in the Level 2 analysis. Once the accident progressions and their associated radiological releases within a plant have been determined, there is enough information to predict consequences to the surrounding population in the Level 3 analysis. The results of the Level 1,2, and 3 analyses are combined in the risk calculation. The Level 1 analysis is also known as a front-end analysis. The Level 2 analysis is also known as the back-end analysis. However, the term backend is loosely used, sometimes referring to just the Level 2 analysis and other times referring to the Level 2 analysis, Level 3 analysis, and risk calculation.

The purpose of this section is to define terms and introduce methods commonly used in Level 2 and 3 analyses. Discussions are focused on risk assessments of nuclear power reactors because most of the PRA activities at the NRC are in this area. At first the focus of the discussions in this section, particularly Section C.4.4.1 (page C-84), may seem to be on performing a PRA. The relevance of the issues will vary, depending on whether a given study relies on results from a surrogate PRA, methods from a surrogate PRA, or performance of a PRA. The same issues are relevant when reviewing a PRA. In performing a PRA, issues are in the future tense, i.e. achieving the objectives. In reviewing a PRA, issues are in the past tense, i.e., determining the extent to which objectives were achieved. Given that there is little formal guidance on the review of a PRA that is analogous to the standard review plan of a plant, the material presented in this section assumes importance.

\footnotetext{
'See Section C.4.4.1 (page C-85) for various definitions of core damage.
} 


\section{C.4.2 Overview}

The PRA analyses discussed here correspond to the shaded boxes in Figure C.4.1:

- Section C.4.3 (page C-76) discusses three types of transformations, the use of results from another (surrogate) PRA, the use of models from a surrogate PRA, and the development of a plant-specific PRA. Appendix B of this report discusses particular situations in the NRC in which the transformations are used.

- Section C.4.4.1 (page C-84) discusses the first part of the Level 2 analysis, which is the development of accident sequences after core damage. The framework of this analysis is an event tree, herein called an accident progression event tree or containment event tree. There is no established or common structure for such an event tree, even though the structure will have a bearing on the extent to which stated purposes of a PRA study are achieved.

- Section C.4.4.2 (page C-91) discusses the second part of a Level 2 analysis, in which the release of radioactive material from the fuel/core debris and the transport of this material through the primary system and containment to the environment is determined. These calculations are also known as the source term analysis. The product of this analysis, the source term, is a collection of parameters that characterize the release to the environment. There are many methods that can be used to perform a source term analysis; the appropriate method will depend on the purpose of the analysis and on the resources available. The analysis is performed whenever the radiological severity of an accident is being assessed.

- Section C.4.4.3 (page C-98) discusses the Level 3 analysis, which is the estimation of health effects and other impacts from a release of radionuclides into the environment. Consequences can be estimated for the offsite population as well as for the onsite population. Most PRAs have focused on offsite consequences.

- Section C.4.4.4 (page C-104) discusses the computation of risk according to two expressions, the ordered set of risk triplets and aggregate risk. The term risk is loosely used to include other quantities, such as the core damage frequency. For this and other reasons, the meaning of risk must be understood to correctly interpret and use results.

- Section C.4.5 (page C-111) discusses uncertainty in the risk estimates. Uncertainty complicates the use of risk estimates. The meaning of the risk estimates and their uncertainty must be understood to correctly use risk estimates.

- Section C.4.6 (page C-116) discusses the use of deterministic calculations in a PRA. Considerable knowledge of severe accident phenomena, the plant, and the code itself is required to perform these calculations.

- Section C.4.7 (page C-120) lists codes frequently seen by the NRC staff and its contractors that are used in Level 2 and 3 analyses.

The guidance in the following sections is necessarily general. Specific guidance will depend on such factors as the objectives of a given study, available resources, attributes of the analytical methods, and attributes of computer codes. 


\section{Supporting} Discussions
Discussions of PRA Analyses

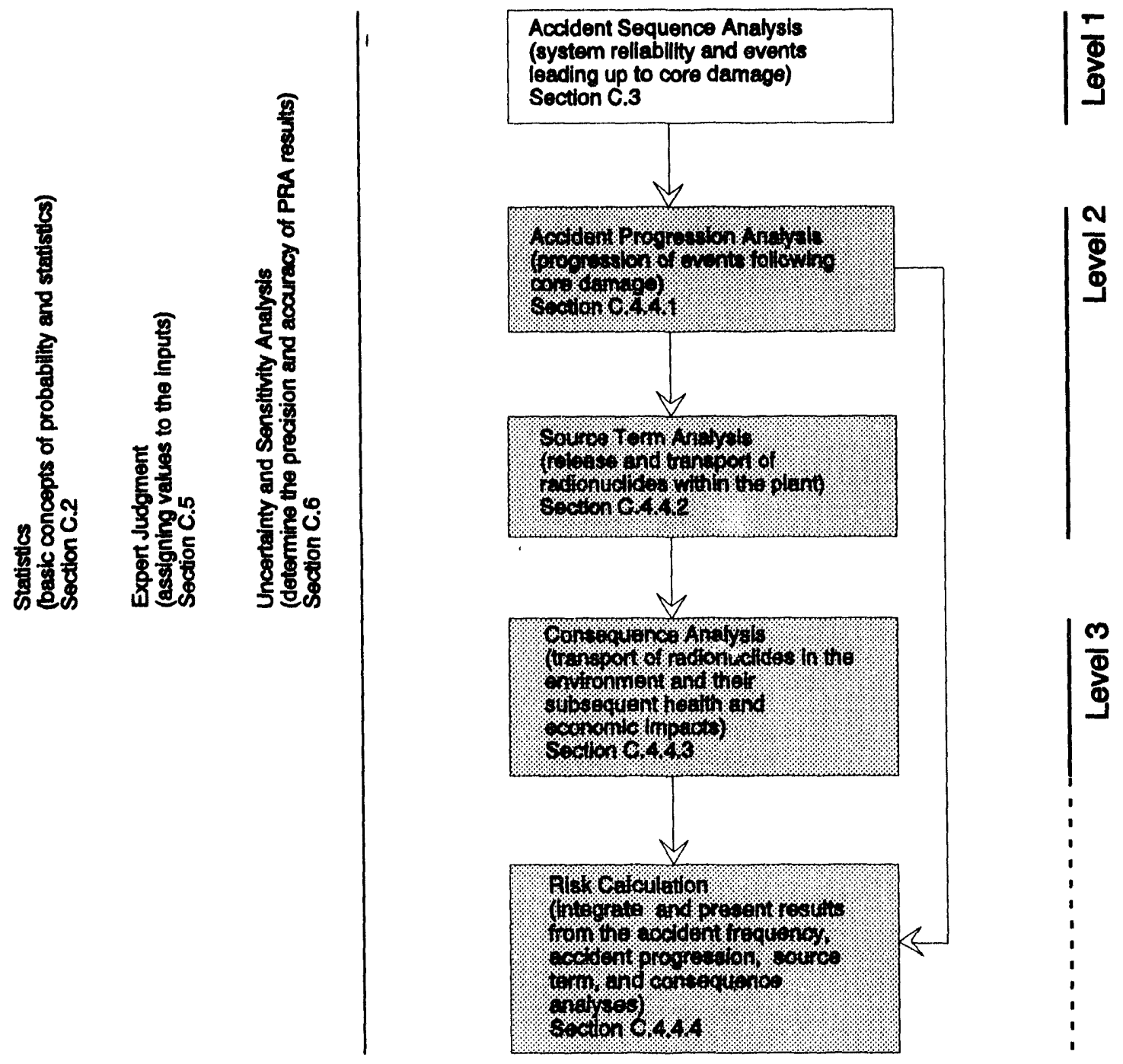

Figure C.4.1 Overview of the discussions on CDF to risk transformations 


\section{C.4.3 CDF to Risk Transformation}

\section{C.4.3.1 Concepts}

Many of the decision criteria that draw from PRA are risk-based, while many of the issues addressed by the NRC staff are analyzed using accident sequence and reliability models (i.e., Level 1 models) with the product being a core damage frequency (CDF) ${ }^{6}$ Thus, it is often necessary to perform an additional analysis that transforms the core damage frequency into an expression for risk. These transformations range from simple transformations that rely on results from surrogate ${ }^{7}$ PRAs to detailed transformations that consist of performing a full-scope Level 3 PRA (i.e., the PRA includes accident progression, source term, consequence, risk integration, and uncertainty analyses). Because a full-scope Level 3 PRA is resource-intensive, the staff relies heavily on the simple transformations. For instance, a simple transformation may be warranted for performing a preliminary ranking and screening of issues, while a more sophisticated method may be justified to support an issue resolution study.

While some general approaches for extrapolating PRA results can be found in Reference C.4.1, currently there is no well detined guidance that instructs the NRC staff on what type of transformation should be used for a given application, which PRA models and data are appropriate, or on how to draw conclusions from existing studies. The level of sophistication used to perform the transformation will depend on many factors, including common practice, available resources (staff time, funding), urgency of subsequent decisions, direct significance of a PRA in regulatory decisions, and the reliability needed in the risk estimates. Lacking specific guidance, the staff must know important aspects of the Level 2 and 3 analyses to determine the applicability of a both a given type of transformation and the means by which the transformation is done to address a stated problem. In Sections C.4.4.1 through C.4.4.4, beginning on page C-84, the aspects of the constituent analyses (accident progression, source term, consequence, and risk integration) of a CDF to risk transformation are discussed.

An integral part of the analytical results from a PRA is uncertainty, which is present regardless of whether or not it is expressed. But to consolidate subjects in Appendix C, the discussions are left in two places. Section C.4.5 (page C-111) discusses the need to express uncertainty in a risk estimate and illustrates how uncertainty can alter perceptions of risk and influence decisions; at this time, the topic is necessarily on an introductory level. This view of uncertainty is a logical extension of the mechanics of the risk calculation itself discussed in the preceding section. Chapter C.6 (page C-149) discusses concepts of and methods for performing an uncertainty analysis; Section C.6.2.2 (page C-151) discusses how uncertainty is typically accounted within the Level 1, 2, and 3 portions of a PRA.

Guidance: Careful thought must be given to make sure that the objectives of the analysis can be achieved with the chosen transformation.

A thorough understanding of the design and operation of a plant is necessary for correct modeling. This understanding goes beyond the gross parameters of a containment. The design details affecting the accident progressions must be identified and taken into account. The vulnerability portions of the containment may not be the structural members but instead the penetrations, the bolting, the seals, materials, or component locations. Thus, the details of the containment may affect the accident progression.

\footnotetext{
- In this section, the acronym CDF refers to core damage frequency. In section C.6.4.1 (page C-160) the same acronym also refers to cumulative distribution function. Both uses are common and are distinguished by the context of their use.

' In this chapter, the term surrogate refers to an existing PRA. Results and models from the existing PRA are then used to infer accident characteristics at the plant being studied, which is referred to as the subject piant.
}

NUREG-1489

C-76 


\section{Guidance: A thorough understanding of the design and operation of a plant is necessary for a risk assessment.}

An understanding of the codes being used to model severe accident progressions is also necessary. The event tree and the codes used to support the development of the event tree introduce artifacts into the results for various reasons, such as inputs are imprecisely known, simplifying assumptions are necessary, and models represent phenomena imperfectly. For this reason, the NRC staff must understand the characteristics of an analysis given the models and relate those characteristics to the subject decisions.

\section{Guidance: An understanding of modeling and the specific codes used in and in support of a PRA is necessary for a risk assessment.}

\section{C.4.3.2 Methods}

In this section, three general classes of transformations will be discussed that range from the very simple use of results from existing studies to the much more complicated analysis involved in a full-scope Level 3 PRA. These discussions are not meant to be a tutorial on how to perform the various transformations, but rather to be an introduction to the types of transformations that are available, including the strengths and weaknesses of each approach. All these approaches start with an accident sequence. The accident sequence can define the events leading up to core damage; it can also define events that are important to the progression of the accident following core damage (e.g., the containment performance). Because most of the NRC staff's effort are involved with Level 1 issues, the former is the more common case.

\section{C.4.3.2.1 Class 1: Simple Transformation}

A simple transformation is based on the premise that accident progression and risk results (i.e., Level 2/3) from surrogate PRAs can be associated with accident sequences in the subject study. Sequences in the subject study can represent an accident at a different plant or can represent an accident at a class of plants (i.e., a generic accident). Because this method uses results from existing PRAs without developing or modifying models, it is the simplest and fastest transformation to perform. However, as discussed below, it is also the most limited in terms of the conclusions that can be drawn from its results.

The three basic elements of this method are as follows. (1) Identify a PRA that can be used as a surrogate (u. the subject study; the surrogate must be relevant to the issue being addressed. (2) Organize the information from the surrogate PRA such that accident progression and risk results can be associated with key accident sequences. (3) Associate the sequence from the subject study with an appropriate sequence from the surrogate study and its corresponding results.

The motivation for using a Class 1 transformation is to learn the relative importance of issues when the commitment of the large amount of resources necessary to perform a detailed Level 3 PRA is not justified. The preliminary ranking and screening of generic issues is an example of this type of situation. Since plant-specific features can have a strong impact on the results, this approach is generally not useful when high reliance is being placed on risk estimates for making regulatory decisions or other decisions involving a large commitment of resources.

The validity of the results will depend on the applicability of the surrogate PRA for the given problem and stated abjective. This approach is based on the assumption that the dominant characteristics of the accident are driven by gross plant features such as its cooling system capabilities and its pressure and volume capabilities, and not by minor features of the plant or of the accident sequences and progressions that threaten it. But evidence from 


\section{C.4 Accident Progression and Risk Analyses \\ C.4.3 CDF to Risk Transformations \\ C.4.3.2 Methods}

past PRAs suggests that there are many plant-specific features that can have a strong influence on the PRA results. Thus, it is necessary to identify any plant-specific features in either the surrogate analysis or the current analysis that could affect the results and then assess the importance of these plant features relative to the objectives of the study. Using this method, minor plant features, accident sequences, and accident progressions are likely to go unappreciated by an analyst. The use of existing results should not be treated as a "black box." The analyst must understand the scope, major assumptions, and factors driving the results of the surrogate PRA. Identifying an applicable surrogate PRA is the central issue with this approach.

To organize the Level 2 and 3 information so that accident sequences from the subject study can be associated with results from the surrogate study, accident progression and consequence results from existing studies are catalogued according to various accident sequence attributes, for example, the type of plant damage state. The level of sophistication used to associate subject accident sequences and progressions with surrogate results depends on the amount of information available regarding the sequences and progressions and the resolution in the catalogue of results. The catalogue of existing information can take on various levels of resolution from simple reference tables of consequences of accidents to large data bases that correlate many different types of results (c.g., frequencies, source terms, consequences) for individual accident progressions. Simple reference tables are useful when only general characteristics of core damage sequences are known (e.g., station blackout core damage sequences). If information about the progression of the accident following core damage is available, detailed tables incorporating attributes of the accident progression should be developed. For instance, accident sequences can be partitioned based on the status of the containment following core damage (e.g., early containment failure, late containment failure, no containment failure):

\section{EXAMPLE}

An example of a simple reference look-up table approach is the cost/benefit analysis described in NUREG-0933 (Ref. C.4.2). The reference table in NUREG-0933 is based on radioactive release categories described in the Reactor Safety Study (Ref. C.4.3). In this table, the person-rem within 50 miles of the site are tabulated for different release categories; each release category is a collection of accident progressions that are expected to result in similar radioactive releases. To use this table, an accident sequence is associated with a release category based on the similarities between the accident sequence being studied and the accident sequences that were used to define the release category in the surrogate analysis. The consequences corresponding to this release category are then applied to the accident sequence. The multiplication of the accident sequence frequency with the consequence yields an estimate of the risk associated with the sequence.

Because this approach is typically used for preliminary screening studies, it is customary to use point estimates. A characterization of the uncertainty in the estimate is not warranted. In most cases, the uncertainty in the point estimate is known to be large, but sufficient information is usually unavailable to make a meaningful quantitative analysis of the uncertainty bounds of these point estimates. Any decisions that rely on numbers produced by this method must be tempered by the knowledge that the uncertainty is generally large.

Many of the simple transformations that are currently being used by the NRC staff utilize information from the Reactor Safety Study (Ref. C.4.3). For instance, the analysis used to prioritize generic safety issues, described in NUREG-0933 (Ref. C.4.2), uses radioactive release categories defined in the Reactor Safety Study (Ref. C.4.3). There has been a considerable amount of research on accident progressions and severe accident phenomena since the publication of the Reactor Safety Study. Much of this new information has been incorporated into recent PRAs such as the NUREG-1150 study (Ref. C.4.4) and a PRA of the LaSalle plant (Ref. (.4.5); these references are valuable sources of Level 2 and 3 information. These PRAs cover both pressurized water reactors (PWRs) and boiling water reactors (BWRs), as well as a variety of containment types. 


\section{C.4 Accident Progression and Risk Analyses \\ C.4.3 CDF to Risk Transformations \\ C.4.3.2 Methods}

The NRC is currently developing data bases that catalogue the wealth of Level 2 and 3 results generated in these PRAs. As an example, Table C.4.1 presents results from the internal events analysis of Surry in NUREG-1150 study (Ref. C.4.4) that are analogous to the table provided in NUREG-0933 (Ref. C.4.2). Similar tables that incorporate additional accident attributes and other plant results can also be generated.

A limitation in the Class 1 transformation is that a quantitative description of uncertainty is lacking. Several factors will limit a quantitative assessment of uncertainty. An uncertainty analysis may not have been done in a surrogate PRA. Even if available, an uncertainty analysis of one plant is difficult to apply to another plant. Models and distributions assigned to variables may reflect plant-specific features, hence, the values in a surrogate risk distribution may be caused by peculiar features of the surrogate plant. But in Class 1 transformations, only surrogate results are being used to make inferences. An additional limitation of Class 1 transformations is that inferences are being made from aggregated results, which cannot be readily traced through the calculations to determine the causes of the results (see Section C.6.9, page C-169 for additional discussion).

Having a capability to readily select intermediate products of the set of PRAs from the NUREG-1150 study (Ref. C.4.4) and the LaSalle PRA (Ref. C.4.5) should enhance the NRC staff's ability to perform Class 1 transformations. The staff is developing an information management system to manipulate the quantitative Level 2 and 3 results of those PRAs in simple ways. Mean and uncertainty estimates of the plant damage state frequencies, source terms, consequences, and risk estimates can be recomputed for selected types of sequences, such as station blackout, transient, and ATWS. The information system allows these manipulations to be done readily and consistently. But even with such a system, at least sume applicability of the surrogate analysis must be demonstrated when making inferences from the analysis of a surrogate plant to a subject plant.

Guidance: Whenever possible, transformations should be based on information from modern PRAs, such as the 'NUREG-1150 study (Ref. C.4.4), rather than from outdated information presented in the Reactor Safety Study (Ref. C.4.3).

While results from existing studies can be useful for screening purposes, experience from past PRAs suggests that there are many plant-specific features that can have a strong impact on risk, and therefore, they should not be used as a replacement for plant-specific studies. Rather, a plant-specific PRA, which accounts for unique features of a plant, should be developed to address plantspecific issues. Existing models can be used to guide the development of new models, but the new model must reflect the design and operation of the plant being studied.

Tabular risk quantities typically come from plant-specific analyses, such as those done in the NUREG-1150 study (Ref. C.4.4). Those risk quantities reflect the plant-specific features as modeled in those particular PRAs. Hence, the risk estimates implicitly carry with them the effects of the accident progressions because of the plant features, the population distributions surrounding the plant, and the artifacts of the PRA models. Before existing information is used, the relevance of these factors in the surrogate estimates on the subject matter must be determined. Surrogate risk estimates should be used only after their applicability has been established. 
C.4 Accident Progression and Risk Analyses

C.4.3 CDF to Risk Transformations

C.4.3.2 Methods

Table C.4.1 Population doses within 50 miles of the Surry reactor

\begin{tabular}{|c|c|c|c|c|c|}
\hline \multirow{3}{*}{$\begin{array}{c}\text { Plant Damage } \\
\text { States }\end{array}$} & \multicolumn{5}{|c|}{ Population Dose Within 50 Miles of the Site (Sv) } \\
\hline & \multirow{2}{*}{$\begin{array}{c}\text { Frequency } \\
\text { Weighted } \\
\text { Average }\end{array}$} & \multicolumn{4}{|c|}{ Partition Based on Containment Failure (CF) } \\
\hline & & Bypass & Early CF & Late CF & No $\mathbf{C F}$ \\
\hline Siow SBO & 400 & 16000 & 13000 & 2500 & 2 \\
\hline LOCAs & 220 & - & 9700 & 2400 & 2 \\
\hline Fast SBOs & 470 & 15000 & 14000 & 2400 & 2 \\
\hline Event V & 11000 & 11000 & - & - & - \\
\hline Transients & 180 & 16000 & 8700 & 2400 & 2 \\
\hline ATwS & 1500 & 16000 & 9500 & 2400 & 2 \\
\hline SGTR & 12000 & 12000 & - & - & - \\
\hline
\end{tabular}

KEY

ATWS = anticipated transient without a scram

LOCA $=$ loss-of-coolant accident

SBO $=$ station blackout

SGTR = steam generator tube rupture

\section{Advantages}

$\triangleright \quad$ A transformation can be performed quickly (i.e., a few days) and requires few resources.

$\checkmark \quad$ The approach is particularly useful for preliminary ranking and screening studies where many issues have to be addressed in a fairly short amount of time.

\section{Disadvantages}

$\triangleright \quad$ The plant-specific features modeled in the surrogate plant are embedded in the results; these features may not be applicable to the study of the subject plant. Similarly, the subject plant may have specific features that were not modeled in the surrogate PRA.

$\triangle \quad$ The Level 2 and 3 models have been replaced with a few representative numbers (e.g., population dose within 50 miles of the site) for various classes of accidents. Hence, detailed characteristics of the accident progressions (e.g., the interaction between the plant and the various phenomena that can occur during the accident) can not be ascertained. With this approach it is difficult to capture any dependencies between the Level 1 analysis and the Level 2 and 3 analysis. 
$\triangleright$

$D$

$\triangle$

The transformations using existing results are limited to the accident sequences and progressions that were analyzed in the surrogate PRA.

Information on uncertainty is difficult to obtain.

The method is difficult to apply to plants that are very different from the surrogate, such as advanced plants.

\section{C.4.3.2.2 Class 2: Modined Surrogate PRA}

In this approach, existing PRA models, rather than results and insights, of a surrogate PRA are modified to be more relevant to the subject plant. Modifications are made to the surrogate models to more closely resemble the design of the subject plant and to account for accidents that were not included in the surrogate PRA. Similarly, data that can have a strong impact on the progression and consequences of the accidents (e.g., containment strength and containment loads) are also modified to better represent the characteristics of the subject plant and the accidents being studied. Hypothetically, the results given by this approach could be at the same level of detail as the surrogate approach on which the models and data are based. In practice, changes in models vary from changes in the gross plant features (e.g., containment strength) to detailed changes in the plant features, plant damage state characteristics, local phenomena, and timing characteristics. In the extreme, detailed modifications yield a plant-specific model.

The complex logic models used in the accident progression analysis are based on many assumptions. The types of accidents that may occur, the arrangement of the plant, the performance of various systems and pieces of hardware can all affect the structure of the models and the results that are generated. Therefore, the applicability of these aspects of the candidate PRA must be reviewed. The selection of appropriate models and the modification of these models and their data must be performed by staff familiar with the plant and with the PRA methods and models.

Class 2 transformations can include an uncertainty analysis using Monte Carlo simulation (Section C.6.3.1, page (-154). Two points need to be established: (1) the surrogate models must have been designed for Monte Carlo simulations and (2) input distributions need to be applicable. Distributions may be developed with either the NR' staff performing the PRA or with formal expert judgment (Chapter C.5, page $C-129)$. If the distributions from the surrogate plant are used without changes, their applicability must be established; otherwise, the distributions must be modified to account for plant-specific features.

\section{Advantages}

$\triangle \quad$ Since the majority of the PRA structure is defined, this approach is not as resource-intensive as developing a PRA from scratch.

D This approach allows some plant-specific information to be explicitly addressed.

$\triangle \quad T_{0}$ the degree to which it is modeled in the PRA, the interaction between the plant and various phenomena can be readily assessed.

D Once a model has been developed, uncertainty and sensitivity calculations can be performed.

$\triangle \quad$ The analyst has access to all the results generated by the PRA models; these results can then be manipulated and displayed to extract meaningful insights from the analysis. Simple transformations rely on existing results and typically yield much less information. 


\section{C.4 Accident Progression and Risk Analyses}

\section{C.4.3 CDF to Risk Transformations}

C.4.3.2 Methods

\section{Disadvantages}

D While not as resource-intensive as developing a plant-specific PRA, a modified surrogate PRA still requires a significant commitment of resources to select an appropriate surrogate, modify the models and data, and perform the calculations.

D Although many of the plant models and data are modified in this approach, there are still many assumptions regarding the surrogate analysis that are embedded in the PRA. Hence, a certain amount of inference is required to apply the results to the issue being addressed.

D The heavy reliance on surrogate models can lead to an omission of important plant-specific features.

\section{C.4.3.2.3 Class 3: Plant-Specific PRA}

The most complicated and resource-intensive transformation is to perform a plant-specific PRA. In this case, accident progression, source term, and consequence analyses are used to perform the transformation. These analyses are discussed in Sections C.4.4.1 (page C-84), C.4.4.2 (page C-91) and C.4.4.3 (page C-98). The appeal of a plant-specific PRA is that it utilizes plant-specific models and incorporates plant-specific data. Hence, the results and insights obtained from this analysis are directly applicable to the plant that is being studied. The scope and structure of the Level 2 and 3 portion of the PRA must still be defined relative to the stated objectives, of the analysis. For example, simplified accident progression models, which still account for plant-specific details, may be useful for obtaining risk values that can then be compared to the safety goals; more detailed models may be needed to assess the impact of changes to technical specifications or to evaluate different accident mitigation procedures. Thus, the objective of the study must be clearly defined and the PRA must be designed to achieve the objective.

A Class 3 transformation is not necessarily a large effort, such as on the same scale as the NUREG-1150 study (Ref. C.4.4). Class 3 refers to an approach and does not imply a size. The event trees many be large or small, depending on factors to be discussed in Section C.4.4 (page C-84). A preliminary transformation was done by the NRC staff and its contractors to study the risk of low power and shutdown operations (Ref. C.4.6 and C.4.7); the event trees modeling the accident progressions following core damage consisted of about ten top event questions. Thus, while efforts similar to the NUREG-1150 study are unlikely in the foreseeable future because of the large amount of resources that are required, Class 3 transformations on a smaller scale seem likely to address specific issues having regulatory significance. They are typically performed to achieve the following:

- Identify and assess plant-specific features and operations that determine risk.

- Obtain numerical results on which high reliance will be placed to make regulatory decisions.

Performing a PRA requires a team with expertise in the design and operation of the subject plant, severe accident phenomena, and PRA methods.

\section{Advantages}

$\triangle \quad$ In constructing a PRA, a framework is developed to systematically delineate and estimate the likelihood of possible accident progressions that can occur at a given plant. From this information, the plant design and procedures can be evaluated.

$D \quad$ Since plant-specific features are explicitly included in the models (e.g., event tree), direct statements can be made about a plant with a minimal amount of inferences. Furthermore, the analyst has access to 


\section{C.4 Accident Progression and Risk Analyses \\ C.4.3 CDF to Risk Transformations \\ C.4.3.3 Applications to Future Designs}

all the results generated by the PRA models; these results can then be manipulated and displayed to extract meaningful insights from the analysis. For example, in addition to absolute values for risk, the PRA can be used to assess the performance of hardware, technical specifications, and emergency response procedures.

D

Once a model has been developed, uncertainty and sensitivity calculations can be performed.

\section{Disadvantages}

D The performance of a PRA is very resource-intensive in terms of both NRC staff time and cost. Performing a PRA entails developing models, collecting data, performing calculations, and analyzing results. Thus, this approach is not used for prioritization exercises when many issues need to be analyzed in a relatively short time.

D Conclusions, insights, and results from a plant-specific PRA may be difficult to generalize to other plants or to generic studies.

Class 3 transformations can include a Monte Carlo simulation of uncertainty. In doing so, a Level 2 analysis should be carefully conducted to ensure consistency with the Level 1 analysis (see footnote on page C-104 for types of integration). A difficulty will be in selecting input variables to be assigned distributions. This is discussed in Section C.6.6 (page C-167).

\section{C.4.3.3 Application to Future Plant Designs}

The new plant designs (evolutionary and advanced reactors) will have configurations and performance requirements that differ from current reactors. The phenomena that will determine the accident progressions in new reactors may be very different as well. A similar situation existed when the NRC staff and its contractors began to study low power and shutdown modes of operation in current plants. During shutdown operations, the containment may be open and the vessel head removed from the vessel. When air can freely enter the vessel, the phenomena are altered by the presence of an oxidizing atmosphere that is absent during full power operation when the vessel is closed. This has precluded the use of Class 1 and Class 2 transformations to study those modes of low power and shutdown operations that significantly differ from full power operation. This circumstance applies to the study of evolutionary and advanced reactors.

\section{Guidance: The use of Class 1 and Class 2 transformations to study evolutionary and} advanced reactors will be limited by a lack of applicable information.

As with low power and shutdown operations, the NRC staff will likely have to rely on Class 3 transformations to study evolutionary and advanced plants. As models are developed and used, Class 1 and Class 2 transformations will become increasing possible. Existing plant models may be used to begin the development of new models. However, the experience to date with the low power and shutdown studies indicates that significant changes in the existing models are necessary.

The NRC staff will encounter different situations with the evolutionary and advanced plants from current practices. The current PRAs were done on plants that have been built. Many plants were completed before or as PRA practices were applied to nuclear safety. The NUREG-1150 Study (Ref. C.4.4) was done on five existing plants. In contrast, a risk assessment of future plants will begin with the plans, particularly in design certification stages. Many details relevant to a PRA will not have been determined, making a risk assessment difficult. Such was the case when the NRC staff reviewed a PRA of an advance plant discussed in Reference C.4.8; here, for 
C.4 Accident Progression and Risk Analyses

C.4.4 Constituents of Transformations

C.4.4.1 Accident Progression Analysis

example, the submittal had rough sketches and terse descriptions of a system proposed to quench the interaction of core debris with the reactor cavity. There will be differences between the as-designed and as-built plant that will also have to be taken into account. Hence, such PRAs will have to be revised at appropriate times; these times have yet to be established.

Guidance: Whether performing or reviewing a PRA of a future plant, the NRC staff will have to be sure that a PRA does not extend beyond the available information. $P R A$ results will have to be given in the context of the unavailable information.

\section{C.4.4 Constituents of Transformations}

Whether performing a transformation, reviewing a transformation, or managing staff (of the NRC or its contractors) performing either activity, an understanding of the constituent analyses is necessary to achieve meaningful results. The method of transformations must be appraised in light of the limitations, strengths, assumptions, sensitivities, and uncertainties of the constituent analyses to determine the extent to which clearly stated objectives will be met. Such an understanding will allow the NRC staff to understand what was done and what needs to be done. The purpose of these sections is to discuss the elements of the accident progression analysis, source term analysis, consequence analysis, and risk calculation. Once the NRC staff understands the aspects of a PRA, they will be able to use PRA and such results in a responsible and educated manner.

Guidance: Regardless of the method that is chosen to perform a transformation from a core damage frequency estimate to a risk estimate, the NRC staff must be fully aware of the constituents of the PRA (i.e., scope, models, and assumptions) yielding the numerical quantities used in a transformation from core damage frequency to risk.

\section{C.4.4.1 Accident Progression Analysis}

\section{C.4.4.1.1 Concepts}

The accident progression analysis continues the first and second elements in the risk triplet $\left\langle\mathrm{s}_{\mathrm{i}}, \mathrm{f}_{\mathrm{i}}, \mathrm{x}_{\mathrm{i}}\right\rangle$ in which the accident scenarios are continued after core damage; here, $s_{i}$ represents the $i$ th scenario (sequence, progression), ${ }^{8} f_{\mathrm{i}}$ is the associated frequency, and $x_{\mathrm{i}}$ is the resulting consequence. The first part of these terms was developed in the accident sequence analysis, discussed in Chapter C.3 (page C-41).

The modeling is done with an event tree. Branch points of the event tree are defined with questions about severe accident phenomena, equipment status, and other aspects of severe accidents; these questions are known as top events. In this context, such an event tree is called a containment event tree (CET) or an accident progression event tree (APET). In early PRAs such as the Reactor Safety Study (Ref. C.4.3), these event trees were simple and emphasized the status of the containment and containment equipment, hence, the term CET. Current PRAs are more detailed, accounting for the interaction of phenomena, the availability of equipment, and the performance of operators as well as the containment response to loads, hence, the term APET.

\footnotetext{
${ }^{8}$ See page $\mathrm{C}-85$ for the distinction between sequence and progression.

${ }^{9}$ See Section C.4.4.4, page C-104, for a discussion of this definition of risk.
} 


\section{C.4 Accident Progression and Risk Analyses \\ C.4.4 Constituents of Transformations \\ C.4.4.1 Accident Progression Analysis}

Although in practice the terms CET and APET are used interchangeably, the convention here is to use the latter term, APET. This portion of an accident sequence is often referred to as the accident progression. ${ }^{10}$

A common practice in beginning an accident progression analysis is to group accident sequences from the Level 1 analysis according to characteristics relevant to the release and transport of radionuclides into the containment, such as the type of initiating event, the status of the injection and core cooling systems, the status of containment sprays, and the reactor pressure. These groups are called plant da.mage states (PDSs) and they constitute the interface between the Level 1 and Level 2 analyses. The sum of the sequence frequencies leading to each plant damage state is the plant damage state frequency." This grouping avoids having to propagate similar individual sequences through an event tree in the accident progression analysis.

Part of the interface is the definition of core damage. Several definitions are commonly used at the NRC, including the uncovery of the top of active fuel (UTAF) and the rupture of the cladding. In some cases, the definition will depend on the purpose of the analysis. In other cases, it will be more arbitrary. But whatever definition is chosen, the point is that the definition be made clear and consistent between the Level 1 and the Level 2 analyses.

An APET resembles the event tree in a Level 1 analysis; top event questions represent key aspects of the accident sequences and branching pathways under each question represent possible outcomes. However, an APET differs from an event tree in the Level 1 analysis in several ways:

- In an APET, the top event questions focus on the occurrence of severe accident phenomena, instead of the availability of equipment and human factors.

- Often the top event questions are not supplemented with fault trees.

- Although the status of equipment and the human factors following core damage are considered, the modeling of their status is not as extensive as in the Level 1 analysis. Relatively fewer systems are modeled in less detail. This does not imply anything about the importance of the modeling in determining the outcomes. An accident progression analysis incorporates additional information not developed in a Level 1 analysis that may be relevant for regulatory decisions. This difference is more pronounced in PRAs of full power operation than in PRAs of low power and shutdown operations.

The effect of the APET is to partition the core damage frequency in the plant damage states among the possible spectrum of accident progressions that can affect the transport and release of radioactive material. Mathematically, this is done by multiplying the core damage frequencies by the probabilities of the pathways. The probabilities of each branch point sum to unity and the frequencies of the endpoints sum to the CDF. The pathways are grouped according to similar characteristics relevant to source terms (see Section C.4.4.2, page C-91). Each group of pathways is referred to as an accident progression bin (APB) or release category. The frequency at the end of each pathway is known as the accident progression frequency. The sum of the accirent progression frequencies within each bin is the bin frequency.

\footnotetext{
${ }^{10}$ Reference C. 4.9 refers to a system sequence as those pathways through a Level 1 analysis and accident sequence as those pathways through an APET; this convention will not be adopted here.

"Some Level 1 analyses are extended into Level 2 without the plant damage state interface; if so, the Level 2 analysis has to be reduced or management efforts would become enormous.
} 
C.4 Accident Progression and Risk Analyses

C.4.4 Constituents of Transformations

C.4.4.1 Accident Progression Analysis

\section{C.4.4.1.2 Methods}

In general, the guidance for an accident progression analysis is less firmly established than the guidance pertaining to the development of a Level 1 analysis. Reference C.4.9 discusses the mechanics of performing an accident progression analysis. Descriptions of state-of-the-art PRAs done by the NRC and its contractors are in References C.4.4 and C.4.5. A few papers can be found on certain aspects of an accident progression analysis, such as Reference C.4.1, but there is no document analogous to a standard review plan or regulatory guide that prescribes the performance of an accident progression analysis. Development and review strategies are left to individual practitioners. Much of the discussion here stems from the experience of the NRC staff and its contractors, NRC-sponsored PRAs (Refs. C.4.4 - C.4.7), and reviews of PRA (e.g., Ref. C.4.8). Lacking such guidance and a basis for developing such guidance at this time, aspects of an APET are discussed here to acquaint the staff with what little information exists.

The size of an APET will reflect the detail with which severe accident issues are treated and the structure of an APET will impact its functional uses (i.e., tracing accident progressions through the APET and managing an APET during an accident progression analysis). This material is useful for defining a framework for performing the various transformations discussed in Section C.4.3 (page C-76) or to review an accident progression analysis.

\section{C.4.4.1.2.1 APET Size}

The size of an APET refers to the number of questions defining branch points that are used to represent the events of accident progressions. The top event question may be either in one APET or in other related APETs (this aspect will be discussed later). Lacking guidance, the proper size can be established in part by establishing the purpose of the PRA. A simple APET may be sufficient to estimate numerical results, whereas a detailsd APET may be necessary to moael system in t.....tion when examining the effect of changes to technical specifications or accident management proct evident. The established purpose may do mo nce a purpose is established, the issues should become imply a preferred overall size of an APET but may also guide the development of specific parts of th. Certain portions may require high detail to achieve a stated purpose while other portions less relevant to the purpose are developed in lesser detail; taken to an extreme, lesser developed portions would be considered as boundary conditions and treated in a minimal way. Other purposes may require a uniform level of detail.

A large-scale APET, in which many facets of severe accident progressions are explicit, is considered by the NRC staff to be on the scale of those found in the NUREG-1150 study (Ref. C.4.4); here, the accident progression is delineated with 75 to 100 top event questions, ${ }^{12}$ forming a complicated logic to explicitly consider many facets of a severe accident. The questions are phrased to define the availability of specific equipment or the occurrence of specific phenomena. The logic acçounts for the interactions among various phenomena. Time frames are explicitly delineated, such as before vessel breach, early after vessel breach, late after vessel breach, and very late after vessel breach. Examples of large-scale APETs are found in the NUREG-1150 study.

In a small-scale APET, the accident progressions are represented in simple terms with about ten top event questions forming a simple logic tree. The questions are phrased in a general way, asking about the main points of an accident progression. The logic accounts for limited interactions among various phenomena. One or two time frames are explicitly delineated, such as before vessel breach and late after vessel breach. An example of

\footnotetext{
12 These refer to the portions of the APET delineating the accident progression. In the NUREG-1150 study (Ref. C.4.4), the APET began with about 30 additional questions used to differentiate individual plant damage states. See page C-90 of this appendix for additional discussion.
}

NUREG-1489 


\section{C.4 Accident Progression and Risk Analyses \\ C.4.4 Constituents of Transformations \\ C.4.4.1 Accident Progression Analysis}

a small scale APET is found in a preliminary study of risk from low power and shutdown operations (Refs. C.4.6 and C.4.7).

Aspects that should be considered when determining the proper size of an APET include the following:

- Although a smali APET treats accident progression events in a simplified manner, the model is easier to visualize than a large APET; a large APET is more difficult to construct and conceptualize than a small APET.

- Increasing the detail of th - questions may assist in answering questions, but only to a point. Afterwards, the ability to ask the questions may exceed the ability to provide meaningful answers about highly uncertain phenomena. Also, models may become increasingly inadequate to assemble highly detailed information; the level of detail at which this occurs will depend on the extent to which a given phenomenon is understood, can be modeled, and can be measured to collect data.

- The level of detail should be consistent with stated purposes of a study.

The schedule and budget made available to perform a PRA imply a limit on the size of a PRA. Thus, the limits on resources can be used by experienced PRA practitioners to establish the detail of a PRA within the constraints of a schedule and budget. An outline of a procedure to establish the size is as follows:

1. Establish goals (broadly stated purposes) and objectives (specific accomplishments).

2. Determine the resources (budget and schedule) available.

3. Define a program (e.g., type of transformation, review of a PRA) within the bounds of the allocated resources.

4. Assess the extent to which the goals and objectives are achieved.

5. Adjust the resources and/or the program accordingly.

Whatever level of detail is chosen, all factors of the accident progressions must, in some way, be taken into account when results are used for regulatory purposes. This accounting may involve much implied information. For example, in replying to the general question, "What is the pressure load in a containment?" consideration would have to have been given to direct containment heating, steam explosion, hydrogen combustion, and base pressure. The question is completely assessed, even if only in ways that are not directly modeled in the APET. Answering the same question by addressing only the pressure rise from, for example, steam explosions, would lead to an incomplete assessment.

\section{Advantages}

$\triangle \quad$ A large APET explicitly accounts for many facets of severe accidents and their interactions. Refined questions may be easier to address than more general questions. 


\section{C.4 Accident Progression and Risk Analyses}

C.4.4 Constituents of Transformations

C.4.4.1 Accident Progression Analysis

$\triangle \quad$ A small APET may require fewer resources and can be completed more readily than a large APET. ${ }^{13}$

$\triangle \quad$ A small APET is easier to display and conceptualize than a large APET.

Disadvantages

$\triangleright \quad$ A large APET can often be difficult to process, display, and conceptualize.

$\triangle \quad$ A small APET will require making inferences about aspects (systems, phenomena, and relationships among them) of the accident progressions that are not explicitly modeled.

The discussion of the APET size thus far has viewed the issue from the standpoint of deciding between a small or a large APET. Some PRAs have been done with both; that is, a small main event tree of, say, ten top event questions, has been supplemented with relevant portions of detailed APETs feeding into the top event questions of the main event tree where appropriate.

EXAMPLE

In a small-scale APET, the pressure load on a containment may appear as follows:

What is the pressure load in the containment?

In a large-scale APET, the same question may be asked in more detail. Consider the following example:

Pressure load in the containment.

Pressure from direct containment heating.

Pressure from steam explosion.

Pressure from hydrogen comuustion

Base pressure in the containment.

Further refinement is possible:

Pressure load in the containment.

Pressure from direct containment heating.

Vessel depressurized.

Mode of vessel failure.

Amount of debris involved in the heating.

Pressure from steam explosion.

Mode of vessel failure.

Amount of debris involved in the interaction.

Amount of water in the reactor cavity.

Pressure from hydrogen combustion.

Extent of $\mathrm{Zr} / \mathrm{H}_{2} \mathrm{O}$ reaction.

Amount of cladding surface.

Amount of in-vessel steaming.

Base pressure in the containment.

\footnotetext{
${ }^{13}$ A large amount of resources are expended in defining the inputs to an accident progression analysis. Thus, the savings in mandating a small APET when performing an accident progression analysis may be small unless the effort to define the inputs is similarly reduced.
}

NURE(j-1489 


\section{C.4 Accident Progression and Risk Analyses \\ C.4.4 Constituents of Transformations \\ C.4.4.1 Accident Progression Analysis}

\section{C.4.4.1.2.2 APET Structure: Unsupplemented vs. Supplemented ${ }^{14}$}

In general, there are two constructions of an APET. (1) An unsupplemented event tree models the bulk of the accident progressions in itself and (2) a supplemented event tree has selected top event questions removed from the main tree and placed in subtrees. Two types of trees have been used as supplements, fault trees and small event trees. Fault trees are more applicable to systems reliability; small event trees are more applicable to the modeling of accident progression phenomena. By grouping together certain ends of each subtree, the subtrees are merged with the main tree. Either style of APET, unsupplemented or supplemented, should lead to similar numerical estimates if adequately constructed. However, there are functional differences.

- Grouping the accident progressions for source term calculations is somewhat more flexible using the unsupplemented method. The grouping is rigid in a supplemented event tree because the subtrees are fixed and attached $i s$ the main tree, thus reducing the flexibility in delineating accident sequence groups to continue in the calculations with source terms, i.e., it reduces the number of accident progression outcomes.

- When the unsupplemented metiod is used, individual pathways can be traced from the accident progression bin at the end of the Level 2 analysis to the plant damage state at the beginning of the accident progression analysis, ${ }^{15}$ which would be important in determining causes of results. Tracing through a supplemented event tree may be possible, but it is much more difficult.

Hypothetically, the constructions should give the same numerical results, although the NRC staff is unaware of any demonstration of this. The constructions are functionally different; the unsupplemented structure facilitates tracing pathways through the event tree whereas the supplemented structure may not do so.

\section{Advantage}

D An unsupplemented APET maintains distinct accident progressions from the plant damage state to the endpoints; this allows the pathways to be grouped in a way that is apart from developing the accident progressions in the APET.

\section{Disadvantages}

$\triangle \quad$ An unsupplemented APET can be difficult to display.

$\triangle \quad$ A supplemented event tree structure obscures the tracing of results from the accident progression bins back to the plant damage states. Pathways merge whenever a top event is defined with a subtree; this has the effect of grouping pathways at these points, making pathways difficult to trace and reducing the flexibility in grouping the pathways.

\footnotetext{
14 These terms are not commonly recognized nomenclature but are used here to discuss the concept.

is Tracing back further through the Level 1 analysis is hampered when plant damage states are the interface between a Level 1 and Level 2 analysis. Plant damage states are used to aggregate sequences from a Level 1 analysis, reducing the calculations in Level 2 by combining similar Level 1 sequences.
} 


\section{C.4 Accident Progression and Risk Analyses}

\section{C.4.4 Constituents of Transformations}

C.4.4.1 Accident Progression Analysis

\section{C.4.4.1.2.3 APET Structure: Composite vs. Individual}

Another facet of the structure of an APET is whether a composite event tree is made for all the plant damage states or individual event trees are made for each plant damage state. The composite structure requires top event questions in the beginning of the APET to serve as switching logic, activating and deactivating various portions of the APET according to the particular plant damage state being processed at any one time; if there are $\mathrm{n}$ plant damage states, then the single APET is used $\mathrm{n}$ times, each time being configured for the characteristics of the given plant damage state by the switching logic. Individual APETs for each of the plant damage states remove the need for the switching logic.

Either construction of the APET may give the same numerical results. Functionally, the constructions are equivalent in that both allow the accident progressions to be traced. Differences in the structures are seen when constructing an event tree and during the management of an accident progression analysis.

\section{$\underline{\text { Advantages }}$}

$\triangle \quad$ A composite APET is easy to manage on a computer and adds assurance of consistent truncation ${ }^{16}$ and logic.

D Lacking the switching logic, individual APETs are relatively easy to formulate and display.

\section{Disadvantages}

$\triangle \quad$ A composite APET is more complicated, must be more explicit in its logic, requires more care in construction than individual APETs, and is more difficult to display than individual APETs.

$\triangle \quad$ Individual APETs have a potential for inconsistent logic.

The guidance on a composite versus individual construction of an APET amounts to the following:

Guidance: A composite APET should be made when the configurations of the plant systems among the plant damage states are similar. This is generally the case in PRAs of full-power operation.

Individual APETs should be made when the configurations of the plant systems among the plant damage states are drastically different. This is generally the case in PRAs of low power and shutdown operations.

\section{C.4.4.1.3 Products}

Products of the accident progression analysis are as follows:

- Delineation of the accident progression pathways.

- Accident progression frequencies (partitioned core damage frequency).

\footnotetext{
16 To simplify the APET calculations, pathways through the event tree are terminated before reaching their respective last questions when the pathway frequency falls below a value defined by the PRA practioner.

NURE(j-1489 
- Accident progression bins, their probabilities, and their uncertainties that can be displayed as groups, such as the modes of containment failure.

\section{C.4.4.2 Radionuclide Release and Transport Analysis}

\section{C.4.4.2.1 Concepts}

The source term analysis addresses the release and transport of radioactive material from the fuel and core debris to the environment; it is performed whenever the radiological severity of an accident is to be assessed. The source term can be used as an estimate of the severity of an accident or it can be used as input to the consequence analysis performed in the Level 3 portion of the PRA, in which the health effects and economic costs of an accident are estimated; whichever way, this forms the first part of the third term in the risk triplet, $<\mathrm{s}_{\mathrm{i}}, \mathrm{f}_{\mathrm{i}}, \mathrm{x}_{\mathrm{i}}>.^{17}$ Here, $s_{\mathrm{i}}$ represents the $\mathrm{i}$ th scenario (sequence, progression), ${ }^{18} f_{\mathrm{i}}$ is the associated frequency, and $x_{\mathrm{i}}$ is the resulting consequence.

The product of the analysis is a collection of parameters, referred to as the source term, that characterizes the type and amount of radioactive material released from the containment, the start and duration of the release, and the location of the release. In this context, containment is generalized to include the region in which engineered features are available to attenuate a release before it enters the environment (e.g., auxiliary building that surrounds the containment building), and the environment is the region where exposure to a release would create a concern. The radiological severity can be estimated either by inferring the potential health effects from the magnitude of the release or by performing a consequence analysis (see Section C.4.4.3, page C-98). In general, the latter is the preferred approach for a PRA because the consequence analysis explicitly accounts for the transport of fission products in the environment, population densities, emergency response, radioactive decay, and the health effects associated with the various isotopes.

The input to the source term analysis is the delineated accident progression from the accident progression analysis (Section C.4.4.1, page C-84). The accident progressions describe the configuration of the plant, the status of systems that can be used to mitigate the release, and the occurrence of phenomena that can impact the source term. The accident progression also describes many other attributes that are not directly relevant to the source term calculation. Thus, the accident progressions are typically collapsed into APBs (release categories) that represent similar boundary and initial conditions for the source term analysis. A source term is then calculated for each accident progression bin. Although in the PRA the source term analysis follows the accident progression analysis, the two are actually intimately coupled in that the release and transport of the radioactive material occurs during the accident progression and is affected by phenomena that occur during this phase of the accident. When the uncertainty in the source term is being assessed, many source terms are estimated for each APB. Methods for performing uncertainty studies in PRAs are discussed in Section C.6.3 (page C-154).

There are three parts to a source term analysis: (1) the estimation of the release of radioactive material from the fuel and core debris, (2) the transport of this material through the primary system and the containment, and (3) the characterization of the release from containment to the environment.

The first part of the analysis is the estimation of the release of radioactive material from the fuel. Because different phenomena and transport processes occur during an accident, the discussion of the release of

\footnotetext{
${ }^{17}$ See Section C.4.4.4, page C-104, for a discussion of this definition of risk. See Section C.4.4.3, page C-98, for a discussion of the second part of the term, consequences.

1" See page C-85 for the distinction between sequence and progression.
} 
C.4 Accident Progression and Risk Analyses

C.4.4 Constituents of Transformations

C.4.4.2 Radionuclide Release and Transport Analysis

radioactive material is often divided into two phases. The in-vessel phase of the release is the release from the fuel during the core degradation process that takes place before vessel failure. The ex-vessel phase of the release consists of three components:

- The release accompanying vessel failure.

- The release that accompanies the interaction between the core debris and the concrete floor (referred to as core-concrete interactions or simply $\mathrm{CCI}$ ), and

- The release of radionuclide material previously deposited on vessel structures and trapped in pools of water (i.e., the suppression pool). Energetic events such as high-pressure melt ejection and fuel-coolant interactions can enhance the release from the core debris at the time of vessel failure.

The second part of the analysis is the determination of the transport of this material released from the fuel and core debris through the primary system and containment. As this material passes through the primary system it is subjected to many removal processes, for example, deposition on structural material in the vessel and on piping surfaces. Similarly, in the containment there are both engineered features (e.g., containment sprays, suppression pool, filters) and natural processes (e.g., gravitational settling) that attenuate the release. The accident progressions delineated in the accident progression analysis (Section C.4.4.1, page C-84) will specify which of these mitigative features are available; the source term analysis will determine the effectiveness of these features to reduce the source term. For example, the accident progression will specify when and if containment sprays are used and the source term analysis will determine the amount of radioactive material removed by the sprays.

The third part of the analysis is the characterization of the release from the containment. There are many attributes of the release that must be characterized by the source term: the time when a release from the containment starts, the type and amount of radioactive material released as a function of time, the energy of the release, and the location of the release. This information can then be used in the consequence analysis to estimate the concentration of radioactive material at various distances from the reactor as a function of time. The detail that is used to express each of these attributes depends on the objective of the analysis, the method used to estimate the source term, and the method used to calculate the consequences. Each of these attributes is discussed in the following paragraphs.

The start of the release is accident-specific and depends on when the containment boundary is breached; when the containment integrity is lost before core damage, the start of the release depends on when core damage occurs. The relationship between this attribute and the start of the evacuation will determine whether the evacuating public is exposed to the plume. The start of the evacuation depends on when a general emergency would be called at the plant (i.e., warning time); there is a delay between the declaration of a general emergency and the actual start of evacuation. Each plant has procedures that guide the operators in determining when a general emergency should be called. This guidance can be different for different accident scenarios. Thus, the timing of this event depends both on the accident scenario and the plant-specific procedures.

The amount of radioactive material that is released from the containment as a function of time is often expressed as a fraction, referred to as the release fraction, of the fission product inventory in the core at the time of the start of the accident. Many radioactive isotopes would be released during a core damage accident. In the source term analysis, attention is directed to the transport of these isotopes from the fuel to the environment rather than the health effects caused by the release. Therefore, in most PRA source term analyses these isotopes are combined into groups that are not based on health effect potential, but rather are based on characteristics that would affect their release and transport through the containment (i.e., chemical and transpor: properties). For most PRA purposes, these isotopes are combined into approximately 10 release groups. These release groups

NUREG-1489 
C.4 Accident Progression and Risk Analyses

C.4.4 Constituents of Transformations

C.4.4.2 Radionuclide Release and Transport Analysis

may be expanded in the consequence analysis to obtain better resolution for bealth effects. For example, in the NUREG-1150 study (Ref. C.4.4), the following nine release groups were defined: inert gases, iodine, cesium, tellurium, strontium, ruthenium, lanthanum, cerium, and barium. In the consequence analysis, which was performed with the MACCS code (Refs. C.4.10 - C.4.12), these nine groups were expanded into 60 radionuclides. The relationship between these release groups and the radioactive isotopes is presented in Table C.4.2. In the NUREG-1150 study (Ref. C.4.4) the groups listed in Table C.4.2 were used. Other combinations are also possible.

Table C.4.2 Isotopes in the release classes from the NUREG-1150 study (Ref. C.4.4)

\begin{tabular}{|c|c|}
\hline Release Class & Isotopes Within the Class \\
\hline Inert Gases & $\mathrm{Kr}-85, \mathrm{Kr}-85 \mathrm{M}, \mathrm{Kr}-87, \mathrm{Xe}-133, \mathrm{Xe}-135$ \\
\hline lodine & I-131, I-132, I-133, I-134, I-135 \\
\hline Cesium & $\mathrm{Rb}-86, \mathrm{Cs}-134, \mathrm{Cs}-136, \mathrm{Cs}-137$ \\
\hline Tellurium & Sb-127, Sb-129, Te-127, Te-127M, Te-129, Te-129M, Te-131M, Te-132 \\
\hline Strontium & Sr-89, Sr-90, Sr-91, Sr-92 \\
\hline Ruthenium & Co-58, Co-60, Mo-99, Tc-99M, Ru-103, Ru-105, Ru-106, Rh-105 \\
\hline Lanthanum & $\begin{array}{l}\text { Y-90, Y-91, Y-92, Y-93, Zr-95, Zr-97, Nb-95, La-140, La-141, } \\
\text { La-142, Pr-143, Nd-147, Am-241, Cm-242, Cm-244 }\end{array}$ \\
\hline Cerium & Ce-141, Ce-143, Ce-144, Np-239, Pu-238, Pu-239, Pu-240, Pu-241 \\
\hline Barium & Ba-139, Ba-140 \\
\hline
\end{tabular}

The resolution in the timing of the release (i.e., the rate and duration of the release from the containment) depends on the method that is being used to estimate the source term. The rate at which the radioactive material would be released from the containment would affect the concentration of radioactive material in the environment. The magnitude, rate, and duration of the release will all be accident-specific.

The release location and the energy of release would affect characteristics of the plume in the environment (e.g., the initial dimension of the plume and the buoyancy characteristics of the plume); they are generally specified only when the source term is used as input to the consequence analysis.

\section{C.4.4.2.2 Methods}

The following three general approaches for estimating source terms in PRA applications will be discussed in this section: deterministic calculations, expert judgment, and parametric codes. 
C.4 Accident Progression and Risk Analyses

C.4.4 Constituents of Transformations

C.4.4.2 Radionuclide Release and Transport Analysis

\section{C.4.4.2.2.1 Deterministic Calculations}

Deterministic codes (often integral severe accident codes) ${ }^{19}$ can be used to estimate the source terms for the accident progressions. These types of codes are discussed in Section C.4.6 (page C-116). Because of the computational resources required to perform deterministic calculations, it is not practical to estimate a source term for every accident progression. Rather, accident progressions that may lead to similar source terms are grouped together and a source term calculation is performed for an accident progression that is representative of the group. The group of accident progressions is referred to as a release category. In this approach, only gross features of the accident progression are considered in the determination of the source term. The number of release categories that can be analyzed is limited by the resources and time available to perform and analyze the calculations. This is the approach that was used in the Reactor Safety Study (Ref. C.4.3), the NRC's first major evaluation of the risk from commercial nuclear plants. Since a limited number of source terms are generated by this approach, consequences associated with each release category can be estimated using state-ofthe-art consequence codes (see Section C.4.4.3, page C-98).

\section{Advantages}

$\triangle \quad$ The phenomena and the interactions between phenomena are explicitly modeled.

$D \quad$ The calculations yield detailed information about the timing of key events during an accident progression.

$\triangle \quad$ The method is scrutable (i.e., the results can be traced back to the models and the input used in the codes) and reproducible.

\section{Disadvantages}

$\triangle \quad$ The selection of appropriate initial and boundary conditions that best represent the many accident scenarios that are included in the release group may be very difficult.

$\triangle \quad$ These codes require significant computational resources.

$\triangleright \quad$ Assessing the uncertainties associated with the source term is difficult with a deterministic code for three reasons: (1) the deterministic codes take a relatively long time to run, which limits the number of parameter variations that can be performed; (2) models for some phenomena may be incomplete or lacking altogether; and (3) these codes represent only one view of source term calculations, even though equally valid alternative models may also exist that are not made use of by the code. See Section C.4.6 (page C-116) for additional discussion.

Guidance: There are many integral severe accident codes that can be used to predict source terms for accident progressions. Because of differences in models, assumptions, and initial and boundary conditions, these codes will often predict widely different results. Thus, the basis and limitations of deterministic calculations must be known if the results are to be used in an appropriate manner in a source term analysis.

\footnotetext{
${ }^{19}$ 'The distinction between a deterministic code and an integral severe accident code is discussed in Section C.4.6 (page C-116).
} 
C.4 Accident Progression and Risk Analyses

C.4.4 Constituents of Transformations

C.4.4.2 Radionuclide Release and Transport Analysis

\section{C.4.4.2.2.2 Expert Judgment}

Expert judgment can be used to estimate the source term associated with the accident progression. The use of expert judgment in PRAs is discussed in Chapter C.5 (page C-129). As with deterministic calculations, it is impractical for the experts to provide source terms for every accident progression individually. Rather, accident progressions that may lead to similar source terms are grouped together and a source term is estimated for the group (i.e., release category). While this approach does not directly use deterministic codes to estimate the source term, because many complicated processes are involved in the generation of the source term, integral severe accident codes such as MELCOR (Ref. C.4.13) are useful tools to aid the experts in their determination of the source term. Since a limited number of source terms are generated by this approach, consequences associated with each release category can be estimated using state-of-the-art consequence codes (see Section C.4.4.3, page (-98).

\section{Advantages}

D Many information sources (e.g., experimental results and deterministic code calculations) can be used to determine the source term and to account for the uncertainty in the source term.

$\triangle \quad$ This method is amenable to the development of uncertainty distributions.

\section{Disadvantages}

$\triangle \quad$ It may be very difficult for the expert to quantify the source term that results from the interaction of many complex phenomena over many types of accident scenarios. It is generally more productive to decompose the problem and have the experts provide information on specific processes and then combine the information using either logic models or mechanistic models.

$\triangleright \quad$ Because this approach requires a significant commitment of resources (e.g., the collection of information, the employment of experts, and the elicitation of experts), source terms for only a few accident sequences can be estimated. This requires the accident progressions to be placed in fairly coarse groups (e.g., release categories).

$\triangle \quad$ Information about the timing of key events during an accident progression tends to be coarse.

\section{C.4.4.2.2.3 Parametric Approach}

A parametric code can be used to estimate a source term for every accident progression or group of accident progressions. Here, the grouping is not nearly as coarse as that used in the previous two approaches. Parametric codes use a combination of parameters, which represent the physics of the accident at a very general level, to estimate the release to the environment. For example, a parameter can be used to represent the fraction of a particular radionuclide in the fuel that is released to the vessel. Another parameter is then used to represent the fraction of the radionuclide that is in the vessel and is released to the containment. The parametric approach is not meant to be a substitute for detailed, mechanistic computer simulation codes. Rather, it is a framework for integrating the results of these codes together with experimental risults and expert judgment, and as such, it draws from the strengths of the previous two methods. In this case, however, the experts provide information on parameters in the parametric code (e.g., release fractions from fuel, retention in the vessel, retention in the containment), not on the individual source terms. This is the approach that was used in NUREG-1150 (Ref. C.4.4), the NRC's update of the Reactor Safety Study (Ref. C.4.3). Since this. apnreach results in a source term for every accident progression or group of accident progressions (potentially 


\section{C.4 Accident Progression and Risk Analyses \\ C.4.4 Constituents of Transformations \\ C.4.4.2 Radionuclide Release and Transport Analysis}

thousands of source terms), it is impractical to estimate consequences for each source term individually. Instead, the source terms must be collapsed into a manageable number of groups. This grouping is usually based on the potential of a source term to cause health effects. A single source term is then defined (e.g., the mean of the group of source terms) to represent the group of source terms. Consequences are then estimated for each source term group.

\section{Advantages}

$\triangle \quad$ Since these codes use very simplistic models, they run very quickly and can be used to estimate many source terms. This eliminates the need to create coarse release categories. For example, 115,000 source terms were estimated with a parametric code in the Sequoyah plant analysis performed as part of the NUREG-1150 study (Ref. C.4.4). These source terms were aggregated into about 60 groups with the PARTITION code (Ref. C.4.14); consequence calculations were performed for each group (see the example beginning on page $\mathrm{C}-109$ illustrating this process in a risk assessment.)

$\checkmark \quad$ The parametric approach is also very amenable to uncertainty studies in which distributions are developed for the various parameters. Because these parameters represent the phenomena at a very general level, it is fairly easy to represent the uncertainty in different phenomena, models, and accidents through these distributions.

\section{Disadvantages}

$D \quad$ Because parametric codes express the physics of many phenomena over a wide range of accident conditions through a single parameter, the interaction between phenomena and the importance of specific phenomena can not be easily determined from this approach.

$\Delta \quad$ Timing information from these codes tends to be very coarse.

$\triangleright$

It may be difficult to accurately mimic the release and transport of the radioactive material with a simple parametric code.

There is no set number or rigorous way to determine the number of source term groups that should appear in a PRA, but several factors should be taken into account. The maximum number of groups should be within the resources allocated for the entire risk assessment. The number of groups should be consistent with the objectives and the construction of the entire PRA, i.e., highly refined risk Level 1 and Level 2 analyses should not be compromised with a coarse aggregation of source terms. The groups should form aggregates of source terms yielding similar consequences.

\section{EXAMPLE}

The source term analyses performed in the Reactor Safety Study (Ref. C.4.3) and NUREG-1150 (Ref. C.4.4) illustrate the use of deterministic and parametric approaches for estimating source terms in a PRA.

The source term analyses performed in the Reactor Safety Study are an example of the deterministic approach. In the Reactor Safety Study, approximately 1000 accident sequences were identified that were potentially capable of causing significant releases of radioactive material from PWR and BWR nuclear power plants. A sequence consists of three elements: the initiating event, particular ESF failures, and the containment failure mode. Because of the computational resources required to estimate the source term with a deterministic code, it was impractical to pe form a calculation for each sequence individually. Rather, sequences from the various event trees were carefully reviewed to identify those involving distinctly different physical processes and different combinations of ESF system failures. This review revealed patterns of similarity that suggested that representative or key sequences could be identified that would define the spectrum of releases. There were 38 PWR and 24 BWR key sequences identified. While the amount of fission products released was based on available 


\section{C.4 Accident Progression and Risk Analyses}

C.4.4 Constituents of Transformations

C.4.4.2 Radionuclide Release and Transport Analysis

research data, the transport of the material was estimated with the deterministic code called CORRAL (Ref. C.4.3). The CORRAL code is a multi-compartment model that represents the following processes: natural transport and deposition, removal of radioactive material by aqueous sprays, recirculation filter systems, once-through filter systems, water pool scrubbing, and leakage or exhaust from containment to the outside atmosphere. Consequences were then estimated for each key sequence using the CRAC code (Ref. C.4.3). Review of these source terms and consequences suggested that the key sequences could be further grouped into release categories. Nine PWR and six BWR release categories were defined. Each of the accident sequences was then assigned to a release category. The allocation of the sequences was based on comparison of the phenomena involved in each sequence with the phenomena involved in the key sequences of the release categories. The source terms for the dominant accident sequences in each release category were reviewed and a representative source term for the release category was conservatively selected.

The source term analyses in the NUREG-1150 study (Ref. C.4.4) are examples of the parametric approach. In the NUREG-1150 study many thousands of accident progressions were delineated. These accident progressions were grouped into sets based on characteristics of the accident that could affect the release and transport of radioactive material; these groups are APBs defined on page C-85. These characte ristics included the extent of core damage (i.e., core damage process arrested in the vessel versus complete core damage with vessel failure and the interaction of core debris with the containment floor), containment failure mode (i.e., leak or rupture), time of the containment failure (e.g., during core damage, at the time of vessel failure, late in the accident), the availability of fission product removal mechanisms (e.g., containment sprays and suppression pool), and the occurrence of certain phenomena (e.g., steam explosions, high-pressure melt ejection, and core-concrete interactions). Source term analyses were performed for each of these APBs using the parametric code XSOR (Ref. C.4.15). Important parameters used in the XSOR codes were quantified by panels of experts (Ref. C.4.16), thus making indirect use of the second method for estimating source terms (see Section C.4.4.2.2.2, page C-95). Because the NUREG-1150 study (Ref. C.4.4) included an uncertainty analysis, many source terms were estimated for each APB. Because of the large number of source terms generated and the computational resources required to perform calculations with state-of-the art consequence codes, it was not practical to estimate the consequences for each source term individually. Rather, source terms that may lead to similar health effects were grouped together and characterized by a single source term. This process was performed with the PARTTTION code (Ref. C.4.14). A consequence calculation using the MACCS code (Refs. C.4.10 - C.4.12) was then performed for each group of source terms using the characteristic source term as a surrogate for the individual source terms in the group. For example, the Peach Bottom internal events analysis that was performed as part of the NUREG-1150 study (Ref. C.4.4) generated thousands of accident progressions that were grouped into 6,944 APBs. The propagation of the uncertainty in the input parameters to the XSOR code resulted in the generation of 66,340 source terms. The PARTTTION code was used to collapse the 66,340 source terms down into 58 source term groups.

Consequences were then estimated for each of these 58 source term groups using the MACCS code.

The major differences between the Reactor Safety Study and the NUREG-1150 study source term analyses include:

1. In the Reactor Safety Study, key sequences were identified that were used to define the spectrum of releases. Source terms were estimated for 38 PWR and 24 BWR key sequences. These key sequences were then further collapsed into release categories (9 PWR and 6 BWR release categories). In the NUREG-1150 study, the plethora of accident progressions are grouped into APBs that still retain detailed characteristics of the accident progressions (the number of APBs range from approximately 1000 to 15000 ). Source terms were then estimated for each APB.

2. In the Reactor Safety Study, the source term analysis was performed with the deterministic code CORRAL (Ref. C.4.3). In the NUREG-1150 study, source terms were estimated with the parametric code XSOR (Ref. C.4.15). A panel of experts was used to develop probability distributions for the important parameters used in these codes. The uncertainty distributions were then propagated through the codes resulting in a distribution for each source term.

3. In the Reactor Safety Study, a representative source term was conservatively selected from the key sequences in each release category. This source term was then used to represent all the accident sequences in a particular release category. In the NUREG-1150 study the thousands of source terms were collapsed, based on potential health effects and timing parameters, into source term groups using the PARTITION code (Ref. C.4.14) (approximately 60 source term groups were defined for each plant).

4. In the Reactor Safety Study, consequences were estimated using the CRAC code for each release category using the representative source term. In NUREG-1150, consequences were estimated for each source term group using the MACCS code (Refs. C.4.10 through C.4.12).

5. In the Reactor Safety Study, uncertainties in the sous ze term were not characterized. In the NUREG-1150 study this uncertainty was characterized. 


\section{C.4.4.2.3 Products}

The basic product from the source term analysis is an estimate of radionuclide releases. Table C.4.3 illustrates the source term for a selected accident analyzed in the NUREG-1150 study (Ref. C.4.4). A source term is estimated for each accident, and because of the large number of accidents delineated in a PRA, many source terms are generated. In this context, the term accident refers to a set of conditions that would lead, within the resolution of the analysis, to essentially the same source term, and as such, many accident progressions are grouped together and treated as a single accident in the source term analysis. As discussed in Section C.4.4.2 (page C-91), the source term has many attributes that describe the release of radioactive material from the containment to the environment. At a minimum, the source term should consist of the type of radioactive material released (e.g., inert gases, iodine, and cesium), the amount of this material released (generally expressed as a fraction of the inventory initially present in the core at the time of an accident), and the timing of the release. When the source term is used as input to a consequence analysis, additional information is included in the source term, for example, the location of the release and energy associated with the release. Because of the large number of source terms generated in a PRA, an effective way to summarize the results is with exceedance frequency curves that are similar in concept to the risk curves that are often used to display consequence results (see Section C.6.4.2 on page C-160).

The exceedance frequency curves are defined by pairs of values $(c, f)$, where $c$ is the parameter of interest (in this case the release fraction of a particular isotope) and $f$ is the frequency with which $c$ is exceeded. Such curves are analogous to complementary cumulative distribution functions (CCDFs) except that the ordinate displays frequency rather than probability. An example of a source term exceedance frequency curve is shown in Figure C.4.2; these particular curves are of the iodine release determined in the analysis of fire accidertc. Peach Bottom reported in Reference C.4.4. In this figure, the variation along a given curve is indicative of the uriation in the source term from different acciderts.

\section{C.4.4.3 Consequence Analysis}

\section{C.4.4.3.1 Concepts}

A consequence analysis is used to estimate the radiological health effects and economic cost of a core damage accident; this is the second part of the third term in the risk triplet, $\left\langle s_{i}, f_{i}, x_{i}\right\rangle .{ }^{20}$ Here, $s_{i}$ represents the $i$ th scenario (sequence, progression), ${ }^{21} f_{\mathrm{i}}$ is the associated frequency, and $x_{\mathrm{i}}$ is the resuiting consequence.

While the source term analysis is the analysis of the release and transport of radioactive material from the fuel and core debris to the environment, the consequence analysis is the analysis of the transport of this material through the environment, the health effects, and the costs that result from this radioactive material. As such, the source term estimated in the Level 2 analysis, described in Section C.4.4.2 (page C-9), forms input for this analysis.

\footnotetext{
${ }^{20}$ See Section C.4.4.4 (page C-104) for a discussion of this definition of risk. See Section C.4.4.2 (page C-91) for a discussion of the first part of the term, radionuclide release and transport.

${ }^{21}$ See page $\mathrm{C}-85$ for the distinction between sequence and progression.
}

NUREG-1489 C-98 
C.4 Accident Progression and Risk Analyses

C.4.4 Constituents of Transformations

C.4.4.3 Consequence Analysis

Table C.4.3 Source term for a selected accident

\begin{tabular}{|c|c|c|}
\hline \multirow[b]{2}{*}{ Attribute } & \multicolumn{2}{|c|}{ Release Segments } \\
\hline & $\begin{array}{c}\text { First Release } \\
\text { (i.e., Puff) }\end{array}$ & $\begin{array}{c}\text { Second Release } \\
\text { (1.e., Tail) }\end{array}$ \\
\hline Start of Release & $3.6 \mathrm{hrs}$ & $3.6 \mathrm{hrs}$ and $3 \mathrm{~min}$. \\
\hline Duration of Release & $3 \min$ & $3.9 \mathrm{hrs}$ \\
\hline Energy of Release & $13 \mathrm{Mw}$ & $0.37 \mathrm{Mw}$ \\
\hline Radionuclide Class & \multicolumn{2}{|c|}{ Release iractions } \\
\hline Inert Gases & 0.79 & 0.21 \\
\hline 1 & 0.005 & 0.06 \\
\hline 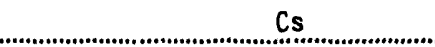 & 0.004 & 0.06 \\
\hline Te & 0.002 & 0.03 \\
\hline $\mathrm{sr}$ & $9 E-04$ & 0.03 \\
\hline Ru & $2 E-04$ & 1.E-4 \\
\hline La & $.9 E-05$ & 0.002 \\
\hline $\mathrm{Ce}$ & $5 E-04$ & 0.004 \\
\hline $\mathrm{Ba}$ & $9 E-04$ & 0.02 \\
\hline
\end{tabular}

NOTES: Warning Time $=1.1$ hours

Elevation of Release $=30 \mathrm{~m}$

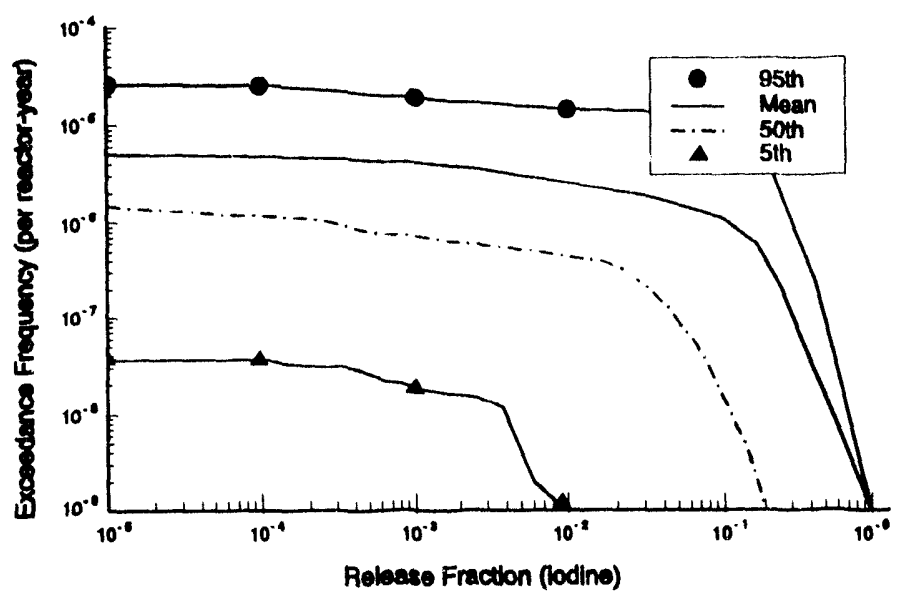

Figure C.4.2 Exceedance frequency curves 


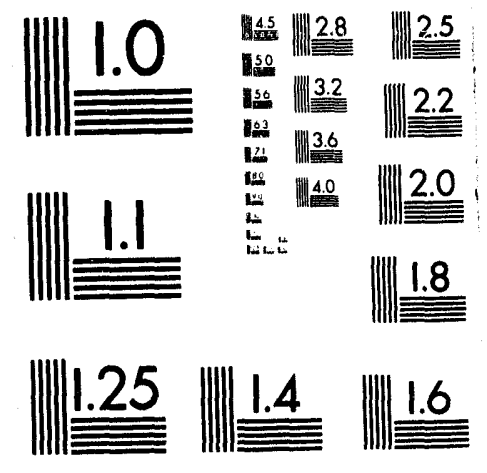



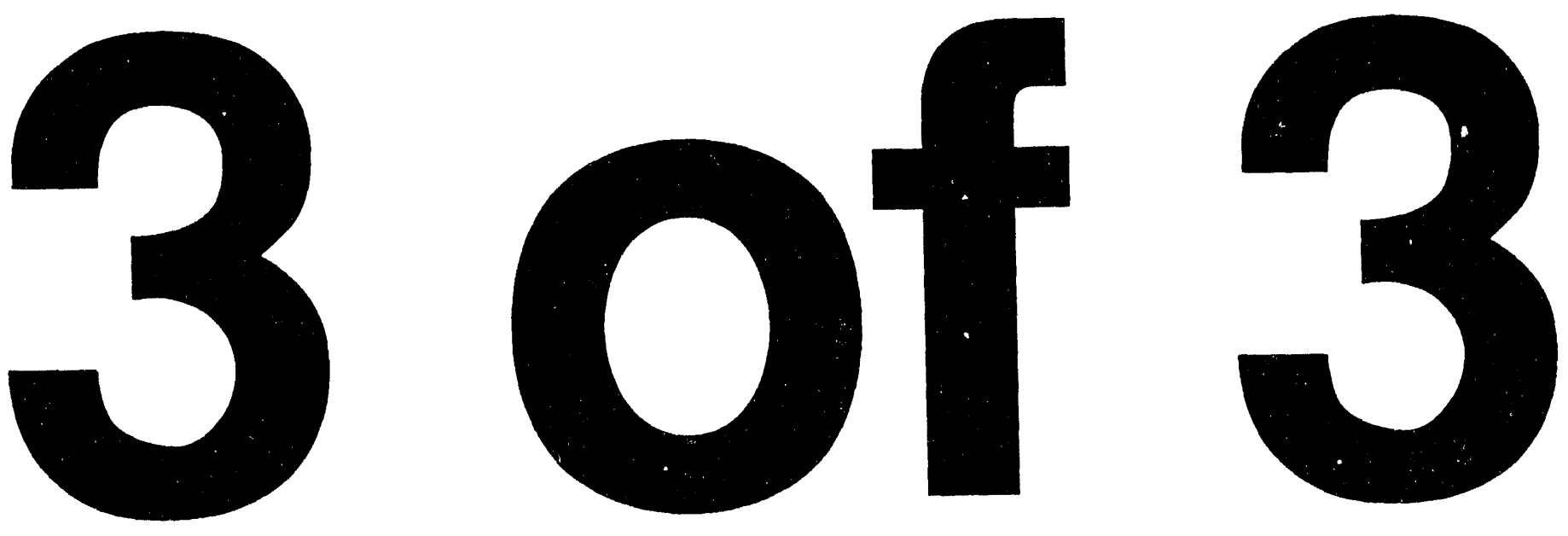
C.4 Accident Progression and Risk Analyses

C.4.4 Constituents of Transformations

C.4.4.3 Consequence Analysis

Consequence models have been used to evaluate severe accident risks, safety goals, risk management strategies, emergency response plans, criteria for reactor siting, and the health benefits of alternative design features. The methods used and the products generated from the consequence assessment will depend on the application. For example, the methods used to perform an offsite consequence assessment are generally not the same as the methods used to estimate onsite consequences. Furthermore, different consequence measures are used for different applications. For example, the quantitative safety goals ${ }^{22}$ established by the NRC require the estimation of prompt fatalities and cancer fatalities for average individuals in the vicinity of the plant, whereas the person-rem averted out to $\mathbf{5 0}$ miles is calculated in analyses performed to support decisions under the backfit rule. Other uses of the consequence products are possible; consequences are estimated whenever there is a need to translate radiological releases into health and cost estimates.

The consequences that would accompany a core damage accident are typically divided into two categories: offsite consequences and onsite consequences. The offsite consequence analysis predicts the health effects to the public and economic impacts that are associated with the dispersal of radioactive materials into the environment beyond the site boundary. The onsite consequence analysis is confined to the region within the site boundary. As such, onsite consequences include health effects to personnel working at the plant at the time of the accident and the cost of replacement power, capital loss, and cleanup of the reactor facility. The consequence assessment for most commercial reactor PRAs is focused on the assessment of offsite consequences because the regulations promulgated and enforced by the NRC emphasize protection of the public. Thus, most of the Level 3 PRAs that are performed, including the five PRAs that were performed as part of NUREG-1150 study (Ref. C.4.4), include only an assessment of offsite consequences. Because of this emphasis on offsite consequences, methods for performing offsite consequence assessments are available, have been subjected to considerable review, and have been applied in many PRAs. This is not so with onsite consequence assessments.

Because of the large size of the onsite population during shutdown and refueling, recent NRC-sponsored PRAs of these modes of operation include an assessment of onsite consequences (Refs. C.4.6 and C.4.7). These assessments, however, are only rough approximation because of the many simplifying assumptions that were made in the study.

\section{Guidance: Although assessments of onsite consequences are not usually considered in commercial reactor PRAs, in some situations an assessment of onsite consequences is appropriate, for example, accidents that might occur during shutdown. However, methods for performing onsite consequence assessments are not as well established as the methods used for offsite assessments.}

\section{C.4.4.3.2 Methods}

As was mentioned previously, the methods used to perform offsite consequence assessments are fairly well established, especially when compared to the methods available for estimating onsite health effects. Thus, this section will focus on the offsite methodology and just highlight some of the unique aspects of onsite consequence assessments.

\footnotetext{
22 The two quantitative safety goals are (1) the risk to an average individual within 1 mile of a nuclear power plant of prompt fatality that might result from reactor accidents should not exceed $1 / 10$ of 1 percent of the sum of prompt fatality risks resulting from other accidents to which members of the U.S. population are generally exposed and (2) the risk to the population within 10 miles of a nuclear power plant of cancer fatalities that might result from nuclear power plant operation should not exceed $1 / 10$ of 1 percent of the sum of cancer fatality risks resulting from all other causes (Ref. C.4.17).
} 


\section{C.4.4.3.2.1 Offsite Consequence Assessment}

State-of-the-art consequence codes are used to perform offsite consequence assessments in PRAs. The principal steps in the offsite consequence analysis are as follows:

1. An analysis of the downwind transport, dispersion, and deposition of the radioactive materials released from the plant.

2. An evaluation of the radiation doses received by the exposed populations via direct (cloudshine, inhalation, groundshine, and skin deposition) and indirect (ingestion) pathways.

3. An analysis of the mitigation of these doses by emergency response actions (evacuation, sheltering, and relocation of people), interdiction of milk and crops, and decontamination or interdiction of land and buildings.

4. A calculation of the health effects and offsite economic consequences resulting from the release.

Typical inputs to a consequence analysis include the following:

- The inventory at accident initiation of those radionuclides important for the calculation of ex-plant consequences.

- The time-dependent atmospheric source term produced by the accident, meteorological data characteristic of the site region (usually 1 year of hourly wind speed, wind direction, atmospheric stability, and rainfall recorded at the site or at a nearby National Weather Service station).

- The population distribution about the reactor site (distributions are constructed from census data).

- Emergency response assumptions for evacuation (delay time before evacuation, area evacuated, average evacuation speed, and travel distance), sheltering, post-accident relocation, and long-term protective measures based on protective action guides (PAGs).

- Land usage (habitable land fractions, farmland fractions) and economic data for the region about the site.

- Data used in the food chain and health effects models.

Over the years, the NRC has sponsored the development of codes to perform consequence calculations, including CRAC (Ref. C.4.3), CRAC2 (Refs. C.4.18 and C.4.19), and MACCS (Refs. C.4.10 - C.4.12). The CRAC code was developed as part of the Reactor Safety Study. CRAC2, released in 1982, incorporated significant improvements over CRAC in the areas of weather sequence sampling and emergency response modeling. MACCS, which is the NRC's current state-of-the-art consequence assessment code, incorporates many improvements over the CRAC codes.

There are major differences between MACCS and CRAC in the atmospheric transport and food pathway models. CRAC models the release as if it were made in a single puff. Particulate material is deposited along the straight-line plume track in proportion to the time-dependent wet or dry deposition rates dictated by weather. This methodology does not properly model the effects from longer term releases, and particularly the effect of wind shifts during such releases. MACCS, on the other hand, allows the time-dependent release to be separated into several releases (puffs), thus accounting for possible wind shifts and other weather changes affecting the 
C.4 Accident Progression and Risk Analyses

C.4.4 Constituents of Transformations

C.4.4.3 Consequence Analysis

isotope distribution in the puff. The end of a release (tail) would be included in one of these separate releases. This is particularly important if the containment were to fail early in the accident. In this case, the puff would include the material released into the containment during the core damage phase of the accident while the tail would include the material that is slowly released during the interaction between the core debris and the containment concrete floor. Improvements have also been made to the health effects and emergency response models, and there have been many improvements in the data used in the models. Because of the many differences between MACCS and the CRAC codes, the differences in the code outputs are difficult to quantify (e.g., the conditions under which CRAC will overpredict early health effects relative to MACCS). There are also other versions of CRAC that are currently being used in PRA applications. These more recent versions (e.g., CRACIT) include modifications that address many of the deficiencies identified in the early versions of CRAC.

Guidance: The MACCS code is the NRC's code for estimating offsite consequences associated with severe accidents at nuclear power plants in PRA applications (the NRC no longer supports the development of the CRAC codes, see Foreword to Reference C.4.12). MACCS was designed for use in PRA applications. Although MACCS is very convenient for probabilistic calculations of consequences, extreme care must be exercised in the MACCS application to any deterministic, or real-time, situations because of limitations of the model and data. Other consequence codes that employ different models and data are also used in PRA applications and, not surprisingly, can yield different results. Thus, it is necessary to understand these differences in order to assess the results.

Although state-of-the-art consequence assessment codes exist and are used in PRA applications, the quality of the output will still depend on the input: good judgment is necessary to select appropriate values for input parameters; the characterization of the source term will also affect the consequence results. For example, early health effects can be particularly sensitive to timing of the release in relation to the timing of emergency actions (i.e., evacuation). In general, latent health effects are not as sensitive to timing parameters.

\section{C.4.4.3.2.2 Onsite Consequence Assessment}

The assessment of onsite health effects is an immature element of the overall PRA consequence methodology. For onsite health effects there are two regions of concern: inside the buildings surrounding the containment and the region outside the building but within the site boundary. The estimation of onsite health effects is of particular concern during shutdown and refueling when the onsite population is larger than during full power operation and when access to these buildings by plant personnel is necessary to restore containment integrity and core cooling.

There are several challenging aspects regarding the assessment of onsite consequences. The onsite population can vary considerably, becoming considerable during shutdown and refueling modes of operation, and the locations of people during the accident are difficult to model. The duration of exposure for plant personnel will be very uncertain. For the assessment of consequences outside the buildings, the effect that the buildings would have on the dispersion and transport of the radioactive material (i.e., building wake effects) must be characterized. Several attempts have been made to model these effects (Refs. C.4.20 - C.4.22); however, the application of the models is for the most part undeveloped. In addition, for some accidents, short-lived radionuclides, which are not considered in the offsite assessment because they have been removed by decay, may be important to the onsite health effects. At present, the methods available for assessing onsite consequences

NUREG-1489 C-102 


\section{C.4 Accident Progression and Risk Analyses \\ C.4.4 Constituents of Transformations \\ C.4.4.3 Consequence Analysis}

are fairly limited and can be used only to support a preliminary analysis, such as those in References C.4.6 and C.4.7.

\section{C.4.4.3.3 Products}

The consequences associated with an accident can be expressed in many ways and displayed in a variety of forms. Representative measures were calculated in the NUREG-1150 study (Ref. C.4.4); these measures are reported in Table C.4.4. The last two measures listed are used in the quantitative safety goal comparison. Although not shown in this table, economic costs associated with the accidents can also be reported. The most basic result is displayed as a CCDF for each consequence measure. Conditional on the occurrence of a source term, the CCDF gives the probability with which a particular consequence will be exceeded, given the variability in the weather conditions that may exist at the time of an accident.

Table C.4.4 Consequence measures reported in the NUREG-1150 study (Ref. C.4.4)

\begin{tabular}{|c|c|}
\hline Consequence Measure & Description \\
\hline Early fatalities & $\begin{array}{l}\text { Number of fatalities occurring within } 1 \text { year of the accident from early exposure (i.e., } \\
\text { exposure incurred within } 7 \text { days of the accident). }\end{array}$ \\
\hline $\begin{array}{l}\text { Total latent cancer } \\
\text { fatalities }\end{array}$ & $\begin{array}{l}\text { Number of latent cancer fatalities from both early and chronic exposure (chronic exposure } \\
\text { is that which is incurred more than } 7 \text { days after the accident). }\end{array}$ \\
\hline $\begin{array}{l}\text { Population dose within } 50 \\
\text { miles }\end{array}$ & $\begin{array}{l}\text { Population dose, expressed in effective dose equivalents for whole body exposure (Sv), from } \\
\text { early and chronic exposure pathways within } 50 \text { miles of the reactor. Because of the nature } \\
\text { of the chronic pathways models, the actual exposure from food and water consumption may } \\
\text { take place beyond } 50 \text { miles (e.g., food and water originating within } 50 \text { miles of the plant } \\
\text { may be consumed by people located beyond } 50 \text { miles). }\end{array}$ \\
\hline $\begin{array}{l}\text { Population dose within } \\
\text { entire region }\end{array}$ & $\begin{array}{l}\text { Population dose, expressed in effective dose equivalents for whole body exposure (Sv), from } \\
\text { early and chronic exposure pathways within the surrounding region. }\end{array}$ \\
\hline $\begin{array}{l}\text { Individual early fatality } \\
\text { risk within } 1 \text { mile }\end{array}$ & $\begin{array}{l}\text { Probability of dying within } 1 \text { year for an individual within } 1 \text { mile of the site exclusion } \\
\text { boundary (i.e., ef/pop, where ef is the number of early fatalities within } 1 \text { mile of the } \\
\text { exclusion boundary, and pop is the population within } 1 \text { mile of the exclusion boundary). }\end{array}$ \\
\hline $\begin{array}{l}\text { Individual latent cancer } \\
\text { fatality risk within } 10 \text { miles }\end{array}$ & $\begin{array}{l}\text { Probability of dying from cancer for an individual within } 10 \text { miles of the plant (i.e., cf/pop, } \\
\text { where cf is the number of cancer fatalities from direct exposure in the resident population } \\
\text { within } 10 \text { miles of the plant, and pop is the population size within } 10 \text { miles of the plant). } \\
\text { The calculation does not include ingestion but does include integrated groundshine and } \\
\text { inhalation exposure. }\end{array}$ \\
\hline
\end{tabular}

The CCDF for latent cancer fatalities of a single source term is shown in Figure C.4.3; this curve is from an analysis of internal events at Surry (Ref. C.4.4). There are similar curves for the other source terms generated in the analysis and for other consequence measures. The curve in Figure C.4.3 can be reduced to a single nutther mean consequence conditional on the source term. This is the value that is used in the calculation of the aggregate risk (see below for definition). The consequences displayed in Figure C.4.3 (along with the CCDF for the other source terms) can be combined with the accident frequencies that lead to these consequences and 
C.4 Accident Progression and Risk Analyses

C.4.4 Constituents of Transformations

C.4.4.4 Risk Calculation

can be displayed in a form similar to a CCDF. Such a figure gives the relationship between the magnitude of the consequence and the frequency at which the consequence is exceeded, as well as the variation in that relationship; the variation along a curve is indicative of the variation in consequences from different types of accidents and from different weather conditions at the time of the accident. This type of figure is discussed in Section C.6.4.2 (page C-160).

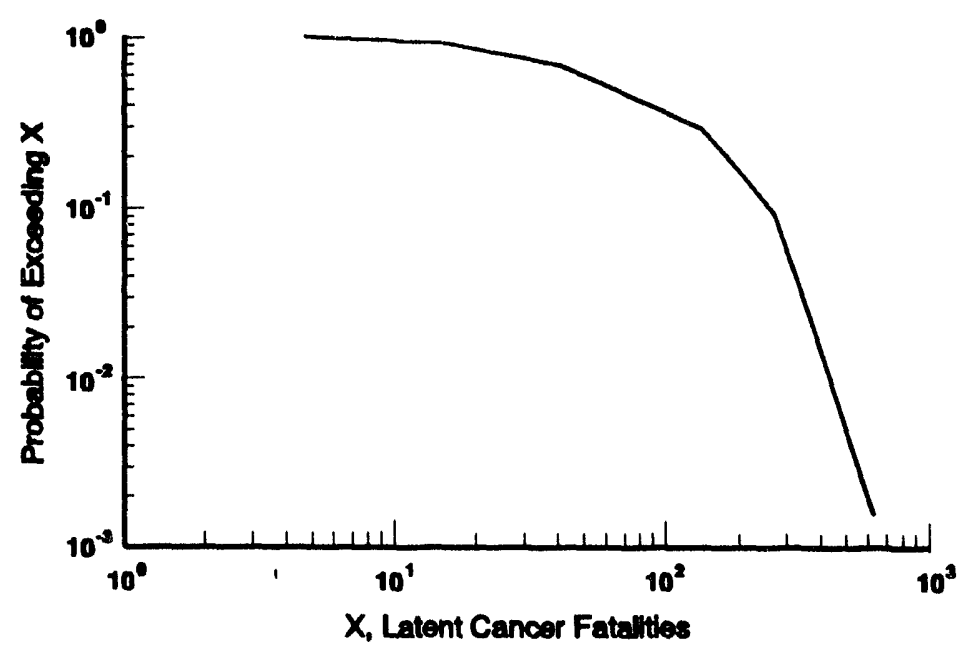

Figure C.4.3 CCDF of latent cancer fatalities

\section{C.4.4.4 Risk Calculation}

\section{C.4.4.4.1 Concepts}

The calculation of risk as was done in the NUREG-1150 study (Ref. C.4.4) is the integration of the accident sequence and reliability analyses (Chapter C.3, page C-41), accident progression analysis (Section C.4.4.1, page C-84), source term analysis (Section C.4.4.2, page C-91), and consequence analysis (Section C.4.4.3, page C-98). Integrating at this stage means to bring together the numerical results of the Level 1, Level 2, and Level 3 analyses. $^{23}$

The term risk is often used loosely. It is common for the NRC staff to refer to the CDF, the conditional containment failure probability, and other quantities as risk. This usage should be avoided. Two common definitions of risk at the NRC are the risk triplet and the aggregate risk. The risk triplet is the $s e t,\left\langle s_{i}, f_{i}, x_{i}\right\rangle$,

\footnotetext{
${ }^{23}$ Three types of integration pertain to performing or reviewing a PRA. Structural integration addresses the interfaces among constituent analyses designed to pass information from one analysis to the next. Numerical integration addresses the correlations between variables, consistent Monte Carlo sampling of the variables in the constituent analyses, and consistently treated issues. Administrative integration addresses the compatibility of analyses by, for example, establishing a level of detail, deciding on the technical issues to develop, and deciding on analytical methods.
}

NUREG-1489 


\section{C.4 Accident Progression and Risk Analyses C.4.4 Constituents of Transformations C.4.4.4 Risk Calculation}

in which $s_{\mathrm{i}}$ represents the $\mathrm{i}$ th scenario (sequence, progression), ${ }^{24} f_{\mathrm{i}}$ is the associated frequency, and $x_{\mathrm{i}}$ is the resulting consequence (Ref. C.4.23). Risk is the set of possible scenarios and their associated frequencies and consequences. This definition distinguishes between low-frequency/high-consequence scenarios and highfrequency/low-consequence scenarios. The other definition of risk is aggregate risk, ${ }^{25}$ which is defined as the sum of the products of the scenario frequencies and the scenario consequences:

$$
\begin{aligned}
R=\sum_{i=1}^{n}\left[F_{i}\right]\left[C_{b}\right] \quad \text { where } R_{a}= & \text { aggregate risk, in units of consequences per unit time } \\
F_{i}= & \text { frequency of the } i^{\text {th }} \text { scenario, in units of events per unit } \\
& \text { time }
\end{aligned}
$$

Here, the symbol for consequences in the aggregate risk definition, $C_{i}$, is equivalent to the symbol $x_{i}$ in the risk triplet definition appearing throughout Appendix C.

Frequency is defined in Section C.2.3 (page C-31); its accounting for the accident sequence analysis is discussed in Chapter C.3 (page C-41); its accounting of the accident progression analysis is discussed in Section C.4.4.1 (page C-84). The concept of consequences is discussed in Section C.4.4.2 (page C-91) and Section C.4.4.3 (page C-98).

The aggregate risk definition is based on the same elements as the triplet definition: accident scenarios, scenario frequencies, and consequences. Although the aggregate risk definition is appealing because it is a single number, information is lost in going from the risk triplet to aggregate risk. Consider the hypothetical situation in Table C.4.5 that has two outcomes, one having a high frequency of a low consequence and the other having a low frequency of a high consequence. Both scenarios have the same components of aggregate risk when viewed from this level. However, they are different when viewed on the level of the risk triplet. ${ }^{26}$ Thus, even though the components of aggregate risk may be the same, regulatory decisions regarding each scenario may be very different. Decisions that are sensitive to the components of an aggregate risk estimate must be made on a caseby-case basis. The situations depicted in Table C.4.5 can be distinguished using the concept of utility. A discussion of utility theory is beyond the scope of this report. However, if it is used, then as discussed in Reference C.4.24, ${ }^{27}$ caution is advisable.

Although there is no general guidance to address the situation represented by Table C.4.5, the following factors should be considered:

- The specific attributes of various sequences.

\footnotetext{
${ }^{24}$ See page $\mathrm{C}-85$ for the distinction between sequence and progression.

${ }^{2 s}$ This term is not commonly recognized nomenclature but is used here to discuss the concept.

${ }^{26}$ A PRA that allows the calculations to be traced would show the reasons for the values; the extent to which this can be done will be determined by such issues as the construction of the APET (see Section C.4.4.1.2, page C-86).

${ }^{27}$ What are called low-frequency/high-consequence events in this report are usually termed low-probability/high-consequence events in the literature. Nevertheless, the concepts of utility are applicable here.
} 
- The reasons for the frequency and consequence values, as determined by tracing the calculations through the event trees.

Table C.4.5 Hypothetical risk triplets collapsed into aggregate risk

\begin{tabular}{|c|c|c|c|c|}
\hline \multicolumn{3}{|c|}{ Risk Triplet } & \multirow{2}{*}{$\begin{array}{l}\text { Components of } \\
\text { Aggregate Risk }\end{array}$} & \multirow{2}{*}{$\begin{array}{l}\text { Aggregate } \\
\text { Risk }\end{array}$} \\
\hline Scenario & Frequency & Consequence & & \\
\hline A & 0.1 & 1 & 0.1 & \multirow{2}{*}{0.2} \\
\hline B & 0.001 & 100 & 0.1 & \\
\hline
\end{tabular}

The NRC staff needs to be aware of the components of risk and present results so as not to mask information that may be important in making decisions. For related discussions, see Chapter C.1 (page C-8) and Figure C.1.1 (page (-9) on combining views from PRAs and Section C.5.6 (page C-139) on combining expert judgments.

One interpretation of aggregate risk is that of the expected value (see Section C.2.2.1.2, page C-21) of total consequences. Since the occurrence of scenarios is unpredictable, the number of scenarios and associated consequences are random variables. Therefore, the total consequences of all scenarios which occur is a random variable. It can be shown that the expected value of this random variable (i.e., total consequences) is the aggregate risk $R_{\mathbf{a}}$.

An important extension of the concept of aggregate risk stems from the consideration of uncertainty in its component frequencies. An important characteristic of this distribution is its expected value, $E\left(R_{q}\right)$, also known as the mean of $R_{a}$. From the equation for $R_{a}$, its mean can be written as a weighted sum of the means of the component frequencies. The equation for aggregate risk and its mean are compared in Table C.4.6. As discussed in Section C.4.5 (page C-112), it is the mean aggregate risk which was compared to NRC safety goals (Ref. C.4.17) in the NUREG-1150 study (Ref. C.4.4).

A pictorial comparison of aggregate risk and mean aggregate risk is shown in Figure C.4.4. This figure simplifies the structure of a PRA in two ways. First, the source terms are not explicitly shown, but their effects are reflected by the consequences. Second, uncertainty in the risk reflects only the uncertainty in the initiating event frequencies and the branch point probabilities. In practice, there is also uncertainty in the source terms associated with any specific accident scenario (see Figure C.4.5 on page C-110), but this uncertainty is suppressed in Figure C.4.4. In both Figure C.4.4 and in practice at the NRC, consequences are modeled with point values: no uncertainty distributions for consequences are used. 
Table C.4.6 Comparison of aggregate risk and mean aggregate risk

\begin{tabular}{||c|c|}
\hline \multicolumn{1}{|c|}{ Aggregate Risk } & Mean Aggregate Risk \\
\hline$R_{a}=\sum_{i=1}^{n} F_{i} C_{i}$ & $E\left(R_{d}\right)=\sum_{i=1}^{n} E\left(F_{i}\right) C_{i}$ \\
$R=$ aggregate risk & $E\left(R_{a}\right)=$ mean aggregate risk \\
$F_{i}=$ frequency of scenario $i$ & $E\left(F_{i}\right)=$ mean frequency of $F_{i}$ \\
$C_{i}=$ consequence of scenario $i$ & $C_{i}=$ consequence of scenario $i$ \\
$i=1 \rightarrow n$, summation over all scenarios & $i=1 \rightarrow n$, summation over all scenarios \\
\hline
\end{tabular}

In Figure C.4.4, the aggregate risk calculation begins with the occurrence of an initiating event with a frequency $F_{1}$, which is partitioned by the branch point probabilities of the event tree (see Section C.4.4.1 for a discussion of how this is done in the accident progression analysis). The top half of Figure C.4.4 shows the aggregate risk calculation when all its component quantities are known. The bottom half shows the aggregate risk calculation as is the usual practice; distributions of the initiating event frequency, $\mathrm{F}$, and selected branch point probabilities, $p$, and other inputs are propagated through the event tree. This gives rise to distributions on $F_{1}$ and $F_{2}$. Although consequences could be represented with a distribution, the current practice at the NRC is to use point values. Multiplying each frequency, $F_{\mathrm{i}}$, with an associated consequence results in aggregate risk, $\mathbf{R}_{\mathrm{a}}$. Repeating the calculation (e.g., Monte Carlo sampling, Section C.6.3.1, page C-154) with points of the input distribution results in a distribution of aggregate risk. The mean aggregate risk is the mean of the distribution of $\mathbf{R}_{\mathbf{a}}$.

See Section C.2.2.2.1 (page C-24) for a discussion of the use of mean and median inputs to produce an output. See Section C.6.3.1 (page C-154) for a commonly used method to propagate uncertainty through a mathematical model.

Guidance: The NRC staff should refer to the sum of the product of the sequence frequency and consequences as aggregate risk.

The term risk should be restricted to the aggregate risk or risk triplet definitions. When the core damage frequency is discussed, the NRC staff should use the terms core damage frequency or $C D F$. When the accident progression frequency is discussed, the term APF should be used. If another definition of the term risk is used, such as in discussions with other agencies, then the terms should be defined.

While the use of an aggregate risk estimate can provide a simple message, it can also mask information important to decisionmakers, as conveyed by the component frequencies and consequences.

Whether reviewing a PRA, performing a PRA, or performing any of the classes of transformations (see Section C.4.3, page (-76), the NRC staff has the responsibility to thoroughly understand the PRA and present its results to support regulatory decisions. Briefly, the understanding of a PRA involves the following: 
C.4 Accident Progression and Risk Analyses

C.4.4 Constituents of Transformations

C.4.4.4 Risk Calculation

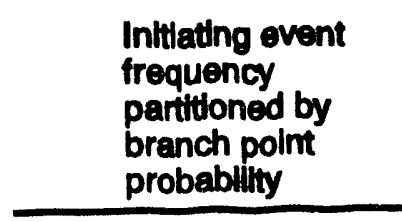

\section{Conse- quences of the sequences}

\begin{tabular}{ll}
$\begin{array}{l}\text { Risk of each } \\
\text { sequence }\end{array}$ & $\begin{array}{l}\text { Aggregate } \\
\text { Risk }\end{array}$ \\
\hline
\end{tabular}

Mean

Aggregate Pisk
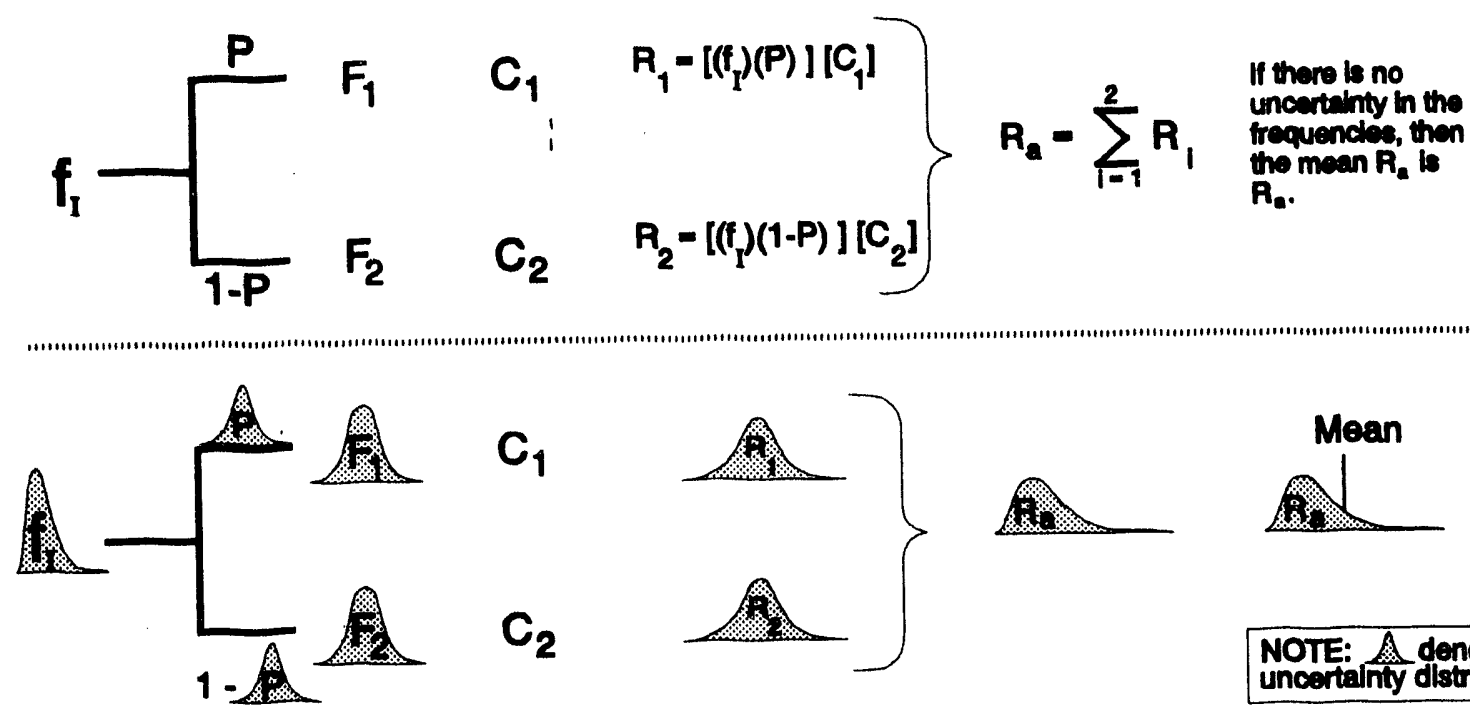

Figure C.4.4 Illustration of aggregate risk and the expected value of aggregate risk

- The sensitivity of PRA results to assumptions.

- The major factors determining the results.

- The characteristics of summary measures such as the mean and median.

- The reasons for presenting results in a particular way for decisionmaking.

A large effort on the part of the NRC staff and its contractors is required to obtain an understanding of a PRA. Many decisions regarding the structure of a PRA must be made on a case-by-case basis, drawing on various disciplines. The alternative is to use PRA with only a partial understanding, possibly using it incorrectly or not using it at all, leaving the staff with a fragmented view.

\section{C.4.4.4.2 Products}

Risk estimates from PRAs of operating power reactors are usually reported by the NRC staff and its contractors using the aggregate risk definition. Such estimates are in terms of a consequence measure during a year of 
C.4 A'ccident Progression and Risk Analyses C.4.4 Constituents of Transformations C.4.4.4 Risk Calculation

operation. This period of the unit operation is called a reactor-year and accounts for the downtime during the calendar year. ${ }^{23}$ Commonly reported risk estimates are as follows:

- Early fatalities/reactor-year

- Latent cancer fatalities/reactor-year

- Population dose within 50 miles of a plant/reactor-year

- Population dose within 1000 miles of a plant/reactor-year

- Average individual early fatality risk within 1 mile of a plant/reactor-year

- Individual latent cancer fatality risk within 10 miles of a plant/reactor-year

The last two measures are defined for comparison with NRC safety goals (Ref. C.4.17). In the NUREG-1150 study (Ref. C.4.4), the contribution of various plant damage states and accident progression bins to the mean estimates were reported along with the risk measures. Typical displays of risk results are discussed in Section C.6.4 (page C-159).

\section{EXAMPLE}

The processes in the NRC staff's PRAs, NUREG-1150 (Ref. C.4.4), are illustrated in Figure C.4.5 as an example of an integrated risk assessment. Inputs are assigned either a point value or a distribution, the letter when an input is shown to have a noticeable influence on the output. The assignment of inputs, most typically the distributions, is done according to the guidelines in Chapter C.5 (page C-129).

The determination of accident sequences leading to core damage is done in the accident sequence analysis. A Level 1 analysis (Chapter C.3, page C-41) begins with the initiating events, grouped according to similarities in the required system response. The events following the initiation (i.e., the accident sequence) are modeled with event trees and fault trees, both of which reflect the relationships of systems and accident phenomena of each group of accident initiators. A Level 1 analysis yields the sequences leading to core damage and their frequencies, accounting for both mechanical failures and human errors. The event trees allow a spectrum of sequences to be delineated, sometimes too many to treat individually. The number of sequences is reduced in two ways:

- A given sequence is no longer followed through the event tree when its frequency falls below a specified value.

- The sequences are grouped according to similar conditions of the plant when core damage is reached.

Even when low-frequency sequences are discontinued, too many sequences remain to propagate individually through the Level 2 analysis. Furthermore, many of the sequences result in the same or similar plant conditions, making the effort to propagate such sequences individually through the Level 2 analysis redundant. Therefore, the sequences (along with their frequencies and the uncertainty in those frequencies) are grouped according to similar attributes, such as the type of initiating event, the status of the injection and core cooling systems, the status of containment sprays, and the reactor pressure. These fixed groups are the plant damage states. The plant damage states constitute the interface between the accident sequence analysis (Level 1) and the accident progression analysis (Level 2).

In the Level 2 analysis, accident progressions are delineated with an accident progression event tree or APET. Branch point probabilities (distributions and point values) reflect the likelihood of the various pathways. The distributions at various points in the APET give rise to distributions at the end of each pathway. The calculations of the accident progression event tree are done with the EVNTRE code (Ref. C.4.25). Other products of the APET are the accident progression bins, which are groups of pathways that have been aggregated according

${ }^{28}$ Risks during shutdown operation are determined separately. The numerator of the shutdown risk calculation is expressed in the same units as those in a PRA of full-power operations. In either calculation, the denominator is in units of time: risk calculations of full-power operation used the time of full-power operation; risk calculations of shutdown operation use the shutdown time. 


\section{C.4 Accident Progression and Risk Analyses}

\section{C.4.4 Constituents of Transformations}

\section{C.4.4.4 Risk Calculation}

to characteristics of the source terms. The characteristics are represented with character strings. Only the character string is passed to the source term calculations. The accident progression bins constitute the interface between the source term and consequence analyses.

Having delineated accident progressions with the APET, grouped the progressions, and labeled the groups with character strings, the source terms of the progressions are calculated with a parametric code (Ref. C.4.15). The parametric code is a collection of simple mass-balance equations, activated by the character strings representing the characteristics of the various progressions. As in the APET calculations, distributions are assigned to the variables and sampled with Latin Hypercube Sampling (see Section C.6.3.2, page C-156) to form many sets of input values for repeated calculations. The result is a distribution of source terms for each accident progression bin.

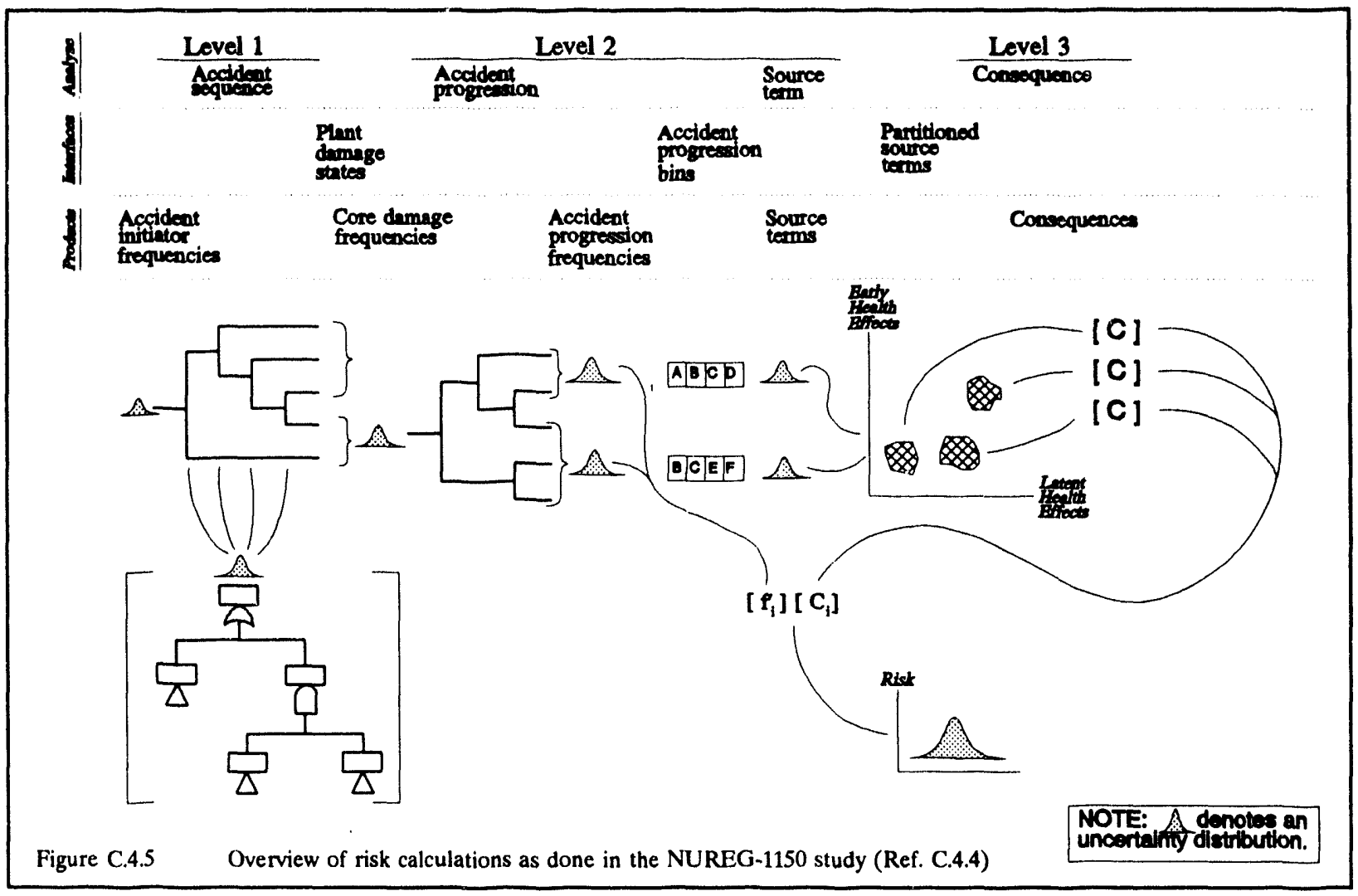

The source terms are too numerous for individual consequence calculations. To reduce the number of source terms to a reasonable amount, they are grouped according to similar characteristics of relevance to consequences. The partitioning of the source terms into groups is a two-stage process. First, the source terms are grouped by three parameters, early health effects, latent health effects, and evacuation time. Second, a frequency-weighted mean is determined for each group. The grouping is done by the PARTTTION code (Ref. C.4.14). The partitioned source terms constitute the interface between the accident progression analysis and the consequence analysis. In effect, the partitioned source terms allow a given consequence calculation to be associated with a group of accident progression pathways.

In the NUREG-1150 study (Ref. C.4.4), six consequence measures were reported: early fatality consequences, total latent cancer fatality consequences, population dose at 50 miles, population dose at 1000 miles, probability of early fatality between 0 and 1 miles, and probability of latent fatality between 0 and 10 miles. The calculations were done with the MACCS Code (Refs. C.4.10 - C.4.12).

Risk is defined as the product of the sequence frequency, the accident progression probability conditional on core damage, and the consequences. The calculation was done with the PRAMIS code (Ref. C.4.26). 


\section{C.4 Accident Progression and Risk Analyses \\ C.4.5 Uncertainty in PRA Results}

\section{C.4.5 Uncertainty in PRA Results}

The concept of uncertainty ${ }^{29}$ in risk when expressed as a distribution of aggregate risk estimates (see page C-105 for definition) must be understood to correctly use the risk results. Each point in a risk distribution is a risk estimate of all the accident sequences delineated in the Level 1 and Level 2 analyses, calculated with a set of inputs selected with Monte Carlo sampling (see Section C.6.3.1, page C-154). This is illustrated in Figure C.4.6. The risk distribution is not a distribution of sequences where high-consequence sequences are confined to the upper tail and low-consequence sequences are confined to the lower tail. The distribution represents uncertainty in the parameters and models of the PRA. The constituents of stochastic uncertainty (accounted by the branches of an event tree resulting in the various accident progressions) are lost when the aggregate risk calculation is done. The way in which uncertainty is treated within the Level 1,2 , and 3 portions of a PRA is discussed in Section C.6.2.2 (page C-151).

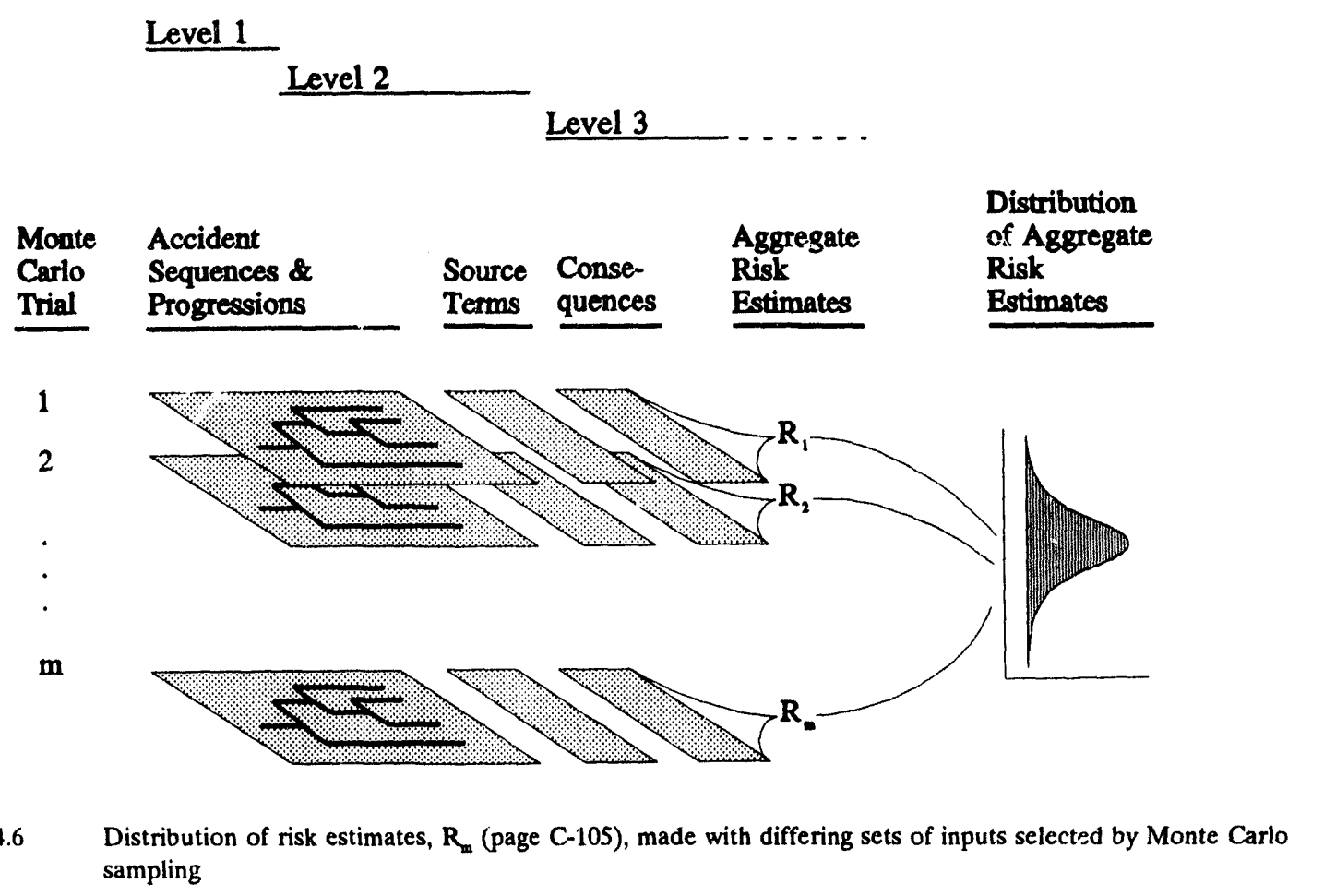

Guidance: To use risk results correctly, the meaning of the results must be understood in two general ways.

(1) The assumptions, inputs, and models introduce numerical artifacts into the analyses. Thus, the way in which the PRA is performed will influence the results.

${ }^{24}$ See Section C.6.2.1, page C-150, for a discussion of the types of uncertainty. 


\section{C.4 Accident Progression and Risk Analyses \\ C.4.5 Uncertainty in PRA Results}

(2) The meaning of the distributions must be understood. The distributions represent the uncertainty in parameters and, to some extent depending on the study, the models of a PRA.

The types of uncertainty must be distinguished when using $P R A$ results, performing a PRA, or reviewing a PRA. See Section C.6.2.1 (page C-149) for a classification scheme of uncertainty.

The aggregation of risk estimates should not mask or destroy information that is important for regulatory decisions. 'If various views of a facility or issue can be taken, such as that of the NRC staff and that of a licensee, PRA results should be presented to reflect the differing views.

The importance of considering uncertainty in the inputs (and other sources discussed in Section C.6.2.1, page C-149) goes beyond just accounting for the inherent imprecision in inputs. Some calculations in PRA involve thresholds, which, depending on whether or not they are met, can have a large influence on subsequent results. A variation change in an input can cause a large change in results when thresholds are involved in calculations. An example is the treatment of the probability of early containment failure in an APET. In some PRAs, such as the NUREG-1150 study (Ref. C.4.4), load pressure and failure pressure values were selected from their respective distributions with Monte Carlo sampling and compared. When the load pressure is greater than the failure pressure, the containment is considered failed and visa versa. If only one calculation was done instead of repeated calculaticns, the view of a plant obtained from the results would be very dependent on the inputs that were chosen, i.e., mean values of containment loads and failure pressures of large dry containments would always predict a zero failure probability. Such results are inadequate for regulatory decisions, particularly when the inputs may have been chosen without awareness of the thresholds. Sensitivity studies are of use in relating changes in inputs to changes in outputs, but accounting for the simultaneous changes in multiple inputs is difficult, particularly when many thresholds are affected in complicated ways. An uncertainty analysis can be used to effectively account for the simultaneous change in multiple inputs. ${ }^{30}$

Guidance: Sensitivity studies on multiple inputs must be done with caution because the change in the output with a given variable may be a function of the values of the remaining inputs.

The need to account for uncertainty has been acknowledged by the Advisory Committee on Reactor Safeguards: "... there is no usefulness in a calculated probability without an associated statement, in some quantitative form, of its uncertainty" (Ref. C.4.27). General guidance on comparing risk estimates to agency goals is found in Reference C.4.17; in their policy statement, the Commission stated the following:

To the extent practicable, the Commission intends to ensure that the quantit tive techniques used for regulatory decisionmaking take into account the potential uncertainties that exist so that an estimate can be made on the confidence level to be ascribed to the quantitative results.

The Commission has adopted the use of mean estimates for purposes of implementing the quantitative objectives of this safety goal policy (i.e., the mortality risk objectives). Use of the mean estimates comports with the customary practices for cost-benefit analyses and it is the correct usage for purposes of the mortality risk comparisons. Use of the mean estimates does

${ }^{3)}$ See Section C.6.2.1 (page C-149) for a distinction between uncertainty and sensitivity analyses.

NUREG-1489 C-112 


\section{C.4 Accident Progression and Risk Analyses}

C.4.5 Uncertainty in PRA Results

not however resolve the need to quantify (to the extent reasonable) and understand those important uncertainties involved in the reactor accident risk predictions. A number of uncertainties (e.g., thermal-hydraulic assumptions and the phenomenology of core melt progression, fission product release and transport, and containment loads and performance) arise because of a direct lack of severe accident experience or knowledge of accident phenomenology along with data related to probability distributions.

In such a situation, it is necessary that proper attention be given not only to the range of uncertainty surrounding probabilistic estimates, but also to the phenomenology that most influences the uncertainties. For this reason, sensitivity studies should be performed to determine those uncertainties most important to the probabilistic estimates. The results of the sensitivity studies should be displayed showing, for example, the range of variation together with the underlying science or engineering assumptions that dominate this variation. Depending on the decision needs, the probabilistic results should also be reasonably balanced and supported through use of deterministic arguments. In this way, judgments can be made by the decisionmaker about the degree of confidence to be given to these estimates and assumptions. This is a key part of the process of determining the degree of regulatory conservatism that may be warranted for a particular decision.

Figure C.4.7 shows a typical display of risk; here, a distribution of a risk estimate is displayed as a density function. ${ }^{31}$ The density function is on the right; to the left of that is a display of the distribution known as a whisker plot. Seldom is the density function constructed owing to the computational and illustrative difficulties. $^{32}$ The relationship between the distribution and the whisker plot is shown by describing how key points in either representation are related when uncertainty is computed with Monte Carlo simulation (see Chapter C.6.3.1, page C-154):

1. Repeated trials of estimating risk are made by sampling the input distributions of a PRA.

2. From the ordered risk estimates, the various percentiles can be readily determined. The upper bound is often taken as the 95th percentile and the lower bound as the 5th percentile. The median is the 50th percentile.

3. The mean is calculated in the usual way, i.e., summing the estimates and dividing by the number of estimates. The mean is an arithmetic mean, not a geometric mean, even though the risk results will be displayed on a logarithmic scale. The percentile of the distribution corresponding to the mean is denoted by $q$.

4. The percentiles directly translate onto a logarithmic scale, which is a typical scale in the PRAs of nuclear power reactors; the lower and upper bounds are the 5th and 95th percentiles, respectively; the 50th percentile is the median; the associated percentile, the $\mathrm{q}$ th percentile, translates as the mean. The logarithmic scale is necessary because of the wide span of risk estimates.

Figure C.4.7 illustrates the reason for taking uncertainty into account. There is no single correct risk estimate in the distribution; each estimate within the distribution has a degree of likelihood associated with it. In Figure

\footnotetext{
${ }^{31}$ As discussed in Section C.6.4 (page C-159), other displays are also convenient and serve other more technical purposes.

${ }^{12}$ Section C.6.4.4 (page C-162) discusses how to convert a histogram into an approximation of a density function; the conversion can sometimes result in large differences between the shapes of these two representations.
} 

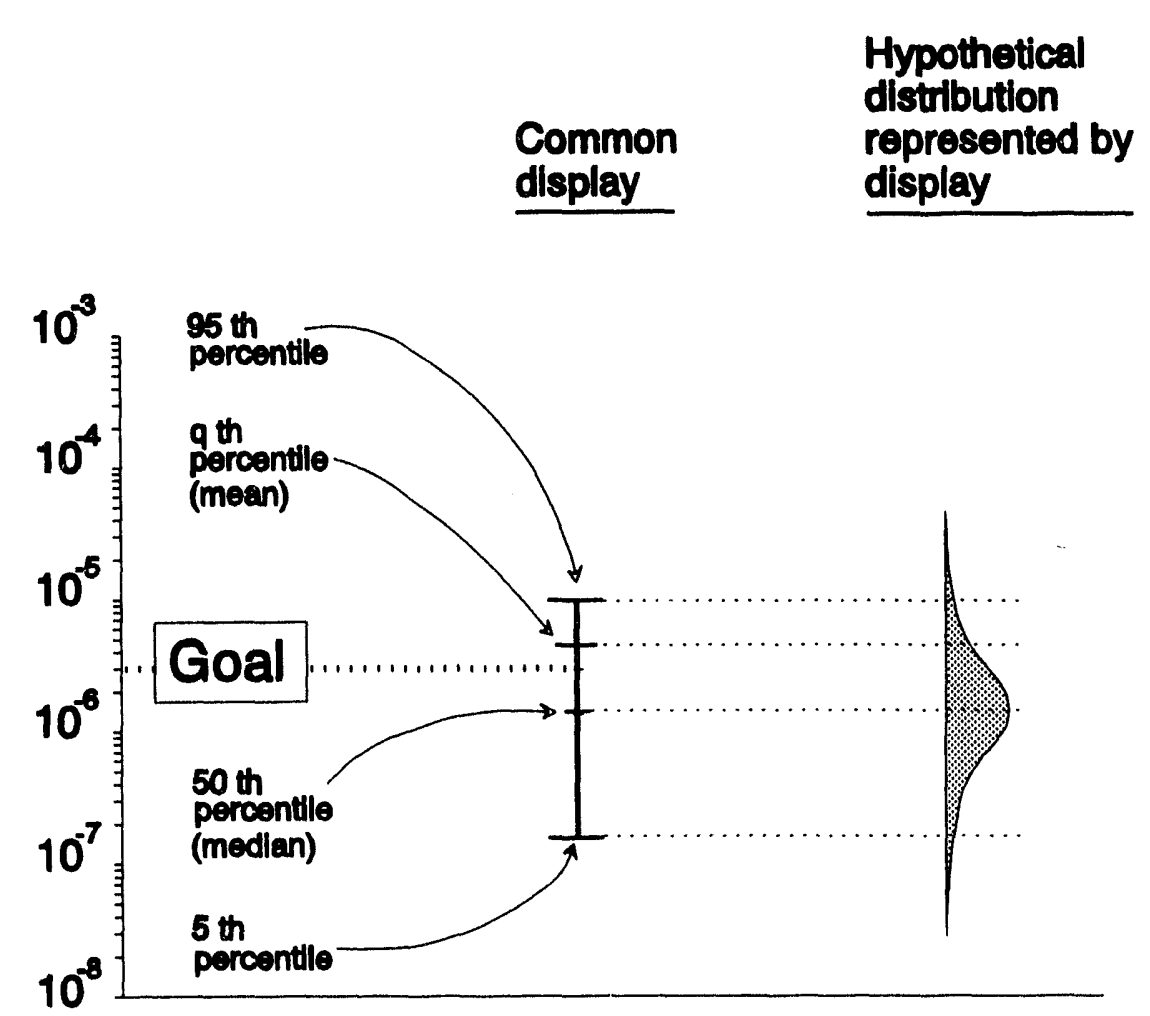

Figure C.4.7 Comparing a PRA risk estimate to a safety goal

C.4.7, values around the median are more likely than values around the mean. If the density function were determined, the likelihood of values within an interval could be determined as the area under the curve within comparable intervals. ${ }^{33}$ Furthermore, although the mean is a measure of central tendency, other measures of central tendency are the mode (most frequent value) and the median (middle value). Unlike the other two measures of central tendency, the mean is influenced by the large values, causing it to shift above what appears to be the center of the distribution (remember, this scale is logarithmic). In this example, the mean is slightly above the goal, even though the bulk (area) of the distribution is below the goal. As Section C.4.4.4.1 (page C-105) discusses, the constituents of the risk triplet should be investigated to determine the reasons for selected estimates. Each estimate in a distribution does not have to be investigated; the NRC staff should be able to state the reasons for estimates in the tails of the distribution, around the median, and around the mean. ${ }^{34}$

Guidance: The NRC staff must understand the properties (i.e., sensitivity) of quantitative measures such as the mean and median when using and interpreting results.

\footnotetext{
${ }^{33}$ For example, determining the area about the mean and then again for an equal linear distance about the median would yield the likelihood of values within those intervals.

${ }^{34}$ The mean is a convenient expression of risk for two reasons. (1) It is consistent with customary practices for cost-benefit analyses and is the correct usage for purposes of the mortality risk comparison (Ref. C.4.17), and (2) it has intuitive appeal in communicating risk to the public because the measure is familiar.
}

NUREG-1489

C-114 


\section{C.4 Accident Progression and Risk Analyses}

C.4.5 Uncertainty in PRA Results

The above concepts of uncertainty are illustrated in Figure C.4.8 with risk distributions from the NUREG-1150 study (Ref. C.4.4). Each of the distributions is far enough from the safety goal to conclude that they are all below the goal. Based on mean risk estimates, the figure shows the following order:

$$
\text { Surry }>\text { Sequoyah }>\text { Zion }>\text { Peach Bottom }>\text { Grand Gulf }
$$

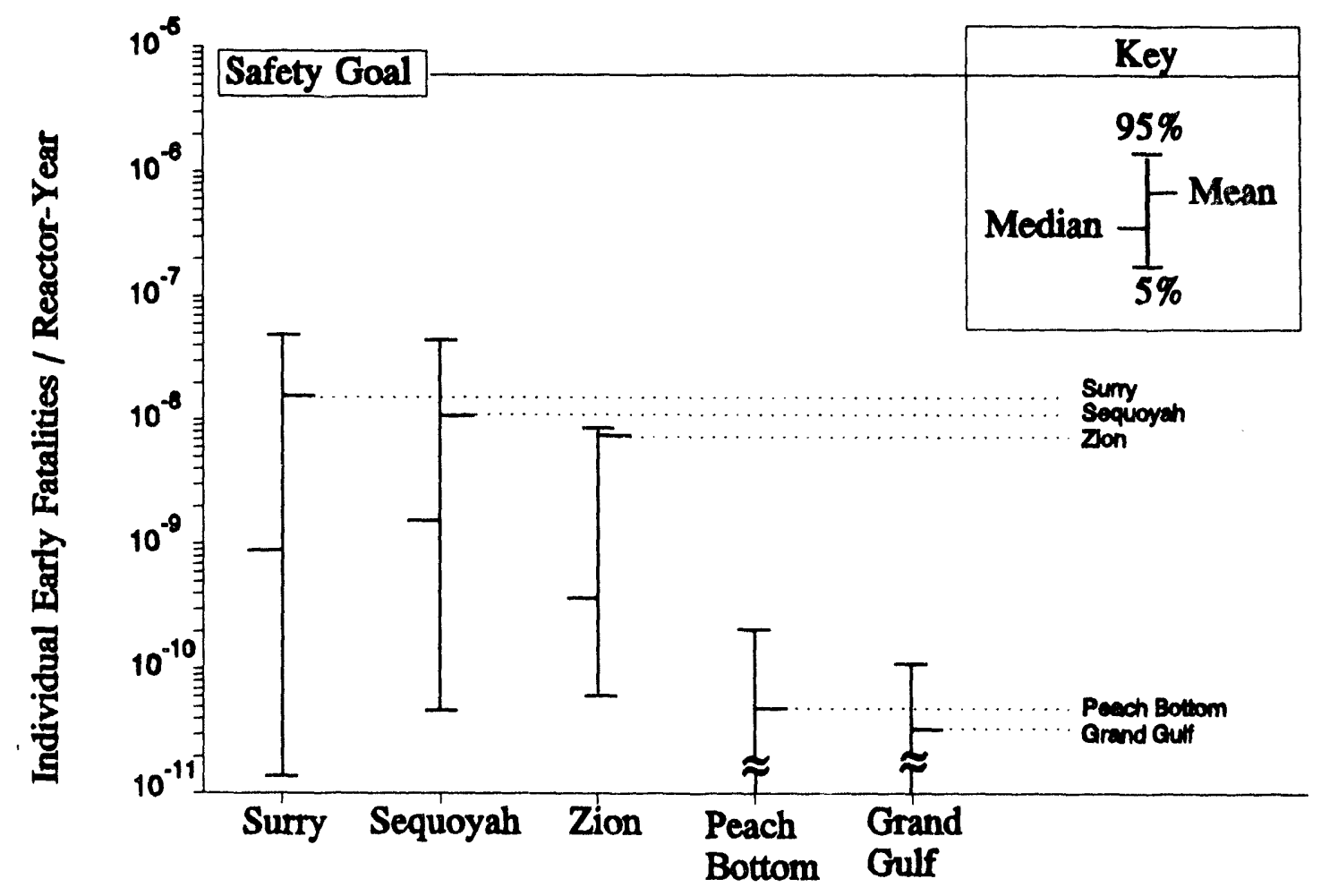

Figure C.4.8 Comparison of risk distributions from the NUREG-1150 study (Ref. C.4.4)

The comparison becomes more complicated when uncertainties are considered. The risk distributions of Surry, Sequoyah, and Zion cannot be ordered. Neither can the distributions of Peach Bottom and Grand Gulf. The following statement can be made:

$$
\text { Surry } \approx \text { Sequoyah } \approx \text { Zion }>\text { Peach Bottom } \approx \text { Grand Gulf }
$$

Although the distributions are more difficult to use than point estimates, the simplicity of using the latter is only an illusion. The uncertainties are present whether or not they are expressed. A major strength of PRA is that it allows a practitioner to express various types of uncertainty (see Section C.6.2.1, page C-149). 


\section{C.4 Accident Progression and Risk Analyses \\ C.4.6 Deterministic Calculations}

The benefit of PRA in the regulatory process is not just in the quantitative risk estimates. The estimates are an issue, particularly when they approach the safety goals or other decision criteria. However, a major benefit is in the qualitative results that come from tracing the various risk estimates giving rise to key points of the distribution back through the PRA, in the process elucidating the reasons for the estimate and comparing the trace of selected risk estimates. This is particularly important when the upper tail of a distribution extends above a goal. For the NRC staff, the issue then becomes one of determining what is in place or can be put in place to keep the circumstances giving rise to the high estimates in a risk distribution under control.

Guidance: Suspecting that an analysis, such as a Level 2 analysis, may have lange
uncertainties is not a reason to preclude an uncertainty analysis. Large
uncertainties are a reason to perform an uncertainty analysis.

Uncertainty needs to be taken into account in comparing quantitative risk estimates to each other, to a goal, or to other decision criteria.

Sensitivity studies need to be done to understand the effects of assumptions and models on PRA results.

Uncertainty analysis using Monte Carlo simulation (see Section C.6.3.1, page C-154) is not only for a comprehensive risk assessment, i.e., Class 3 transformations (Section C.4.3.2.3 page C-82). Class 2 transformations (Section C.4.3.2.2, page C-81), using surrogate models, are just as amenable as Class 3 transformations to an uncertainty analysis. In either case, a formal treatment of uncertainty is not necessarily an enormous effort as was done in the NUREG-1150 study (Ref. C.4.4); here, many variables were assigned distributions and many of those distributions were formulated using formal expert judgment (see Chapter C.5, page C-129). However, PRAs (i.e., Refs. C.4.6 and C.4.7) and reviews of PRAs (i.e., Ref. C.4.8) utilizing Monte Carlo simulations were done on a small scale, involving a few variables having distributions assigned by the project staff (see Chapter C.5 (page C-129) for a formal assignment of distributions to input variables).

\section{C.4.6 Deterministic Calculations}

Deterministic codes in support of the Level 2 portion of a PRA are used to predict the course of an accident progression, given a set of inputs describing the plant configuration and the operation of systems used to respond to a potential accident. Deterministic calculations are vital analyses that are used to support the development and quantification of PRA models (e.g., accident progression event trees). Deterministic analyses are also used when PRAs are reviewed to ensure that the assumptions used in the PRA are valid (e.g., system success criteria) and that important phenomena have been included in the PRA and are being treated appropriately.

Two general types of deterministic codes are used to support accident progression and source term analyses: separate effects codes and integral severe accident codes. Separate effects codes (sometimes referred to as detailed mechanistic codes) usually address specific phenomena and incorporate state-of-the-art mechanistic models, and as such, usually produce results that are the realistic assessment of the behavior of the phenomena. ${ }^{35}$ An integral severe accident code simulates specific accident scenarios from the start of the accident to the end of radioactive release from the containment, and as such integrates models of many different phenomena. Because of the breadth of the analysis, severe accident codes typically include simplified representations of the detailed mechanistic models included in many of the separate effects codes. There are

${ }^{35}$ See Section C.2.2.2.1 (page C-24) for a discussion of how this compares to a best estimate. 
many different integral severe accident codes that are currently being used; these codes may address different phenomena, employ different models for the same phenomena, and vary in terms of the flexibility allowed in specifying the input (e.g., the plant configuration and parameters used in the code). An example of the relationship between the NRC's integral severe accident codes and various separate effects codes is illustrated in Figure C.4.9. Deterministic codes commonly seen at the NRC are listed in Section C.4.7 (page C-120).

TIER 1: Integrated Codes

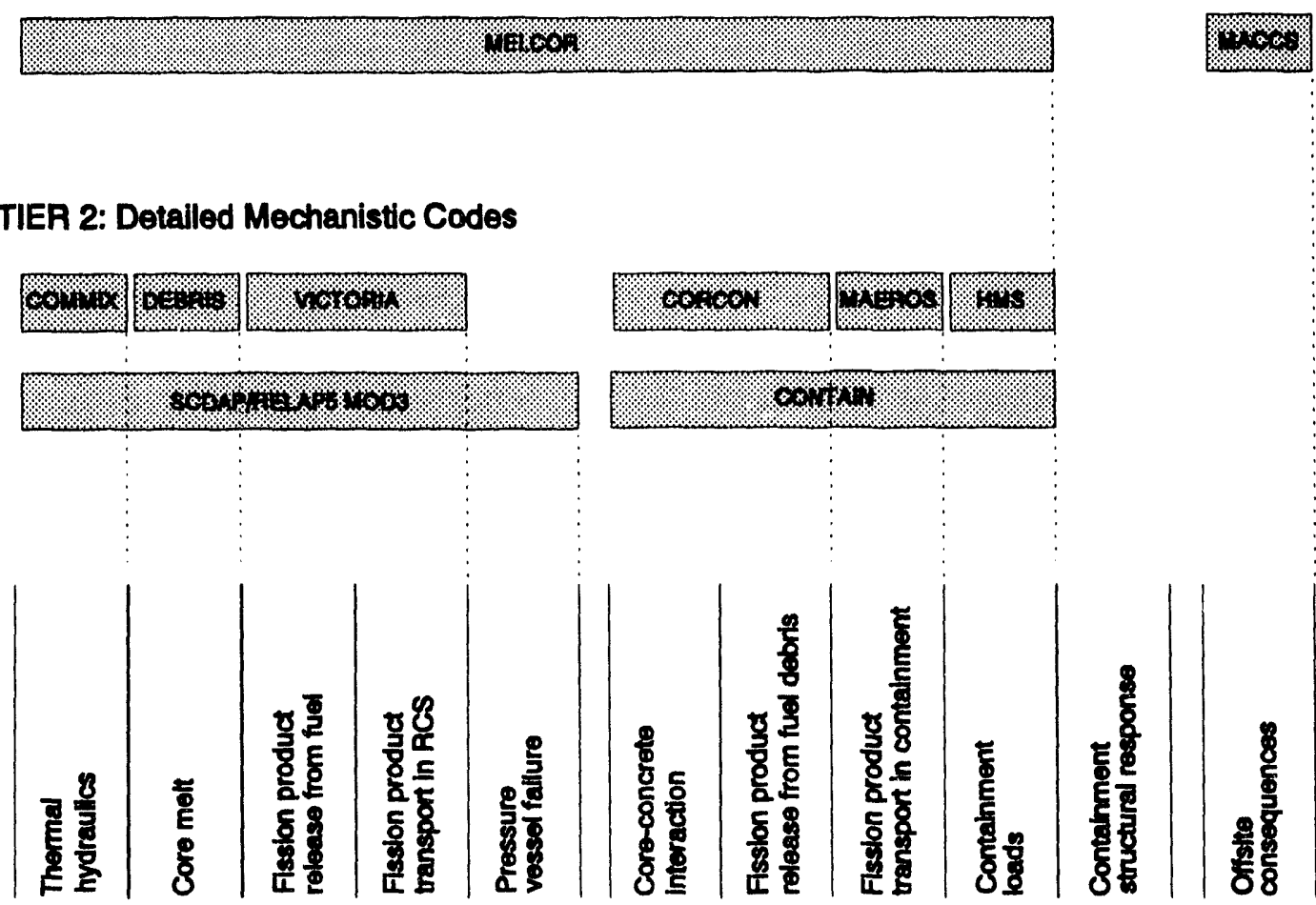

General Progression of Accident Phenomena

$\rightarrow$

Figure C.4.9 Deterministic codes commonly used by the NRC

Each code has its advantages and disadvantages. MELCOR and MAAP (an industry-sponsored code analogous to the NRC code MELCOR, see page C-122) have differences in models, inputs, and assumptions regarding highly uncertain severe accident phenomena. Some of the differences are large while other differences are small. Some of the difference may affect results of interest while other differences may be of no consequence. Added to this complexity is the difference in the architecture of the codes. Some codes, such as MELCOR, allow the user a great deal of freedom in specifying input to the code (i.e., develop a plant-specific model with any desired level of detail, adjust the values of parameters used in various models). In other codes, such as MAAP, the plant model and many of the parameters are "hardwired" into the code structure. While the former requires considerably more effort to develop an input deck, it allows the user the flexibility to perform many different 


\section{C.4 Accident Progression and Risk Analyses \\ C.4.6 Deterministic Calculations}

types of sensitivity analysis (e.g., assess the impact of the plant geometry, nodalization, and values used for parameters in the code).

A general statement about which code is better cannot be made because such a determination is relative to the objectives of a study. MELCOR and MAAP have differences in models, inputs, and assumptions. Some of the differences are large while others are small. Some of the difference may affect results of interest while other differences may be of no consequence. The ambiguity results from the large uncertainty inherent in severe accident phenomena. Realizing this, the issue becomes one of determining which features of a code are relevant for the intended purpose of the PRA.

The adequacy of a code should be determined based on the features necessary to achieve the intended purpose. Uses and appraisals of PRAs will require the NRC staff to know at least basic characteristics of these codes. These evaluations will not be simple; a complex code may have more detail than can be thoroughly supported by experiments; a simple code may gloss over important details that impact on regulatory decisions. Information for supporting such a determination regarding MELCOR (Ref. C.4.13) and MAAP can be found in Reference C.4.28. ${ }^{36}$

Integral severe accident codes are used to provide insights into the possible progressions of the accident. Results from these code calculations are used to estimate the timing of key events in the accident (e.g., the onset of core damage, the time at which the vessel fails, the time when the containment fails), the conditions in the containment as a function of time (e.g., temperature, pressure, composition of the atmosphere), and the release and transport of radioactive material in the containment. Since these codes include deterministic rather than stochastic models, they delineate a single accident progression based on a given set of inputs. Hence, the inputs to the deterministic codes are changed to simulate different accident scenarios. Separate effects codes are used to assess phenomena that are not included in integral severe accident codes or when a more detailed representation of certain phenomena is required. For example, many integral severe accident codes do not contain models that address the physics associated with hydrogen detonations, and therefore, these events are analyzed using separate effects codes. Similarly, separate effects codes are often used to assess the response of the containment to loads placed on it during the course of an accident.

The results from deterministic analyses are incorporated into the Level 2 analysis in the following manner:

- With a set of reasonable inputs, deterministic calculations show the progression of an accident. Calc dlations are performed for the important sequences that lead to core damage; sensitivity calculations are performed to investigate important facets of the accident.

- Following a general understanding of severe accident progressions from deterministic calculations and other sources of information, major events that can affect the progression of the accident can be identified. These events and their order form some of the top events of the APET.

- Calculations supplemented by other information serve as the basis for quantifying the PRA models. Expert judgment techniques are often used to translate results from deterministic analyses into a form suitable for probabilistic analysis. For example, a deterministic calculation may indicate that, based on the prescribed initial and boundary conditions, a combustible mixture of hydrogen will form in the containment and combustion of this mixture will result in a peak pressure $P_{\text {burn }}$. However, the initial and boundary conditions are uncertain and there are many uncertainties associated with phenomena

\footnotetext{
${ }^{36}$ Reference C.4.28 supports many of the Individual Plant Examination Program (IPE), under which many utilities are using the MAAP code.
} 
involved in this process, for example, the amount of hydrogen produced, the likelihood that the mixture will ignite, and once ignited, the rate of combustion. Thus, the results from the calculations are assessed in light of the uncertainties involved in the process to yield expressions for the likelihood that the burn occurs and the likelihood that various pressures are realized.

When used to support PRAs, the deterministic analyses should be structured to give realistic results. Bounding and sensitivity analy'ses can be useful when exploring the range of answers that are possible, however, the PRA should not be biased toward the bounds (i.e., based solely on conservative analysis).

While deterministic analyses are a necessary part of a Level 2 analysis, there are several factors that limit their use in PRAs:

- The performance of a deterministic analysis is resource-intensive. It can take a significant amount of time to develop a model of the plant, perform the calculations, and analyze the results.

- Because deterministic codes usually include a substantial amount of detail in the models, they require a significant amount of computer resources. A single simulation can take as much as 24 hours of cpu time on a VAX computer, which limits the number of scenarios that can be analyzed. Usually ten or so accident progressions are simulated with the code, having been selected to extend the calculations of important sequences coming from the Level 1 analysis. However, there is no definite number of calculations; the PRA practitioner performs enough calculations to support the effort within the bounds of available resources.

- A comprehensive assessment of the uncertainty associated with the accident progression is difficult to perform with deterministic codes because (1) the codes take a relatively long time to run, which limits the number of parameter variations that can be performed, and (2) deterministic codes account for only the phenomena they model. Other views of the accident progression requiring other models are also valid.

A substantial amount of skill and knowledge is required to use a deterministic code. For instance, the phenomena occurring during a severe accident must be clearly understood in order to select the appropriate code and to specify input variables. The uncertainty in these variables must also be assessed. Similarly, to construct an accurate plant model it is necessary to have a clear understanding of the configuration of the plant, its associated systems and hardware, and the procedures that are used at the plant. Finally, the code must be thoroughly understood, including the details for the models, the relationships among the models, and the limitations of the analysis. ${ }^{37}$

Guidance: Considerable skill and knowledge are needed to perform supporting deterministic accident progression calculations.

The selection of the code will depend on its use and the phenomena that are key to determining the accident progression of interest.

\footnotetext{
${ }^{37}$ The need to understand the calculations can at times be subtle. Weeks after a contractor performed a calculation with MELCOR (Ref. C.4.13), some of the output files were lost. The calculation was redone with the same input deck and the same version of the code. Even so, noticeable changes in some of the results were found. The contractor learned that the staff at the computer center had changed the operating system of the computer. Apparently, some of the results were affected by the rounding error caused by the way in which an operating system performed various mathematical operations. While at first this may be disturbing, this experience emphasizes the need to understand the calculations.
} 
C.4 Accident Progression and Risk Analyses

C.4.7 Codes

Because of differences in models, assumptions, initial conditions, and boundary conditions, the results from the codes will vary. The variations can lead to widely divergent views on the progression of severe accidents. For this reason, the results from a code must be interpreted in light of a detailed understanding of the code and how the calculations were set up. Any code and its constituent models will introduce artifacts; the extent to which the artifacts determine results needs to be understood. For example, the time step and the nodalization of the core will sometimes influence the results.

When codes and their manuals are used and compared, the versions of the codes must be known. Some codes, such as MELCOR and MAAP, are continually being modified.

Integral severe accident codes should not be used in place of probabilistic modeling. Rather, deterministic calculations are used to support the development and quantification of PRA models.

\section{C.4.7 Codes}

This section lists codes that are frenuently used to perform a Level 2 and 3 PRA. The codes have been divided into three groups: event tree codes, Jeterministic codes, and consequence analysis codes.

Many codes are available that allow event trees to be developed, displayed, and evaluated. Section C.3.5 (page C-63) lists many of these codes. Event tree codes listed in Section C.3.5 (page C-63) rely on graphical techniques to build trees. The code EVNTRE (Ref. C.4.25), listed in Table C.4.7, utilizes logical statements to represent the event tree structure; it is useful when large trees are being developed and graphical display is no long reasonable.

Major deterministic codes seen at the NRC are listed in Table C.4.8. For the sake of brevity, many deterministic codes are not mentioned here. A list of such codes frequently seen at the NRC is in Chapter 3 of Reference C.4.29. Among the larger codes more commonly seen at the NRC are the STCP (Refs. C.4.29 and C.4.30), MELCOR (Ref. C.4.13), and MAAP (see Table C.4.8, page C-122). The STCP is no longer being developed by the NRC, however, it is occasionally used by the industry and abroad. The current NRC code for integrated calculations is MELCOR. The industry frequently uses MAAP. In addition, there are many separate effects codes that model portions of a severe accident progression; many of these codes are incorporated, in full or in part, into the above integrated codes. Some of these separate effects codes are shown in Figure C.4.8.

Tables C.4.9 and C.4.10 lists consequence codes used in a PRA; Table C.4.9 shows a sample of domestic codes; Table C.4.10 shows a sample of codes used by the European community. The MACCS code is the NRC's PRA code for estimating offsite consequences associated with severe accidents. CRACIT was developed in the mid1970s following release of the Reactor Safety Study (Ref. C.4.3) to address most of the shortcomings identified by industry representatives in the CRAC model. The MACCS code also corrected many of the early criticisms, however, there remain some basic differences between CRACIT and MACCS as follows:

- CRACIT is able to treat changes in wind direction as well as difficult atmospheric dispersion effects (caused by land-water interfaces and complex terrain) using a variable trajectory plume model, while MACCS uses a straight-line model.

- $\quad$ CRACIT uses the health effects models from the Reactor Safety Study (Ref. C.4.3).

NUREG-1489 
Table C.4.7 Code used to process an event tree

\begin{tabular}{|l|l|}
\hline Program: & EVNTRE \\
Source: & Sandia National Laboratories \\
System: & $\begin{array}{l}\text { Developed on a VAX, but can be installed on a PC. } \\
\text { EVNTRE is used to build and process a large event tree. In processing, the branch } \\
\text { point probabilities and the results of simple deterministic functions are propagated } \\
\text { along the accident progressions. The code has the capability to process multiple sets of } \\
\text { inputs generated from Monte Carlo sampling (see Section C.6.3.1, page C-154). } \\
\text { C.4.25 }\end{array}$ \\
\hline
\end{tabular}

- CRACIT can utilize meteorological data from several locations to model more realistically long-range plume transport.

- CRACIT calculates doses to evacuees that can travel along more realistic exit routes (variable trajectory) in a time-dependent manner.

The appropriateness of the trajectory model will depend on the characteristics of the subject site, the problem (integral, point effects), and the availability of data. A paucity of data may limit the benefits. With the trajectory model, more calculations are needed to converge on the final results. The appropriateness of a particular code depends on the specific attributes of the subject.

The health effects models in CRACIT were chosen to provide a basis for comparing Level 3 results with the Reactor Safety Study (Ref. C.4.3) and with other Level 3 studies the code developer was performing in the late 1970 s and early 1980s. These were the only major Level 3 studies performed; they preceded the release of such health effects information as in References C.4.32 through C.4.35.

\section{C.4.8 Summary}

Three general approaches for translating core damage sequences into an expression for risk are presented: (1) using results from a surrogate PRA, (2) modifying models and data in a surrogate PRA, and (3) performing a plant-specific PRA. The strengths and weaknesses of each method define the types of issues that each method is best suited to address. The first two approaches rely on information from surrogate PRAs, and as such, any risk estimates obtained from these approaches are based on the surrogate plant features, the population distributions surrounding the plant, and the artifacts of the PRA models. Before information from a surrogate PRA is used, the relevance of these factors on the subject matter must be determined. Surrogate risk estimates should be used only after their applicability has been established. 


\section{C.4 Accident Progression and Risk Analyses \\ C.4.8 Summary}

Table C.4.8 Major deterministic codes used at the NRC in support of an accident progression analysis

\begin{tabular}{|c|c|}
\hline Program: & Source Term Code Package (STCP) \\
\hline Source: & Battelle Columbus Division \\
\hline System: & Mainframe, PC \\
\hline Description: & $\begin{array}{l}\text { The STCP began as a collection of separately developed codes modeling major aspects } \\
\text { of severe accident progressions. As the need became apparent, the codes were } \\
\text { combined. However, there was no overall architecture. Although the code has been } \\
\text { replaced by MELCOR, it is still commonly used. } \\
\text { C. } 4.29 \text { and C. } 4.30\end{array}$ \\
\hline Program: & MELCOR \\
\hline Source: & Sandia National Laboratories \\
\hline System: & VAX, PC \\
\hline Description: & $\begin{array}{l}\text { MELCOR is currently used by the NRC for deterministic modeling of severe accident } \\
\text { progressions. The code was designed with a definite architecture to perform } \\
\text { calculations in a consistent and integrated manner. It is still under development but is } \\
\text { distributed through a user's group. }\end{array}$ \\
\hline Reference: & C.4.13 \\
\hline Program: & MAAP \\
\hline Source: & Fauske and Associates \\
\hline System: & $\begin{array}{l}\text { Written in standard Fortran } 77 \text {, MAAP will run on almost any mainframe. PC } \\
\text { Version: } 386 \text { machine or faster having a DOS extender, math co-processor, 15M bytes. } \\
\text { Four M bytes are needed to run, six M bytes are needed to compile. Three M bytes } \\
\text { are needed for each run. The code is distributed as a source listing and in an } \\
\text { executable form. }\end{array}$ \\
\hline Description: & $\begin{array}{l}\text { MAAP is an industry-sponsored code, developed as an alternative to the STCP and } \\
\text { MELCOR. Like MELCOR, it has a definite architecture to perform calculations in an } \\
\text { integrated and consistent manner. The code is much smaller than MELCOR (Ref. } \\
\text { C.4.13). }\end{array}$ \\
\hline Ref'erence: & $\begin{array}{l}\text { MAAP User's Manual, Fauske and Associates, Burr Ridge, Ill, March 1990. Tel. (708) } \\
\text { 323-8750. Proprietary. Not publicly available. }\end{array}$ \\
\hline
\end{tabular}

While results from surrogate studies can be useful or screening purposes, experience from past PRAs suggests that there are many plant-specific features that can have a strong impact on risk. Therefore, surrogate studies should not be used as a replacement for plant-specific studies. Instead, a plant-specific PRA that accounts for the unique features of a plant should be developed to address plant-specific issues. Existing models can be used to guide the development of new models; however, the new models must reflect the design and operation of the plant being studied. 
Table C.4.9 Domestic codes used in consequence assessments

\begin{tabular}{|c|c|}
\hline Program: & CRAC2 \\
\hline Source: & Sandia National Laboratories \\
\hline System: & PC, mainframe \\
\hline References: & $\begin{array}{l}\text { CRAC2 was developed to estimate the offsite consequences of potential severe accidents at nuclear } \\
\text { power plants. CRAC2 utilizes an improved meteorological sampling scheme over CRAC1-the } \\
\text { consequence code used in the reactor safety study. CRAC2, which is the predecessor to MACCS, } \\
\text { can be used to estimate both early and latent health effects and economic costs. } \\
\text { C. } 4.18, \text { C. } 4.19\end{array}$ \\
\hline Program: & CRACIT \\
\hline Source: & Pickard, Lowe, and Garrick (PLG) \\
\hline System: & $\mathrm{PC}$, mainframe \\
\hline Description: & $\begin{array}{l}\text { Calculation of Reactor Accident Consequences. CRACIT was developed to model changes in wind } \\
\text { direction, complex atmospheric dispersion effects, and doses to evacuees who travel along variable } \\
\text { trajectory exit routes. }\end{array}$ \\
\hline References: & C.4.31 \\
\hline Program: & MACCS 1.5.11.1, \\
\hline Source: & Sandia National Laboratories \\
\hline System: & IBM 486PC, VAX \\
\hline Description: & $\begin{array}{l}\text { The MACCS code was developed to estimate the offsite consequences of potential severe accidents } \\
\text { at nuclear power plants. The principal phenomena considered in MACCS are atmospheric } \\
\text { transport, mitigative actions based on dose projection, dose accumulation by a number of pathways } \\
\text { including food and water ingestion, early and latent health effects, and economic costs. The } \\
\text { MACCS code can be used for a variety of applications, including PRAs of nuclear power plants } \\
\text { and other nuclear facilities, sensitivity studies to gain better understanding of the parameters } \\
\text { important to PRA, and cost-benefit analyses. }\end{array}$ \\
\hline References: & C. 4.10, C.4.11, C. 4.12 \\
\hline
\end{tabular}

Regardless of the method that is chosen to translate core damage sequences into an expression of risk, the NRC staff must be fully aware of the scope, models, and assumptions used in the PRA. The Level 2 and 3 analyses consist of four constituent analyses: the accident progression, the source term, the consequence, and the risk integration analyses. An assessment of the uncertainty in the products from each of these analysis is often included in the PRA. 
Table C.4.10 Consequence codes used by the European Community

\begin{tabular}{||l|l||}
\hline $\begin{array}{l}\text { Program: } \\
\text { Source: }\end{array}$ & $\begin{array}{l}\text { COSYMA } \\
\text { Commission of the European Communities } \\
\text { IBM-3090, Programs written in FORTRAN-77 } \\
\text { COSYMA was developed for assessing the off-site consequences of accidental releases of } \\
\text { radioactive material to the atmosphere and is designed for use in probabilistic risk assessments. It } \\
\text { estimates both "early" and "late" health effects as well as economic cost associated with an } \\
\text { accident. } \\
\text { C.4.36 }\end{array}$ \\
References: & $\begin{array}{l}\text { UFOMOD } \\
\text { Kernforschungszentrum Karlsruhe } \\
\text { PC } \\
\text { Source: } \\
\text { System } \\
\text { Description: }\end{array}$ \\
$\begin{array}{l}\text { The program system UFOMOD is an advanced probabilistic accident consequence assessment } \\
\text { code. An early version of UFOMOD was used in the German Risk Study. More recently it has } \\
\text { been completely restructured and revised in all models and data sets and it was released in 1988 as } \\
\text { the program system UFOMOD. } \\
\text { C.4.37 }\end{array}$ \\
\hline
\end{tabular}

The accident progression analysis is the first part of the Level 2 analysis. The framework of this analysis is an event tree, which is called a CET or APET. Each path through the APET describes an accident progression beyond core damage. The effect of the APET is to partition the core damage frequency in each plant damage state among the possible accident progressions that can affect the transport and release of radioactive material. The APET includes events such as the recovery of core cooling, the amount of core damage, the occurrence of key phenomena, the structural response of the containment to loads placed on it during an accident, and the effect of plant features designed to mitigate an accident (e.g., containment sprays and igniters). The products of the accident progression analysis are the delineations of the possible accident progressions and the frequencies of these progressions.

The release of radioactive material from the fuel and core debris and the transport of this material through the primary system and containment to the environment is analyzed in the source term analysis. The source term analysis is the second part of the Level 2 analysis and is performed whenever the radiological severity of an accident is being assessed. The product of this analysis is the source term, which is a collection of parameters: that characterize the type and the amount of radioactive material released from the containment, the start and duration of the release, and the location of the release. Both parametric and deterministic codes have been used to perform a source term analysis. Each method has its strengths and weaknesses. The appropriate method will depend on the objective and scope of the analysis and on the resources that are available.

The Level 3 analysis consists of the consequence analysis, in which the transport of radioactive material in the environment and the resulting health effects and economic costs are determined. Consequences can be estimated for the offsite population as well as for the population at the site. Because the mission of the NRC is to protect public health and safety, most PRAs have focused on offsite consequences. State-of-the-art codes, such as the MACCS code, are used for estimating offsite consequence in PRA applications. Results from consequence codes 
can be expressed in many ways and displayed in a variety of forms; the appropriate measure and display format will depend on the application and on the intended audience.

Risk integration brings together the products of the Level 1, the Level 2, and the Level 3 analyses. Two definitions of risk are commonly seen by the NRC staff: the risk triplet and iggregate risk. $A$ risk triplet is defined as $\left\langle s_{i}, f_{i}, x_{i}\right\rangle$, where $s$ represents a scenario, $f$ is the frequency of occurrence of scenario $s$, and $x$ is the consequence associated with scenario $s$. Aggregate risk is the summation over all accidents of the product $f_{i}, x_{i}$. Unfortunately, the term risk is often used to describe many different products of the PRA (i.e., it has been used to describe the core damage frequency or other quantities such as containment failure frequency). At the NRC, the term should be restricted to the aggregate risk definition and the risk triplet definition. To avoid confusion, the term risk should be defined if it is used in another way.

Deterministic analyses are important tools used to support Level 2 and 3 analyses. Two general types of deterministic codes are used to support the development and quantification of accident progression and source term models: separate effects codes (also called mechanistic codes) and integral severe accident codes. Separate effects codes usually address specific phenomena and incorporate state-of-the-art mechanistic models. Integral severe accident codes simulate specific accident scenarios from the start of the accident to the end of the radioactive release from the containment and as such "integrate" models of many different phenomena. The code to use will depend on the use and on the phenomena that are key to determining the progression of the accident. Because of differences in models, assumptions, initial conditions, and boundary conditions, the results from different codes will vary. The variations can lead to widely divergent views of the progressions of severe accidents. For this reason, the results from a code must be interpreted in light of a detailed understanding of the code and how the calculations were performed. When used to support PRAs, the deterministic analysis should be structured to give realistic results. Bounding and sensitivity analyses can be useful when exploring the range of possible answers; however, the PRA should not be biased toward the bounds (i.e., based solely on conservative analyses). Deterministic codes should not be used in place of Level 2 and 3 analyses. 


\section{REFERENCES FOR CHAPTER C.4}

C.4.1 F. T. Harper, "Current Status, Uses, and Limitations of Probabilistic Accident Progression Analyses and Source Term Analyses," Proceedings of the CSNI Workshop on PSA Applications and Limitations, NUREG/CP-0115 (Sandia National Laboratories, SAND90-2797), NRC, February 1991.

C.4.2 R. Emrit et al., "A Prioritization of Generic Safety Issues," NUREG-0933, Main Report and Supplements 1 - 12, NRC, July 1991.

C.4.3 NRC, "Reactor Safety Study - An Assessment of Accident Risks in U.S. Commercial Nuclear Power Plants," WASH-1400 (NUREG-75/014), October 1975.

C.4.4 NRC, "Severe Accident Risks: An Assessment for Five U.S. Nuclear Power Plants," NUREG-1150, December 1990.

C.4.5 T.D. Brown et al., "Integrated Risk Assessment for the LaSalle Unit 2 Nuclear Power Plant," NUREG/CR-5305 (Sandia National Laboratories, SAND90-2765), Volume 1, Main Report, August 1992; Volume 2, Appendices, May 1993; Volume 3, "MELCOR Code Calculations," NRC, October 1992.

C.4.6 T. D. Brown, Sandia National Laboratories, to C. P. Ryder, NRC, Letter Report, Subject: "Summary of an Abridged Assessment of Shutdown Risk of a Mark III Boiling Water Reactor: POS 6: Early Refueling," October 27, 1993."

C.4.7 V. Mubayi, Brookhaven National Laboratory, to C. P. Ryder, NRC, Letter Report, Subject: "Abridged Risk Study During Low Power/Shutdown Operation at Surry," August 10, 1993."

C.4.8 Policy Issue, from James M. Taylor, Executive Director for Operations, to The Commissioners, "Draft Safety Evaluation Report on the General Electric Boiling Water Reactor Design Covering Chapter 19 of the Standard Review Plan, 'Response to Severc Accident Policy Statement," SECY-91-309,' NRC, September 1, 1991.*

C.4.9 J.W. Hickman, "PRA Procedures Guide," NUREG/CR-2300, Volumes 1 and 2, NRC, January 1983.

C.4.10 J.A. Rollstin, D.I. Chanin, and H-N. Jow, "MELCOR Accident Consequence Code System (MACCS): Programmer's Reference Manual," NUREG/CR-4691, Volume 3 (Sandia National Laboratories, SAND86-1562), NRC, February 1990.

C.4.11 D.I. Chanin et al., "MELCOR Accident Consequence Code System (MACCS) User's Guide," NUREG/CR-4691, Volume 1 (Sandia National Laboratories, SAND86-1562), NRC, February 1990.

- Copies are available for inspection or copying for a fee in the NRC Public Document room. 
C.4.12 H-N. Jow et al., "MELCOR Accident Consequence Code System (MACCS) - Model Description," NUREG/CR-4691, Volume 2 (Sandia National Laboratories, SAND86-1562), NRC, February 1990.

C.4.13 R.M. Summers, "MELCOR 1.8.0: A Computer Code for Nuclear Reactor Severe Accident Source Term and Risk Assessment Analyses," NUREG/CR-5531 (Sandia National Laboratories, SAND900364), NRC, January 1991.

C.4.14 R.L. Iman et al., "PARTITION: A Program for Defining the Source Term/Consequence Analysis Interface in the NUREG-1150 Probabilistic Risk Assessments," NUREG/CR-5253 (Sandia National Laboratories, SAND90-0364), NRC, May 1990.

C.4.15 P. Cybulskis, "Assessment of the XSOR Codes," NUREG/CR-5346 (Battelle Columbus Division, BMI-2171), NRC, November 1989.

C.4.16 F.T. Harper et al., "Evaluation of Severe Accident Risks: Quantification of Major Input Parameters. Experts' Determination of Source Term Issues," NUREG/CR-4551, Volume 2, Rev. 1, Part 4 (Sandia National Laboratories, SAND86-1309), NRC, June 1992.

C.4.17 NRC, "Safety Goals for the Operation of Nuclear Power Plants" (Corrections and Republication of Policy Statement), Federal Register, Volume 51, No. 162, pp. 30028 - 30033, August 21, 1986.

C.4.18 L.T. Ritchie et al., "Calculations of Reactor Accident Consequences, Version 2, CRAC2: Computer Code User's Guide," NUREG/CR-2326 '(Sandia National Laboratories, SAND81-1994), NRC, April 1983.

C.4.19 L.T. Ritchie et al., "CRAC2 Model Description," NUREG/CR-2552 (Sandia National Laboratories, SAND82-0342.), NRC, April 1984.

C.4.20 J.V. Ramsdell, Jr., "Diffusion in Building Wakes for Ground-Level Releases," Atmospheric Environment, Volume 24B, No. 3, pp. 377-388, 1990.

C.4.21 D. Randerson, Ed., Atmospheric Science and Power Production, DOE/TIC-27601, United States Department of Energy, 1984.

C.4.22 NRC; "Almospheric Dispersion Models for Potential Accident Consequence Assessments at Nuclear Power Plants," Regulatory Guide 1.145, Revision 1.

C.4.23 S. Kaplan and B.J. Garrick, "On the Quantitative Definition of Risk," Risk Analysis, Volume 1, pp. $11-27,1981$.

C.4.24 R. de Neufville, Applied Systems Analysis: Engineering Planning and Technology Management, McGraw-Hill Publishing Company, 1990.

C.4.25 J.M. Griesmeyer and L.N. Smith, "A Reference Manual for the Event Progression Analysis Code (EVNTRE)," NUREG/CR-5174 (Sandia National Laboratories, SAND88-1607), NRC, September 1989. 


\section{C.4 Accident Progression and Risk Analyses}

C.4.26 R.L. Iman, J.D. Johnson, and J.C. Helton, "PRAMIS: Probability Risk Assessment Model Integration System," NUREG/CR-5262 (Sandia National Laboratories, SAND88-3093), May 1990.

C.4.27 Letter from David A. Ward, Chairman, ACRS, to Ivan Selin, Chairman, U. S. Nuclear Regulatory Commission, "Implementation of the Safety Goal Policy," June 12, 1992."

C.4.28 J. U. Valente and J. W. Yang, "MAAP 3.0B Code Evaluation," L-1499, Final Technical Report, Main Report, Appendices A - F, Brookhaven National Laboratory, October 1992."

C.4.29 M. Silberberg et al., "Reassessment of the Technical Bases for Estimating Source Terms," NUREG0956, NRC, July 1986.

C.4.30 J.A. Gieseke et al., "Source Term Code Package: A User's Guide (MOD 1)," NUREG/CR-4587 (Battelle Memorial Institute, BMI-2138), NRC, July 1986.

C.4.31 Consolidated Edison Company of New York, Inc., "Indian Point Probabilistic Safety Study," Section 6, "Site Consequence Analysis," Power Authority of the State of New York, 1982."

C.4.32 J.S. Evans et al., "Health Effects Model; for Nuclear Power Plant Accident Consequence Analysis, Part I: Introduction, Integration, and Summary, Part II: Scientific Basis for Health Effects Models," NUREG/CR-4214 (Harvard School of Public Health, SAND85-7185), NRC, August 1985.

C.4.33 International Commission on Radiological Protection, "Recommendations of the International Commission on Radiological Protection," ICRP Publication 26, Pergamon Press, New York, January 1977.

C.4.34 National Academy of Sciences, Health Effects of Exposure to Low Levels of Ionizing Radiation, BEIR V, National Academy Press, Washington, DC, 1990.

C.4.35 International Commission on Radiological Protection, Ann. ICRP, 1990, Recommendation of the Intemational Commission on Radiological Protection, Publication 60, 21:1-201, 1991.

C.4.36 Kernforschungszentrum Karlsruhe (KfK), Federal Republic of Germany, and National Radiological Protection Board (NRPB), United Kingdom, "COSYMA A New Programme Package for Accident Consequence Assessment," Commission of the European Communities, Report EUR 13028, September 1990."

C.4.37 J. Ehrhardt et al., "The Program System UFOMOD for Assessing the Consequences of Nuclear Accidents," Kernforschungszentrum Karlsruhe, Institut für Neutronenphysik und Reaktortechnik, Report KfK 4330, October 1988."

- Copies are available for inspection or copying for a fee in the NRC Public Document room. 


\section{C.5 EXPERT JUDGMENT}

\section{C.5.1 Learning Objectives}

Expert judgment provides an essential part of the information used in probabilistic risk assessments and performance assessments. Although such judgment has always been used in safety work (usually under the name of engineering judgment), a need to trace and defend the information has led to the development of formal methods. This section provides background information on formal techniques for obtaining, evaluating, and processing expert judgment. The reader should gain an understanding of the following:

- Circumstances requiring the use of formal expert judgment

- Formal probability elicitation processes

- Alternative approaches to organizing experts

- Psychological biases affecting expert judgment

- Criteria for evaluating assessed probabilities

- Methods for combining judgments

\section{C.5.2 Concepts}

Expert judgment is an essential element in conducting a PRA. It pervades the choice of models, data sets, and parameter values. The question is not whether expert judgment should be used, but instead, how it is to be used. Important sources of information for probability risk analyses include the results of experiments and observation, mathematical and computer models of the physical and chemical processes, and expert judgments. Expert judgments may take many forms, such as recommendations, criticisms, scenarios, value judgments, and various estimates; judgments given as probabilities are often called degrees of belief to distinguish them from relative frequencies (see Section C.2.2.1.1, page C-18).

This section focuses on methods to formally obtain and process expert judgment. There are various ways to organize the assessments to gain as much information as possible from a group of experts. When planning a PRA, it is appropriate to consider a number of expert judgment techniques, ranging from an informal process to the full formal process.

Guidance: Although the full extent of the methodology is appropriate only under special circumstances, the NRC staff should adapt portions of the methodology as needed.

Situations in which expert judgment is necessary include the following:

- Experts can provide the mechanism to integrate knowledge from multiple sources. There are multiple, perhaps conflicting, sources of information.

- Information exists that is relevant but not directly applicable to the PRA. For example, failure rates estimated from data on nuclear submarine components may not be directly applicable to nuclear power generation. Experts may provide a calibrating mechanism and account for the additional uncertainty in using such information. 
- Experimental data require interpretation. Scaling up from a model containment test or extrapolating the results of a geochemistry experiment to the more complex real environment of a nuclear waste repository requires interpretation. Experts may provide this function.

- Experimental or observational data cannot be obtained because of temporal or economic considerations. Experts may provide this by using analogy, physical principles, and qualitative basis in the absence of hard data. However, there should be a sound basis for the judgments.

Although expert judgment is useful in the above situations, it is not always necessary to employ a formal process. A formal process, which often requires the use of experts beyond the immediate staffing of a project, should be considered when the questions being addressed are important for one or both of the following reasons:

- The inputs to a PRA will have a large impact on the results of the PRA and subsequent regulatory decisions.

- Issues in a PRA require an interdisciplinary approach to be resolved.

Expert judgment identifies what is known and unknown by describing a quantıty or event through a probability distribution.

Encoding beliefs as probabilities does not necessarily make these judgments more valid or accurate than they are. It allows judgments to be explicitly manipulated in a mathematical way so they can be combined and appraised with other sources of information.

Some people object to the formal elicitation and encoding of judgments into probability distributions because they believe opinion is being substituted for objective scientific research. However, an expert's role is not creating knowlcdge, but providing a picture of the current state of knowledge. The primary advantages of using formal methods are that the process of risk quantification can be better accounted and defended and that incomplete and conflicting information can be addressed. While a disadvantage may be that the process is costly, the lack of a traceable and defendable study can be costly too when additional analyses and debates result.

\section{C.5.3 Formal Use of Expert Judgment}

The evaluation of risks for the purpose of policy and decisionmaking has led to the development of formal methods for the collection of expert judgment through the elicitation of probabilities (Refs. C.5.1 - C.5.6). The steps in a formal process include the selection and definition of issues, the selection of experts, the organization of multiple experts, preparation of elicitation, elicitation procedures, the processing of judgments, and the documentation of procedures, findings, and rationales.

\section{C.5.3.1 Selecting and Defining Technical Issues}

Important issues are identified by the current state of knowledge and requirements of a risk assessment. Sensitivity and uncertainty analyses (Chapter C.6, page C-149) lend additional support to this effort. The cost effectiveness of gathering information from alternative sources is also a consideration in selecting issues for expert judgment. In some instances, alternative sources of information may be available but only at great cost or time. The alternative sources of information also may be unreliable, as when data or models from studies made under circumstances different from those under investigation, or when the behavior of a system, measured in a specific environment, is extrapolated to a different environment. 
Achieving an accurate, logically complete, and understandable description of an issue to be addressed by experts is critically important. The description of the issue under assessment must be complete and without unstated assumptions; everything must be made explicit to avoid any disagreement. Reference C.5.7 suggests the clairvoyance test. If, after reading the description of the issue, a clairvoyant would be able to answer the question without asking for any additional information, the issue description is complete. Often, those preparing the description of the issue will make contextual assumptions that are not obvious. Conversely, experts often make assumptions that were not intended by the person preparing the description of the issue.

Guidance: Complex problems may be decomposed into a number of smaller issues. The principle behind decomposition is that better quality probability distributions can be obtained when the assessment tasks are easier. This happens when the decomposition is scientifically sound. A disadvantage of decomposition is that reconstructing the original problem may not be straightforward. Empirical evidence shows that this principle holds (Refs. C.5.8 and C.5.9).

Decomposition can be done by the experts or by an external analyst. Moreover, when multiple experts are used, each expert can use a distinct decomposition, or a consensus decomposition may be reached. Using a single decomposition has several advantages. First, the costs of processing the judgments are reduced because only one model or decomposition, usually implemented as a computer model, is needed. Second, comparisons among the assessments for components of the decomposed problem are facilitated when all experts use the same decomposition.

A drawback of using a single decomposition is that all experts may be forced to take a single view of the issuc; diversity of opinions is subjugated. Experience has shown (Refs. C.5.9 and C.5.10) that the decomposition is an important determinant of judgments. The unfortunate consequence of enforcing a single decomposition for all experts is that it creates the appearance of homogeneity of opinions; it can lead to the understatement of uncertainty and greater confidence than warranted.

Experts should be asked to respond to questions only about quantities that are meaningful to them. This means that these questions should involve either (theoretically) observable quantities or calculated quantities that are familiar to the experts. A theoretically observable quantity is one that could be measured, if sufficient time and resources were made available to do so. An example of a familiar calculated quantity is the standard deviation of the peak ground acceleration at a given site as a function of the distance from the earthquake's epicenter and magnitude. Experts in ground motion are familiar with this quantity.

Explaining (o experts the nature of the uncertainties that they are to address is important. This is best explained with an example. In the NUREG-1150 study (Ref. C.5.1), containment failure pressure is one of the issues of concern. Figure C.5.1 shows the expert-supplied ranges of the probabilities of the containment failure pressure (given certain conditions). The $X s$ in this figure are the point values that were used in the study. This formulation is based on the assumption that one and only one of these five possible values of the pressure will be realized. In the terminology of Reference C.5.11, the model of the world (the failure pressure) is deterministic and the uncertainties are expressed by probabilities over the possible values of the pressure. This is similar to the branches in a Level 2 event tree (see Section C.4.4.1, page C-84).

Another formulation of the problem is to postulate that all five values of the pressure can be realized, each with its uwn frequency. Then the uncertainties in these frequencies would have to be quantified using subjective probabilitics. In the terminology of Reference C.5.11, the model of the world contains uncertainties in this case (the frequencies of the five possible values of the failure pressure). This is similar to the handling of system 


\section{C.5 Expert Judgment}

\section{C.5.3 Formal Use of Expert Judgment}

unavailabilities in a Level 1 event tree, where probability distributions are developed for each unavailability (see Section $(-3.3 .4$, page $(-53)$.

This distinction was not part of the expert training sessions in the NUREG-1150 study (Ref. C.5.1), and it occasionally created confusion. For the failure pressure, it was stated that there may be randomness about each of these pressures and "there was a great deal of discussion concerning this issue due to the difficulties in defining the meaning of the failure pressure distributions derived for this issue. Each reviewer had a somewhat different interpretation of the input that was being required as well as of the use of the input in the LHS sensitivity analysis." It was finally decided that this stochastic variability was "generally small" and it was dropped from further analysis. This means that the first formulation given above (no uncertainties in the model of the world) was adopted.

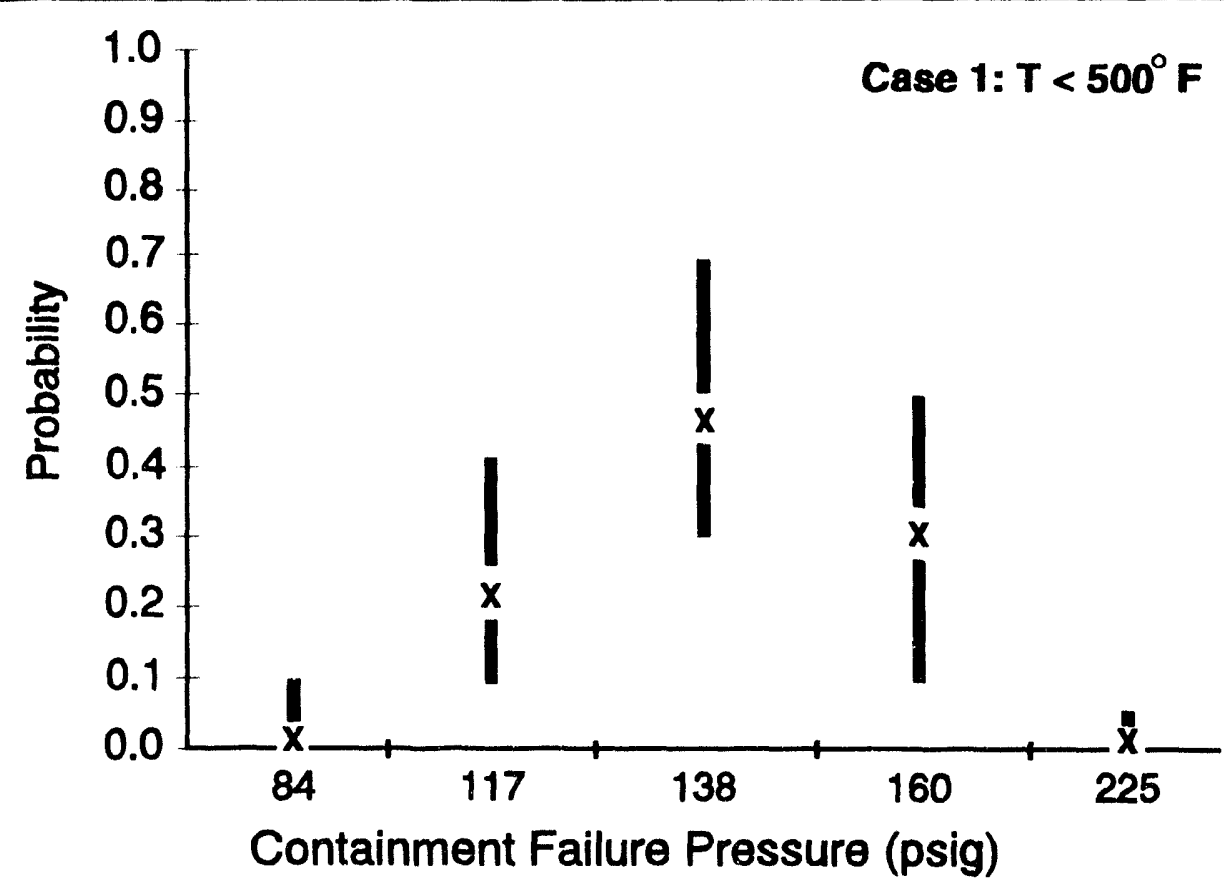

Figure C.5.1 Expert-supplied probabilities of containment failure pressure

\section{C.5.3.2 Selecting Experts}

An expert is someone who has special skills and training resulting in superior knowledge about a particular field and access to that knowledge (Ref. C.5.5). The identification of experts is an important stage in the process of acquiring expert judgments.

Experts can be identified through literature searches, registries of professional organizations, consulting firms, research laboratories, governmental agencies, and universities. A formal nomination process is sometimes used, particularly when controversy is possible. The criteria for selection should be specific and documented and should include the following: 
1. Evidence of expertise, such as publications, research findings, degrees and certificates, positions held,' awards, etc.

2. Reputation in the scientific community, including knowledge of the quality and importance of the nominee's work and the nominee's ability to provide the desired judgments.

3. Availability and willingness to participate.

4. Understanding of the general problem area.

5. Impartiality, including the lack of an economic or personal stake in the potential findings.

6. Inclusion of a multiplicity of viewpoints.

Motivational biases may affect an expert's judgment. Motivational biases arise from economic interests. political beliefs, or personal interest in future research efforts. However, excluding an expert because of potential bias may prevent relevant information from being discussed. A solution to this dilemma was used in the NUREG1150 study (Ref. C.5.1), in which potentially biased authorities were allowed and encouraged to submit their opinions.

The number of experts on a panel usually ranges from three to ten. There is little benefit to adding additional experts since they are very likely to be redundant. The circumstances that often control the number of experts on a panel include the availability of true experts, the resources available, and the diversity of approaches to the problem. Experience with the NUREG-1150 study shows that panels of four to eight experts work well. The larger the panel of experts, the more difficult the scheduling and logistics become.

A principal motivation for using multiple experts is to allow for a diversity of points of view. Selecting experts with a single viewpoint defeats the purpose of using multiple experts. Sometimes, it is known beforehand what viewpoints the experts are likely to express and what factors they will consider to be important in resolving issues. Experts can then be selected to reflect these alternative viewpoints. Another way to ensure diversity is to select experts from different organizations and experts with different backgrounds. Often these differences are correlated with technical differences. Expertise, however, is paramount and should not be sacrificed simply to ensure diversity.

\section{C.5.3.3 Organizing Assessments}

There are several approaches to organizing a group of experts. The desired approach will depend on the scope of the issues being addressed, the amount and type of interaction among the experts, the amount of redundancy, and the role of the experts in defining objectives.

Guidance: The simplest organization is either one expert or several experts working in isolation (i.e., not sharing information) from each other. When there are several experts addressing the same issues, there is some useful redundancy because multiple experts provide alternative viewpoints, thus increasing the potential for describing uncertainty. $A$ benefit of isolating experts is that strong personalities cannot dominate the group. The difficulty with isolated experts is that information is not shared, thus reducing the individual expert's knowledge. 
Multiple experts can be organized into a panel or teams. A panel of experts is made up of experts with similar disciplines exchanging information and responding independently. In contrast, a team of experts is made up of experts having dissimilar disciplines who work on separate parts of a larger problem. The division of labor among the experts on a team may be imposed by the staff organizing a study or the experts may be allowed to sort out their responsibilities. The team format is advantageous when the subject matter transcends several disciplines. The communication among experts is enhanced in the team format when compared to isolated experts working on distinct parts of the problem.

\section{C.5.3.4 Preparing for Elicitation}

The elicitation process is more than just the application of probability assessment tools to the judgment of experts. The experts must prepare and be prepared for the experience. Often, experts in a substantive field such as enginecring or health may not be effective in expressing their knowledge in the form of probability distributions (Refs. C.5.12 and C.5.13). Training the experts in forming probability distributions is an essential step in elicitation.

Guidance: The fundamental objectives of elicitation training are as follows:

- To help the experts express their beliefs as probability disiributions,

- To provide an overview of the project and how the expert's knowledge will be used,

- To introduce the experts to the tasks they must perform,

Training familiarizes experts with the tasks they must perform. Although practice may not lead to perfect elicitations, evidence shows that practice improves elicitations (Refs. C.5.14 and C.5.15).

\section{C.5.3.5 Elicitation of Probability Distributions}

The elicitation sessions should be held immediately following the discussion of the issue analyses. An elicitation team should meet separately with each expert. This avoids group dynamics that may suppress information if the expert judgments were obtained in a group setting. The elicitation team should consist of a substantive expert, a normative expert, and a recorder. It is also useful to add as a fourth member the person who will prepare the final documentation.

The elicitation sessions serve two purposes. The first purpose is to obtain the decompositions and quantitative assessments for each issue from each of the experts. Irisofar as possible, the uncertainty of each quantitative assessment should also be elicited. The second purpose is to obtain the rationales for the decompositions and assessments. The experts should be questioned about their stated beliefs and asked to reflect on and explain the reasoning behind the decompositions and quantitative assessments they have provided.

Much of the documentation of the experts' assumptions and reasoning can be completed during the elicitations. However, some follow-up work is usually necessary to fill in voids in the logic provided by the experts or obtain missing assessments.

The procedures for the elicitation of probability distributions are well established and can be found in decision analysis and psychology (Refs. C.5.10, C.5.12, C.5.16, and C.5.17). Successful elicitation is usually accomplished through the use of specialists, sometimes termed normative experts (Ref. C.5.10).

NUREG-1489 
Many elicitation techniques have been proposed and evaluated in experiments (Refs. C.5.10 and C.5.18). The proposed techniques range from simply asking for the probability of an event or an interval of values (direct assessment) to ranking of outcomes or hypothetical sample results from which probabilities are later derived using some type of algorithm. These latter techniques are known as indirect assessment methods, although this term is not uniformly applied. Reference C.5.12 states that there is little support in the literature for concluding that indirect methods are preferable. Moreover, such methods are not transparent and the expert may have difficulty in understanding the purpose of the questions being asked.

Common practice is to use several elicitation techniques in a single assessment session to facilitate cross and consistency checks (Ref. C.5.5). When assessing continuous distributions, for example, direct elicitation of interval probabilities and interval bisection, the process of dividing successive intervals into subintervals of equal probability can be used together (Ref. C.5.18). The specialist guiding the elicitation will ask questions that permit comparisons of probabilities. When inconsistencies are found, the specialist should inform the expert about the incompatibility of the probabilities and assist in modifying the assessments and reconciling the differences.

Other methods of expert judgment elicitation include category rating, rank ordering, pair comparisons, and ratio scaling (Ref. C.5.19). The Success Likelihood Index Methodology (SLIM) has been used extensively in human reliability analysis (see Section C.3.3.5, page (-60).

Near the end of the elicitation session, if possible, the expert should be presented with a summary of the findings. This might entail some curve fitting and rough recomposition of a decomposed problem to obtain an overall assessment. Offering immediate feedback allows modification of the assessments to be made while the assessment team is still assembled. Sometimes a review of the preliminary results will alert an expert to an important omission or misinterpretation by either the expert or the probability specialist.

\section{C.5.3.6 Processing Expert Judgments}

The goal of processing judgments is two-fold: to produce a usable product for the ensuing analysis and to preserve intact the experts' judgments. Judgments usually require some processing to put them in a usable form by the policy-maker. Assessments obtained using indirect methods, for example, must be translated into probabilities or densities. Distributions for continuous quantities are most often assessed by obtaining several points on the distribution function and then fitting or interpolating to obtain the remainder of the distribution.

\section{C.5.3.7 Documentation}

Regardless of how well an expert judgment elicitation process is designed and implemented, adequate documentation is required. The entire expert elicitation process should include documentation of the procedures and criteria for selecting experts and issues, copies of the elicitation issues and supporting materials, and the results of the clicitation sessions. Most importantly, the detailed rationale of the assessments, the methods, and results of any post-elicitation processing of the judgments should be provided. Moreover, as new evidence becomes available, understanding the rationale for probability distributions will allow the judgments to be reinterpreted instead of being discarded. For example, the updating of some distributions obtained in the NUREG-1150 study (Ref. C.5.1) was undertaken by Sandia National Laboratories (Ref. C.5.20). Without explicit rationales, updating these distributions would be difficult. 


\section{C.5 Expert Judgment}

C.5.5 Evaluating the Quality of Judgments

\section{C.5.4 Biases in Probability Elicitation}

Numerous types of biases in probability formation have been identified (Ref. C.5.21). Perhaps the most notorious is overconfidence, the tendency to give probability distributions that are narrower than they should be.

Work with experts in technological risk assessment has shown another bias to be prevalent among engineers and scientists: judgments based on the results of a single computer model or experiment. Other information is ignored and the model or experiment is treated as infallible. This bias is related to the anchoring bias (failure to adequately adjust an initial estimate) and the availability bias (giving too much weight to readily available information) (Ref. C.5.15).

Experts may provide assessments that are biased toward a favorable outcome. This is the optimism bias. For example, engineers underestimated by one-half the time required to repair electric generators (Ref. C.5.22). Similarly, if a researcher develops a theory or mechanism that predicts a particular type of failure, the researcher may give too much weight to the theory or mechanism. Anchoring, availability, and optimism biases may contribute to location bias; controlled experiments have shown that these biases tend to shift a distribution away from the true value. Stimulus spacing bias reflects a tendency of experts to have similar rating distances between all events or objects judged (Ref. C.5.19). Thus, skewed distributions tend to be flattened out.

\section{C.5.5 Evaluating the Quality of Judgments}

It is common practice to judge the quality of a single forecast retrospectively by comparing that forecast to a realization. For example, if the forecast is that an event will occur, then the forecast is validated by the occurrence of that event. Likewise, when the forecast is about a value, say next year's growth in GNP, the goodness of the forecast is judged retrospectively by the closeness of the forecast to the true value. A measure of the deviation of the forecast value from the true value serves to evaluate this closeness.

The goodness or quality of probabilities is more difficult to judge. If a probability of 0.7 is assigned to the occurrence of an event, both the occurrence and nonoccurrence of the event are consistent with this assignment. Based on a single realization, it is impossible to judge the goodness of an isolated probability or probability distribution, unless a probability of near zero or near one is assigned to an event. However, it is possible to judge the goodness of a set of probabilities or a set of probability distributions when the outcomes are known.

\section{C.5.5.1 Calibration}

Probabilities may be said to be good in the sense that they correctly reflect uncertainty. Much work has been accomplished on the quality of probabilities obtained from weather forecasters. One of the activities of a weather forecaster is to provide predictions of precipitation. Since 1965, U.S. Weather Service forecasters have been required to provide these forecasts in the form of probabilities. Calibration is the extent to which probabilities for events conform with the frequencies with which these events occur. Thus, the stated probabilities of precipitation should correctly reflect the frequencies with which rain occurs. On those days that the weather forecaster announces a $60 \%$ chance of rain, for example, it should rain $60 \%$ of the time. If for every forecast value ( $10 \%$ chance of rain, $20 \%$ chance of rain, etc.) the observed frequency of rain corresponds to the forecast, then the forecast is well calibrated.

One property of a set of well calibrated probabilities is that a plot of the probabilities against the observed frequencies will depict a 45 degree line (assuming that the scales of the two axes are the same). Figure C.5.2 is such a plot for weather forecasters (Ref. C.5.17) and displays a remarkable degree of calibration. The numbers in brackets indicate the number of forecasts in which the corresponding abscissa was given. The 


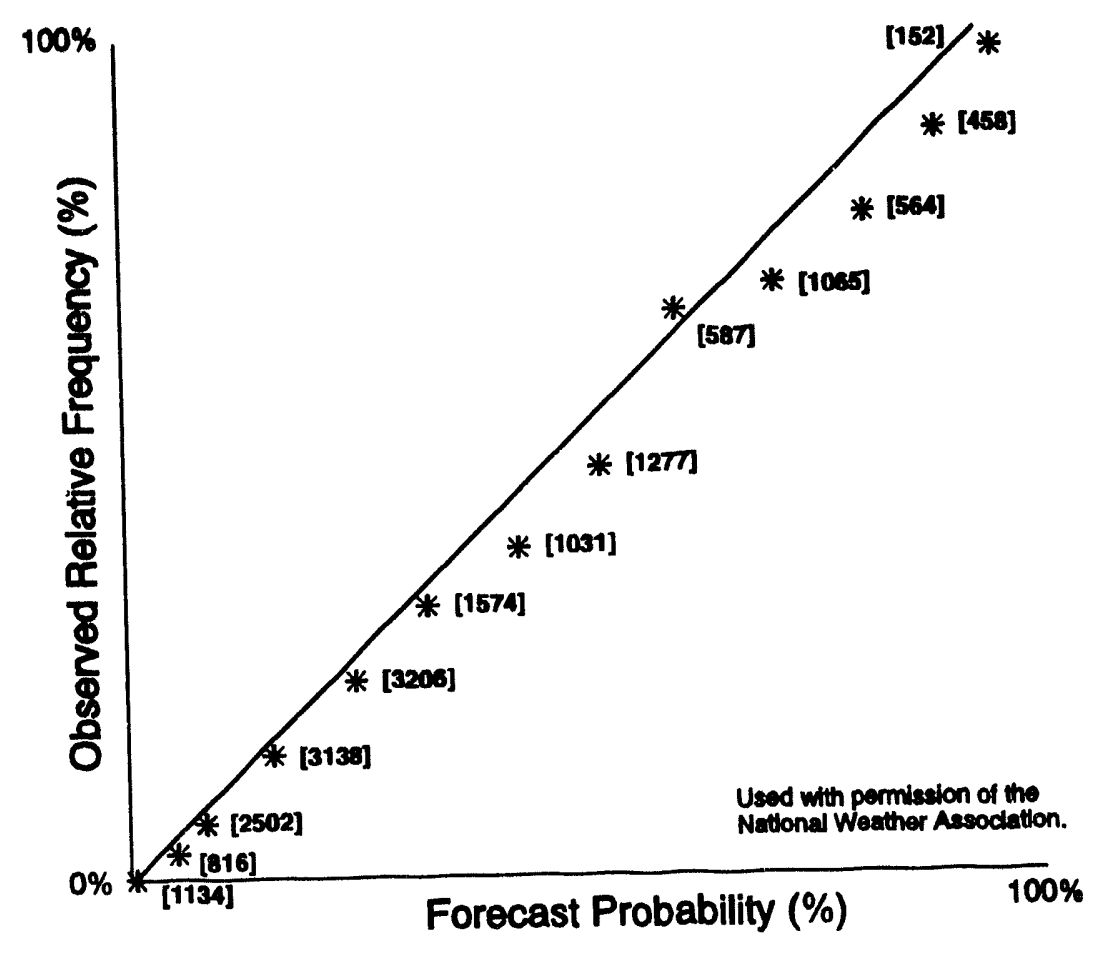

[ ] = number of forecasts

Figure C.5.2 Probability of precipitation forecasts versus observed relative frequency of precipitation (Ref. C.5.17)

ordinate shows the fraction of times that the forecast was correct. Weather forecasts tend to be well-calibrated because the weather forecasters practice at the task, receive continual feedback about their performance, and forecast for similar events; they are rewarded for doing well. Unfortunately, in PRA, the assessments made by experts are not of a repetitive nature and, because probabilities are often assigned to very rare events, the true values or probabilities do not become known.

The issue of calibration has been addressed in PRAs (Ref. C.5.23), but in the context of mean component maintenance duration. Table C.5.1 compares actual data and expert judgments. Listed in the table are the mean values and error factors (ratios of $95^{\mathrm{b}}$ percentiles to the medians) of actual data and the expert-estimated distributions that have been used in several PRAs. Here, the experts have been asked to provide assessments of a physically realizable distribution of maintenance durations. Also listed are the characteristics of distributions based on a detailed analysis of component histories at nine operating nuclear power plants. The ratio of the observed to the predicted mean and error factor for each category of components is also given in Table C.5.1. These results indicate the following:

- The expert-estimated error factors are generally two to four times smaller than the observed error factors. This is a clear case of overconfidence. 
Table C.5.1 Comparison of data and expert opinion on the distribution of component maintenance time (Ref. C.5.23)

\begin{tabular}{|c|c|c|c|c|c|c|c|}
\hline \multirow[b]{2}{*}{ Component Type } & \multirow{2}{*}{$\begin{array}{l}\text { Maximum } \\
\text { Allowable } \\
\text { Maintenance } \\
\text { Duration } \\
\text { (Hours) }\end{array}$} & \multicolumn{2}{|c|}{$\begin{array}{l}\text { Data Based } \\
\text { (Observed) }\end{array}$} & \multicolumn{2}{|c|}{$\begin{array}{l}\text { Expert-Estimated } \\
\text { (Predicted) }\end{array}$} & \multicolumn{2}{|c|}{$\begin{array}{l}\text { Ratio of Observed to } \\
\text { Predicted }\end{array}$} \\
\hline & & $\begin{array}{l}\text { Error } \\
\text { Factor }\end{array}$ & Mean & $\begin{array}{l}\text { Error } \\
\text { Factor }\end{array}$ & Mean & $\begin{array}{l}\text { Error } \\
\text { Factor }\end{array}$ & Mean \\
\hline Pumps & $\begin{array}{c}\text { None } \\
168 \\
72 \\
\leq 24\end{array}$ & $\begin{array}{c}22.1 \\
6.2 \\
5.9 \\
4.2\end{array}$ & $\begin{array}{r}265 \\
29 \\
11 \\
7\end{array}$ & $\begin{array}{l}6.2 \\
1.8 \\
1.5 \\
1.5\end{array}$ & \begin{tabular}{r|}
116.0 \\
40.4 \\
20.9 \\
10.8
\end{tabular} & $\begin{array}{l}3.56 \\
3.44 \\
3.93 \\
2.80\end{array}$ & $\begin{array}{l}2.28 \\
0.72 \\
0.53 \\
0.65\end{array}$ \\
\hline Valves & $\begin{array}{l}\text { None } \\
72 \text { or } 168 \\
\leq 24\end{array}$ & $\begin{array}{r}26.2 \\
5.2 \\
3.8\end{array}$ & $\begin{array}{c}135 \\
9 \\
4\end{array}$ & $\begin{array}{l}6.2 \\
1.8 \\
1.5\end{array}$ & $\begin{array}{r}116.0 \\
40.4 \\
20.9\end{array}$ & $\begin{array}{l}4.23 \\
2.89 \\
2.53\end{array}$ & $\begin{array}{l}1.16 \\
0.47 \\
0.19\end{array}$ \\
\hline Heat Exchanger & & 4.6 & 580 & 6.2 & 116.0 & 0.74 & 5.03 \\
\hline Other ${ }^{-}$ & $\begin{array}{l}\text { None } \\
>72 \\
48 \text { or } 72 \\
\leq 24\end{array}$ & $\begin{array}{c}11.0 \\
3.0 \\
7.3 \\
5.8\end{array}$ & $\begin{array}{c}39 \\
37 \\
14 \\
6\end{array}$ & $\begin{array}{l}6.2 \\
1.8 \\
1.5 \\
1.5\end{array}$ & \begin{tabular}{c|}
116.0 \\
40.4 \\
20.9 \\
10.8
\end{tabular} & $\begin{array}{l}1.77 \\
1.67 \\
4.87 \\
3.87\end{array}$ & $\begin{array}{l}0.34 \\
0.92 \\
0.67 \\
0.56\end{array}$ \\
\hline
\end{tabular}

* Based on plant technical specifications.

** Diesel generators, fans, electrical equipment, and heat exchanger having technical specifications.

From Reliability Engineering and Systems Safety, Volume 20, A. Mosleh et al., "A Critique of Current Practice for the Use of Expert Opinions in Probabilistic Risk Assessment," pages 63-85. Copyright 1988. Reprinted with kind permission from Elsevier Science Ltd, The Boulevard, Langford Lane, Kidlington 0X5 1GB, UK.

- In ten of the twelve cases listed, the magnitude of the error in estimating the mean value is within a factor of 3. Also, the expert estimates seem to be biased toward long durations since 75 percent of the estimates are above the observed values.

In Reference C.5.24, observed and predicted reliability parameters for some 130 diverse pieces of equipment and systems used in nuclear power plants are evaluated. The predicted values include both direct assessments by experts and the results of analysis. The objective is to examine correlations between the predicted and observed values. Based on the results of Reference C.5.24, 63 percent of all predicted values are found to lie within a factor of 2 from the observed values and 93 percent within a factor of 4 . Furthermore, there is no systematic bias in either direction. Finally, the ratio of observed to predicted values is found to be approximately lognormally distributed.

Reference C.5.25 provides contradictory evidence suggesting that there may, in fact, be a systematic bias. In particular, it finds that observed failure rates generally lie in the right-hand tails of the predicted distributions, which were based on IEEE-Standard 500 (Ref. C.5.26) and the Reactor Safety Study (Ref. C.5.27). Reference C.5.28 offers an explanation for this phenomenon, suggesting that the distributions may be overly narrow instead of indicating bias, a result of expert 'overconfidence.' Following these observations, Reference C.5.28 suggests that the distributions in the Reactor Safety Study should be broadened by taking the endpoints of the assessed ranges at the 20th and 80th percentiles of lognormal distributions instead of the $5^{\text {th }}$ and $95^{\text {th }}$, a recommendation that has been questioned (Refs. C.5.29 and C.5.30).

NUREG-1489 
The evidence is not conclusive about the reason for the data falling outside the range; e.g., a bias toward low values, overconfidence, or both. However, more recent studies, such as Reference C.5.31, that explicitly account for plant-to-plant variability, using actual operating experience, lypically find error factors roughly twice as large as those suggested by the Reactor Safety Study (Ref. C.5.27). Th is suggests that the distribution in the Reactor Safety Study may be overly narrow.

Another example of expert underestimation is found in Reference C.5.32. In this study, nuclear power plant operators are asked to estimate the median time taken by the control room crew to perform a specific task. It is found that these estimates are smaller (by about a factor of 3 ) than the value suggested by operating experience.

Assessment of probability distributions for continuous quantities is most often accomplished by assessing certain quantiles of the distributions such as the median, $0.25,0.75,0.05$, and 0.95 quantiles. The remainder of the cumulative distribution function (CDF) is inferred from these several points. For continuous quantities, the underlying probability function is a density and thus one cannot compute probabilities of individual values. Instead, probabilities for intervals of values can be computed.

An approach to measuring and displaying calibration (Refs. C.5.16 and C.5.18) is to use the cumulative probabilities of the observed values. For example, if the CDFs $F_{1}(x), F_{2}(x), \ldots$ are assessed and the resulting observed values are $x_{i}$, then the quantities $p_{i}=F_{i}\left(x_{i}\right)$ should be uniformly distributed between 0 and 1 . This is the same as saying that $5 \%$ of the quantities should appear in the lower $5 \%$ tails and $10 \%$ in the lower $10 \%$ tails.

In summary, calibration is associated with the accuracy of probabilities, i.e., how well they predict the relative frequencies of events.

\section{C.5.5.2 Refinement}

The amount of information in a probability or probability distribution is sometimes called its refinement. Other terms used are resolution, precision, or sharpness. These terms are not precisely defined in the literature. Generally, they are used to express something about the concentration of probabilities assigned to various outcomes.

In principle, expert judginents can be evaluated using the concepts of calibration and refinement, but in practice one rarely has the information needed to make a formal evaluation. Instead, one must examine the process used to coliect the judgments and the rationales supporting the judgments in drawing conclusions about the quality of the information.

\section{C.5.6 Combining Expert Judgments}

Many applications of formalized expert judgment in PRA utilize multiple experts to provide information. The reasons for this redundancy include:

- Allowing for multiple points of view,

- Obtaining a perspective on the inherent uncertainty, and

- Obtaining quality probability distributions.

It is reasonable to expect the combined results from multiple experts will provide both better point estimates and better calibrated probability distributions than those from individuals. 


\section{C.5 Expert Judgment \\ C.5.6 Combining Expert Judgments}

There are two basic approaches to combining probability distributions obtained from experts, behavioral and mathematical. In behavioral approaches, a single probability distribution from multiple experts is obtained by requiring the experts to develop a consensus distribution. There may be situations in which the experts are unable to develop a consensus distribution. Furthermore, uncontrolled interaction among the experts can lead to problems. Methods have been developed to deal with these problems. The Delphi method (Refs. C.5.33 and C.5.34), for example, limits expert interaction to the exchange of anonymous evaluations among the experts. The method was developed to reduce potential bias stemming from dominance by one expert by virtue of position or reputation. These problems can result from reluctance to give truthful answers before a superior who holds different views, or when judgments go against company policy, or may damage the organization.

A competing behavioral approach is the nominal group technique (Ref. C.5.35). In this approach, the experts meet face to face but provide initial judgments without discussion. After all judgments are given and, perhaps, summarized, there is discussion. The experts are then asked to reconsider their judgments, again individually. The final judgments are then aggregated mathematically.

Reference C.5.4 employed a combination of individual elicitation procedures and the Delphi technique. After independently collecting judgments as probability distributions from each expert, the resulting probability distributions and rationales were shared among the experts, who were allowed to revise their estimates.

Reference C.5.36 proposes an elicitation method in which the experts provide evidence to a moderator. The moderator forms the probability distribution using the information from the multiple experts and presents this distribution to the experts for their comment and approval. The goal in this method is not to satisfy each expert individually, but to obtain a distribution that the experts agree represents the range of opinion within the group.

While the approach in Reference C.5.36 has yet to be evaluated, studies have evaluated both the Delphi and nominal group techniques. Reference C.5.37 found virtually no difference between the results of the two methods.

A variety of mathematical aggregation rules for probabilities have been proposed. References C.5.38 and C.5.39 provide a review of these techniques and their mathematical properties. Mathematical aggregation is often performed through the use of linear opinion pools (Ref. C.5.40). A linear opinion pool is simply a weighted average of the probabilities or probability densities provided by the experts. The probabilities are averaged but the values of the variable being assessed are not averaged. Averaging probabilities maintains the range of values of the variables submitted by all experts.

Another aggregation procedure is to use the information provided by the experts as evidence that is to be processed via Bayes' theorem (Refs. C.5.41 and C.5.42). The credibility of the experts' estimates is modeled by the likelihood function. In the case of a normal distribution for the likelihood function, the posterior mean is a lincar combination of the experts' estimates with coefficients that depend on the variance of each estimate and the relevant correlation coefficients. This is different from the linear opinion pool, in which probabilities are averaged. However, linear pools that average the expert estimates have also been prepared (Ref. C.5.43). Although linear opinion pools are straightforward and widely used, they make no allowance for dependency among experts. If, for example, the experts were well-calibrated and independent in a statistical sense, a linear opinion pool would greatly underutilize their judgments. Methods for dealing with dependence in a Bayesian analysis are discussed in References C.5.44 through C.5.46.

An alternative to a linear opinion pool is geometric averaging, which is, of course, tantamount to averaging the logarithms of the probabilities. Since small probabilities (e.g., 10 $0^{-5}$ ) are often displayed and thought of as logarithms, this may seem to be a natural method of'aggregation in a PRA. Geometric averages of probabilities, however, yield a value of zero if any constituent probability is zero. This is a very serious drawback since one 
expert can dictate regions of zero probability and thus exclude from the analysis parameter values thought important by others. Reference C.5.47 shows that the geometric averaging of expert estimates corresponds to a Bayesian model with a lognormal likelihood function.

It is common practice to use equal weights for all experts. Unequal weighting has been proposed to take advantage of differences in expertise and differences in calibration. One approach is to have the experts rate themselves as to their own expertise. This can be done on an overall basis or on a question-by-question basis. Evidence shows, however, that when experts evaluate themselves, personality plays a stronger role than demonstrated expertise. Another approach, which avoids this problem, is to have the experts rate one another, as in De Groot's method (Ref. C.5.39). It is also possible for the sponsor of the activity to rate the experts, a priori, although this approach may not be defensible since the sponsor may have some idea as to how the experts will respond. The underlying model of the world as well as the information elicited from the experts are very important in dealing with opinion aggregation (Ref. C.5.48).

IEEE Std-500 (Ref. C.5.26) pools failure rate estimates of some 200 experts into a group estimate by taking the geometric average as follows:

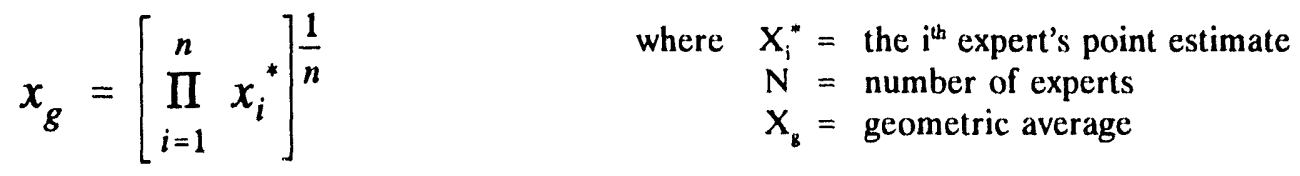

According to the IEEE Standard, two basic reasons justify this methodology. (1) The analytical techniques need not be more sophisticated than the pool of estimates (experts' opinion) to which they are applied. Therefore, a simple averaging technique (equal weights) seems to be satisfactory, as well as efficient, especially when the quantity of the collected data is large. (2) Geometric averaging is preferred since "it was observed that the distribution of estimates was better represented by failure rate exponent averages than by mantissa averages."

Reference C.5.48 shows that a Bayesian analysis of these expert estimates with a lognormal likelihood function leads to a median of the posterior distribution as follows:

$$
x_{50}=x_{0}^{\omega_{0}} \prod_{i=1}^{n}\left(\frac{x_{i}^{*}}{b_{i}}\right)^{\omega_{i}}
$$

where the quantities $b_{i}$ represent systematic biases and the weights $\omega$ reflect the uncertainties and correlations among the expert estimates. Comparing $\mathrm{X}_{\mathrm{g}}$ and $\mathrm{X}_{\mathrm{s}_{0}}$ leads to the conclusion that the simple geometric average of IEEE Std-500 (Ref. C.5.26) is based on the following assumptions: (1) All the experts are equally competent, (2) no expert has systematic biases, (3) all the experts are independent, and (4) the preceding three assumptions are valid regardless of what value the experts are estimating (e.g., high, low). Similar conclusions are reached in Reference C.5.48 using frequentist methods. A linear opinion pool by averaging probabilities cannot be used, as was done in the NUREG-1150 study (Ref. C.5.1), because experts were not asked to supply the probabilities of the various values of the failure rates. C.: the other hand, the above expressions have the form of a linear opinion pool on the logarithms of the estimates (which leads to geometric averaging).

A second example is the treatment of the containment failure pressure in the NUREG-1150 study (Ref. C.5.1) that was discussed on page C-131. The linear opinion pool approach, as done in the NUREG-1150 study, was applicable. Applying a Bayesian analysis would be much harder than the cases discussed above, because the space of all possible probability distributions that the experts might give would have to be considered. 
A rather complex, but apparently workable, scheme based on calibration scores has been developed in Reference C.5.6. In this method, the experts are screened through the use of seed calibration questions for which the answers are known. The calibration of each expert is judged by using a statistical test of calibration. The judgments of those experts who pass the test are then combined, using a linear rule with weights that are functions of their calibration scores and the refinement in their distributions.

Although it is clear that using multiple experts is a good idea, the evidence on how to combine their judgments is not conclusive. Reference C.5.17 suggests that linear opinion pools perform as well or better than other, more complex, methods.

When the variability among the experts is greater than the uncertainty for each expert, a simple aggregation method is sometimes used. Each expert's assessment is replaced by a central value (the "best" estimate) and the central values are plotted. Converting the plot of central values to a box-and-whisker plot is a convenient way to summarize the assessments and to reflect the uncertainties.

While consensus methods are often easy to implement (e.g., averaging over the experts), they should not be automatically applied without careful consideration. Because one of the primary goals of the expert judgment process is to reflect the state-of-art uncertainty as expressed by the diversity of expert judgments, an aggregation method should not be used if it tends to mask the diversity of expert judgment. For example, consider one case where half the experts judge the probability $P$ of a phenomenon to be close to 0 while the other half judge $P$ to be close to 1 . Averaging over the experts is equivalent to a second case where all the experts judge $P$ to be approximately half. However, these two cases are quite different since there is no disagreement (and hence uncertainty) in the second case. In the first case, the decisionmaker does not know what to assign to $\mathrm{P}$, while in the second case, a decisionmaker would have high confidence that $\mathbf{P}$ is approximately half. If the decisionmaker would make one decision when $P=0$ and another decision when $P=1$, premature averaging in the first case might deprive the decisionmaker of cssential information. In general, an aggregation method should be used only if a sensitivity study indicated that it does not destroy information that might significantly affect the options of a decisionmaker.

The purpose of the sensitivity studies (see Section C.6.5, page C-164) is to determine the effect of the individual judgments on the PRA results and, consequently, on the regulatory decisions at hand. If the distributions are similar, they can be readily combined.

Guidance: The aggregation of expert judgment should not mask or destroy information that is important for regulatory decisions. If experts disagree and the different judgments have an important impact on regulatory decisions, then the results should be presented in a manner that reflects the disagreements.

For related discussions, see Chapter C.1 (page C-8) and Figure C.1.1 (page C-9) on combining views from PRAs and Section C.4.4.4 (page $\mathrm{C}-105$ ) on aggregating risk triplets to form aggregate risk estimates.

\section{C.5.7 Advantages, Disadvantages, and Cautions}

The advantages, disadvantages, and cautions of expert judgment in PRA should be appreciated in the context of the situations described in Section C.5.2 (page C-129). While judgments in various forms are always utilized, the formal processes described are more relevant to complex problems in which information from experiments and experience is lacking. 


\section{Advantages}

D The formal use of expert judgment can address issues where disparate, perhaps conflicting, and incomplete sources of information are to be found.

$\triangle \quad$ The formal use of expert judgment can express the existing uncertainty about events.

D The formal use of expert judgment can address situations in which other sources of information would be too costly or the desirable information, e.g., experimentation, could not be produced in time.

D The process allows a variety of approaches, data sources, models, etc., through the use of several experts.

$D \quad$ The primary use of expert judgment enhances the extent to which the processing of information can be accounted and traced.

\section{$\underline{\text { Disadvantages }}$}

D Some critics do not accept the process, believing it to be non-scientific or used as a substitute for experimentation, observation, or modeling.

$\triangleright \quad$ The costs of a formal expert judgment process can be high, particularly when several experts are used to address each issue. However, lacking formal expert judgment on important issues may also be costly when criticisms lead to additional analyses and debates.

D Expert judgments are subject to various biases, especially when ascertaining high consequence or low probability events.

\section{Cautions}

Technical and administrative planning are essential supporting elements of formal expert elicitation. Considerable effort must be expended to develop the case structure (boundary conditions of the physical problem and supporting information) that is necessary to obtain elicited information. A dry run should be performed to test the case structure. When multiple panels of experts are to be employed, it is best to undertake the first panel as a pilot project and allow the learning during the pilot phase to help direct the process for the ensuing panels.

The NRC staff should take precautions to avoid commonly made errors in obtaining formal expert judgment:

$\triangleright \quad$ Using too few experts or forming a group of experts having an insufficient range of expertise.

$\triangle \quad$ Making an insufficient effort to precisely define the issues.

$\triangle \quad$ Using unqualified people to conduct an elicitation process.

U Using ad hoc elicitation procedures.

$\triangleright \quad$ Using an aggregation process that masks or destroys information. 
$\checkmark \quad$ Making an insufficient effort to document the products (Section C.5.8, page C-144, lists the products of expert judgment).

Dangers arise from not using formal expert judgment. Because of the diversity of disciplines needed to support a PRA, having project staff provide information for uncertain inputs may result in using inappropriate data and models. Also, there is a possibility of having to repeat an analysis as a result of an unfavorable peer review when information has been inappropriately brought into a study.

\section{C.5.8 Products}

1. Issues and the structure (decomposition) of the problem.

2. Individual quantitative judgments. Typically, these judgments are in the form of probability distributions; sometimes, they are in the form of ranges (see Chapter C.2, pages C-20 and C-24, for a discussion of the distinction between the two terms).

3. Results of the PRA, based on either aggregated or individual expert judgments.

4. Documentation of the issues, methods, results, and rationales.

\section{C.5.9 Summary}

Although not appropriate in all situations, 'expert judgment often plays an important role in PRA. Formal procedures have been developed, as part of the PRA process, to collect such judgments from experts. These procedures include selection and organization of experts, issue identification and description, training, eliciting judgments, processing and combining results, and documenting the process and the findings.

Probabilities elicited from experts may be subject to psychological biases. Psychological biases result from the human mind's inability to impartially evaluate information and extract probabilities from that information. The most significant psychological bias is overconfidence, which is the tendency to give probabilities that reflect more knowledge than is warranted.

The quality of probabilities from experts can be measured through calibration and refinement. Well calibrated probabilities correctly reflect the relative frequencies of events to which they are assigned. Refinement refers to the ability to distinguish among possible outcomes. For example, a uniform probability distribution distinguishes less than a highly peaked distribution over the same interval.

It is often desirable or necessary to combine the judgments of several experts, which can be done through behavioral methods or by mathematical aggregation. Evidence suggests that the benefits that arise from differential weighting of experts is small or nonexistent. However, care should be taken that the aggregation of expert judgment does not mask or destroy essential information. 


\section{REFERENCES FOR CHAPTER C.5}

C.5.1 S.C. Hora and R.L. Iman, "Expert Opinion in Risk Analysis: The NUREG-1150 Methodology," Nuclear Science and Engineering, Volume 102, pp. 323-31, 1989.

C.5.2 R.L. Keeney and D. von Winterfeldt, "Eliciting Probabilities from Experts in Complex Technical Problems," IEEE Transactions on Engineering Management, 38, pp. 191-201, 1991.

C.5.3 Electric Power Research Institute, "Seismic Hazard Methodology for the Central and Eastern United States," Volume 1, "Methodology," NP-4726, EPRI, July 1986.

C.5.4 M.W. Merkhofer and A.K. Runchal, "Probability Encoding: Quantifying Judgmental Uncertainty over Hydrologic Parameters for Basalt," Proceedings of the Conference on Geostatistical, Sensitivity and Uncertainty Methods for Ground-Water Flow and Radionuclide Transport Modeling, B.E. Buston, Editor, Battelle Press, Columbus, Ohio, pp. 629-648, 1989.

C.5.5 E.J. Bonano et al., "Elicitation and Use of Expert Judgment in Performance Assessment for HighLevel Radioactive Waste Repositories," NUREG/CR-5411 (Sandia National Laboratories, SAND891821), NRC, May 1990.

C.5.6 R.M. Cooke, Expens in Uncertainty: Expent Opinion and Subjective Probability in Science, Oxford University Press, New York, 1991.

C.5.7 C.S. Spetzler and C.A. Stael von Holstein, "Probability Encoding in Decision Analysis," Management Science, Volume 22, pp. 340-352, 1975.

C.5.8 S.C. Hora, N.G. Dodd, and J.A. Hora, "The Use of Decomposition in the Probability Assessment of Continuous Variables," Behavioral Decision Making, Volume 6, pp. 133-147, 1993.

C.5.9 D. MacGregor et al., "Structuring Knowledge Retrieval: An Analysis of Decomposing Quantitative Judgments," Organizational Behavior and Human Decision Processes, 42, pp. 303-323, 1988.

C.5.10 M.A. Mcyer and J.M. Booker, Eliciting and Analyzing Expert Judgment: $A$ Practical Guide, Academic Press, New York, NY, 1991.

C.5.11 G. Apostolakis, "The Concept of Probability in Safety Assessments of Technological Systems," Science, Volume 250, pp. 1459-64, 1990.

C.5.12 D. von Winterfeldt and W. Edwards, Decision Analysis and Behavioral Research, Cambridge University Press, Cambridge, England, 1986.

C.5.13 S. Lichtenstein et al., "Calibration of Probabilities: The State of the Art to 1980," Decision Making and Change in Human Affairs, H. Jungermann and (j. de Zeeuw, Editors, Reidell, Dordrecht Holland, pp. 275-324, 1982.

C.5.14 S. Lichtenstein and B. Fischhoff, "Training for Calibration," Organizational Behavior and Human Performance, Volume 26, pp. 149-171, 1980. 
C.5.15 M. Alpert and H. Raiffa, "A Progress Report on the Training of Probability Assessors," Judgment Under Uncertainty: Heuristics and Biases, D. Kahneman, P. Slovic, and A Tversky, Editors, Cambridge University Press, Cambridge, England, pp. 294-305, 1982. .

C.5.16 M. Morgan and M. Henrion, Uncertainty: A Guide to Dealing with Uncertainty in Quantitative Risk and Policy Analysis, Cambridge University Press, Cambridge, England, 1991.

C.5.17 A.H. Murphy and R.L. Winkler, "Can Weather Forecasters Formulate Reliable Probability Forecasts of Precipitation and Temperature?" National Weather Digest, 2, pp. 2-9, 1977.

C.5.18 S.C. Hora et al., "Assessment of Probability Distributions for Continuous Random Variables: A Comparison of the Bisection and Fixed Value Methods," Organizational Behavior and Human Decision Processes, Volume 51, pp. 133-155, 1992.

C.5.19 O. Svenson, "On Expert Judgments in Safety Analyses in the Process Industries," Reliability Engineering and System Safety, Volume 25, pp. 219-256, 1989.

C.5.20 A.L. Camp et al., "Level III Probabilistic Risk Assessment for N Reactor," WHC-MR-0045 (SAND 89-2102), Volume 2, Westinghouse Richland Company, Richland, Washington, 1990.

C.5.21 B. Fischhoff, "Debiasing," Judgment Under Uncertainty: Heuristics and Biases, D. Kahneman, P. Slovic, and A. Tversky, Editors, Cambridge University Press, Cambridge, England, pp. 422-444, 1982.

C.5.22 J.B. Kidd, "The Utilization of Subjective Probabilities in Production Planning," Acta Psychologica, Volume 34, pp. 338-47, 1970.

C.5.23 A. Mosleh et al., "A Critique of Current Practice for the Use of Expert Opinions in Probabilistic Risk Assessment," Reliability Engineering and System Safety, Volume 20, pp. 63-85, 1988.

C.5.24 E. R. Snaith, The Correlation Between the Predicted and Observed Reliabilities of Components, Equipment, and Systems, NCSR R 18, National Center of Systems Reliability, UK Atomic Energy Authority, Culcheth, United Kingdom, 1981.

C.5.25 G. Apostolakis et al., "Data Specialization for Plant-Specific Risk Studies," Nuclear Engineering and Design, Volume 56, pp. 321-329, 1980.

C.5.26 IEEE, "IEEE Guide to the Collection and Presentation of Electrical, Electronic, Sensing Component, and Mechanical Equipment Reliability Data for Nuclear Power Generating Stations," IEEE Std-5001984, Institute of Electrical and Electronics Engineers, New York, NY, 1983.

C.5.27 NRC, "Reactor Safety Study - An Assessment of Accident Risks in U.S. Commercial Nuclear Power Plants," WASH-1400 (NUREG-75/014), October 1975.

C.5.28 (j. Apostolakis, "Data Analysis in Risk Assessments," Nuclear Engineering and Design, Volume 71, pp. 375-381, 1982.

C.5.29 H. F. Martz, "On Broadening Failure Rate Distributions in PRA Uncertainty Analyses," Risk Analysis, Volume 4, No. 1, pp. 15-23, 1984.

NURE( $;-1489$ 
C.5.30 (i. Apostolakis, "The Broadening of Failure Rate Distributions in Risk Analysis: How Good the Experts?" also H. F. Martz response to the preceding letter, Risk Analysis, Volume 5, pp. 89-95, 1985.

C.5.31 A. Mosleh and G. Apostolakis, "Combining Various Types of Data in Estimating Failure Rates," Transactions of the 1983 Winter Meeting of the American Nuclear Society, San Francisco, California, 1983.

C.5.32 N. Dalkey and O. Helmer, "An Experimental Application of the DELPHI Method to the Use of Experts," Management Science, Volume 9, pp. 458-467, 1963.

C.5.33 H.A. Linstone and M. Turoff, Editors, The Delphi Method: Techniques and Applications, Addison Wesley, Reading, Mass., 1975.

C.5.34 A. Van de Ven and A. Delbecq, "Nominal vs Interacting Group Processes for Committee Decision Making Effectiveness," Academy of Management Joumal, Volume 14, pp. 203-212, 1971.

C.5.35 S. Kaplan, "'Expert Information' versus 'Expert Opinions,' Another Approach to the Problem of Eliciting/Combining/Using Expert Knowledge in PRA," Reliability Engineering and System Safety, Volume 35, pp. 61-72, 1992.

C.5.36 G. W. Fischer, "Scoring Rule Feedback and the Overconfidence Syndrome in Subjective Probability Forecasting," Organizational Behavior and Human Performance, Volume 29, pp. 357-69, 1982.

C.5.37 V. R. R. Uppuluri and D. A. Seaver, "Formal Procedures for Obtaining a Consensus of Opinion: A, Critical Evaluation," Oak Ridge National Laboratory, U.S. Department of Energy, March 1986.

C.5.38 C. Genest and J.V. Zidek, "Combining Probability Distributions: A Critique and an Annotated Bibliography," Statistical Science, Volume 1, pp. 114-148, 1986.

C.5.39 M. H. DeGroot, "Reaching a Consensus," Joumal of the American Statistical Association, Volume 69, pp. 118-121, 1974.

C.5.40 D. V. Lindley, "The Use of Probability Statements," Accelerated Life Testing and Expent Opinions in Reliability, D.V. Lindley and C.A. Clarotti, Editors, North Holland, Amsterdam, 1988.

C.5.41 P. Morris, "Combining Expert Judgments," Management Science, Volume 23, pp. 679-693, 1977.

C.5.42 C. (ienest and M.J. Schervish, "Modeling Expert Judgments for Bayesian Updating," The Annals of Statistics, Volume 14, pp. 1198-1212, 1985.

C.5.43 R. T. Clemen and R. L. Winkler, "Limits for the Precision and Value of Information from Dependent Sources," Operations Research, Volume 33, pp. 427-442, 1985.

C.5.44 S. Chhibher and G. Apostolakis, "Some Approximations Useful to the Use of Dependent Information Sources," Reliability Engineering and System Safety, Volume 42, pp. 67-86, 1993.

C.5.45 E.J. Bonano and (i.E. Apostolakis, "Theoretical Foundations and Practical Issues for Using Expert Judgments in Uncertainty Analysis of High-Level Radioactive Waste Disposal," Radioactive Waste Managentent and the Nuclear Fuel Cycle, Volume 16, pp. 137-159, 1991. 
C.5 Expert Judgment

C.5.46 A. Mosleh and G. Apostolakis, "Models for the Use of Expert Opinion," Low Probability HighConsequence Risk Analysis, edited by R.A. Waller and V.T. Covello, Plenum Press, NY, 1984.

C.5.47 S. Chhibber et al., "A Taxonomy, of Issues Related to the Use of Expert Judgments in Probabilistic Safety Studies," Reliability Engineering and System Safety, Volume 38, pp. 27-45, 1992.

C.5.48 H.F. Martz and M.C. Bryson, "A Statistical Model for Combining Biased Expert Opinions," IEEE Transactions on Reliability, R-33, pp. 227-232, IEEE, 1984. 


\section{C.6 UNCERTAINTY AND SENSITIVITY ANALYSES}

\section{C.6.1 Learning Objectives}

The learning objectives for readers of this section are as follows:

- Understand the basic concepts of uncertainty and sensitivity analyses.

- Identify the sources and types of uncertainty.

- Describe available uncertainty and sensitivity analysis methods, including their limitations.

- Read and interpret different types of uncertainty displays.

With these learning objectives, this section discusses both uncertainty analysis methods (i.e., tools for making calculations) and risk characterization (e.g., display of results for decisionmakers).

\section{C.6.2 Concepts}

PRA accounts for processes and phenomena that are not well known, often because they occur infrequently and involve severe conditions that are difficult to replicate and instrument. Therefore, PRA results are inherently uncertain. But this does not render PRA results useless to decisionmakers. Decisions can be supported by PRA results. For this reason, care must be taken to present results in a manner that is enlightening and useful to decisionmakers.

\section{C.6.2.1 Types of Uncertainty}

PRA point estimates are uncertain because of imprecision in the input variables and construction of PRA models. Uncertainty denotes imprecisions in the PRA analyst's knowledge or available information about the input parameters to PRA models, the PRA models themselves, and the outputs from such models. Uncertainty in the output of a PRA is important for the NRC staff to understand because it can have an impact on regulatory decisions. For example, if decisionmakers are comparing two estimates, whether or not the differences between the estimates are significant depends upon the uncertainties associated with them. If the uncertainties about the two estimates are much larger than the differences between the two results, then the differences may not be meaningful. However, just having results in terms of uncertainty is not enough. Uncertainties are often presented in vague ways, using terms such as uncertainty bounds without describing what they mean. Understanding and characterizing PRA results from a perspective of uncertainty is necessary and is accomplished through uncertainty and sensitivity analyses.

Uncertainty analysis is the quantification of the imprecision in the PRA estimates that results from imprecisely formulated PRA models and imprecisely known input variables. Sensitivity analysis is the determination of the impact of changes in the input variables and model structures on the PRA estimates and the uncertainty (either the total uncertainty or a portion of the uncertainty). Uncertainty analysis attempts to determine the collective impact of the uncertainty in all important parameters and models, while sensitivity analysis addresses the impact of either irdividual or selected groups of parameters and models. Uncertainties and sensitivities need to be considered together to fully understand PRA results. 
C.6 Uncertainty And Sensitivity Analyses

C.6.2 Concepts

C.6.2.1 Types of Uncertainty

\section{Guidance: Before decisionmakers can determine how PRA results should influence their decisions, they must understand the estimates, including their precision and limitations.}

Uncertainty and sensitivity analyses should be considered as supplements to one another and not mutually exclusive alternatives. In most cases, PRA results should be accompanied by uncertainty and sensitivity studies if they are to be used in important decisions.

Types of uncertainties are often described in vague ways. Alternative interpretations and definitions exist for classifying the different types of uncertainty. For the purposes of this report, two general types of uncertainties, stochastic uncertainties and state-of-knowledge uncertainties, can be defined; the latter can be further subdivided' into parameter, model, and completeness uncertainties (Refs. C.6.1 and C.6.2):

$D \quad$ Stochastic uncertainty is due to inherent variability in some measurable physical quantity. This type of uncertainty results when an experiment is repeated under identical conditions and different outcomes are observed. Stochastic uncertainty is inherent in the physical process involved; it cannot be reduced by enlarging the data base. However, enlarging the data base can provide information about the probability distribution of the stochastic uncertainty, but this information reduces the knowledge uncertainty, not the stochastic uncertainty (Ref. C.6.2).

D State-of-knowledge uncertainty results from a lack of complete information about systems, phenomena, and processes. For example, there is stochastic uncertainty resulting from the fact that a pump will not start every time. However, the uncertainty in the precise failure rate is a state-of-knowledge uncertainty. State-of-knowledge uncertainty can be more easily understood by considering its three major types, parameter uncertainty, model uncertainty, and completeness uncertainty.

- Parameter uncertainty results from lack of knowledge about the correct inputs to models being used in the analysis. The parameters of interest may be inputs to either the PRA models themselves or a variety of physical and process models that influence the PRA process.

- Model uncertainty occurs because perfect models cannot be constructed. Models of physical processes generally have many underlying assumptions and often are not valid for all possible cases. Often, there are alternative models proposed by different analysts, and it is not known which, if any, of the models is the most appropriate one (each alternative will have its own deficiencies). The PRA models themselves, such as the event trees and fault trees, can be constructed in different ways, and those alternative constructions can change the results.

- Completeness uncertainty refers to the uncertainty as to whether or not all the significant phenomena and relationships have been considered, e.g., whether all accident scenarios that could significantly affect the determination of risk have been identified. Completeness uncertainty is similar to modeling uncertainty, but occurs at the initial stage in an analysis. In addition to inadequate identification of the physical phenomena, completeness uncertainty can also result from inadequate consideration of human error, software reliability, or interactions and dependencies among the elements of the process being modeled. Some PRA practitioners consider completeness uncertainty as a subset of model uncertainty. In any event, completeness uncertainty is rarely, if ever, treated in a PRA. 


\section{C.6.2.2 Uncertainties Considered in PRAs}

The types of uncertainty discussed above exist throughout a PRA. However, in practice the treatment of uncertainty is usually incomplete and can vary in each level of the PRA. This occurs when PRA practitioners focus on areas they believe to be most important and areas for which methods are available. The discussion below describes the current practices. Figure C.6.1 shows the various PRA levels and summarizes the types of uncertainties typically included. Additional details of the calculations represented by each box are in Sections C.3 (page C-41), C.4.4.1 (page C-84), C.4.4.2 (page C-91), C.4.4.3 (page C-98), and C.4.4.4 (page C-104).

\section{C.6.2.2.1 Level 1}

Stochastic uncertainty in a Level 1 PRA is expressed in fault trees and event trees. The trees account for alternative outcomes that are expected to vary from one accident to the next in a random manner. State-ofknowledge uncertainty is present in two forms, as parameter and modeling uncertainty. Parameter uncertainty occurs in the values assigned to the inputs; this uncertainty is usually treated by Monte Carlo simulation (see Section C.6.3.1, page C-154). Elements of a PRA subject to model uncertainty include human error probability, success criteria, and sometimes fault trees and event trees; these uncertainties are rarely treated.

\section{EXAMPLE}

Consider a one-out-of-two system of diesel generators; the system is operable (that is, it supplies the required power) when at least one of the diesels is available. Both generators are on standby and are supposed to come on line upon demand.

Since usually the diesels are nominally identical, the model that is commonly used is the binomial distribution (Section C.2.3, page C-31). The probability that the system is operable is as follows:

$$
\begin{aligned}
P(1 \text { or } 2 \mathrm{DG} \text { avail } \mid \mathrm{p}, \mathrm{M})=2 \mathrm{pq}+\mathrm{p}^{2} \quad \text { where } \mathrm{p} & =\mathrm{P}(\text { one diesel generator is available }) \\
\mathrm{q} & =1-\mathrm{p} \\
\mathrm{M} & =\text { set of model assumptions }
\end{aligned}
$$

The binomial distribution models the stochastic uncertainty; it deals with the uncertainty of whether one, two, or none of the generators will be available on demand (in the terminology of Reference C.6.3, this is the model of the world).

The notation employed shows explicitly that the calculated probability is conditional on knowing the numerical value of $p$ and on the validity of a number of assumptions. The uncertainties that are associated with these conditions are of the state-of-knowledge type. If the value of $p$ is unknown, the issue of parameter uncertainty arises. What is known about this value is expressed in terms of the state-of-knowledge probability density function $\pi(p)$. As statistical experience is collected, this distribution is updated using Bayes' theorem.

The set of assumptions $M$ for the binomial distribution is $M=\{p$ is constant; diesels are independent $\}$.

If there is uncertainty about the validity of either of these assumptions, that would be model uncertainty. For example, the diesels may not really operate independently of each other, in which case additional models may be introduced to actount for these dependencies. Furthermore, even if the above assumptions are reasonable (from studying the system, all conceivable reasuns for invalidating them the assumptions have been eliminated), the conceptions of the system may be fallible in that something is not modeled, e.g., a coupling mechanism. This creates completeness uncertainty, which is obviously difficult to treat. 
C.6 Uncertainty and Sensitivity

C.6.2 Concepts

C.6.2.2 Uncertainties Considered in PRAs

\section{Major Uncertainties Included}

\section{Areas of a PRA}

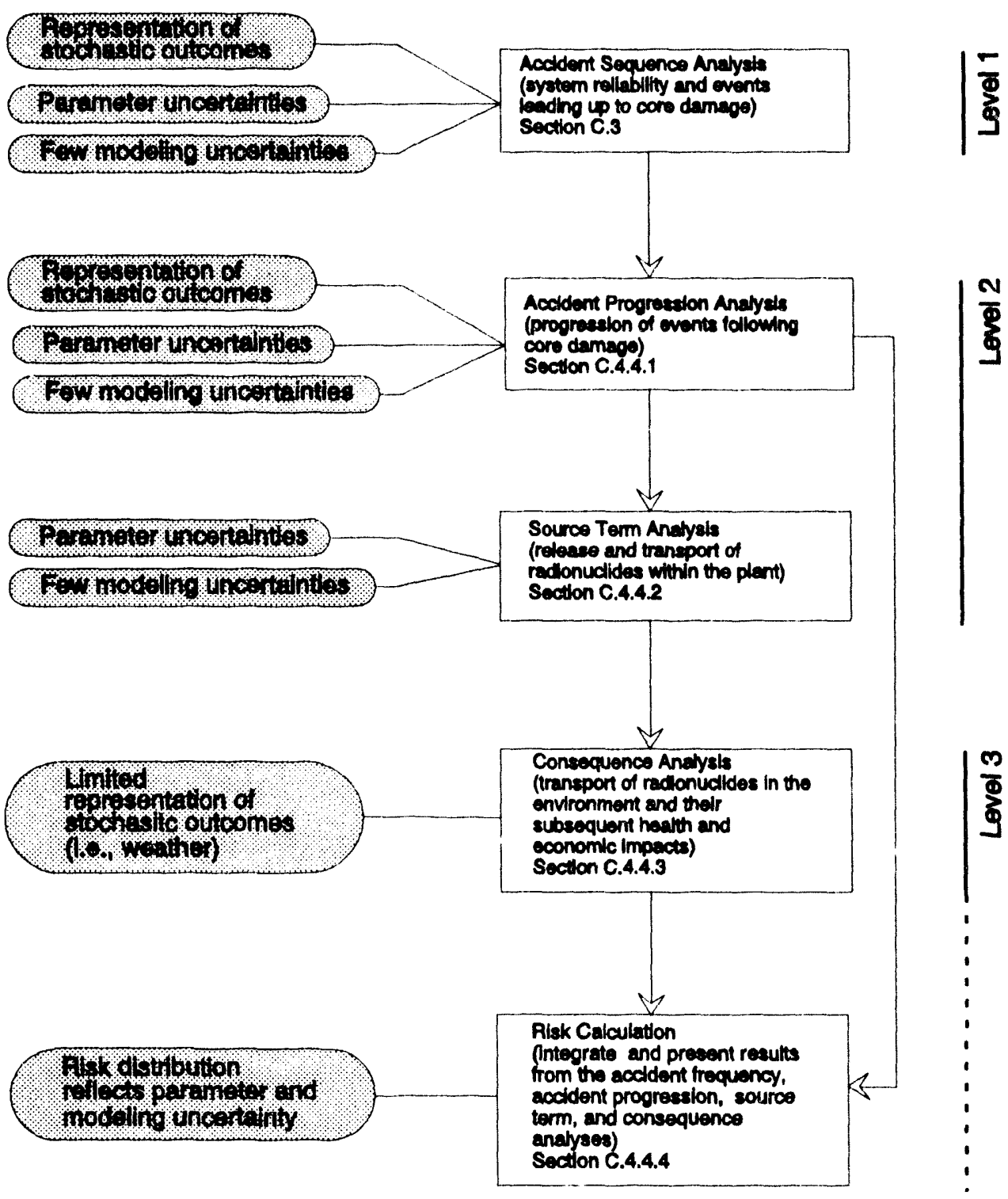

Figure C.6.1 Major uncertainties included in a PRA

NUREG-1489

C-152 


\section{C.6 Uncertainty and Sensitivity \\ C.6.2 Concepts}

C.6.2.3 Data and Information

\section{C.6.2.2.2 Level 2}

The accident progression portion of the Level 2 PRA has uncertainty characteristics very similar to the Level 1 PRA. The events are different, but the types and treatment of uncertainty are the same as for the Level 1 PRA discussed above. As in the Level 1 analysis, stochastic uncertainty (see Section C.6.2.1, page C-150) is accounted for by the various branches in the Level 2 accident progression event tree. The state of knowledge uncertainty associated with the input parameters of the accident progression event tree (e.g., probabilities and parameters that represent physical quantities such as the amount of hydrogen produced) is also explicitly considered. This uncertainty can be treated using the formal expert judgment process and is expressed in the form of the distributions developed for the parameters (see Chapter C.5, page C-129 for a discussion of the formal expert judgment process).

The uncertainties included in the source term analysis are typically limited to the state of knowledge uncertainties in the input parameters to the source term model (e.g., the amount of a particular radionuclide that is released from the damaged core). In contrast to the Level 1 and accident progression analyses, a typical source term analysis, e.g., as in the NUREG-1150 study (Ref. C.6.4), stochastic uncertainties associated with the release and transport of radioactive material are usually not taken into account.

Similar to the other portions of the PRA, the uncertainty associated with the completeness of the Level 2 models is not usually treated.

\section{C.6.2.2.3 Level 3}

Consequence uncertainties have not been routinely treated in as much detail as Level 1 and Level 2 PRA uncertainties. Traditionally, only the stochastic uncertainties caused by weather have been explicitly treated in uncertainty analyses. Other uncertainties are addressed through sensitivity studies. Development of consequence uncertainty methods is currently being researched.

\section{C.6.2.2.4 Risk Calculation}

A risk distribution represents uncertainty in the parameters and models of the PRA to the extent that these uncertainties were included in the PRA. As a practical matter, only the important items of these uncertainties are included. The constituents of stochastic uncertainty (accounted for by the branches of the event tree resulting in the various accident progressions) are lost when the aggregate risk is calculated is done. For an illustration, see Section C.4.5 (page C-111).

\section{C.6.2.3 Data and Information}

Interpretation of data is important in determining the uncertainties in parameters. Adequate failure data are often unavailable or poorly reported. In developing the distribution for the failure rate, the analyst must determirie how to use the available data. For example, motor-operated valve data may be available for a particular valve, all valves in a system, all valves in a plant, or all valves in a group of plants. Further, the data could be grouped by valve type, size, or manufacturer. An analyst must determine which data are relevant and whether the data are all of equal significance. In some cases, statistical analyses of plant-to-plant variations can be helpful.

There are many different treatments of uncertainty that are possible and many different definitions and categorizations. Given this, the following guidance can be stated: 
C.6 Uncertainty and Sensitivity

C.6.3 Methods - Uncertainty Analysis

C.6.3.1 Monte Carlo Simulation

Guidance: The scope of the uncertainty analysis should be clearly delineated, and analysts should clearly state their definitions and categorizations of uncertainty.

The analyst should explicitly state which uncertainties are being addressed.

The analyst should, to the extent possible, identify the uncertainties that have not been included.

The methods used to evaluate each type of uncertainty should be clearly described.

For further reading on types of uncertainties, see References C.6.5 through C.6.14.

\section{C.6.2.4 Classical and Bayesian Views}

The generation of uncertainty estimates for the output of PRA models requires a process for propagating uncertainties in individual parameters through the PRA model. Methods for performing this propagation are discussed in later subsections. Each method requires the input parameters to be formulated in a particular manner in order to perform the propagation. There are two philosophically different approaches for this formulation (and the corresponding propagation methods), one based on classical statistics and one based on Bayesian methods.

Some aspects of the differences between classical and Bayesian methods were discussed in Section C.2.2.2.2 (page C-25) and Section C.2.2.2.3 (page C-26). For the purposes of this discussion, classical methods do not assume shapes of probability distributions for either the input parameters or the output variables. As noted earlier, Bayesian methods treat input parameters as random variables and develop probability distributions to describe the uncertainty in those parameters. The Bayesian approach allows results to be provided in the form of probability distributions. The shape of the distributions and associated characteristics provide a great deal of information about the output variables. Virtually all recent PRAs, including the NUREG-1150 study (Ref. C.6.4), have relied on Bayesian techniques. In fact, all the methods discussed in this section except one, the Maximus/Bounding (Section C.6.3.3.3, page C-159), are normally applied in a Bayesian manner, and even the Maximus/Bounding method has many subjective elements. More information concerning comparisons of classical and Bayesian techniques can be found in References C.6.5 and C.6.15 through C.6.17.

\section{C.6.3 Methods - Uncertainty Analysis}

\section{C.6.3.1 Monte Carlo Simulation}

Monte Carlo Simulation (generally referred to as Monte Carlo Sampling by PRA analysts) and a variation called Latin Hypercube Sampling (LHS) are the most widely used uncertainty propagation methods in PRAs. Monte Carlo simulation is a mathematical experimentation method. In basic Monte Carlo simulation, a simple random sampling (SRS) process is used to select sets of input parameter values to be used to quantify the uncertainty. LHS is a more restricted method, as discussed later. The parameters to be sampled by either method include component unavailabilities, human error probabilities, the probability of occurrence of particular phenomena, and other parameters of the PRA models. Each set of parameter values is called an observation. The result of quantifying each observation is an estimate of the output of the model (such as core damage frequency or risk measures). The entire collection of observations, the sample, yields a distribution for the output variable. The approach is Bayesian, requiring distributions to be determined for the input variables. 
In general, a Monte Carlo simulation with SRS involves four steps:

1. Determine a probability distribution for each input variable. In some cases, a joint probability distribution may be necessary to account for interactions among variables.

2. Randomly select values from the probability distributions to form sets of inputs, taking into account dependencies and correlations.

3. Perform calculations using each set of inputs.

4. Generate and characterize the distribution of the output variable. Characteristics of distributions are discussed in more detail in Section C.2.2.1.2 (page C-21).

An example output distribution from an analysis with a sample size of 20 is shown in Figure C.6.2. In this case, the 20 observations represent 20 separate estimates of core damage frequency. Since each observation in the sample quantification is equally probable and therefore weighted equally, the distribution function of Figure C.6.2 is readily generated. The observations are sorted, each is assigned a probability of $1 / 20$, and the cumulative (empirical) distribution function is plotted. The lowest estimate of core damage frequency has a value of 0.05 on the $y$-axis, the next lowest estimate corresponds to 0.1 , and so on. The cumulative probability corresponding to each frequency estimate is the probability of a core damage frequency less than or equal to that frequency. A better representation of the output can be obtained through more observations. Other types of distribution functions (e.g., probability density functions) can be produced with additional work.

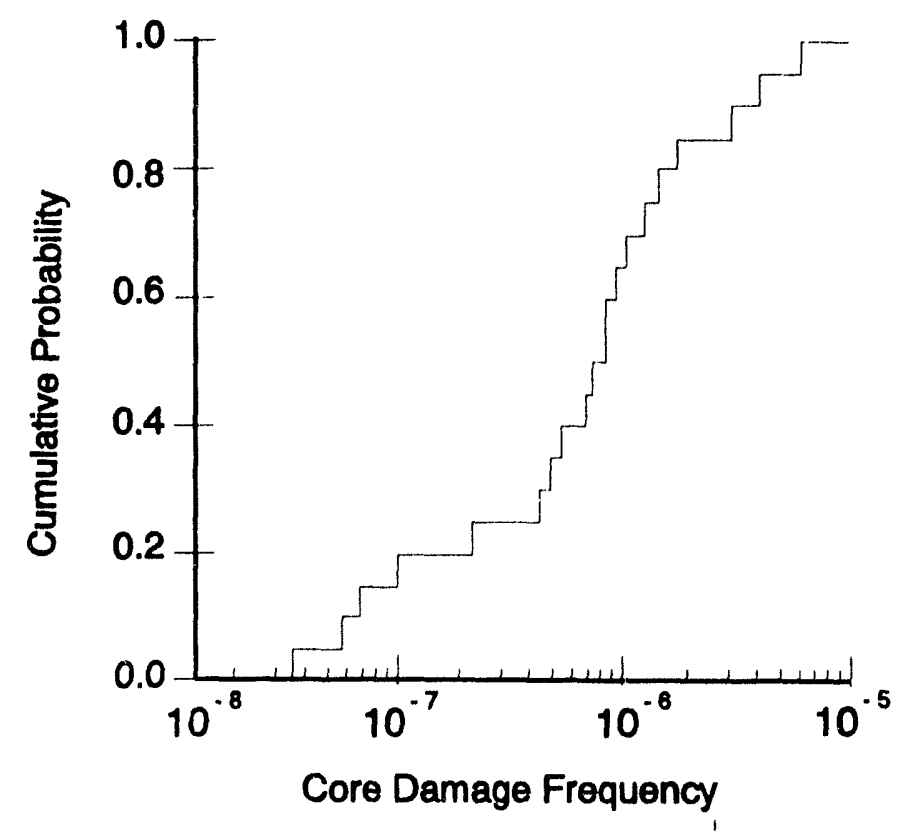

Figure C.6.2 Output distribution from a Monte Carlo sample 
C.6 Uncertainty and Sensitivity

C.6.3 Methods - Uncertainty Analysis

C.6.3.2 Latin Hypercube Sampling

The mean of the distribution is simply the average of the 20 observations. Quantiles of the distribution are readily obtained from the figure by picking points off the $y$-axis and finding the corresponding value. The quantiles are estimates from the sampling process. The accuracy of this output distribution is a function of the sample size. As more observations are included, the accuracy in the output distribution improves. Here, accuracy means the degree to which the true output distribution is achieved, given that all the input distributions are correct. It is often difficult to determine when sufficient accuracy has been achieved. One approach is to repeat the calculation with different random number seeds or larger sample sizes to determine how the distribution changes. If the changes are unimportant, then the calculation is usually deemed sufficiently accurate.

\section{Advantages}

$\triangle$ Complete flexibility in the selection of input distributions.

$\triangleright \quad$ Any specified accuracy of the output distribution can be achieved, limited by the cost of the computations and computer round-off errors.

$\triangle \quad$ The method is easy to implement.

\section{Disadvantages}

$\triangle \quad$ Computer costs and computation times can become prohibitive in large problems.

$\triangle$ Accuracy is difficult to obtain in the tails of an output distribution. This is particularly true for problems involving highly skewed input distributions with long tails.

The strengths of this method generally outweigh the disadvantages, and it remains a powerful method for PRA users. For further reading on Monte Carlo sampling with SRS, see References C.6.5, C.6.13, C.6.15 and C.6.16.

\section{C.6.3.2 Latin Hypercube Sampling}

LHS (Ref. C.6.18) was developed to improve upon the efficiency of the Monte Carlo Approach with SRS, and was used in the NUREG-1150 study (Ref. C.6.4). Latin Hypercube Sampling is currently the method of choice for large PRA studies.

LHS is a stratifi $I$ sampling technique, involving the same four steps that were described for Monte Carlo simulation with SRS. However, the details of the second and third steps are very different. In the second step, prior to selecting the sampled values, the probability distribution of each input variable is divided into discrete intervals, where each interval has an equal probability of occurrence. Figure C.6.3 shows how a cumulative distribution function for an input variable is divided into equal probability intervals, in this case five intervals. Each interval is then sampled an equal number of times, although each selection within an interval is randomly obtained. This approach ensures that all parts of a distribution are sampled. For most problems, LHS will require a much smaller sample size to achieve the same accuracy in the mean value as SRS. As with SRS, the output distribution and its attributes are readily obtained. 


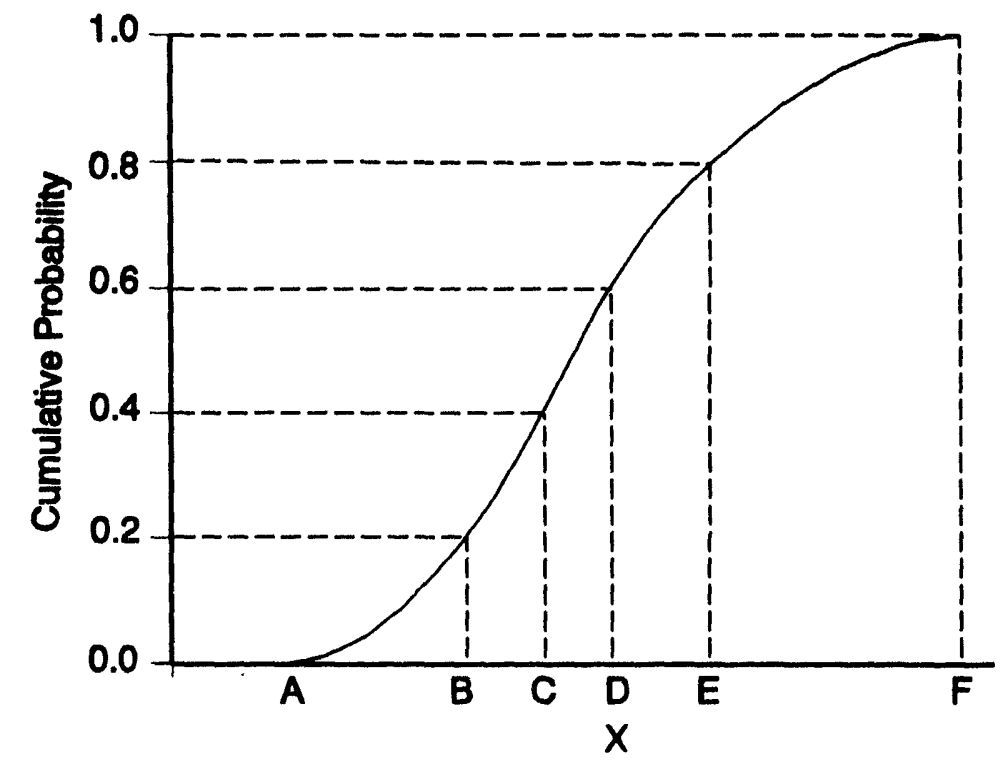

Figure C.6.3 Selection of intervals for Latin Hypercube sampling

\section{Advantages}

$\triangle \quad$ Increased accuracy in the output distribution compared to SRS for the same number of observations.

$\Delta \quad$ LHS ensures that all parts of the input distributions are sampled, leading to less chance of a sample that is nonrepresentative of the output distribution.

\section{Disadvantages}

$\triangle \quad$ Computer costs and computation times can become significant in large problems, although much less than costs and times required to achieve the same accuracy with SRS.

D In problems involving highly skewed input distributions with long tails, it is difficult to obtain accuracy in the tails (and sometimes the mean value) of the output distribution, although this is less of a problem than for SRS.

Because of the reduced computer costs, LHS is the method of choice for most PRA studies. For further reading on LHS, see References C.6.5, C.6.13, C.6.17, and C.6.18. 
C.6 Uncertainty and Sensitivity

C.6.3 Methods - Uncertainty Analysis

C.6.3.3 Other Uncertainty Analysis Methods

\section{C.6.3.3 Other Uncertainty Analysis Methods}

\section{C.6.3.3.1 Method of Moments}

The Method of Moments is an approach that generates lower order moments, such as the mean and variance, of the output distribution by propagating the moments of the input distributions through the PRA model. The number of moments that need to be generated is usually equal to the number of unknown parameters in the selected output distribution. Once the moments of the output distribution have been calculated, the moments can be matched to the moments of a chosen distribution. The quantiles of the chosen distribution can then be calculated. Typically, the first two moments of a two-parameter output distribution are generated, although higher order moments can also be addressed. A key advantage of this method is that the entire form of the input distributions need not be determined. For simple linear models, the first two moments are generally easy to determine, based on the mean values of the input variables and the partial derivatives of the PRA model with respect to each of the input variables (a low order Taylor series expansion). Higher order moments rapidly become more complex to deal with. As problems become nonlinear, include correlated variables, and become very large, the method generally becomes impractical. More information concerning this method can be found in References C.6.5, C.6.15, C.6.19, and C.6.20.

\section{C.6.3.3.2 Propagation of Discrete Probability Distributions}

Propagation of Discrete Probability Distributions (DPD) is a technique in which the basic event distributions are discretized, and a discrete representation of the output distribution is calculated. First, a distribution is determined for each of the input variables, then these distributions are divided into discrete intervals (the number of discrete intervals can be different for each distribution). A value for each interval is chosen, and the probability that the input variable probability occurs in each interval is calculated. Thus, the distribution of each variable is discretized into $\mathrm{n}$ values, each value with a corresponding probability. The output variable is evaluated $\mathrm{n}^{\mathrm{k}}$ times, where $\mathrm{k}$ is the number of independent variables. The result of each evaluation has an associated probability equal to the product of the probabilities of the independent variables. Thus, a DPD can be constructed from these values. The DPD technique is a valid method, but becomes quickly impractical for large problems with many variables. It is sometimes used in limited studies of selected issues, but not in more general studies. Additional discussion of this method can be found in References C.6.5 and C.6.21.

Response surface approaches involve developing an approximation to the PRA model. This approximation is used as a surrogate for the original model in subsequent uncertainty and sensitivity analyses. In order to develop a response surface, an experimental design process is used to select sets of input parameters for use in the quantification process. Many different experimental design methods are available. It is not necessary that a probabilistic approach be used to select the sets of input parameters, although this is often done. Next, the PRA model is quantified for each set of selected input parameters. Finally, a response surface approximation is fitted to the results. Often, a least squares technique is used to construct this approximation. Generally, only low order terms are included in the approximation, although this need not be the case. Once a response surface approximation has been generated, it can be manipulated in various ways in uncertainty and sensitivity studies. The shape and properties (such as mean and variance) of the output distribution are readily estimated. While a valid method, the approach is difficult to implement for large problems with dependencies among the variables. For further information concerning response surface methods, see References C.6.13 and C.6.22. 


\section{C.6.3.3.3 Maximus/Bounding Approach}

The Maximus/Bounding Approach involves both a classical approach to determine a confidence interval and a subjective approach to determine bounds. In this approach, data supporting the input parameters are divided into two categories. Data based on tests and experiments are classified as objective data, while data based on more subjective approaches (such as expert judgment) are classified as subjective data. The objective data are propagated through the model using the Maximus method to determine statistical confidence intervals, while the subjective data are addressed with a subjective bounding approach. Further information about the Maximus/Bounding Approach can be found in References C.6.16 and C.6.23.

\section{C.6.4 Display and Interpretation of Uncertainties}

The concept of uncertainty importance and the identification of uncertainty drivers are discussed in Section C.6.5.3 (page C-166).

It is important for decisionmakers to understand the uncertainties present in an analysis and the particular parameters and issues that drive the uncertainty. A crucial element in supporting decisionmaking is displaying the uncertainties for decisionmakers so that those uncertainties are more easily understood.

There are many possible alternative displays. Significant experience in communicating PRA results guide the following discussions; even so, the techniques for displaying displays continues to evolve. These displays can be confusing, or even misleading, unless they are properly characterized. Most decisionmakers are not PRA experts or statisticians. Complex uncertainty analysis displays will be ineffective in communicating with them. For the most part, decisionmakers should be provided with enough information to understand the issues and make informed judgments. However, displays that represent subtle and complex probabilistic concepts should be avoided.

On the other hand, PRA experts can make use of very complex displays in their attempts to unravel the important insights in the results. Before describing the individual display possibilities, it is worthwhile to consider some gencral topics that relate to all these methods.

While many properties of a distribution can be generated from an uncertainty analysis (using Bayesian methods), decisionmakers are sometimes interested in the best estimate. In the NUREG-1150 study (Ref. C.6.4) and most recent PRAs, the mean values of the output distributions are used as best estimates when such characterizations are necessary. Most PRA analysts will present either the mean or the median as their best estimate; however, the term best estimate has no precise meaning (see Section C.2.2.2.1, page C-24).

\section{Guidance: The term "best estimate" generally should be avoided. When a result is presented as "best estimate," it should be accompanied by a clear description of what is meant by "best estimate" and how the result was calculated.}

Mean values are used in the regulatory process. In particular, comparisons with safety goals are done with mean values (see Section C.4.5, page C-112) as are cost-benefit studies used in regulatory analyses (Ref. C.6.24). The use of mean values implies that an uncertainty analysis must be performed. Reflecting this, the guidance for PRA use in issue resolution (Chapter B.4) indicates the need for uncertainty analyses and the use of mean values.

A particular concern in the analysis of rare events is the treatment of the tails of the distributions. The analysis may predict an extremely low likelihood of catastrophic events. Those not familiar with risk analysis often key 


\section{C.6 Uncertainty and Sensitivity \\ C.6.4 Display and Interpretation of Uncertainties}

on the extreme events (e.g., catastrophic accidents killing tens of thousands of people) without considering their likelihood. For example, if an event can be expected to occur once every trillion years, it may reasonably be neglected in the analysis. Some analyses, such as the NUREG-1150 study (Ref. C.6.4), displayed many of the output distributions with the tails truncated so that events that were extremely improbable were not displayed. The choice of a truncation level is based on judgment, considering the overall risk profile that is being portrayed. References C.6.25 and C.6.26 provide recommended cutoff levels for most PRAs:

- $10^{-7}$ for plant damage state frequencies

- health risks at $10^{-2}$ to $10^{-3}$ times the normal occurrence rate

- $10^{-7}$ to $10^{-8} /$ reactor year for risk curves

Data, assumptions, and models are seldom refined enough to serve as a basis for these small quantities, even though they can be computed. Smaller estimates than listed above should not simply be dismissed, but the analysis has the burden of justifying them, which will be difficult. Because they would be regarded with much skepticism, smaller estimates, if they are displayed, should not play much if any role in regulatory decisions. These guidelines should be considered approximate, depending upon the particular intent of the display.

\section{Guidance: Careful discussions should accompany the display of the tails of a distribution.}

\section{C.6.4.1 PDFs and CDFs}

PRA uncertainties are often displayed as either probability density functions (PDFs) or cumulative distribution functions (CDFs) ${ }^{38}$ The meaning and interpretation of these functions is discussed in Section C.2.2.1.2 (page C-21) and will not be repeated here.

\section{C.6.4.2 CCDFs and Risk Curves}

Complementary cumulative distribution functions (CCDF) and risk curves are commonly displayed in PRAs, particularly as an output from a Level 3 PRA analysis. A CCDF is complementary to the CDF;

$$
\mathrm{CCDF}=1-\mathrm{CDF} .
$$

The CDF shows the probability that a parameter value less than or equal to the chosen value will be achieved, while the CCDF shows the probability that a parameter value greater than the chosen value will be achieved. While CCDFs have their place in risk assessments, they are often confusing to the uninitiated and should be used with caution.

Based on the axioms of probability, CCDFs and CDFs are both bounded between zero and one. Risk curves are similar in appearance to CCDFs, but use frequency rather than probability as the dependent variable and are not bounded between zero and one (frequency can exceed one). The risk curve allows one to determine the frequency with which a particular consequence level will be exceeded. Figure C.6.4 shows an example of a risk curve. For example, in Figure C.6.4 it can be seen that the frequency of accidents resulting in 1 or more latent cancer fatalities is approximately 0.05 per year. It is common to display risk curves on a logarithmic scale. When the logarithmic scale is used, a lower truncation value must be selected. This choice of truncation value dictates the magnitude of consequences that will be displayed. Lower truncation values correspond to greater consequences.

\footnotetext{
${ }^{38}$ Here, the acronym CDF refers to cumulative distribution function. Elsewhere in Appendix C, the same acronym also refers to core damage frequency. Both uses are common and are distinguished by the context of their use. 


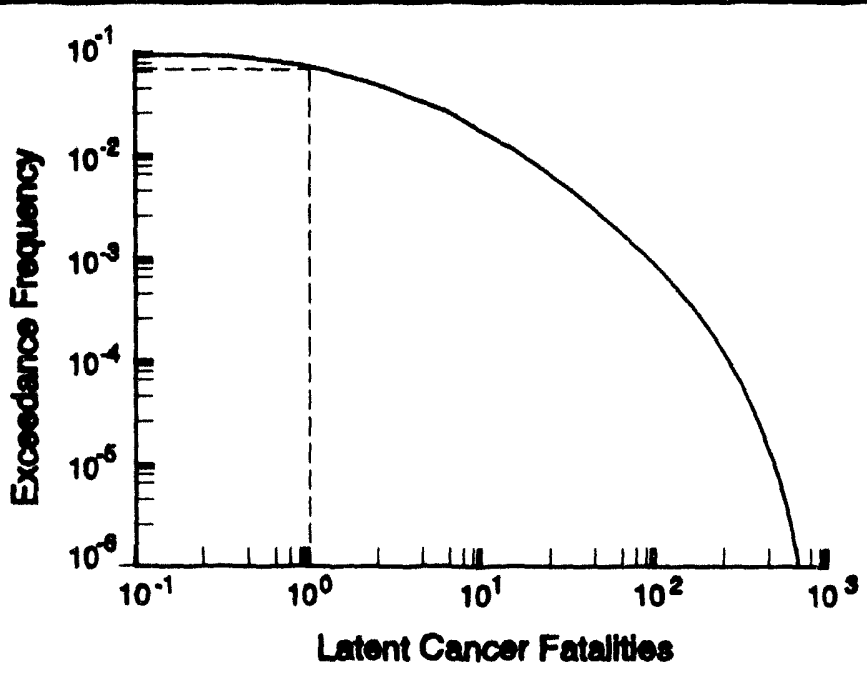

Figure C.6.4 Risk curve from a Monte Carlo sample

\section{C.6.4.3 Box and Whisker Plots}

Box and whisker plots are sometimes used to characterize the magnitude of the uncertainty without specifying the shape of a distribution function. Figure C.6.5 depicts a box and whisker plot. In this case, the box represents the uncertainty range from the $25^{\text {th }}$ to the $75^{\mathrm{th}}$ quantiles, and the whiskers represent the range from the $5^{\text {th }}$ to $95^{\text {th }}$ quantiles. On occasion, analysts will select different quantiles for display, so it is important to ascertain the particular quantiles chosen. Medians are normally dispiayed on the plots, and means are sometimes displayed. Sometimes only a box plot (without the whiskers) is presented, depicting a selected uncertainty range. Past experience indicates that box plots are relatively effective tools for communicating with those who are unfamiliar with risk assessment.

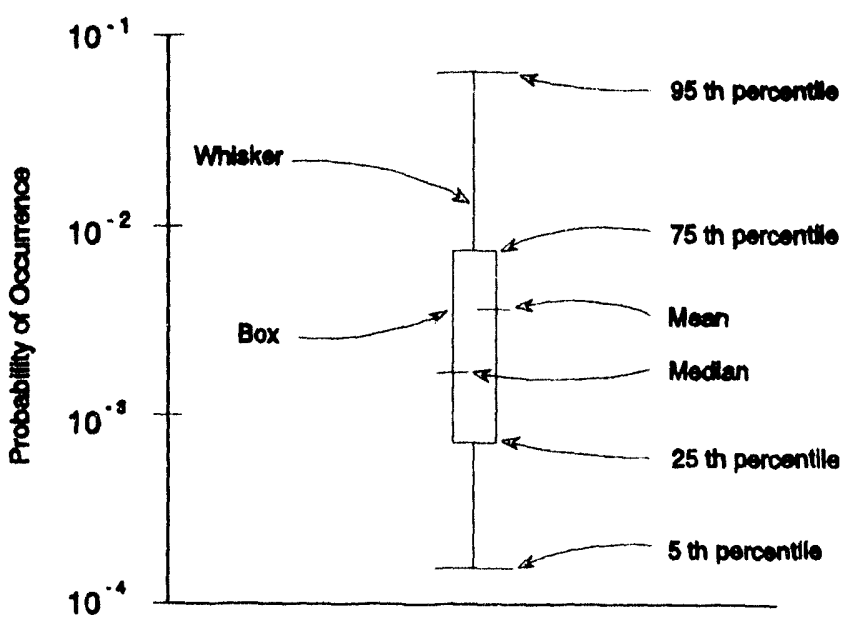

Figure C.6.5 Box and whisker plot 


\section{C.6.4.4 Histograms}

A histogram is an effective tool for displaying the results of sampling analyses. A histogram is developed by simply counting the number of outcomes that fall within a given range. Figure C.6.6 shows an example of a histogram of the type that was presented in the NUREG-1150 study (Ref. C.6.4). In this particular case, the axis is divided into equal intervals on a logarithmic scale. The length of each bar is proportional to the number of LHS results that fell within that interval. The probability density function of the log frequency can be approximated by dividing the histogram lengths by the product of the log interval widths and the total histogram lengths. The accuracy of the approximation depends on the sample size and the number of intervals used in forming the histogram. It is unnecessary for each interval to contain sample members.

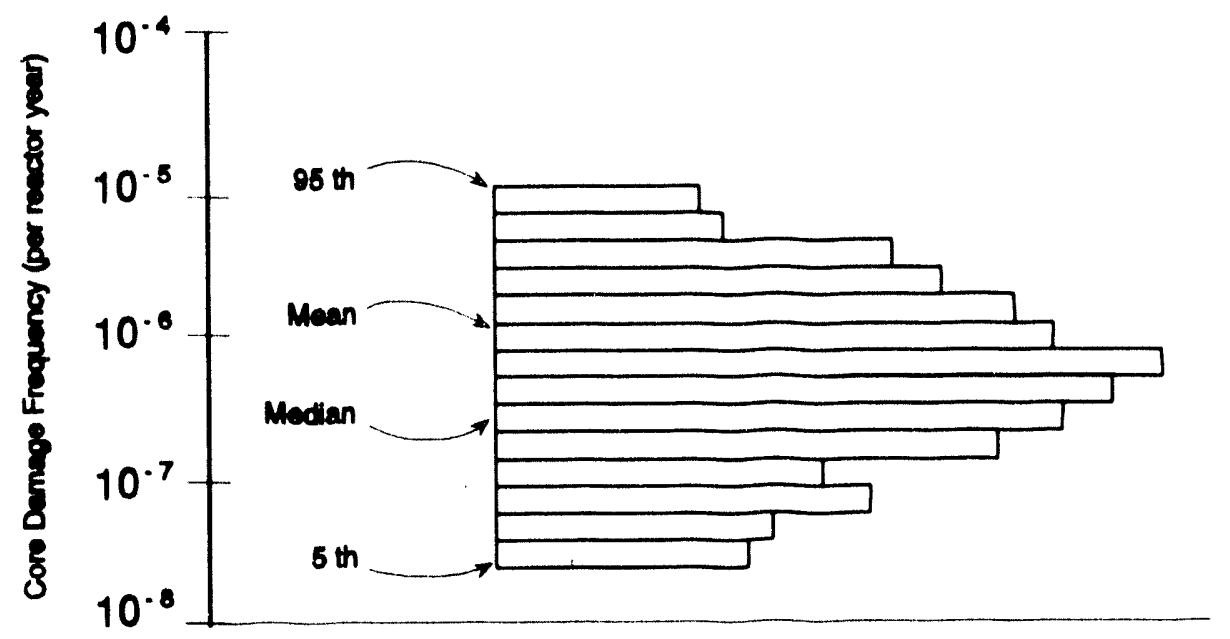

Figure C.6.6 Histogram display

\section{C.6.4.5 Multiple Distribution Displays}

Thus far, the development of individual output distributions (describing the uncertainty in an output variable) has been discussed. Often, it is also important to know the uncertainty in the output distribution itself. In that case, a family of curves or a distribution of curves may be developed, rather than a single probability distribution. At least two approaches are used to create such multiple distribution representations. In some cases, a particular variation (e.g., lognormal) will be assumed about the distribution and this variation will represent the uncertainty in the parameters of the distribution. This technique is often used when time-reliability type curves are being generated. Figure C.6.7 displays a distribution assumed about the time-reliability curve for recovering off-site power. The uncertainty in the result at a given time is represented by the width of the assigned distribution at that time.

Another approach is used to display the output when multiple outcomes are possible. For example, if Latin Hypercube or Monte-Carlo sampling is used for a Level 3 PRA evaluation, then a single observation will produce 


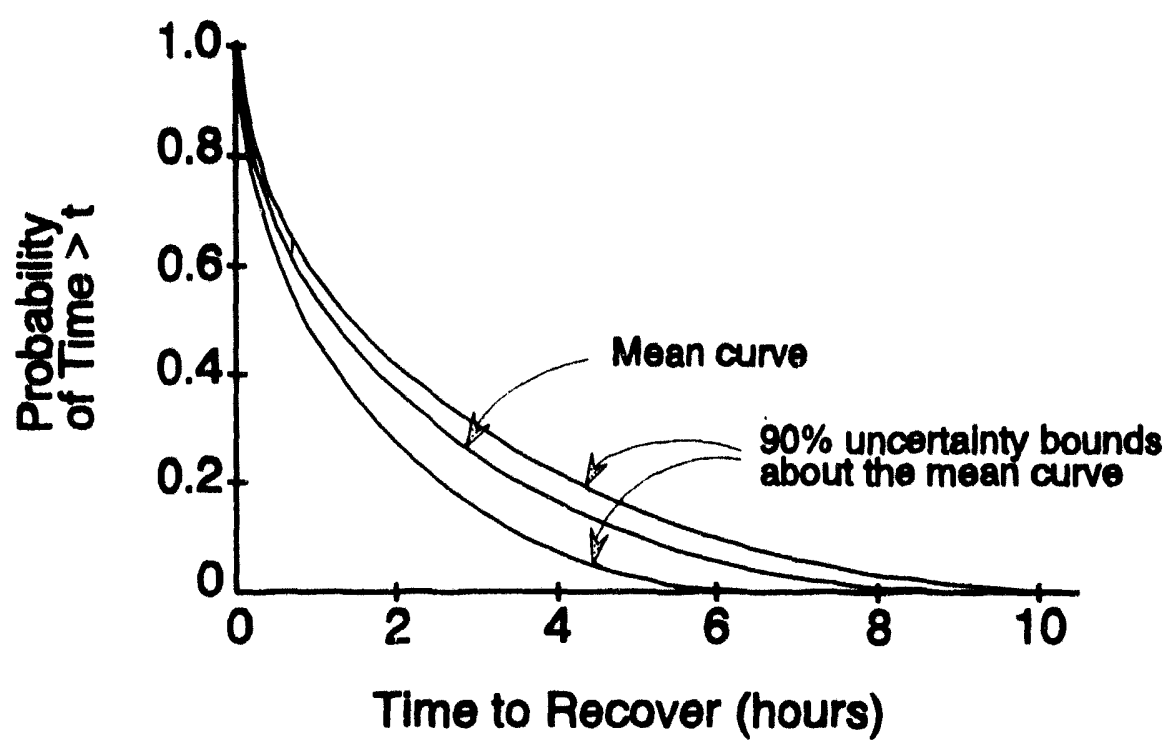

Figure C.6.7 Uncertainty in time-dependent recovery

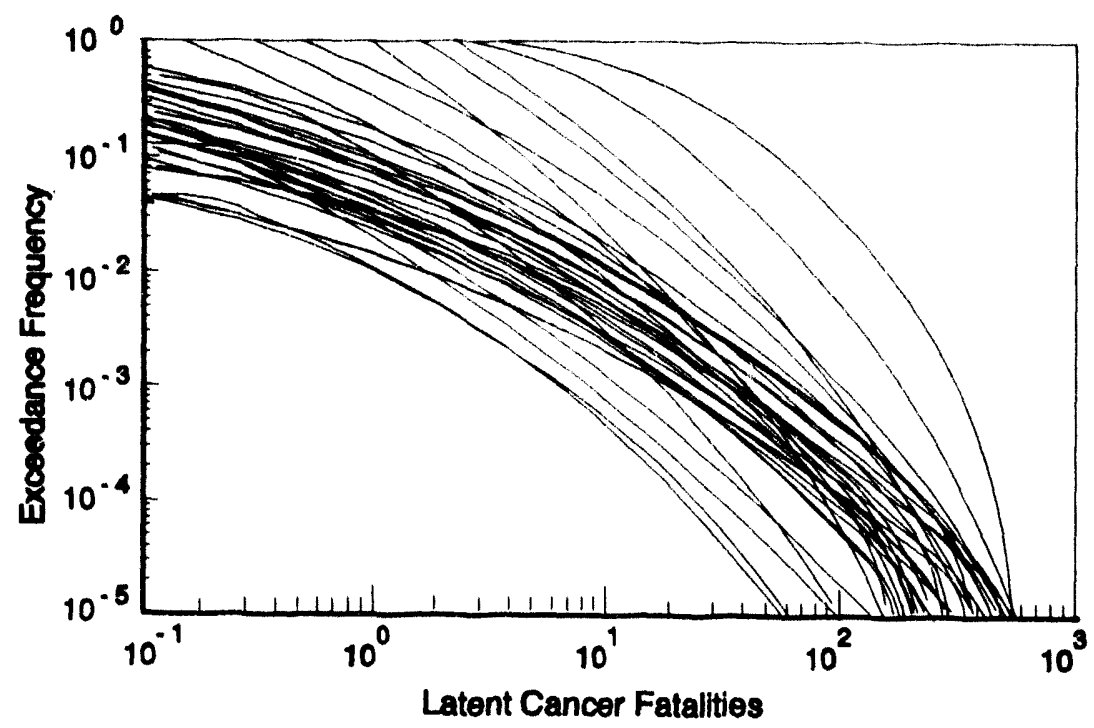

Figure C.6.8 Family of risk curves

many outcomes, each with a different consequence. This variation can be represented as a CCDF or risk curve. However, the input variables leading to this CCDF or risk curve are uncertain, and each of the repeated observations will lead to a different risk curve. The overall results of such sampling can be displayed as the entire family of such curves. This family of curves can be further processed to determine a set of curves representing the quantiles for each point along the $\mathrm{x}$-axis. Figures C.6.8 and C.6.9 show the result of such an 
C.6 Uncertainty and Sensitivity

C.6.5 Methods - Sensitivity Analysis

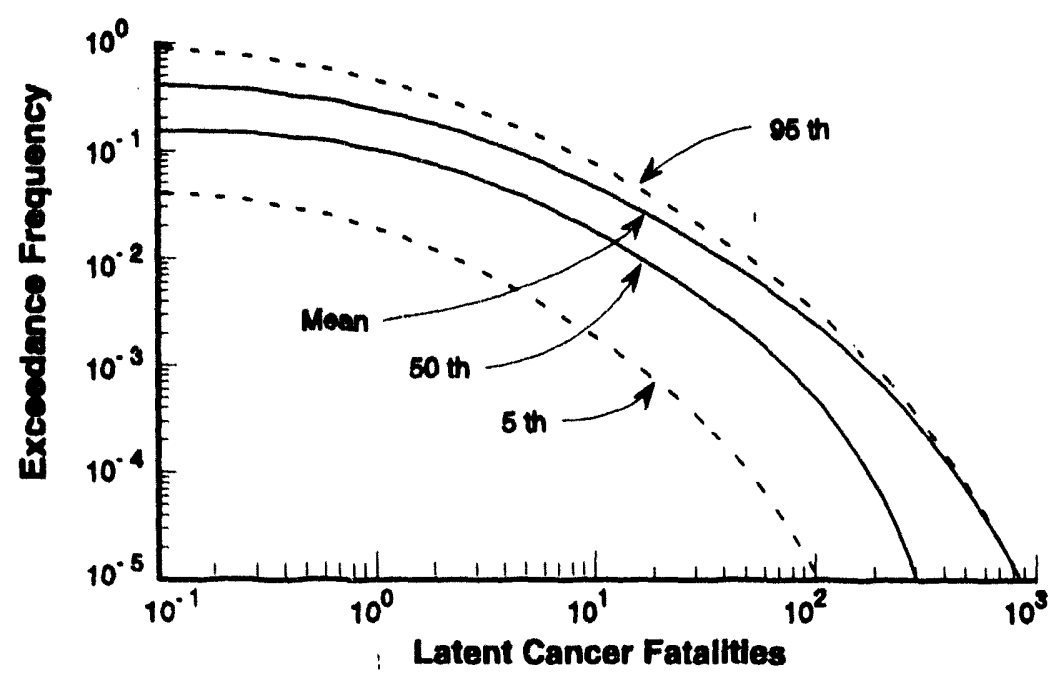

Figure C.6.9 Ouantiles about a risk curve ,

approach; Figure C.6.9 has been extracted from Figure C.6.8. The meaning of the repeated calculations and quantile values depends on the method of analysis. The particular method to be used is driven by the purpose of the analysis. Sometimes the individual risk curves represent alternative sensitivity cases, with a particular value or set of values varied in a manner distinct from the base case analysis. In other cases, the analyst may be attempting to display different types of uncertainty, that is, the individual curves reflect one type of uncertainty while the differences between curves reflect another type of uncertainty. These differences are complicated and difficult to understand. Because of their complexity, multiple distribution displays are generally of value only to risk assessment experts. Additional information is in References C.6.6 and C.6.13.

\section{C.6.5 Methods - Sensitivity Analysis}

There are many different techniques for performing sensitivity analyses. In general, these techniques are designed to determine the importance of key assumptions and parameter values to the results. The most commonly applied methods are "one-at-a-time" methods, in which assumptions and parameters are examined individually. These methods are very valuable and powerful, because the analyst can vary virtually any input or model and perform a carefully controlled analysis of its importance. However, because they do not capture the full effect of interactions among variables, one-at-a-time methods should be used with caution.

Sometimes groups of variables are changed, but the groupings are based on the judgment of an analyst who wishes to understand certain relationships. The possibilities for sensitivity studies are almost limitless. The analyst simply has to change a parameter value (or distribution) or the form of the model and rerun the calculation (sometimes only portions of the calculation). Sensitivity calculations provide insights, but do not necessarily reflect valid hypotheses. Setting a variable to zero or one does not mean that zero or one is a valid possibility. While such calculations can be performed arbitrarily at the discretion of the PRA analyst, there are some systematic approaches for performing sensitivity studies. Some of the most commonly applied methods are discussed below. 
Importance calculations are routinely performed in PRAs, particularly in the Level 1 portion, to determine the contribution of particular input variables. These calculations systematically consider all the variables in the input model on a one-at-a-time basis. While there are many variations, importance measures generally fall into one of four groups:

1. Risk Reduction

2. Risk Increase

3. Uncertainty Importance

4. Partial Derivative

Each of these is discussed below. Additional information concerning these and other importance measures and methods of computation is contained in References C.6.18 and C.6.27 - C.6.30.

\section{C.6.5.1 Risk Reduction Importance Measure}

\section{C.6.5.1.1 General}

The risk reduction is a measure of the change in the output variable (usually core damage frequency) as a result of setting an input variable to zero. The calculation may be done as a ratio or a difference. This measure applies only to probabilities and frequencies. Risk reduction importance calculations involve eliminating a postulated failure to determine how much better the plant would be if a problem were perfectly fixed. Because there is uncertainty in the output distribution, there is related uncertainty in the risk reduction values.

When estimated in conjunction with an LHS uncertainty analysis, variables are set to zero on a one-at-a-time basis, while the other variables are sampled in the usual manner.

Giuidance: Those component failures, human errors, and initiating events with high risk reduction values are candidates for efforts to improve reliability and reduce risk.

\section{C.6.5.1.2 Fussell-Vesely Importance Measure}

The Fussell-Vesely importance measure is the risk reduction measure normalized to the core damage frequency. ${ }^{39}$ It is an indication of the fraction of the minimal cut set upper bound (or sequence frequency) that involves the cut sets containing the basic event of concern. It is calculated by finding the minimal cut set upper bound of those cut sets containing the basic event of concern and dividing it by the minimal cut set upper bound of the top event (or of the sequence). The equation of the Fussell-Vesely importance measure is as follows:

$$
F V=[F(x)-F(0)] / F(x)
$$

where $F(x)=$ minimal cut set upper bound (sequence frequency) evaluated with the basic event probability at its mean value

$\mathbf{F}(0)=$ minimal cut set upper bound (sequence frequency) evaluated with the basic event probability set to zero

\footnotetext{
"This is a loose usage of the term risk. See Section C.4.4.4 (page C-107) for discussion.
} 


\section{C.6.5.2 Risk Increase Importance Measure}

The risk increase (sometimes called risk achievement) importance measure is essentially the reverse of the risk reduction importance measure. For risk increase calculations, the values for the input variables are set to one, and the output variables are recalculated. The calculation may be done as a ratio or a difference. This measure is meaningful only for variables that can be represented as probabilities. For example, initiating event frequencies can assume values greater than one and should not usually be calculated using this measure.

Guidance: The risk increase measure is useful for assessing which elements of the risk model are the most crucial for maintaining risk at current levels.

Elements with high risk increase values are the ones that will have the most impact if their failure rate should unexpectedly increase. As with risk reduction, uncertainty in the risk increase estimates is usually included.

\section{C.6.5.3 Uncertainty Importance}

The uncertainty importance measure focuses on the contribution of a particular input variable to uncertainty in the output. In the method described in Reference C.6.30, the uncertainty importance is estimated with respect to the variance in the output distribution. In particular, if the variance of a particular input distribution is set to zero, how much is the variance in the output distribution reduced? Using a Monte Carlo simulation approach (with either SRS or LHS), the uncertainty importance can be readily determined by fixing the input variable at its expected value and repeating the sampling analysis to recalculate the output distribution. However, because of volatility in estimating the expected values of skewed distributions and sensitivity to the shapes of the tails of, the distributions, the calculation is often performed on a logarithmic scale, that is, with respect to the variance in the logarithm of the output variable.

Another approach for estimating uncertainty importance involves examining the response of fixed quantiles of the output distribution, such as the 0.05 and 0.95 quantile, to changes in the uncertainties in the input parameters. This approach calculates a ratio, $R_{.05}$, of the 0.05 quantile of the output distribution, when the individual input variable is held at its mean value, to the 0.05 quantile from the basic uncertainty calculation. A similar ratio, $\mathrm{R}_{99}$, is calculated for the 0.95 quantiles. These quantiles allow the analyst to consider how the overall output distribution may be shifted as a result of eliminating selected uncertainties. Some new approaches for examining uncertainty importance are described in References C.6.3 and C.6.31.

\section{C.6.5.4 Birnbaum's Structural Importance Measure}

The Birnbaum importance measure is an indication of the sensitivity of the accident sequence frequency to a particular basic event (Ref. C.6.28). The approach is a partial derivative approach, where the partial derivative of the cut set expression is taken with respect to each basic event. In practice, the partial derivative is often approximated by the following expression:

$$
\begin{aligned}
B=F(1)-F(0) & \text { where } F(1)=\quad \begin{array}{l}
\text { accident sequence frequency evaluated } \\
\text { with the chosen basic event probability set to unity }
\end{array} \\
\mathrm{F}(0)= & \begin{array}{l}
\text { accident sequence frequency evaluated with the } \\
\text { chosen basic event probability set to zero }
\end{array}
\end{aligned}
$$


C.6 Uncertainty and Sensitivity C.6.5 Methods - Sensitivity Analysis

This is exactly correct if the cut set expression is linear in the selected event and the selected event is independent of all other events. This is often not the case in PRA; Birnbaum importance calculations must be carefully examined.

Partial derivative measures tend to overemphasize the importance of variables with small values. Because basic event probabilities in PRA can vary over several orders of magnitude, Birnbaum importance measures should not be used as the sole measure of the importance of an event.

\section{C.6.5.5 Other Sensitivity Methods}

The importance methods described in the previous section are generally applied to Level 1 PRA models. There are additional techniques available, some of which can be applied to both Level 1 PRA models and Level 2 and 3 models.

\section{C.6.5.5.1 Regression Techniques}

Regression analysis is a method for approximating the relationship between an output variable and one or more input variables. In PRA, regression methods are important in helping to identify the input variables that are influential contributors to the uncertainty in the output variable. In linear regression analysis, a linear equation is developed and its predictions are compared to actual output (i.e., risk estimates). Simple linear regression accounts for only one input variable, while multiple linear regression (most commonly used in PRA) accounts for two or more inputs simultaneously. Many different variations of regression analysis exist and are discussed in the literature (Refs. C.6.32 - C.6.34). Linear regression refers to the formulation of the regression equations; nonlinear PRA models can be treated within this framework. Nonlinear regression methods are rarely used in PRA because of their complexity. Rank regression involves ranking the values from the observations and performing the regression analysis on the ranks, rather than on the actual data.

\section{C.6.5.5.2 Multivariate Analyses}

One-at-a-time sensitivity studies are relatively straightforward to perform and interpret. However, in complex PRA models there are often complex interactions and dependencies among the variables. For example, the occurrence of a catastrophic steam explosion might depend on the values of two input variables, the fraction of the core slumping into the lower plenum and the amount of water present. Changing the two variables individually to their extreme conservative values might produce benign results, while changing them simultaneously to their extreme values might result in a catastrophic explosion. Currently, finding such interactions among variables and evaluating their importance is dependent upon the insights and expertise of the technical specialists and PRA analysts. However, there are some methods, such as regression techniques, that can be considered for multivariate analysis, and new methods are under development. More information on these advanced topics is provided in References C.6.14, C.6.35, and C.6.36.

\section{C.6.6 Selecting Variables for an Uncertainty Analysis}

Typically, uncertainty analyses consider only a subset of the parameters and models that are included in a PRA. Variables not included in the uncertainty analysis are held fixed at a nominal (usually mean) value while the other parameters are varied. This lack of completeness in treatment is due primarily to computational limitations associated with sampling processes. The number of observations needed in a sampling process increases with the number of parameters included in the analysis. Further, computer storage requirements and analyst time in developing distributions increase significantly. In the NUREG-1150 study (Ref. C.6.4), a few hundred (out of thousands) of the input parameters were varied in the risk uncertainty analyses. 
C.6 Uncertainty and Sensitivity

C.6.5 Methods - Sensitivity Analysis

\section{Guidance: Given practical limitations, it is important that the key variables be carefully selected and that most of the uncertainty be captured in the analysis.}

There is no rigorous analytical way to select the variables for an uncertainty analysis. The current practice is to use past PRAs and sensitivity studies. The NRC staff should consult with experts in uncertainty analysis.

When beginning an uncertainty analysis, there are often many variables for which probability distributions have not been generated. If resource limitations prevent an in-depth evaluation of many variables, then it is important that the most significant variables be selected for treatment. There are various techniques that can be applied to identify those variables that are most important to the uncertainty. Sensitivity techniques, such as described in Section C.6.5, can provide some insights into the variables that are likely to be most important. Scoping studies with uncertainty analyses are also useful in this regard; such scoping studies do not involve extensive efforts to find and utilize available information and often result in relatively large uncertainties for the variablcs in question. Regression analyses and other techniques can then be used to determine whether or not particular variables are sufficiently important to warrant the development of more precise distributions. Examples of methods to assign distributions in these scoping studies include the maximum entropy approach (Section C.2.3, page C-30) or zero-one sampling.

The NRC staff is conducting research into selecting inputs for a detailed uncertainty analysis. Based on this work, a procedure that can be applied for either the maximum entropy or zero-one sampling approaches to identify the most important variables is presented below:

1. Identify and list all inputs that are candidates for the uncertainty analysis.

2. Assign accurate distributions for all inputs for which such distributions are available.

3. Assign maximum entropy or zero-one distributions to the remaining variables.

4. Perform an uncertainty analysis and use regression analysis or other techniques to screen out variables unimportant to the uncertainty, realizing that variables can be unimportant to uncertainty, but important to risk.

5. Expend appropriate resources to develop more realistic distributions for those variables that significantly affect the uncertainty.

6. Perform the final uncertainty analysis.

In some cases, probability distributions are available for most of the variables, but there are simply too many variables to include in the analysis. In this case, the analysis can be broken into parts, such as core damage frequency and accident progression, and each part can be examined in detail. The most important variables from each part can then be included in the overall analysis.

In the NUREG-1150 studies (Ref. C.6.4), a detailed treatment of the Level 1 uncertainties was obtained and then the most important variables affecting the uncertainty were carried forward to the integral Level 3 analysis. The Level 1 uncertainties were recalculated, varying only the subset of variables to ensure that the output distributions did not change significantly. This approach can be applied to all parts of the PRA. The most important limitation of this approach is that different measures are being used to evaluate each part of the PRA. A variable that had little impact on the uncertainty in core damage frequency was not included in the overall risk uncertainty calculation, but it might have had an impact on accident progression or parts of the overall analysis. 
Sensitivity studies can provide additional information on the selection of variables, but there is currently no rigorous approach that can be applied.

\section{C.6.7 Correlations and Dependencies}

Correlations and dependencies among variables were defined in Section C.2.2.1.2 (page C-19). Here, the impact of correlation on uncertainty and sensitivity results is briefly discussed. The previous section noted that one-at-atime sensitivity studies can be misleading if correlations among key variables are not considered.

Guidance: Often the effect of correlations and dependencies is to increase the magnitude of the uncertainties, extending the tails of the output distributions.

In an analysis based on sampling, more samples are often produced at the high and low ends of the distributions. Mathematically, correlation can result in either increases or decreases in the magnitude of the uncertainties and the mean values. However, the dominant correlations in many PRA models tend to be of the type that increase both the magnitude of the uncertainty and the mean values, although the median may be largely unaffected. Therefore, the reader should note that both the mean value and the uncertainty are probably underestimated if correlation has not been properly included. For more information on correlation and its impact on uncertainty analysis, see References C.6.5, C.6.32, C.6.33, and C.6.37.

\section{C.6.8 Completeness}

Uncertainties and sensitivities can only be addressed for those variables and modeling assumptions that can be propagated through the PRA model. For example, if some human error or external events are not included, the uncertainty analysis is incomplete. Throughout Chapter C.3, many issues were identified that are difficult to model or are often not modeled at all in current PRAs. These issues include some types of human errors and time dependencies.

\section{Guidance: Incompleteness in the uncertainty analysis will result in an underestimate of the uncertainty.}

In some cases sensitivity studies can be formulated to assess the significance of these issues; however, such studies are usually very limited in scope.

\section{C.6.9 Plant-to-Plant Variability}

The difficulties of applying the data and models from one plant to other plants are discussed in Section C.2.4 (page C-32). Similarly, it is not generally valid to extend uncertainty and sensitivity results performed on one plant to other plants. Such an extension would introduce a new source of uncertainty that could not be readily assessed. The NUREG-1150 study (Ref. C.6.4) and other studies have shown that the magnitude of the uncertainty varies substantially among plants and that the importance calculations produce very different results. Uncertainty and sensitivity results from another plant can be used to perform a reasonableness check to see if all important uncertainties have been considered and to see if uncertainties are being treated consistently from one plant to another.

Guidance: In general, extending uncertainty and sensitivity results performed on one plant to other plants is invalid. 
C.6 Uncertainty and Sensitivity

C.6.10 Summary

\section{C.6.10 Summary}

This section provides an introduction to the concepts associated with uncertainty and sensitivity analysis. The basic points to be obtained are as follows:

- Uncertainty and sensitivity studies should accompany most PRA studies that are to be used in issue analysis and resolution (see Chapter B.4).

- For PRA uses in screening issues, uncertainty analyses are considered unnecessary but sensitivity studies are recommended (see Chapter B.3). When screening issues, a formal uncertainty analysis is in general unnecessary. Nevertheless, uncertainties that could influence priorities need to be identified. This can be done with a sensitivity analysis.

- There are different types of uncertainty. The scope of an uncertainty analysis should be clearly delineated.

- The methods used in uncertainty and sensitivity studies should be identified. Each method has its own strengths and weaknesses.

- Displays of uncertainty should be no more complex than necessary for the decisionmaker.

- Bayesian methods are generally accepted as the most practical for most modern PRA studies.

- The selection of variables and the treatment of correlation and dependencies are important factors in an uncertainty analysis.

- Uncertainty results can not generally be extended to other plants. 


\section{REFERENCES FOR CHAPTER C.6}

C.6.1 J.W. Hickman, "PRA Procedures Guide," NUREG/CR-2300, Volume 1, NRC, January 1983.

C.6.2 Y.-T. Wu et al., "Uncertainty Evaluation Methods for Waste Package Performance Assessment," NUREG/CR-5639, NRC, January 1991.

C.6.3 M. D. McKay, "Latin Hypercube Sampling as a Tool in Uncertainty Analysis of Computer Models," Proceedings of the Winter Simulation Conference, Arlington, Va, December 13-16, IEEE, 1992.

C.6.4 NRC, "Severe Accident Risks: An Assessment for Five U.S. Nuclear Power Plants," NUREG-1150, Volumes 1 and 2, Appendices A, B, and C, December 1990; Volume 3, Appendices D and E, January 1991.

C.6.5 M. P. Bohn, T.A. Wheeler, and G.W. Parry, "Approaches to Uncertainty Analysis in Probabilistic Risk Assessment," NUREG/CR-4836 (Sandia National Laboratories, SAND87-0871), NRC, January 1988.

C.6.6 S. Kaplan and B.J. Garrick, "On the Quantitative Definition of Risk," Risk Analysis, Volume 1, pp. 1127, 1981.

C.6.7 G. W. Parry, "On the Meaning of Probability in Probabilistic Safety Assessment," Reliability Engineering and System Safety, Volume 23, pp. 309-314, 1988.

C.6.8 G. W. Parry, "On One Type of Modeling Uncertainty in Probabilistic Risk Assessment," Nuclear Safety, Volume 24, pp. 624-627, 1983.

C.6.9 G. E. Apostolakis, "Uncertainty in Probabilistic Safety Assessment," Nuclear Engineering and Design, Volume 115, pp. 173-179, 1989.

C.6.10 N. Siu and G. Apostolakis, "On the Quantification of Modeling Uncertainty," 8th International Conference on Structural Mechanics in Reactor Technology, Brussels, Belgium, August 19-23, Community of European Communities (CEC), 1985.

C.6.11 G.W. Parry, "A Discussion on the Use of Judgment in Representing Uncertainty in PRAs," Nuclear Engineering and Design, Volume 93, pp. 135-144, 1986.

C.6.12 G. Apostolakis, "The Concept of Probability in Safety Assessments of Technological Systems," Science, Volume 250, pp. 1359-1364, 1990.

C.6.13 J. C. Helton et al., "Sensitivity Analysis Techniques and Results for Performance Assessment at the Waste Isolation Pilot Plant," SAND90-7103, Sandia National Laboratories, March 1991.

C.6.14 S. Chhibber et al., "A Probabilistic Framework for the Analysis of Model Uncertainty," Trans IChemE, Volume 69, Part B, May 1991.

C.6.15 H.F. Martz et al., "A Con r wison of Methods for Uncertainty Analysis of Nuclear Power Plant Safety System Fault Tree Models," NUREG/CR-3263 (Los Alamos National Laboratory, LA-9729-M5), NRC, June 1983. 
C.6.16 S.C. Hora and R.L. Iman, "A Comparison of Maximus/Bounding and Bayes/Monte Carlo for Fault Tree Uncertainty Analysis," SAND85-2939, Sandia National Laboratories, March 1986.

C.6.17 M.D. McKay et al., "A Comparison of Three Methods for Selecting Values of Input Variables in the Analysis of Output from a Computer Code," Technometrics, Volume 21, No. 2, pp. 239-245, May 1979.

C.6.18 R.L. Iman and M.J. Shortencarier, "A FORTRAN 77 Program and User's Guide for the Generation of Latin Hypercube and Random Samples for Use with Computer Models," NUREG/CR-3624 (Sandia National Laboratories, SAND83-2365), NRC, June 1984.

C.6.19 H. F. Martz and Ray A. Waller, Bayesian Reliability Analysis, Krieger, Malabar, Florida, 1991.

C.6.20 S. Kotz and N. Johnson (eds.), Encyclopedia of Statistical Sciences, Wiley and Sons, 1985.

C.6.21 S. Kaplan, "On the Method of Discrete Probability Distributions in Risk and Reliability Calculation -Application to Seismic Risk Assessment," Risk Analysis I, pp. 189-196, 1981.

C.6.22 A. I. Khuri and J. A. Cornell, Response Surfaces, Marcel Dekker, Inc. 270 Madison Ave. NY, NY 10016, 1987.

C.6.23 R.G. Easterling, F.W. Spencer, and K.V. Diegert, "Estimation, Uncertainty Analysis, and Sensitivity Analysis: Directions for RMIEP," Sandia National Laboratories, January 4, 1985."

C.6.24 R. Emrit et al., "A Prioritization of Generic Safety Issues," NUREG-0933, Main Report and Supplements $1-12$, NRC, July 1991.

C.6.25 H.J.C. Kouts et al., "Special Committee Review of the Nuclear Regulatı ; Commission's Severe Accident Risk Report (NUREG-1150)," NUREG-1420, NRC, August 1990.

C.6.26 T. Molina, "Proceedings of the CSNI Workshop on PSA Applications and Limitations," NUREG/CP0115 (Sandia National Laboratories, SAND90-2797), NRC, February 1991.

C.6.27 W.E. Vesely et al., "Measures of Risk Importance and Their Applications," NUREG/CR-3385 (Battelle Memorial Institute, BMI-2103), NRC, July 1983.

C.6.28 E.J. Henley and H. Kumamoto, Reliability Engineering and Risk Assessment, Prentice-Hall Inc., 1981.

C.6.29 R. A. Barlow et al., Reliability and Fault Tree Analysis, Society for Industrial and Applied Mathematics, 33 South 17 Street, Philadelphia, PA 19103, 1975.

C.6.30 R.L. Iman and S.C. Hora, "A Robust Measure of Uncertainty Importance for Use in Fault Tree System Analysis," Risk Analysis, Volume 10, No. 3, 1990.

C.6.31 M.D. McKay et al., "An Alternative View of Sensitivity in the Analysis of Computer Codes," Proceedings of the American Statistical Association Section on Physical and Engineering Sciences, Boston, MA, August 9-13, American Statistical Association, 1992.

\footnotetext{
- Copies are available for inspection or copying for a fee in the NRC Public Document room.
} 
C.6.32 R.L. Iman and W.J. Conover, "Sensitivity Analysis Techniques: Self-Teaching Curriculum," NUREG/CR-2350 (Sandia National Laboratories, SAND81-1978), NRC, June 1982.

C.6.33 R. L. Iman and W. J. Conover, Modem Business Statistics, Second Edition, John Wiley \& Sons, 1989.

C.6.34 B. Ostle, Statistics in Research, Iowa State University Press, 1964.

C.6.35 M. E. Johnson, Multivariate Statistical Simulation, John Wiley \& Sons, 1987.

C.6.36 Letter from M. D. McKay, Los Alamos National Laboratory, to C. Lui, U. S. Nuclear Regulatory Commission, Subject; Details of Sensitivity Analysis and Uncertainty Analysis Task To Be Done at LANL, dated September 15, 1992."

C.6.37 Q. Zhang, "A General Method Dealing with Correlations in Uncertainty Propagation in Fault Trees," Reliability Engineering and System Safety, Volume 26, pp. 231-247, 1989.

\footnotetext{
- Copies are available for inspection or copying for a fee in the NRC Public Document room.
} 


\section{INDEX}

Accident progression $\ldots \ldots \ldots \ldots \ldots \ldots \ldots \ldots \ldots \ldots, \mathbf{C}-85$

analysis $\ldots \ldots \ldots \ldots \ldots \ldots \ldots \ldots \ldots \ldots \ldots, \mathbf{C}-84$

analysis in the NUREG-1150 study $\ldots \ldots \ldots \ldots \ldots$ C-109

back-end analysis $\ldots \ldots \ldots \ldots \ldots \ldots \ldots \ldots \ldots, \mathrm{C}-10$

bin $\ldots \ldots \ldots \ldots \ldots \ldots \ldots \ldots \ldots \ldots \ldots \ldots, \mathbf{C}-85$

containment event tree (CET) $\ldots \ldots \ldots \ldots \ldots \ldots$, C-84

defined $\ldots \ldots \ldots \ldots \ldots \ldots \ldots \ldots \ldots \ldots \ldots \ldots$, C-85

event tree $\ldots \ldots \ldots \ldots \ldots \ldots \ldots \ldots \ldots \ldots \ldots$, C-84

event tree, supplemented/unsupplemented . . . . . . C-89

frequency $\ldots \ldots \ldots \ldots \ldots \ldots \ldots \ldots \ldots \ldots$ C-85

relationship of APET and CET . . . . . . . . C-84

similarity to Level 1 event tree . . . . . . . . . . C 85

Accident progression analysis, methods

event tree size $\ldots \ldots \ldots \ldots \ldots \ldots \ldots \ldots \ldots \ldots \ldots$ C-86

event tree, composite vs. individual $\ldots \ldots \ldots \ldots \ldots$ C-90

event tree, supplemented/unsupplemented . . . . . . C C-89

Accident sequence analysis . . . . . . . . . . . C -49

Aggregate information

expert judgment $\ldots \ldots \ldots \ldots \ldots \ldots \ldots \ldots \ldots$, C-139

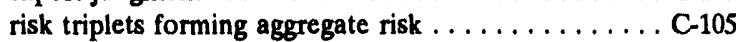

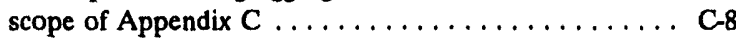

views from differing PRAs $\ldots \ldots \ldots \ldots \ldots \ldots \ldots, \mathrm{C}-8$

Aggregate risk

defined $\ldots \ldots \ldots \ldots \ldots \ldots \ldots \ldots \ldots \ldots$, C-105

Aggregation

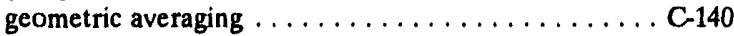

mathematical . . . . . . . . . . . . . . . . . . . C-140

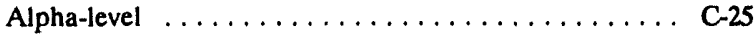

Alternative hypothesis $\ldots \ldots \ldots \ldots \ldots \ldots \ldots \ldots, \mathrm{C}-25$

Analysis

accident progression $\ldots \ldots \ldots \ldots \ldots \ldots \ldots \ldots$ C-84

accident progression and risk $\ldots \ldots \ldots \ldots \ldots \ldots, \mathbf{C}-73$

accident sequence $\ldots \ldots \ldots \ldots \ldots \ldots \ldots \ldots \ldots, C_{-49}$

back-end $\ldots \ldots \ldots \ldots \ldots \ldots \ldots \ldots \ldots \ldots$, C-10

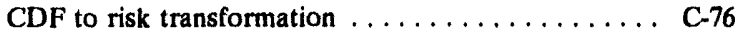

component reliability . . . . . . . . . . . . C 42

consequence $\ldots \ldots \ldots \ldots \ldots \ldots \ldots \ldots \ldots \ldots \ldots$ C-98

dependent failure $\ldots \ldots \ldots \ldots \ldots \ldots \ldots \ldots \ldots$ C-52

deterministic calculations $\ldots \ldots \ldots \ldots \ldots \ldots \ldots \ldots$ C-116

external events ................... C-60

fire $\ldots \ldots \ldots \ldots \ldots \ldots \ldots \ldots \ldots \ldots \ldots, \mathbf{C}-60$

human reliability $\ldots \ldots \ldots \ldots \ldots \ldots \ldots \ldots \ldots \ldots$ C-57

radionuclide release and transport $\ldots \ldots \ldots \ldots \ldots \ldots$ C-91

risk calculation $\ldots \ldots \ldots \ldots \ldots \ldots \ldots \ldots \ldots \ldots$. . . . . . . . . . .

seismic $\ldots \ldots \ldots \ldots \ldots \ldots \ldots \ldots \ldots \ldots \ldots \ldots$ C-60

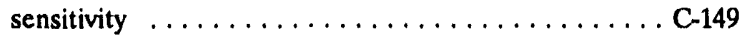

software reliability $\ldots \ldots \ldots \ldots \ldots \ldots \ldots \ldots \ldots \ldots,-62$

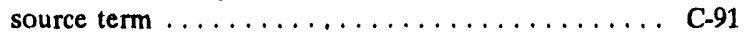

system reliability $\ldots \ldots \ldots \ldots \ldots \ldots \ldots \ldots \ldots$, C-44

uncertainty $\ldots \ldots \ldots \ldots \ldots \ldots \ldots$ C-149, C-154, C-158

APB $\ldots \ldots \ldots \ldots \ldots \ldots \ldots \ldots \ldots \ldots \ldots \ldots \ldots$

APET $\ldots \ldots \ldots \ldots \ldots \ldots \ldots \ldots \ldots \ldots \ldots \ldots$ C-84

Application-specific data $\ldots \ldots \ldots \ldots \ldots \ldots \ldots$, C-32

Asymptotic unavailability . . . . . . . . . . . C-44

Availability $\ldots \ldots \ldots \ldots \ldots \ldots \ldots \ldots \ldots \ldots$, C-44

bias, in expert judgment . . . . . . . . . . . . C-136

Axioms of probability . . . . . . . . . . . .

Back-end analysis . . . . . . . . . . . . . . C-10

defined (footnote) $\ldots \ldots \ldots \ldots \ldots \ldots \ldots \ldots \ldots$ C-73

Bathtub curve $\ldots \ldots \ldots \ldots \ldots \ldots \ldots \ldots \ldots, \mathrm{C}-42$
Bayes' theorem $\ldots \ldots \ldots \ldots \ldots \ldots \ldots \ldots \ldots$ C-140, C-151

Bayesian

estimation in statistics $\ldots \ldots \ldots \ldots \ldots \ldots \ldots \ldots \ldots, \quad \mathbf{C - 2 7}$

updating $\ldots \ldots \ldots \ldots \ldots \ldots \ldots \ldots \ldots \ldots \ldots \ldots$ C-27

Behavior

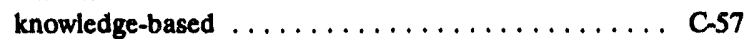

rule-based $\ldots \ldots \ldots \ldots \ldots \ldots \ldots \ldots \ldots \ldots \ldots \ldots$, C.57

Best estimate . . . . . . . . . . . . . . . . . . . C-159

defined $\ldots \ldots \ldots \ldots \ldots \ldots \ldots \ldots \ldots \ldots \ldots \ldots$, C-24

for decisionmakers . . . . . . . . . . . . . . . C-159

in expert judgment $\ldots \ldots \ldots \ldots \ldots \ldots \ldots$, C-142, C-159

in human reliability analysis $\ldots \ldots \ldots \ldots \ldots \ldots \ldots, C_{-57}$

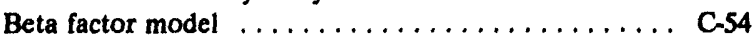

Beta family of distributions $\ldots \ldots \ldots \ldots \ldots \ldots \ldots$, C-32

Beta random variable $\ldots \ldots \ldots \ldots \ldots \ldots \ldots \ldots \ldots, \mathbf{C}_{-21}$

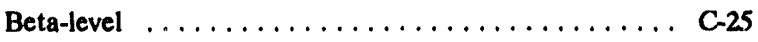

Bias

anchoring, in expert judgment $\ldots \ldots \ldots \ldots \ldots \ldots$ C-136

availability, in expert judgment $\ldots \ldots \ldots \ldots \ldots \ldots$ C-136

in expert judgment $\ldots \ldots \ldots \ldots \ldots \ldots \ldots \ldots \ldots \ldots$ C-136

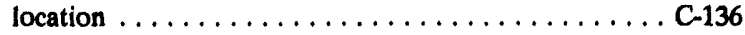

optimism, in expert judgment . . . . . . . . . . C-136

overconfidence, in expert judgment $\ldots \ldots \ldots \ldots \ldots$ C-136

psychological, in expert judgment . . . . . . . . . C-136

statistics $\ldots \ldots \ldots \ldots \ldots \ldots \ldots \ldots \ldots \ldots \ldots, C_{-23}$

stimulus spacing, in expert judgment $\ldots \ldots \ldots \ldots \ldots$ C-136

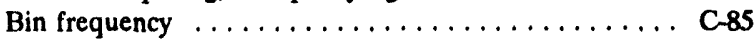

Binomial distribution $\ldots \ldots \ldots \ldots \ldots \ldots \ldots$, C-20, C-31

Birnbaum importance measure $\ldots \ldots \ldots \ldots \ldots \ldots \ldots$ C-166

Birnbaum's structural importance . . . . . . . . . C-166

Block diagram .................... C-45

Box and whisker plot $\ldots \ldots \ldots \ldots \ldots \ldots \ldots \ldots \ldots$ C-161

Calibration, in expert judgment $\ldots \ldots \ldots \ldots \ldots \ldots$ C-136

Causal dependencies $\ldots \ldots \ldots \ldots \ldots \ldots \ldots \ldots$ C-53

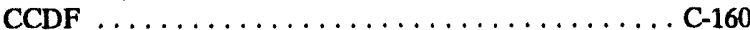

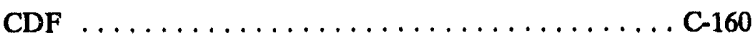

core damage frequency $\ldots \ldots \ldots \ldots \ldots \ldots \ldots, \mathrm{C}-76$

cumulative distribution function $\ldots \ldots \ldots \ldots, \mathrm{C}-21, \mathrm{C}-160$

Center of a distribution $\ldots \ldots \ldots \ldots \ldots \ldots \ldots \ldots \ldots, \mathbf{C}-23$

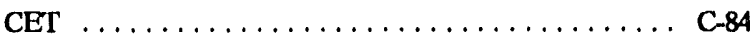

Chain rule $\ldots \ldots \ldots \ldots \ldots \ldots \ldots \ldots \ldots \ldots$ C-20, C-36

Clairvoyance test $\ldots \ldots \ldots \ldots \ldots \ldots \ldots \ldots \ldots \ldots$ C-131

Classical estimation . ................ C-25

Codes, accident progression analysis

EVNTRE $\ldots \ldots \ldots \ldots \ldots \ldots \ldots \ldots \ldots \ldots \ldots$ C-121

MAAP $\ldots \ldots \ldots \ldots \ldots \ldots \ldots \ldots \ldots \ldots \ldots$, - 122

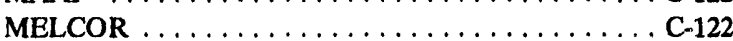

separate effects $\ldots \ldots \ldots \ldots \ldots \ldots \ldots \ldots \ldots \ldots$ C-116

Source Term Code Package (STCP) $\ldots \ldots \ldots \ldots \ldots$ C-122

types, detailed mechanistic $\ldots \ldots \ldots \ldots \ldots \ldots \ldots \ldots$ C-116

types, deterministic $\ldots \ldots \ldots \ldots \ldots \ldots \ldots \ldots \ldots$ C-116

types, integral severe accident $\ldots \ldots \ldots \ldots \ldots \ldots$ C-116

Codes, consequence analysis

COSYMA $\ldots \ldots \ldots \ldots \ldots \ldots \ldots \ldots \ldots \ldots \ldots, \mathbf{C}_{-123}$

CRAC2 ........................

Codes, reliability analysis

CAFTA ....................... C-65

FRANTIC ABC $\ldots \ldots \ldots \ldots \ldots \ldots \ldots \ldots \ldots \ldots \ldots$

IRRAS $\ldots \ldots \ldots \ldots \ldots \ldots \ldots \ldots \ldots \ldots \ldots \ldots$ C-64

LHS $\ldots \ldots \ldots \ldots \ldots \ldots \ldots \ldots \ldots \ldots$, C-63 


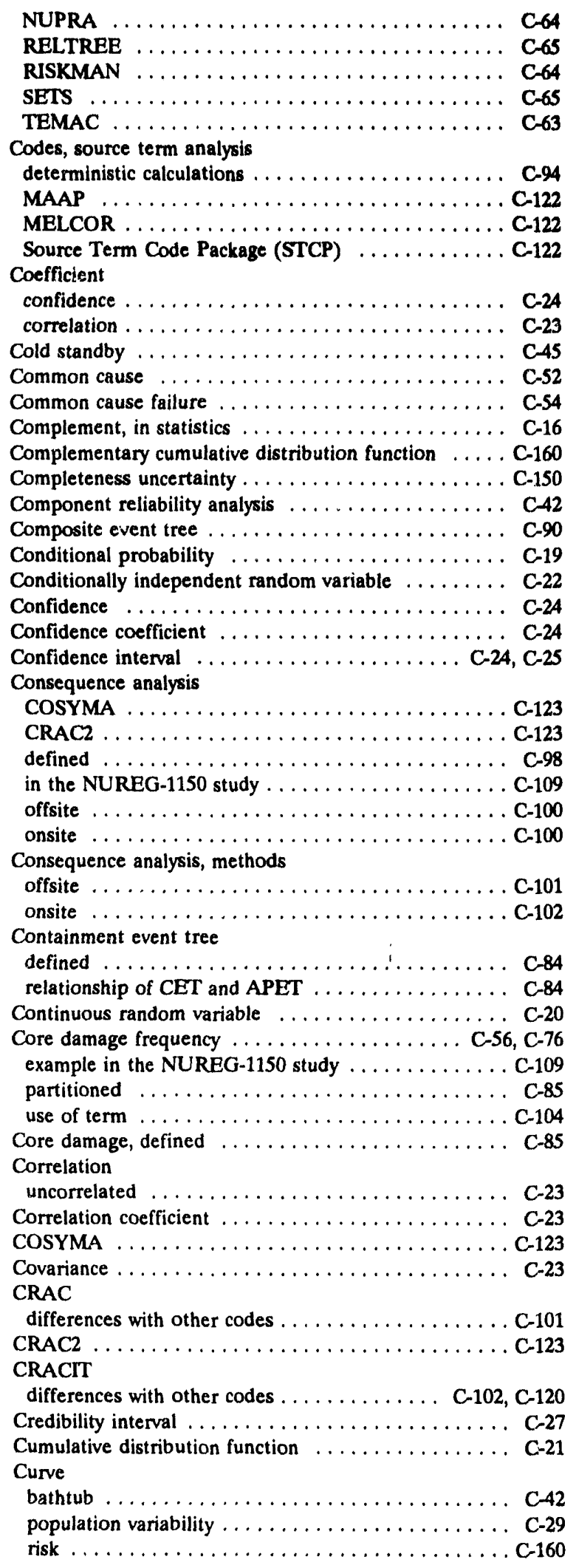

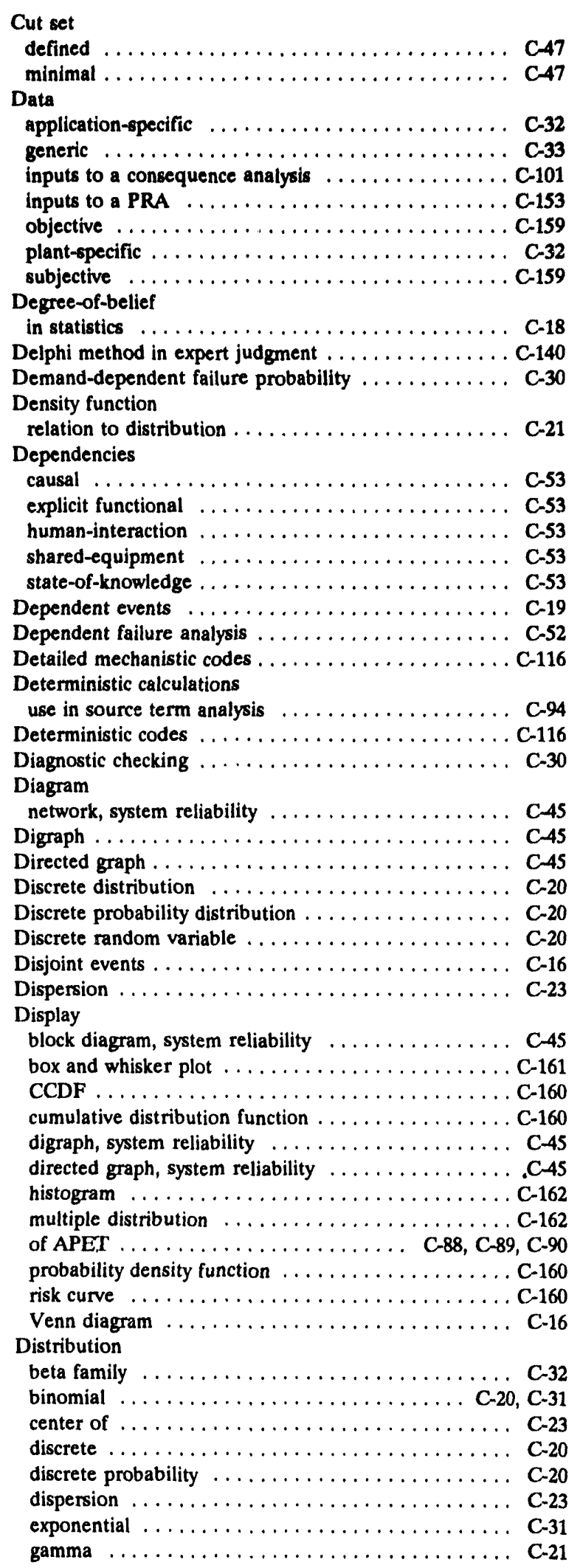


gamma family $\ldots \ldots \ldots \ldots \ldots \ldots \ldots \ldots \ldots \ldots, C_{-32}$

lognormal, use as a prior $\ldots \ldots \ldots \ldots \ldots \ldots \ldots \ldots$ C-31

mean of . . . . . . . . . . . . . . . . . . . C-21

median of $\ldots \ldots \ldots \ldots \ldots \ldots \ldots \ldots \ldots \ldots \ldots \ldots$

mode of $\ldots \ldots \ldots \ldots \ldots \ldots \ldots \ldots \ldots \ldots \ldots \ldots$

percentile of $\ldots \ldots \ldots \ldots \ldots \ldots \ldots \ldots \ldots \ldots \ldots \ldots$

plant-specific $\ldots \ldots \ldots \ldots \ldots \ldots \ldots \ldots \ldots \ldots \ldots \ldots$ C-30

Poisson . . . . . . . . . . . . . . . . . C-20, C-31

posterior $\ldots \ldots \ldots \ldots \ldots \ldots \ldots \ldots \ldots \ldots \ldots \ldots \ldots, \mathbf{C - 2 7}$

prior $\ldots \ldots \ldots \ldots \ldots \ldots \ldots \ldots \ldots \ldots \ldots \ldots$ C-26

probability ....................... C-20

quantile of $\ldots \ldots \ldots \ldots \ldots \ldots \ldots \ldots \ldots \ldots \ldots, \mathbf{C}-23$

quartiles of $\ldots \ldots \ldots \ldots \ldots \ldots \ldots \ldots \ldots \ldots \ldots, C_{-23}$

range of $\ldots \ldots \ldots \ldots \ldots \ldots \ldots \ldots \ldots \ldots \ldots \ldots$

relation to density function $\ldots \ldots \ldots \ldots \ldots \ldots \ldots$, -21

site-specific $\ldots \ldots \ldots \ldots \ldots \ldots \ldots \ldots \ldots \ldots \ldots$ C-30

spread $\ldots \ldots \ldots \ldots \ldots \ldots \ldots \ldots \ldots \ldots \ldots \ldots \ldots$

standard deviation of $\ldots \ldots \ldots \ldots \ldots \ldots \ldots \ldots \ldots$ C-23

use of statistical inference $\ldots \ldots \ldots \ldots \ldots \ldots \ldots \ldots$

variance of $\ldots \ldots \ldots \ldots \ldots \ldots \ldots \ldots \ldots \ldots \ldots \ldots$

Weibull $\ldots \ldots \ldots \ldots \ldots \ldots \ldots \ldots \ldots \ldots \ldots \ldots$

Distribution function $\ldots \ldots \ldots \ldots \ldots \ldots \ldots \ldots \ldots \ldots$ C-21

Distribution-free method $\ldots \ldots \ldots \ldots \ldots \ldots \ldots \ldots$ C-2A

DPD ........................ C-158

Elicitation training . . . . . . . . . . . . . . C-134

Empirical Bayes . . . . . . . . . . . . . . . . . . . . . C-29

Empirical probabilities $\ldots \ldots \ldots \ldots \ldots \ldots \ldots \ldots \ldots$ C-16

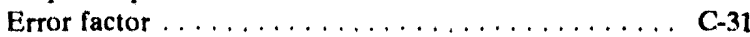

Estimate

interval, defined $\ldots \ldots \ldots \ldots \ldots \ldots \ldots \ldots \ldots \ldots$ C-2A

point, defined $\ldots \ldots \ldots \ldots \ldots \ldots \ldots \ldots \ldots \ldots \ldots$

Estimation

Bayesian $\ldots \ldots \ldots \ldots \ldots \ldots \ldots \ldots \ldots \ldots \ldots \ldots \ldots$ C-27

classical $\ldots \ldots \ldots \ldots \ldots \ldots \ldots \ldots \ldots \ldots \ldots \ldots \ldots \ldots$ C-25

Estimator

unbiased $\ldots \ldots \ldots \ldots \ldots \ldots \ldots \ldots \ldots \ldots \ldots$ C-23

Estimators $\ldots \ldots \ldots \ldots \ldots \ldots \ldots \ldots \ldots \ldots \ldots \ldots \ldots$ C-23

Event

defined, statistics $\ldots \ldots \ldots \ldots \ldots \ldots \ldots \ldots \ldots \ldots$

top $\ldots \ldots \ldots \ldots \ldots \ldots \ldots \ldots \ldots \ldots \ldots \ldots$ C-84

Event tree .................. C-49, C-84, C-89

composite $\ldots \ldots \ldots \ldots \ldots \ldots \ldots \ldots \ldots \ldots \ldots$

individual $\ldots \ldots \ldots \ldots \ldots \ldots \ldots \ldots \ldots \ldots \ldots \ldots$

supplemented . . . . . . . . . . . . . . . . C-89

unsupplemented $\ldots \ldots \ldots \ldots \ldots \ldots \ldots \ldots \ldots \ldots$ C-89

Events

disjoint $\ldots \ldots \ldots \ldots \ldots \ldots \ldots \ldots \ldots \ldots \ldots \ldots \ldots$

mutually exclusive $\ldots \ldots \ldots \ldots \ldots \ldots \ldots \ldots \ldots \ldots, \ldots \ldots \ldots$

Ex-vessel phase . . . . . . . . . . . . . . . C-92

Expectation . . . . . . . . . . . . . . . . . C-21

Expected value

accident sequence analysis $\ldots \ldots \ldots \ldots \ldots \ldots \ldots \ldots$ C-51

defined $\ldots \ldots \ldots \ldots \ldots \ldots \ldots \ldots \ldots \ldots \ldots \ldots \ldots$

of aggregate risk $\ldots \ldots \ldots \ldots \ldots \ldots \ldots \ldots \ldots$

of total consequences . . . . . . . . . . . . . C-106

Expert judgment

anchoring bias . . . . . . . . . . . . . C.136

availability bias .................. C-136

Baycs' theorem . . . . . . . . . . . . . . . . . C-140

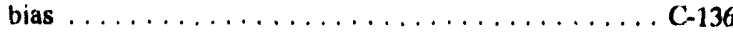

calibration of probabilities $\ldots \ldots \ldots \ldots \ldots \ldots \ldots,-136$

combining distributions, behavioral . . . . . . . C-140 combining distributions, mathematical . . . . . . . C 140

criteria for selecting experts . . . . . . . . . . C-132

Delphi method $\ldots \ldots \ldots \ldots \ldots \ldots \ldots \ldots \ldots \ldots \ldots$ C 140

expert, defined $\ldots \ldots \ldots \ldots \ldots \ldots \ldots \ldots \ldots \ldots \mathrm{C}_{132}$

expert, normative . . . . . . . . . . . . . . . C-134

geometric averaging . . . . . . . . . . . . . . C-140

in determining source terms $\ldots \ldots \ldots \ldots \ldots \ldots \ldots$ C-95

linear opinion pool $\ldots \ldots \ldots \ldots \ldots \ldots \ldots \ldots \ldots$ C-140

linear opinion pools . . . . . . . . . . . . . . C-140

mathematical aggregation rules $\ldots \ldots \ldots \ldots \ldots \ldots, \mathrm{C}-140$

nominal group technique $\ldots \ldots \ldots \ldots \ldots \ldots \ldots \ldots$ C-140

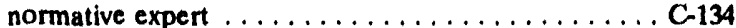

optimism bias $\ldots \ldots \ldots \ldots \ldots \ldots \ldots \ldots \ldots \ldots \ldots \ldots$

panel . . . . . . . . . . . . . . . . . . C-134

probability assessment . . . . . . . . . . . C -135

probability elicitation, direct $\ldots \ldots \ldots \ldots \ldots \ldots \ldots$-135

probability elicitation, indirect $\ldots \ldots \ldots \ldots \ldots \ldots$ G-135

psychological bias $\ldots \ldots \ldots \ldots \ldots \ldots \ldots \ldots \ldots \ldots \ldots, 136$

rationale of assessments . . . . . . . . . . . . C-135

refinement $\ldots \ldots \ldots \ldots \ldots \ldots \ldots \ldots \ldots \ldots \ldots \ldots$ C-139

selecting experts $\ldots \ldots \ldots \ldots \ldots \ldots \ldots \ldots \ldots \ldots \ldots$ C-132

Stimulus spacing bias $\ldots \ldots \ldots \ldots \ldots \ldots \ldots \ldots \ldots$. $\ldots \ldots \ldots$

team $\ldots \ldots \ldots \ldots \ldots \ldots \ldots \ldots \ldots \ldots \ldots \ldots \ldots$

techniques for obtaining judgments $\ldots \ldots \ldots \ldots \ldots \mathrm{C}-135$

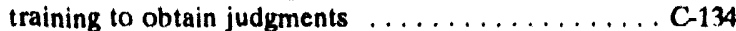

use in source term analysis $\ldots \ldots \ldots \ldots \ldots \ldots \ldots$ C-95

ways of selecting important issues $\ldots \ldots \ldots \ldots \ldots \ldots$ C-130

Explicit functional dependency $\ldots \ldots \ldots \ldots \ldots \ldots \ldots$ C-53

Exponential density function $\ldots \ldots \ldots \ldots \ldots \ldots \ldots$ C-23

Exponential distribution . . . . . . . . . . . . . . C-31

Exponential random variable $\ldots \ldots \ldots \ldots \ldots \ldots \ldots \ldots, C_{21}$

External events analysis $\ldots \ldots \ldots \ldots \ldots \ldots \ldots$ C-60

Failure

common cause ......................... C-54

Pailure mode effect and criticality analysis . . . . . . C -46

Failure modes and effects analysis $\ldots \ldots \ldots \ldots \ldots \ldots$ C-46

Fault tree $\ldots \ldots \ldots \ldots \ldots \ldots \ldots \ldots \ldots \ldots \ldots$ C-46, C-51

Fire analysis $\ldots \ldots \ldots \ldots \ldots \ldots \ldots \ldots \ldots \ldots \ldots \ldots \ldots$

FMEA $\ldots \ldots \ldots \ldots \ldots \ldots \ldots \ldots \ldots \ldots$ C-46

FMECA $\ldots \ldots \ldots \ldots \ldots \ldots \ldots \ldots \ldots$ C-46

Frequency

accident progression $\ldots \ldots \ldots \ldots \ldots \ldots \ldots \ldots \ldots, \mathbf{C}-85$

accident progression bin $\ldots \ldots \ldots \ldots \ldots \ldots \ldots \ldots$ C-85

core damage $\ldots \ldots \ldots \ldots \ldots \ldots \ldots \ldots$ C-56, C-76, C-85

core damage, use of term . . . . . . . . . . . . . . . C-104

defined $\ldots \ldots \ldots \ldots \ldots \ldots \ldots \ldots \ldots \ldots \ldots \ldots \ldots$ C-31

plant damage state $\ldots \ldots \ldots \ldots \ldots \ldots \ldots \ldots$. . . . . . . . .

Frequentist view of probability $\ldots \ldots \ldots \ldots \ldots \ldots \ldots$ C-16

Front-end analysis $\ldots \ldots \ldots \ldots \ldots \ldots \ldots \ldots \ldots \ldots$

defined (footnote) $\ldots \ldots \ldots \ldots \ldots \ldots \ldots \ldots \ldots$ C-73

Function

complementary cumulative . . . . . . . . . . . . C 160

cumulative distribution $\ldots \ldots \ldots \ldots \ldots \ldots \ldots$ C-21, C-160

density $\ldots \ldots \ldots \ldots \ldots \ldots \ldots \ldots \ldots \ldots \ldots \ldots \ldots$ C-21

distribution $\ldots \ldots \ldots \ldots \ldots \ldots \ldots \ldots \ldots \ldots \ldots \ldots$

exponential density $\ldots \ldots \ldots \ldots \ldots \ldots \ldots \ldots \ldots \ldots$ C-23

probability density . . . . . . . . . . . . . C-21, C-160

probability mass $\ldots \ldots \ldots \ldots \ldots \ldots \ldots \ldots \ldots \ldots \ldots$

relation to distribution $\ldots \ldots \ldots \ldots \ldots \ldots \ldots \ldots \ldots, \ldots$

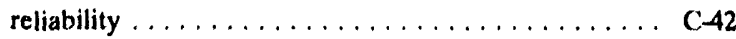

structure form of a fault tree . . . . . . . . . . . C -48

Fussell-Vesely importance measure .......... C-165 
Gamma family of distributions $\ldots \ldots \ldots \ldots \ldots \ldots \ldots$, C-32

Gamma random variable $\ldots \ldots \ldots \ldots \ldots \ldots \ldots \ldots, \mathbf{C}-21$ Generic

data $\ldots \ldots \ldots \ldots \ldots \ldots \ldots \ldots \ldots \ldots \ldots \ldots$ C-32, C-33

Geometric averaging $\ldots \ldots \ldots \ldots \ldots \ldots \ldots \ldots \ldots$ C-140

Goodness-of-fit test $\ldots \ldots \ldots \ldots \ldots \ldots \ldots \ldots$, C.24, C-2S

Guidance

aggregate information $\ldots \ldots \ldots \ldots \ldots \ldots \ldots, \mathbf{C}-112, \mathbf{C}-142$

analysis of future plants $\ldots \ldots \ldots \ldots \ldots \ldots \ldots \ldots, \mathbf{C}-83$

Bayesian methods . . . . . . . . . . . . . . . . . C.29

best estimate, use of term $\ldots \ldots \ldots \ldots \ldots \ldots$ C.24, C-159

calculate fault tree probabilities $\ldots \ldots \ldots \ldots \ldots \ldots$ C 49

calculate probability of union set $\ldots \ldots \ldots \ldots \ldots \ldots$ C-19

CDF to risk transformation, caution $\ldots \ldots \ldots \ldots \ldots$, C-84

CDF to risk transformation, choosing a . . . . . . C-76

CDF transformation, basis of . . . . . . . . . . . C-79

central assumption in reliability theory $\ldots \ldots \ldots \ldots, C-62$

chain rule to calculate probability $\ldots \ldots \ldots \ldots \ldots$, C-20

classical methods . . . . . . . . . . . . . . . . . C-29

classical vs. Bayesian . . . . . . . . . . . . . . . . C-29

common cause failure $\ldots \ldots \ldots \ldots \ldots \ldots \ldots \ldots$ C-56

consequence code, choice of $\ldots \ldots \ldots \ldots \ldots \ldots \ldots$ C-102

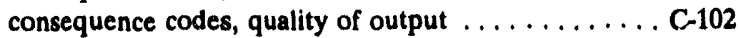

consequence, choice of code $\ldots \ldots \ldots \ldots \ldots \ldots \ldots$ C-102

core damage frequency, use of term . . . . . . . . . C-107

correlations, effect of $\ldots \ldots \ldots \ldots \ldots \ldots \ldots \ldots$ C-169

dependencies, effect of $\ldots \ldots \ldots \ldots \ldots \ldots \ldots$ C-169

deterministic code, choice of $\ldots \ldots \ldots \ldots \ldots \ldots \ldots$ C.119

deterministic code, use of $\ldots \ldots \ldots \ldots \ldots \ldots \ldots$ C-119

deterministic codes, use of $\ldots \ldots \ldots \ldots \ldots \ldots \ldots$ C-120

deterministic codes, use of results $\ldots \ldots \ldots \ldots \ldots \ldots$-120

display of PRA results, distribution $\ldots \ldots \ldots \ldots \ldots$ C-160

event tree, composite structure $\ldots \ldots \ldots \ldots \ldots \ldots$ C-90

event tree, individual structure . . . . . . . . . . C -90

expert judgment, decomposing problems $\ldots \ldots \ldots \ldots$ C-131

expert judgment, indirect techniques $\ldots \ldots \ldots \ldots \ldots$ C-135

expert judgment, organizing experts $\ldots \ldots \ldots \ldots \ldots$ C-133

expert judgment, training objective $\ldots \ldots \ldots \ldots \ldots$ C-134

expert judgment, use of methods ........ C-129, C-130

failure rate $\ldots \ldots \ldots \ldots \ldots \ldots \ldots \ldots \ldots, \mathrm{C}-43, \mathrm{C}-53$

frequentist view of probability $\ldots \ldots \ldots \ldots \ldots \ldots, C-18$

inclusion-exclusion rule $\ldots \ldots \ldots \ldots \ldots \ldots \ldots \ldots$, C-19

independent events .................. C-19

integral Level 2 codes, choosing . . . . . . . . . . . C C-94

interpretation of confidence interval $\ldots \ldots \ldots \ldots \ldots$ C-24

interpretation of probability interval $\ldots \ldots \ldots \ldots \ldots$, C-27

mean of system unavailability . . . . . . . . . . C-53

meaning of risk results $\ldots \ldots \ldots \ldots \ldots \ldots \ldots \ldots$ C-114

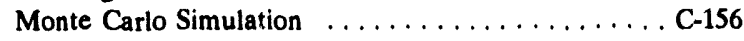

mutually exclusive events . . . . . . . . . . . . . C-19

onsite consequences, when necessary $\ldots \ldots \ldots \ldots, \ldots,-100$

rare event approximation $\ldots \ldots \ldots \ldots \ldots \ldots \ldots, \mathrm{C}-19$

risk increase $\ldots \ldots \ldots \ldots \ldots \ldots \ldots \ldots \ldots \ldots \ldots$. $\ldots \ldots$.166

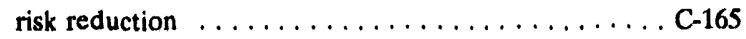

risk, use of term . . . . . . . . . . . . . . . C-107

sensitivity analysis, need for $\ldots \ldots \ldots \ldots \ldots$ C-116, C-150

subjectivist view of probability $\ldots \ldots \ldots \ldots \ldots \ldots$ C-18

surrogate uncertainty analysis $\ldots \ldots \ldots \ldots \ldots \ldots$ C-169

uncertainty analysis, basis $\ldots \ldots \ldots \ldots \ldots \ldots . . \ldots \ldots$

uncertainty analysis, need for . . . . . . . C-116, C-150

uncertainty analysis, selecting inputs $\ldots \ldots \ldots \ldots \ldots$-168

uncertainty, completeness . . . . . . . . . . . . C-169 use of Handbook in HRA . . . . . . . . . . . . C-57

use of judgment in assessing HERs $\ldots \ldots \ldots \ldots \ldots$ C-60

use of PRA results . . . . . . . . . . C C-111, C-150

HCR/ORE $\ldots \ldots \ldots \ldots \ldots \ldots \ldots \ldots \ldots \ldots$ C-59

HEP $\ldots \ldots \ldots \ldots \ldots \ldots \ldots \ldots \ldots \ldots \ldots \ldots \ldots$ C.57

HER $\ldots \ldots \ldots \ldots \ldots \ldots \ldots \ldots \ldots \ldots \ldots \ldots$ C.57

Histogram $\ldots \ldots \ldots \ldots \ldots \ldots \ldots \ldots \ldots \ldots \ldots \ldots$, C-162

approximation of a PDF $\ldots \ldots \ldots \ldots \ldots \ldots \ldots \ldots \mathrm{C}_{-162}$

Hot standby $\ldots \ldots \ldots \ldots \ldots \ldots \ldots \ldots \ldots \ldots, 4.45$

Human error

probability $\ldots \ldots \ldots \ldots \ldots \ldots \ldots \ldots \ldots \ldots \ldots$ C.57

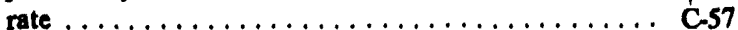

Human Reliability Analysis $\ldots \ldots \ldots \ldots \ldots \ldots \ldots$ C.57

Human-interaction dependency $\ldots \ldots \ldots \ldots \ldots \ldots$, C.53

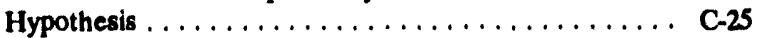

alpha-level $\ldots \ldots \ldots \ldots \ldots \ldots \ldots \ldots \ldots \ldots \ldots$ C-25

alternative $\ldots \ldots \ldots \ldots \ldots \ldots \ldots \ldots \ldots \ldots \ldots$ C-25

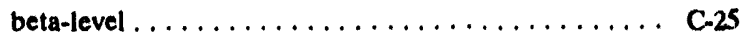

defined $\ldots \ldots \ldots \ldots \ldots \ldots \ldots \ldots \ldots \ldots \ldots \ldots, C_{\text {C-25 }}$

goodness-of-fit test $\ldots \ldots \ldots \ldots \ldots \ldots \ldots \ldots$, C-24, C-25

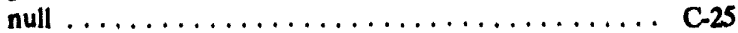

power of the test $\ldots \ldots \ldots \ldots \ldots \ldots \ldots \ldots \ldots$ C-25

rejection $\ldots \ldots \ldots \ldots \ldots \ldots \ldots \ldots \ldots \ldots \ldots, C_{-25}$

significance level $\ldots \ldots \ldots \ldots \ldots \ldots \ldots \ldots \ldots \ldots, \mathbf{C}-25$

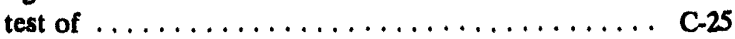

test, operating characteristics $\ldots \ldots \ldots \ldots \ldots \ldots \ldots$ C-25

Type I error $\ldots \ldots \ldots \ldots \ldots \ldots \ldots \ldots \ldots \ldots \ldots \ldots$, C-25

Type II error $\ldots \ldots \ldots \ldots \ldots \ldots \ldots \ldots \ldots \ldots \ldots \ldots$ C-25

Importance calculations $\ldots \ldots \ldots \ldots \ldots \ldots \ldots \ldots, \mathrm{C}-165$

In-vessel phase $\ldots \ldots \ldots \ldots \ldots \ldots \ldots \ldots \ldots \ldots$, C-92

Inclusion-exclusion principle $\ldots \ldots \ldots \ldots \ldots \ldots \ldots$, C-19

Inclusion-exclusion rule $\ldots \ldots \ldots \ldots \ldots \ldots \ldots$, C-36

Independent events $\ldots \ldots \ldots \ldots \ldots \ldots \ldots \ldots \ldots$ C-19

Indicator variable $\ldots \ldots \ldots \ldots \ldots \ldots \ldots \ldots \ldots \ldots$, C 48

Individual event trees . . . . . . . . . . . . . C-90

Inference

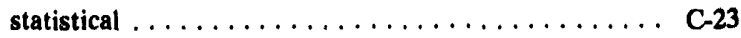

Initiating ovent $\ldots \ldots \ldots \ldots \ldots \ldots \ldots \ldots \ldots \ldots, \mathrm{C}-49$

Initiating events $\ldots \ldots \ldots \ldots \ldots \ldots \ldots \ldots \ldots \ldots, C_{-49}$

Integral

Level 1, 2, and 3 analysis (footnote) . . . . . . . C-104

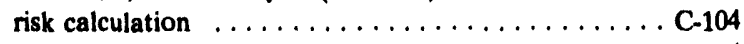

severe accident code . . . . . . . . . . . . . . . C-94

Integral severe accident codes $\ldots \ldots \ldots \ldots \ldots \ldots \ldots$ C-116

Integration

administrative $\ldots \ldots \ldots \ldots \ldots \ldots \ldots \ldots \ldots \ldots \ldots$ C-104

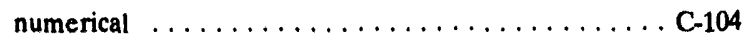

risk calculation $\ldots \ldots \ldots \ldots \ldots \ldots \ldots \ldots \ldots$ C-104

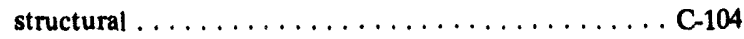

Intersection $\ldots \ldots \ldots \ldots \ldots \ldots \ldots \ldots \ldots, \mathrm{C}-16$

Interval

confidence $\ldots \ldots \ldots \ldots \ldots \ldots \ldots \ldots \ldots$, C-24, $\mathbf{C}-25$

credibility $\ldots \ldots \ldots \ldots \ldots \ldots \ldots \ldots \ldots \ldots \ldots$, C-27

estimate, defined $\ldots \ldots \ldots \ldots \ldots \ldots \ldots \ldots \ldots, C-24$

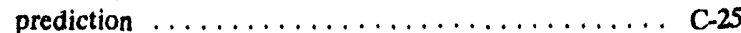

probability $\ldots \ldots \ldots \ldots \ldots \ldots \ldots \ldots \ldots \ldots \ldots$, C-27

tolerance $\ldots \ldots \ldots \ldots \ldots \ldots \ldots \ldots \ldots \ldots \ldots \ldots$. $\ldots \ldots \ldots$

K-out-of-n system $\ldots \ldots \ldots \ldots \ldots \ldots \ldots \ldots \ldots$ C-45

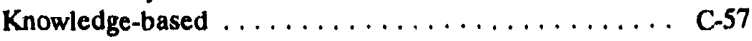

Latin Hypercube Sampling . . . . . . . . . . C-154, C-156

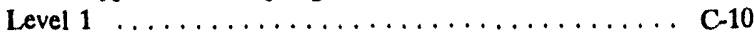

Level 1 analysis $\ldots \ldots \ldots \ldots \ldots \ldots \ldots \ldots \ldots, C-73$ 


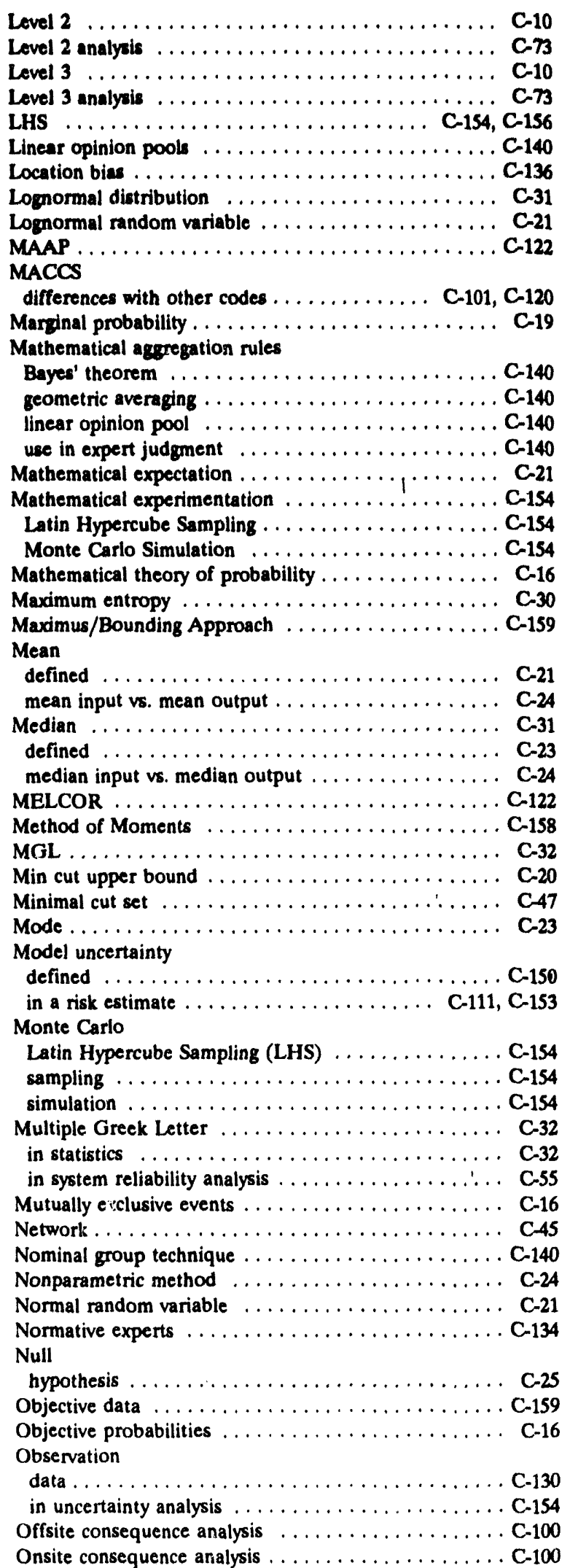

Operating characteristic $\ldots \ldots \ldots \ldots \ldots \ldots \ldots \ldots \ldots$ C-25

Outcomes $\ldots \ldots \ldots \ldots \ldots \ldots \ldots \ldots \ldots \ldots \ldots$ C-15

Panel, in expert judgment $\ldots \ldots \ldots \ldots \ldots \ldots \ldots \ldots$ C-134

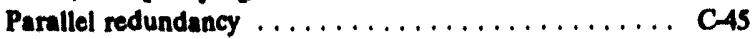

Parameter uncertainty

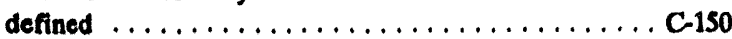

in a risk estimate $\ldots \ldots \ldots \ldots \ldots \ldots \ldots \ldots, \mathrm{C}-111, \mathrm{C}-153$

Parameters ....................... C-23

Parametric family $\ldots \ldots \ldots \ldots \ldots \ldots \ldots \ldots \ldots \ldots, \mathbf{C - 2 3}$

Parametric statistical inference $\ldots \ldots \ldots \ldots \ldots \ldots \ldots, \mathbf{C}-23$

PARTITION code $\ldots \ldots \ldots \ldots \ldots \ldots \ldots \ldots \ldots \ldots \ldots$ C-110

PDF $\ldots \ldots \ldots \ldots \ldots \ldots \ldots \ldots \ldots \ldots \ldots$ C-21, C-160

PDS $\ldots \ldots \ldots \ldots \ldots \ldots \ldots \ldots \ldots \ldots \ldots, \mathbf{C}-85$

Percentile $\ldots \ldots \ldots \ldots \ldots \ldots \ldots \ldots \ldots \ldots \ldots \ldots$ C-23

Plant damage state

defined $\ldots \ldots \ldots \ldots \ldots \ldots \ldots \ldots \ldots \ldots \ldots$ C-85

defined, by NRC staff in NUREG-1150 . . . . . . . . C-109

frequency $\ldots \ldots \ldots \ldots \ldots \ldots \ldots \ldots \ldots \ldots \ldots \ldots, \mathbf{C}-85$

Plant-specific data $\ldots \ldots \ldots \ldots \ldots \ldots \ldots \ldots \ldots$, C-32

Plent-specific distribution $\ldots \ldots \ldots \ldots \ldots \ldots \ldots \ldots, \mathbf{C}-30$

Plant-to-plant variability . . . . . . . . . . . . . . . . . . C-169

Point estimate $\ldots \ldots \ldots \ldots \ldots \ldots \ldots \ldots \ldots \ldots$ C-24

Poisson distribution $\ldots \ldots \ldots \ldots \ldots \ldots \ldots \ldots$, C-20, C-31

Population variability curve $\ldots \ldots \ldots \ldots \ldots \ldots \ldots \ldots$ C-29

Power of the test $\ldots \ldots \ldots \ldots \ldots \ldots \ldots \ldots \ldots \ldots, \mathbf{C}-25$

PRAMIS code . . . . . . . . . . . . . . . . C-110

Prediction interval $\ldots \ldots \ldots \ldots \ldots \ldots \ldots \ldots \ldots \ldots, \mathbf{C}-25$

Prior distribution $\ldots \ldots \ldots \ldots \ldots \ldots \ldots \ldots \ldots$, C-26

Probabilistic risk assessment . . . . . . . . . C-15

Probability

conditional $\ldots \ldots \ldots \ldots \ldots \ldots \ldots \ldots \ldots \ldots \ldots$ C-19

distribution $\ldots \ldots \ldots \ldots \ldots \ldots \ldots \ldots \ldots \ldots \ldots, \mathbf{C - 2 0}$

empirical $\ldots \ldots \ldots \ldots \ldots \ldots \ldots \ldots \ldots \ldots \ldots$ C-16

experiments $\ldots \ldots \ldots \ldots \ldots \ldots \ldots \ldots \ldots \ldots \ldots$ C-15

frequentist view $\ldots \ldots \ldots \ldots \ldots \ldots \ldots \ldots \ldots \ldots, C-16$

marginal $\ldots \ldots \ldots \ldots \ldots \ldots \ldots \ldots \ldots \ldots \ldots \ldots$ C-19

mass function $\ldots \ldots \ldots \ldots \ldots \ldots \ldots \ldots \ldots, C_{\text {-20 }}$

objective $\ldots \ldots \ldots \ldots \ldots \ldots \ldots \ldots \ldots \ldots \ldots$ C-16

of failure on demand $\ldots \ldots \ldots \ldots \ldots \ldots \ldots \ldots \ldots$, C-30

of frequency $\ldots \ldots \ldots \ldots \ldots \ldots \ldots \ldots \ldots \ldots, C_{-18}$

subjectivist view $\ldots \ldots \ldots \ldots \ldots \ldots \ldots \ldots \ldots \ldots$, C-18

Probability density function

approximation with a histogram . . . . . . . C-113, C-162

defined $\ldots \ldots \ldots \ldots \ldots \ldots \ldots \ldots \ldots \ldots \ldots, C_{-21}$

display, in uncertainty $\ldots \ldots \ldots \ldots \ldots \ldots \ldots, \mathrm{C}-160$

Probability elicitation

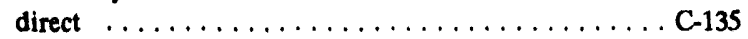

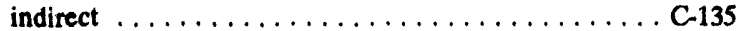

Probability interval . . . . . . . . . . . . . C-27

Propagation of DPD $\ldots \ldots \ldots \ldots \ldots \ldots \ldots \ldots \ldots$ C-158

Quantile ......................... C-23

Quartiles ...................... C-23

Radionuclide release and transport

see Source Term . . . . . . . . . . . . . . C-91

Random sample $\ldots \ldots \ldots \ldots \ldots \ldots \ldots \ldots \ldots \ldots \ldots$ C-23

Random variable $\ldots \ldots \ldots \ldots \ldots \ldots \ldots \ldots \ldots \ldots$ C-15

beta $\ldots \ldots \ldots \ldots \ldots \ldots \ldots \ldots \ldots \ldots \ldots \ldots$ C-21

conditionally independent $\ldots \ldots \ldots \ldots \ldots \ldots \ldots, C-22$

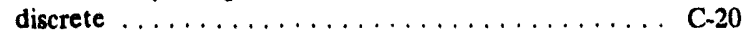

exponential $\ldots \ldots \ldots \ldots \ldots \ldots \ldots \ldots \ldots \ldots \ldots$ C-21

gamma $\ldots \ldots \ldots \ldots \ldots \ldots \ldots \ldots \ldots \ldots \ldots \ldots, C-21$

lognormal $\ldots \ldots \ldots \ldots \ldots \ldots \ldots \ldots \ldots \ldots, C-21$ 
normal $\ldots \ldots \ldots \ldots \ldots \ldots \ldots \ldots \ldots \ldots \ldots \ldots \ldots \ldots \ldots, \mathbf{c} 21$

Range ...................... C-24

Rare event approximation $\ldots \ldots \ldots \ldots \ldots \ldots \ldots \ldots \ldots$ C-19

Reactor-year, defined . . . . . . . . . . . . . C-109

Redundancy

defined in Level $1 \ldots \ldots \ldots \ldots \ldots \ldots \ldots \ldots$

parallel $\ldots \ldots \ldots \ldots \ldots \ldots \ldots \ldots \ldots \ldots \ldots \ldots \ldots C_{-45}$

standby $\ldots \ldots \ldots \ldots \ldots \ldots \ldots \ldots \ldots \ldots \ldots$

Refinement . . . . . . . . . . . . . . . C-139

Regression analysis $\ldots \ldots \ldots \ldots \ldots \ldots \ldots \ldots \ldots \ldots$ C-167

Rejection, of a hypothesis $\ldots \ldots \ldots \ldots \ldots \ldots \ldots \ldots$ C-25

Release category . . . . . . . . . . . . . C-85, C-94

Release fraction $\ldots \ldots \ldots \ldots \ldots \ldots \ldots \ldots \ldots \ldots \ldots \ldots$ C.92

Reliability analysis

beta factor model . . . . . . . . . . . . . . . . C.S4

failure mode and criticality anal. . . . . . . . C-46

failure modes and effects anal. . . . . . . . . . . . . . . C-46

software $\ldots \ldots \ldots \ldots \ldots \ldots \ldots \ldots \ldots \ldots \ldots$ C-62

Reliability analysis, methods

accident sequence $\ldots \ldots \ldots \ldots \ldots \ldots \ldots \ldots \ldots \ldots, 49$

component reliability . . . . . . . . . . . . C-42

dependent failure $\ldots \ldots \ldots \ldots \ldots \ldots \ldots \ldots \ldots \ldots$ C-s2

external events $\ldots \ldots \ldots \ldots \ldots \ldots \ldots \ldots \ldots \ldots \ldots$ C-60

fault tree $\ldots \ldots \ldots \ldots \ldots \ldots \ldots \ldots \ldots \ldots \ldots \ldots$

fire $\ldots \ldots \ldots \ldots \ldots \ldots \ldots \ldots \ldots \ldots \ldots, C_{-60}$

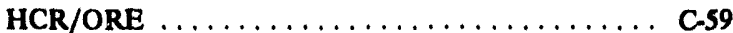

human reliability $\ldots \ldots \ldots \ldots \ldots \ldots \ldots \ldots \ldots$ C-57

seismic $\ldots \ldots \ldots \ldots \ldots \ldots \ldots \ldots \ldots \ldots \ldots$

SLIM-MAUD $\ldots \ldots \ldots \ldots \ldots \ldots \ldots \ldots \ldots \ldots$ C $60 . \ldots$

software $\ldots \ldots \ldots \ldots \ldots \ldots \ldots \ldots \ldots \ldots \ldots$ C-62

system $\ldots \ldots \ldots \ldots \ldots \ldots \ldots \ldots \ldots \ldots \ldots \ldots \ldots \ldots$

THERP . . . . . . . . . . . . . . . . C-59

Reliability function $\ldots \ldots \ldots \ldots \ldots \ldots \ldots \ldots \ldots \ldots, \ldots \ldots$

Response surface $\ldots \ldots \ldots \ldots \ldots \ldots \ldots \ldots \ldots \ldots \ldots$ C-158

Risk

aggregate definition $\ldots \ldots \ldots \ldots \ldots \ldots \ldots \ldots \ldots$ C-105

analysis in the NUREG-1150 study . . . . . . . C-109

curve . . . . . . . . . . . . . . . . . . . C-160

increase, method of analysis . . . . . . . . . . C-166

reduction, method of analysis . . . . . . . . C-165

risk triplet definition $\ldots \ldots \ldots \ldots \ldots \ldots \ldots \ldots \ldots$. . . . . . . . .

Risk triplet

defined $\ldots \ldots \ldots \ldots \ldots \ldots \ldots \ldots \ldots \ldots \ldots \ldots$. $\ldots \ldots 4$

in Level $1 \ldots \ldots \ldots \ldots \ldots \ldots \ldots \ldots \ldots \ldots \ldots \ldots \ldots, \ldots \ldots$

Rule-based behavior $\ldots \ldots \ldots \ldots \ldots \ldots \ldots \ldots \ldots$ C-57

Sample

in uncertainty analysis $\ldots \ldots \ldots \ldots \ldots \ldots \ldots \ldots$ C-154

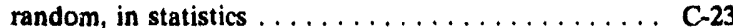

space $\ldots \ldots \ldots \ldots \ldots \ldots \ldots \ldots \ldots \ldots \ldots \ldots \ldots \ldots$

Seismic analysis $\ldots \ldots \ldots \ldots \ldots \ldots \ldots \ldots \ldots \ldots$ C $6 \ldots$

Selecting variables for an uncertainty analysis . . . . . C-167

Sensitivity analysis . . . . . . . . . . . . . . . C-149

Sensitivity, methods

Birnbaum impurtance measure $\ldots \ldots \ldots \ldots \ldots \ldots$ C-166

Birnbaum's structural importance $\ldots \ldots \ldots \ldots \ldots \ldots$ C-166

Fussell-Vesely importance measure .......... C-165

importance measure $\ldots \ldots \ldots \ldots \ldots \ldots \ldots \ldots \ldots$ C-165

multivariate analysis $\ldots \ldots \ldots \ldots \ldots \ldots \ldots \ldots \ldots$ C-167

regression analysis $\ldots \ldots \ldots \ldots \ldots \ldots \ldots \ldots \ldots \ldots$ C-167

risk increase $\ldots \ldots \ldots \ldots \ldots \ldots \ldots \ldots \ldots \ldots \ldots$ C-166

risk reduction $\ldots \ldots \ldots \ldots \ldots \ldots \ldots \ldots \ldots \ldots \ldots$

uncertainty importance measure $\ldots \ldots \ldots \ldots \ldots \ldots$ C-166
Separate effects codes . . . . . . . . . . . . . C-116

Shared-equipment dependency $\ldots \ldots \ldots \ldots \ldots \ldots \ldots$ C-53

Significance level $\ldots \ldots \ldots \ldots \ldots \ldots \ldots \ldots \ldots \ldots \ldots \ldots$ C-2S

Simificant

frequency of a plant damage state $\ldots \ldots \ldots \ldots \ldots \ldots$ C-160

variables for an uncertainty analysis . . . . . . . C-167

Site-specific distribution $\ldots \ldots \ldots \ldots \ldots \ldots \ldots \ldots \ldots \ldots$ C-30

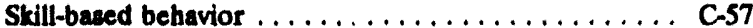

SLIM-MAUD $\ldots \ldots \ldots \ldots \ldots \ldots \ldots \ldots \ldots \ldots \ldots \ldots \ldots$ C $60 \ldots$

Software Reliability Analysis $\ldots \ldots \ldots \ldots \ldots \ldots \ldots \ldots, \mathrm{C}-62$

Source term . . . . . . . . . . . . . . . . . . . . . C.91

analycis in the NUREG-1150 study . . . . . . . C-109

defined $\ldots \ldots \ldots \ldots \ldots \ldots \ldots \ldots \ldots \ldots \ldots \ldots \ldots$ C.91

ex-veseel phase $\ldots \ldots \ldots \ldots \ldots \ldots \ldots \ldots \ldots \ldots \ldots$ C-92

in-vesucel phase . . . . . . . . . . . . . . . . . . . C.92

relcase category $\ldots \ldots \ldots \ldots \ldots \ldots \ldots \ldots \ldots \ldots$ C-94

release fraction $\ldots \ldots \ldots \ldots \ldots \ldots \ldots \ldots \ldots \ldots \ldots, \ldots \ldots$

use of deterministic calculations . . . . . . . . . C C-94

use of expert judgment $\ldots \ldots \ldots \ldots \ldots \ldots \ldots \ldots \ldots$ C-95

Source term analysis, methods

deterministic calculations . . . . . . . . . . . . C-94

expert judgment $\ldots \ldots \ldots \ldots \ldots \ldots \ldots \ldots \ldots \ldots \ldots \ldots$.95

parametric approach $\ldots \ldots \ldots \ldots \ldots \ldots \ldots \ldots \ldots, \mathbf{C}-95$

Source Term Code Package (STCP) . . . . . . . . . C-122

Spread $\ldots \ldots \ldots \ldots \ldots \ldots \ldots \ldots \ldots \ldots \ldots \ldots \ldots \ldots \ldots$, C-23

Standard deviation $\ldots \ldots \ldots \ldots \ldots \ldots \ldots \ldots \ldots \ldots \ldots$ C-23

Standby

cold . . . . . . . . . . . . . . . . . . . . . . C -45

hot $\ldots \ldots \ldots \ldots \ldots \ldots \ldots \ldots \ldots \ldots \ldots \ldots \ldots$

redundancy $\ldots \ldots \ldots \ldots \ldots \ldots \ldots \ldots \ldots \ldots \ldots$ C-45

State-of-knowledge

in statistics $\ldots \ldots \ldots \ldots \ldots \ldots \ldots \ldots \ldots \ldots, \mathbf{C}-18, \mathbf{C}-26$

uncertainty, defined $\ldots \ldots \ldots \ldots \ldots \ldots \ldots \ldots \ldots \ldots \ldots, \ldots \ldots \ldots$

Statistical

dependent $\ldots \ldots \ldots \ldots \ldots \ldots \ldots \ldots \ldots \ldots \ldots \ldots$. . . . . . . .

independent $\ldots \ldots \ldots \ldots \ldots \ldots \ldots \ldots \ldots \ldots \ldots \ldots$ C-19

Statistical inference

parametric ......

Statistical methods

distribution-free $\ldots \ldots \ldots \ldots \ldots \ldots \ldots \ldots \ldots \ldots \ldots$ C-2A

nonparametric $\ldots \ldots \ldots \ldots \ldots \ldots \ldots \ldots \ldots \ldots$ C-2A

Stochastic

random variable $\ldots \ldots \ldots \ldots \ldots \ldots \ldots \ldots \ldots \ldots, \ldots$-15

Stochastic uncertainty

defined $\ldots \ldots \ldots \ldots \ldots \ldots \ldots \ldots \ldots \ldots \ldots$ C-150

Structure function $\ldots \ldots \ldots \ldots \ldots \ldots \ldots \ldots \ldots \ldots$

Subjective data . . . . . . . . . . . . . . . . C-159

Subjectivist view of probability $\ldots \ldots \ldots \ldots \ldots \ldots \ldots$ C-18

Supplemented event tree . . . . . . . . . . . . . C-89

System

defined, Level $1 \ldots \ldots \ldots \ldots \ldots \ldots \ldots \ldots$. . . . . . . . . .

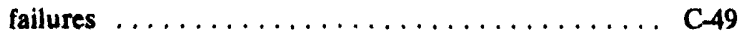

k-out-of-n $\ldots \ldots \ldots \ldots \ldots \ldots \ldots \ldots \ldots \ldots \ldots \ldots \ldots \ldots \ldots, C_{-45}$

System reliability analysis $\ldots \ldots \ldots \ldots \ldots \ldots \ldots \ldots \ldots$ C-44

Team, in expert judgment $\ldots \ldots \ldots \ldots \ldots \ldots \ldots$ C-134

Test

clairvoyance $\ldots \ldots \ldots \ldots \ldots \ldots \ldots \ldots \ldots \ldots \ldots \ldots \ldots$ C-131

of a hypothesis $\ldots \ldots \ldots \ldots \ldots \ldots \ldots \ldots \ldots \ldots \ldots$

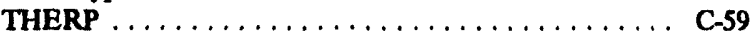

Thresholds . . . . . . . . . . . . . . . . . . C-112

Time-dependent failure rate $\ldots \ldots \ldots \ldots \ldots \ldots \ldots \ldots \ldots$ C-31

Tolerance interval $\ldots \ldots \ldots \ldots \ldots \ldots \ldots \ldots \ldots \ldots \ldots$ 
Top event $\ldots \ldots \ldots \ldots \ldots \ldots \ldots \ldots \ldots \ldots, C_{-84}$

Tree

composite event tree $\ldots \ldots \ldots \ldots \ldots \ldots \ldots \ldots \ldots, \mathbf{C} 90$

event $\ldots \ldots \ldots \ldots \ldots \ldots \ldots \ldots \ldots \ldots \ldots \ldots$ C-49, C-84

fault $\ldots \ldots \ldots \ldots \ldots \ldots \ldots \ldots \ldots \ldots, 4-46, C-51$

individual event tree $\ldots \ldots \ldots \ldots \ldots \ldots \ldots \ldots \ldots$, C-90

supplemented event tree $\ldots \ldots \ldots \ldots \ldots \ldots \ldots \ldots$ C-89

unsupplemented event tree $\ldots \ldots \ldots \ldots \ldots \ldots \ldots$ C-89

Triplet

defined $\ldots \ldots \ldots \ldots \ldots \ldots \ldots \ldots \ldots \ldots \ldots$ C-104

in system reliability (Level 1) . . . . . . . . . . C-51

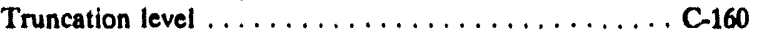

Type $\mathbf{I}$ error $\ldots \ldots \ldots \ldots \ldots \ldots \ldots \ldots \ldots \ldots \ldots \ldots$, C-25

Type II error $\ldots \ldots \ldots \ldots \ldots \ldots \ldots \ldots \ldots \ldots \ldots$ C-25

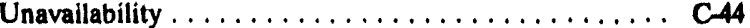

asymptotic $\ldots \ldots \ldots \ldots \ldots \ldots \ldots \ldots \ldots \ldots$ C-44

Unbiased estimator $\ldots \ldots \ldots \ldots \ldots \ldots \ldots \ldots \ldots, \mathbf{C - 2 3}$

Uncertainty

accounting for thresholds $\ldots \ldots \ldots \ldots \ldots \ldots \ldots \ldots$ C-112

analysis, defined $\ldots \ldots \ldots \ldots \ldots \ldots \ldots \ldots \ldots$ C-149

defined $\ldots \ldots \ldots \ldots \ldots \ldots \ldots \ldots \ldots \ldots \ldots$ C-149

in a deterministic code . . . . . . . . . . . . . . C-119

Uncertainty importance measure $\ldots \ldots \ldots \ldots \ldots \ldots$ C-166

Uncertainty, display

box and whisker plot $\ldots \ldots \ldots \ldots \ldots \ldots \ldots \ldots \ldots$ C-161

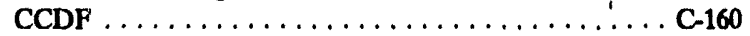

CDF $\ldots \ldots \ldots \ldots \ldots \ldots \ldots \ldots \ldots \ldots \ldots \ldots$ C-160

histogram $\ldots \ldots \ldots \ldots \ldots \ldots \ldots \ldots \ldots \ldots \ldots, 162$

multiple distribution $\ldots \ldots \ldots \ldots \ldots \ldots \ldots \ldots \ldots$ C-162

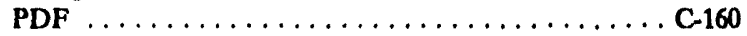

risk curve $\ldots \ldots \ldots \ldots \ldots \ldots \ldots \ldots \ldots \ldots$ C-160
Uncertainty, methods

Latin Hypercube Sampling (LHS) . . . . . . C-154, C-156

mathematical experimentation ............. C-154

Maximus/Bounding Approach . . . . . . . . . . . . C-159

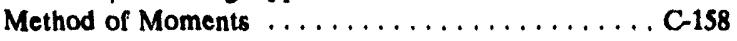

Monte Carlo Simulation ................. C-154

Propagation of Discrete Probability Distributions ... C-158

response surface $\ldots \ldots \ldots \ldots \ldots \ldots \ldots \ldots \ldots, \mathrm{C}-158$

selection of variables . . . . . . . . . . . . . C-167

Uncertainty, typis

completeness, defined $\ldots \ldots \ldots \ldots \ldots \ldots \ldots \ldots$ C-150

model, defined $\ldots \ldots \ldots \ldots \ldots \ldots \ldots \ldots \ldots \ldots$, C-150

model, in a risk estimate $\ldots \ldots \ldots \ldots \ldots \ldots, \mathrm{C}-111, \mathrm{C}-153$

parameter, defined $\ldots \ldots \ldots \ldots \ldots \ldots \ldots \ldots$ C-150

parameter, in a risk estimate $\ldots \ldots \ldots \ldots \ldots, \mathrm{C}-111, \mathrm{C}-153$

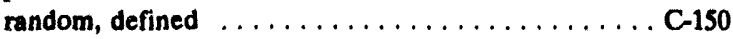

state-of-knowledge, defined $\ldots \ldots \ldots \ldots \ldots \ldots \ldots$ C-150

stochastic, defined $\ldots \ldots \ldots \ldots \ldots \ldots \ldots \ldots \ldots \ldots \ldots$ C-150

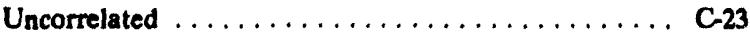

Union ........................... C-16

Unsupplemented event tree $\ldots \ldots \ldots \ldots \ldots \ldots \ldots \ldots$ C-89

Upper bound $\ldots \ldots \ldots \ldots \ldots \ldots \ldots \ldots \ldots \ldots \ldots$ C-19

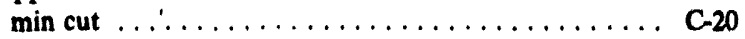

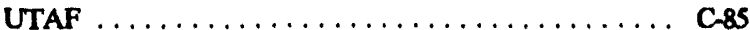

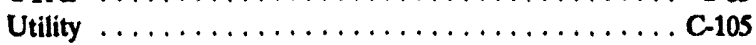

Variable

indicator, in reliability analysis $\ldots \ldots \ldots \ldots \ldots \ldots, C_{-48}$

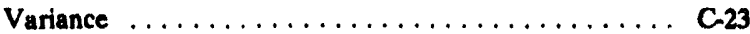

Venn diagram $\ldots \ldots \ldots \ldots \ldots \ldots \ldots \ldots \ldots \ldots \ldots$ C-16

Weibull distribution $\ldots \ldots \ldots \ldots \ldots \ldots \ldots \ldots, C_{-44}$ 
$1 !$
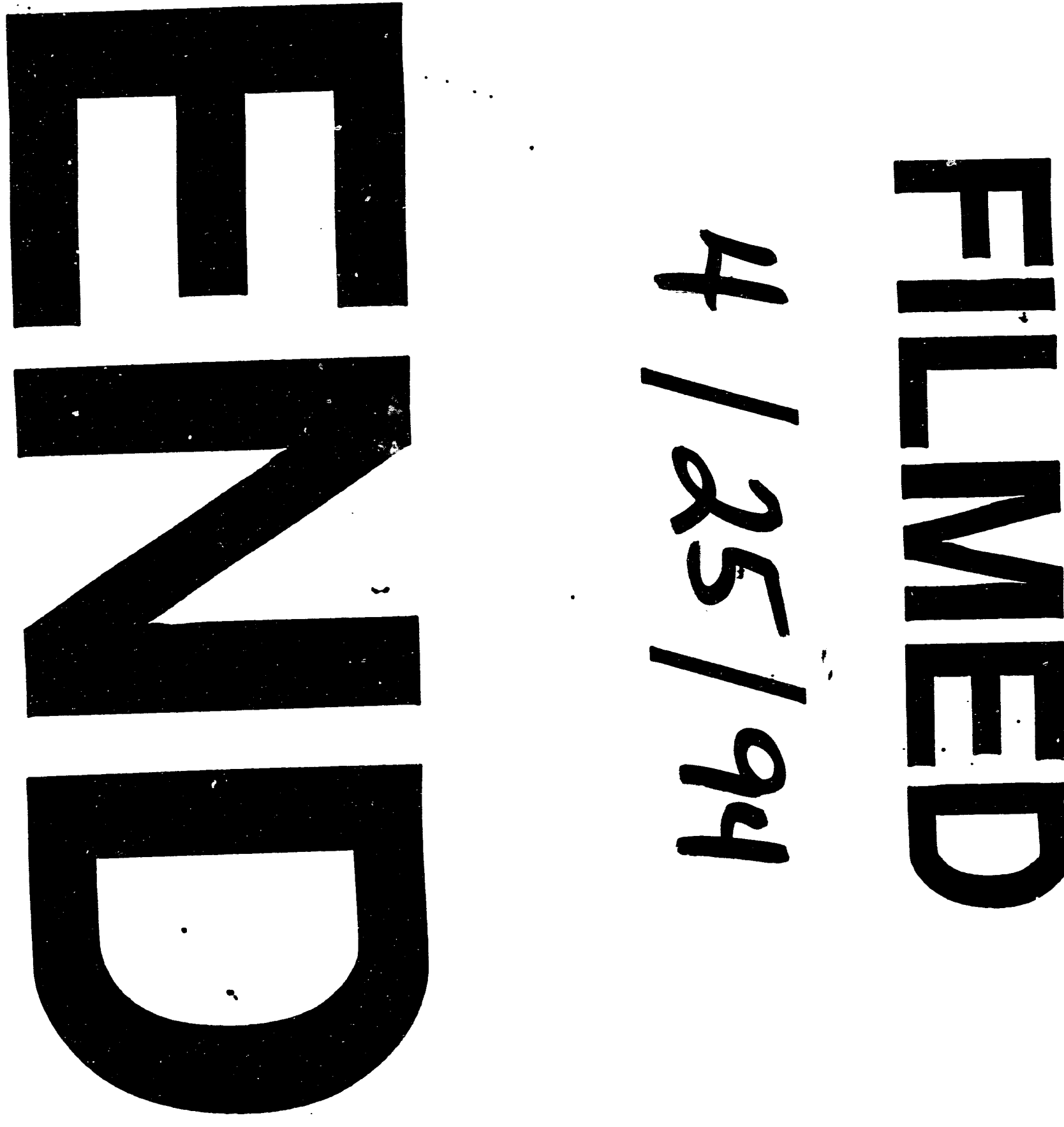

$\rightarrow$

$\infty$

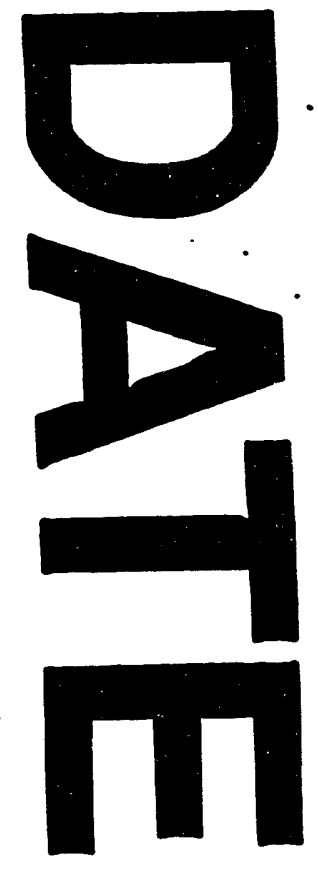




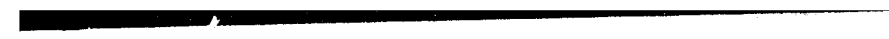

